\title{
Creating New Standards: Jazz Arrangements Of Pop Songs
}

A thesis presented as partial fulfillment of the requirements for the degree of

\author{
Master of Music \\ in Jazz Performance
}

New Zealand School of Music,

Auckland New Zealand

Trudy Lile

2009 
Creating New Standards: Jazz Arrangements Of Pop Songs

$\begin{array}{lr}\text { Contents } & 2\end{array}$

$\begin{array}{lr}\text { Acknowledgements } & 5\end{array}$

$\begin{array}{lr}\text { Abstract } & 6\end{array}$

$\begin{array}{lr}\text { General Introduction } & 8\end{array}$

$\begin{array}{lr}\text { Part One - Background } & 9\end{array}$

1.1 Jazz definitions

1.2 Development of Jazz Repertoire 12

1.2.2 Jazz Standards

1.3 The Adoption of Pop and Modern Music 13

1.3.1 Jazz Pop

1.3.2 Miles Davis 14

$\begin{array}{ll}\text { 1.3.3 Herbie Hancock } & 17\end{array}$

$\begin{array}{ll}\text { 1.3.4 Acid Jazz } & 18\end{array}$

$\begin{array}{ll}\text { Part Two - Analysis of Existing Arrangements } & 19\end{array}$

$\begin{array}{ll}2.1 \text { Melody } & 20\end{array}$

2.1.1 Adapting the melody

2.2 Rhythm

2.2.1 Changing the groove

2.2.2 Tempo

2.2.3 Changes of meter

29

2.3 Instrumentation and Texture

2.3.1 Size of the group 
2.4.1 Introductions

2.5.1 Modulation

2.5.2 Seventh Chords and Extensions

2.5.3.2 Diatonic and Tritone Substitution

3.1.1 Adapting the melody 
3.2.1 Groove

$\begin{array}{lr}\text { 3.2.2 Changes of tempo } & 80\end{array}$

3.2.3 Changes of meter 83

$\begin{array}{ll}3.3 \text { Instrumentation } & 89\end{array}$

3.3.1 Size of the group

3.3.1.1 Jazz Duo

$\begin{array}{ll}\text { 3.3.1.2 Jazz quintet } & 90\end{array}$

$\begin{array}{ll}\text { 3.3.1.3 Large ensemble } & 92\end{array}$

$\begin{array}{ll}3.4 \text { Structure } & 95\end{array}$

3.4.1 Introductions

3.4. 1.1 Introductions in free time

$\begin{array}{lr}\text { 3.4.2 Endings } & 100\end{array}$

$\begin{array}{ll}\text { 3.4.3 Solos Sections and Improvisation Platforms } & 102\end{array}$

$\begin{array}{lc}\text { 3.4.3.1 Cycles } & 103\end{array}$

$\begin{array}{lr}\text { 3.4.4 Vamps } & 104\end{array}$

$\begin{array}{ll}\text { 3.5 Harmony } & 107\end{array}$

3.5.1 Modulation

$\begin{array}{ll}\text { 3.5.2 Seventh Chords and Extensions } & 108\end{array}$

$\begin{array}{lr}\text { 3.5.3 Harmonic Substitution } & 110\end{array}$

3.5.3.1Turnarounds

3.5.3.2 Diatonic Substitution $\quad 111$

3.5.3.3 Melody Notes As Extensions Of The Chord 112 
Conclusion

Bibliography

Appendix 1. Discography

Appendix 2. Score and Cd of Original Songs Part Two

Appendix 3. Score and Cd of Transcriptions Part Two

Appendix 4. Score and Cd of Original Songs Part Three

Appendix 5 Scores of New Arrangements Part Three 


\section{Abstract}

This study involves the research, analysis, and performance of existing arrangements of songs that have been played and recorded by jazz musicians, and are identifiable as pop songs of the last thirty years. This project will discuss the development of these songs as new repertoire in the jazz idiom. In particular it will examine transcriptions of arrangements by Herbie Hancock, Dianne Reeves, Brad Meldau, Charlie Hunter, Christian McBride, and Bob Belden. The analysis of these transcriptions will consider the techniques these musicians used in their arrangements including reharmonisation, melodic interpretation, rhythm, and restructuring of the form of the original song.

Further, the techniques identified in the analyses will be applied in the creation of new arrangements of similar songs from that era for jazz ensemble of various sizes. 


\section{Acknowledgements}

I would like to thank the following people whose encouragement and support helped this project come to fruition.

Thank you to the staff at New Zealand School of Music, in particular the practical advice and enthusiasm of Phil Broadhurst and Donald Maurice, and to Norman Meehan for his scholarly wisdom in guiding me with writing this thesis.

Thanks also to my friends and colleagues for giving me time in their busy schedules to share their practical knowledge, and for their continuous support throughout this project particularly Kevin Field, Alan Brown, Larry Koonse and Pete France for their harmonic enthusiasm, and also Stephen Morton-Jones, Dixon Nacey, Susan De Jong and Rodger Fox who provided valuable suggestions.

Thanks also to all of the musicians who performed for their high level of expertise, attention to detail and energy in the performance of the arrangements and transcriptions.

A very large thank you is extended to all of my friends and family for their tireless support, endless enthusiasm and patience, and for my absence during the writing preparing and performing of this topic. 


\section{General Introduction}

"So this is jazz.... that peculiar word"

- Henry Osgood ${ }^{1}$

This thesis examines the expansion of jazz repertoire by introducing contemporary pop music into jazz repertoire. It is presented in three parts and the first begins with a background section involving discussion of how jazz is defined. This includes identifying features of jazz such as texture, rhythm, harmony, and the definitions of jazz standards, jazz pop, jazz-fusion and acid jazz, with further explanation in the Appendices. There will also be a discussion of the influence jazz artists such as Miles Davis, Herbie Hancock, Bob Belden and the effectual incorporation of pop songs into their repertoire.

Part Two of this study will examine a selection of transcriptions of arrangements of pop songs as recorded by jazz artists. These artists include Herbie Hancock, Dianne Reeves, Brad Meldau, Charlie Hunter, Christian McBride, Lisa Bassenge, Michelle Nicolle and Bob Belden. Analysis of these transcriptions will identify and discuss the incorporation jazz elements used in the arrangements such as melody, rhythm, texture, structure and harmony, in comparison with the original song.

The third part of this study involves analyses and application of techniques found in the transcriptions and used in new arrangements of a selection of pop songs from the same era. Discussion of these arrangements will also examine jazz elements under the headings of melody, harmony, rhythm, texture, and structure in comparison to the original songs.

Copies of all of the originals scores, transcriptions of the new versions, scores of the new arrangements as well as audio recordings of all original songs and transcriptions, will be included in the Appendices.

The final section is a conclusion, which will discuss findings made in this study.

\footnotetext{
${ }^{1}$ Andrew Clark, Riffs and Choruses, London: Continuum, 2001 pp.16
} 


\section{PART ONE - Background}

\subsection{Jazz Definitions}

"The history of jazz shows, that it is a melting pot of music"

The definition of jazz is contentious, and it has become a symbol of American culture and pace and embraces it's moving spirit. It is a broad term that is applied and includes a large family of music, not just a specific style. Eclectic in nature, it incorporates a variety of styles and draws influence from Afro-American blues and spirituals, as well as marches, popular song, ragtime and European Art music. Jazz is widely considered to be an art-music.

As with any art form the artists will always be reluctant to define their craft. There will always be controversy as to what is seen as "true" jazz, and to what the definition is as the art form evolves. Traditional jazz enthusiasts will always have an opinion, yet the art form must be able to transform and absorb new influences in order to develop.

There has been much discussion surrounding both the origins of the word Jazz and the art form itself. Although use of this term came into wide usage from 1913-1915, theories about the derivation of the word jazz are varied and controversial. While some definitions suggest that it comes from the 'jasper', meaning to chat or to gossip, other speculative interpretations intimate an injection of energy and excitement, while others a step further and derive it from black slang literally meaning "sexual intercourse".

Attempts to define jazz must attempt to include both musicological and social factors. It is important to understand that factors such as politics, society and race give context to an art form, and have shaped jazz history and sound. The United States of America have gone as far as declaring jazz to be a cultural and truly American art form.

\footnotetext{
${ }^{2}$ Stuart Nicholson, Is Jazz dead (or has it moved to a new address) Routledge 2005 pp 131
} 
On September 23rd, 1987, the House of Representatives passed a bill proposed by Democratic Representative John Conyers, Jr. to define jazz as a unique form of American music stating, among other things, "...that jazz is hereby designated as a rare and valuable national American treasure to which we should devote our attention, support and resources to make certain it is preserved, understood and promulgated." It passed the Senate on November 4th, $1987^{\text {,3 }}$

The particular feel or spirit of jazz is a result of its technical properties. It is essentially melodic and rhythmic improvisation that could be described as spontaneous composition on a standardised form or structure.

"Jazz trumpeter Wynton Marsalis describes jazz as "a series of blues based melodies". 4

"Jazz melody is inherently in jazz improvisation itself"

\section{Generally the musical elements of jazz include:}

- Improvisation - The major distinguishing factor in the style of music. It can take place individually and collectively within the group performance, at various points in the format of the song. The level of improvisation can inspire interaction, energetic response and emotional colour, making each performance unique and different.

- Structure - Jazz has developed certain specific musical forms including twelve bar blues, popular songs of the day mostly of a thirty-two bar form, and especially composed pieces.

\footnotetext{
${ }^{3}$ Jazz From Wikipedia, the free encyclopedia,1980s-2000s, http://en.wikipedia.org/wiki/Jazz accessed October 2nd 2008

${ }^{4}$ Robert O'Meally, The Jazz Cadence Of American Culture, Columbia University Press, New York 1998 pp 449

${ }^{5}$ Andrew Clark, Riffs and Choruses, London: Continuum, 2001 pp. 14
} 
- Ensemble - The jazz ensemble is also an identifying feature of jazz. There is no limit to the size of the ensemble, ranging from duo to big band.

- Rhythm is one of the most significant characteristics of jazz is it's rhythm. Swing-feel refers to the tripletised feel of the quaver beat, with the emphasis on the 'off beats' and the strongest beats being 2 and 4 , as opposed to classical music. See appendix 1 for jazz definitions for further explanation. There is also much use of syncopation and polyrhythms are derived from African influences.

- Harmony in jazz is based on a blend of blues and European traditions. It is derived generally from classical or Western Art Music but gains its unique quality with how it is blended with African rhythms. As with American culture, jazz is a fusion of many cultures, which influence it's sound, though the majority of the harmony is based on the European tempered major/minor tonal system. ${ }^{6}$

${ }^{6}$ Ed Byrne Theory: History of Jazz Harmony http://ezinearticles.com/Jazz-Theory:-History-ofJazz-Harmony\&id=247269Jazz 


\subsection{The Development of Jazz Repertoire}

Jazz repertoire is vast and diverse. It includes many varieties and styles of songs from numerous cultures that provide platforms for improvisation.

\subsubsection{Jazz Standards}

As discussed, jazz musicians have drawn on repertoire from blues, cultural influences roots, dances, marches and composed much of their own material. They also drew on identifiable popular tunes, such as music from Broadway shows and Tin Pan Alley, and also from films. The quality of the compositions was enhanced by the content of the lyrics and together established the public popularity of the songs. These became improvisation platforms for jazz musicians, and began to be performed more often, helping to add popularity to the song.

This repertoire has proved so popular with jazz musicians that it has been notated and catalogued, and much of it is still performed regularly today. They are instantly recognisable as part of the standard jazz repertoire, hence they are referred to as jazz standards.

American standards are defined as popular music and enduring songs written after World War One, predating the rock and roll era of the 1950s. The "Great American Songbook" is a term that encompasses these songs, by composers and lyricists such as Irving Berlin, Harold Arlen, Jerome Kern, George Gershwin and Ira Gershwin, Richard Rodgers, Lorenz Hart, Oscar Hammerstein, Johnny Mercer, Dorothy Fields, Hoagy Carmichael, Cole Porter, and a host of others. Big band leaders such as Tommy Dorsey, Cab Calloway, Benny Goodman, and Count Basie also helped further develop the genre of "pop standards" by incorporating arrangements of popular songs of the time into their repertoire. Vocalists from the big band era, including Frank Sinatra, Doris Day, Ella Fitzgerald, and Dinah Shore enjoyed huge success as a result. 


\subsection{Adoption of Pop and Modern Music}

"The great tone is the tone that goes beyond all usual imagination".

From the late 1960s artists such as Miles Davis and Tony Williams again moved away from the comfort zones and confines of the label of "jazz". They were also aware of the restrictions and subsequent categorization maintained and controlled by record companies.

Their interest spread to many other musical genres and combined the influences of African and Indian cultures, as well as the music of popular black music such as that of Jimi Hendrix and Sly and The Family Stone. The resulting sound evolved from technical accomplishment of the musicians, an appropriation of the other styles, combined with a creative freedom for the performers. Fusion was born.

"The ongoing debate between those who draw on inspiration on jazz's historical past...and the continuous revolution of the avant-garde and the commercial orientation of fusion" ${ }^{8}$

\subsubsection{Jazz Pop}

Jazz pop was a term developed and made famous by pianist Ramsey Lewis and his Trio, who became well known for his reinterpretations of popular hit songs of the 1960s and 1970s. There has been some inclusion into the jazz repertoire of songs from some popular rock bands of the 1960s and 1970s that work well as a basis for reinterpretation and improvisation. These include composers from popular and rock bands, such as Sir Paul McCartney and the late John Lennon from The Beatles. There are many recorded examples of versions of their songs including leading jazz musicians such as Herbie Hancock, and Nils HenningOrsted-Pederson. Similarly, songs from the Motown era by composers such as

\footnotetext{
${ }^{7}$ Stuart Nicholson, Jazz rock: a history, New York: Schirmer Books 1998 pp ix

${ }^{8}$ Stuart Nicholson, Is Jazz dead (or has it moved to a new address) Routledge $2005 \mathrm{pp} \mathrm{x}$
} 
Stevie Wonder are also played, recorded and reinterpreted often by jazz musicians.

Jazz has had its share of traditional contemporary performers such as Wynton Marsalis who want to retain the neo-classical sound of the 1960s. However it has also embraced new technology in sound and recording techniques. New technology has also become part of jazz vocabulary. In the 1990s the sound of jazz began to include sequencing, programming, DJ's and other assorted electronica. Part of the reason for adoption is because the cost of new technology has diminished considerably. The other part is because jazz artists have also used this to not only broaden their appeal, but because of the musical and exploratory possibilities while also absorbing the colour of contemporary youth.

\subsubsection{Miles Davis}

Miles Davis not only recorded and performed contemporary songs; he also toured the world with sell out performances as a jazz artist. He embraced the contemporary popular cultures of the day and included number one hits on several of his albums, released only a few years after the release of the original song.

“He wanted to make popular or 'folk' music. The fact that he wasn't afraid to cover popular songs throughout his life-whether Some Day My Prince Will Come or Time After Time is an expression of this."

Unlike many great artists in the past who became famous posthumously, Miles Davis was a highly successful jazz artist during his lifetime. As well as composing many jazz tunes in the jazz, trumpeter Miles Davis also incorporated best selling popular songs of the 1980s on his albums.

\footnotetext{
${ }^{9}$ Paul Tingen, Miles Beyond pp99
} 
In 1984 Miles recorded a number of pop hits, with the idea that arranger Gil Evans could arrange an album of them. These included Chaka khan's Through the Fire, Tina Tuner's What's Love Got To Do With It, Dionne Warwick's Deja Vu, Cindy Lauper's Time After Time, and various other tracks by Toto and Nick Kershaw, and some of them were later performed live. ${ }^{10}$

Miles' version of Time After Time, was included on the1995 album 'You're Under Arrest'. Time After Time was Cindy Lauper's number one hit, from her debut album 'She's So Unusual', which sold over five million copies. Miles and Cindy Lauper became friends, as she cherished his version of her song. He even composed a tune for her entitled I Cant Stay Away From You, and did an instrumental version called Morrisine for an upcoming tour.

"Miles versions of Time After Time and Human Nature were incredibly successful and became hits in various countries.....'You're Under Arrest' went on to become one of his best selling albums, selling more than 100,000 copies within weeks of it's release. The recordings marked Miles's breaking out of the jazz market and into the worldwide youth market, and the beginning of his final years as an international celebrity and superstar"11

The success of these jazz renditions of these pop songs does not necessarily equate to good to music. They also developed dubious notoriety amongst more traditional jazz musicians and fans, as they came to be played on smooth jazz radio stations and muzak tapes in shopping malls, cafes and restaurants. ${ }^{12}$ These instrumental versions recorded versions are not particularly innovative. They have basically been presented in a pop style but played by jazz artists and

\footnotetext{
10 Paul Tingen, Miles Beyond: The Electric Years of Miles Davis1969-1991, Billboard Books, New York 2001 pp 217

11 Paul Tingen, Miles Beyond: The Electric Years of Miles Davis1969-1991, Billboard Books, New York 2001 pp 219

12 Paul Tingen, Miles Beyond: The Electric Years of Miles Davis1969-1991, Billboard Books, New York 2001 pp 219
} 
they are very similar to the original renditions. The backings played by the band are very similar to the original versions, with the trumpet following the original ballad style of the melody in a similar fashion. There is little in the way of improvisation, and rearrangement as such. However, Miles did include these two tunes in his live sets, and did recompose them more. Live versions of Human Nature became a showcase for Alto Saxophonist Kenny Garrett, whose solo over the Milestones chord progression, transformed the song from its original format. ${ }^{13}$ 'Perfect Way' was the planned title of the album 'Tutu'. Recorded in 1986 'Tutu', Miles released a version of the 1980s pop hit by Scritti Politti, Perfect Way. This version was laden with drum programming, leaving Miles very little space to interpret the song, as he had in the style of Time After Time or Human Nature. However, this album was also successful as a crossover between jazz and the popular and rock genres, earning Miles another Grammy, this time for Best Jazz Instrumental Performance, and Best Recording Packaging.

There have been many 'smooth jazz' renditions of popular songs. Smooth jazz is a genre of jazz that grew out of fusion. The resulting 'slick' or more contemporary sound of smooth jazz is generally not as focused on improvisation but on a combination of commercial production techniques as well as rhythms and grooves. Synthesized or electronic instruments were added into the arrangements, the melody often played by soprano or alto saxophones, the harmony commonly covered midi-guitar, and light funk grooves in the rhythm section. Though these versions tend to have a melodic emphasis, the result often having a lighter appeal than the versions that use a more acoustic and traditional jazz flavour.

Some critics such as Stuart Nicholson have dismissed the smooth jazz concept.

\footnotetext{
13 Paul Tingen, Miles Beyond: The Electric Years of Miles Davis1969-1991, Billboard Books, New York 2001 pp 260
} 
"Smooth jazz radio stations demanded music with a catchy melodic hook, a bright and breezy theme, a contagious backbeat, and tunes that lasted no more than four minutes"14

Commercial forces exert pressure to build audience size and inevitably prospects of profitability, creating a tension as it would for any art form.

\subsubsection{Herbie Hancock}

Herbie Hancock's album 'The New Standard'was released in 1995. Produced by Bob Belden, the album comprised of his versions of contemporary pop songs by artists such as Prince, Stevie Wonder, The Beatles, Peter Gabriel, Kurt Cobain, Paul Simon and Don Henley. Musical devices used in these rearrangements included reharmonisation, the addition of vamps, changes of tempi, as well as different instrumental textures.

Reviewer Scott Yanow described the album:

"Hancock was able to transform the potentially unrewarding music into creative jazz and the results are often quite hard-swinging and certainly never predictable...Herbie Hancock has successfully created a memorable set of "new" music."15

In a similar vein, Hancock's album Possibilities was released ten years later in 2005. This project not only included songs by pop artists, it also utilized pop singers such as Christina Aguilera, John Mayer, Jonny Lang, Joss Stone, Sting, and Annie Lennox, Santana and Paul Simon in the performances. Although there is a wide range of songs, beautiful reharmonisations, creating a range of styles and moods on this album, jazz listeners were less than convinced. Some say the result was a jazz album done in a pop style rather than an album of arranged pop songs, performed by a unique collaboration of jazz and pop artists. However, it

\footnotetext{
${ }^{14}$ Stuart Nicholson, Is Jazz dead (or has it moved to a new address) Routledge group 2005, pp 11

${ }^{15}$ Scott Yanow, The New Standard Overview, All Music guide, accessed November $16^{\text {th }} 2008$
} 
remains an example of a 'pop-jazz' album that created much interest, especially for the listener who hasn't listened to much jazz. ${ }^{16}$

\subsubsection{Acid Jazz}

In the late 1980s, a group of English DJ's created the term Acid Jazz. This referred to an instrumental jazz funk, where they played entire jazz album tracks for the dance crowds in dance culture. ${ }^{17}$ One of the most significant Albums created of this time was DJ Geoff Wilkinson's was best selling album Hand on the Torch. The single form this album entitled "Cantaloop (Flip Fantasia)", was released in 1993. It used a repeated sample of the funky piano riff, and a trumpet solo on Herbie Hancock's "Canteloupe Island" from 1964. This remained popular in the dance scene for two years. Miles Davis' 1991 album 'Doo Bop' is laced with hip hop, an excellent example of and presented in the style of the English acid jazz scene.

The next part of this thesis examines how contemporary jazz artists have appropriated pop material as repertoire for their jazz performances and recordings.

\footnotetext{
${ }^{16}$ Thom Jurek, Possibilities: Overview All Music guide, accessed November $16^{\text {th }} 2008$

${ }^{17}$ Stuart Nicholson, Is Jazz dead (or has it moved to a new address) Routledge 2005, pp 141
} 


\section{PART TWO - ANALYSIS OF EXISTING ARRANGEMENTS}

This section analyses arrangements by jazz artists, of a selection of pop songs from the last thirty years, and consider the adaptation of melody, the changes in structure in the song, changes in instrumentation, and the application of jazz harmony.

This section includes songs originally written by popular artists such as Don Henley, Kurt Cobain, Peter Gabriel, Prince, Madonna, Sting, as well as the bands Radiohead and Simple Minds. Each of these tunes has been recorded as a jazz arrangement, by jazz musicians including Brad Mehldau, Billy Childs, Charlie Hunter, Bob Belden, Herbie Hancock, Lisa Bassenge, Christian Mc Bride and Michelle Nicolle. 


\subsection{Melody}

The melody is one of the most important defining features of a song. The lyrics also play a role in recognition of the tune though there will be limited discussion of the impact in relation to other musical elements of these in this research. For contemporary popular songs the melody often makes them recognisable to a large audience. Norman David expressed the importance melodic treatment:

"The manner in which an arranger works with melodies is crucial to the eventual impact and success of an arrangement". ${ }^{18}$

The melody can be adapted and enhanced by a jazz arranger while taking into consideration other musical elements such as rhythm, harmony, structure and instrumentation.

A vocalist is not always a prerequisite of a jazz ensemble and these pop songs can also be performed as instrumental versions yet still function melodically and emotionally.

\subsubsection{Adapting the melody}

The original version of Don Henley's New York Minute is a repeated note melody based mostly on two notes $\mathrm{D}$ and Eb with a crotchet chordal vamp played by the piano. As we can see in figure 1, the range of notes is extended slightly in bars 17 and 18 , up to the $\mathrm{G}$ and down to the $\mathrm{Bb}$ at the end of the verse.

${ }^{18}$ Norman David, Jazz Arranging, Ardsley House, Publishers, 1998 p53 
Don Henley: New York Minute, bars 11-18 - 0.54"
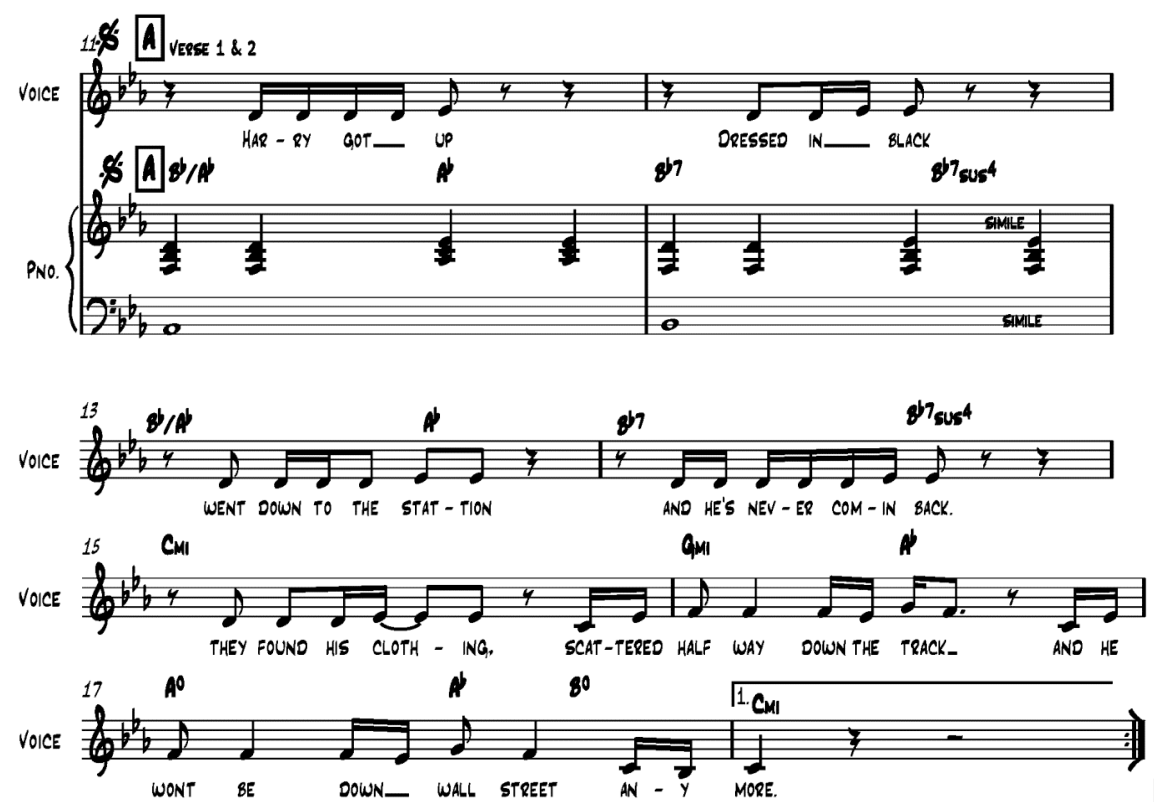

Figure 1

In Bob Belden's arrangement of New York Minute from Herbie Hancock's 1995 album 'The New Standard', the melody has been adapted to be played at a much faster tempo. The band plays a two bar vamp line, while the melody is played in unison by tenor saxophone and guitar.

The melody has been simplified with less repeated notes, and adapted to the new tempo which is now twice as fast as before; the bar length has doubled (figure 2). It has also been rhythmically altered to off- beat quavers resolving onto the first beat of the next bar. As we can see in figure 2, the melody is cut up at bar 26 by an extra eight bar section of the vamp, before returning at bar 42 with a similar vamp but in the new key of Ab.

Bob Belden: New York Minute bars 18-49 - 0.18"

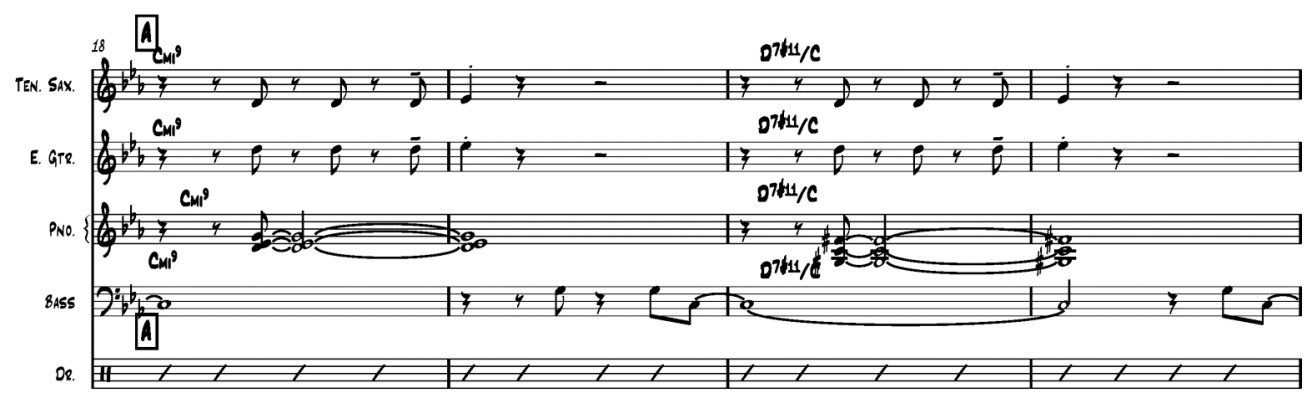



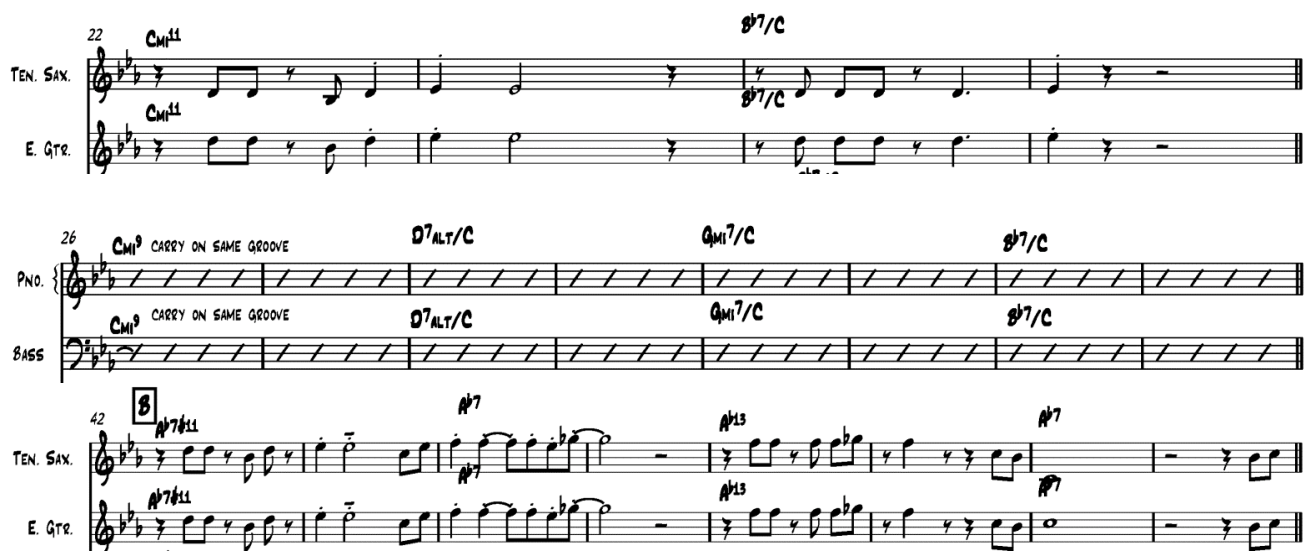

Figure 2

Very few pop songs are non-vocal or instrumental arrangements. The musical style of Prince is very much vocal-based, and can be summed up as wild fusion of funk, rock, new wave, and soul; each album he releases reveals musical diversity and growth, but with a willingness to experiment and explore different sounds, textures, and genres. The album '1999' sold over three million copies and was released in 1983. The single itself is an end-of-the-millennium anthem, and is constructed almost entirely on synthesizers played by Prince himself.

As we can see in figure 3 below the melody of the original version of 'Prince's' 1999 , is built on two bar repeated note phrases within a small range of pitch. Each phrase is altered slightly in pitch, the second one is a third lower than previous phase, the next a third higher. At bar 25 the melody returns to the same pitch as the beginning in bar 13 .

Prince: 1999 bars 13-28

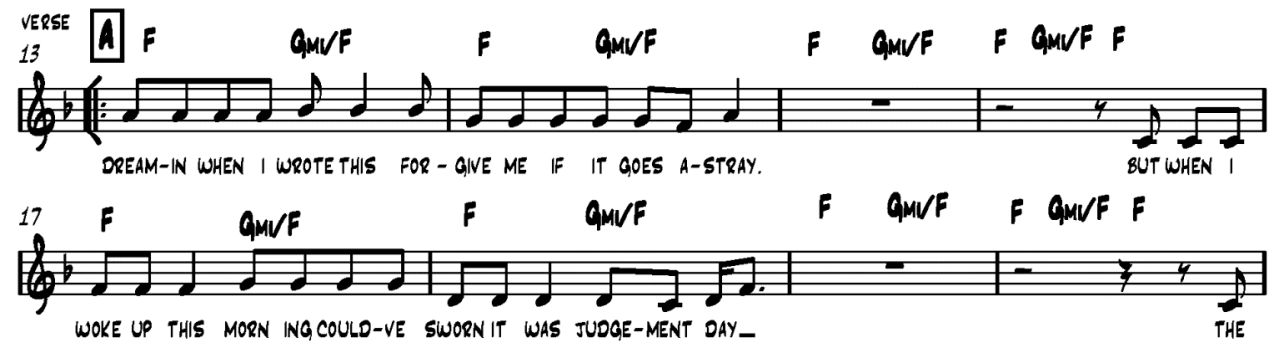




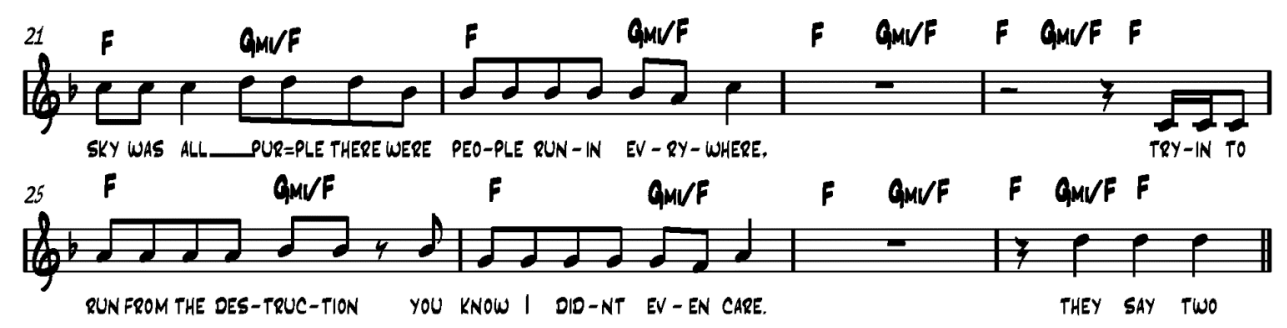

Figure 3

The melody has been adapted to fit electric guitar in Bob Belden's version of Prince's 1999. As we can see in figure 4 the guitarist plays the melody in octaves. The melodic shape is essentially retained but with some alternating notes at the end of each phrase. The melody also has an impact on the instrumentation with the added impact of being played in the octaves on guitar to cut above the large ensemble that fills out the harmony.

Bob Belden: 1999 bars 10-25
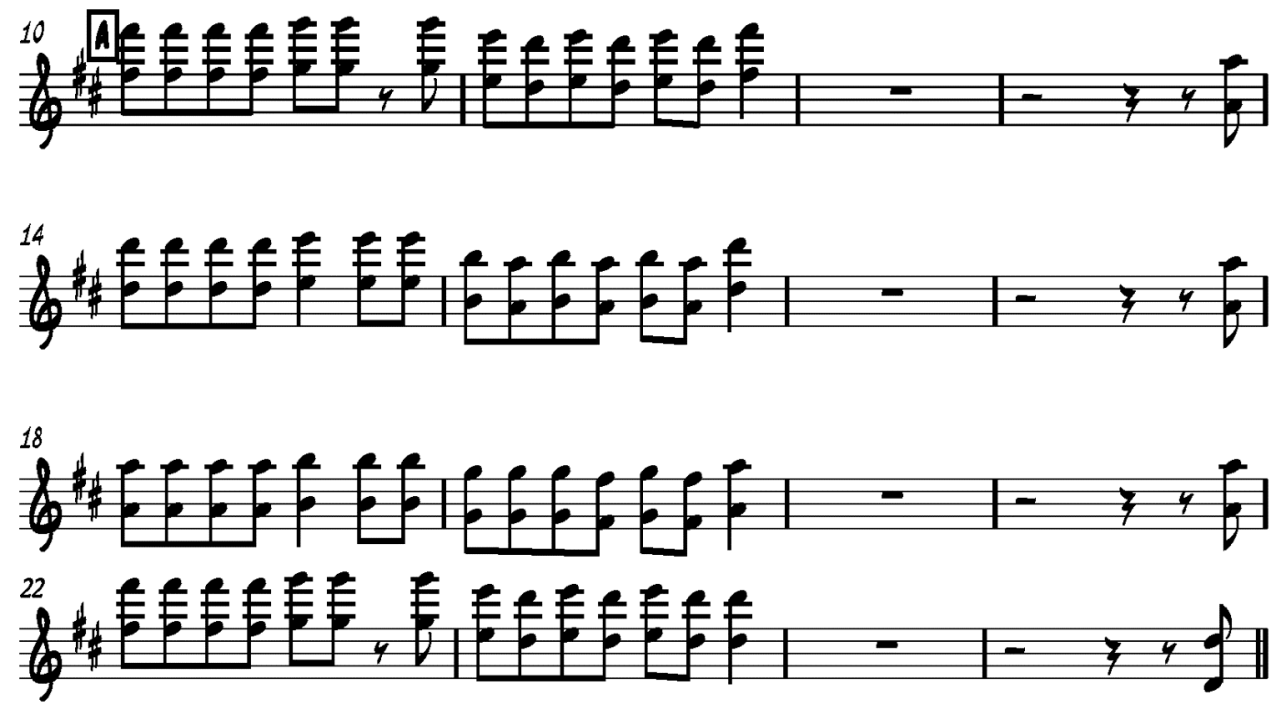

Figure 4 


\subsection{Rhythm}

Rhythm is a very mutable element in writing a jazz arrangement. Many rhythmic decisions can be made and manipulated within the jazz arrangement, including the choice of tempo, time signature, as well as the general feel or groove.

New arrangements of pop songs played or recorded by other artists, are often slowed down and performed as ballads, or have completely different time signatures or grooves added to them, often based on a vamp, as the basis of a new texture.

As you would expect with jazz performers, the interaction or intensity of the musicians in the band may change, sometimes resulting in the different tempo for each performance.

\subsubsection{Changing The Groove}

There are several ways that a jazz feel can be achieved in a jazz arrangement of a pop song. Changing the type of groove or feel from the original song, is one way in which to achieve this. The obvious way to add a jazz feel to a pop song would be to add a jazz swing quaver feel. However there are many other types of grooves that can be used, many of which come from the influence of world music.

In 1984 vocalist and bass player Sting from 'The Police', began a solo career and maintained a healthy preoccupation with expanding the boundaries of pop music, and incorporated elements of jazz, classical, and world beat into his music. 
'Sting's' Sister Moon (fig 5) already has a $12 / 8$ feel, and the bass line is almost in a swing feel, reminiscent of Gershwin's It Aint Necessarily So from 'Porgy and Bess'. We then see the melody of the original version in figure 6 below.

Sting: Sister Moon, Introduction

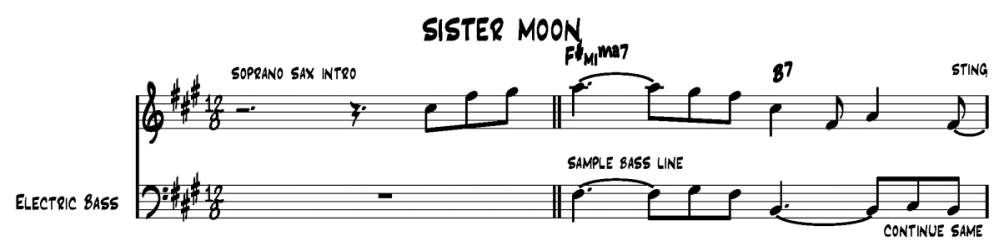

Figure 5

Sting: Sister Moon, melody bars 6-10

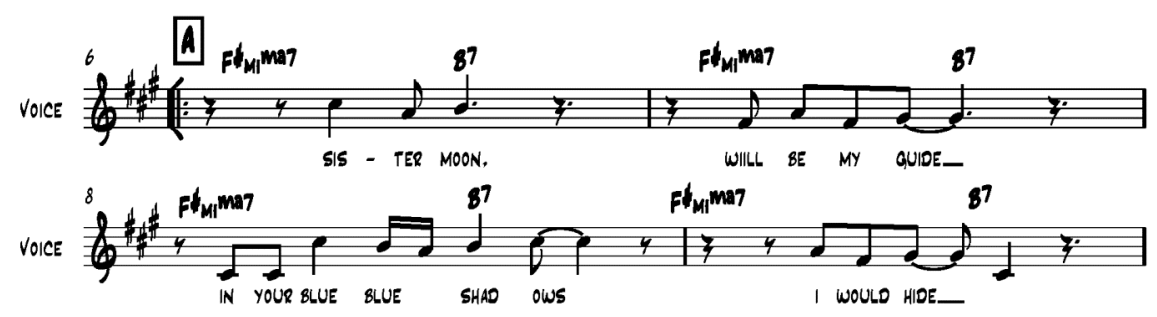

Figure 6

In 2005 Herbie Hancock released the twice Grammy nominated album 'Possibilities', an album which included a collaboration with many pop artists including Sting and others and contained a wide range of songs, styles, and moods. Sting had suggested Sister Moon, and Hancock had called on West African guitarist Lionel Loueke, member of the student band of the Thelonious Monk Institute of jazz in Paris, to come up with ideas for an arrangement of this song. 
The new arrangement of Sister Moon is influenced by guitarist Lionel Loueke's African rhythm. The arrangement is based on an African- style vamp played in unison by Fender Rhodes and bass, with drums and percussion reinforcing the twelve quaver beats, and emphasising the second and fourth beats of the bar. At bar 3 a contrasting yet complementary rhythmic guitar line is layered on top of this groove, outlining more notes in the chord, which we can see in figure 7 below.

Herbie Hancock: Sister Moon bars 3-7

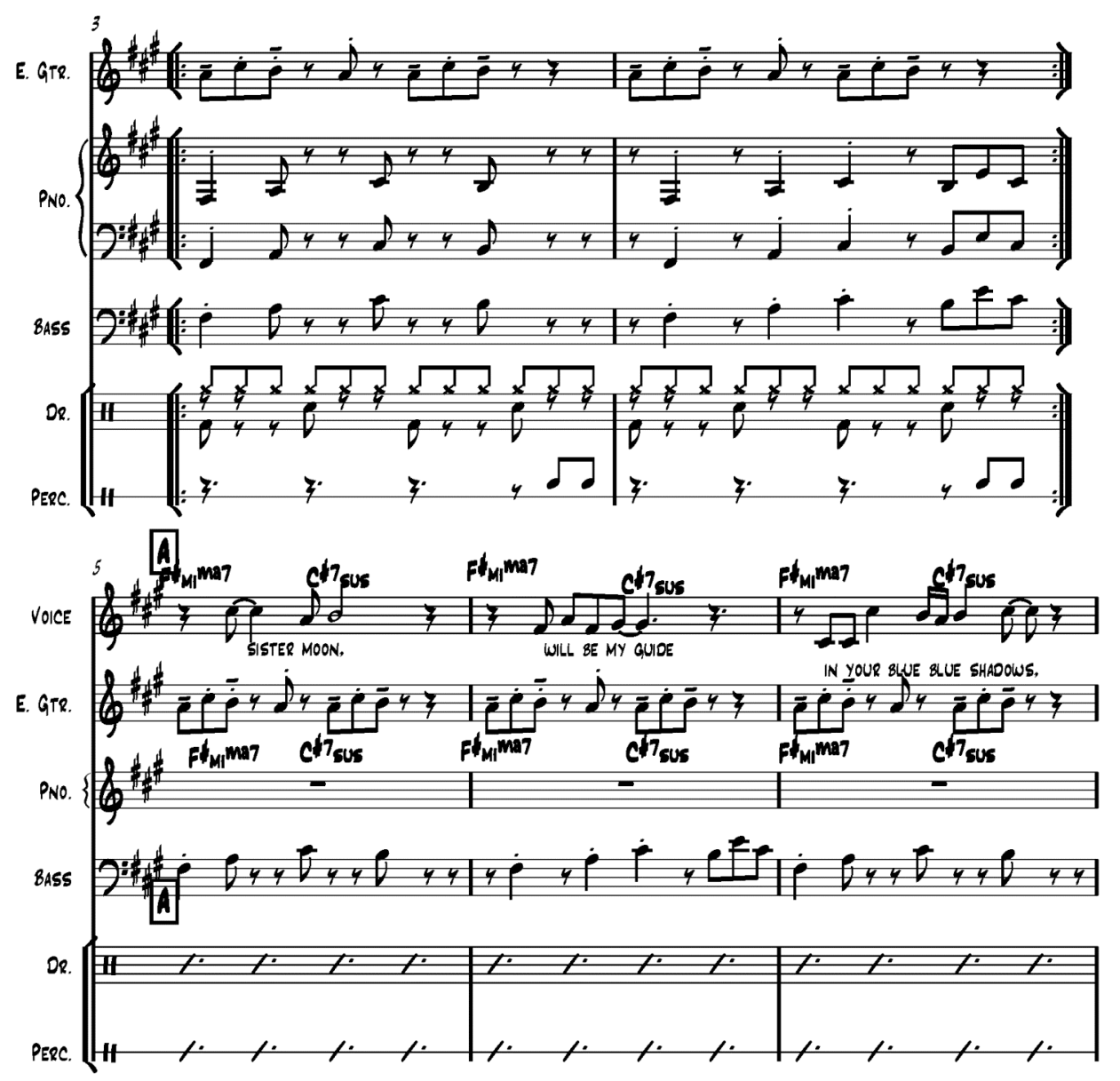

Figure 7 
Hancock said about playing his groove:

"It was something that took us pro's a while to really grasp the heart of it. It wasn't that we couldn't play it, but to really own it, it took a while." 19

The initial groove continues underneath the floating melody until bar 13, the next section where the band plays the chords in a definite rhythmic pattern, which adds another rhythmic jazz influence (Fig 8). These hits give a definite uniformity to the harmonic progression.

Herbie Hancock: Sister Moon bars 13-15

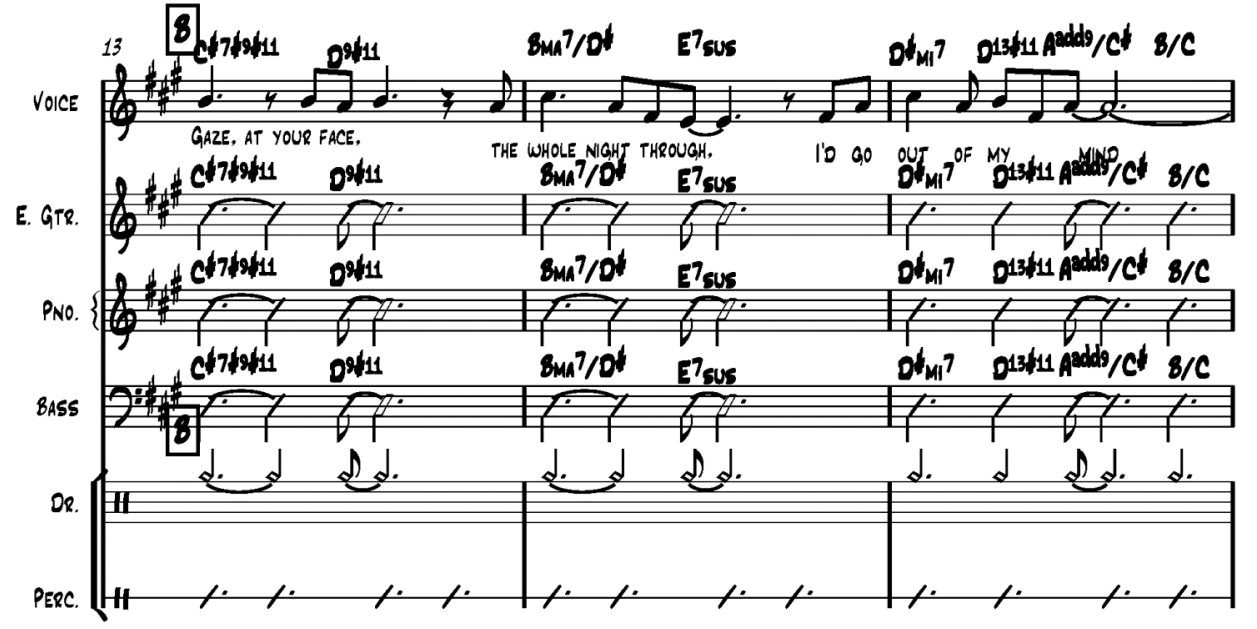

Figure 8

Other examples of groove changes in the music from these transcriptions to consider include Charlie Hunter's faster version of Come As You Are in a swing

${ }^{19}$ Herbie Hancock, transcription by Trudy Lile of Possibilities DVD, Magnolia, 10060, 2006 
five feel, and Christian McBride's contrastingly slow and haunting arrangement of Walking On The Moon, which originally had a reggae feel. Also mentioned already are the modal arrangement of New York Minute, which was originally a rock ballad, and the funk sixteenth Motown feel of Bob Belden's arrangement of 1999 , formerly played with a rock feel.

\subsubsection{Changes of tempo}

Bob Belden's arrangement of 'New York Minute' from Herbie Hancock's 'The New Standard' is much faster than Don Henley's original version. A fast uptempo swing feel is retained throughout the song, perhaps reflecting the fast hectic pace of life in the Big Apple.

The original ballad version of this song has a crotchet pulse throughout the verse, see figure 9. The intensity of the chorus section of the song is enhanced by the addition of drums.

Don Henley: New York Minute bars 11-12

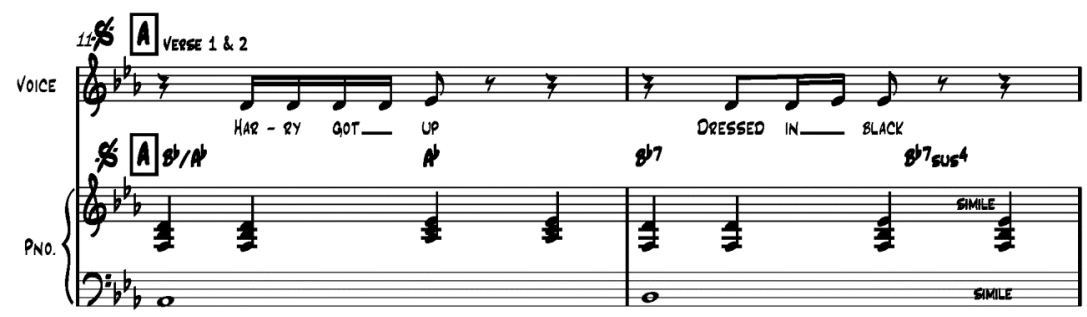

Figure 9

The new arrangement has a groove that is based on a two bar vamp, see figure 10 below, which the bass anticipates with a syncopated rhythm and the piano plays a chord on the anticipation of the second beat, with chord alterations each time. 
Herbie Hancock: New York Minute bars 18-21

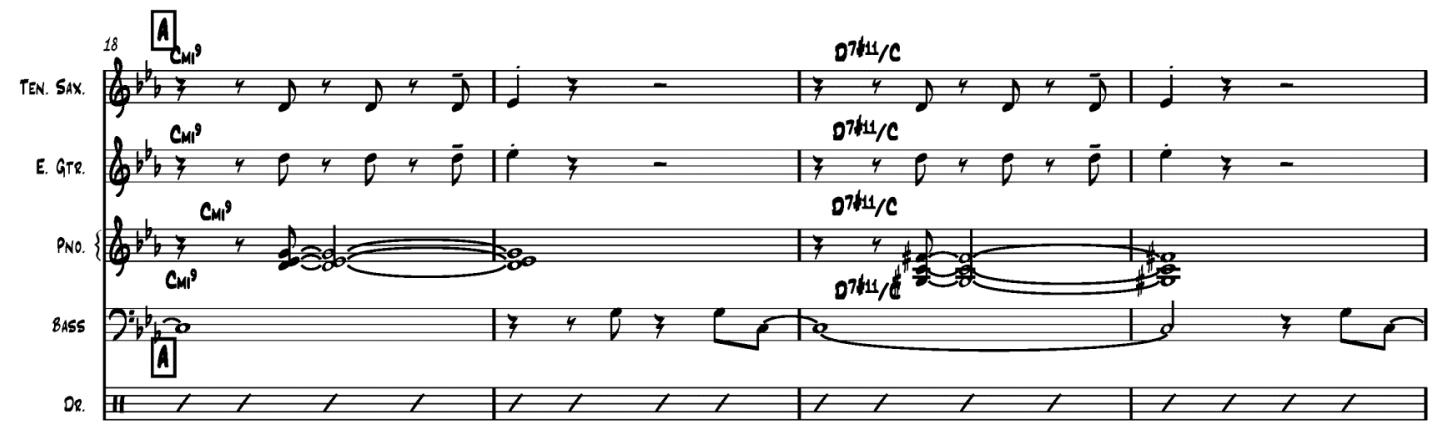

Figure 10

This continues through the form of the tune until bar 59, where there is a more open modal feel in $\mathrm{F}$ minor, which allows the band to play and interact more spontaneously in a jazz style underneath the melody. This open feel continues through the chord changes at the end, at bars 76 to 79 .

\subsubsection{Changes Of Meter}

For additional rhythmic variety an arrangement can be in a different time signature than $4 / 4$, and it can also contain several different meter changes. How the different meters are linked in terms of pulse is vital to the effectiveness of this concept.

Described as pop punk rock superstar band of the 1980s, 'The Police' released the album 'Reggatta de Blanc' in 1979. This album contained two anthemic hit singles Message in a Bottle and Walking On The Moon.

As we can see in figure 11 the chorus section in the original version of Walking On The Moon is a simple but effective four-bar pattern repeated four times with different lyrics each time. 
Sting: Walking On The Moon, chorus

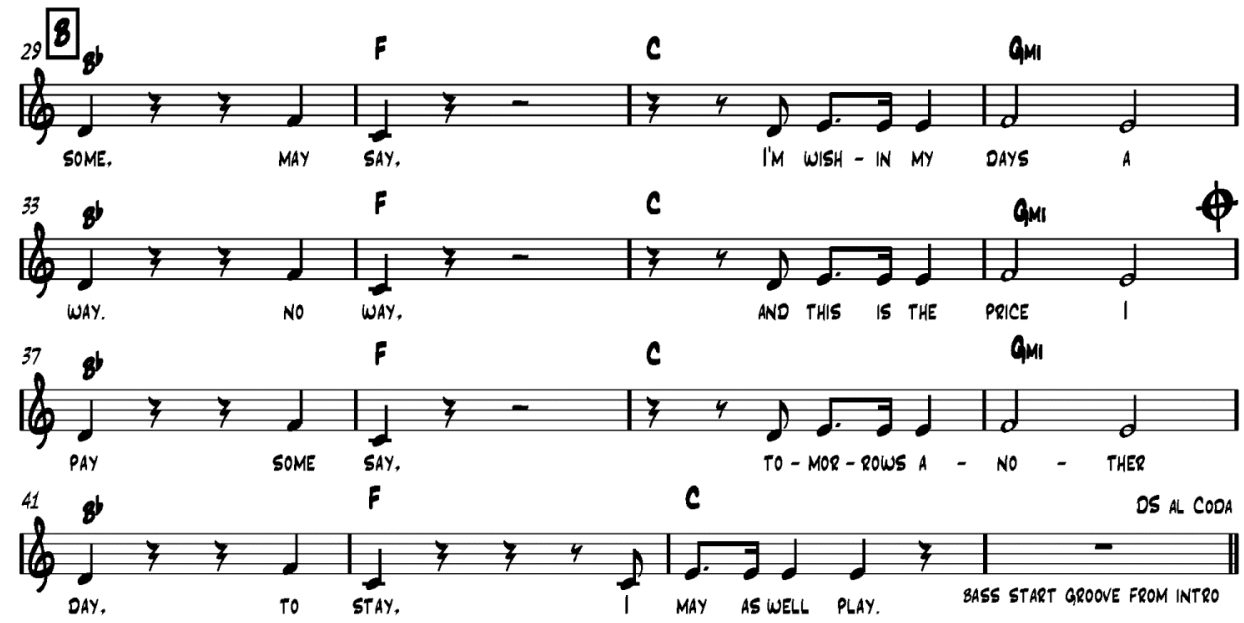

Figure 11

Jazz bassist Christian Mc Bride established himself as one of the most popular bass players of the 1990s, and played and toured with Sting amongst others. His album 'Sci-Fi' was released in 2000, which incorporates some of the pop, funk and fusion styles he grew up with.

In the chorus section of his instrumental version of Walking On The Moon, the time signature is changed from 4/4 to three in a bar, see figure 12 below. The melody played by bass clarinet is adapted to the new time signature for sixteen bars beginning at bar 21 , and the drums provide the consistent crotchet pulse beneath. This definitely adds to the overall eerie free quality achieved in the arrangement. 


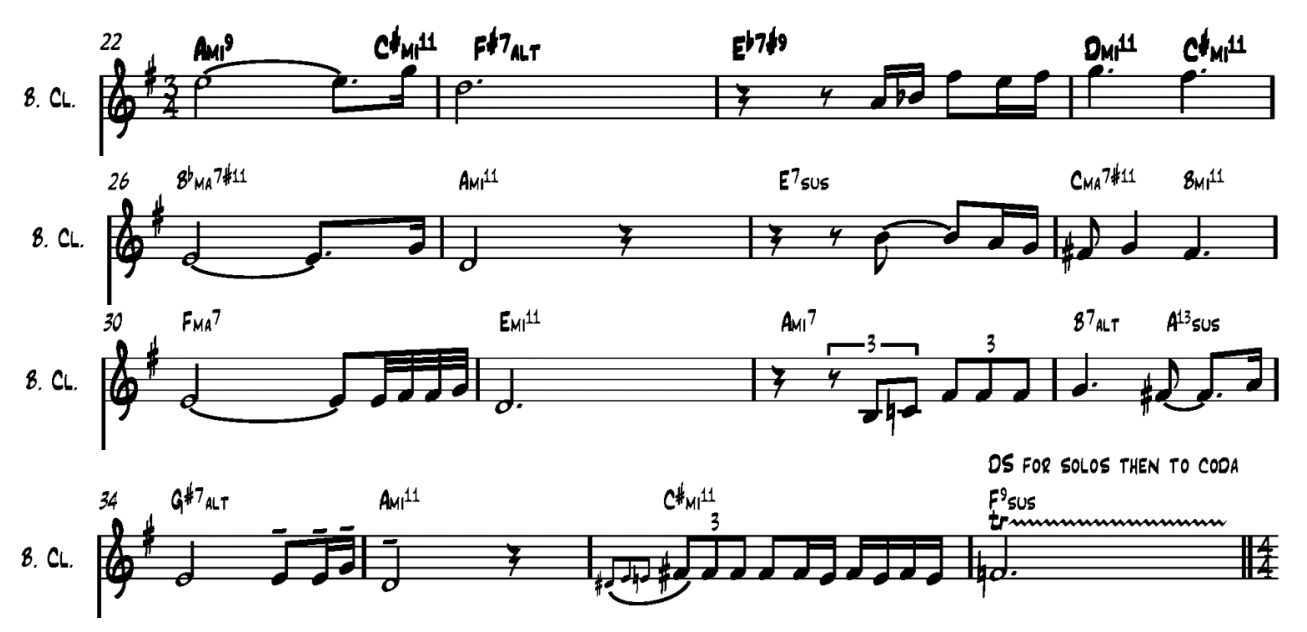

Figure 12

Don't You forget About Me by 'Simple Minds' is an excellent example of the NewWave era and can be regarded as an anthem of the mid 1980s. This hugely successful single was released on the sound track to the movie "Pretty in Pink" in 1985, as well as on the band's album "Glittering Prize 81/92". It has been described:

This is a pretty terrific pop single, appealingly dramatic in a teen-angsty kind of way, with a great tension-and-release chorus and a classic iteration of the old "bass and drum breakdown swelling into an anthemic final chorus" trick that uses Michael Mac Neil's symphonic synthesizer style to its fullest. ${ }^{20}$

The beginning of the song features synthesisers and guitars playing strong dotted rhythms spelling out a two-chord vamp with vocal fills in alternate bars. When the verse begins at bar 9 the bass plays a driving repeated note rhythm over a harmonically simple, four bar pattern, see figure 13 below.

Simple Minds: Don’t You Forget About Me, bars 1-16

\footnotetext{
${ }^{20}$ Stewart Mason, Don't You Forget About Me; Song Review, All Music, accessed January $9^{\text {th }}$ 2009
} 

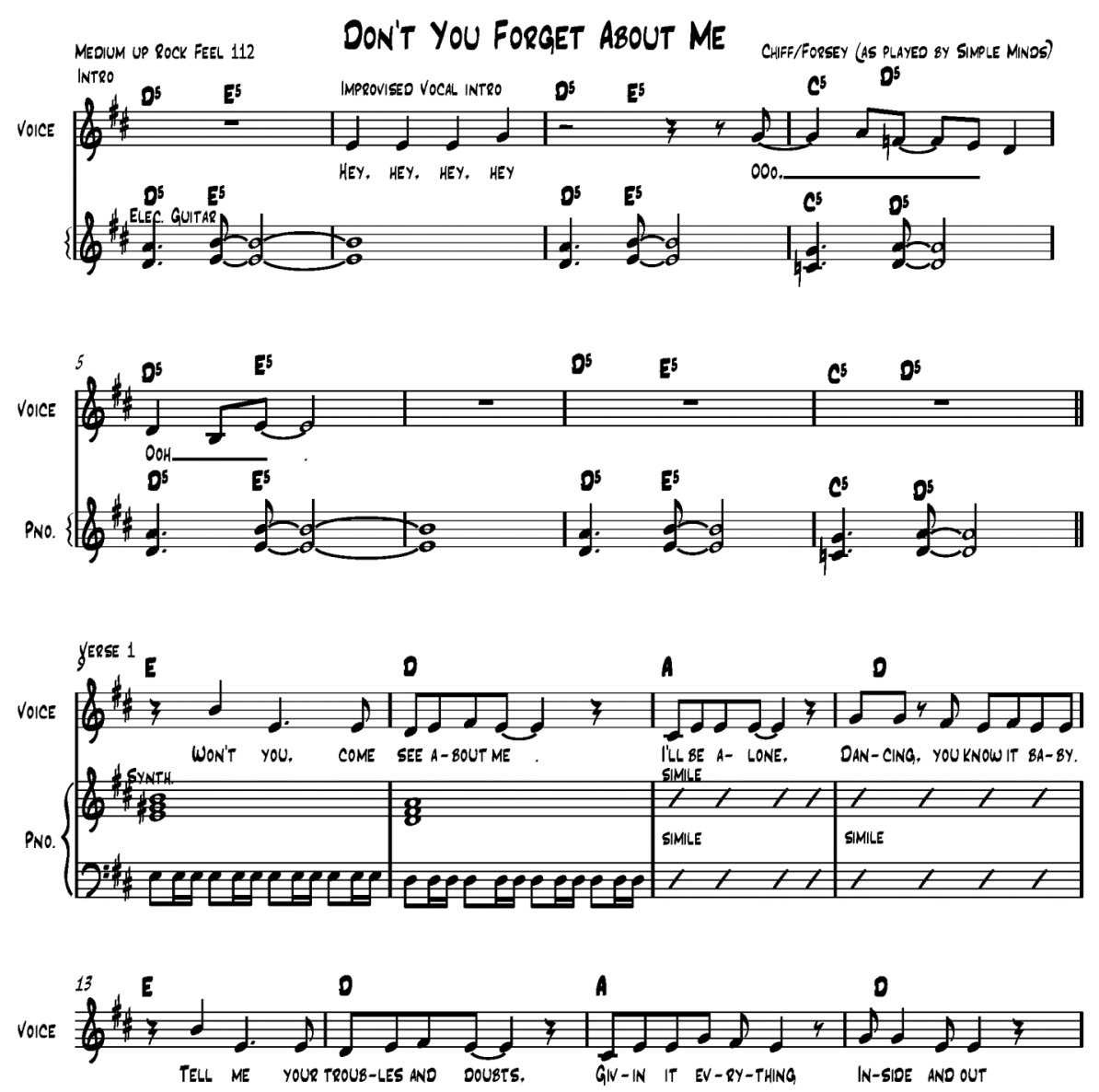

Figure 13

Celebrated Australian jazz vocalist Michelle Nicolle released a version of this song on her album 'The Crying Game' in 2003, a collection of songs that have appeared in films or on sound tracks.

Nicolle's stripped back arrangement of this song is slower and less cluttered than the original version and contains several seamless changes of meter. It begins in $6 / 8$ with a two bar opening dotted rhythmic phrase played by piano followed by a repeated note, answering phrase played by flugelhorn that anticipates the beat. This develops rhythmically until the beginning of the verse, where the piano sets up the verse at bar 13 with a triplet figured that is sustained for the bar, underneath the vocal entry. The melody line further establishes the change of 
meter to $4 / 4$, where the dotted crotchet pulse becomes the slow crotchet pulse of the new time signature, see figure 14 below.

Michelle Nicolle: Don't You About Me Introduction
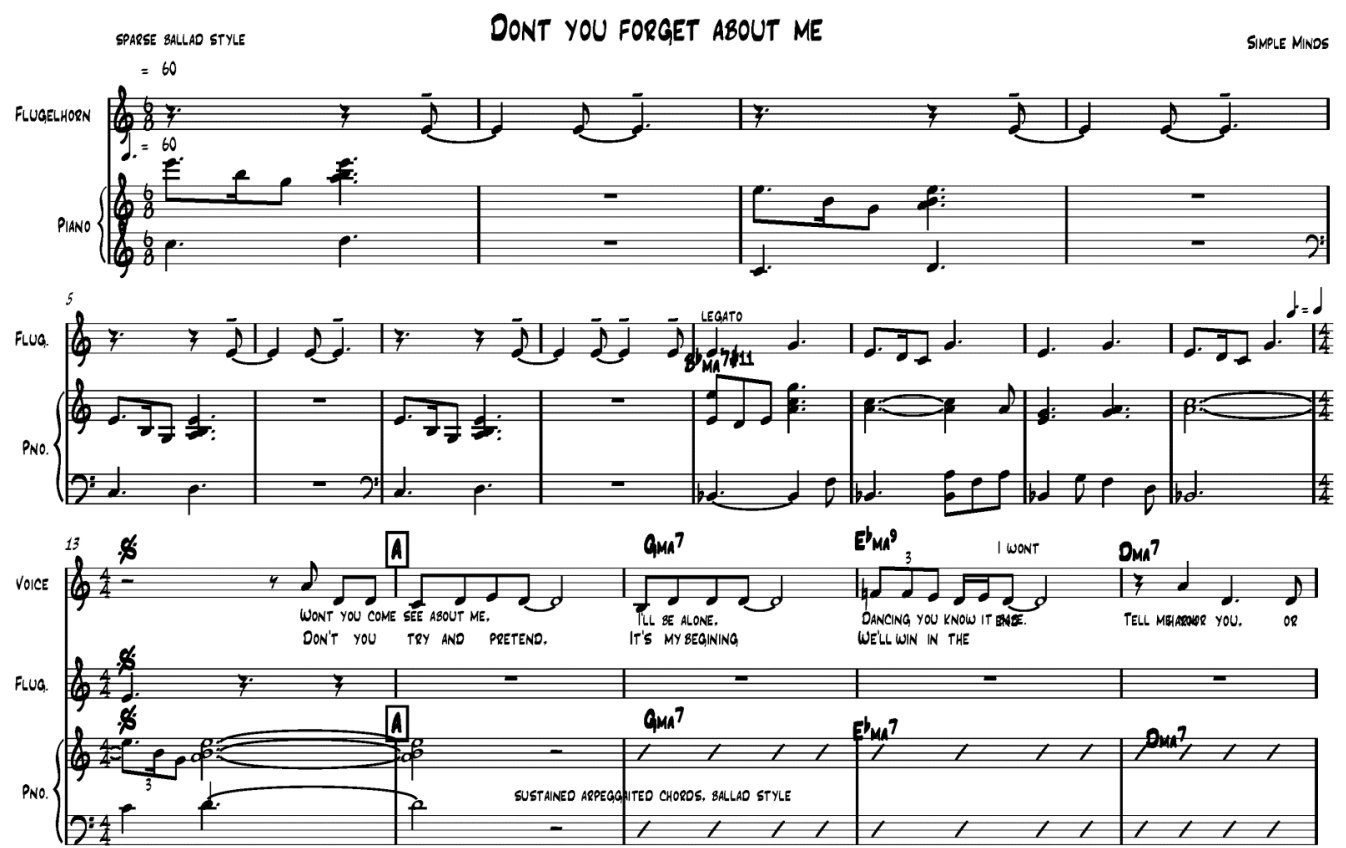

Figure 14

There is another change of meter from $4 / 4$ to $6 / 8$ at the bridge section in bar 37 . From there the piano outlines the chords sparsely with occasional quaver movement. In figure 15 below, the harmonising backing line that the flugelhorn plays at bar 31 , is the same rhythm as the opening of the vocal phrase at the chorus and this adds fullness and rhythmic support to the change of section. 


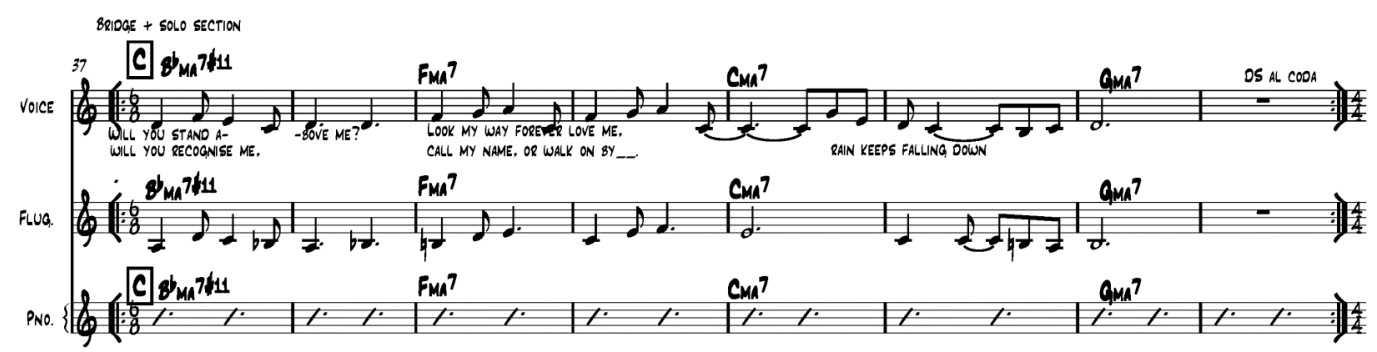

Figure 15

After the flugelhorn solo the meter changes back to $4 / 4$ for the verse in the same manner with the piano playing the dotted triplet figure as seen in figure 14. The song continues through to the chorus section as before but has one more time signature change in the coda section at bar 56 where it changes to and remains in $6 / 8$ until the end.

Michelle Nicolle: Don't You About Me 53-end
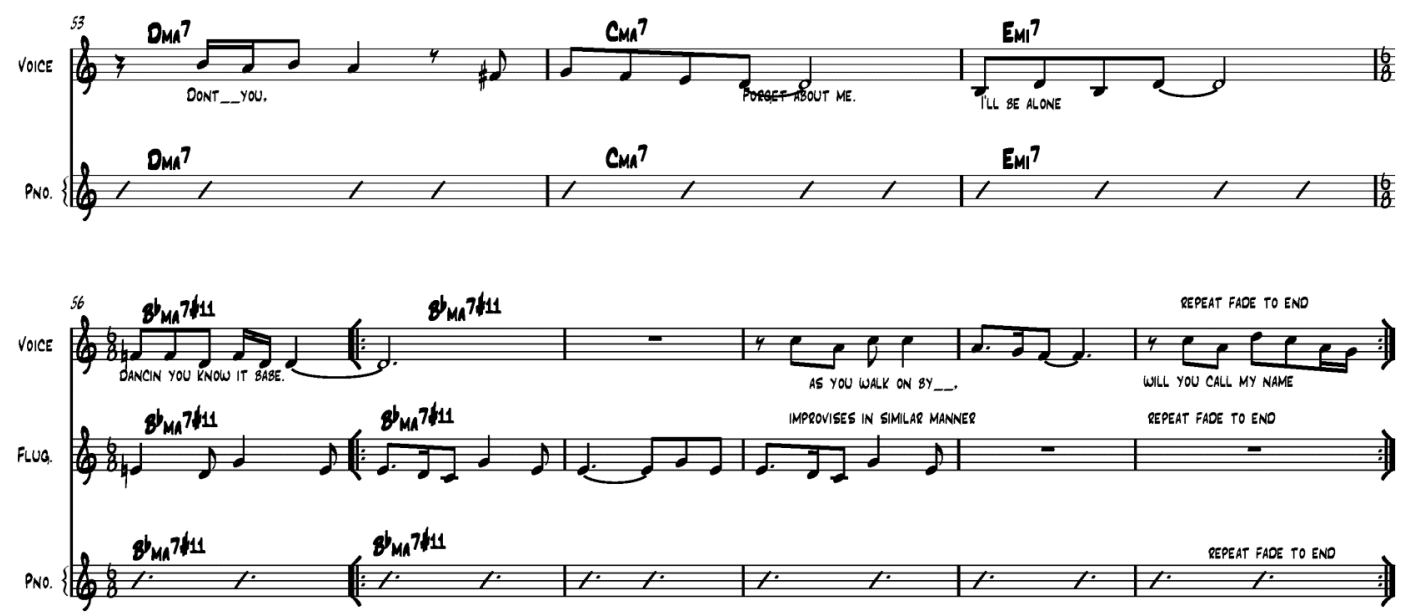

Figure 16

\subsection{Instrumentation And Texture}




\subsubsection{Size of the group}

The instrumentation used by bands from the 1980s featured heavy use of new technology of the day. Synthesisers and guitars appeared everywhere, sometimes playing the bass lines, combined often with the use of synthesised drums and primitive drum machines.

The line up for 'Simple Minds' was typical for a band of this time when they made hit single Don't You Forget About Me, with vocals, electric guitars, synthesisers or keyboards, bass and drums, (often electric drums). See figure 17.

Simple Minds: Don't You Forget About Me, bars 1-8
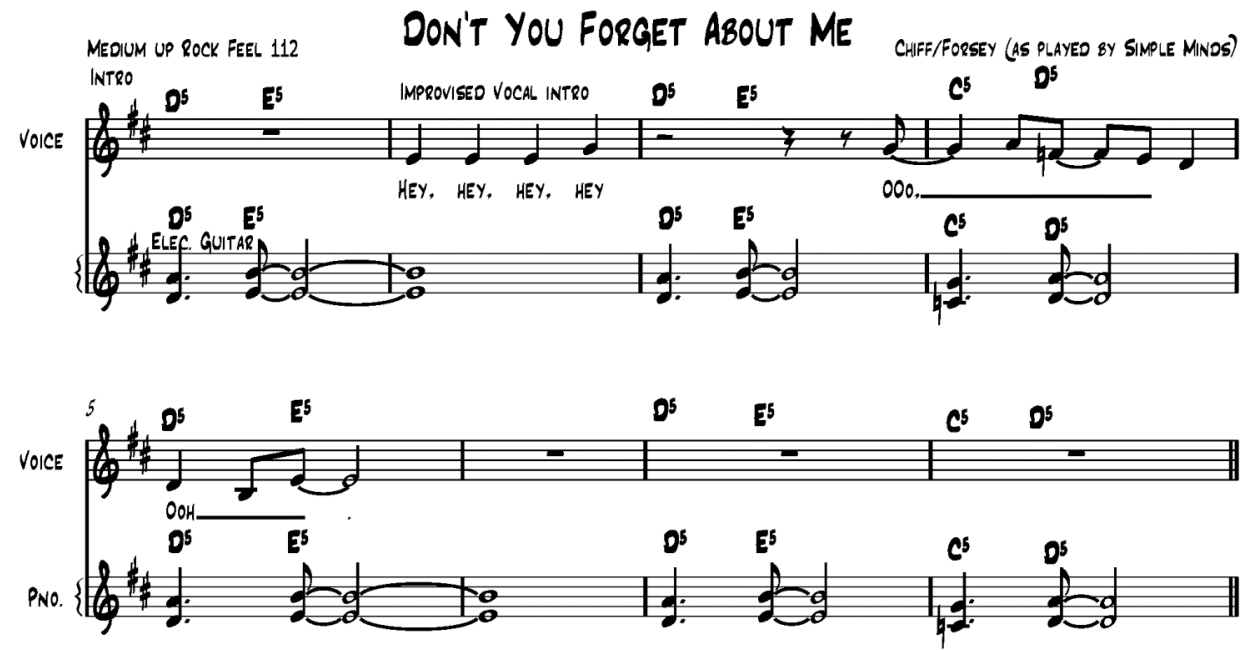

Figure 17

\subsubsection{Jazz Duo}


Michelle Nicolle released her album 'The Crying Game' in 2003, which is a collection of songs that have appeared in films or on sound tracks. Her version of Don't you forget about me has been stripped down to vocalist playing piano, with opening melodic and backing lines played by flugelhorn, see figure 18 .

Michelle Nicolle: Don't You Forget About Me, Introduction
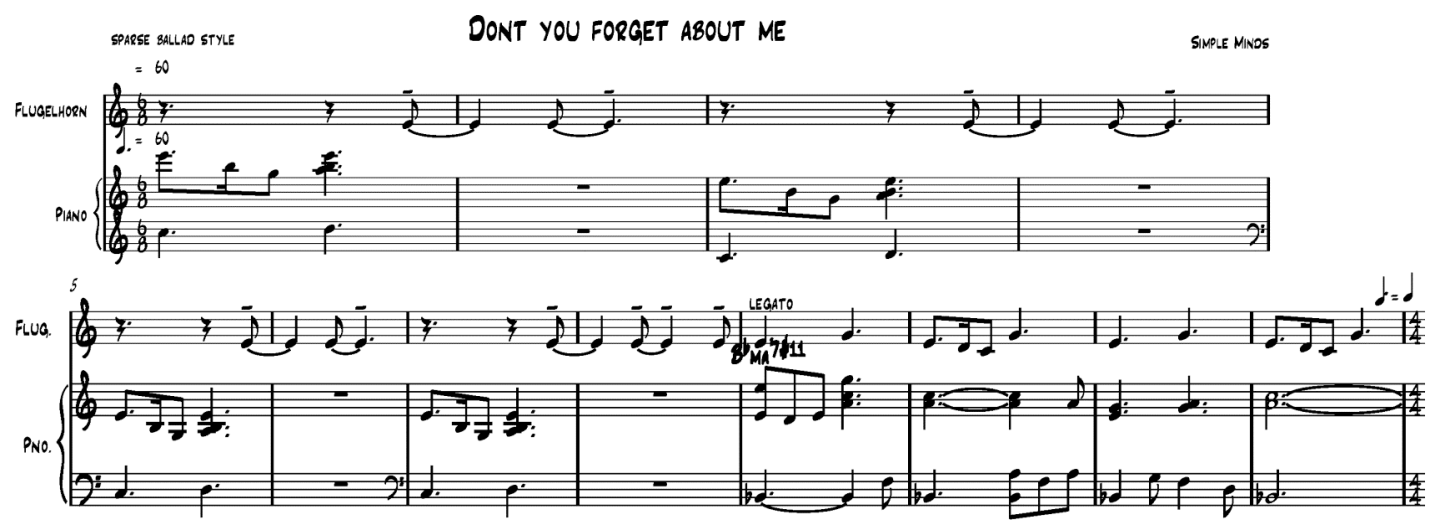

Figure 18

As well as the opening conversation between piano and flugelhorn, the flugelhorn also plays a backing line to the vocals at the bridge then continues with a solo on the same bridge section, which we can see in figure 19.

Michelle Nicolle: Don't You About Me bars 13-16

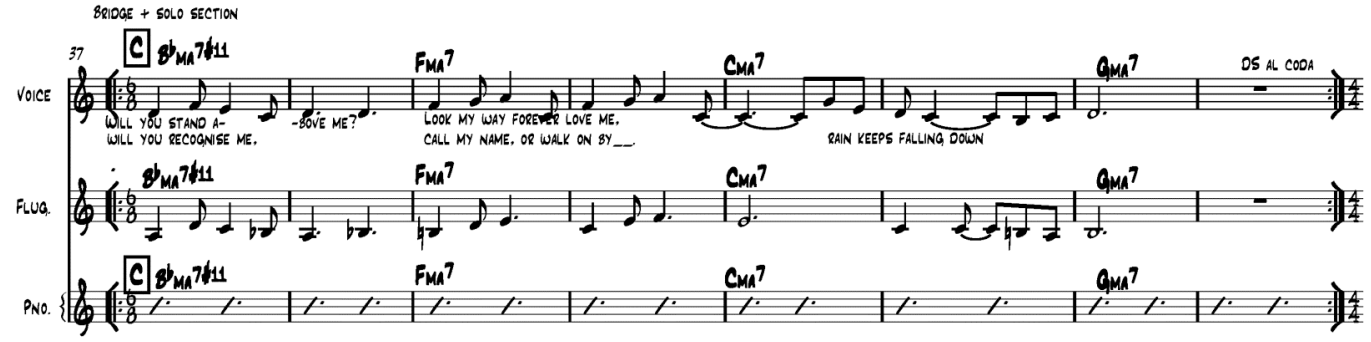

Figure 19

There is less density in the texture than the original version, which allows the listener the opportunity to hear every word of this sad but beautiful love song. This uncluttered and sparse environment of this jazz duo, allows the vocalist much more freedom and a more effective lyric interpretation as a result. The slower tempo and the small ensemble means that the vocalist can be more 
liberal with the phrasing of the melody, and can colour individual words without disrupting the ensemble.

Radiohead's 1997 album 'OK Computer' helped established them as one of the most inventive modern rock bands of the 1990's. Their instrumentation is of guitars, electronic rhythms, eerie keyboards sounds, odd time signatures, and complex syncopations.

Their song Exit Music (For A Film) features finger style acoustic guitar lines over the chord changes providing a platform for the powerful yet tortured drone of Thom Yorke's vocals, see figure 20 below. More dynamic building is created throughout the song with extra keyboards and rhythm section support, providing increased tension until the wind down of the journey at the end of the song.

Radiohead: Exit Music (For A Film) Introduction

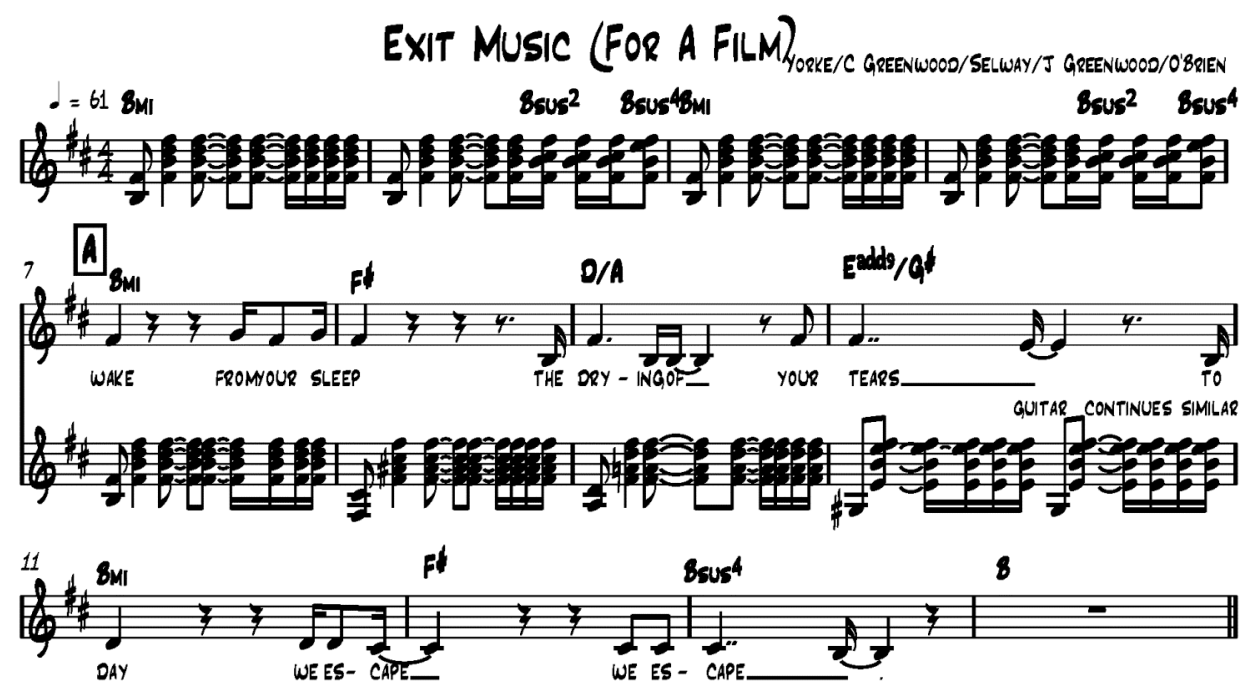

Figure 20

\subsubsection{Jazz piano trio}


The trio of piano, bass and drums is a popular combination in jazz, and can produce a wide range of colours and dynamics. Jazz pianist Brad Meldau is another jazz artist introducing pop songs into his repertoire. He recorded two versions of Exit Music (For A Film), one of them a live recording, but both in piano trio format.

The arrangement begins with an adaptation an almost classical sounding of the original guitar riff on piano. The melody begins at bar 3 in figure 21 , and is voiced above this accompanying vamp.

Brad Mehldau: Exit Music (For A Film) bars 5-12 - 0.13"
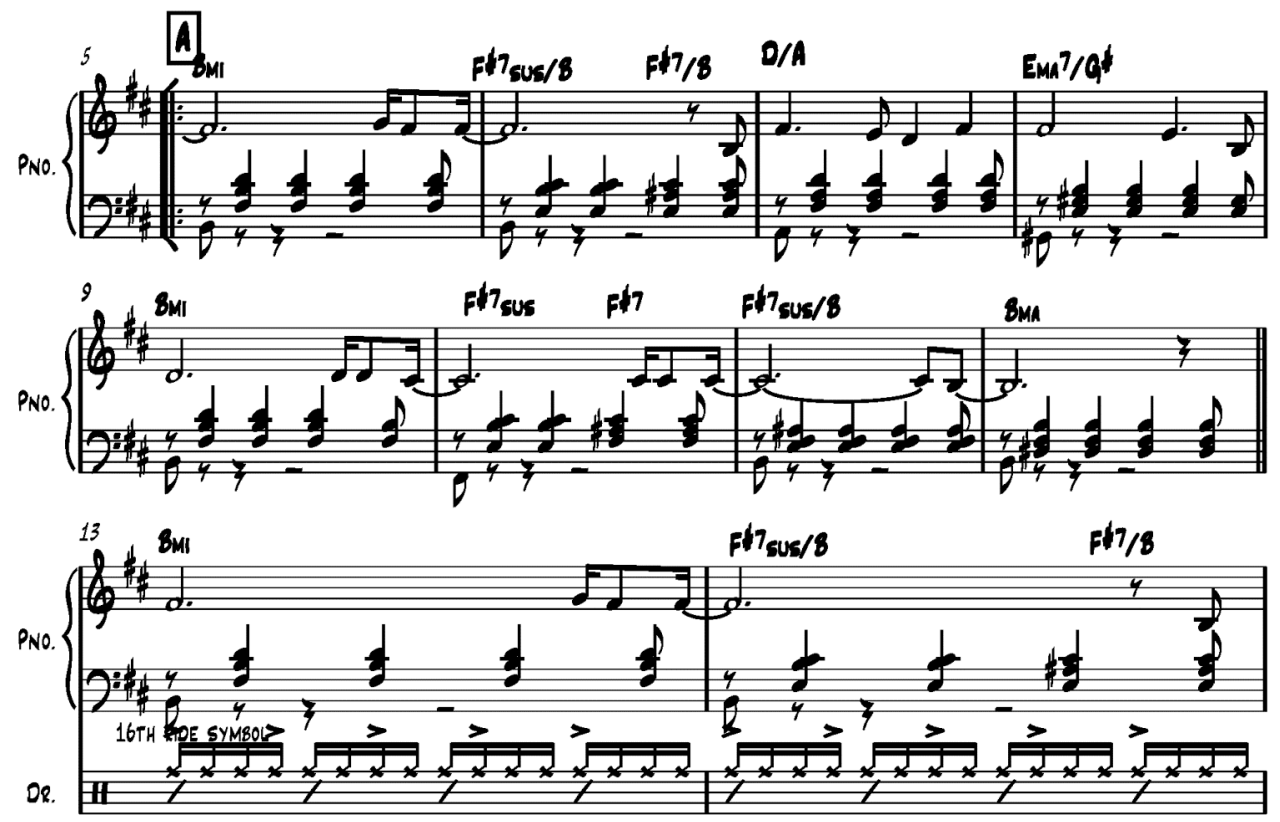

Figure 21

Although there are more sustained notes at the ends of the short phrases, the melodic treatment is very similar to that of the original version by Radiohead, in Mehldau's version. As we can see in figure 21 the drums enter for the second verse at bar 13 with an insistent sixteenth note feel on high hat, with bass entering at the beginning of the next section (bar 28), with a relaxed two feel. 
Although this is an instrumental version, through individual interpretation of the phrasing of the melody, Mehldau manages to capture the story-telling capacity of the original version. Dynamics and tension build throughout the song, and are released at the finish.

Madonna's Like A Virgin from the album of the same name is one of the songs that helped to propel her to super stardom and can be classified as from the dance pop genre.

The original band lineup is similar to the 'Simple Minds' line up, but with even more synthesizers, with brassy arpeggiated lines from the beginning, keyboard pad sounds in the bridge, with driving bass lines, as seen in figure 22.

Madonna: Like A Virgin, Introduction
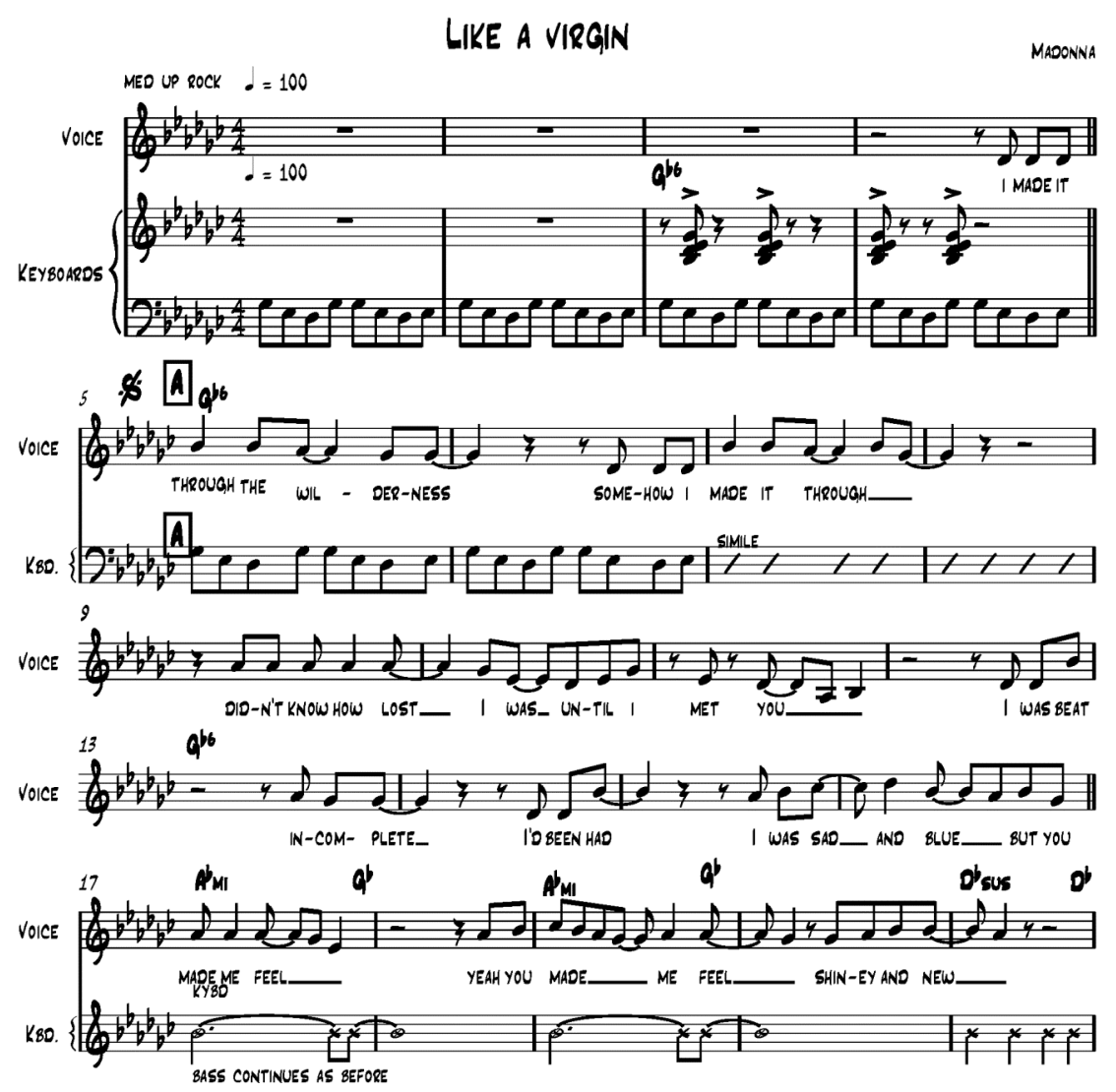


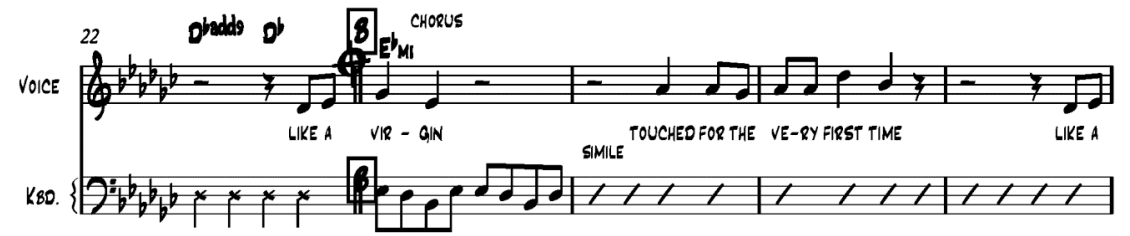

Figure 22

\subsubsection{Jazz vocal trio}

A trio of vocalist with piano and bass is also a common line up for a jazz ensemble. German jazz vocalist Lisa Bassenge's arrangement of Like a Virgin, allows fluidity and breathing space. From her 2001 album 'Going Home' it begins with what sounds like a freely improvised foundation of plucked sounds. This is created by one hand plucking the strings inside the piano, while the other hand mutes the strings that are being played, with plucked sympathetic double bass lines. The melody line soars above this pizzicato-like, 'colla voce' texture with the entry of the first verse.

Lisa Bassenge: Like A Virgin, Introduction

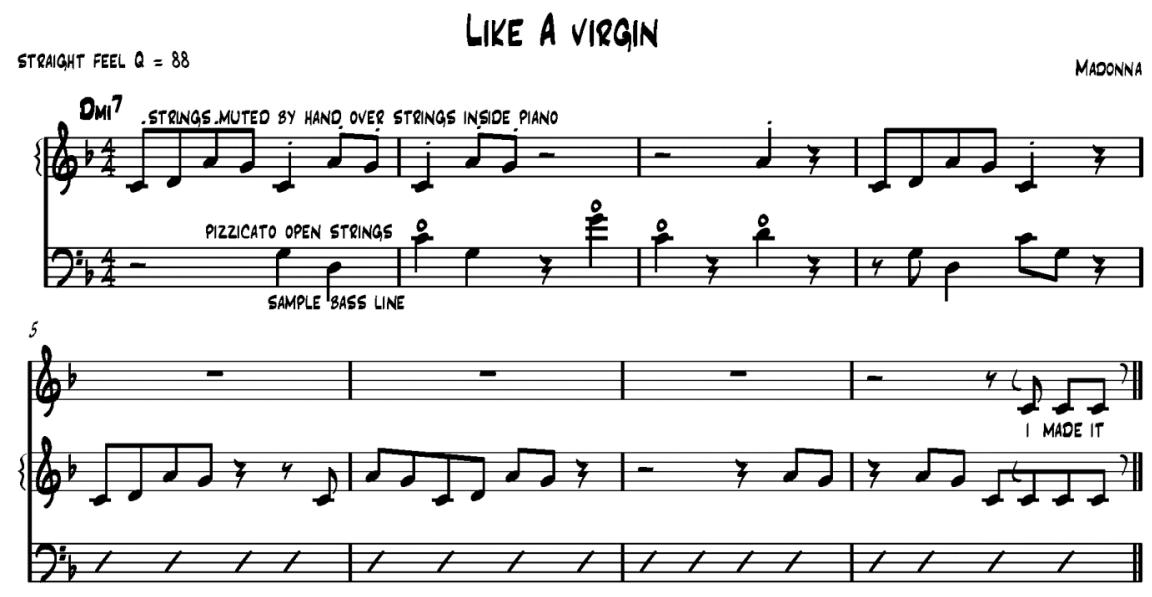




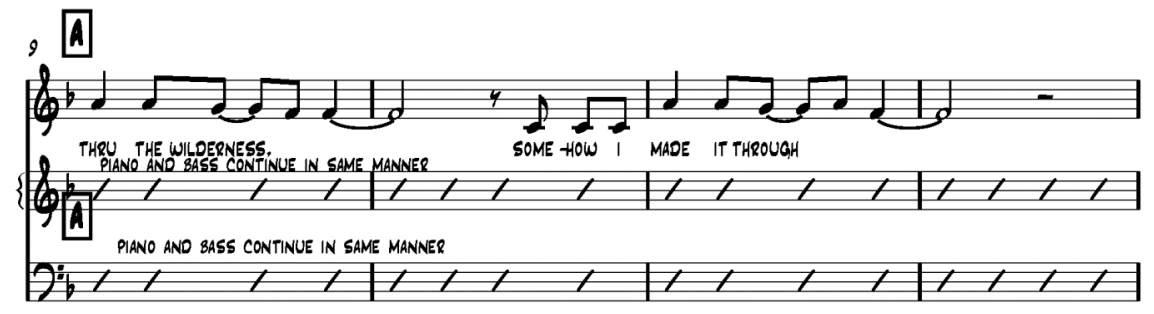

Figure 23

In the following chorus section the piano and bass follow a more supportive homophonic role with the melody, but is much more organic in it's accompaniment than the original.

The classic rock line up vocals, guitar bass, and drums was the basis of the huge sound of 1990's 'grunge' band 'Nirvana'. The dark undercurrents of Nirvana's sound are both fiery and melodic, with a wall of distorted guitars, and pop melodies merged with post-industrial white noise.

Their song Come As You Are from the album highly successful second album 'Nevermind' begins with a repeated guitar riff, which continues underneath the melody line when it enters at bar 4 until the chorus at bar 10 in figure 24 . 
Kurt Cobain: Come As You Are, bars 1-10

COME AS YOU ARE

COBAIN
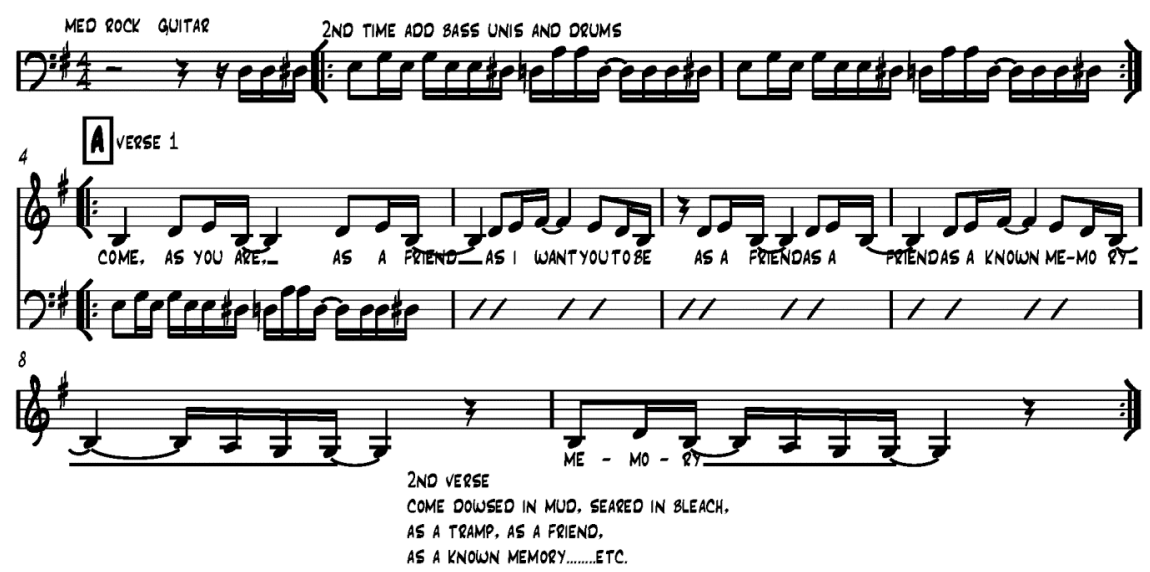

Figure 24

This riff continues at bar 14 at the end of the chorus before repeating back to bar 4 for the second verse.

\subsubsection{Non-standard jazz trio}

Charlie Hunter's unusual style of guitar involves playing an extra string on his instrument to create his own bass lines. This means that he can function as a bass-less self-sufficient keyboard-less trio with tenor saxophone and drums. This allows for a special arrangement for this trio of 'Nirvana's' Come as You Are, from the 1995 album 'Bing, Bing, Bing' which begins cheekily with the guitar riff from Nirvana's other highly successful rock Anthem from the same album Smells Like Teen Spirit.

Kurt Cobain: Smells Like Teen Spirit riff

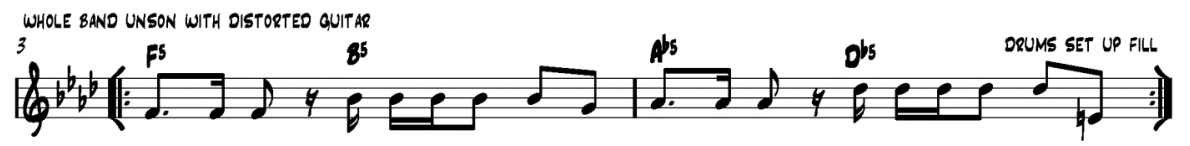

Figure 25 
In figure 26 we see that this opening riff from Smells Like Teen Spirit is then layered over the top of the bass line playing the original guitar riff, now in the new time signature of $6 / 4$, while the drums steam ahead with a straight ahead jazz feel.

Charlie Hunter: Come As You Are, Introduction

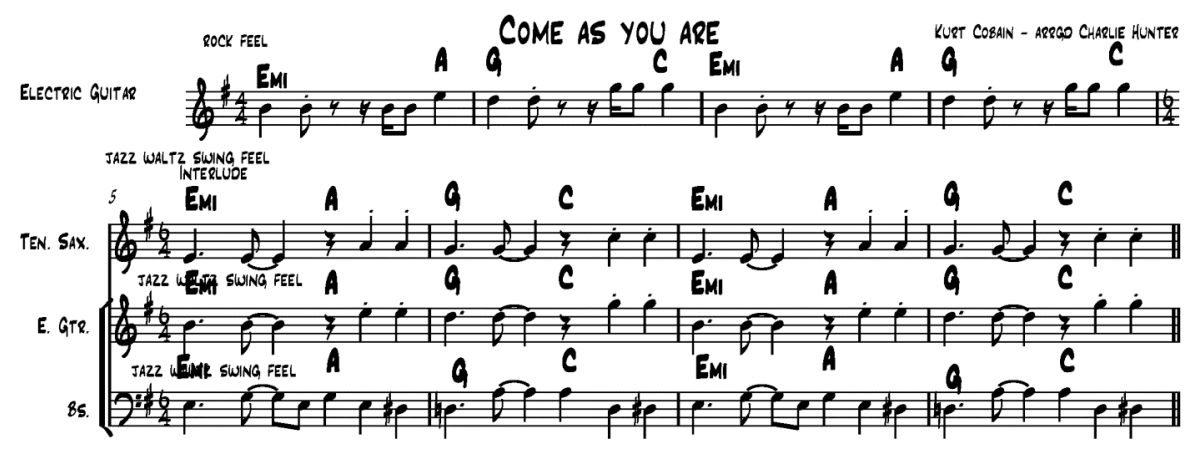

Figure 26

The melody of the song is shared between guitar and tenor saxophone, while occasionally the saxophone plays a supporting long note line in the solo section to enhance the bass line.

In your Eyes has been described as Peter Gabriel's greatest love song, and although it had a similar 1980s lineup of vocals, synthesizers or keyboards, bass and drums, it also demonstrates Gabriel's ability to combine strong song writing with his interest in African percussion. The underlying texture of the song has a keyboard-based riff that continues with through the chord changes, with the same rhythm throughout. 
Peter Gabriel: In Your Eyes, bars 3-7

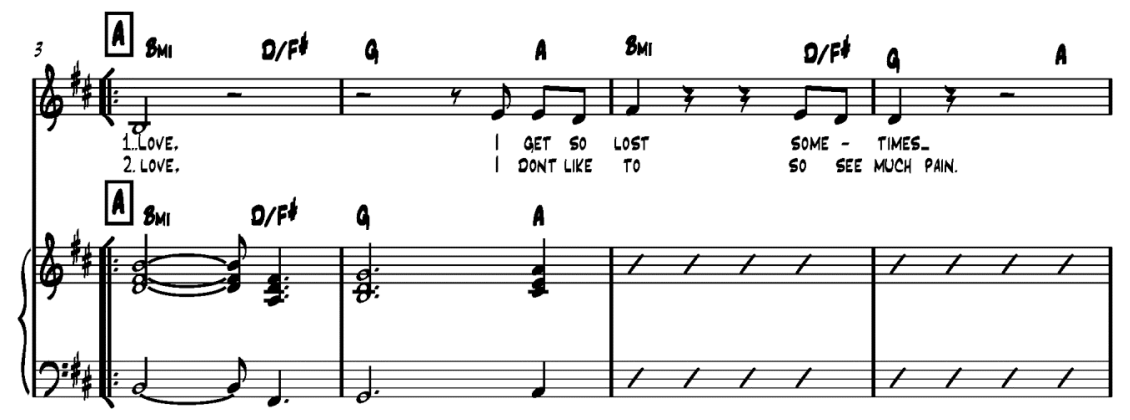

Figure 27

An acoustic arpeggiated guitar line helps to build tension just before the chorus, which we can see in figure 28.

Peter Gabriel: In Your Eyes, bars 3-719-22

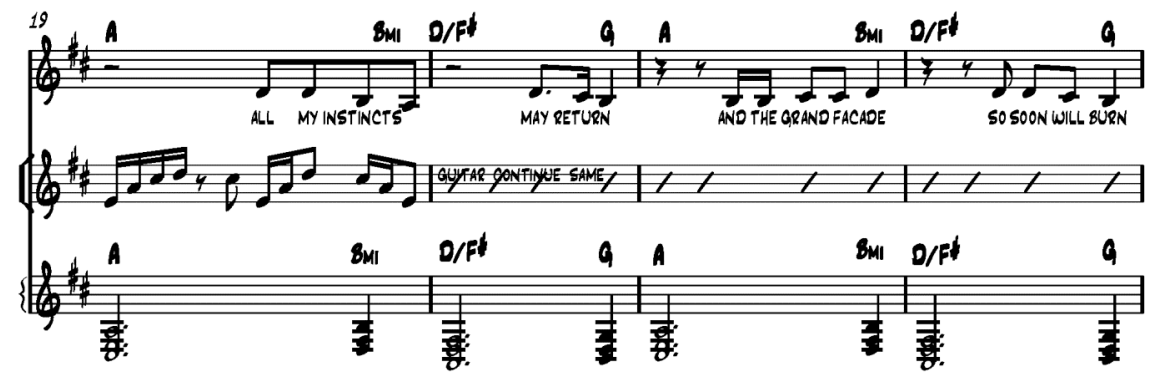

Figure 28

\subsubsection{Jazz quintet}

A quintet comprising of vocalist or other frontline instrumentalist, guitar, piano bass and drums is a standard lineup for a contemporary jazz ensemble. With the addition of percussion this is the arrangement for Billy Childs version of In Your Eyes released on American jazz vocalist Dianne Reeves album 'Bridges' in 1999.

The texture of this arrangement is light and acoustic, and features unison lines played by piano guitar and bass and percussion beneath the vocal line, and has 
many syncopated hits creating tension and release underneath the melody, which we can observe in figure 29.

Billy Childs: In Your Eyes, bars 5-8

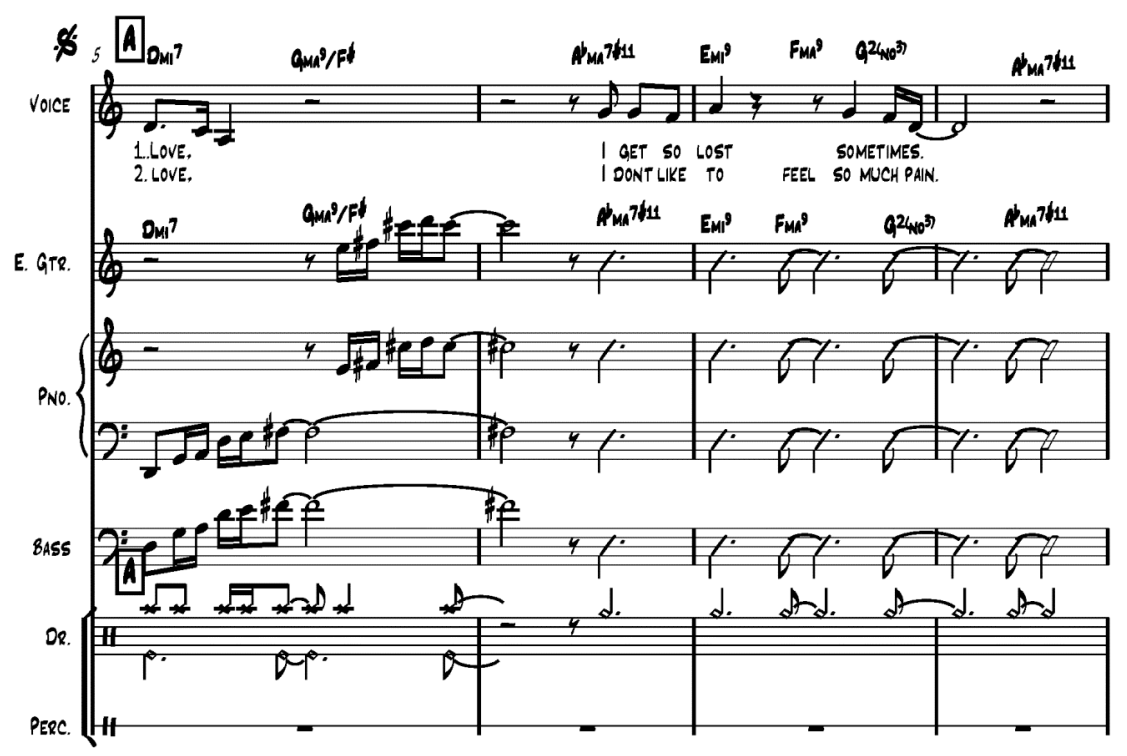

Figure 29

There is a similar but busier arpeggiated guitar line in bar 21 of the new arrangement, compared to bar 19 of the original version (Fig 30). This adds rhythmic drama leading to the chorus.

Billy Childs: In Your Eyes, bars 21 -22

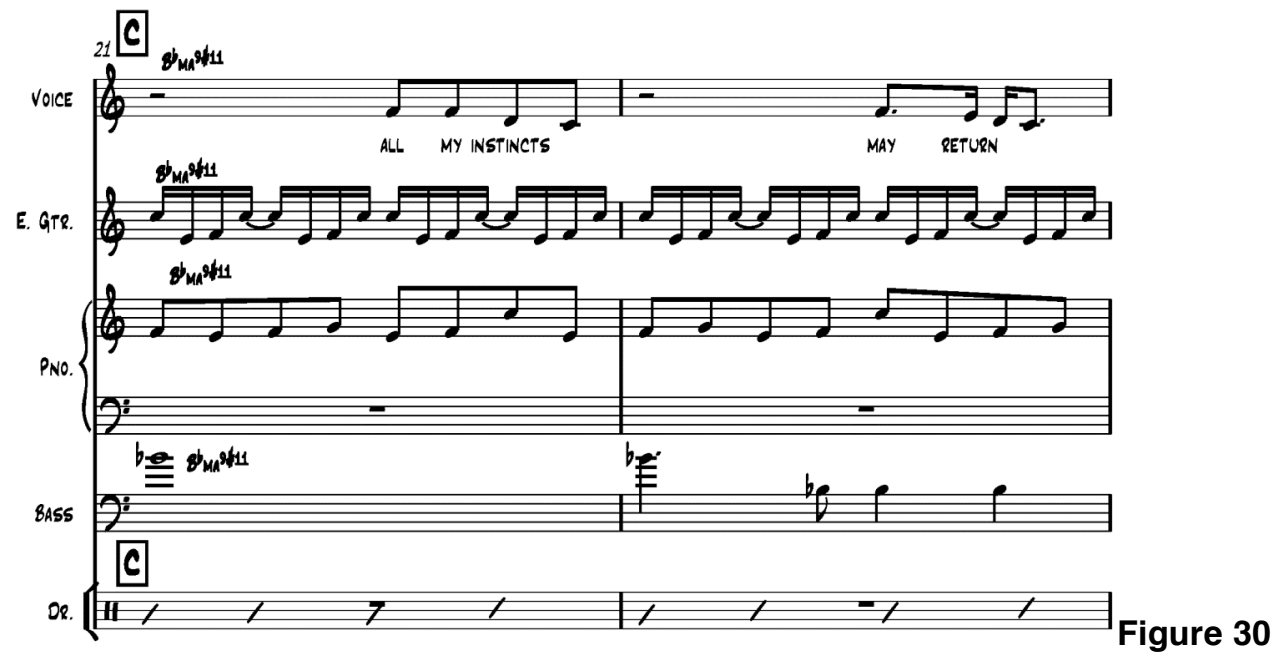




\subsubsection{Large ensemble}

The song 1999 is constructed almost entirely on synthesizers played by Prince himself. In figure 31 we can see the simple two-chord vamp over top of a repeated note bass line.

Prince: 1999 bars 9-20

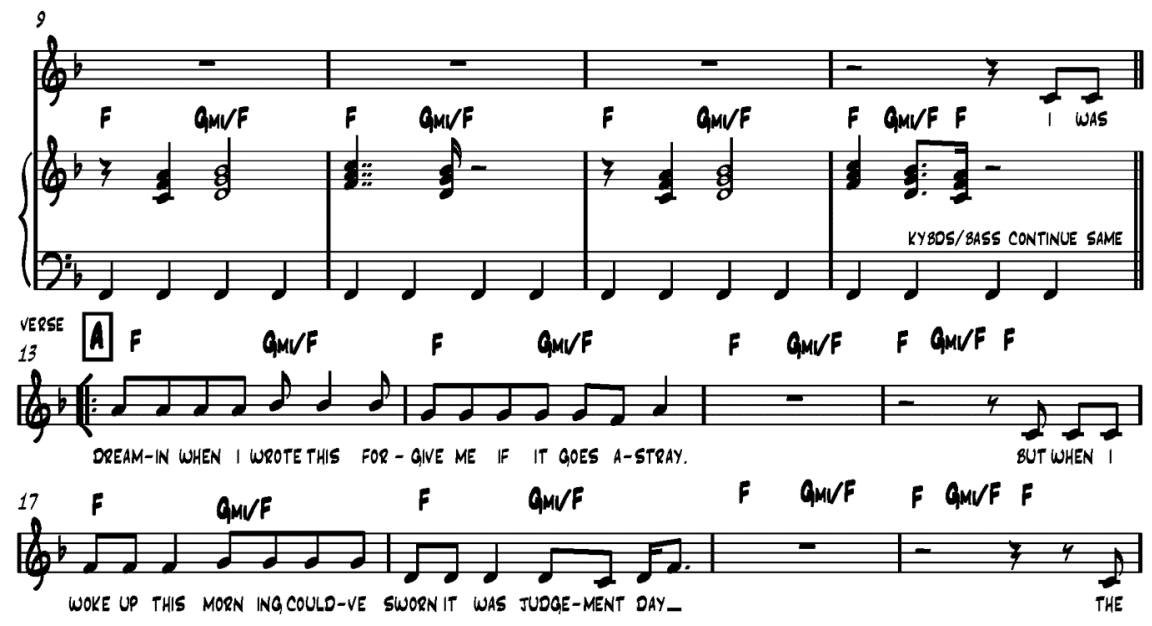

Figure 31

Bob Belden's thoughts on arranging this song were:

Absorbing all of this pop orchestration stuff and I had these pop tunes that I could kind of reconstruct like turning "1999" into James Brown or turning "Diamonds and Pearls" into the Motown stuff from Marvin Gaye...........We're supposed to look for things to bring into jazz and we're supposed to look for things to bring jazz into. Jazz to me is an attitude. It is not anything that you can write down ${ }^{21}$

Bob Belden's exuberant up-tempo arrangement of 1999 sounds like a 'Tower of Power'-inspired organ trio with a large horn section and bass lines, and strong funk drum support. The harmony is filled out in the large ensemble with short stabs and melodic and rhythmic riffs, spread through the horn section.

21 Robin Tolleson Bob Belden: JAZZ MEETS POP Accessed August 7th 2008 
Bob Belden: 1999 Introduction

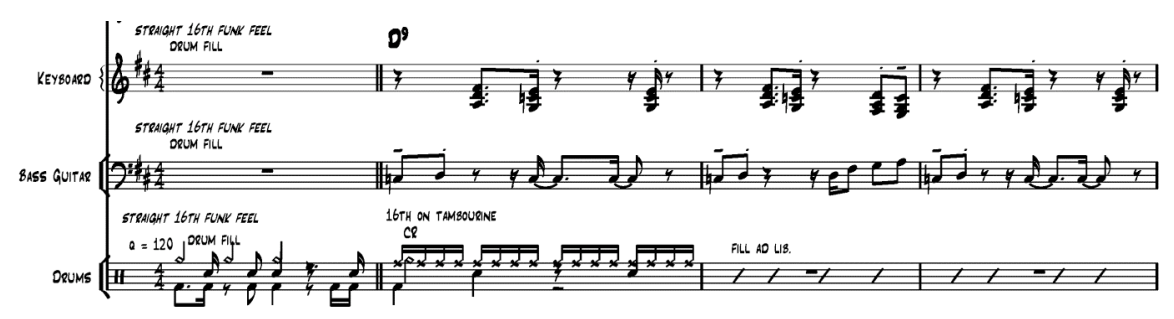

Figure 32

\subsubsection{Adding background lines}

Adding background lines, rhythmic hits and stabs, can add or relax rhythmic intensity in an arrangement.

A full horn section in Belden's arrangement of 1999 with trumpets, saxophones and trombones plays cheeky riffs behind the melody, and the soloist, while baritone saxophone doubles the bass line in places. Guitar enters at bar 26, figure 33, playing the melody in octaves, and the horn section play harmonically supportive dotted note stabs.

Bob Belden: 1999 bars 26-30

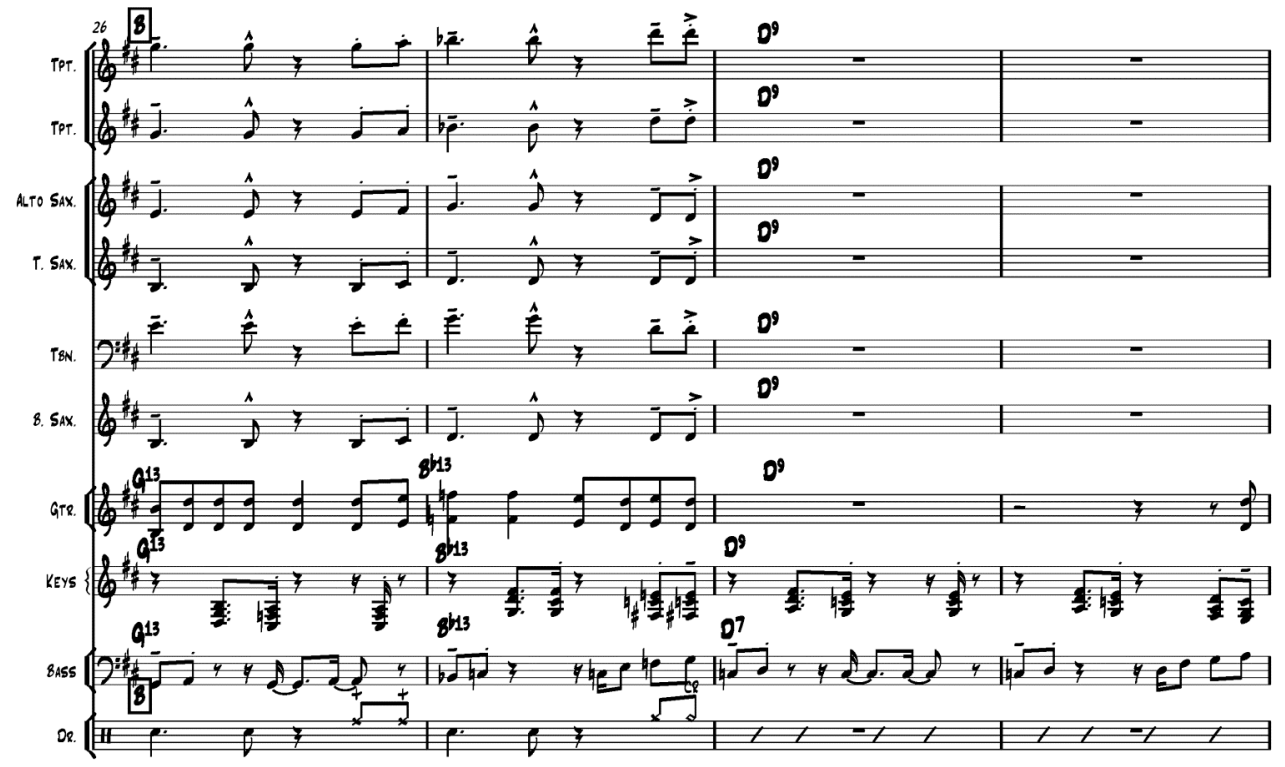

Figure 33 
More of these horn lines appear throughout the solos, and help to build in rhythmic intensity. A good example is in bars $62-71$, figure 34, where they play a harmonised offbeat semiquaver riff that is a third higher in the second eight bars.

Bob Belden: 1999 bars 62-71

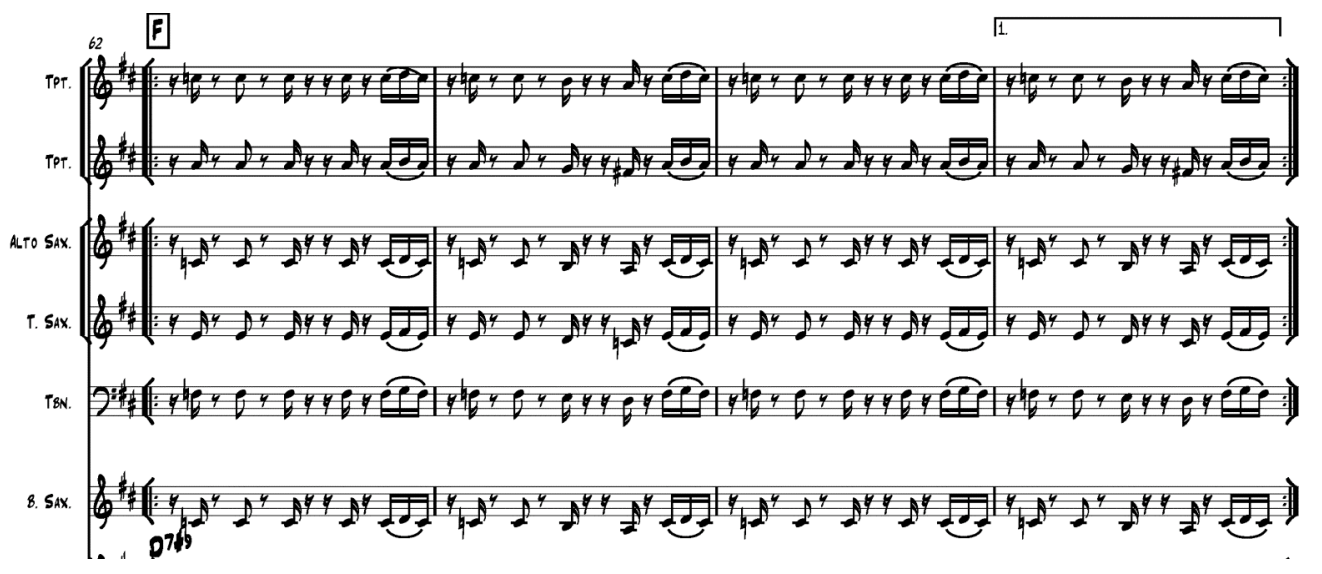

Figure 34

The trombones start playing long notes in the second solo at bar 88 that are expanded throughout the horn section by bar 95. A new syncopated one bar riff is added at bar 96 , with baritone saxophone doubling the first part of the bass line.

Bob Belden: 1999 bars 96-97

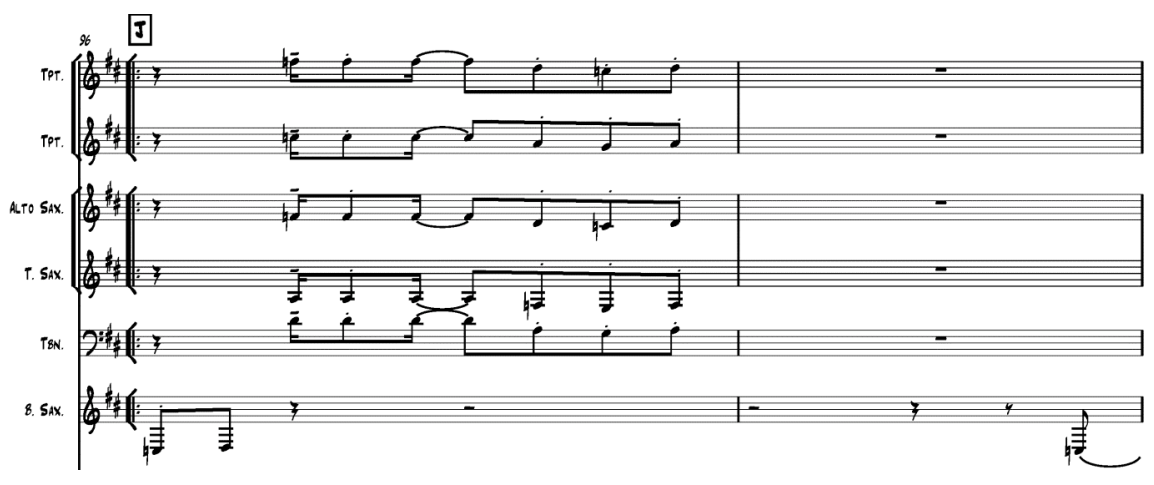

Figure 35 
At bar 105 in figure 36 a repeated note riff is harmonised by the horn section, that also builds in pitch and intensity until the loud note with a big fall off at bar 117, where the drum solo begins.

Bob Belden: 1999 bars 105-106

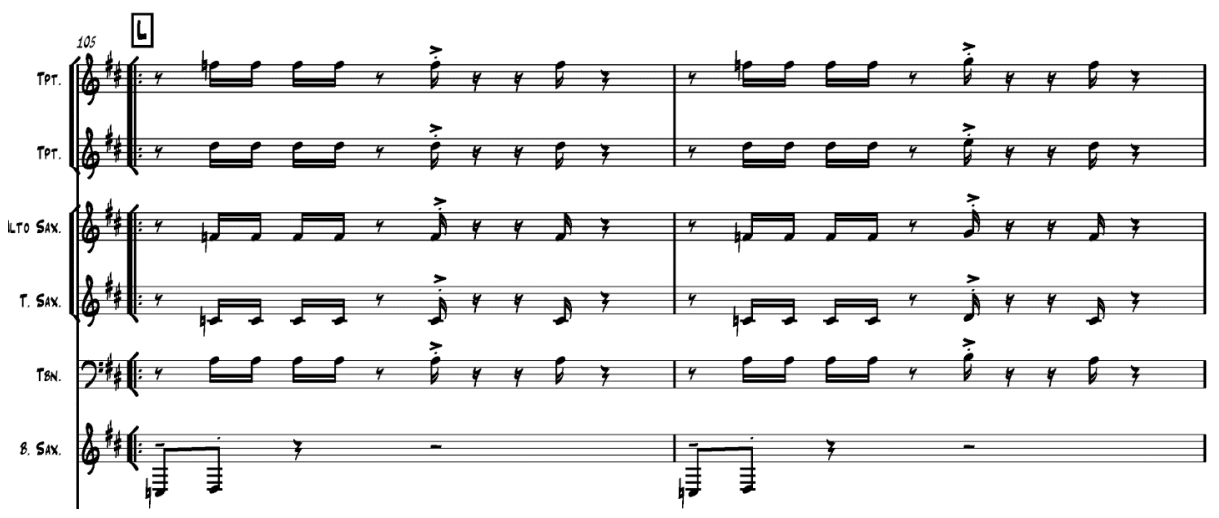

Figure 36

In figure 37 the short repeated stabs at bar 118 , signal the end of the return of the whole band, which then sets up the initial groove again. This time with the return of the melody, a background line of an alternating note riff played by the saxophones adds intensity to what the rhythm section is playing. This riff is gradually adopted by the whole horn section, and helps the song to end in excitement. 
Bob Belden: 1999 bars 118-122

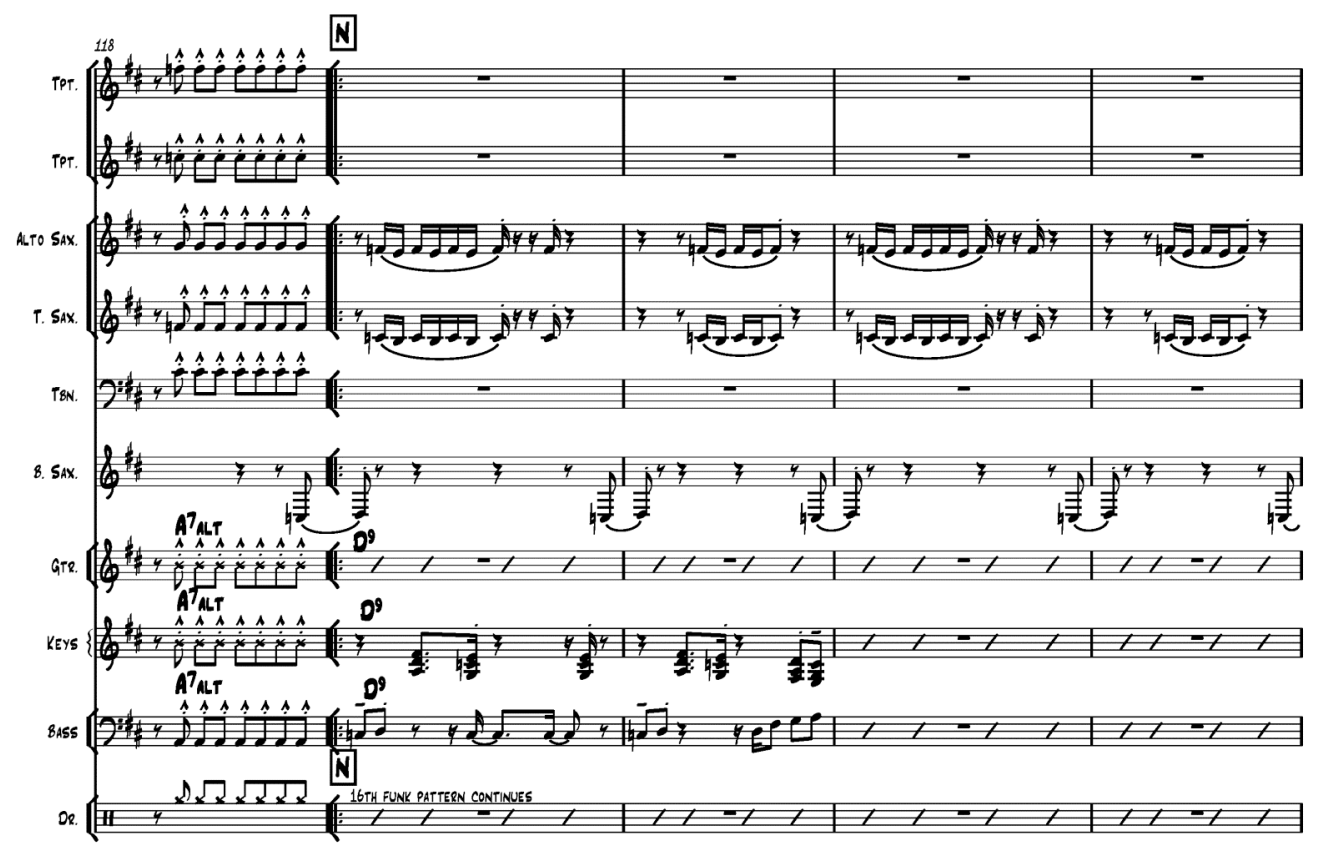

Figure 37 


\subsection{Structure}

Determining the overall structure of the song is important when considering new arrangements of pop songs in a jazz style. The structure can be enhanced and provide an opportunity for the jazz artist to individually reinterpret the song as well as a platform to improvise a solo at some point during the arrangement. It is possible to create a new introduction or ending, add extra sections and can choose how much of the form of the song to improvise on.

The standard structure for jazz improvisation for many songs played or recorded by jazz musicians, is to add an introduction, then play the melody (the in-head), then to start improvising over the chords from where the melody started, which becomes what we refer to as 'the form'. Then after each soloist has finished, the melody is repeated once more, the 'out-head'. Often there follows a short coda or 'tag', where two to four bars are repeated a few times, usually with a standard cadential progression, finishing with a chord in the tonic key, thus ending the song. Pop songs are generally shorter in length than jazz arrangements, and don't necessarily follow this structure because there is very little improvisation, if any at all. Jazz performers have several options with what part of the song (whether it is the whole or only part of it) over which they can improvise and also whether there is more than one soloist, or even whether it is one soloist at a time.

\subsubsection{Introductions}

Adding an introduction to an arrangement gives the listener (and the musicians) an opportunity to get into the mood or the style of the song. As previously mentioned the introduction can also help to establish the texture as well as preview of the original song. It can also surprise the listener, as is often the case in the reworking of popular songs played by jazz performers. 
'The Police' released Walking On Moon the 1979 album 'Reggatta de Blanc' which can be translated literally as white reggae, which may help describe the original feel of this song. As we can see in figure 38 below, this song starts as a spacious trio, with drums playing light reggae feel with a continuous pulse provided by the drummer playing swing feel on the hi hat, and bass and guitar playing lines based on sparse fills, under a floating vocal melody.

Sting: Walking On The Moon, Introduction bars 1-14

\section{WALKING ON THE MOON}

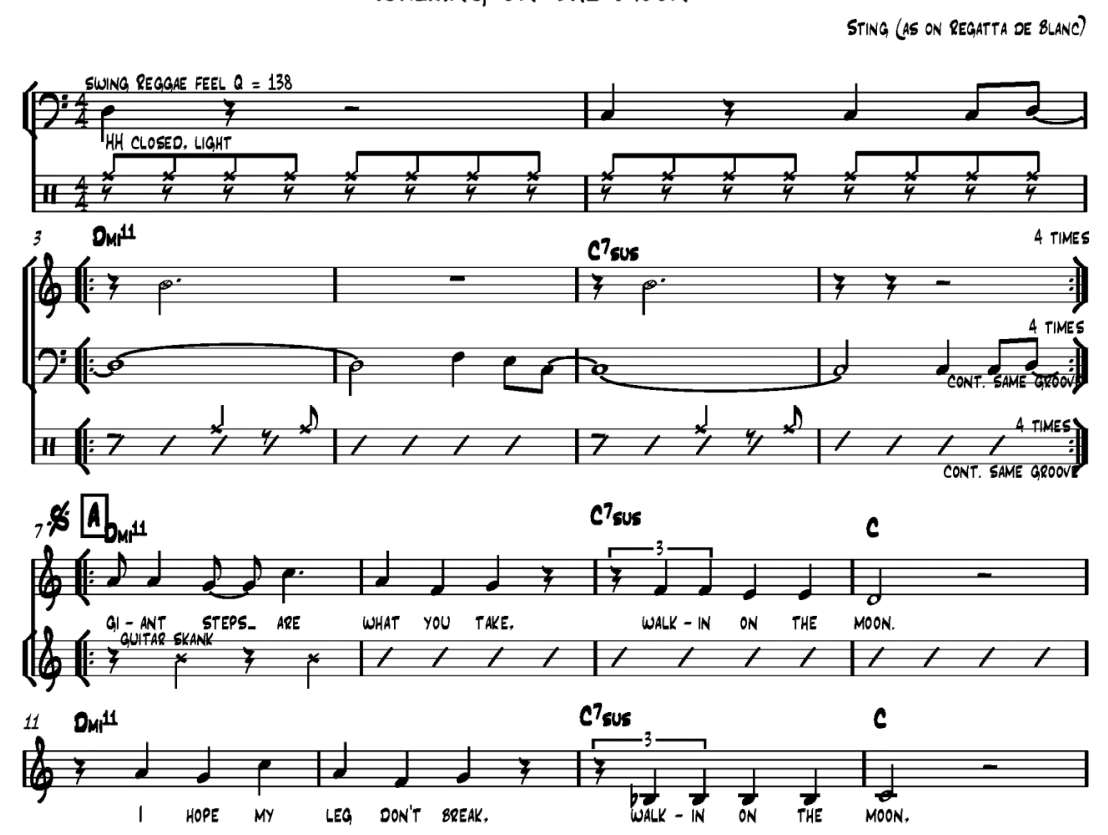

Figure 38

\subsubsection{Introductions in free time}


A common way to start a jazz arrangement is to add an introduction in free time with little or no pulse.

The beginning of Christian McBride's arrangement of Walking On The Moon features a 'colla voce' introduction with a spacious melodic conversation between bass clarinet and double bass, one of the highlights of this version. The tempo is slower than the original and has a spacious quality. This is achieved by a slow four in a bar feel as well as the instrumentation, which helps to give an overall oneiric effect. There is light sparse comping by piano, occasional strummed chords played by acoustic guitar, and the accompanying drums playing mallet cymbals rolls and crashes with a light crotchet pulse played as a rim shot.

Christian McBride: Walking On The Moon, Introduction

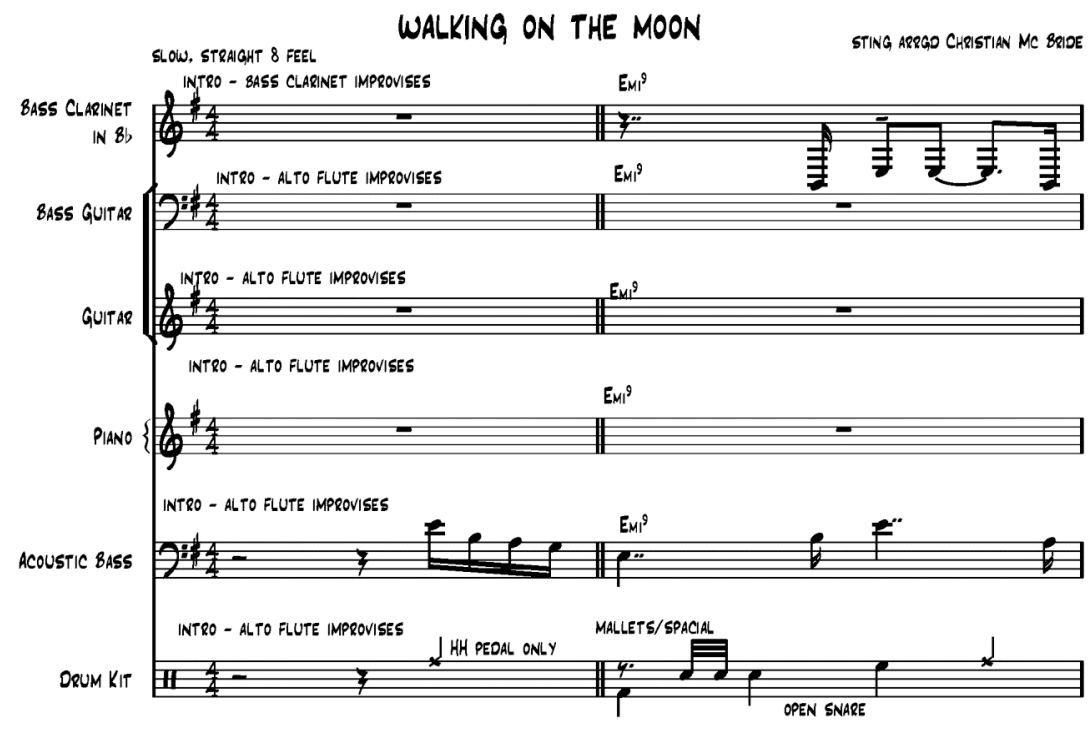




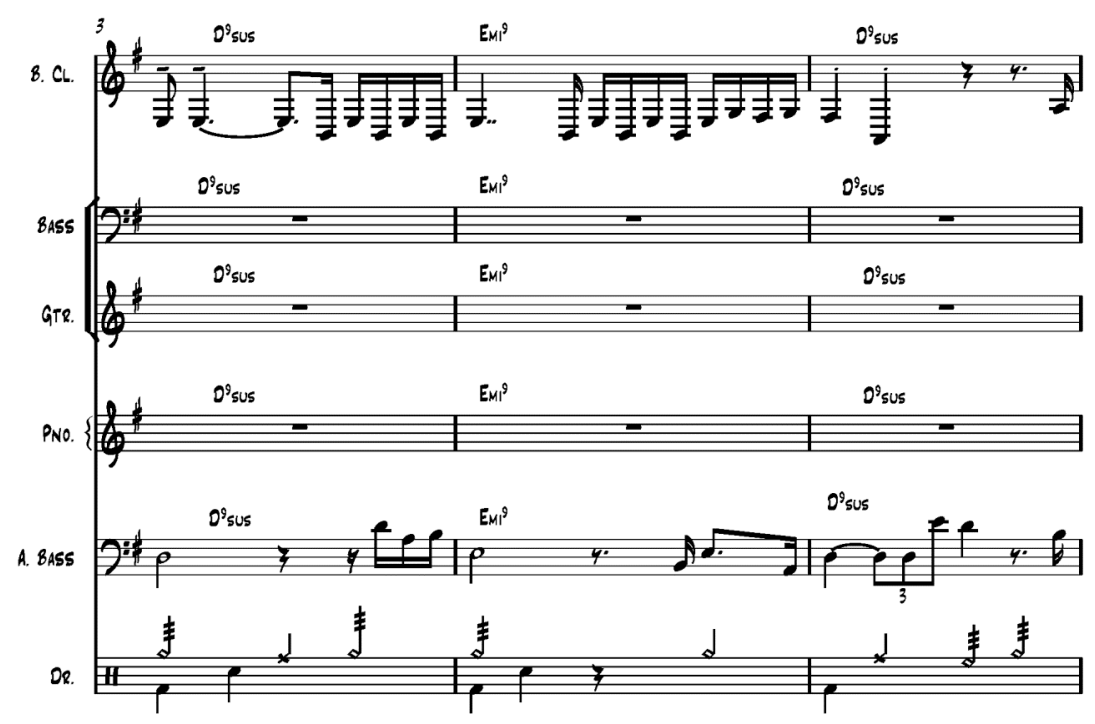

Figure 39

In figure 40 we can see that electric bass plays the melody in harmonics in the verse section, while the bass line role, is played by another bass player on double bass.

Christian McBride: Walking On The Moon, bars 


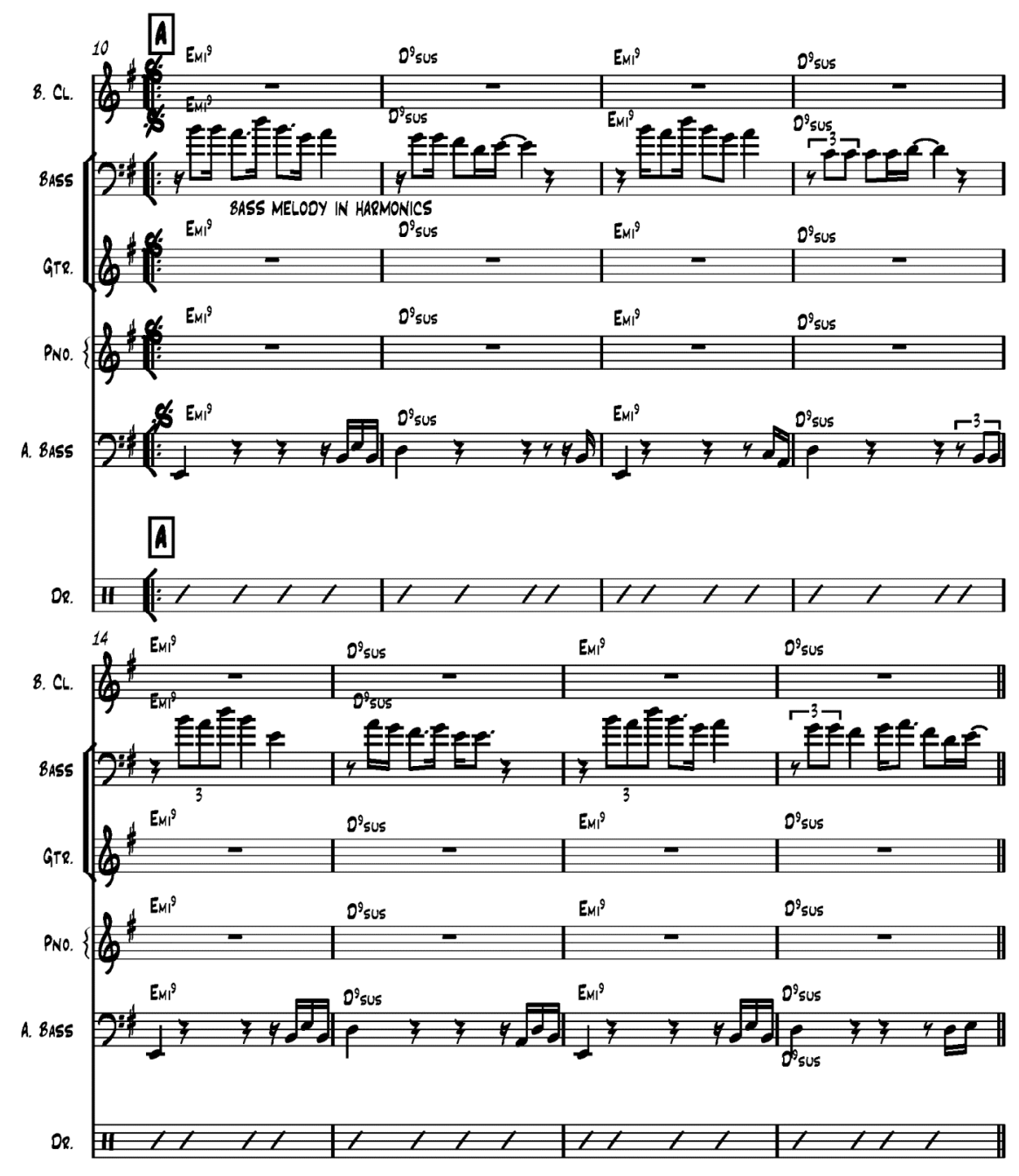

Figure 40

The sixteen bar verse which starts at bar 10, has an additional four bars added at the end, allowing more bass clarinet lines and double bass interaction. The chorus remains sixteen bars in length but in triple time. Bass clarinet takes the first solo from the beginning of the verse at bar 10, with electric bass joining in the improvisation at bar 22, the chorus, while bass clarinet plays a secondary solo behind it. There is no repeat of the melody at the end of this arrangement; improvisation develops between the two soloists during the outro with the conversation taking full flight until it fades away. 


\subsubsection{Endings}

A common ending for many pop songs from the last thirty years is to repeat and fade out on the last few bars of the song, often with some form of improvisation. In this collection of pop songs, most of the jazz arrangements have also taken this approach.

An example of this is the original version of In Your Eyes by Peter Gabriel, which ends on a four bar repeated section. As we can see in figure 41 below the guitar continues to play an arpeggiated line, and the two bar vamp from the chorus section also remains. After a few repeats a wailing vocalist improvises in African style above this texture, and the song fades to nothing.

Peter Gabriel: In Your Eyes, ending

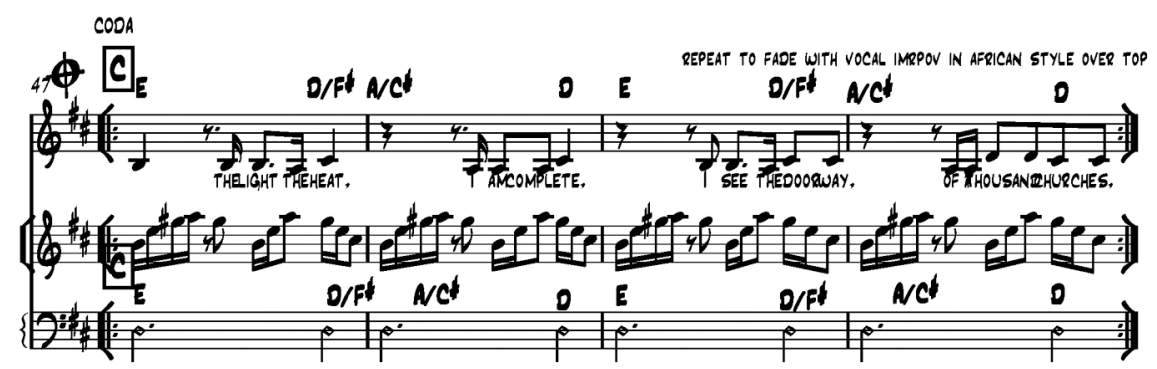

Figure 41

Billy Child's version of In Your Eyes has a variation to this as the chorus section has been extended to an eight bar repeat rather than the four bar section as in the original. We can see in figure 42 that the band maintains the unison hits from the chorus section and the vocalist improvises after the first repeat, but in jazz scat style, which eventually fades out.

Billy Childs: In Your Eyes, ending 


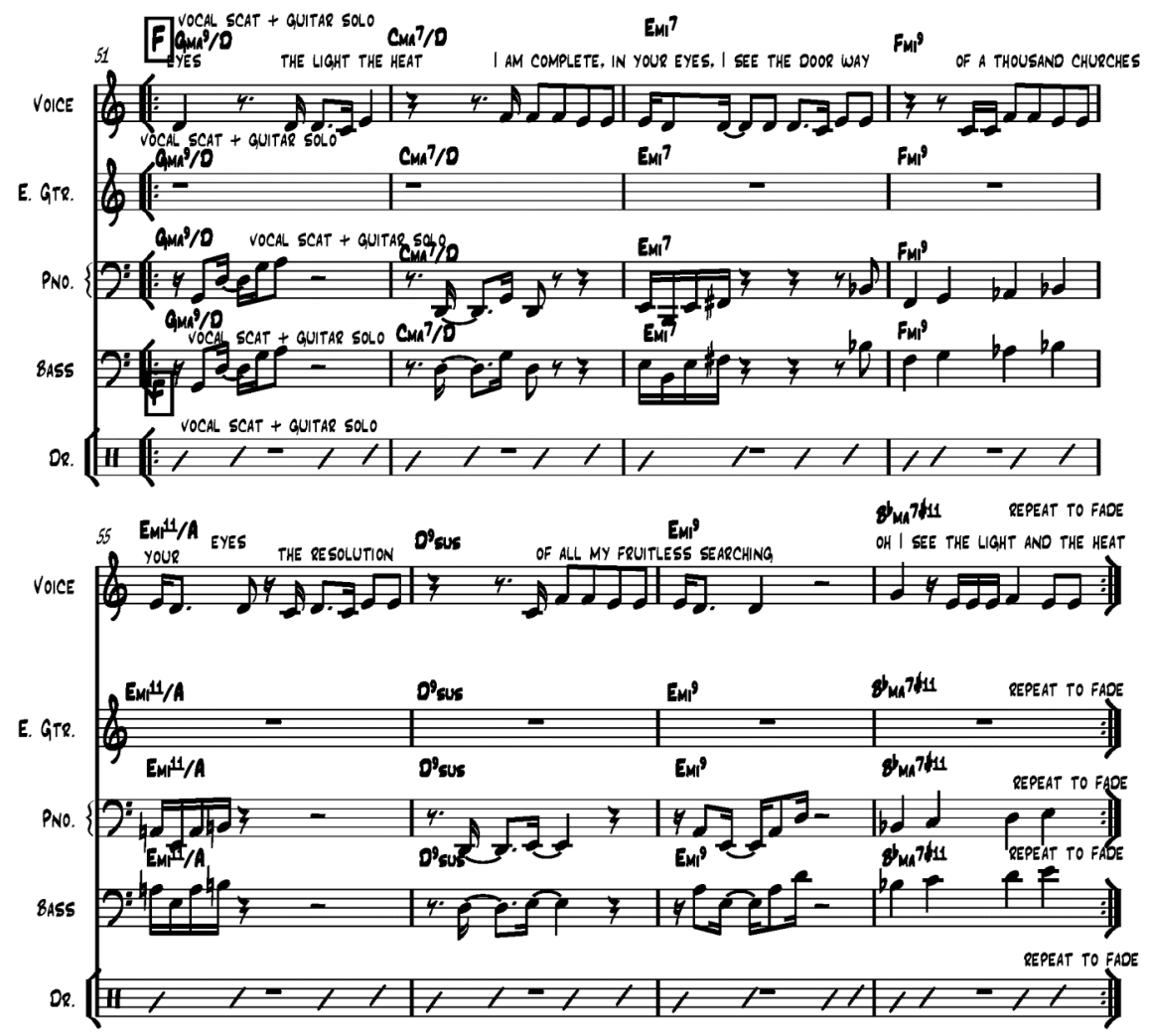

Figure 42

\subsubsection{Solos Sections and Improvisation Platforms}

Where, how much and how many performers can improvise in an arrangement is a big factor in making structural decisions. There are many choices; the solo could over the whole form of the song, part of the form, the introduction or the ending, or sections can also be added to the structure.

The structure of the original version of Peter Gabriel's In Your Eyes song is retained in the new version with only slight alteration. The main addition to the structure is that of a repeated two bar vamp solo section at bar 45 after the chorus section and before the second verse, which can see in figure 43. This is a very brief 8 bar piano solo and over a two chord vamp, and is harmonically simple considering the reharmonisation earlier in the arrangement. 
Billy Childs: In Your Eyes bars 45-46

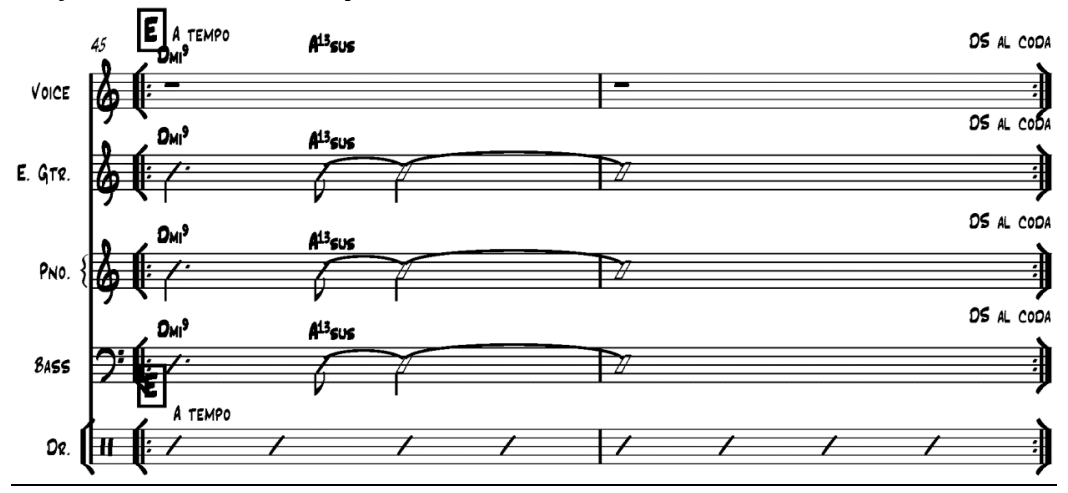

Figure 43

Brad Mehldau's arrangement of Radiohead's Exit Music (For A Film) also retains the structure of the original song but at bar 44 a repeated eight bar improvisation section has been added which we can see in figure 44 below. This piano solo starts slowly and is repeated many times, building into a big frenzy.

Brad Mehldau: Exit Music (For A Film) bar 44-51

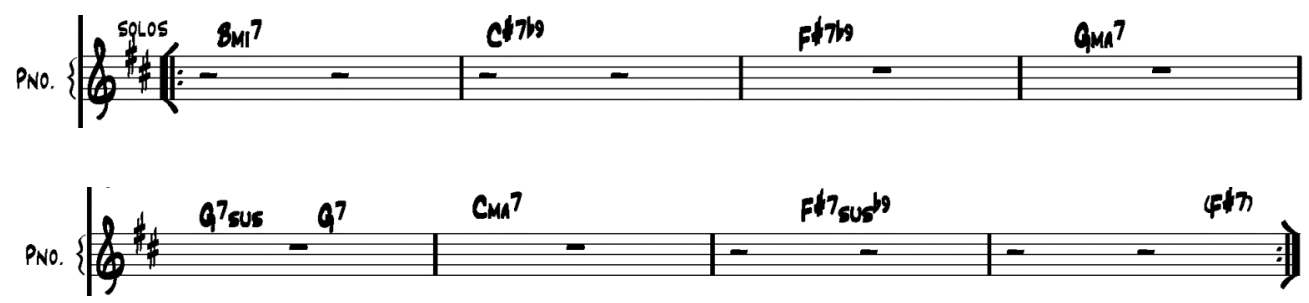

Figure 44

Harmonically it moves between the tonal centers of $B$ minor, $G$ major and $C$ major which provides an angular twist to the harmonic movement.

Near the end of the solo Mehldau quotes the melody from bar 46 of the original tune, which leads to the last verse of the original version of the song, which becomes the out-head in the arrangement, ending very similarly to the original. 


\subsubsection{Vamps}

Adding a vamp to an arrangement is a way to make it have a contemporary feel. The texture created by vamps can also have simultaneous rhythmic, harmonic and implications.

Vamps have been used in writing many pop songs and Princes 1999 is a good example of one. Below in figure 45 we can see the introduction to the original song, which is a four bar brassy sounding keyboard vamp over an urgent repeated note bass line.

Prince: 1999 bars 9-20

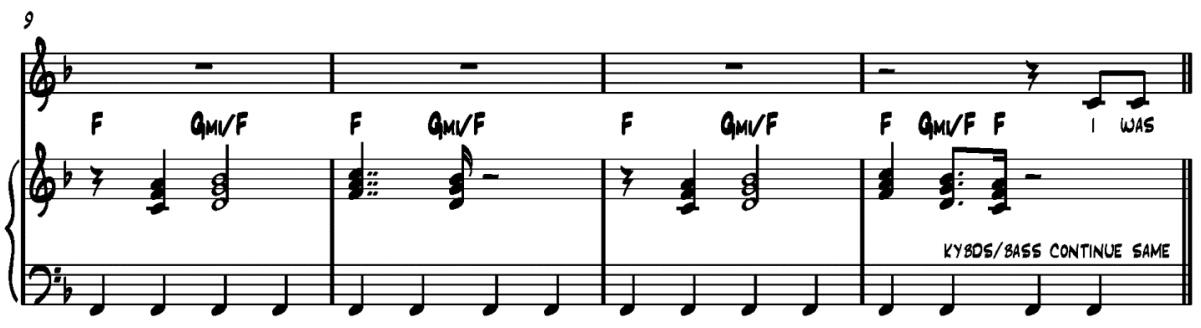

Figure 45

Bob Belden's arrangement of Princes'1999 also begins with a vamp, and a two bar organ trio vamp to helps establish the funky Motown sound that Belden intended in the new arrangement, see figure 46. The new tempo and the groove are both established by this new vamp.

Bob Belden: 1999 Introduction

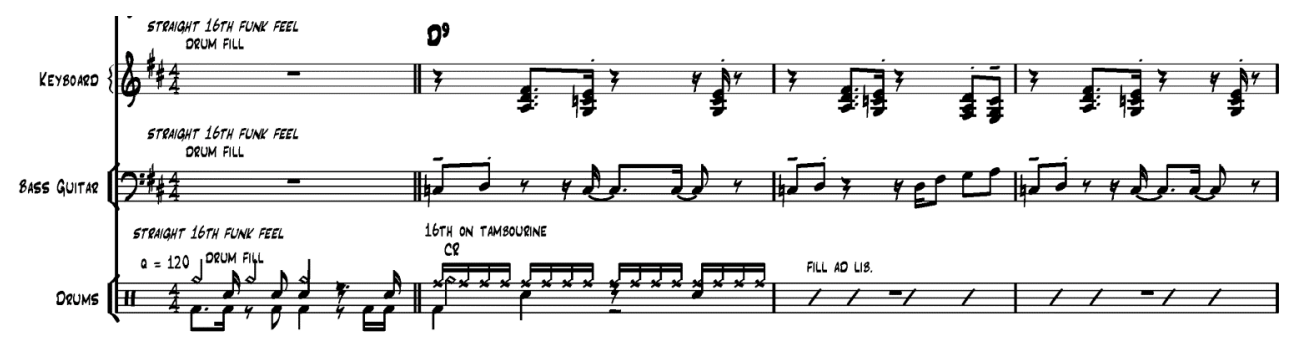

Figure 46 
After a melodic introduction, Don Henley's original version of New York Minute goes into a crochet vamp at the beginning of the verse, which is played by electric piano and has a calming effect on the mood of the music, see figure 47 below.

Don Henley: New York Minute, bars 11-18-0.54"

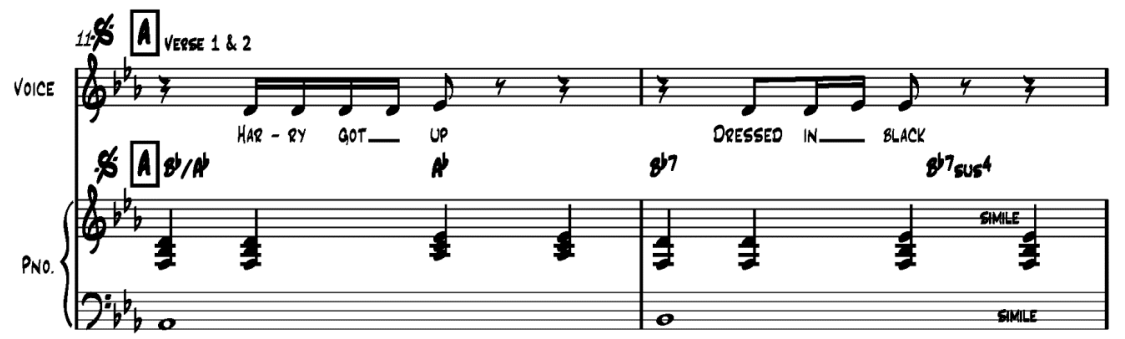

Figure 47

Bob Belden's arrangement of New York Minute also has a vamp but this time it is two bars long with four different chords in eight bar sections. This is based on a syncopated bass figure followed by an anticipated piano chord and helps to establish a sense of urgency with the up-tempo modal swing feel. One reviewer has this to say about this:

By adding vamps, reharmonising the chord structures, sometimes quickly discarding the melodies and utilizing an all-star band, Hancock was able to transform the potentially unrewarding music into creative jazz. ${ }^{22}$

Bob Belden: New York Minute, Introduction vamp

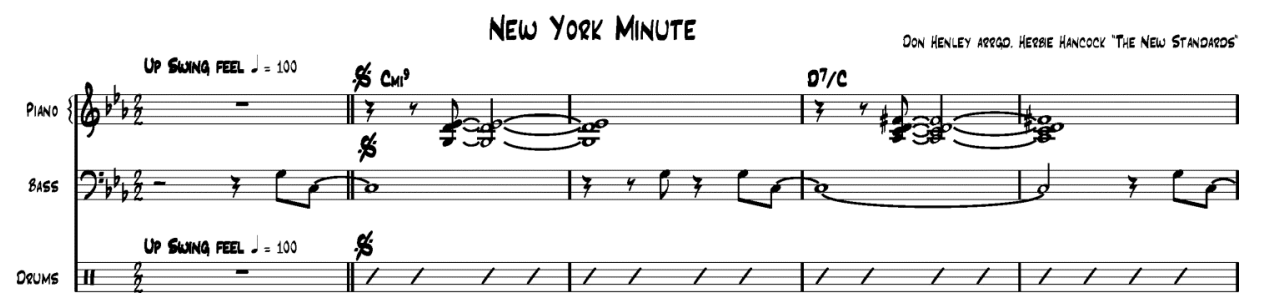

${ }^{22}$ Scott Yanow, The New Standard; Overview, All Music accessed January $13^{\text {th }} 2009$ 


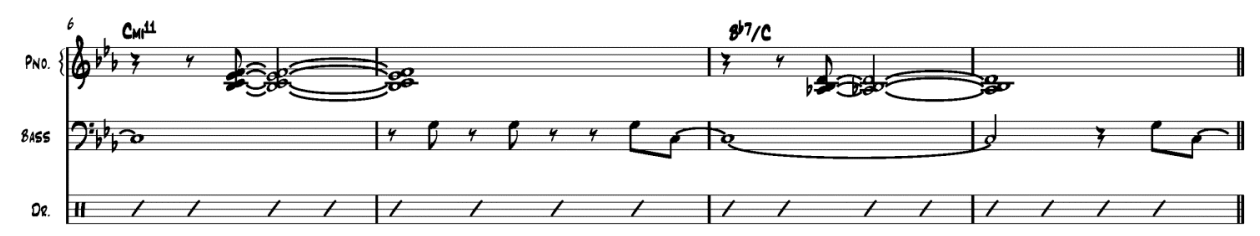

Figure 48 


\section{5 - Harmony}

Reharmonisation is an obvious tool when rearranging any tune to add a jazz flavour. It can be subtle by modulating to another key within the arrangement or adding sevenths and extensions to the existing chords; or complex by substituting different harmony. This can add many different colours to the mood of the lyrics and the song itself.

\subsubsection{Modulation}

Modulating to a different key has been used in many pop songs and jazz arrangements, often to add intensity near the end of the song.

This is the case for the first modulation that takes place in Lisa Bassenge's arrangement of Like A Virgin at bar 68, which is the start of the last verse. As we can see in figure 49 there is a brief break at bar 67 , the vocalist enters with the melody of the three pick up notes a semitone higher. The verse continues in the new key of $\mathrm{F \#} \mathrm{major,} \mathrm{and} \mathrm{the} \mathrm{previous} \mathrm{harmony} \mathrm{used} \mathrm{in} \mathrm{the} \mathrm{verse} \mathrm{and} \mathrm{the}$ beginning of the chorus is transposed up to the new key.

Lisa Bassenge: Like A Virgin bars 61-69
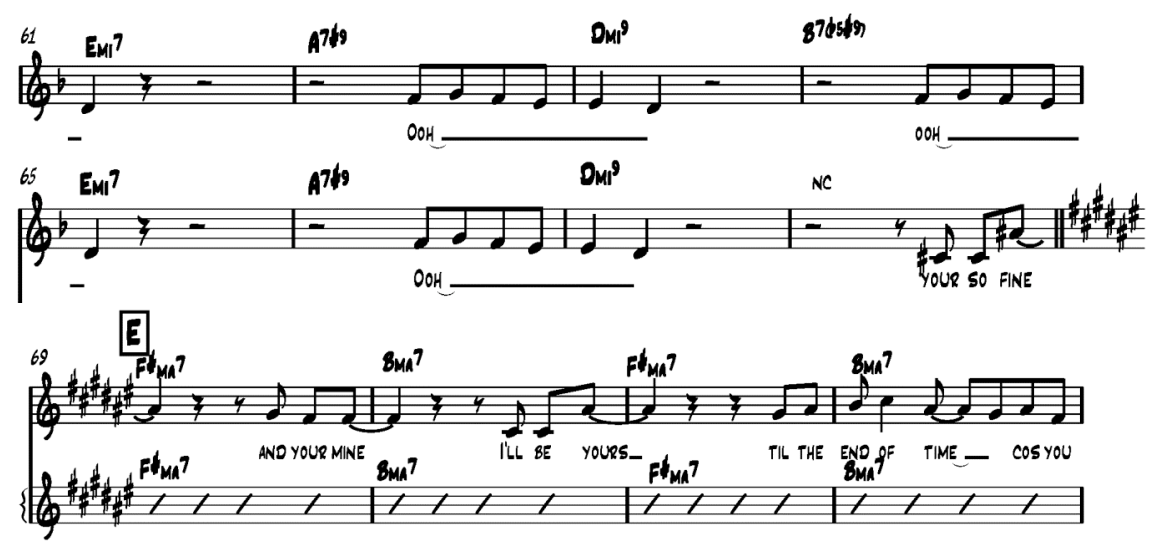

Figure 49 
At bar 84 in the middle of the last chorus, there is another clever but abrupt modulation, using the pivot note $\mathrm{F}$ in the melody which becomes the third of the next chord $\mathrm{D}$ mi7, as we can observe in figure 50.

Lisa Bassenge: Like A Virgin bars 77-87

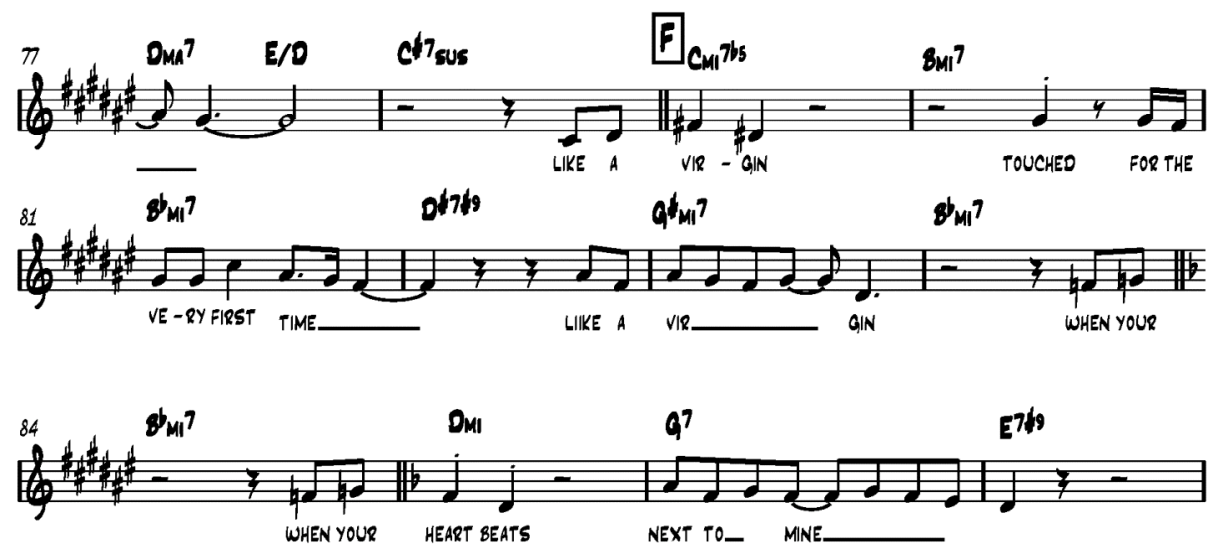

Figure 50

Here it modulates back down a semitone to the relative minor tonality of $D$ minor. Both of these modulations are abrupt but the second one adds an element of surprise for the listener, as well as drawing on the technical and aural skill of the vocalist.

\subsubsection{Seventh Chords and Extensions}

Most of the harmony used in pop songs is triadic although there is the occasional dominant seventh chord.

The original harmony in Prince's 1999 is based on diatonic triads. As we can see in figure 51 , in the chorus section he uses the chords of $\mathrm{Bb}$ and $\mathrm{D}$ minor, then it returns to the original vamp of $F$ alternating with $G m i 7 / F$. 
Prince: 1999 , bars 29-36

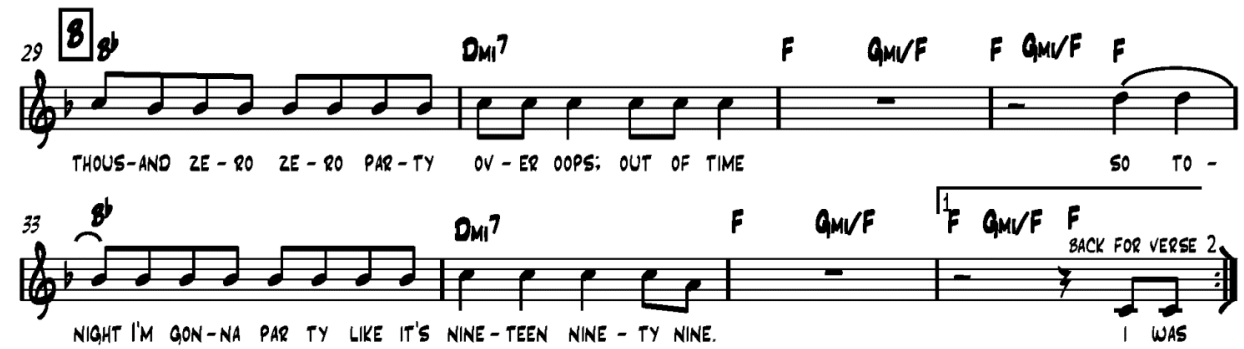

Figure 51

In his arrangement of the same song Bob Belden's has replaced the triads with dominant thirteenth chords to create a Motown style sound of funky Hammond trio, see figure 52 .

Bob Belden: 1999 bars 26-33

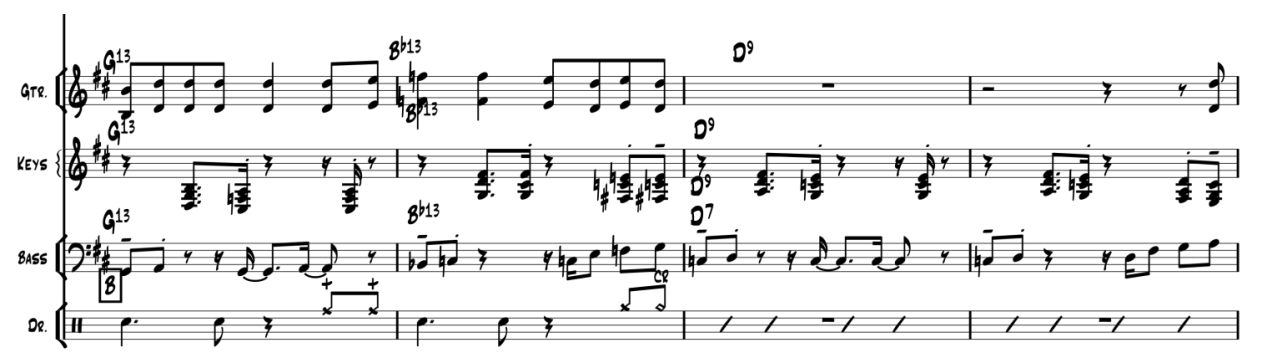

Figure 52 


\subsubsection{Harmonic Substitution}

\subsubsection{Turnarounds}

The original harmony used in the verse of Sting's Sister Moon is based on a two chord vamp of $\mathrm{F \# mi/ma7} \mathrm{and} \mathrm{B7} \mathrm{which} \mathrm{is} \mathrm{repeated} \mathrm{for} \mathrm{the} 8$ bar verse.

Sting: Sister Moon bars 6-9

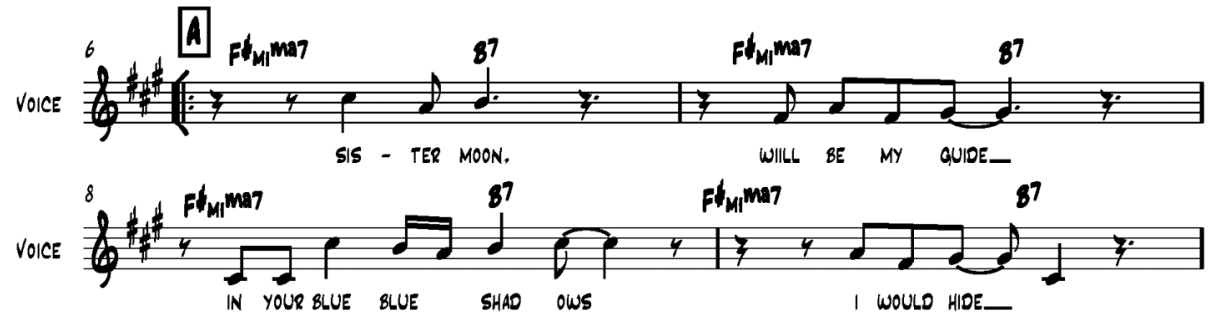

Figure 53

Herbie Hancock's arrangement retains most the harmony in the first section of the verse of Sting's song Sister Moon. As we can see in figure 54 he retains the $\mathrm{F \# mi/ma7} \mathrm{chord} \mathrm{but} \mathrm{adds} \mathrm{a} \mathrm{juicy} \mathrm{suspended} \mathrm{sound} \mathrm{to} \mathrm{the} \mathrm{C \# 7sus} \mathrm{chord.}$

However the Hancock surprise comes as a form of chordal turnaround at bar 1516. Although there several slash chords used in the original harmony, Hancock uses more harmonic substitutions of them and creates more angst in the music.

Sting: Sister Moon bars 14-17

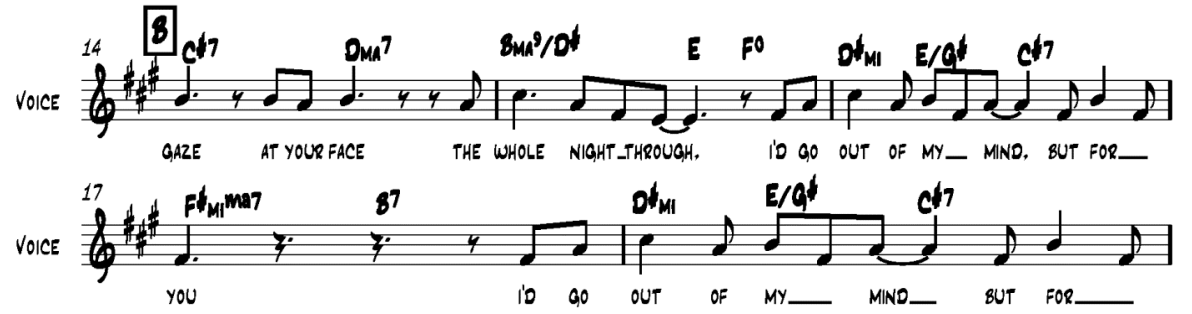

Figure 54

Like to the original version there is an upwardly moving bass line but the resolution to an ambiguous polychord B/C creates much tension (Fig 55). By 
combining the two chords, he cleverly resolves onto Bbma7\#5 in bar 16. A melodic pedal point is created when the melody note is sustained over the augmented Bbma7 chord, and then bar 15 is repeated but resolves harmonically to Gma7\#11 second time. In bar 18 this chord is a substitution a tri-tone away from of Gma7\#11 for the C\#9sus, leading back to F\# minor which follows in the next section.

Herbie Hancock: Sister Moon bars 13- 18

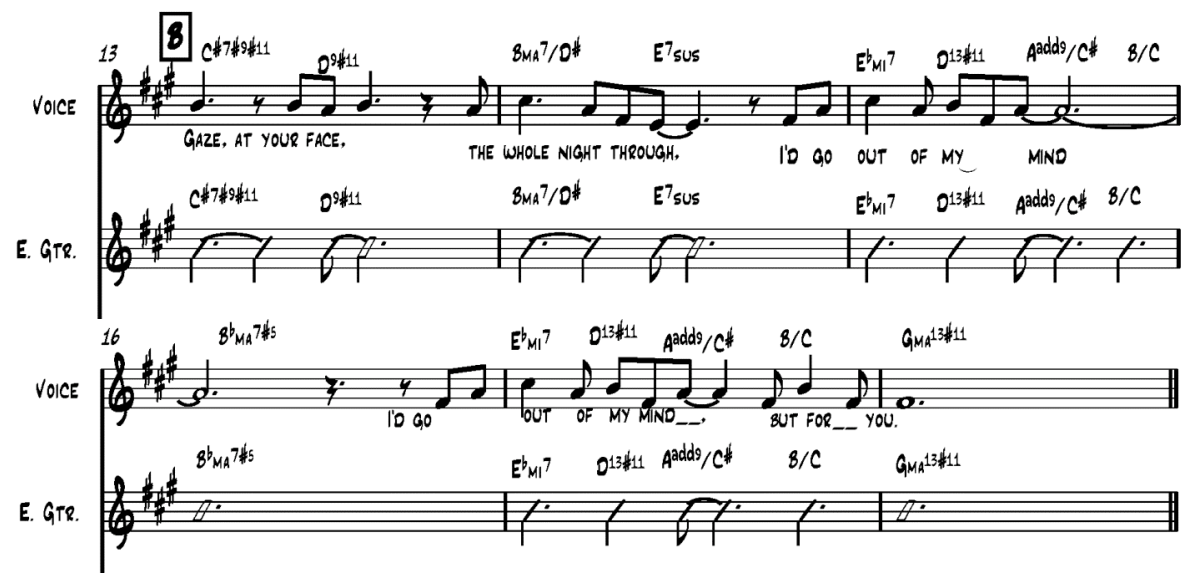

Figure 55

As with the original version, there is modulation in the next verse up to $\mathrm{Bb}$ minor in bar 37. At bar 41 in figure 56, there is another crunchy turnaround that starts in the tonic, and this time has a chromatically downward moving bass movement. This is abruptly modulates back to the original key in bars 43 and 44 , as it did previously in bars 17-18. At bar 45 the last two bars of the verse return to the original key two bars earlier before the piano solo.

Herbie Hancock: Sister Moon bars 41-46 


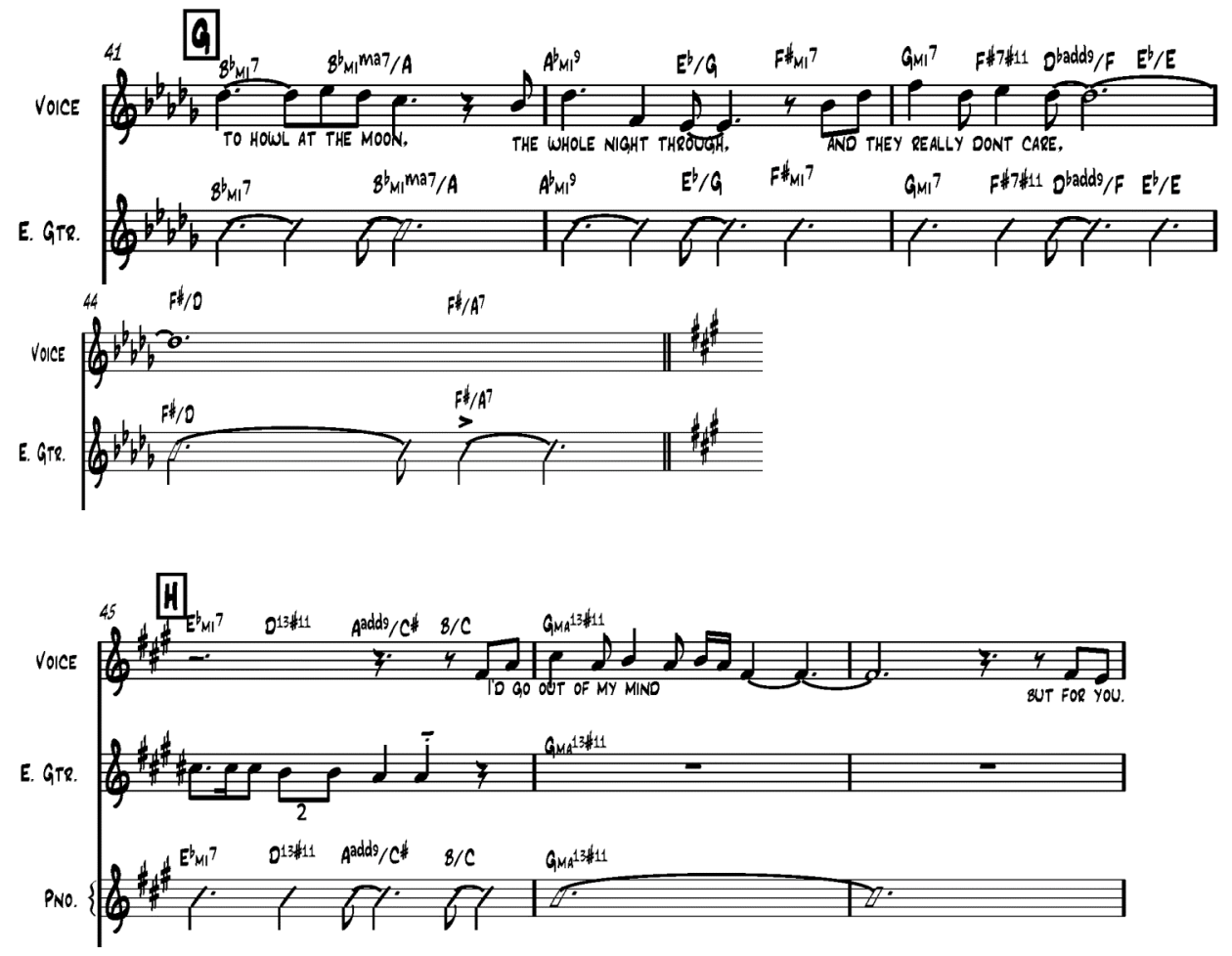

Figure 56

\subsubsection{Diatonic and Tritone Substitution}

A diatonic substitution is a simple chord substitution that can be made when there are two different seventh chords that have three notes in common.

Although these two chords will sound similar it allows a different bass note as well as the option of more extension notes.

The original version of 'Simple Minds' Don't you Forget About Me is based on a four bar pattern of primary chords I V IV V.

Simple Minds: Don't You Forget About Me, verse

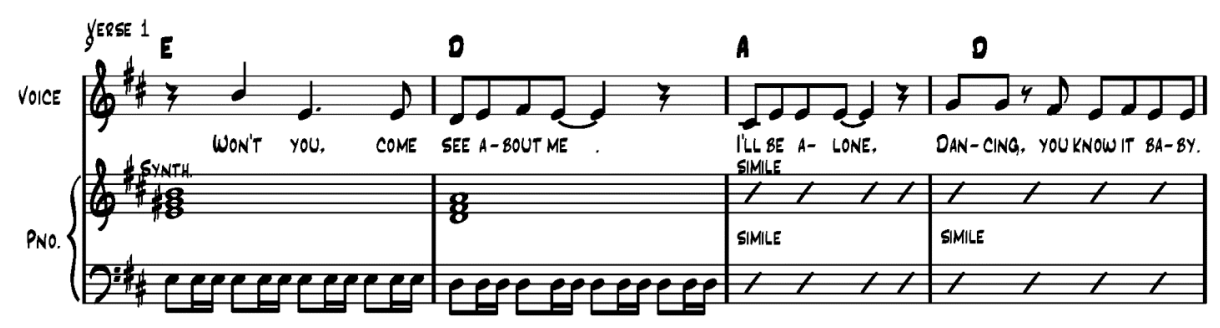




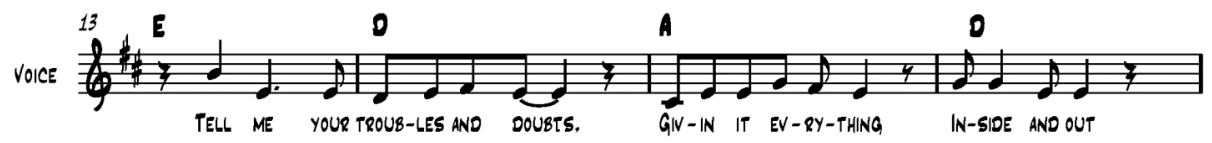

Figure 57

Michelle Nicolle's reharmonisation of Don't you Forget About Me uses four bar blocks with diatonic and tritone substitution. The first happens in bar 16, where Ebma7 a tritone substitution of the dominant chord has been used, as we can see in figure 58.

Michelle Nicolle: Don't You Forget About Me bars 13-16
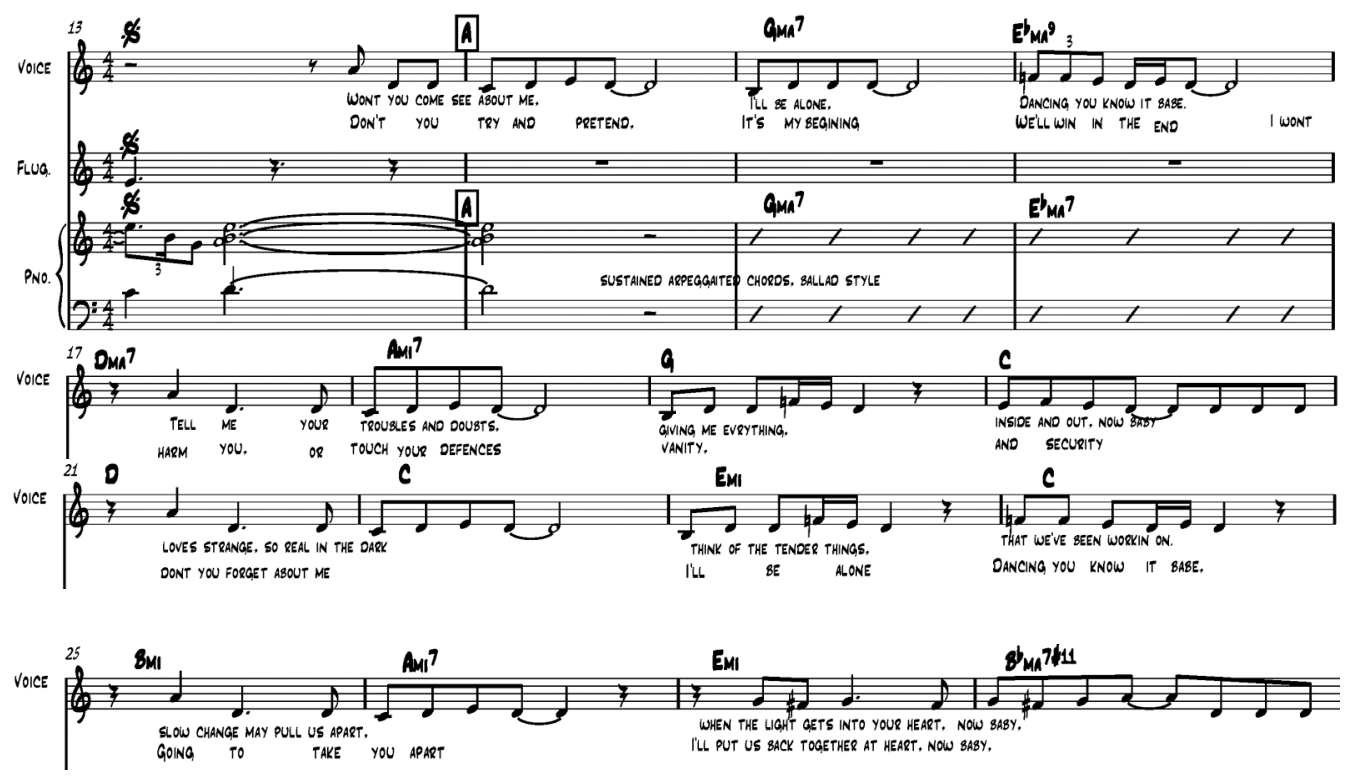

Figure 58

In the next four bar block, a more colourful Ami7 has been used, a diatonic replacement for the original $\mathrm{C}$ chord, giving a different bass note. Similarly, in bar 22 an Emi7 has been used in place of the original $G$ chord. The last four bar set of bars $25-28$, are all reharmonised; the original $D$ chord has been replaced by $B m i 7$, the $C$ in the next bar by Ami7, the next has Emi7 instead of $G$, and the richness of Bbma7\#11, at the end of the verse. This reharmonisation helps to create more expression in the music, enhancing the lyrics and melody. 


\subsubsection{Melody Notes As Extensions Of The Chord}

Careful inspection of what the melody notes are in relationship to the chord played with them can give insight to other harmonic possibilities. Most pop songs are built in triad choices and very rarely use seventh degrees on the scale.

In the original version of Walking On The Moon this is indeed the case, see figure 59. The first note of the chorus in bar 33 is the third degree of $\mathrm{Bb}$, the $\mathrm{C}$ is the fifth of $F$, and $E$ is the third of $C$. Unusually the $F$ is the seventh of $\mathrm{Gmi}$ in bar 36 but it does add more colour to the melody.

Sting: Walking On The Moon, bars 33-44

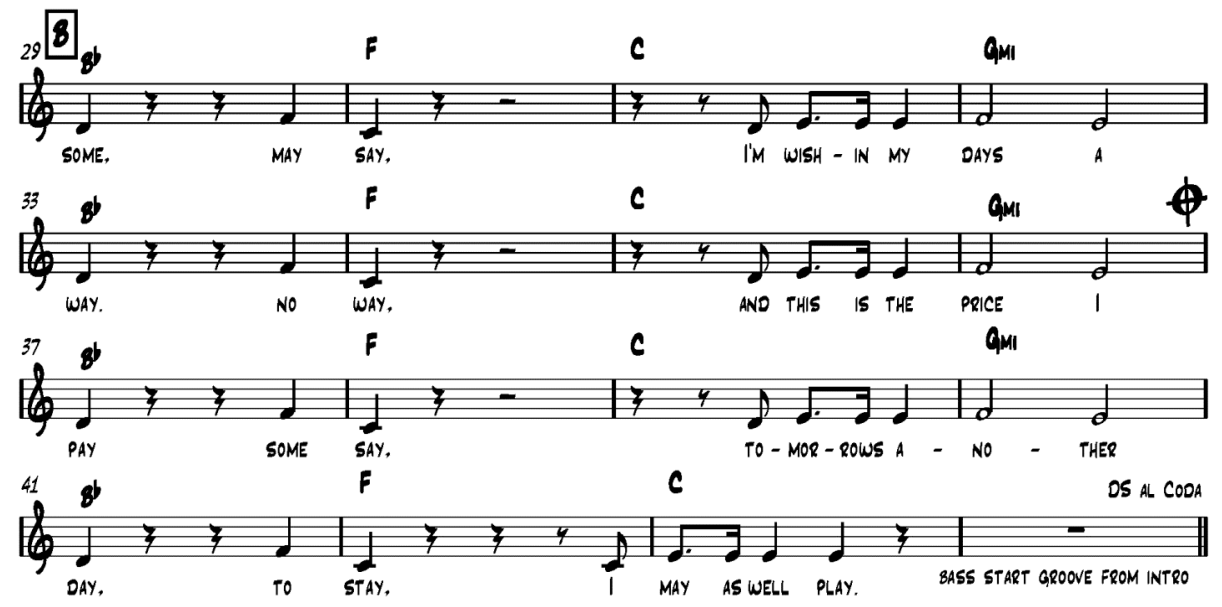

Figure 59

In the chorus section of the new arrangement of Walking On The Moon, Christian Mc Bride's has reharmonised the originally simple four bar chord repeated sequence in a non-diatonic fashion with melody notes falling on the some of the most colourful notes in the chords. As we can see in figure 60, the melody sits on the $D$, which is the sharpened fifth degree of F\#7alt in bar 23. Another example is the $F \#$ which is the sharp $9^{\text {th }}$ of the Eb7\#9 in bar 24 , and the $G$ which is the eleventh degree in bar 25.

The passing chords in the fourth bars of the sequences are particularly colourful. An example in figure 60 is in bar 25 where the Dmi11 and the C\#mi11 resolve 
onto Bbma7\#11 which is a secondary dominant of the starting Ami11.

Christian Mc Bride: Walking On The Moon bars 22-37
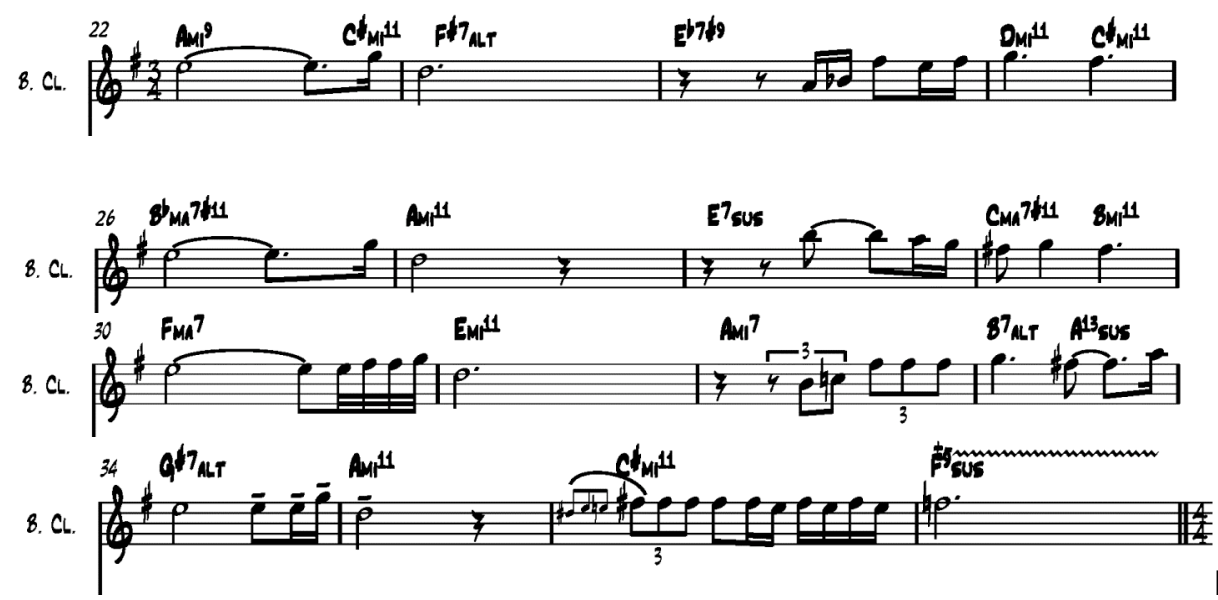

Figure 60

This reharmonisation of this melody is rich and interesting and further enhances the eerie quality of this arrangement. 


\section{PART THREE - The Tool Box}

"All arranging is really the art of being able to conceive a musical effect and then transfer it to paper so that the particular effect comes alive."23

There are many techniques to consider when making jazz treatment of a pop song, including treatment of the melodic line, the harmony, the rhythm, the form and the instrumentation. One of the tasks of the arranger is to be aware of the intended effect on the listener in how the material is presented.

This section discusses techniques, ideas and principles I applied in arrangements of pop songs for jazz ensemble. The songs chosen for these arrangements are from the same era as those in the previous section, and are songs composed in the last thirty years.

${ }^{23}$ Dick Grove, Arranging Concepts Complete; The ultimate arranging course of today's music, Alfred Publishing Co, Inc, 1989, page iv 


\subsection{Melody}

\subsection{Adapting the melody}

\subsubsection{Jazz Feel}

The melody of a pop song is one of its most recognisable features and can be adapted to have a jazz feel. As discussed previously in Part Two the adaptation can involve other musical elements simultaneously such as rhythm and instrumentation.

New Zealand band Stellar* features the talents singer/songwriter and guitarist Boh Runga. The top 20 hit Violent was released in 1999 on the Tom Bailey produced debut album 'Mix'. Described by reviewer Kelvin Hayes as "pleasant, slightly alternative pop/rock". ${ }^{24}$

The melody from the chorus of the original version of Violent was already rhythmically exciting (figure 61); there are two four bar phrases and with the exception of the first few notes the melody is predominantly syncopated.

Stellar: Violent, chorus section bars 52-59

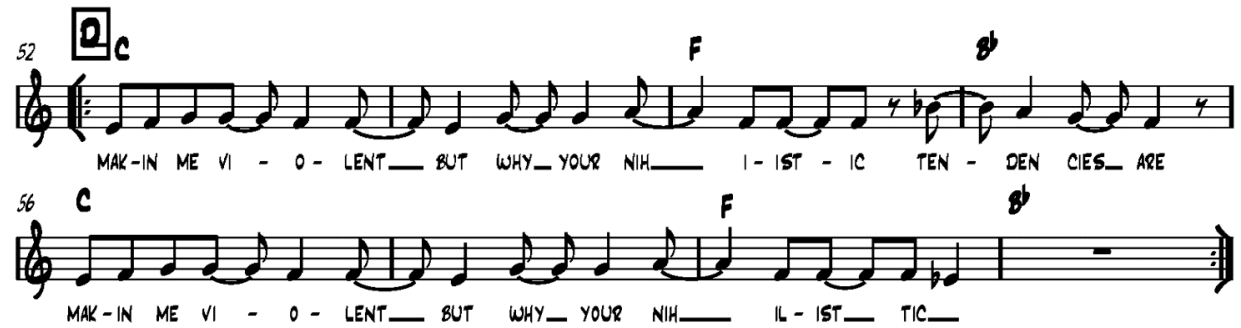

Figure 61

This melody can be adapted to have more of a jazz feel. My arrangement of this tune for big band starts with the melody of the chorus section, which is doubled on many instruments including flute, saxophones, trumpets, and rhythm section;

\footnotetext{
${ }^{24}$ Kelvin Hayes: Album review, All Music Accessed $19^{\text {th }}$ November 2008
} 
the listener is introduced to the song with a high level of energy and a full sound not to mention a loud dynamic. See the score in figure 62 below.

Trudy Lile: Violent, Introduction

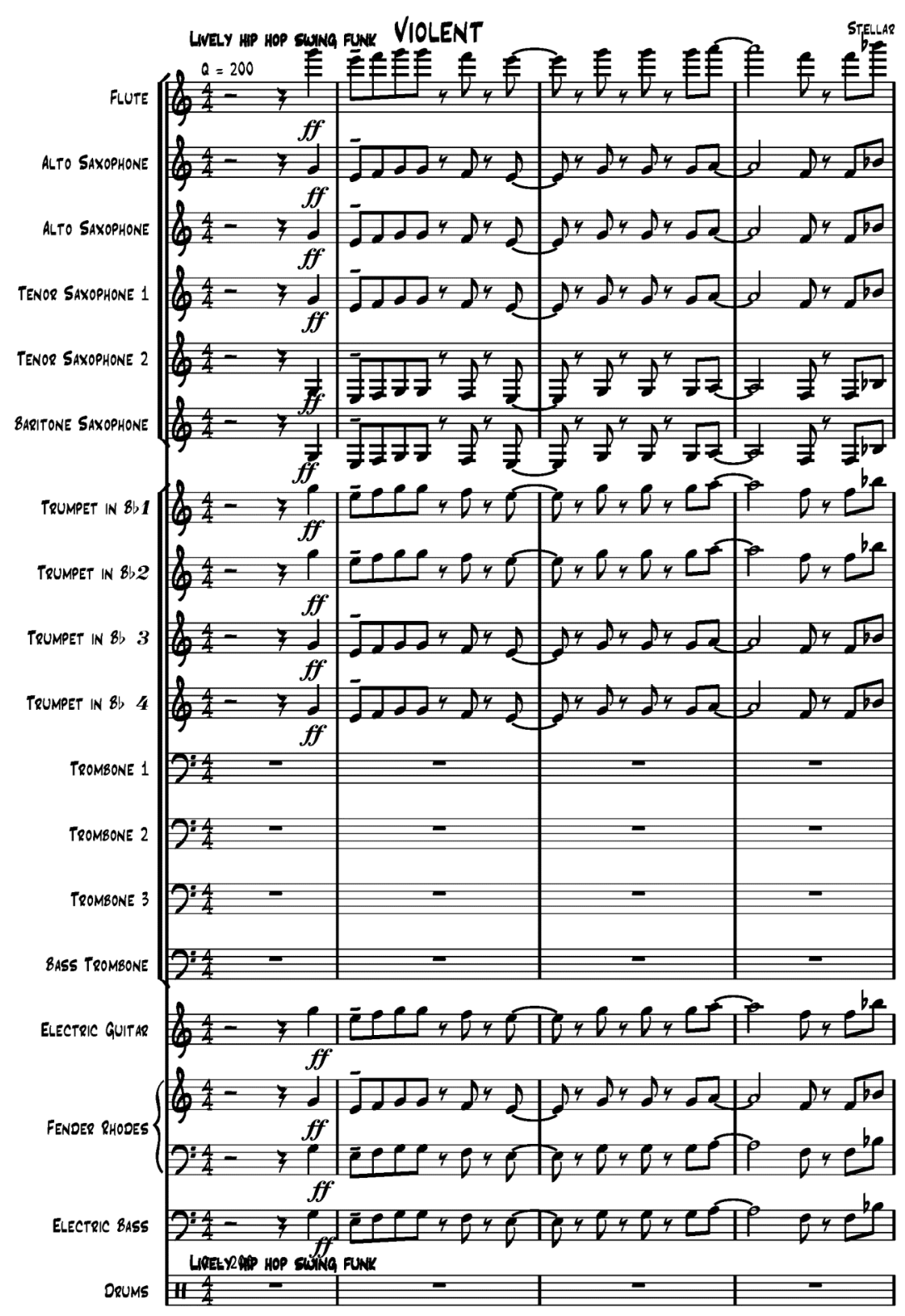

Figure 62

In the new arrangement a swing feel has also been added, to give a jazz rhythmic feel to the melody. Anticipation and slight changes of emphasis have also been added to enhance this effect. An example of this is in figure 63 below 
where the notes of the second bar are on the beat and not syncopated, with the exception of the last beat where the anticipation into the next bar remains.

Trudy Lile: Violent, chorus section bars 37-44
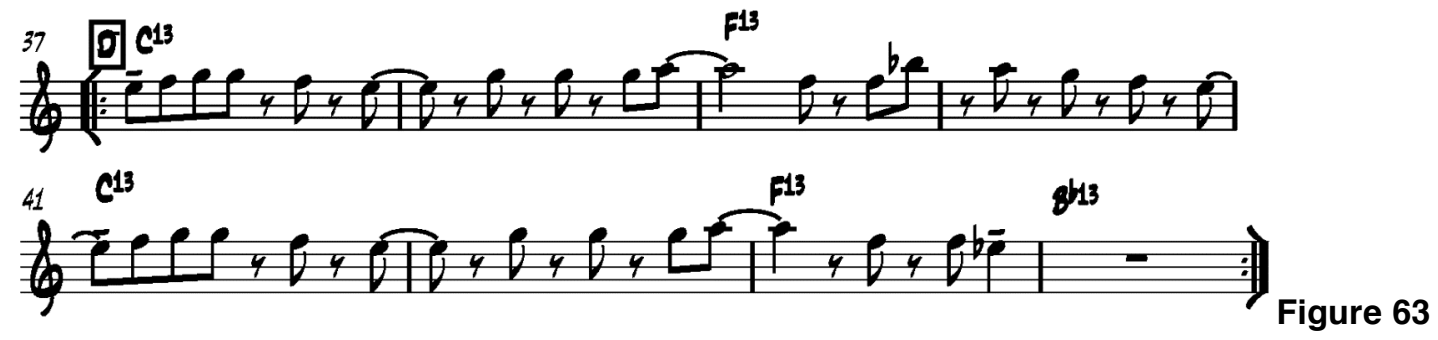

In places melodies from the original tune are used in the arrangement as leading melodic or backing-lines. This adds an element of recognition and cohesion for the listener. In the new arrangement the tenor saxophones and trombone section balance out the texture by playing a harmonized syncopated line that was a guitar riff from the original song.

Trudy Lile: Violent, chorus section bars 37-38

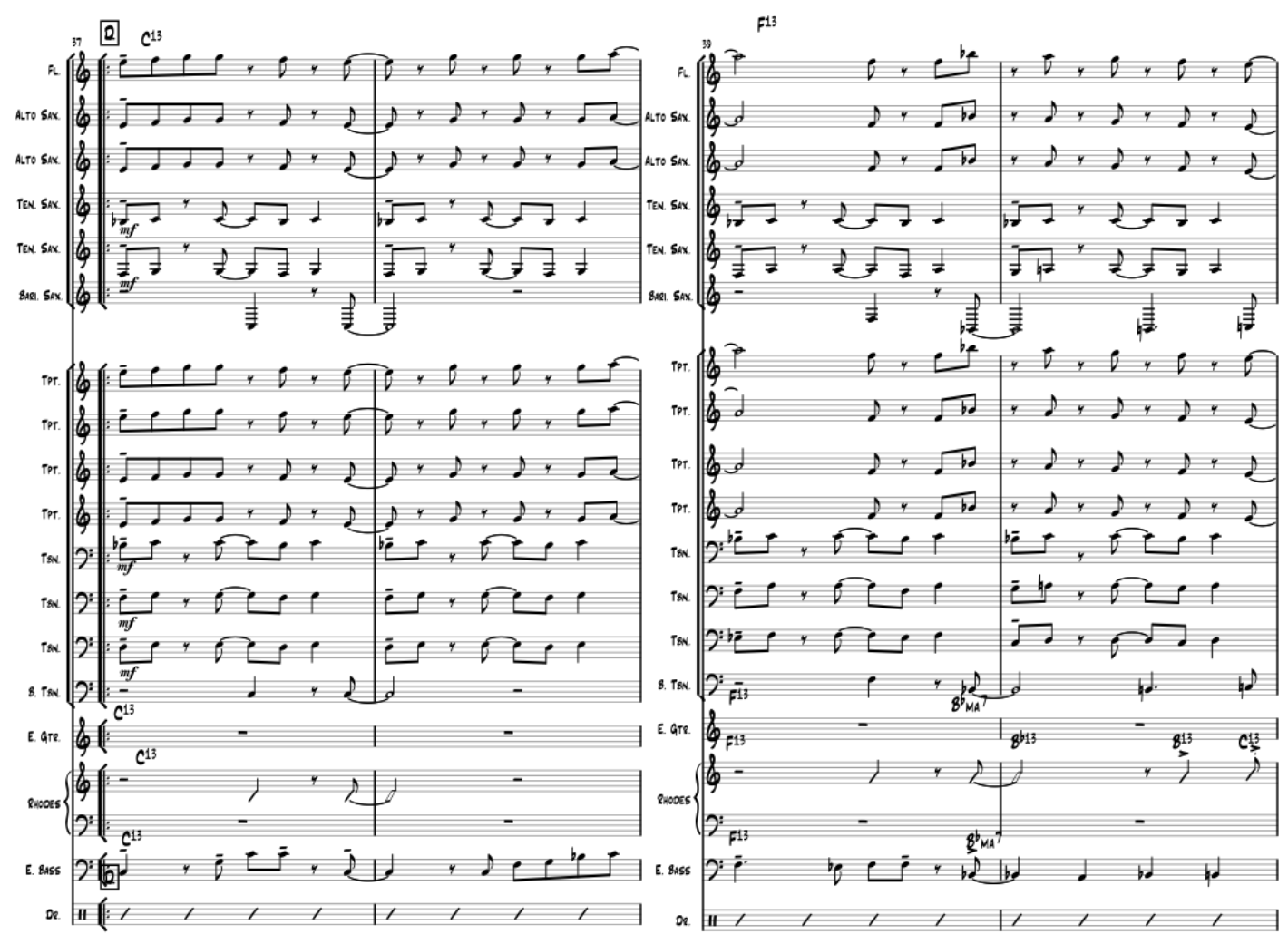

Figure 64 
In the new arrangement the horns enter with a melodic riff at bar 14 , which is a melodic fragment from the original version of the song. See the original version of the melody from the bridge section below in figure 65 , and how it is used in the new arrangement in figure 66.

Stellar: Violent, chorus section bars $43-50$

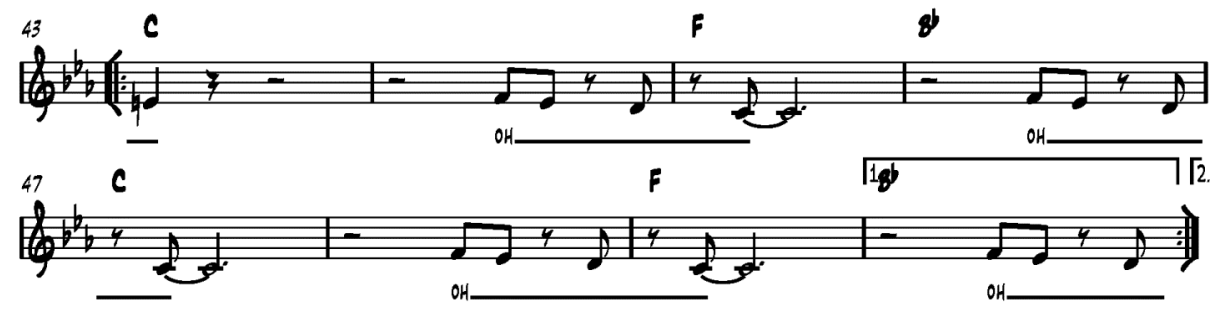

Figure 65

Trudy Lile: Violent, chorus section bars 37-38

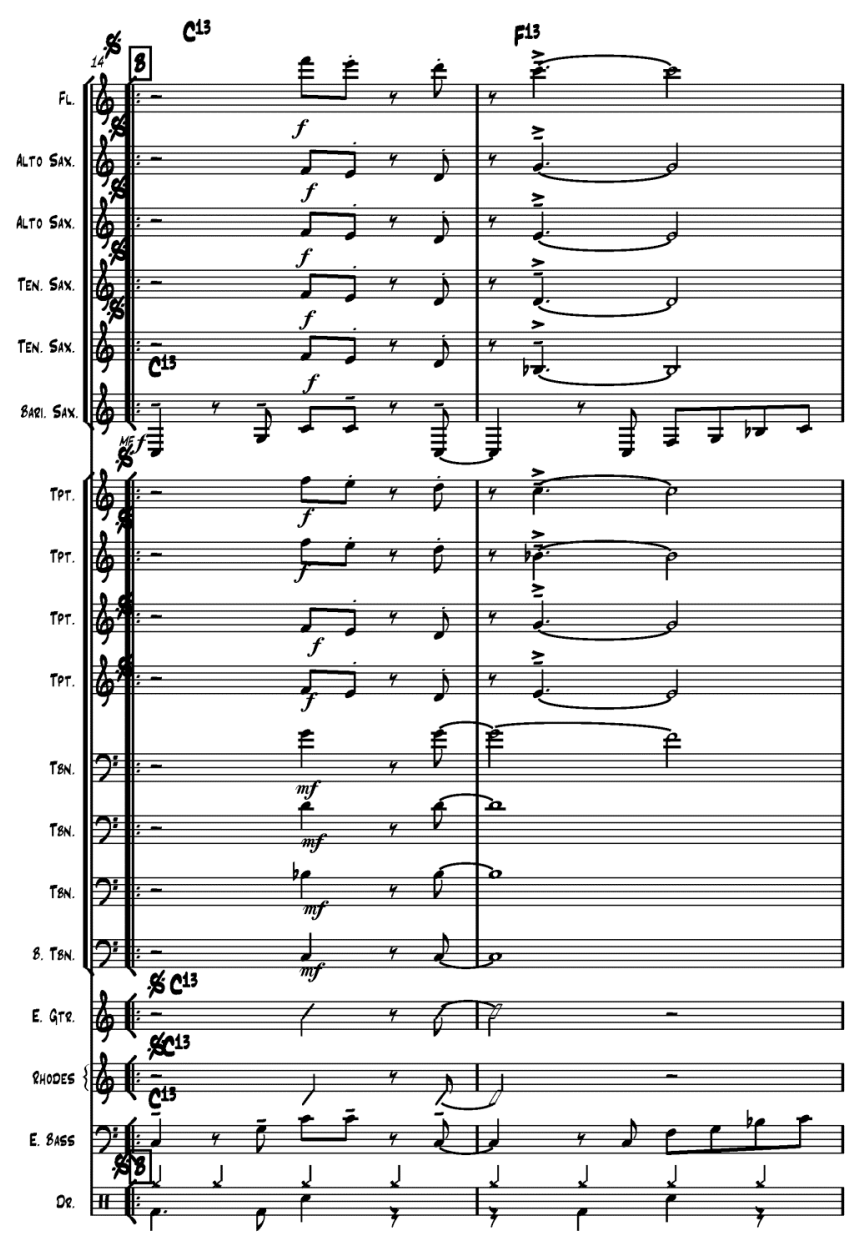

Figure 66 
The new arrangement finishes in a similar fashion using this melodic figure. This time it is repeated three times, and has been extended melodically at the end of each phrase. The arrangement finishes loudly with a similarly big impact as in the introduction. See figure 67 below.

Trudy Lile: Violent, Coda section

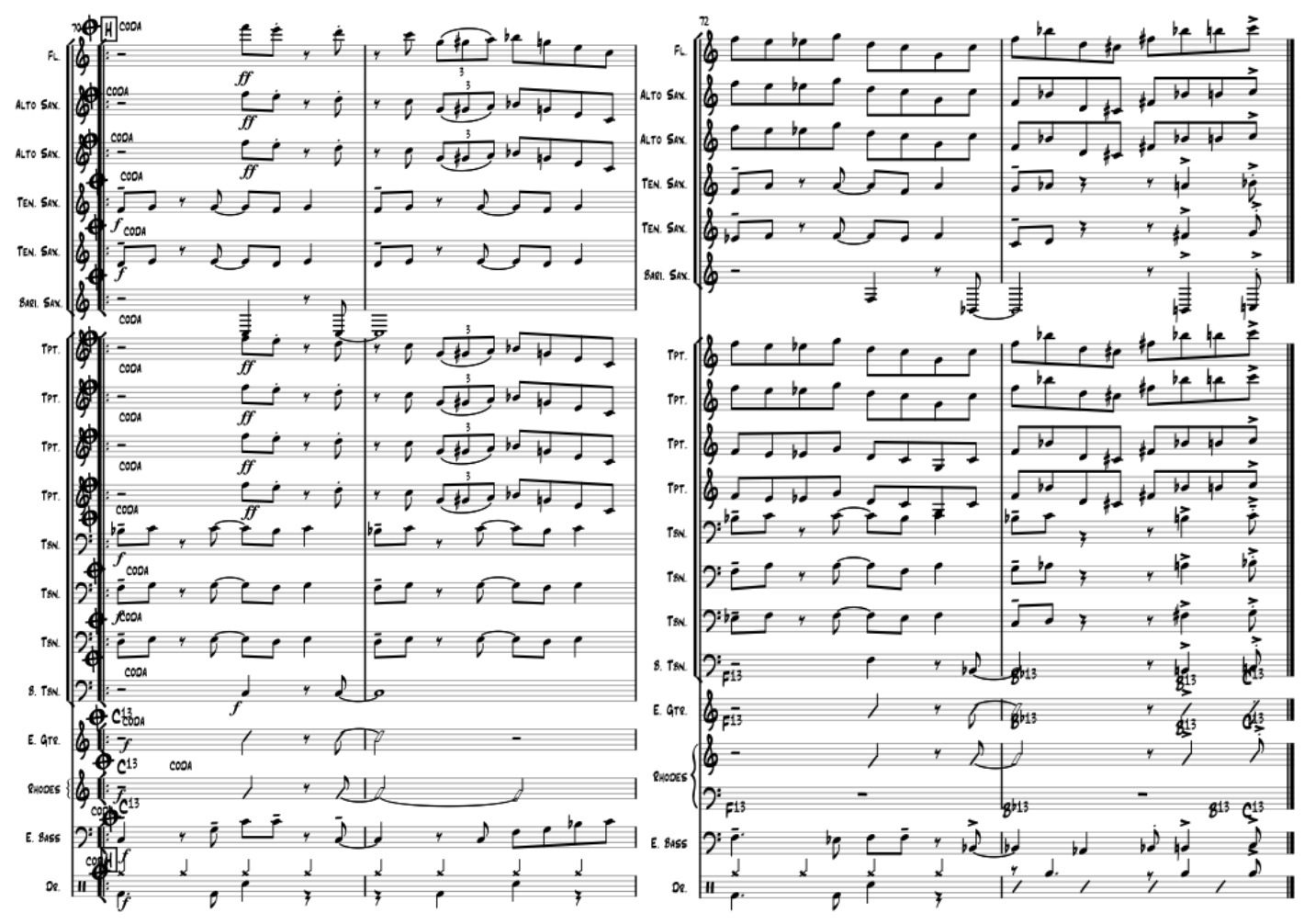

Figure 67

\subsection{Melodic pedal points}

Sections of the melody can be emphasised by elongating them and pedal points can be generated. This creates a suspended effect and can highlight important lyrics or parts of the melody.

Fragile is song from Sting's album 'Nothing like the sun' released 1987, and several jazz artists including pianist Billy Childs and vocalist Cassandra Wilson have recorded jazz versions of it. 
The original chorus of Fragile is simple and features a repeated four bar phrase that moves by step in a downward direction repeated (figure 68).

Sting: Fragile, Chorus section
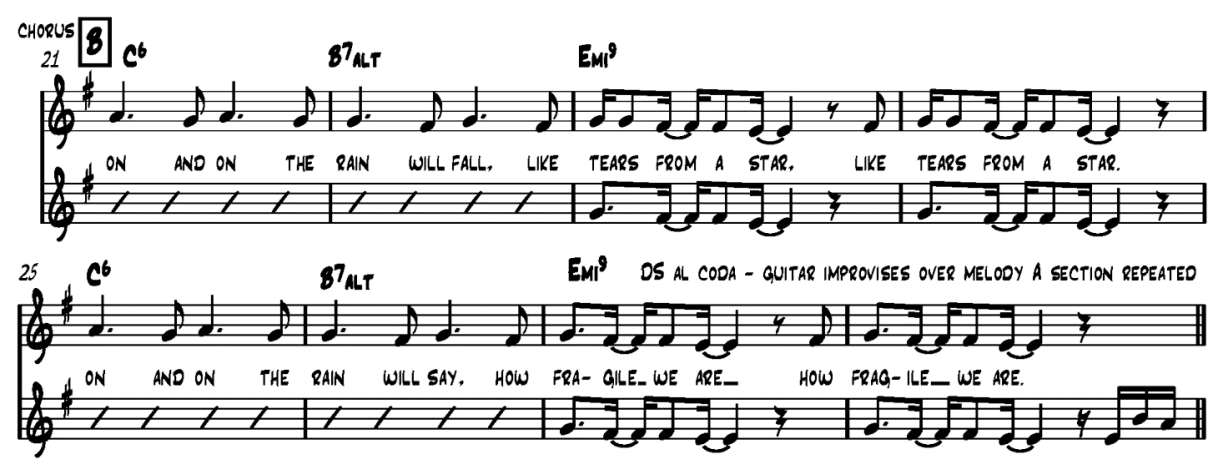

Figure 68

In my arrangement of Fragile for big band, the melody has been doubled in length at the chorus section. In figure 69 below, we can see that the melody in bar 37 has been adapted to the new time signature of $6 / 8$, adding a rhythmic element, and the first two bars have been extended to be a four bar phrase. This helps to give the illusion of the music being half the tempo.

Trudy Lile: Fragile, chorus section

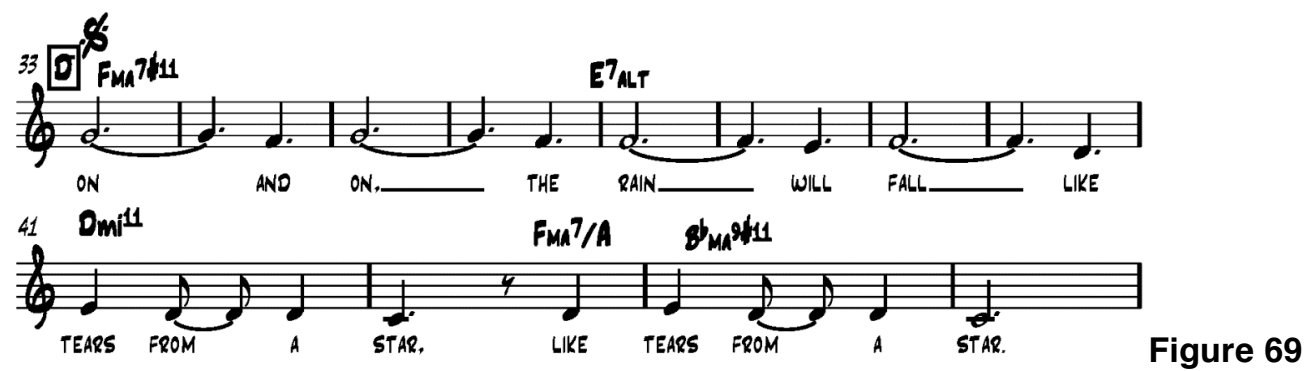

This manipulation of melody was observed in the transcription of Herbie Hancock's Sister Moon, where the last two bars of the melody were repeated in the bridge section. In my arrangement of Fragile the second four bar phrase of the chorus section is not repeated, as seen in figure 69 .

The next section will look at rhythmic elements used in the new arrangements. 


\subsection{Rhythm}

A range of tempi are available to arrange songs, and consequently a variety of rhythmic possibilities are available to jazz arrangers. However specific ideas and instructions written into the score can influence the performance.

Many tunes are often played at a different tempo to the original. In the standard jazz repertoire, songs are performed in a variety of tempi and many slow tunes can be performed at faster tempi. In contrast to this, and particularly with the development of smooth jazz, it has been more common for arrangements of pop tunes by jazz artists to be played slower than the original songs.

\subsubsection{Groove}

Another consideration when arranging pop songs is to change to the type of feel or groove of the song. This can be done in several ways, from adapting the song to a new time signature or by applying a new feel or groove at the same speed. The most obvious choice would be to add a jazz swing feel but there are many "World" grooves such as those of South American styles of music that can also be used. These include Bossa Nova, Samba, Salsa and Cha-Cha-Cha and Calypso just to name a few.

The song Rock With You was released on the 1979 breakthrough album 'Off the Wall', which helped establish Michael Jackson "as an artist of astonishing talent". ${ }^{25}$ Produced by Quincy Jones, the music is clean, mainstream pop, featuring disco beats, and funk guitars.

The new arrangement of Rock With You has been written at the same tempo but this time with the groove of Cha-Cha-Cha. The feel is established by the rhythm

\footnotetext{
${ }^{25}$ Stephen Thomas Erlewine: Album review, All Music, accessed November $19^{\text {th }} 2008$
} 
section in the introduction and features a piano montuno, as shown in figure 70 below.

Trudy Lile: Rock With You, Introduction

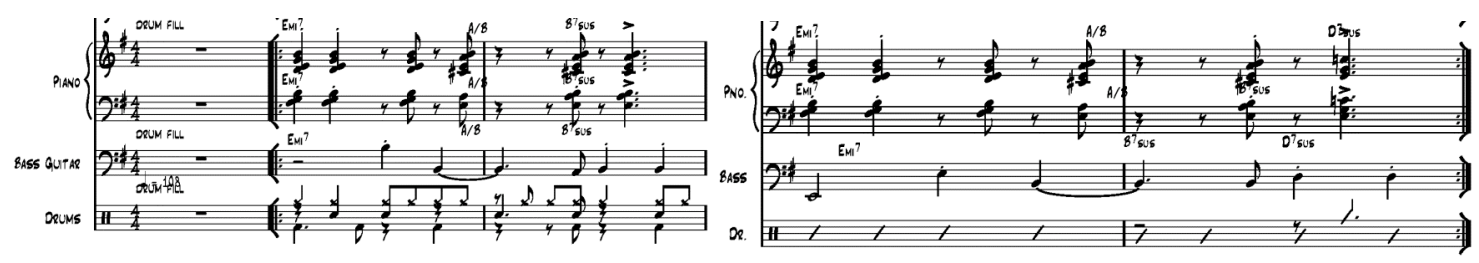

Figure 70

This feel is maintained throughout the piece and the big band is featured with various rhythmic elements of the Cha-Cha-Cha in the arrangement. The shout chorus (bar 54), features another type of piano montuno. Syncopated alternating quavers are scored in the trombone and trumpet sections of the big band (figure 71).

Trudy Lile: Rock With You, Shout Chorus bars 54-61

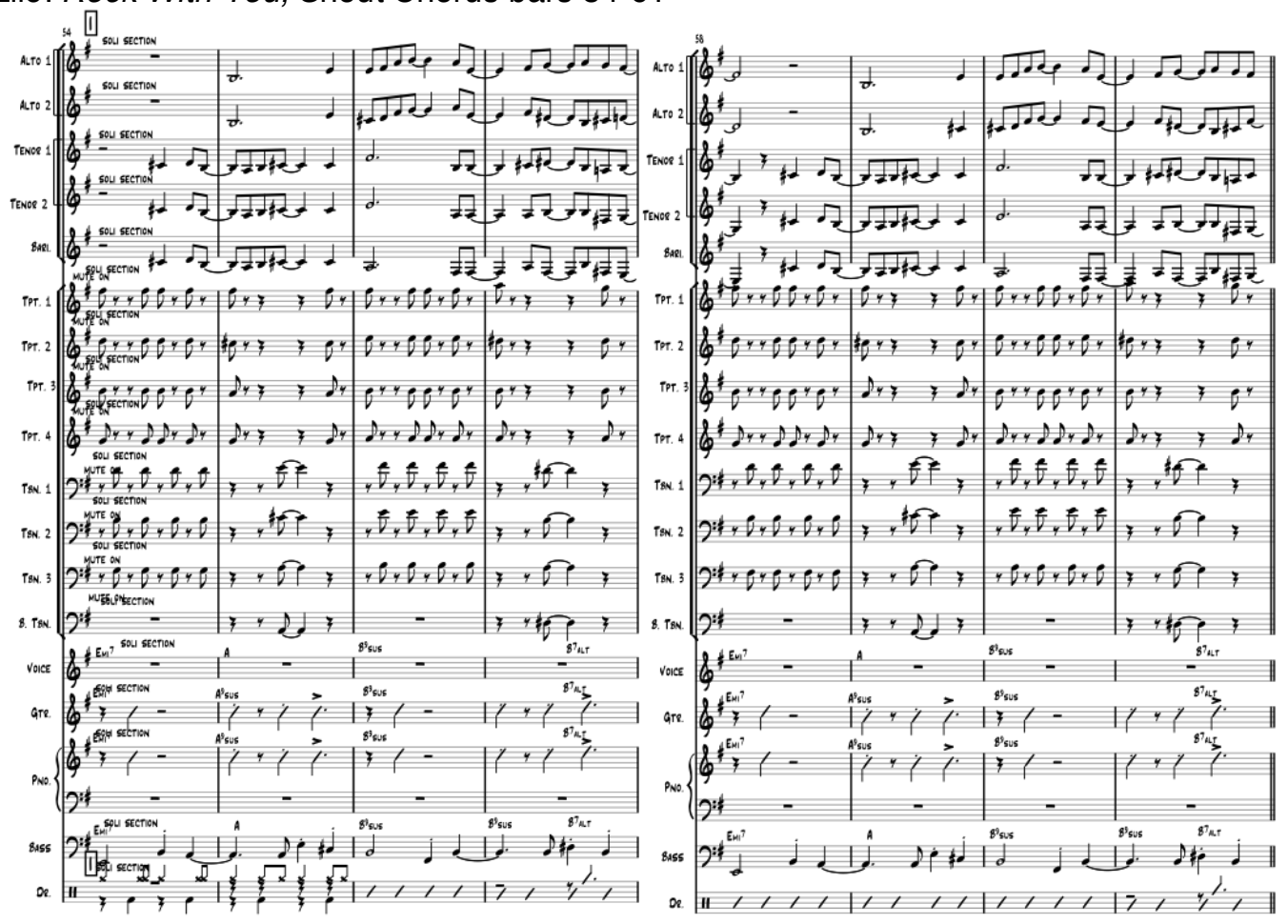

Figure 71 


\subsubsection{Changes of Tempo}

Changing the tempo of the new arrangement can have an impact on many musical elements at once, which can encourage a change of intensity in the performance. By slowing the tempo of the song there is more space for lyric interpretation, and by speeding up the tempo, the melody can by adapted and rephrased more simply. It is also possible to play slightly ahead of or behind the beat, and this instruction can be included in the score of the arrangement. "The effect is a kind of pressure to play faster or slower without actually changing the tempo"26 Playing slightly behind the beat creates a calm, lazy, spacious feel to the music. By contrast playing ahead of the beat helps to create a sense of urgency or energy.

Cyndi Lauper's poignant love song Time After Time was released on her highly successful album of the new wave era 'She's so unusual' in 1984. It has been played and recorded by several jazz artists, most notably Miles Davis, Cassandra Wilson and Tuck and Patti. The rhythmic feel is of the original song is of a rock ballad: a straight feel with instrumentation that is typical of a song from that era. Repeated notes are played by guitar, with a triadic keyboard vamp, as seen in figure 72.

Cyndi Lauper: Time After Time, Introduction

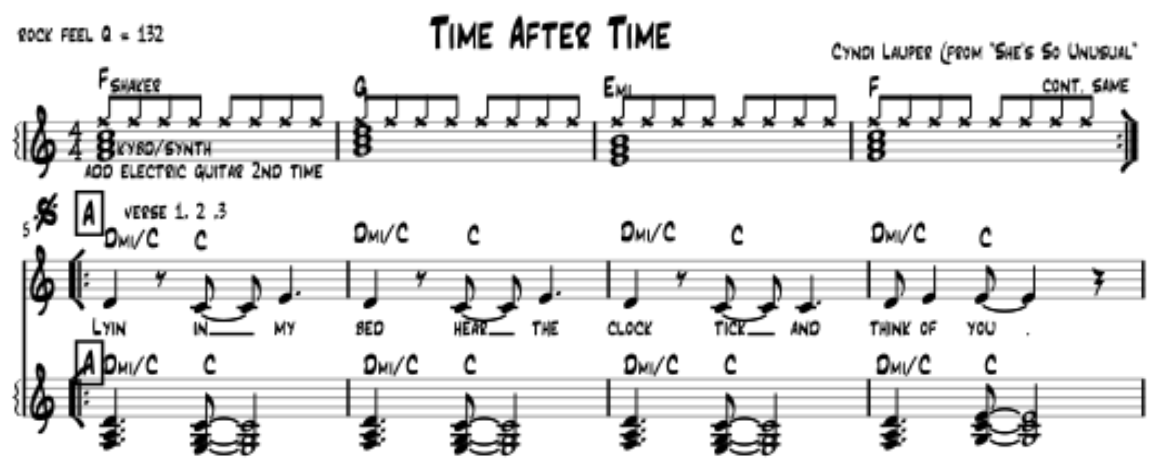

Figure 72

\footnotetext{
${ }^{26}$ Paul Rinzler, Jazz Arranging and Performance Practice; A guide for small ensembles, Scarecrow Press, Maryland, 1999, pp58
} 
My arrangement of this song starts with a freely improvised introduction and a swing-feel at a slower tempo than the original from bar 17 , the chorus section. The band is directed to play with a lazy 'two' feel as well as 'behind the beat', to retain the intended relaxed mood of the arrangement. See figure 73 compared to the new version in figure 74 below.

Cyndi Lauper: Time After Time, bar 13

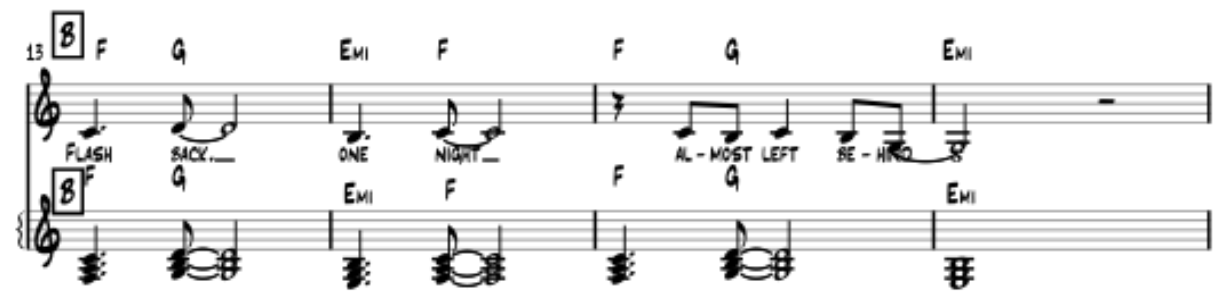

Figure 73

Trudy Lile: Time After Time, bar 17

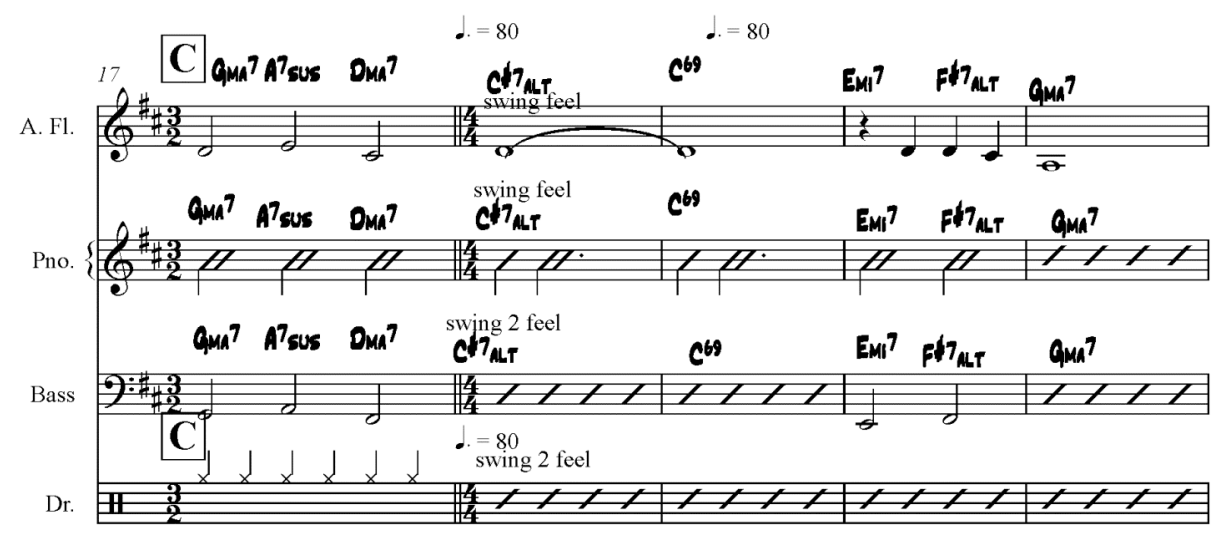

Figure 74

In figure 74 we can also observe the rhythmic impact on the melody in the new arrangement. Bars 13 and 14 of the original song are now played in a 3/2 bar in bar 17 of the new version. A melodic pedal point is created in bar 18 of the new arrangement, where the last note of the phrase is sustained for an extra bar (figure 74). This creates a feeling of suspension in the song after which the melody continues in the next bar. 
As with Herbie Hancock's arrangement of 'Sting's' Sister Moon, specific rhythmic hits have been added for chords written in the score during the chorus section, with some chords anticipated in a jazz style, though similar to the original, see figure 75 and figure 76.

Cyndi Lauper: Time After Time, bar 13

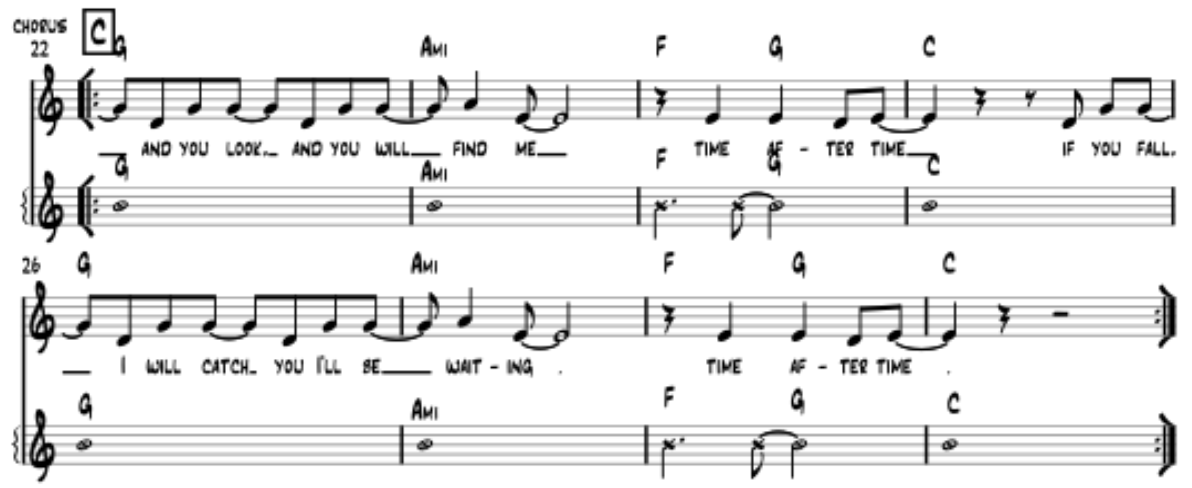

Figure 75

Trudy Lile: Time After Time, bar 17

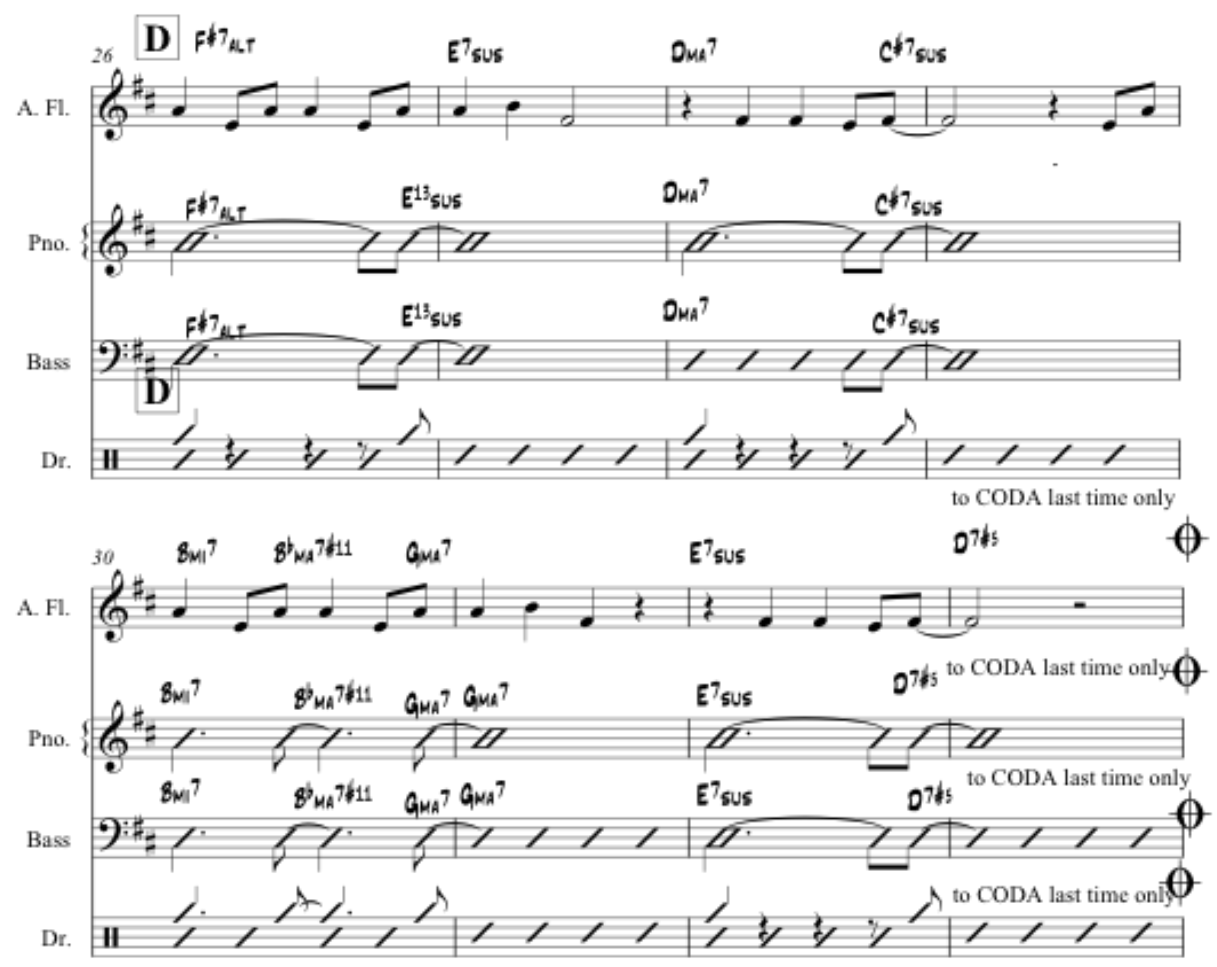




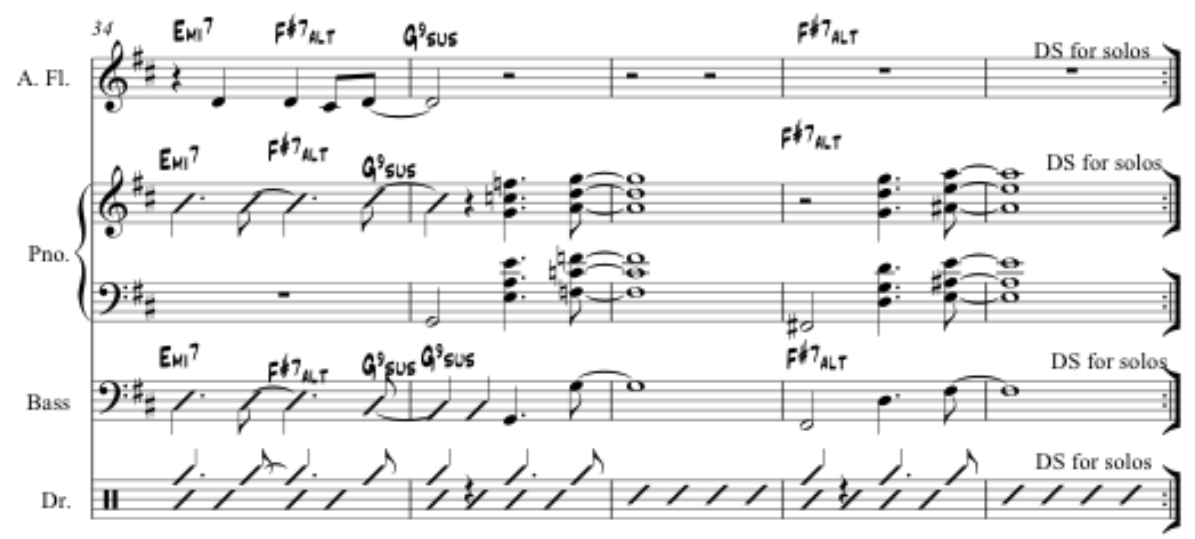

Figure 76

These hits help to control where the rhythmic harmony is placed in the arrangement, and lead back to the original vamp used in the introduction in bars 35 to 38 (figure 76 ).

\subsubsection{Changes Of Meter}

As with most pop music, 4/4 is also the most common time signature in jazz. Another dimension can be added by changing the melody to fit with the new time signature. This rhythmic change will mean that the melody and other musical factors also have to be modified.

Kurt Cobain's Smells Like Teen Spirit is a single from the highly successful 1991 album 'Nevermind' by pop grunge band 'Nirvana'. The song is built on melodic and rhythmic ideas that are repeated with the same four chords of throughout, as we can see in figure 77 below.

Nirvana: Smells Like Teen Spirit, bars 9-28

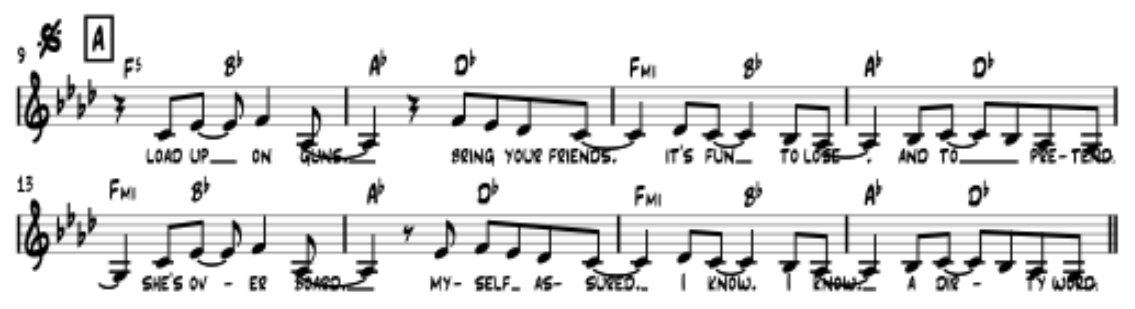



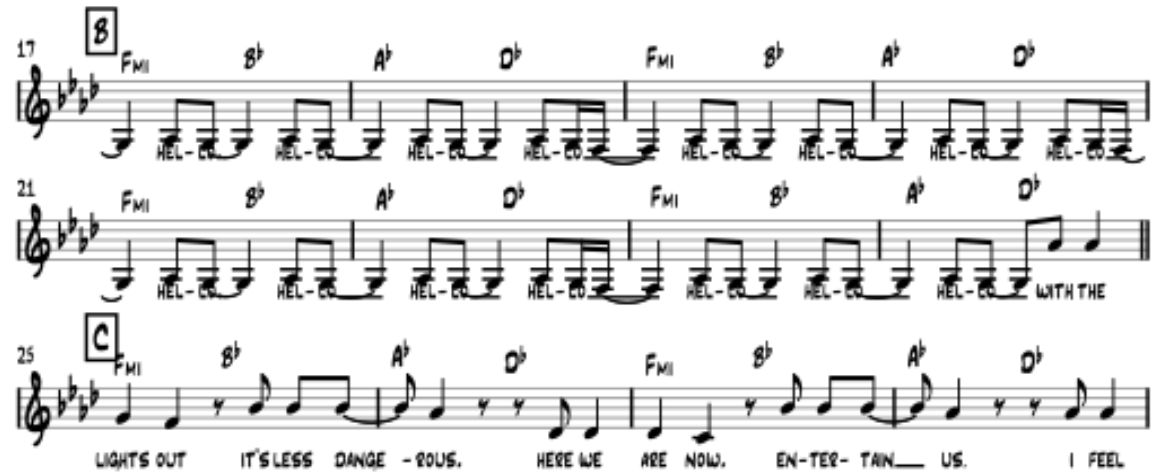

Figure 77

My instrumental arrangement of Cobain's Smells like Teen Spirit has been adapted to the new time signature of $5 / 8$. It is preceded by an introduction in $4 / 4$ with material from another Nirvana song, Lithium, an idea used in Charlie Hunter's arrangement of Come As You Are. Then there is a complete change to a faster tempo in the new time signature set up by a two bar vamp. As we can see in figure 76 below, the bar is subdivided with an uneven pulse of three plus two, under the rhythmically altered melody. The rhythm section continues in the same rhythmic manner as the vamp in the verse but with altered harmony.

Changing the time signature gives a new and fresh sound to a very well-known rock grunge song.

Trudy Lile: Smells Like Teen Spirit, introduction vamp

SMELLS LIKE TEEN SPIRIT

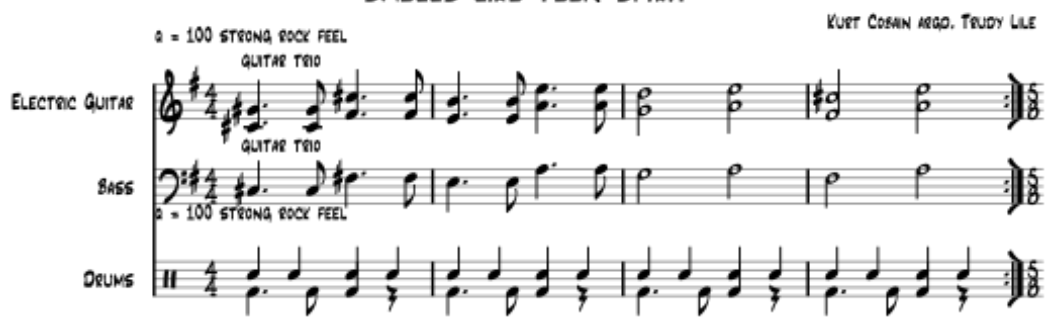




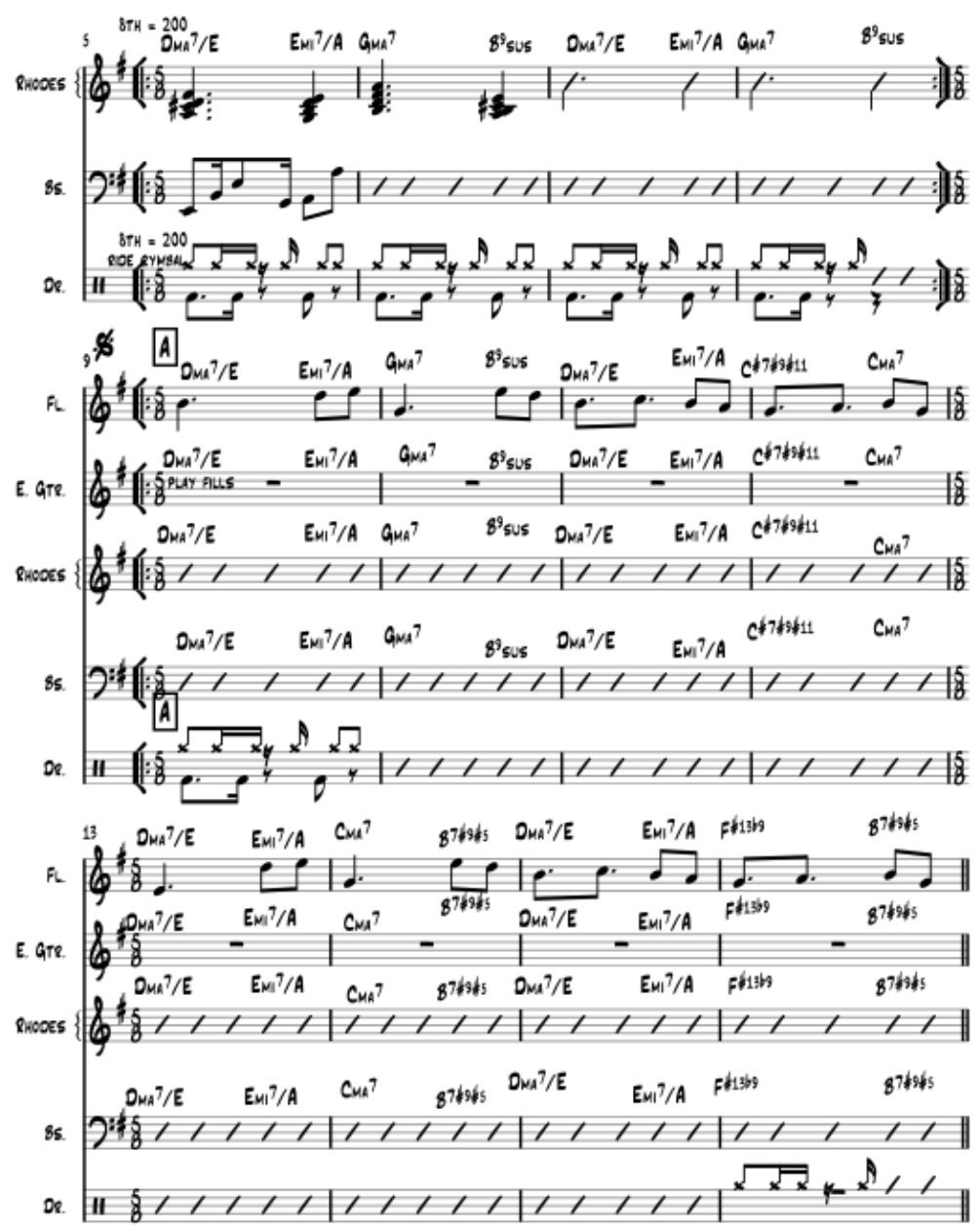

Figure 76

The emotionally tender love song Message to My Girl first appeared on Spilt Enz 'Conflicting Emotions' album in 1983. As we can see in figure 77 below, it starts with a typical rock ballad set up on drums, which continues and is followed by a keyboard melody. This goes into a crotchet pulsed vamp on keyboards at bar 3 and the supporting rhythm from the band is sparse throughout the song. 
Split Enz: Message To My Girl, introduction and verse

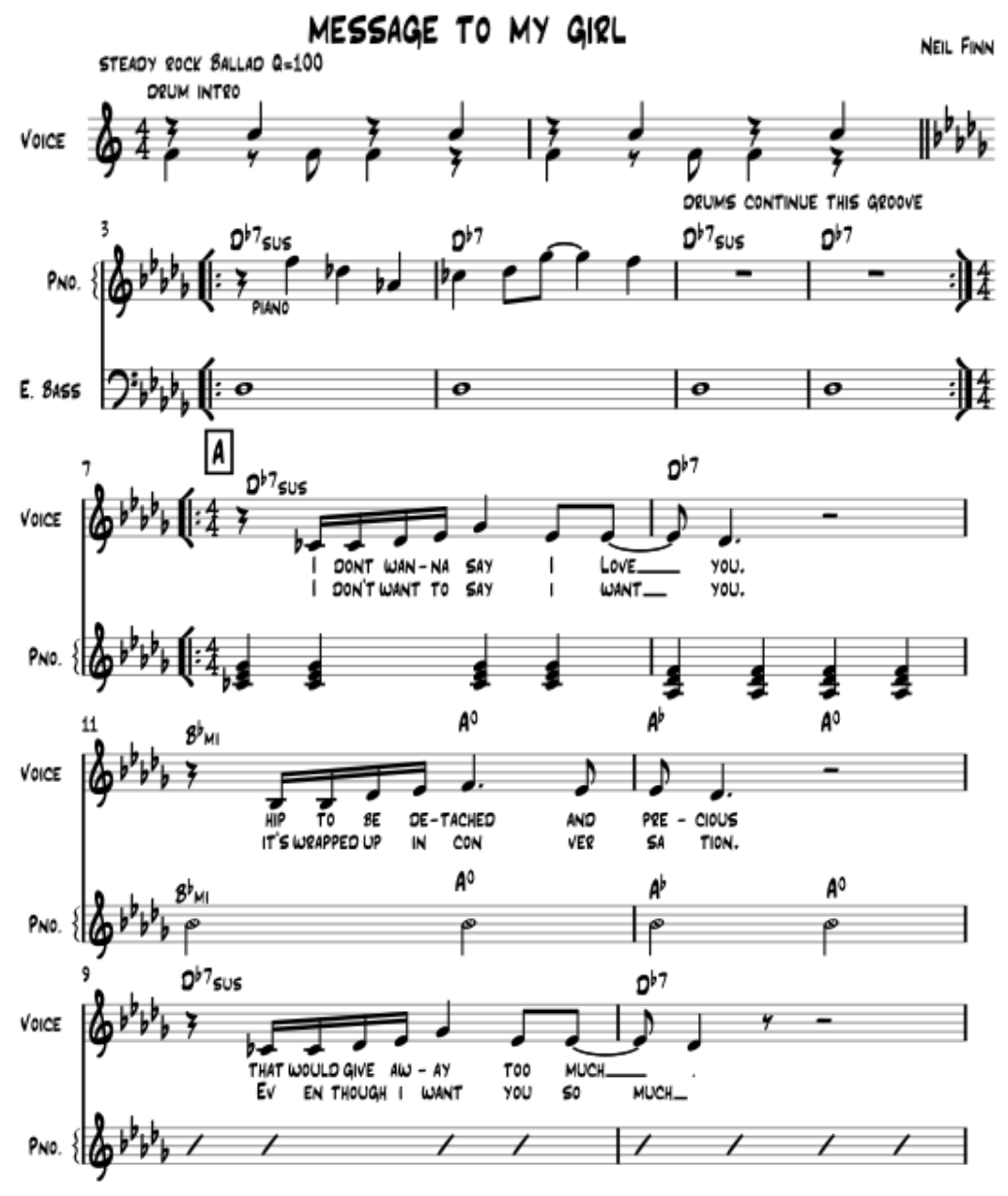

Figure 77

My arrangement of this song uses several changes of time signature similar to those observed in the Michelle Nicolle's arrangement of Don't You Forget About Me. Some of these changes are in conjunction with structural changes, and instrumental sections have been added to provide solo platforms. As we can see in figure 78 below, the colla voce introduction is freely improvised in $6 / 8$. This changes to $4 / 4$ at the beginning of the verse (bar 13) led by the vocalist and the quaver pulse is in common with both time signatures. 
Trudy Lile: Message To My Girl, Introduction and Verse
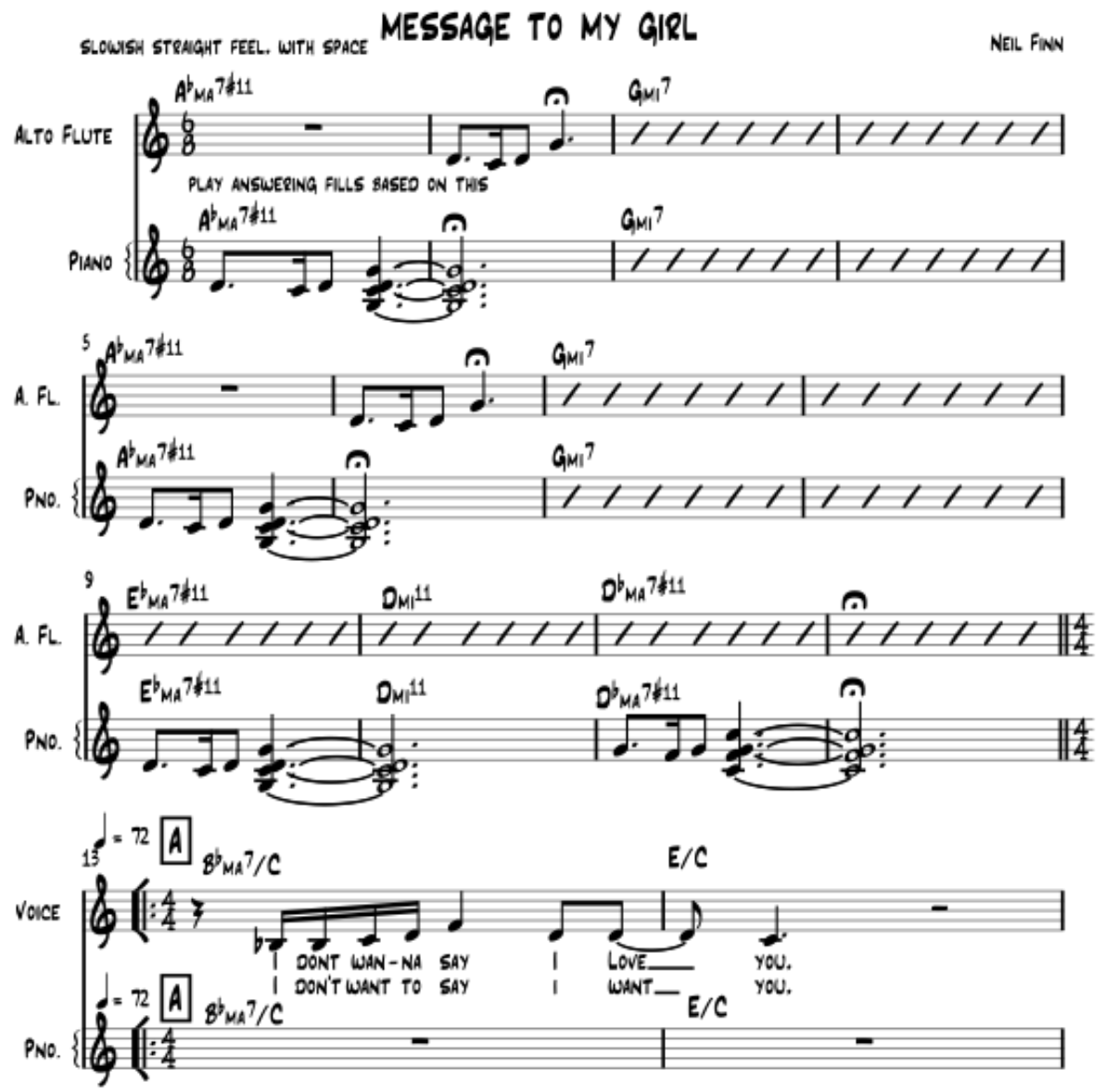

Figure 78

The lilting 6/8 time signature returns in bar 21 just before the entry of the chorus, producing a lift to the feel. In figure 79 we can see that it changes back to $4 / 4$ at bar 27 , which is reinforced by supporting crotchet line in the piano part, and the energy previously built by the $6 / 8$ appears to be released.

Trudy Lile: Message To My Girl, bar 19 into chorus section

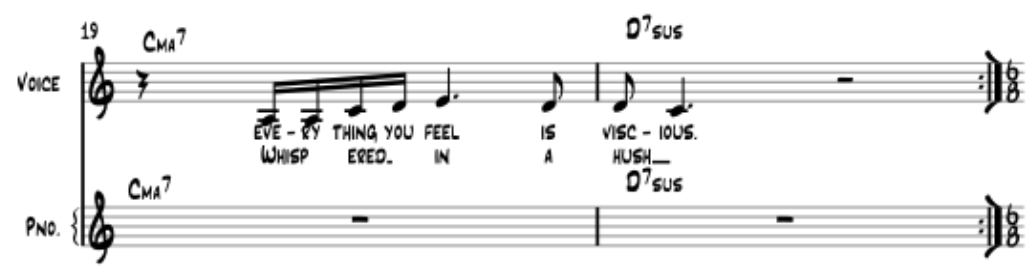



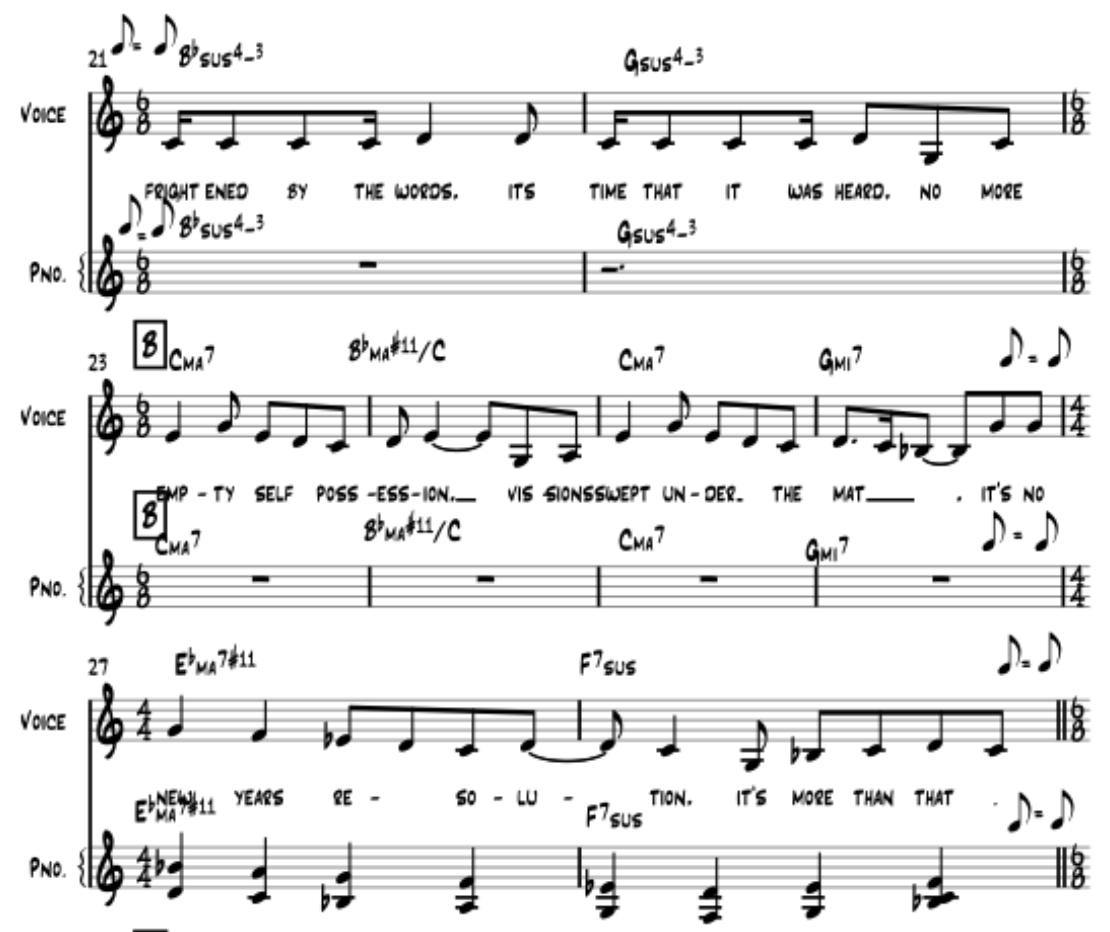

C

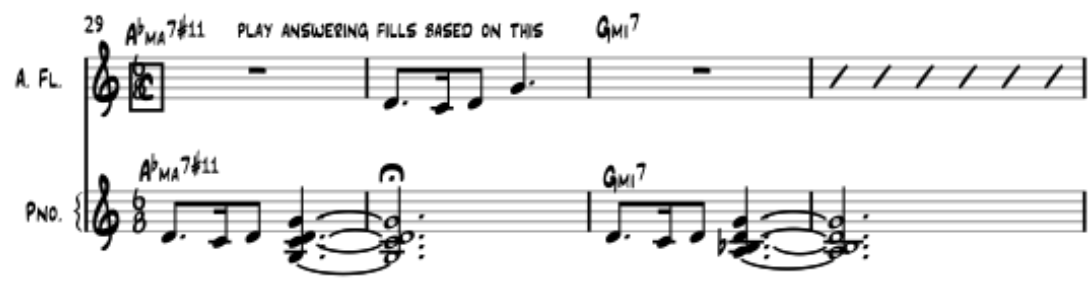

Figure 79

We can also see that the interlude section at bar 29 changes back to the original time signature of $6 / 8$ for a small instrumental improvisation section that has been added before the third verse. These time signature changes help to highlight the various sections of the song, as well as provide tension and release that draws attention to the lyrics. 


\subsection{Instrumentation and Texture}

\subsubsection{Size of the group}

By varying the size of the ensemble a variety of musical colours can be achieved; from the acoustic sound of a duo or trio to the full force of a big band.

Often the opportunity for individual lyric interpretation can be enhanced by the space available in a smaller ensemble, yet the opportunity to build an energetic improvisation can also be supported by the energy of a large ensemble.

\subsubsection{Jazz Duo}

The instrumentation of the original version of Message To My Girl by Split Enz was similar to other bands of the time, vocals with electric piano, keyboards, guitar, bass, and drums. It was played at a moderate tempo with a straight feel, with a moderate amount of intensity that lifted slightly during the chorus section.

The new arrangement of Message to My Girl is in a ballad style, as a vocal duo with piano, and the vocalist doubling on alto flute for the improvising sections, though this would also work as a trio with the addition of a different instrument for the solos.

The sparse nature of the duo texture allows the vocalist to have more space to interpret more freely in an uncluttered environment. In addition, the slower speed allows plenty room for individual interpretation of the melody and interactional improvising between the piano and flute. The pianist can fill out the harmony while retaining a spacious feel. This allows freedom for the vocalist to reinterpret and rephrase the melodic line, and for the pianist to interact with it. 
In figure 80 we can see that there is a suggestion of melodic riff and harmony in the score of the introduction in free colla voce time, to encourage melodic improvised interaction between alto flute and piano.

Trudy Lile: Message to my Girl, Introduction

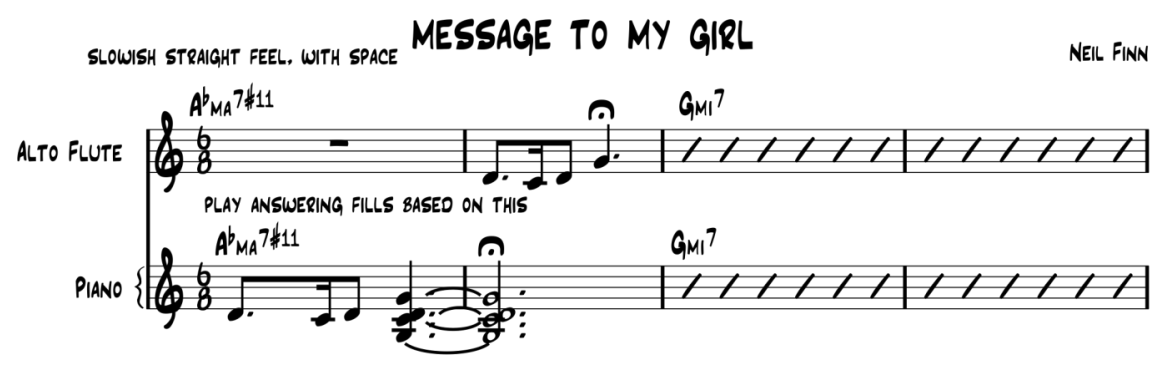

Figure 80

This happens again in the Interlude between verse two and three at bar 29 but with slightly more feeling of pulse. As discussed previously there are supporting lines written into the piano that help to establish the changes of time signature in the chorus, and there is a solo section at the end of the song.

\subsubsection{Jazz quintet}

The band line-up for the original version of 'Roxy Music's' More Than This was also typical of the 1980s with vocals, guitars, synthesisers, bass and drums, and the song has an energetic feel throughout.

My arrangement of this song is for quintet of vocalist, acoustic guitar, piano, bass and drums. The new feel is a slightly slower Bossa Nova style, and part of the guitarist's role is to maintain this groove throughout the song, with the support of the rhythm section, this gives the tune a light Brazilian flavour.

Writing a unison line for a group that is complementary to the style or groove that is being created can establish the groove as well as grab the attention of the audience. As we can see in figure 81 , this arrangement begins and ends with a 
syncopated unison line played in unison by alto-flute, guitar, piano, and bass and with the instruction to build the dynamic on each of the four repeats. The bass line continues this into the next section where the guitar starts the bossa nova groove.

Trudy Lile: More Than This, Introduction
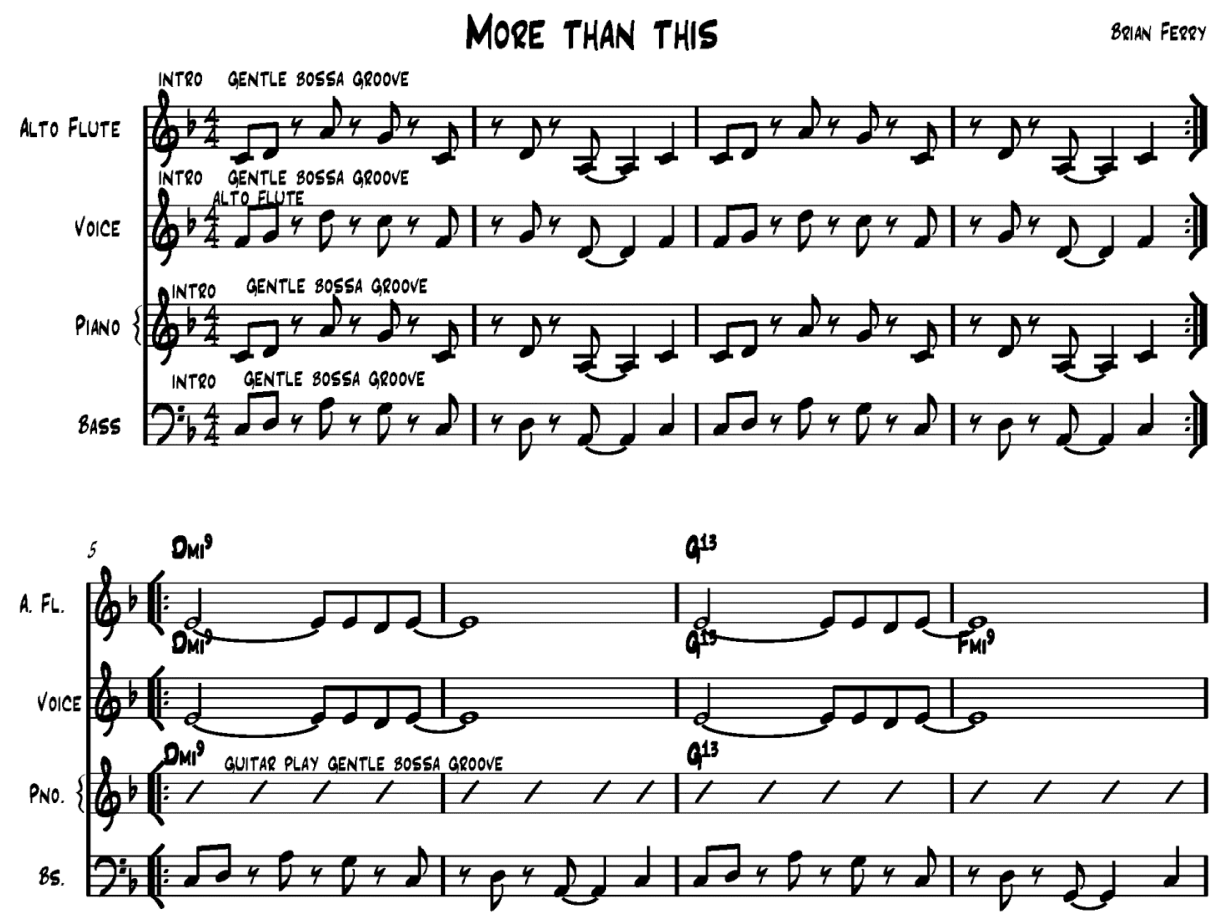

Figure 81

The arrangement is symmetrical: exactly the same material used in the introduction is used in the ending of this arrangement, but in reverse. The unison line finishes the song, which is preceded by the eight bars from bar $5-12$. The texture diminishes and the arrangement finishes by fading away with the unison line. 


\subsubsection{Large ensemble}

When writing an arrangement of a pop song for larger ensemble, the addition of background lines can add intensity and energy to the texture of the song. As well as utilising the instruments in the ensemble, complementary background lines can be added behind improvisation solos and important sections of the song, and for sections that require melodic support. Background lines can range from being a few sustained notes, short melodic and rhythmic fragments, to melodic counterpoint behind the soloist.

The original version of Sting's Fragile was played by a relatively small ensemble; vocals with acoustic guitar, keyboards, bass and drums. The Latin sounding texture was achieved with a syncopated guitar line that shifts around the chord changes, as we can see if figure 82 below.

Sting: Fragile, bars 9-14
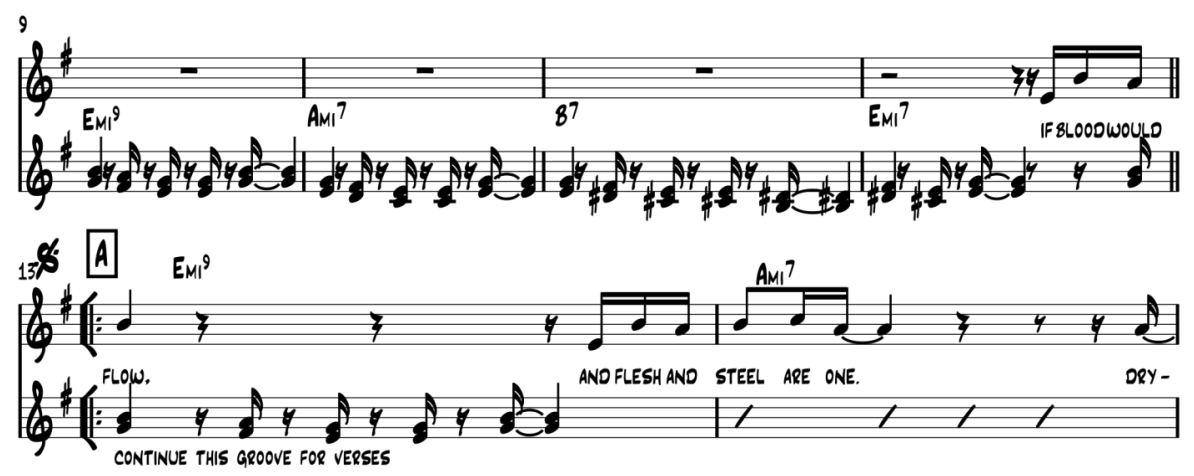

Figure 82

A rhythmic layering approach is used to create a different texture in the new arrangement of Fragile. The instrumentation is big band with no trumpet section, to create a darker texture overall. The introduction begins with a four bar Afroinspired unison vamp played by piano and rhythm section, with the guitar playing a clave above it. In figure 83 we can see layers of instruments playing background lines to support the vocal entry in the verse from bar 11. Muted 
trombones and tenor saxophones play a syncopated line that fills out the harmony as well as providing another rhythmic layer.

Trudy Lile: Fragile, verse bars 11-18

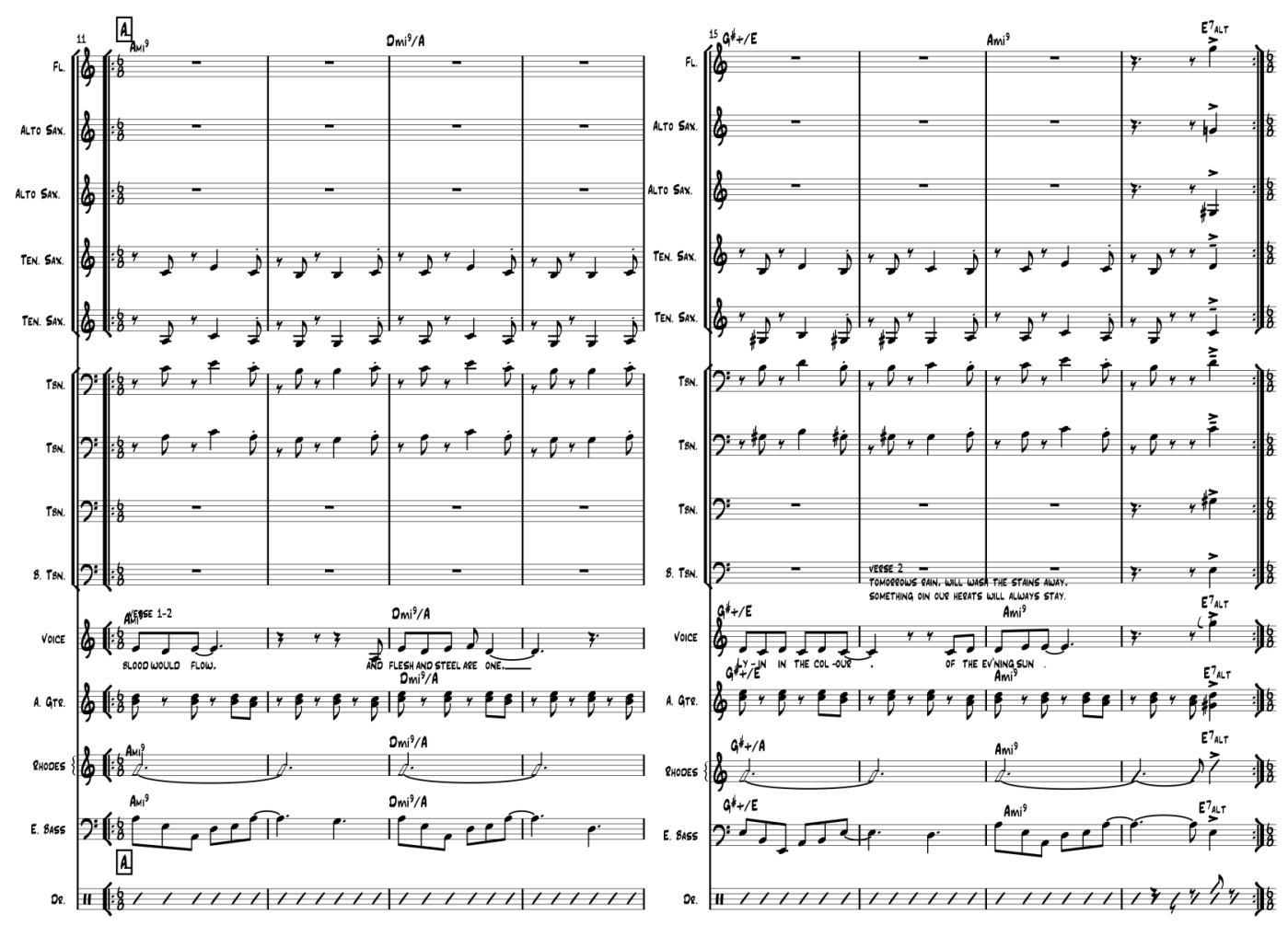

Figure 83

Background lines can be shared and alternated within the arrangement. They can have the supportive effect of backing vocal lines that fill out the harmony underneath the melody. They can also offer counterpoint with rhythmic figures.

In the big band arrangement of Michael Jackson's Rock With You, several of these features occur simultaneously. In figure 84 the saxophone section plays a line that harmonises with the melody in alternating bars. The trombone section also fills out the harmony in these bars similar to the original backing vocal line. The background lines written in the trumpet section provide counterpoint with a semiquaver line from the introduction of the arrangement. 
Trudy Lile: Rock With You, Chorus section

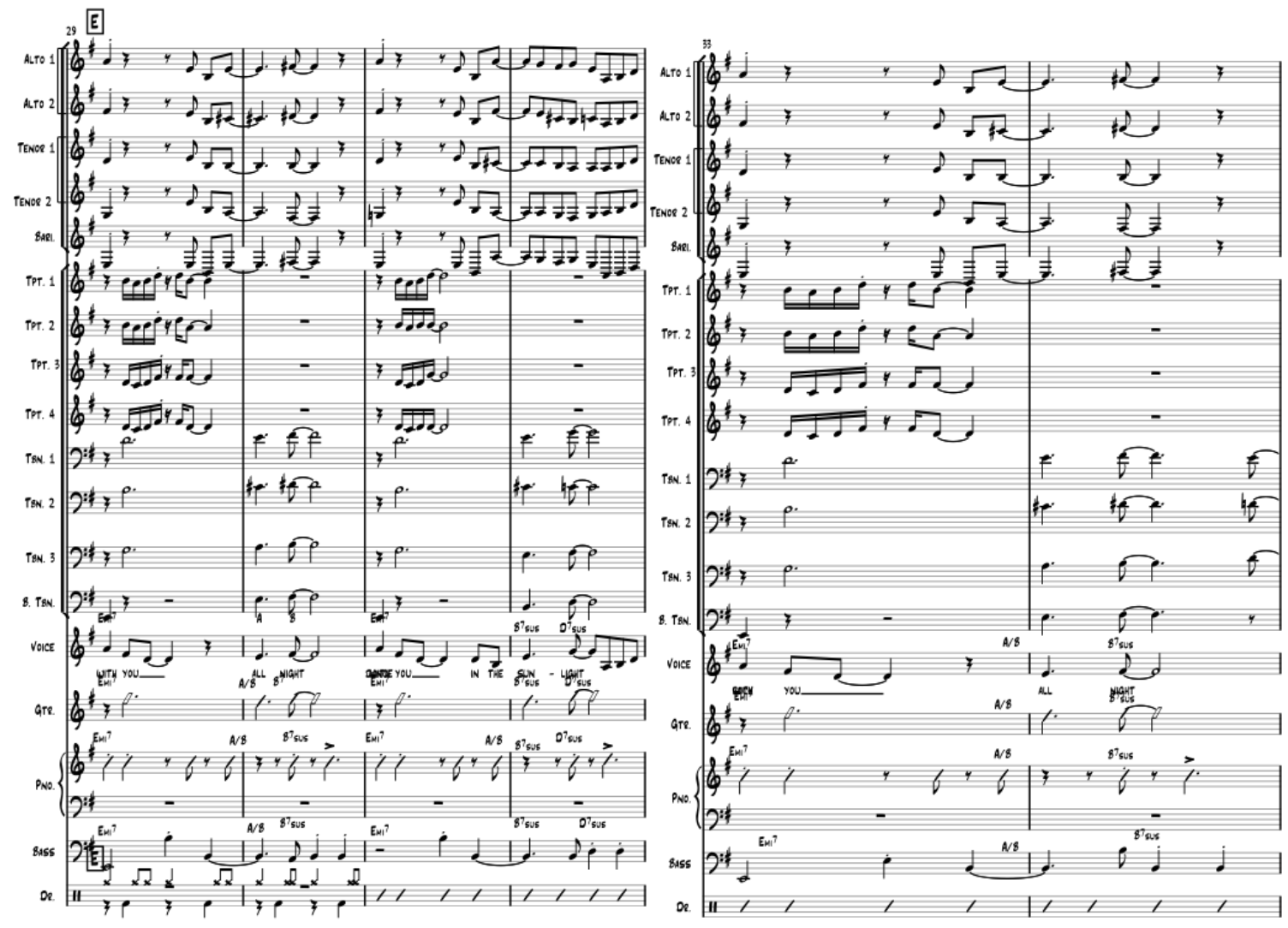

Figure 84 


\subsection{Structure}

When making an arrangement for jazz ensemble, manipulation of the structure requires careful consideration. When arranging for jazz ensemble sections can be added to or extended within the structure of the original song such as introductions, interludes and endings. The arranger can also choose whereabouts in the form of the song improvisation can take place, and whether to add new sections for this.

\subsubsection{Introductions}

Adding an introduction to an arrangement gives the listener an opportunity to get into the mood or the style of the song. There are many ways to do this. The introduction can be a preview of the arrangement or can also help to establish the groove and the harmony.

\subsection{1 Introductions in free time}

Often in pop songs the introduction sets up the groove and mood of the song. They can vamp ideas as well as set the mood and tempo of the song.

This is the case with Bob Marley's love song Is This Love, released on 'The Wailers' live album 'Babylon By Bus' (1978), and described as "arguably the most influential live reggae album ever"27. The song starts with the establishment of the reggae groove featuring a bass-line played in unison with guitar as seen in figure 85, and clavinet playing an off-beat 'skank' above it.

\footnotetext{
${ }^{27}$ Lindsay Planer: Album Review, All Music, Accessed November $20^{\text {th }} 2008$
} 
Bob Marley: Is This Love Introduction
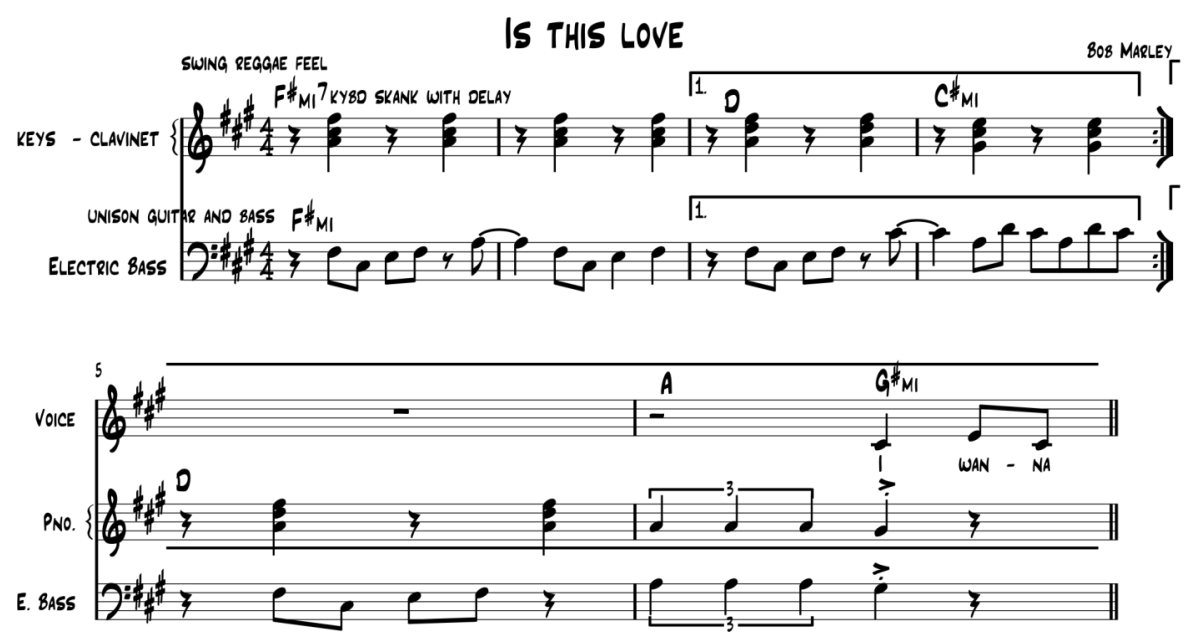

Figure 85

Melodic material from the original song adds cohesion in the new version as well as familiarity, and this can make a great introduction to an arrangement. In the new arrangement of Is This Love for jazz quintet, a section has been added with the melody from bar 43 , the last four bars of the original song, to be played in free or rubato time by flute and piano. There are three two-bar phrases with two extra bars added between each phrase to create a suspended feeling. This makes a twelve bar section that ends on a pause in the melody with a four-chord turnaround before the melody starts, see figure 86 and 87 .

Bob Marley: Is This Love, bars $43-50$
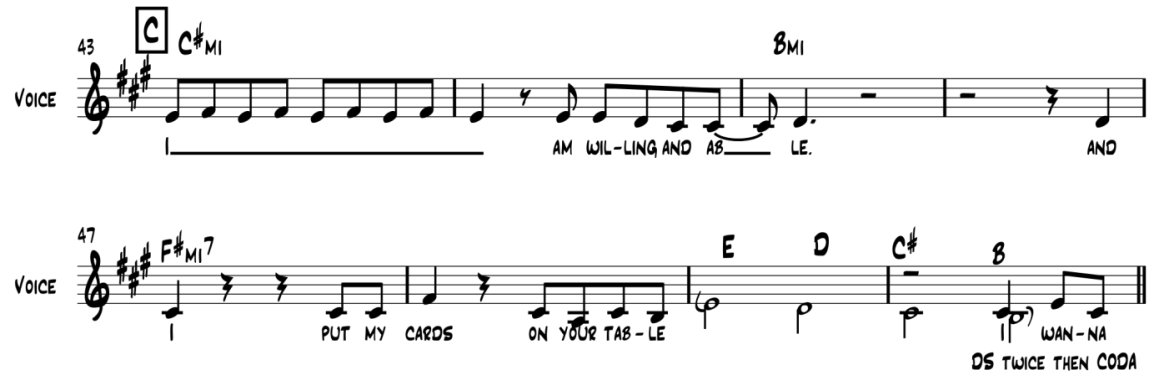

Figure 86 
Trudy Lile: Is This Love, Introduction

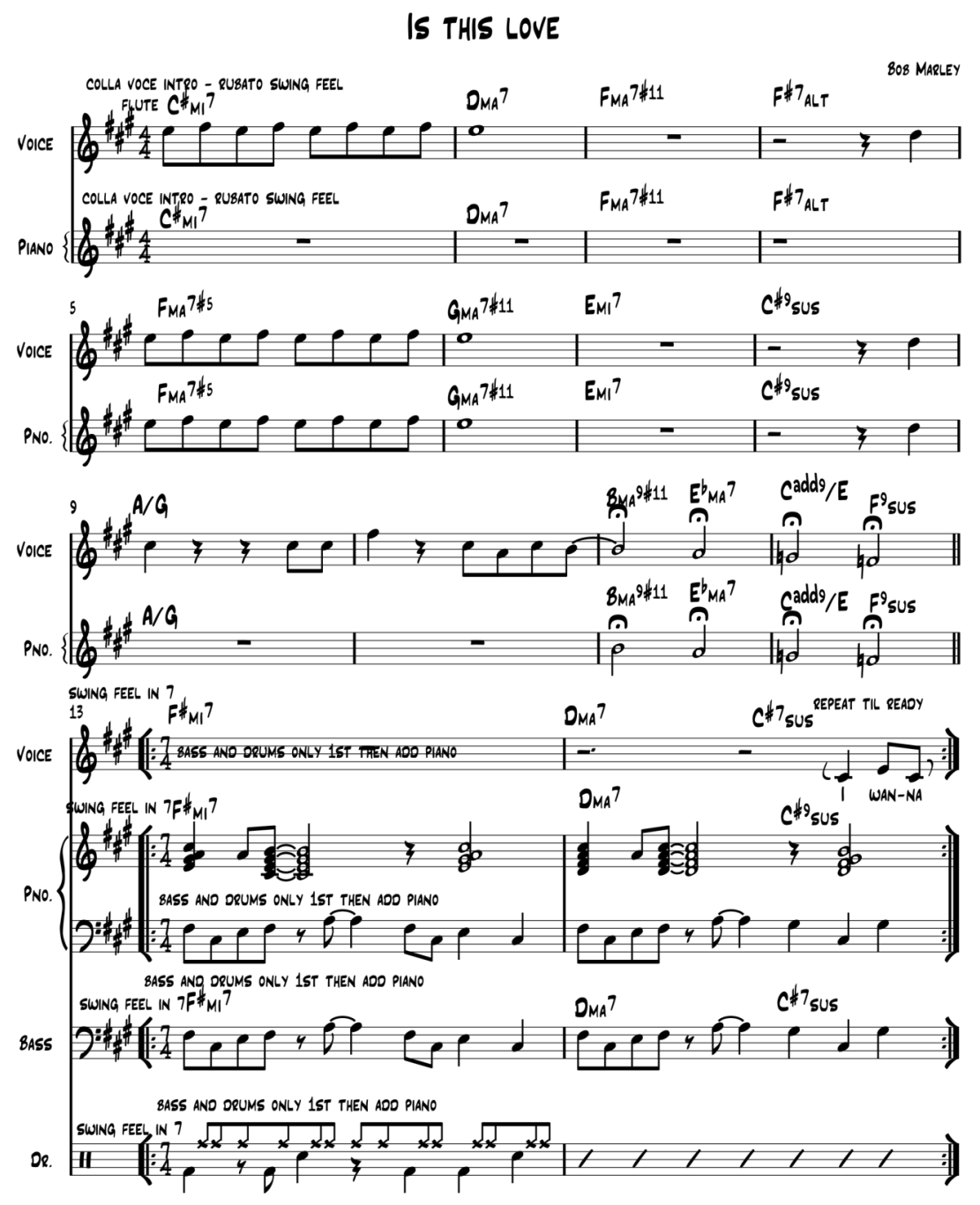

Figure 87

The introduction then goes into a groove section in the new time signature of $7 / 4$, with an adapted bass line based on the original, and layers of rich new harmony set up by a piano vamp. This continues underneath the melody in the verse section that follows, as it does in the original version of the song.

An introduction in free time can also depend be without any rhythmic pulse. The success of this type of introduction will rely somewhat on the amount of rehearsal and the rapport of the performers within the ensemble. For continuity in the 
arrangement a few directions can be offered in the score to the performers, but much is left to their discretion and collaboration.

Cyndi Lauper's poignant song Time After Time was released on her highly successful album 'She's so unusual' in 1984.

"One of the great new wave/early MTV records, She's So Unusual is a giddy mix of selfconfidence, effervescent popcraft, unabashed sentimentality, subversiveness, and clever humor. ${ }^{28}$

As we can see in figure 88 below, the original song starts with a brief yet rhythmically strong introduction, typical for pop songs of this era. There is a repeated note line played by synthesisers, with guitar fills over held chords played on another keyboard. When the verse starts at bar 5 the melody is accompanied by a dotted note keyboard vamp and drum machine rhythms.

Cyndi Lauper: Time After Time, Introduction bars 1- 16
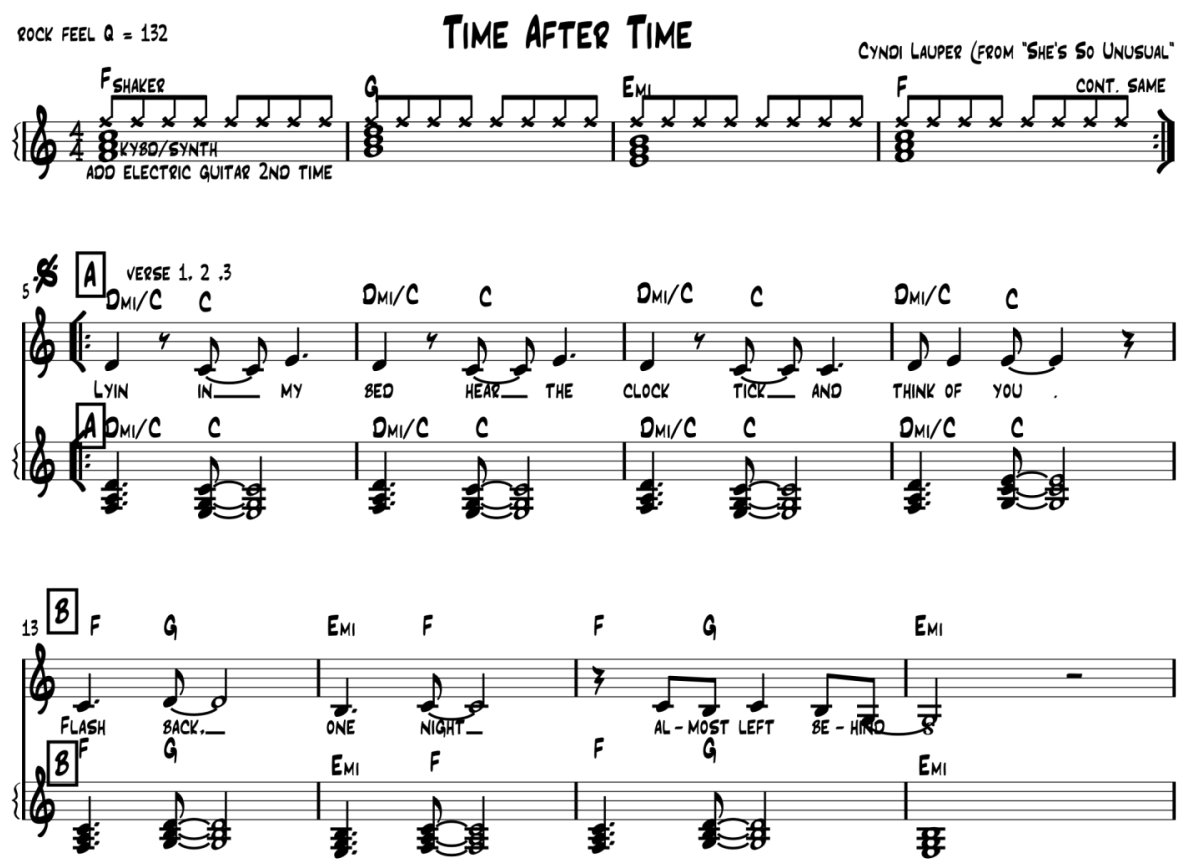

Figure 88

${ }^{28}$ Stephen Thomas Erlewine: Album Review. All Music, Accessed November $19^{\text {th }} 2008$ 
My arrangement of Time After Time is much longer than the original, and starts freely with improvised introduction with no pulse. It is scored for jazz quartet of alto flute, piano, bass and drums. This introduction is reminiscent of the one in Christian McBride's Walking On The Moon, and has been written to encourage improvisational conversation between the musicians.

The score has a voicing for a quartal vamp to be played by piano reminiscent of a clock chime reinforcing the temporal theme, with long pedal notes in the bass, leaving the drums free to colour with mallets on cymbals, toms and open snare. This introduction is of indefinite length but has two sections; when the second section is cued the vamp becomes two bars in length for increased intensity, see figure 89. This blends into the next section of the song when the flute player chooses to start playing the melody rhythmically freely over the same vamp.

Trudy Lile: Time After Time, Introduction

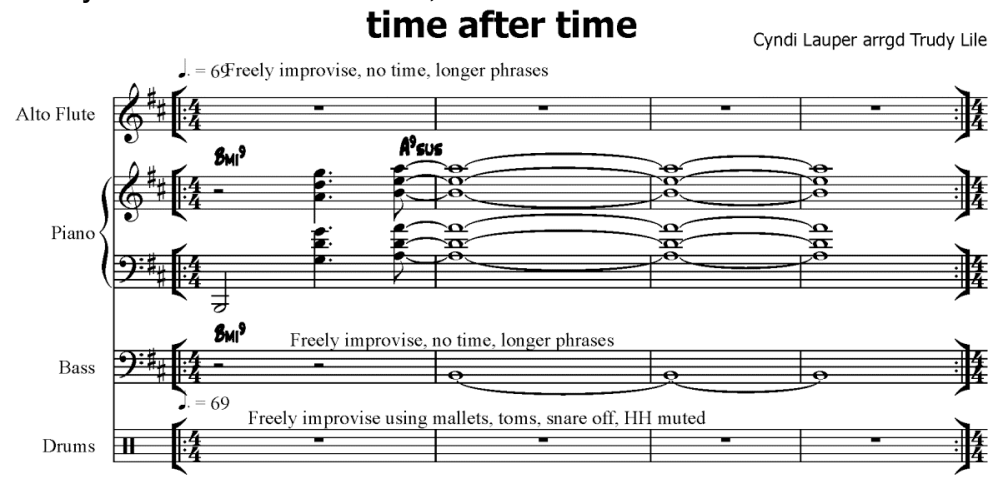




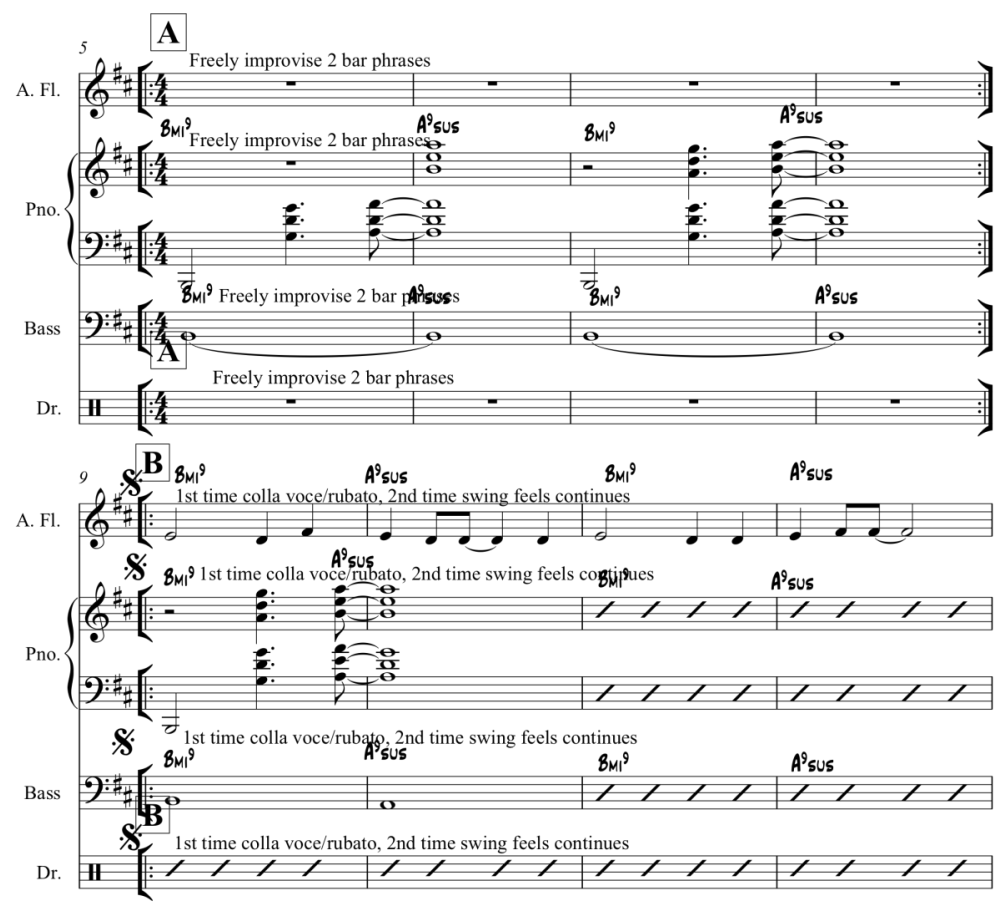

Figure 89

\subsubsection{Endings}

As mentioned earlier many pop songs end with a 'repeat to fade' section. This can also be used when arranging for jazz ensemble and can act as an improvisation section.

This concept is used in my arrangement of Message To My Girl. Rather than improvising over the whole form of the song, after the third verse a four bar repeated section has been added as the improvisation section for alto flute and piano, with piano once again providing the harmonic and rhythmic support. This provides a more manageable solo section for the duo that is rhythmically strong with a simpler harmonic framework for the accompanying pianist. This is similar to the arrangement by Michelle Nicolle of Don't You Forget About Me, where the eight bar improvisation section was added after the bridge for flugelhorn and piano. 
Trudy Lile: Message To My Girl, Ending
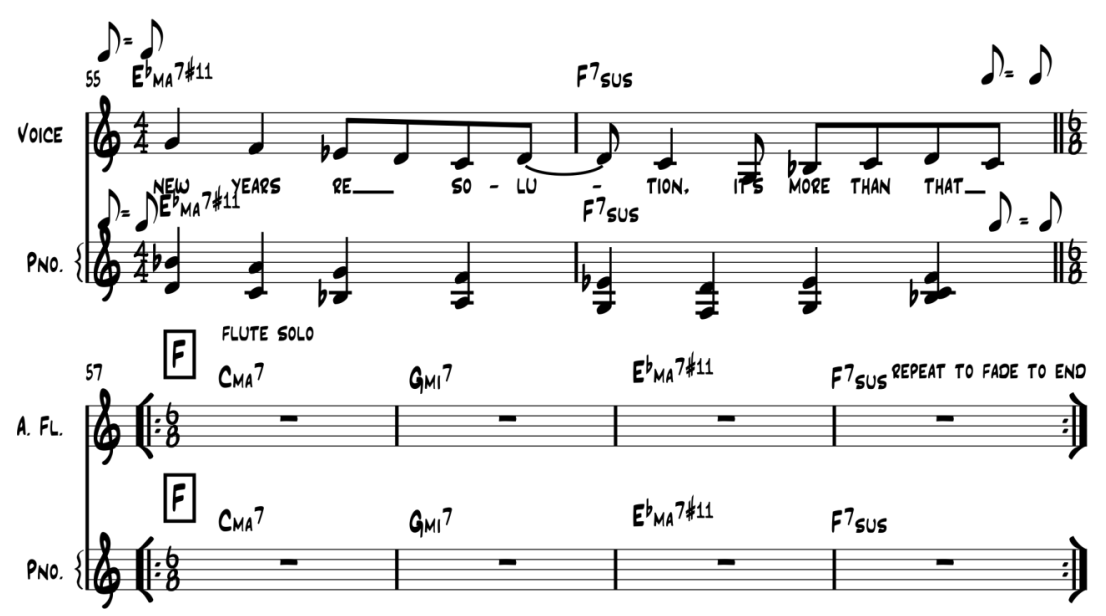

Figure 89

Adding a tag is a very common ending for a jazz arrangement. It is where a small phrase is repeated several times, and sometimes the harmony is altered on the repeats.

In the arrangement of Smells Like Teen Spirit, I have introduced a standard jazz ending. As we can see in figure 90 the last four bars from bars 35 to 38 are repeated three more times as a coda section to end the song.

Trudy Lile: Smells Like Teen Spirit, Coda section

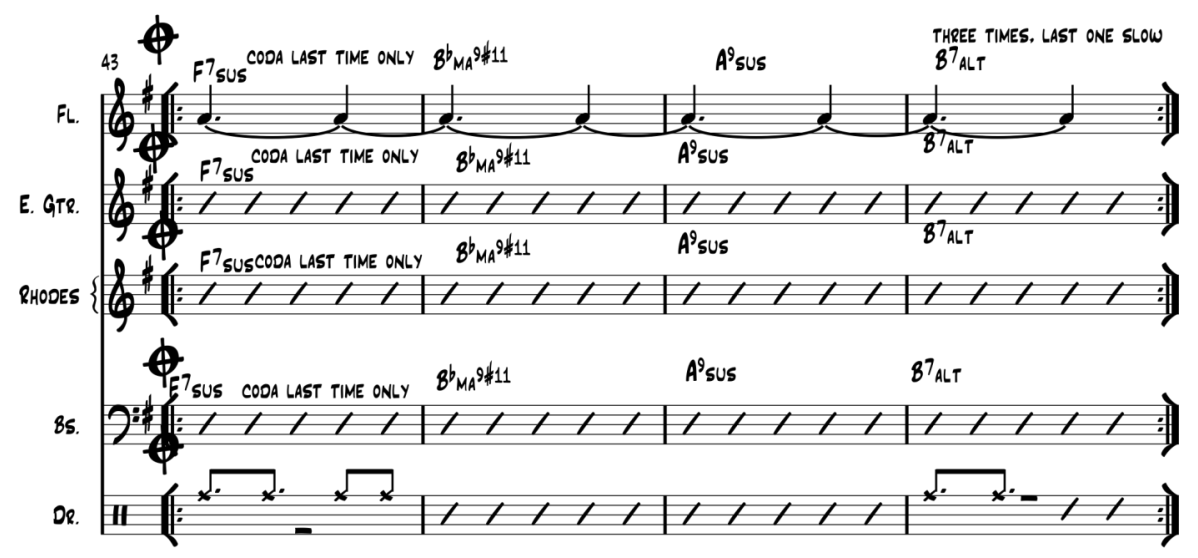

Figure 90 
The repeat to fade ending doesn't work as effectively when arranging for a large ensemble. A set ending has been used in the arrangement of Sting's Fragile for big band. In figure 91 we can see a four bar tag based on the end of the chorus section is repeated three times, with solo melodic fills. After this there is a three bar harmonised ending played by the whole big band, based on strong rhythmic line that superimposes three beats in a bar over the $6 / 8$ time signature.

Trudy Lile: Fragile, Coda

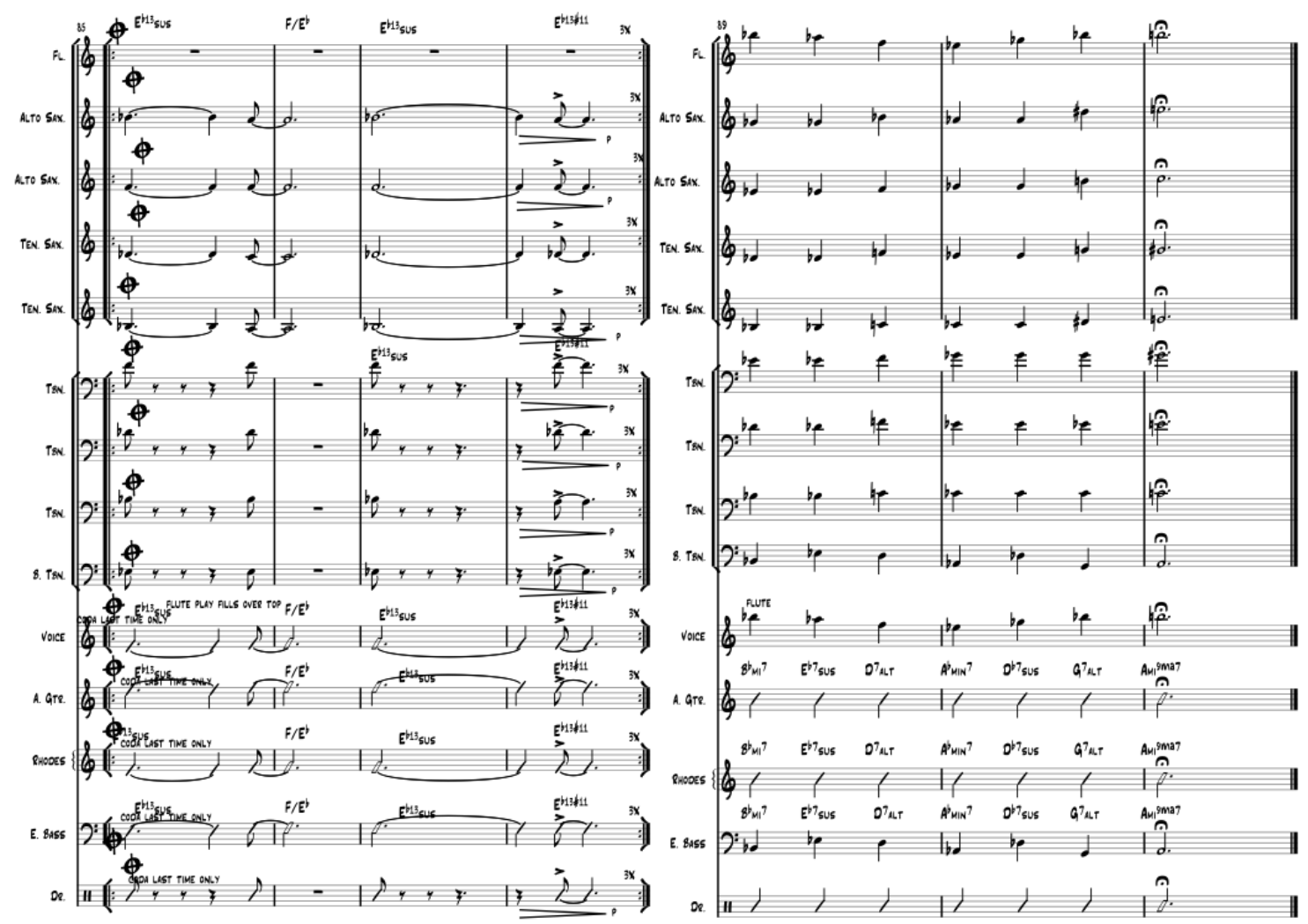

Figure 91

\subsubsection{Solos Sections and Improvisation Platforms}

Determining the overall structure of the song is important in writing new arrangement of pop songs in a jazz style. Obviously when, and how many performers can improvise is a factor for jazz arrangements. 
There are many choices; solos could be over the whole form of the song, part of the form, the introduction or the ending, or sections can also be added to the structure.

\subsubsection{Cycles}

Familiar harmonic progressions can be added to the reharmonisation of a song, or in the case of Violent, can be inserted into the solo section as a something more interesting to improvise over. This section is based on the Coltrane Matrix, which is built on a series of major thirds preceded by the dominant chord of each.

Chord // Ima7 bllI7 / bVI7ma7 VII7 / IIIma7 V7 / Ima7 //

Key of C// Cma7 Eb7 / Abma7 B7 / Ema7 G7 / Cma7 //

Trudy Lile: Violent, Solo section
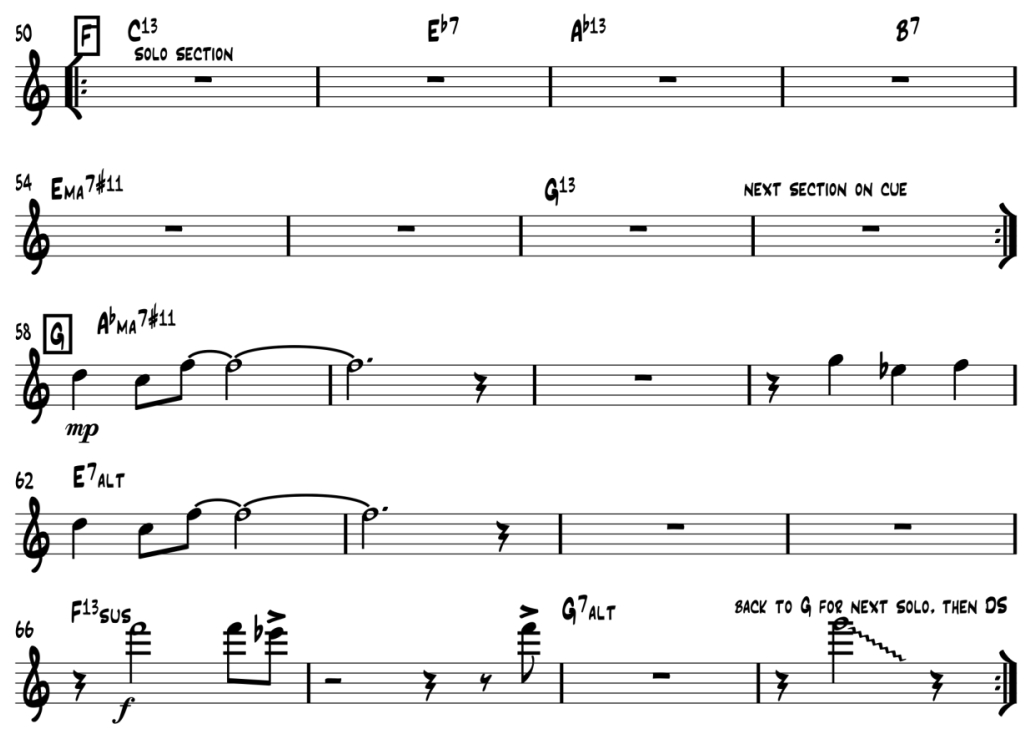

Figure 92

The repeated eight bar section at bar 50 of Violent finishes on $\mathrm{G} 7$ for the last two bars. The solo continues to bar 58 to finish at bar 69 where background lines are played by the rest of the big band on cue. 


\subsubsection{Vamps}

Vamps have been used in pops songs for many years and can be used in a variety of ways in an arrangement. They can facilitate changes of texture, meter, harmony, and can be platforms for improvisation.

The original version of the song High And Dry by Radiohead was released on the 1995 album 'The Bends'. It begins with a strummed guitar vamp based on three chords over four bars. As we can see in figure 93, this continues as the melody begins at bar 6 until the chorus section where there is a change of texture as more intensity appears with angst-ridden lyrics.

Radiohead: High And Dry, Introduction
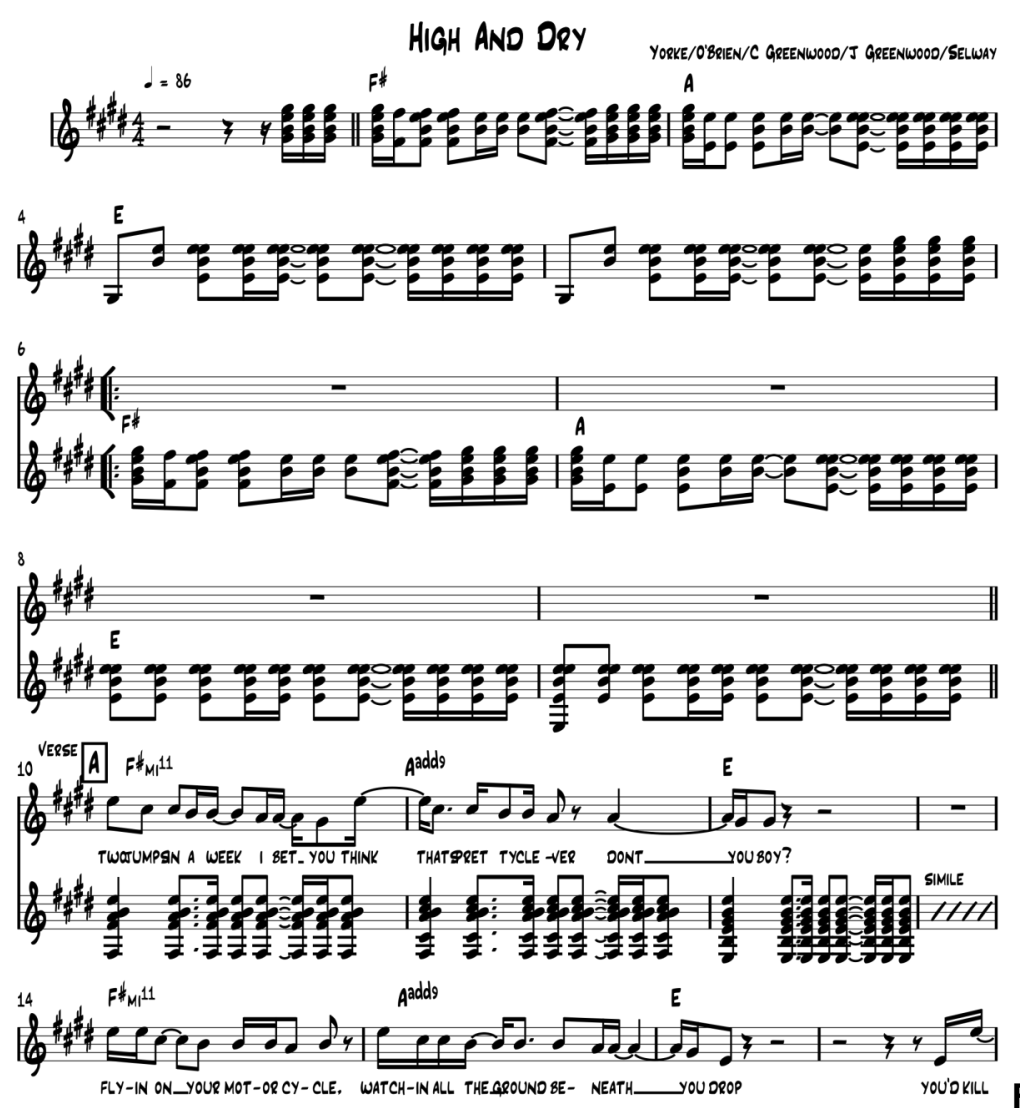

Figure 93

By using a vamp section into the introduction the arranger can help to establish a new time feel or groove for the song. Specific chord voicings and rhythms can be written for these. 
A major feature of my arrangement of High And Dry is a two bar vamp to be played by the pianist and bassist, see figure 94. It also appears throughout the arrangement to add cohesion. This vamp first appears in the introduction, then again in between verses, after the solo section and as the ending.

Trudy Lile: High And Dry, Intro

HIGH AND DRY

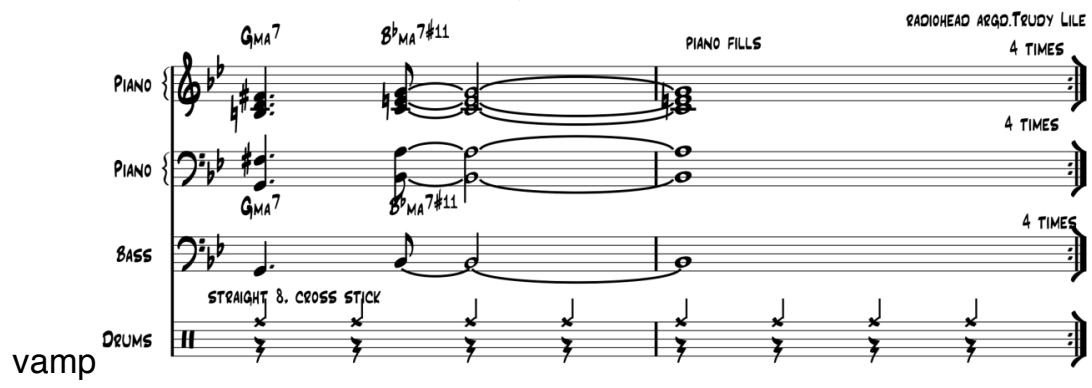

Figure 94

Also of structural note in this arrangement, a section has been added for improvisation. As we can observe in figure 95, it is a repeated eight bar section and with rich harmony that ends with the same chords as the vamp. Both the vamp and the reharmonisation add a contemporary jazz flavour to the arrangement. This is similar to Brad Mehldau's version of Exit Music For A Film, where he added an eight bar section for piano solo, also with harmonic variation from the original. 
Trudy Lile: High And Dry, solo section bars 18-

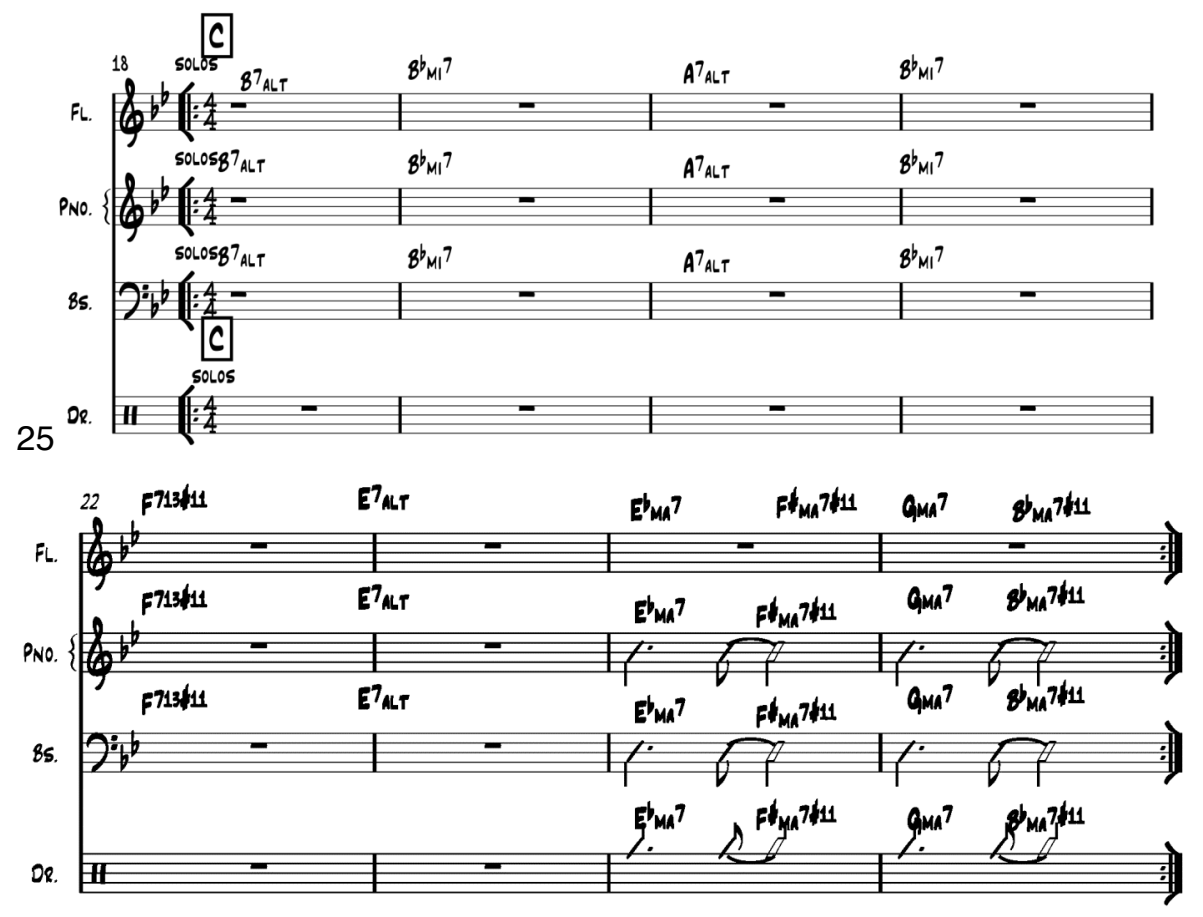

Figure 95 


\subsection{Reharmonisation}

The application of jazz harmony is a colourful tool when making jazz

arrangements of pop songs. Often the harmony of the original song is fairly straightforward, with few chords, most of them triads.

When making an arrangement for jazz ensemble, the harmony can be manipulated in many ways. These include modulation, adding sevenths and extensions to the triads, creating turnarounds, using familiar jazz progressions, as well as harmonic substitutions and slash chords. Sometimes harmonic variety can provide a more challenging platform the performers to improvise upon.

\subsubsection{Modulation}

Modulating to another key has been used in many pop songs and is a useful tool for arrangement purposes. In the new arrangement of High and Dry, a sudden unexpected modulation takes place at bar 36, (as seen in the arrangement of Like A Virgin by Lisa Bassenge). As we can observe in figure 96 this takes place with no harmonic preparation and is lead by the vocalist who sings the next phrase a semitone higher.

Trudy Lile: High And Dry, bars 34-40
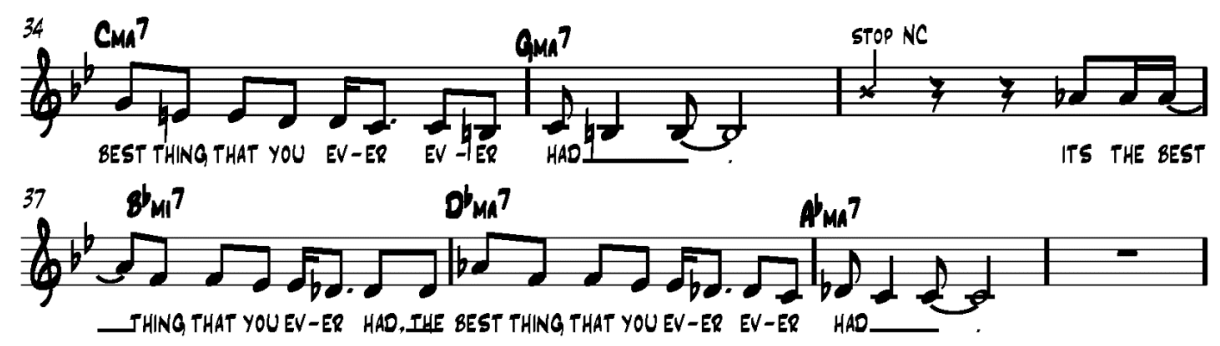

Figure 95 
Another sudden modulation back to the original key occurs at bar 48 , where the vocalist holds a long note while the band stops completely. The pick up notes of the melody in the next phrase, are transposed down a semitone and the band rejoins at bar 48 with the next chord.

Trudy Lile: High And Dry, bars 34-40

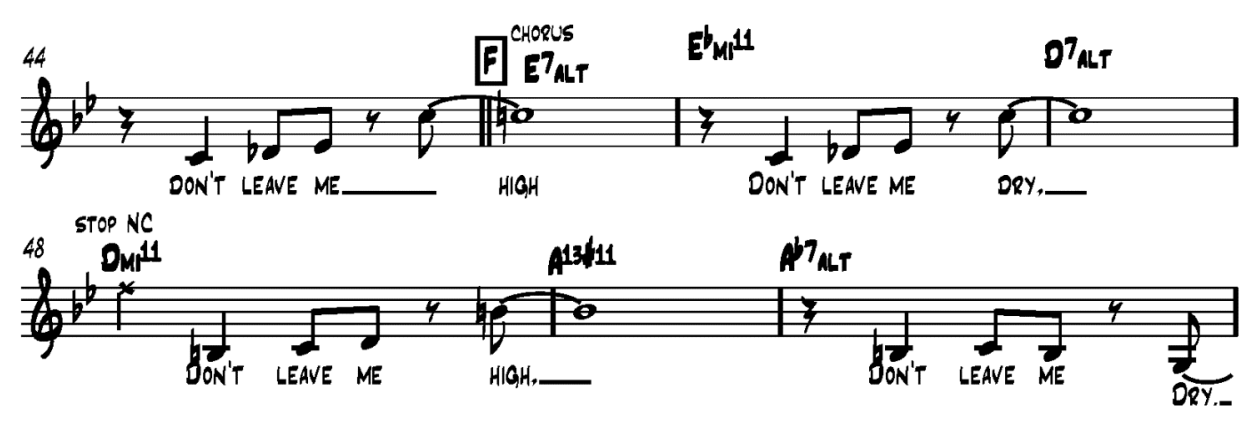

Figure 96

The effect of this stop and break is that of a fake ending, and the vocalist is left high and dry, the title of the song.

\subsubsection{Seventh Chords and Extensions}

Most harmony in pop or rock music uses triads and the occasional dominant seventh chord. Sometimes in the case of grunge rock guitarists, there are not even triads, instead there are open intervals known as power chords where they play only the tonic and the fifth. An example of this can be heard in the opening riff of Nirvana's Smells Like Teen Spirit (figure 97).

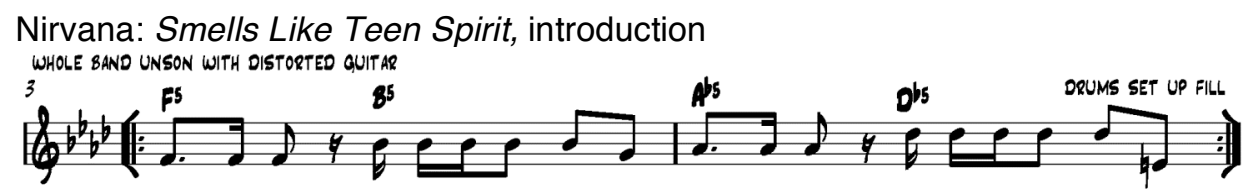

Figure 97 
Jazz harmony can be added to the arrangement with the addition of sevenths and other extensions to major and minor triads. The original version of Violent (figure 98), has triadic harmony throughout, mostly using the primary triads of chord I, IV and V (C, F and G).

Stellar: Violent, Chorus Section

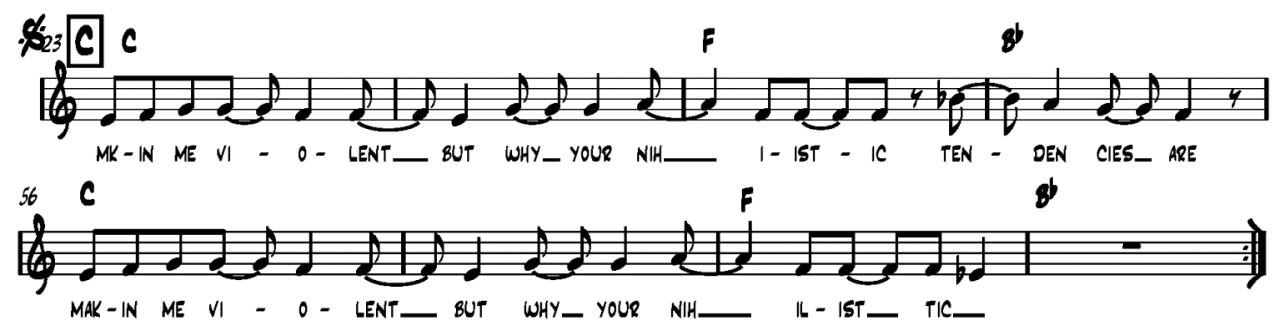

Figure 98

Trudy Lile: Violent, Chorus Section

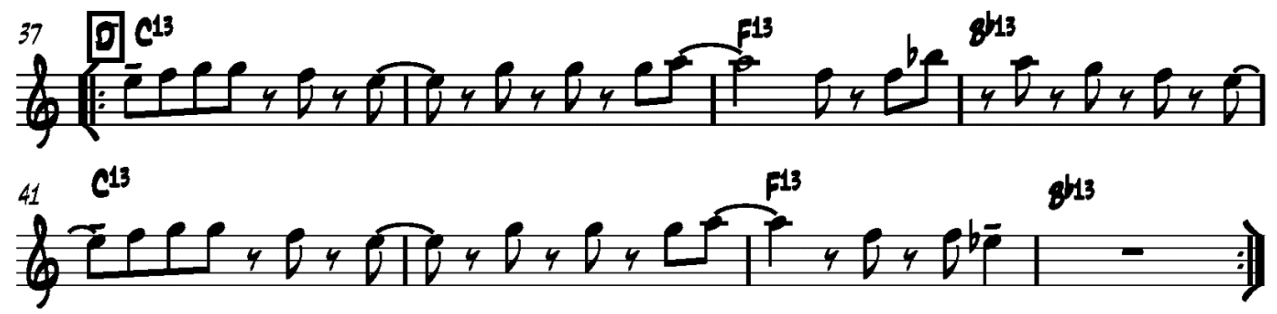

Figure 99

The new arrangement of Violent replaces these triads with dominant thirteenth chords, see figure 99. It doesn't have more chords than the original but the voicing of the chords by the keyboard player is richer, giving a contemporary jazz blues flavour. 


\subsubsection{Harmonic Substitution}

After examination of the existing harmony and notes of the melody there are many harmonic substitutions that can be added to an arrangement. Depending on the arrangement and also the size of the ensemble there are various harmonic substitution options available.

\subsubsection{Turnarounds}

Adding a turnaround to a song helps to prepare the listener for a return to the tonic at the top of the form and can also help to end the song effectively. Most commonly, a turnaround is usually a two or four bar chord progression found at the end of an eight bar phrase, or at the end of section. It is usually based on the cycle of fourths and various substitutions of, so that it harmonically establishes the tonic of the next section.

However the harmony for turnarounds may be substituted further, as is the case with the turnaround added in bars 9 and 10 of the new arrangement of Bob Marley's Is this love. This is harmonically rich providing a dramatic approach to the next section. The bass line moves in an upward motion even though the melody is descending, see figure 100 .

Trudy Lile: Is This Love, bars 9-11

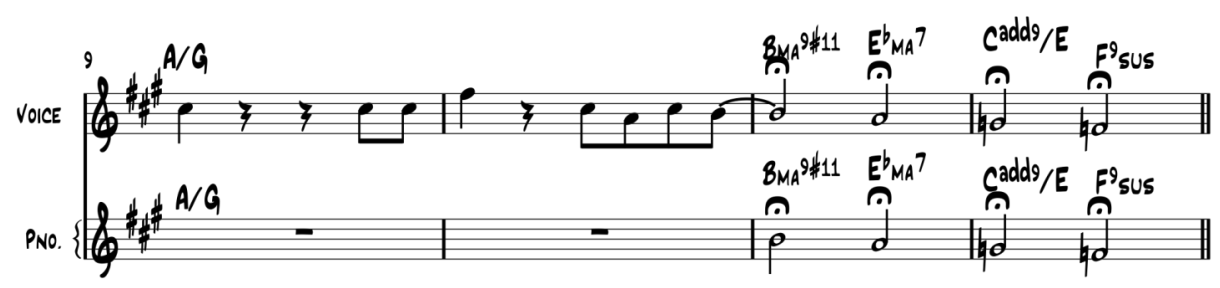

Figure 100 


\subsubsection{Diatonic Substitution}

As discussed in the analysis section, harmonic substitutions can be made diatonically, where chords have notes in common, and also by substituting chords a tri-tone away from the original chord.

My arrangement of 'Radiohead's' High And Dry uses both of these techniques in the reharmonisation of the chorus section. In figure 101 a chord sequence is created that starts with a substitution of the original chord Ami7, a chord built on a note a tri-tone away from it's original root (as did the arrangement of Like $A$ Virgin, discussed in the harmony section of the transcriptions). There is another similar substitution in bar 10 where $\mathrm{C \# 7alt} \mathrm{replaces} \mathrm{the} \mathrm{Gma7.} \mathrm{These} \mathrm{bars}$ alternate with a passing chord of Dmi11 in bars 9 and 11 . In bar 12 the tonality is changed to a crunchy dominant chord of $A 13 \# 11$. In the next bar by Ab7alt, which is a tri-tone substitution for dominant chord preceding Gma7 in bar 14.

Trudy Lile: High And Dry, chorus

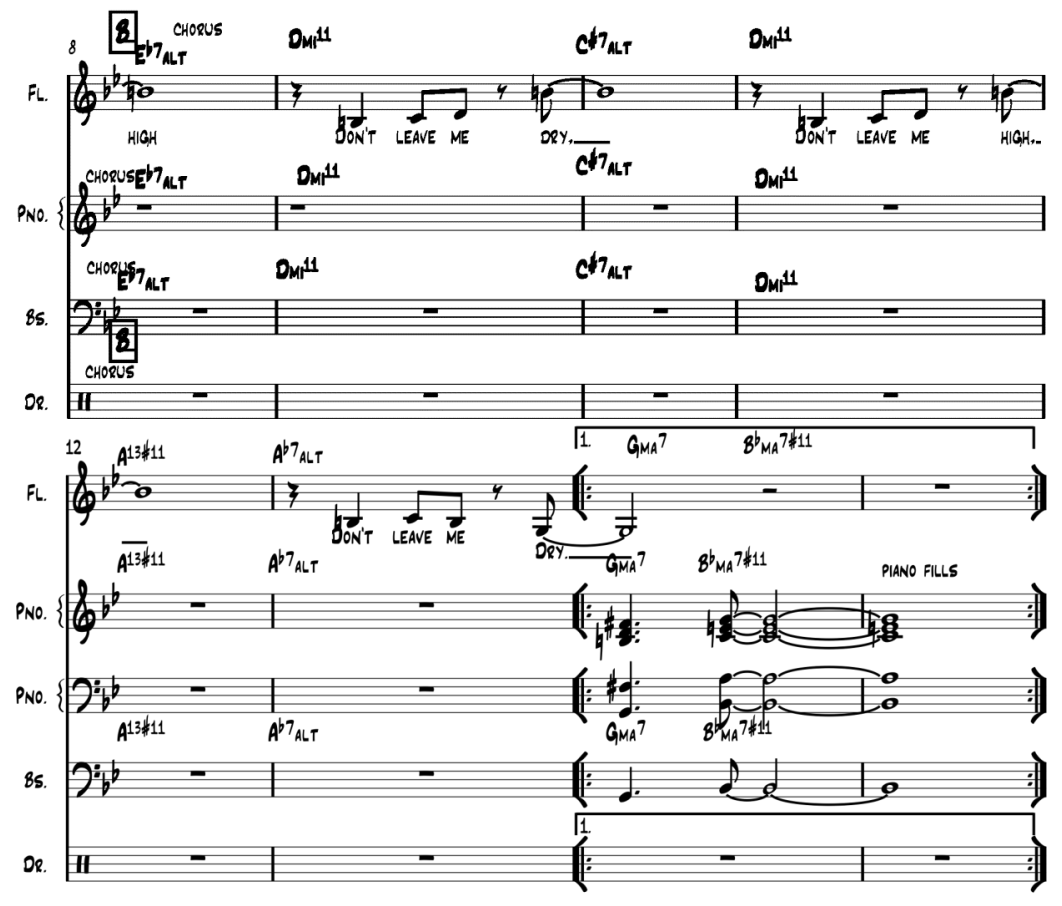

Figure 101 


\subsubsection{Melody Notes As Extensions Of The Chord}

After careful examination of the melody in relationship to the original harmony, choices can be made as to what other chords also fit with these notes. Often in the original version of the song, the melody notes are notes within the triad or dominant seventh chord; it is rare that they are extensions of these chords. In figure 102 we can see the melody notes in the original version of chorus of Time After Time, at the beginning of each chord are the are the root notes of a the first two chords $G$ and Ami, the major seventh of $F$, and the major sixth of the $G$, and then the major third of the $\mathrm{C}$ chord in bar 37.

Cyndi Lauper: Time After Time, chorus section

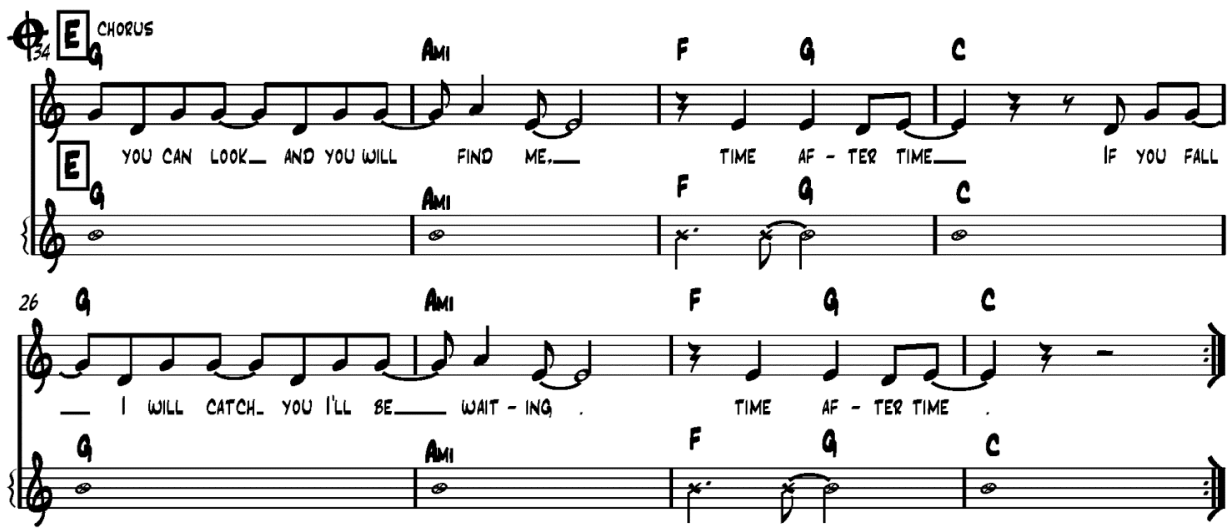

Figure 102

In the chorus section of the new version of this song, the melody notes at the beginning of each chord are now the flattened ninth of the F\#7alt, the fourth of the E7sus, the major third of Dma7, and the fourth of C\#7sus. This is similar to the reharmonisation used in the chorus section of Christian Mc Bride's arrangement of Walking On The Moon. 
Trudy Lile: Time After Time, chorus section

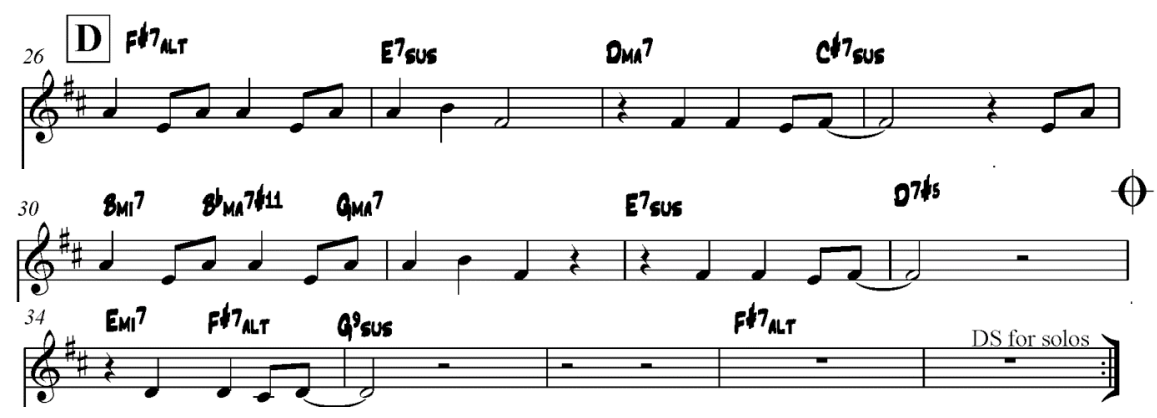

Figure 103

\section{Slash Chords}

Slash chords are triads or seventh chords over bass notes, and often imply a specific voicing to be played by the chord player.

The original version of Smells Like Teen Spirit is based on a simple two bar fourchord groove.

Nirvana: Smells Like Teen Spirit, Bar 5-8

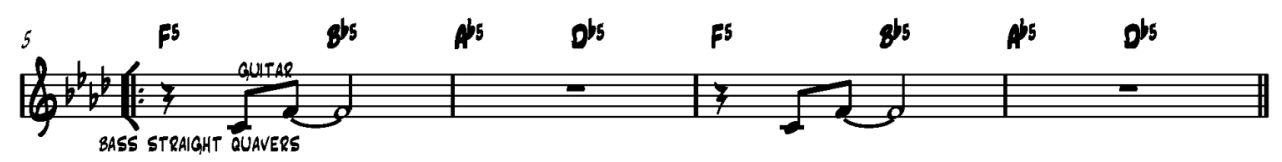

Figure 103

Slash chords have been substituted into the groove at bars 5 to 8 of the new arrangement of this song. In figure $103 \mathrm{Dma7} / \mathrm{E}$ has been used in place of the $\mathrm{E}$ and Emi7/A in place of the A. In the next bar what would have originally been a $C$ major chord transposed into the new key, has been substituted with a B9sus. The voicings of these chords as well as the reharmonisation give the arrangement a contemporary jazz flavour. 
Nirvana: Smells Like Teen Spirit, Bar 5-8

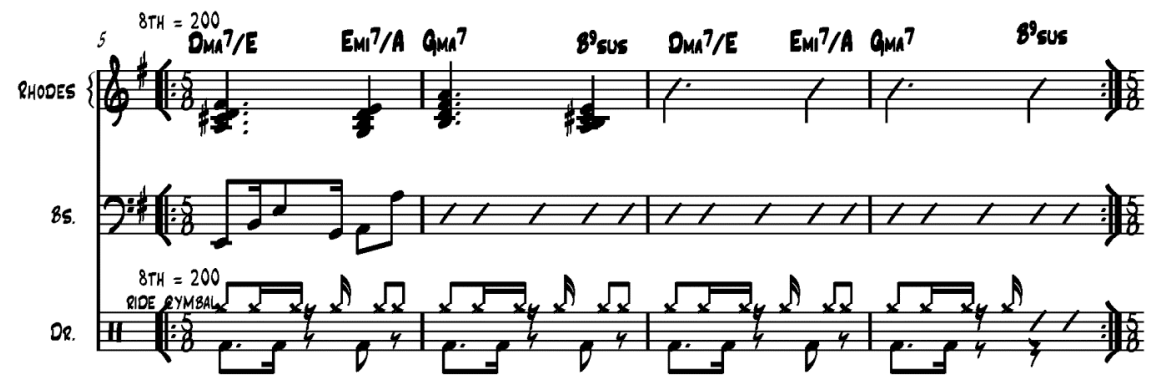

Figure 104

In the verse section of the original version of Message To My Girl, the harmony alternated between Suspended chords and major chords, see figure 105.

Split Enz: Message To My Girl, verse section

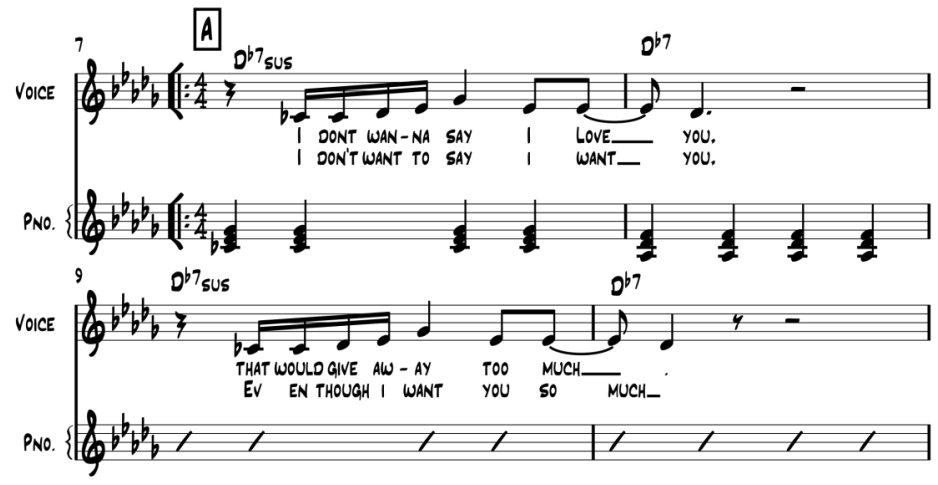

Figure 105

In the verse of the new arrangement of Message To My Girl the suspended chord in the first bar has been retained with a slash chord of Bbma7/C. In bar 14 in figure 106 an E/C gives a rich augmented sound, followed by a D/C and the return of the Bbma7/C bar 15. The E/C appears again in bar 16 followed by B7alt, which acts as a pivot chord before the Ami7 the following bar. 
Trudy Lile: Message To My Girl, verse section

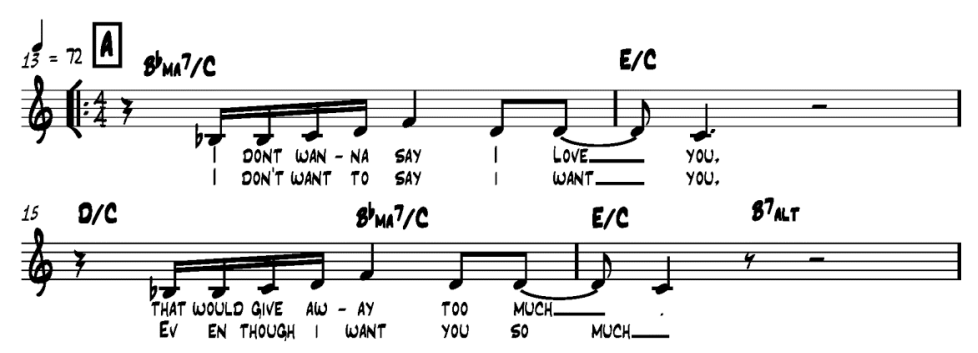

Figure 106

This makes the harmony sound more edgy, adding tension and release to the song, painting the words more colourfully than in the original version. 


\section{Conclusion}

As a result of this study several factors have become clear to me. A good arrangement can encourage further freedom and spontaneity that is expected from jazz performers and various arrangement tools can be used to create stylish jazz versions of pop songs from the last thirty years. The melodies of these songs can be enhanced musically by incorporating various jazz elements. Often jazz arrangers and performers have relied on their reharmonisation skills to present new repertoire but there are other effective arrangement skills that can be explored. These include rhythmic, structural, textural and harmonic changes and often they can occur simultaneously.

Rhythmic manipulation such as performing the songs at completely different tempi definitely have an effect on the reinterpretation: songs that had been arranged to be performed at slower tempi, had more space for the individual performer to re-phrase the melody and draw attention to certain lyrics for example.

Arrangements that made songs faster were also effective if other aspects of the arrangement worked in conjunction, such as the harmony and structural elements.

Changes of meter also provide interesting opportunities to approach melodic phrasing. Using odd time signatures adds a challenge as well as a fresh perspective to the performers. Changes of meter within the arrangement also offer exciting tools for performers.

Presenting the songs with different grooves also provides a new viewpoint. There are many types of rhythmic grooves from world music and other genres to be explored when arranging for jazz ensemble. These can be used successfully without necessarily changing the tempo of the original song. 
Changes of groove can have textural impact on the arrangement. Experimenting with the texture can provide colour to the original song. The type of groove will sometimes be dependent as to the size of the ensemble and will provide challenges for the arranger on how it can be most effectively used in the arrangement. Writing clear directions for the rhythm section including rhythmic hits and chordal voicings gives clear direction to the performers resulting in an effective arrangement. Melodic hooks from the original song can be used as background lines in the arrangement and supply even more cohesion in the new version.

Structural changes can be made to the original song. Introductions can set up the style of the new arrangement and can be added using material from the original song in free time. Platforms for improvisation need to be considered and can be added in the middle or at the end of the song, although the whole form of the song can be improvised over too. A variety of endings can be considered to conclude the song. Many of the transcriptions considered in this study finished with repeat to fade endings, with improvisation over the top of them.

Creating chordal vamps provides a contemporary feel to the song. They have rhythmic, textural and harmonic effects on the arrangement. Vamps can be used to establish tempo and time signature changes, or used as improvisation sections, introductions, interludes and endings.

Pedal points are another colourful way of altering the melody. Stops and pauses can be added into the melody creating drama for the audience as well as the performer. The melody line can even be elongated at certain points. This has the effect of highlighting certain lyrics and works well in conjunction with reharmonisation techniques such as chord substitution and even abrupt modulations.

There are many ways of adding jazz harmony to a pop song. Harmonic alteration generally considers the melody. This can include adding sevenths and other 
extensions to the existing chords, diatonic substitution, inserting turnaround progressions, tri-tone substitution, and with melody notes becoming unusual extensions of the chords.

Ultimately the success of the arrangement is dependent on the interpretation by the jazz performers. A lot of Information can be provided within the arrangement though the interaction and collaboration of the performers is necessary.

Developing successful jazz arrangements of songs from the last thirty years can help to broaden the appeal of jazz to non-jazz audiences. Jazz listeners can appreciate the range of skills used in the arrangement and the resulting musical performance. Non-jazz audiences will recognise the songs being presented in a style in which they may not have heard previously. By adding songs that are familiar to a wider audience into the jazz repertoire it is hoped that this is a positive step toward developing a wider audience for jazz while retaining the artistic integrity of the jazz artists. 


\section{Bibliography}

Clark, Andrew. Riffs and Choruses, London: Continuum 2001

Coker, Jerry. A guide to jazz composition and arranging, Germany: Advance Music, 1998

David, Norman. Jazz Arranging, New York: Ardsley House Publishers, c1998

Davis, Francis. Bebop and nothingness: jazz and pop at the end of the century, London: Omnibus, 2001

Davis, Francis. Like young: jazz and pop, youth and middle age, Cambridge, Mass: Da Capo Press 2001

Freeman, Phillip. Running the voodoo down: the electric music of Miles Davis San Francisco: Backbeat Books 2005

Grove Dick, Arranging Concepts Complete; The ultimate arranging course of today's music, Van Nuys, CA: Alfred Publishing Co,1989

Mandel Howard. Future Jazz Oxford ; New York : Oxford University Press, 1999

Nicholson, Stuart. Jazz rock: a history, New York: Schirmer Books 1998

Nicholson, Stuart. Is Jazz dead (or has it moved to a new address) New York:

Routledge, 2005 
O'Meally, Robert. The Jazz Cadence Of American Culture, New York: Columbia University Press, 1998

Pease, Ted and Pullig, Ken. Modern jazz voicings: arranging for small and medium ensembles Boston, Berklee Press 2001

Porter L, Lester Young, Ann Arbor: University of Michigan Press, 2005

Rinzler Paul. Jazz Arranging - A guide for small ensembles London : Scarecrow, 1999

Tingen, Paul. Miles Beyond: The Electric Years of Miles Davis1969-1991, New York Billboard Books, 2001

\section{Websites}

Ed Byrne: http://ezinearticles.com/Jazz-Theory:-History-of-JazzHarmony\&id=247269

Stephen Erlwine Thomas: Song review, All Music, http://www.allmusic.com/cg/amg.dll?p=amg\&sql=10:fbfoxq9aldde"

Stephen Erlewine Thomas: Album review, All Music, http://www.allmusic.com/cg/amg.dll?p=amg\&sql=10:a9fixq95ld6e

Stephen Thomas Erlewine: Album Review. All Music, http://www.allmusic.com/cg/amg.dll?p=amg\&token=ADFEAEE67B1BD246AC742 0C79A364AC8A07CE5078810DA8D12254B4792BB345CC3036CFD4AC38FB7 
D0861FF035A9E02FAC450DD3CAE91AF9D664383789E7B61145\&sql=10:fbfox q9aldde Accessed november 19th

Kelvin Hayes: Album review, All Music, http://www.allmusic.com/cg/amg.dll?p=amg\&sql=11:k9fixqq0ldke T0

http://www.jazzweekly.com/interviews/belden.html

Thom Jurek, Possibilities: Overview, All Music, http://www.allmusic.com/cg/amg.dll?p=amg\&sql=10:anfpxqusld0e accessed November $16^{\text {th }} 2008$

Stewart Mason, Don't You Forget About Me; Song Review, All Music, http://www.allmusic.com/cg/amg.dll?p=amg\&sql=33:w9fexq8rldde accessed January $9^{\text {th }} 2009$

Lindsay Planer: Album Review, All Music, http://www.allmusic.com/cg/amg.dll?p=amg\&token=ADFEAEE67B1BD246AC742 0C79A364AC8A07CE5078810DA8D12254B4792BB345CC3036CFD4AC38FB7 D0861FF035A9E02FAC450DD3CAE91AF9D6663A3789E6B61145\&sql=10:gifix gwgldde Accessed November $20^{\text {th }} 2008$

Robin Tolleson: Bob Belden: JAZZ MEETS POP Mar 1, 1999 12:00 PM http://mixonline.com/mag/audio_bob_belden_jazz/ Accessed August 7th 2008 
Scott Yanow, The New Standard Overview, All Music guide,

http://www.allmusic.com/cg/amg.dll?p=amg\&sql=10:hzfpxqwhldje accessed January $13^{\text {th }} 2009$

http://en.wikipedia.org/wiki/Traditional_pop_music

http://en.wikipedia.org/wiki/Jazz standard

Herbie Hancock Interview, transcription by Trudy Lile of Possibilities DVD, Magnolia, 10060, 2006 


\section{Appendix 1 - Discography}

New York Minute - Don Henley 'The End of the Innocence' 1989 Geffen 2-2421

- Herbie Hancock 'The New Standard' 1995 Verve

1999 - '1999' Prince 1983 Warner Bros 23720

- Bob Belden 'When the Doves Cry: The Music of Prince' 1993 Metro Blue 7243

Sister Moon - Sting, 'Nothing like the sun' 1987, A\&M

- Herbie Hancock, Possibilities 2005 Vector/Hancock 70013

Walking On The Moon - 'The Police', Reggatta de Blanc 1979 A\&M 4792

- Christian Mc Bride ‘Sci-Fi ‘ 2000, Verve 543915

Don't You Forget About Me - Simple Minds, 'The Breakfast Club' 1985,

- Michelle Nicolle, 'The Crying Game' 2003ABC JAZZ/Universal

Exit Music (For A Film) - Radiohead ‘OK Computer’ 1997 Capitol 55229

- Brad Meldau, The Art of the Trio, Vol. 3: Songs 1998 Warner Bros

- Brad Meldau, The Art of the Trio, Vol. 4: Back at the Vanguard, 1999

Warner Bros

Like A Virgin - Madonna, 'Like a Virgin' 1984 CD Sire 2-25157

- Lisa Bassenge ‘Going Home’, 2001 Minor Music 801091 
- Lisa Bassenge ‘Reprise-Jazz meets Pop’ 2005 Nova 3108252

Come As You Are - Nirvana, 'Nevermind' 1991 DMG 24425

- Charlie Hunter, 'Bing, Bing, Bing' 1995, Blue Note 31809

In Your Eyes - Peter Gabriel, 'So' 1986, Geffen

- Dianne Reeves, 'Bridges' May 4, 1999, Blue Note 33060

Violent - Stellar, 'Mix' 1999 Sony

Fragile - Sting, 'Nothing Like The Sun' 1987 A\&M

Rock With You - Michael Jackson, 'Off the wall' 1979 Epic EK-35745

Time After Time - Cyndi Lauper, 'She’s so unusual' 1984 Portrait 9R9-39610

Smells Like Teen Spirit - Nirvana, 'Nevermind' 1991 DMG 24425

Message To My Girl - Split Enz ‘Conflicting Emotions’ 1983 Mushroom

Is this love - Bob Marley and The Wailers, 'Babylon By Bus', 1978 Tuff Gong 11

More Than This - Roxy Music, 'Avalon' Roxy Music 1982 Virgin

High And Dry - Radiohead, 'The Bends' 1995 Capitol 29626 
Appendix 2

Scores of Original Songs - Part Two 


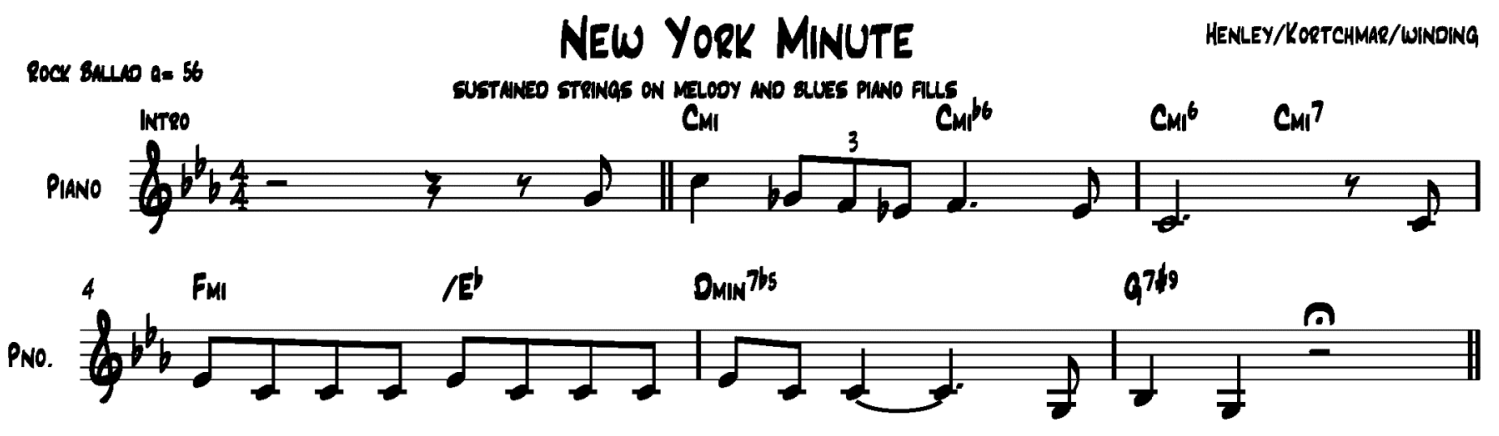

WTH DQUMS IN 4 NND BASS PEOM C 2ND fIME
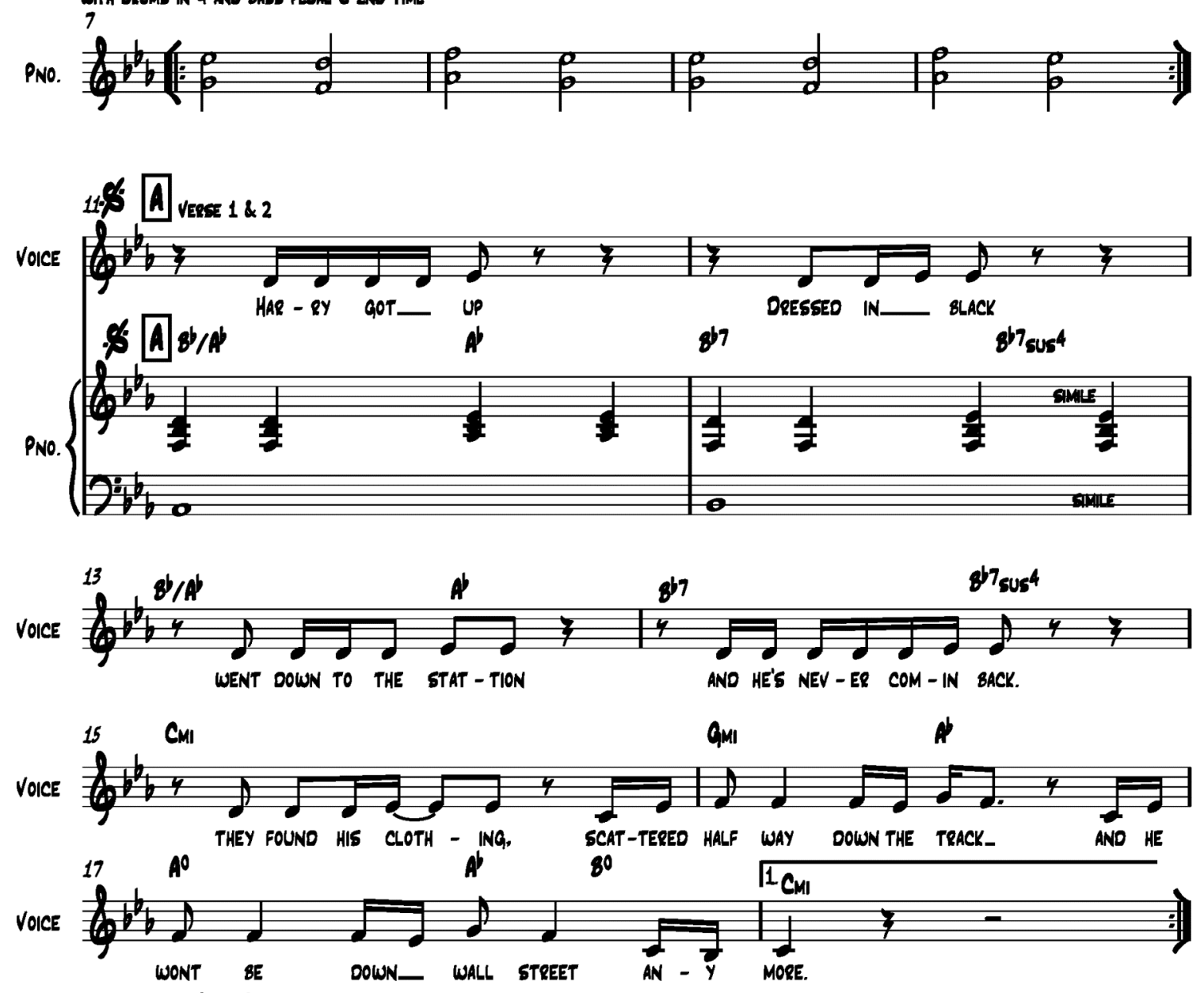

VERSE 2

HE HAO A HOME, LOVE OF A GMR, SUT MEN GET LOST SOMETIMES, AS YEABS UNFUR.

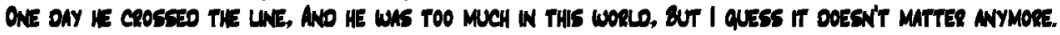
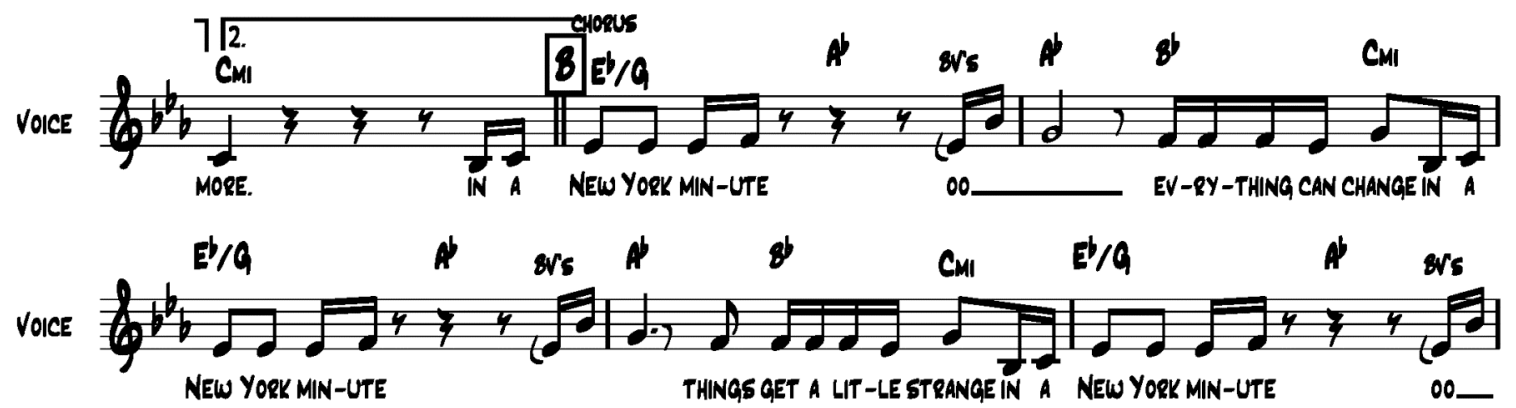
2

VOICE

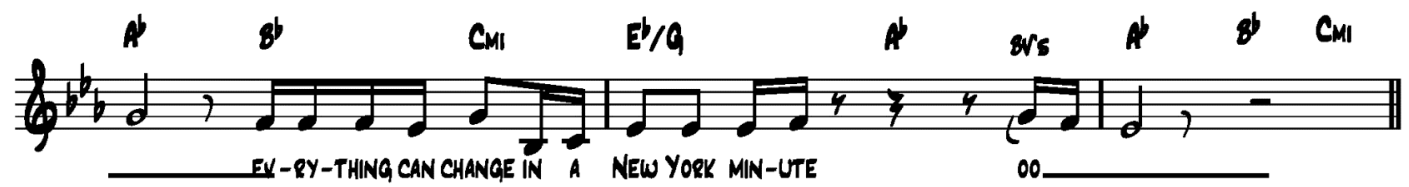

Verse 3

VOICE

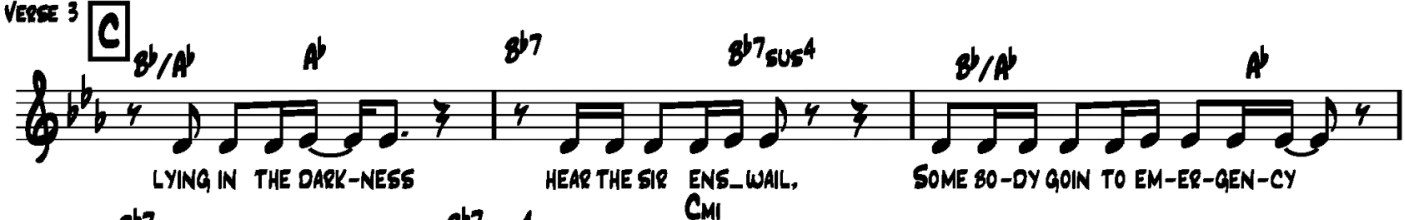

VOICE

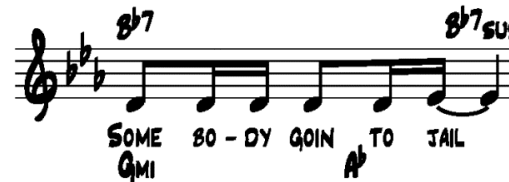

CMI

VOICE
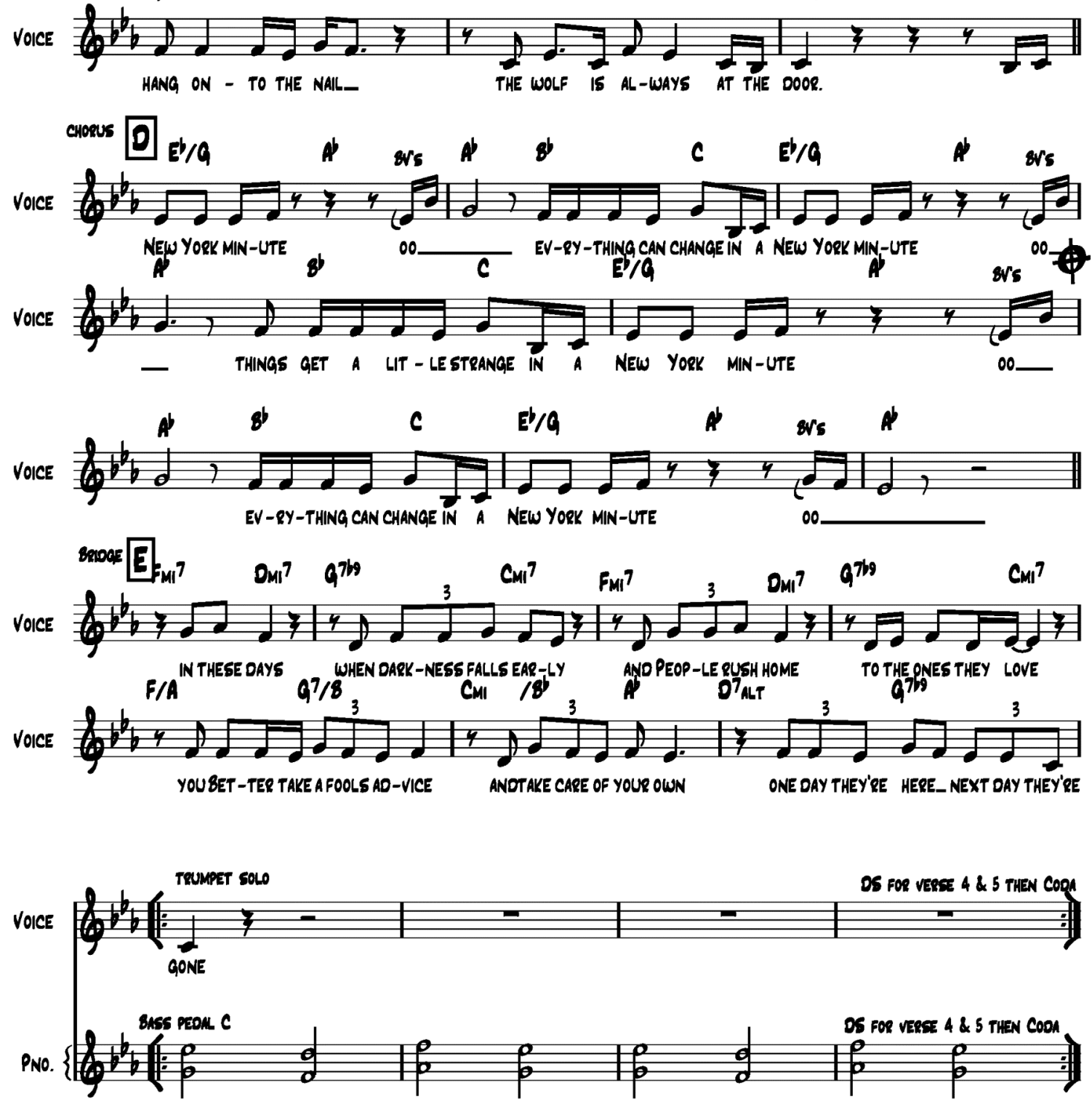

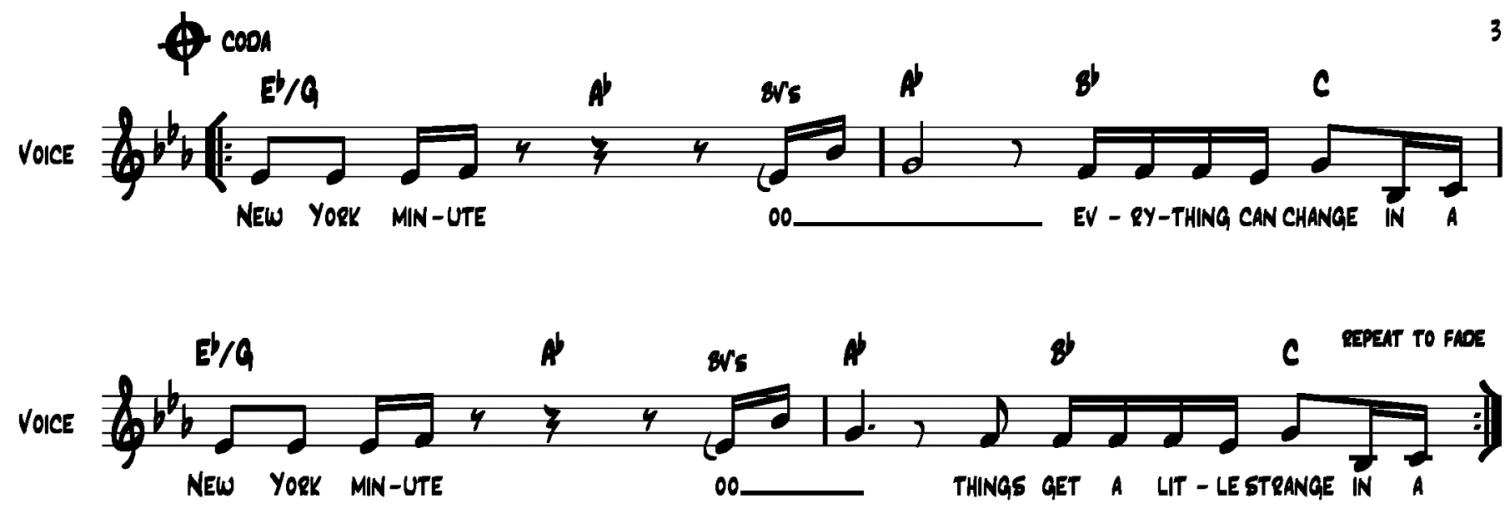

VEREE 4

I pulled my coat around my shoulders

And took a walk down through the park

The leaves were falling around me

The groaning city in the gathering dark

On some solitary rock

A desperate lover left his mark,

"Baby, I've changed. Please come back.

VERSE 5

"What the head makes cloudy

The heart makes very clear

The days were so much brighter

In the time when she was here

But I know there's somebody somewhere

Make these dark clouds disappear

Until that day, I have to believe

I believe, I believe 
EXIT MUSIC (FOR A FILM)

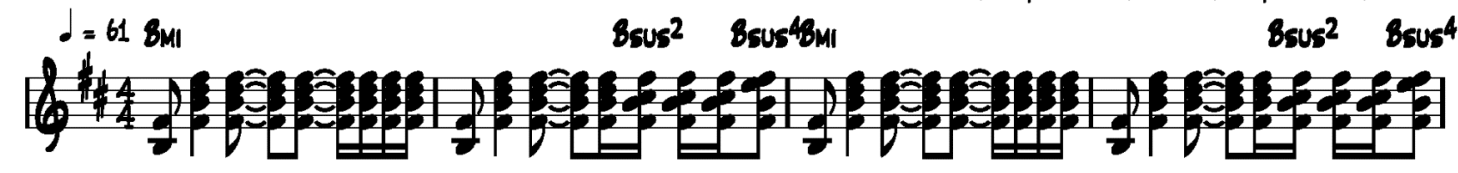

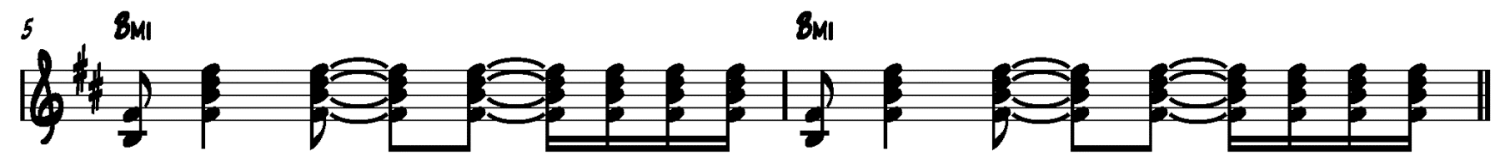

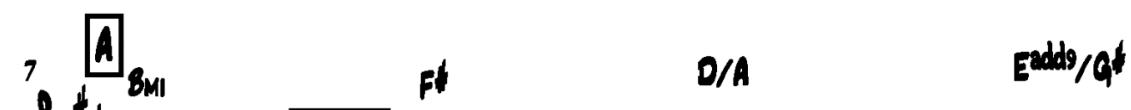

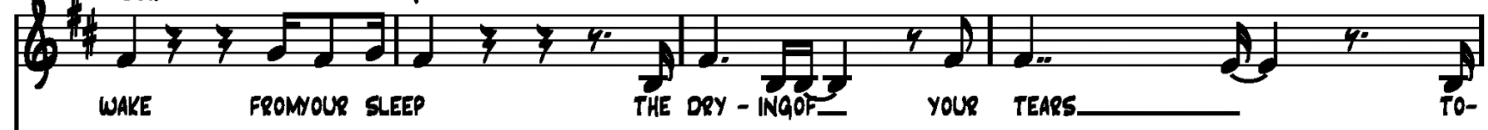
(6) GUITAR CONTINUES SIMILAR
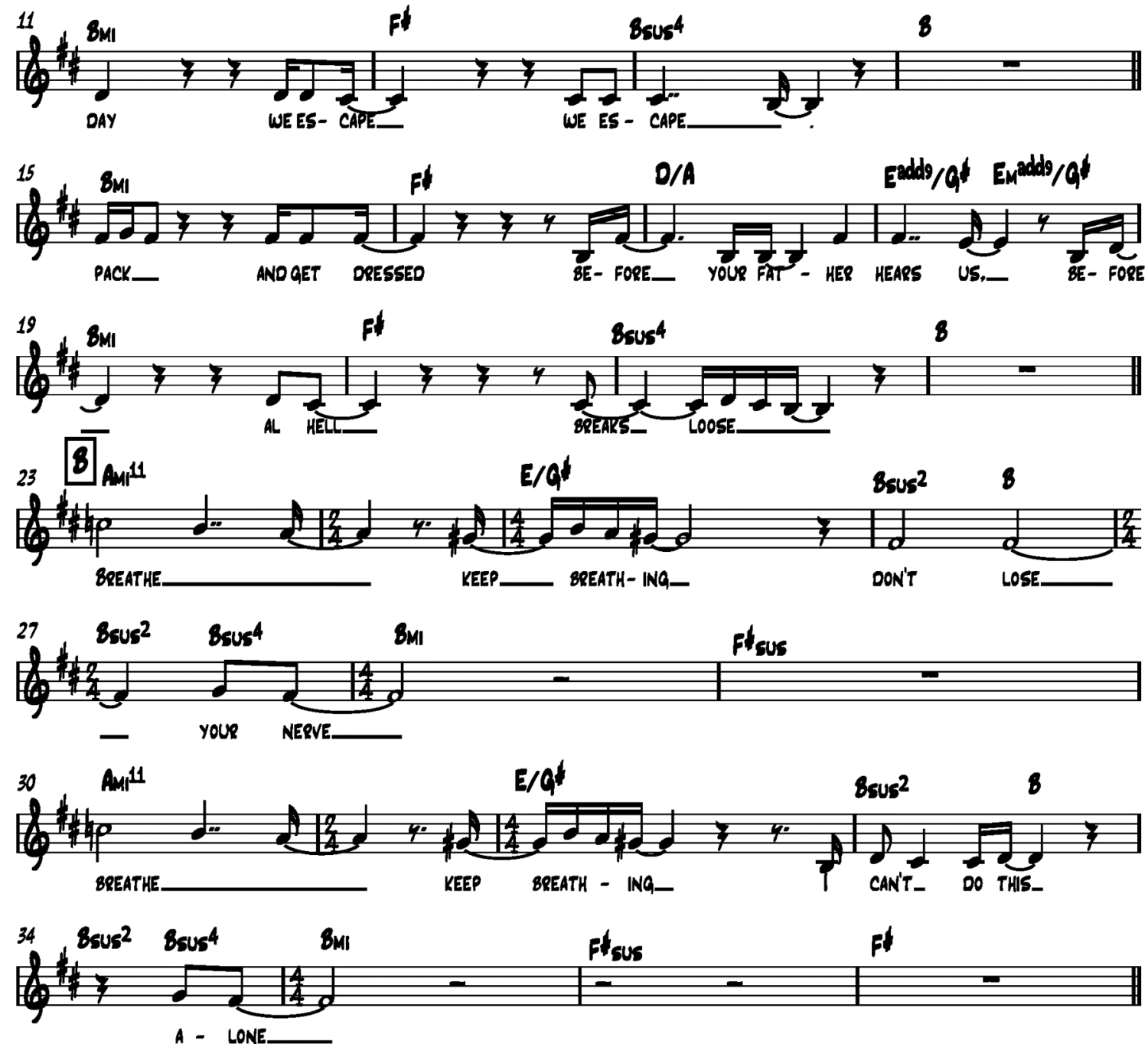

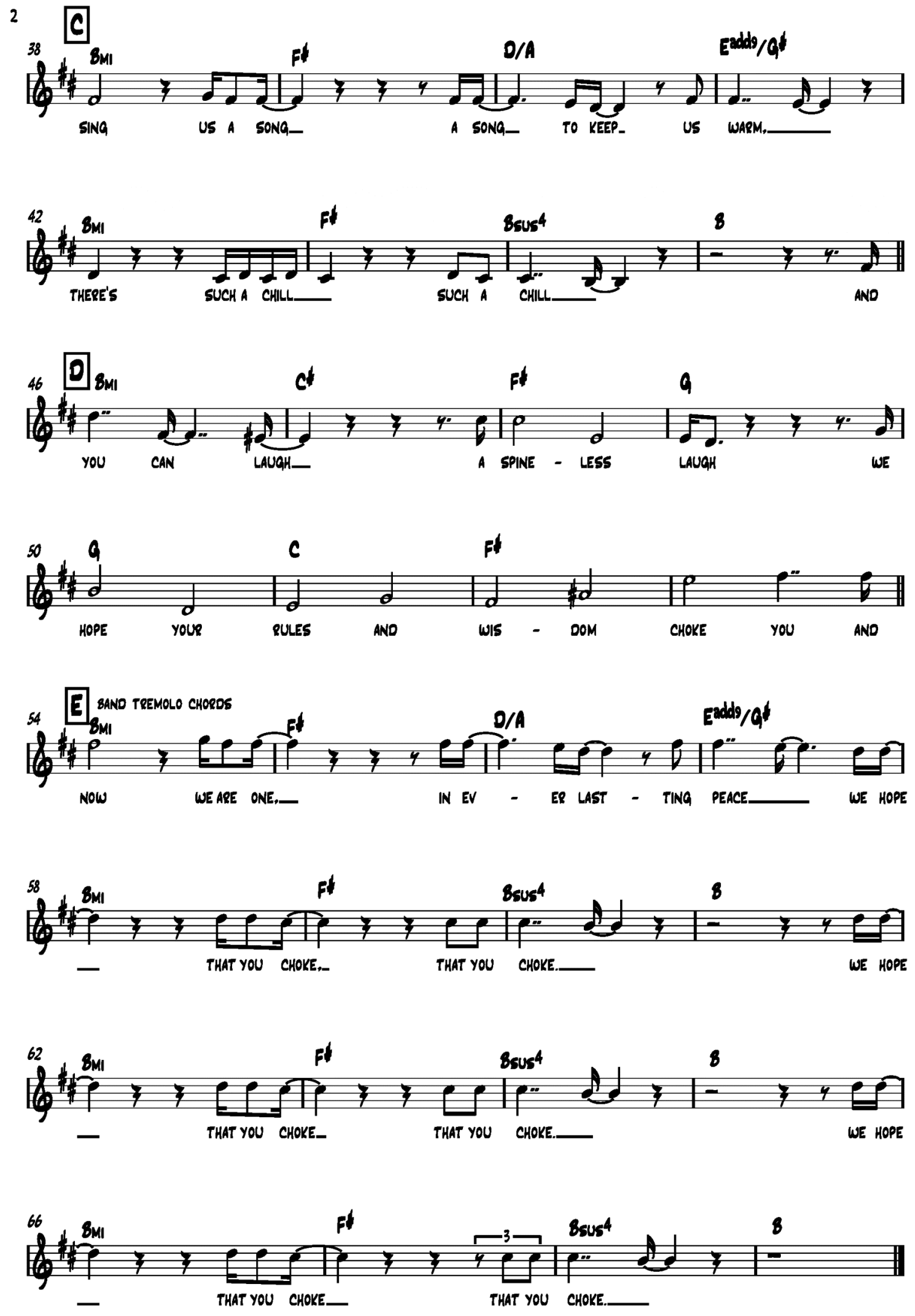

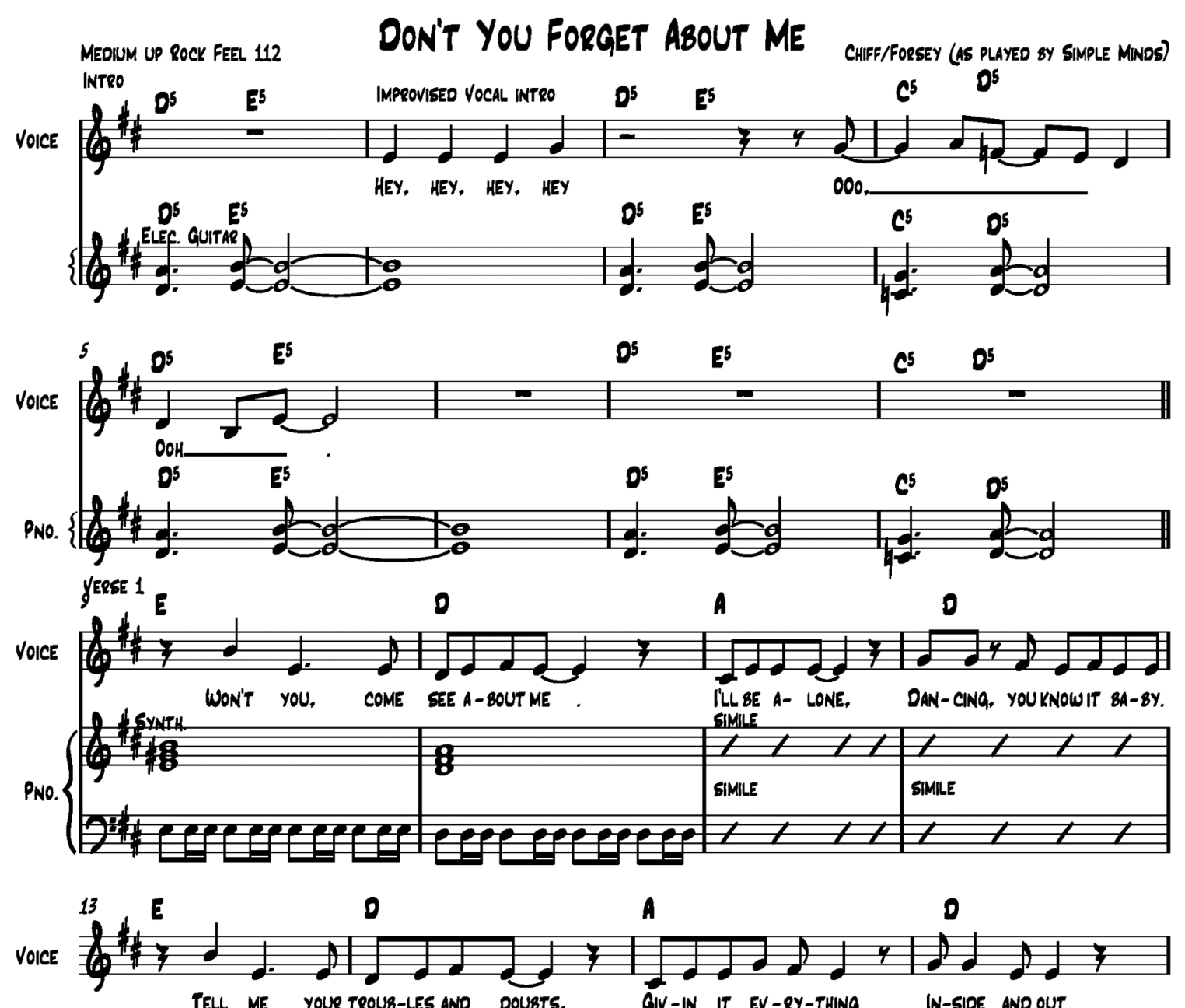

TELL ME YOUR TROUB-LES AND DOUBTS, GIV-IN IT EN-RY-THING IN-SIDE AND OUT
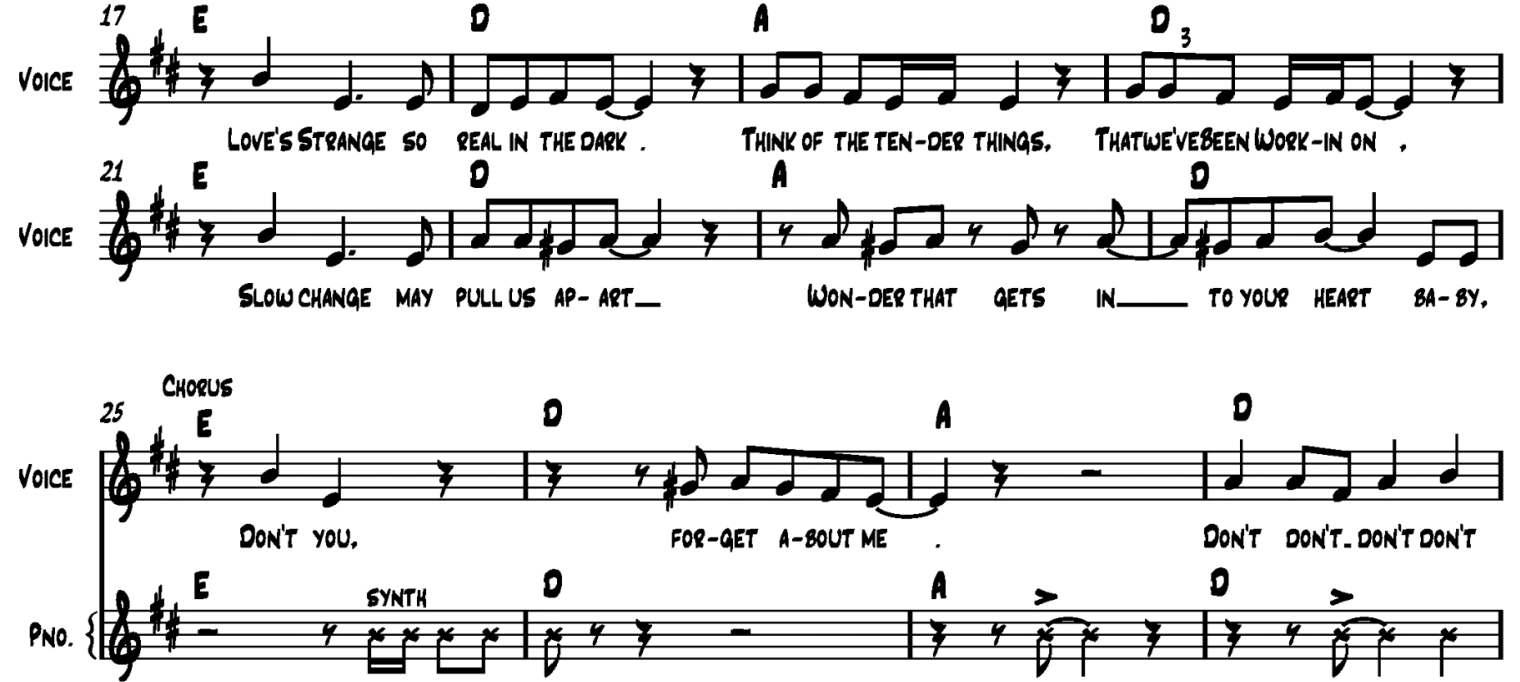


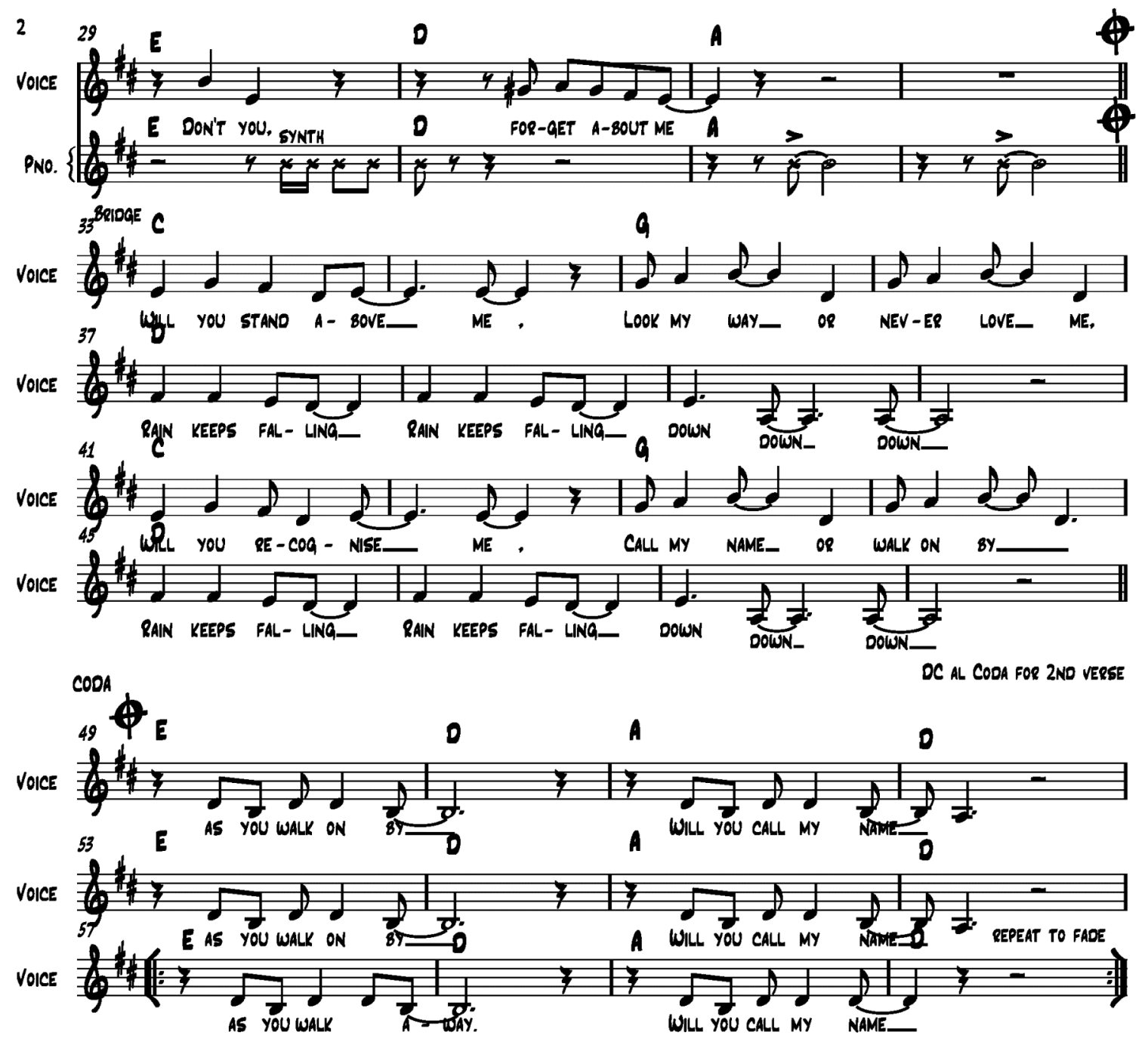

VERSE 2

DON'T YOU, TRY AND PRETEND, IT'S MY BEGINNING WE'LL WIN IN THE END. I WONT HARM YOU, OR TOUCH YOUR DEFENCES, VANITY AND SECURITY.

DON'T YOU FORGET ABOUT ME, GOIN TO TAKE YU APART,

I'LL PUT US BACK TOGETHER AT HEART, BABY. 


\section{COME AS YOU ARE}

CoBAIN

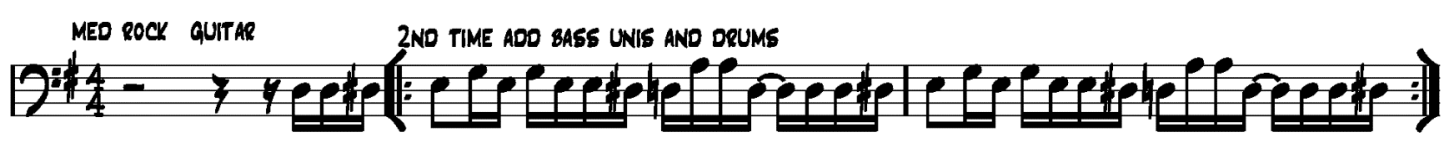

4 AERSE 1

SOIf

8

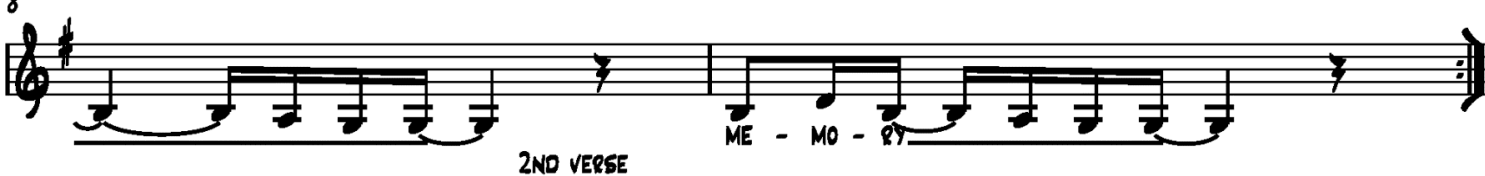

2ND VEREE

COME DOUSEO IN MUD, SEARED IN BLEACH,

AS A TRAMP. AS A FRIEND.

EQIOGE

14 Guitar solo

(8)

SRIOGE

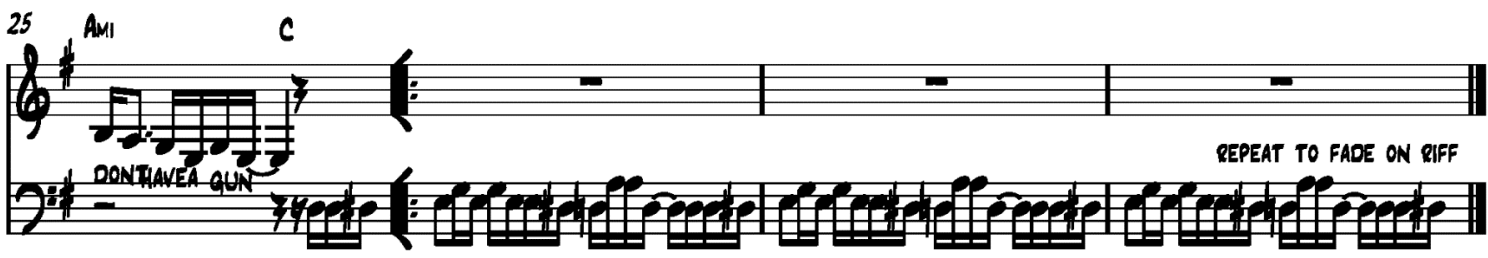



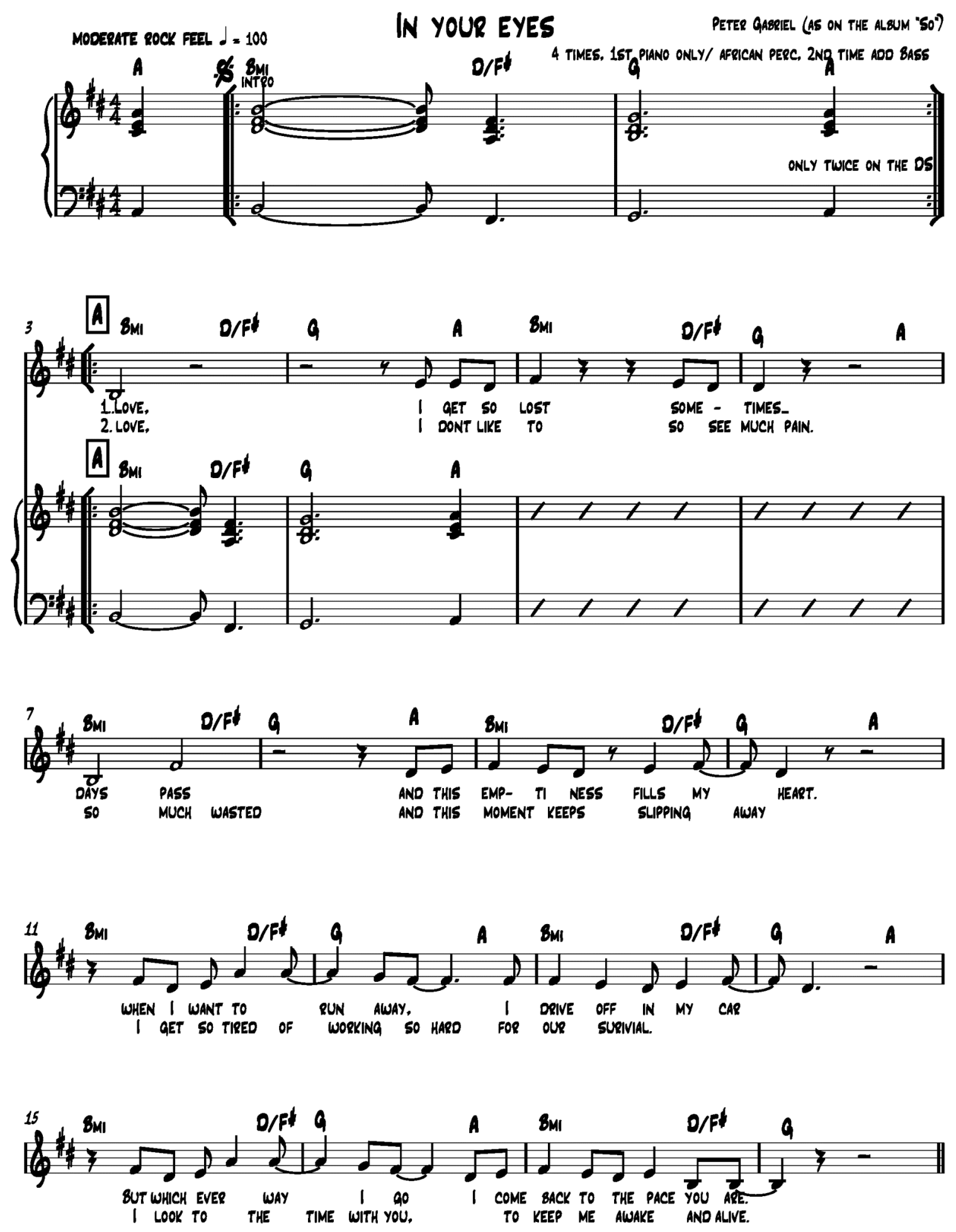

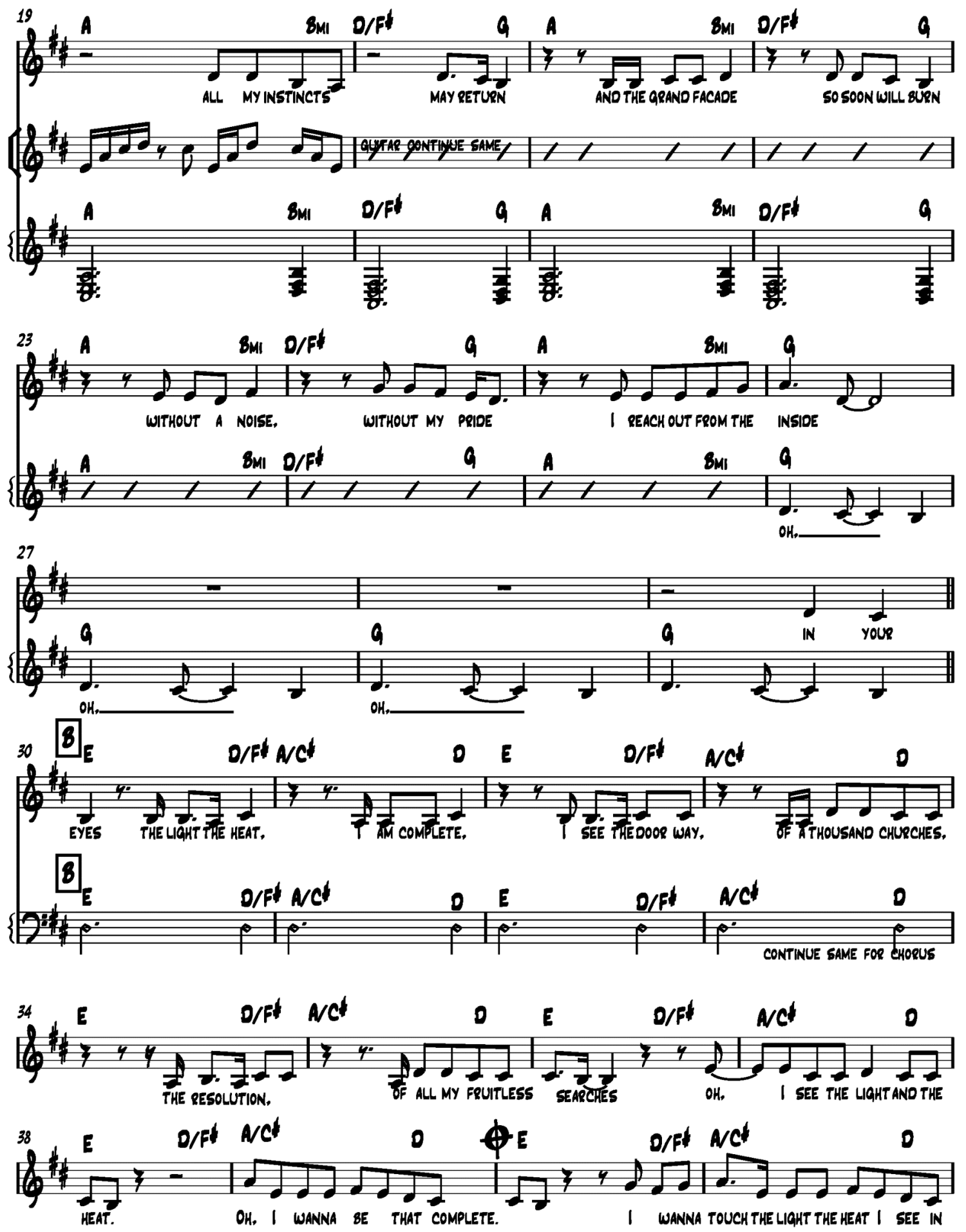


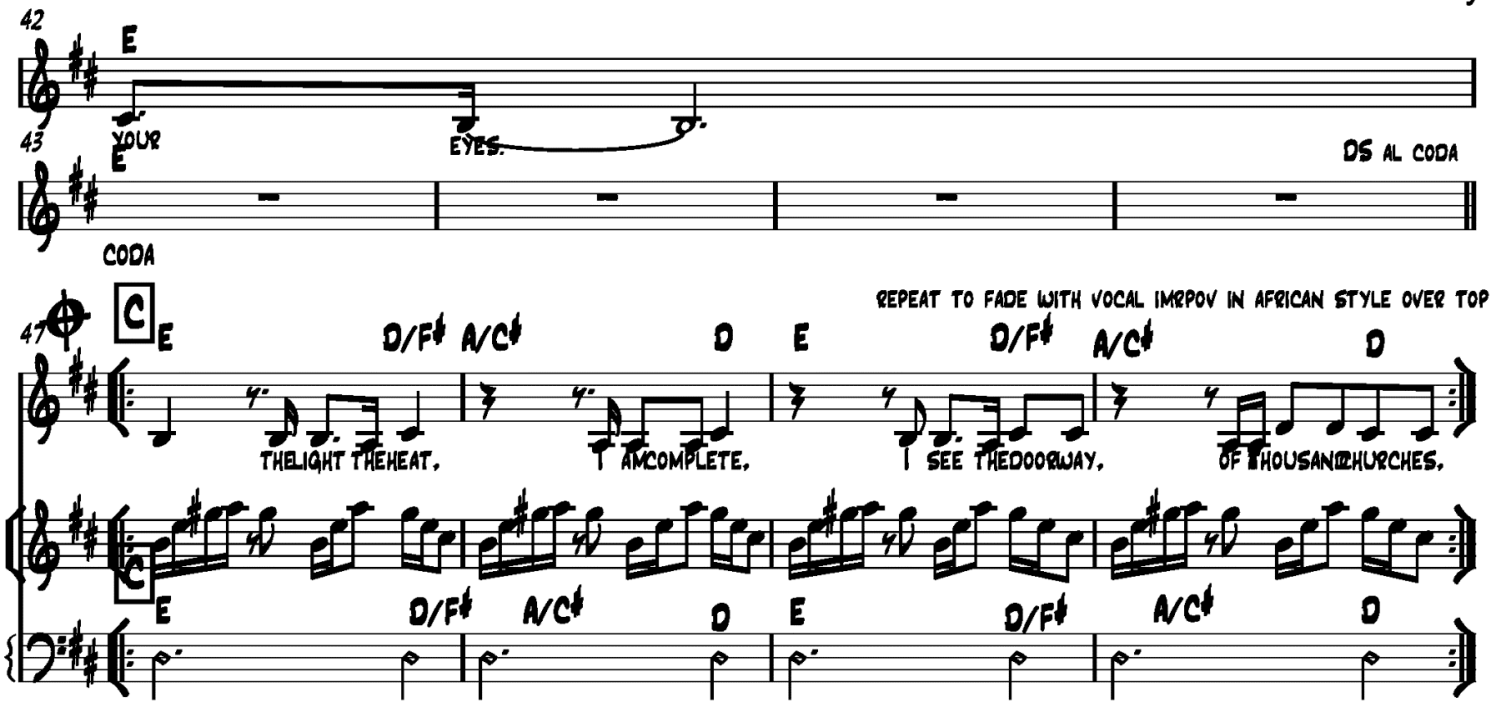




\section{WALKING ON THE MOON}

Sting (AS ON REgatTa de BLANC)
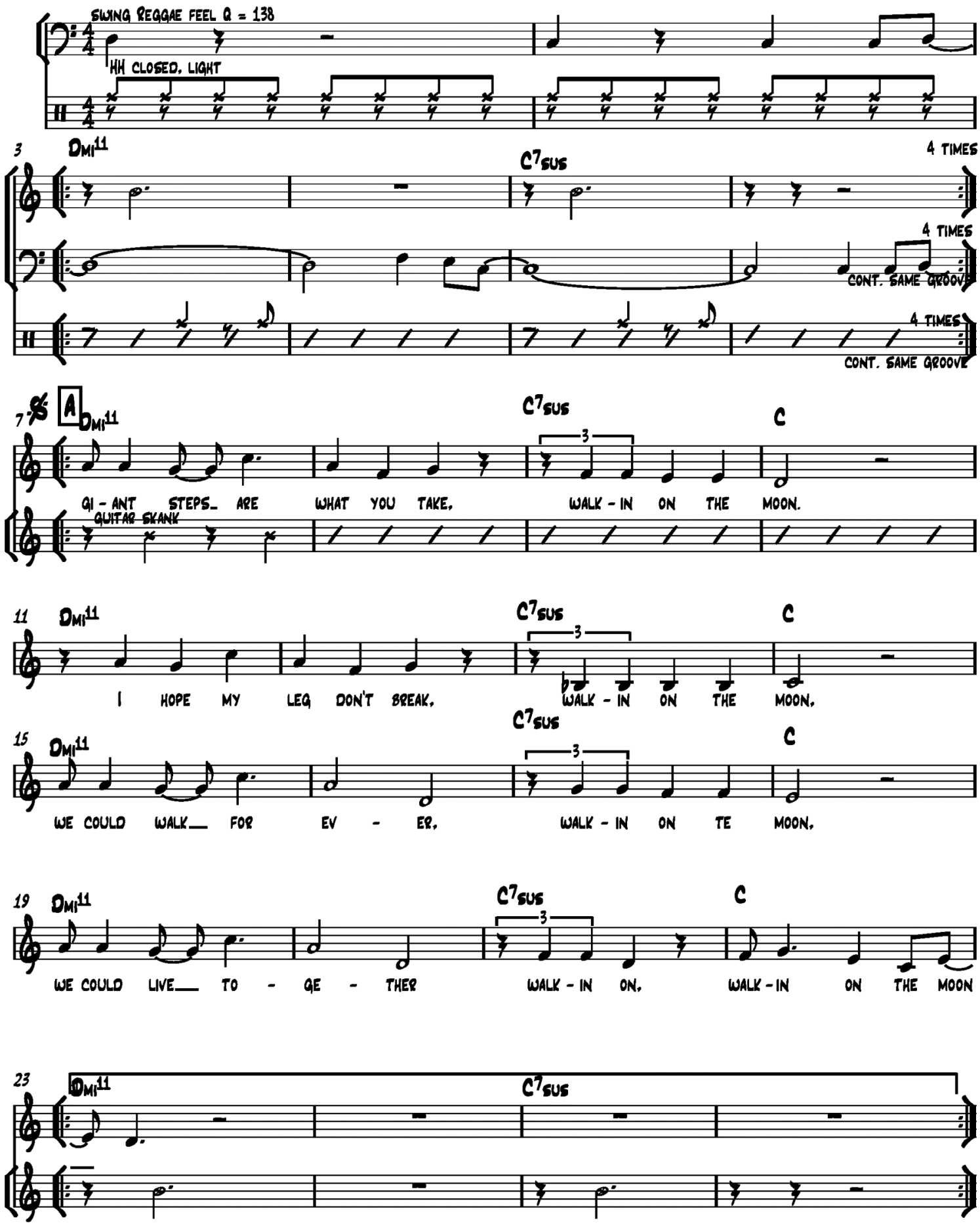
VERSE 2 - WALKIN BACK FROM YOUR HOUSE, WALKIN ON THE MOON.

WALKIN BACY FROM YOUR HOUSE, WALKIN ON THE MOON.

WE CAN HAROLY TOUCH THE GROUNO. WALKIN ON THE MOON.

WE DON'T HAROLY MAKE NO SOUND. WALKIN ON, WALKIN ON THE MOON.
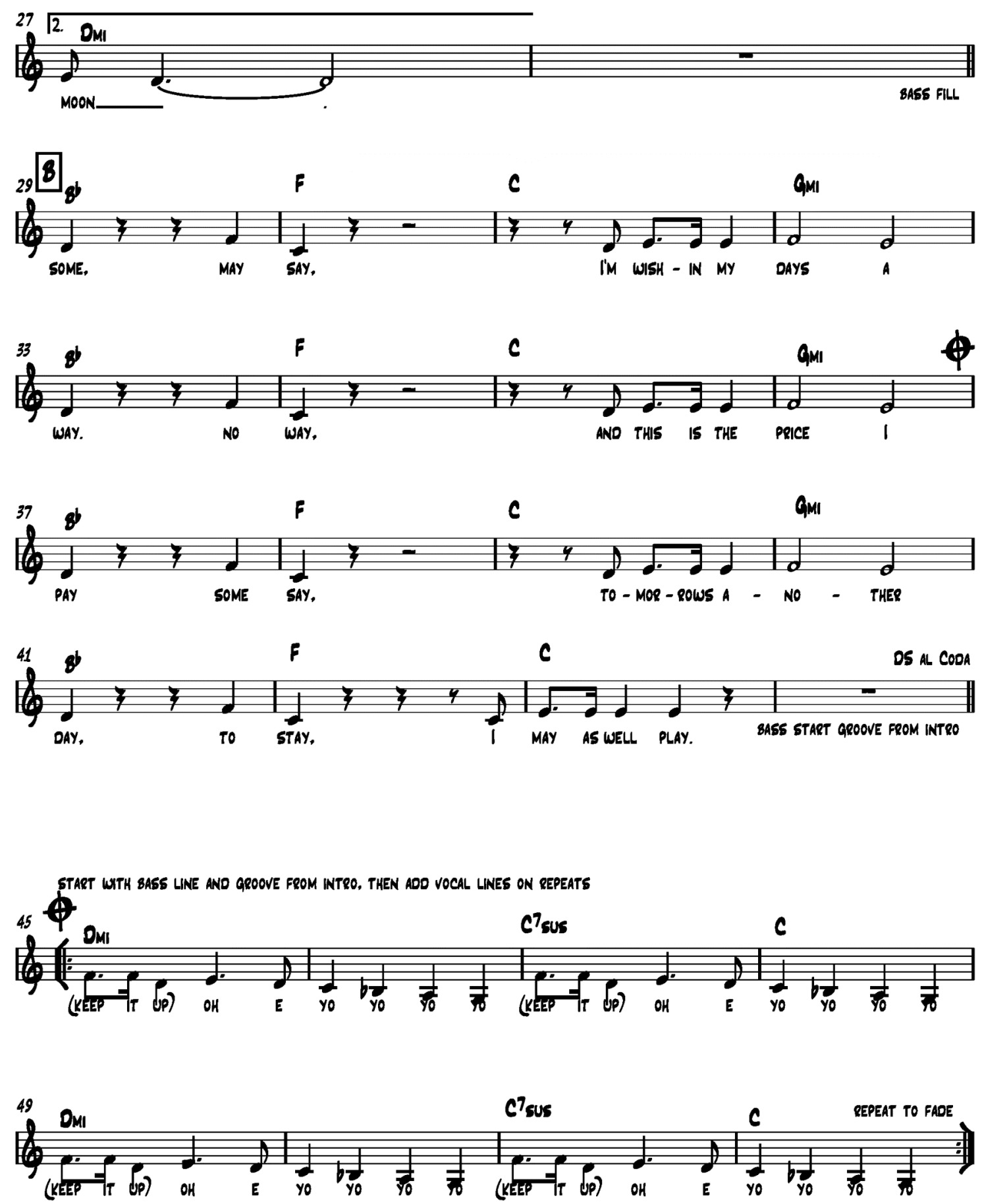

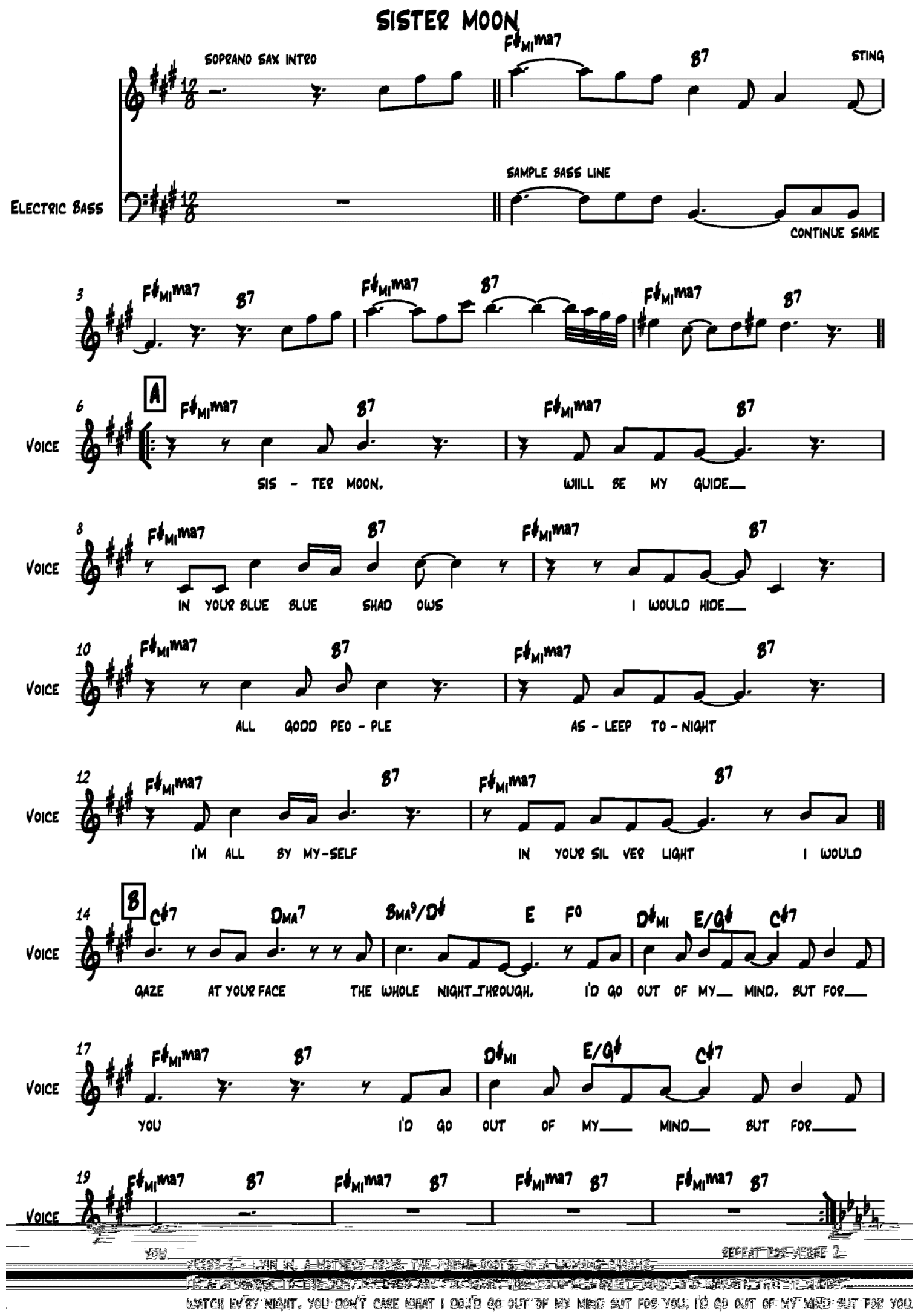

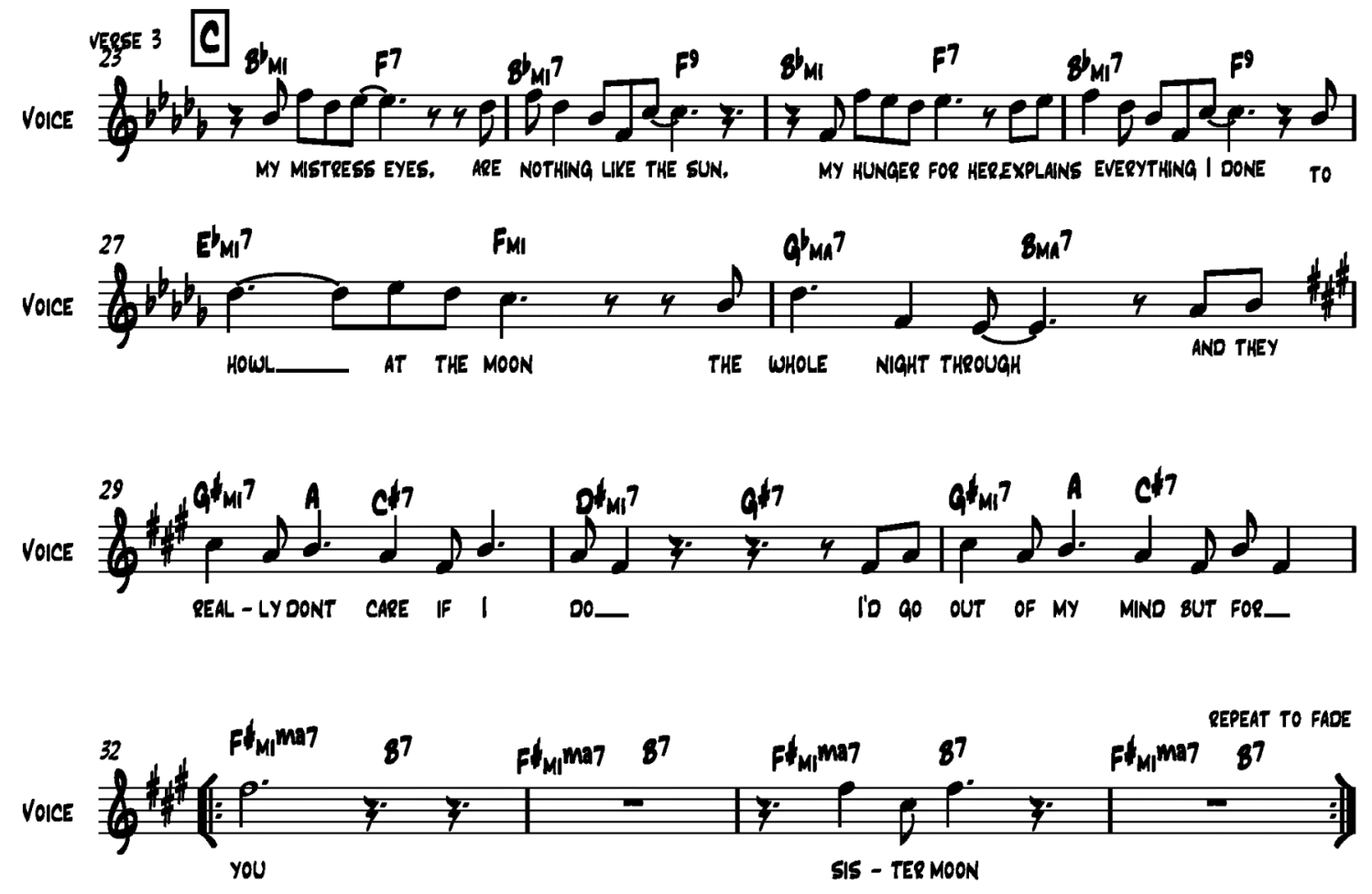

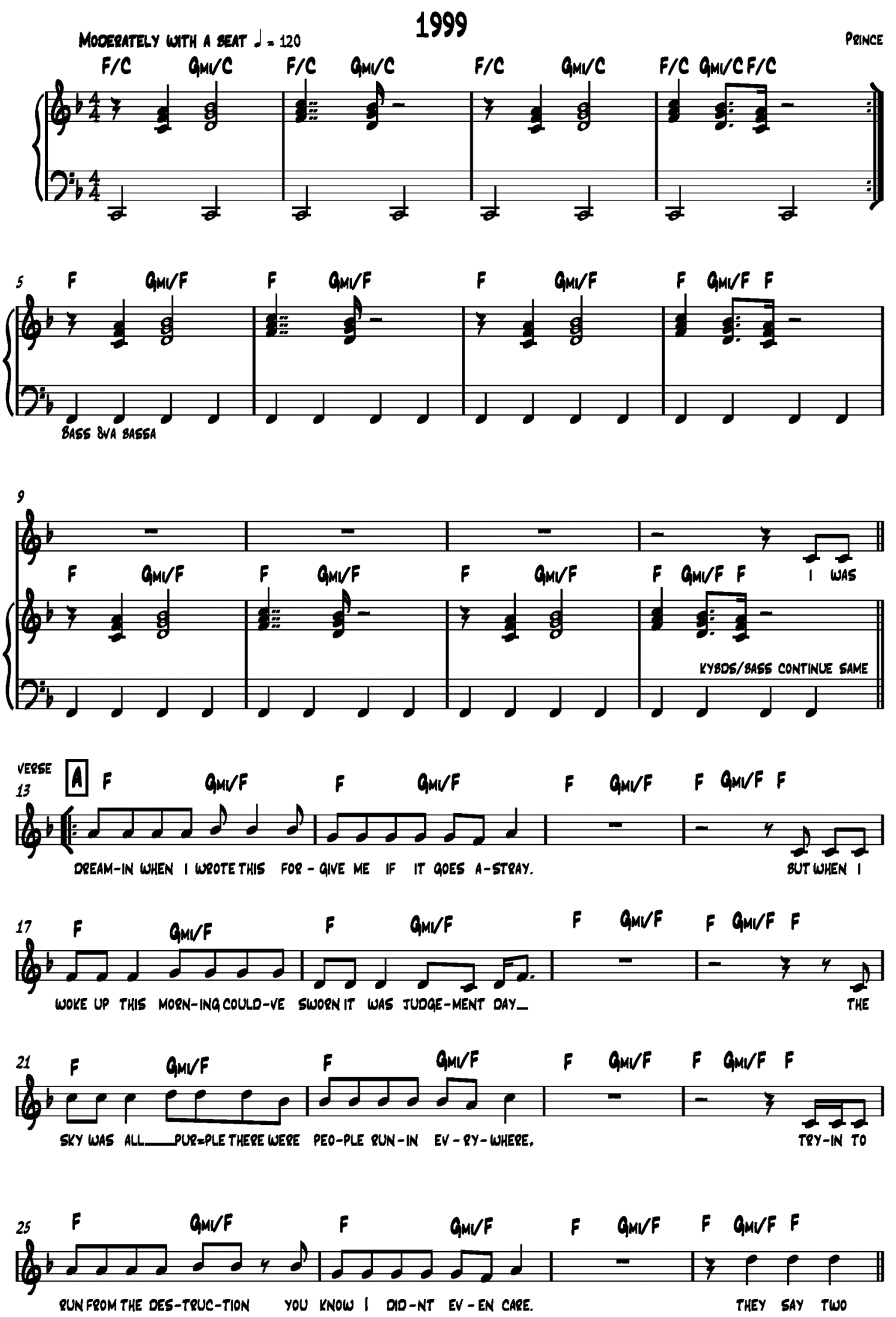

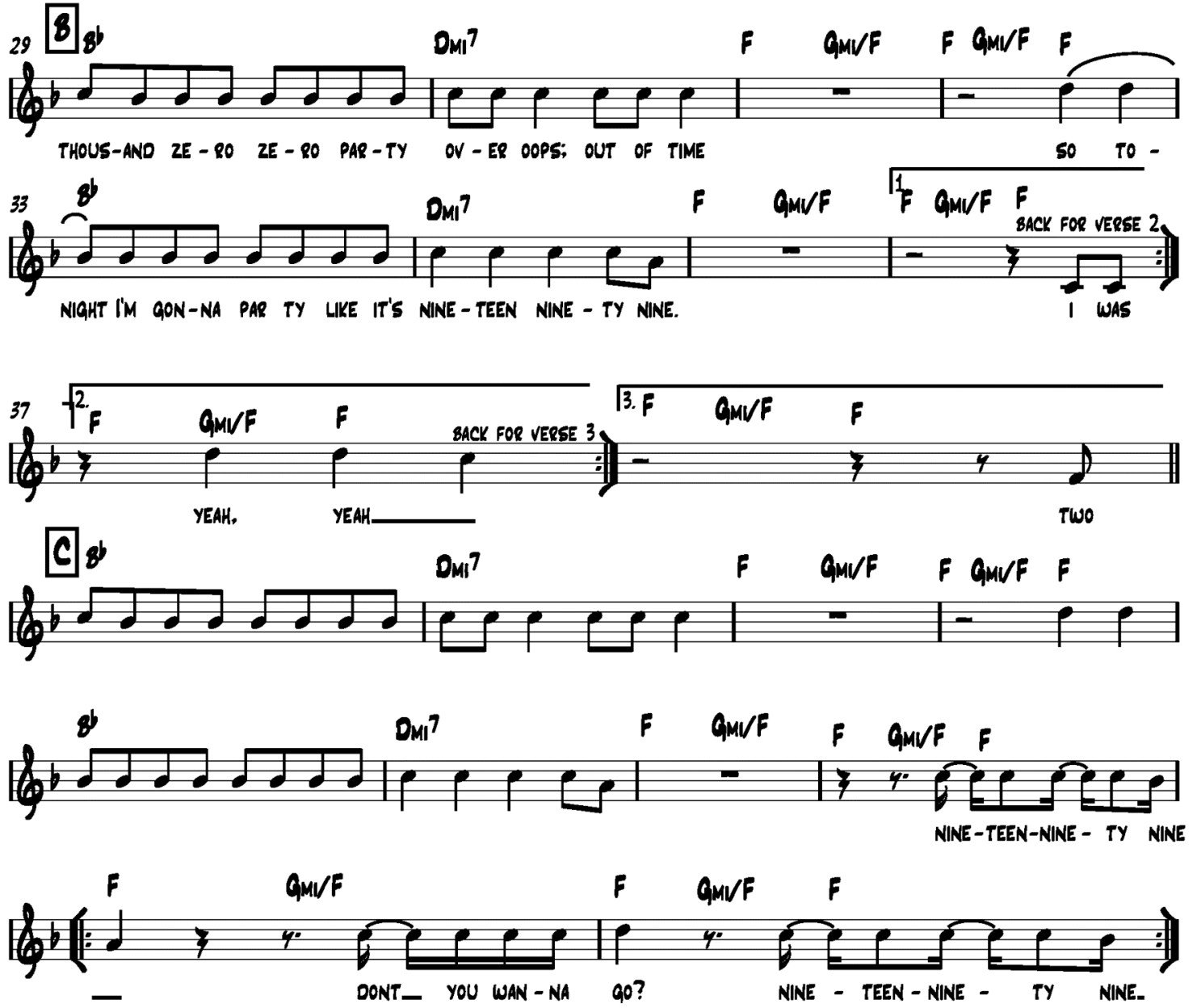

VERGE 2

I WAS DREAMIN WHEN I WROTE THIS. SO SUE ME IF I GO TOO FAST.

BUT LIFE IS LIKE A PARTY ANO PARTIEES AREN'T MEANT TO LAST.

WAR IS ALL AROUND US MY MINO SAYS PREPARE TO FIGHT,

SO IF I GOTTA DIE IM GONNA LISTEN TO MY BOOY TO NIGHT.

(TO CHORUS)

VEREE3

IF YOU DIDN'T COME TO PARTY SONT BOTHER KNOCKIN ON MY DOOR.

IVE GOT A LION IN MY POCKET AND BABY. HE'S READY TO ROAR.

EV'RYBOOYS GOT A BOMB, WE COULO ALL OIE ANY DAY,

BUT BEFORE I'LL LET THAT HAPPEN, ILLL DANCE MY LIFE AWAY. 


\section{Appendix 3}

Scores of Transcriptions - Part Two 


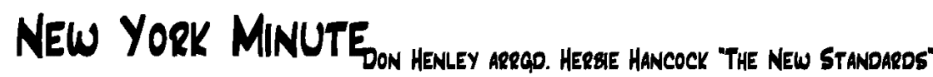

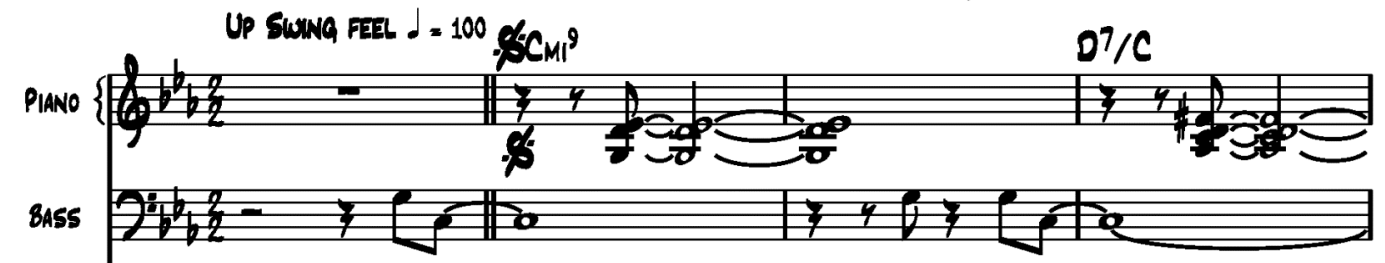
UP SUWVG FEEL $d=100 \%$

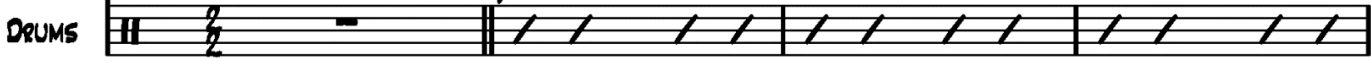

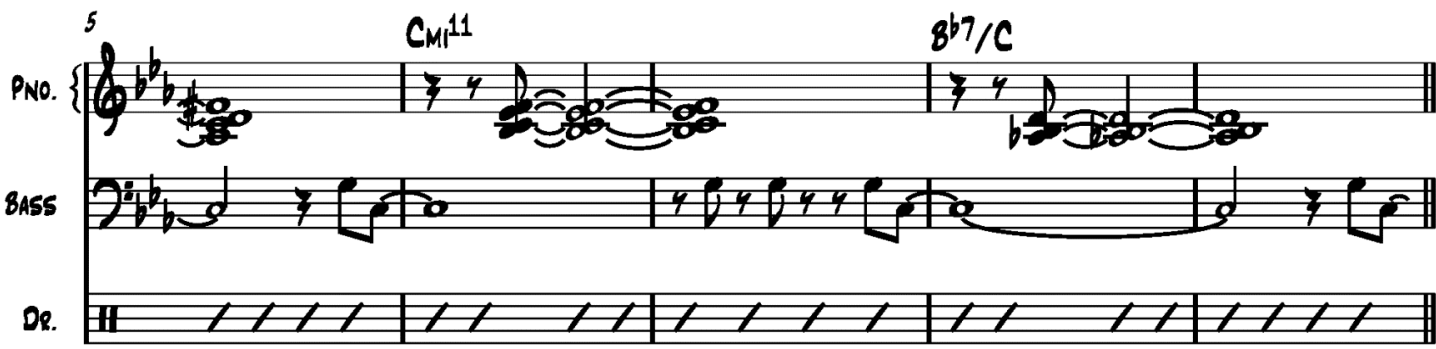

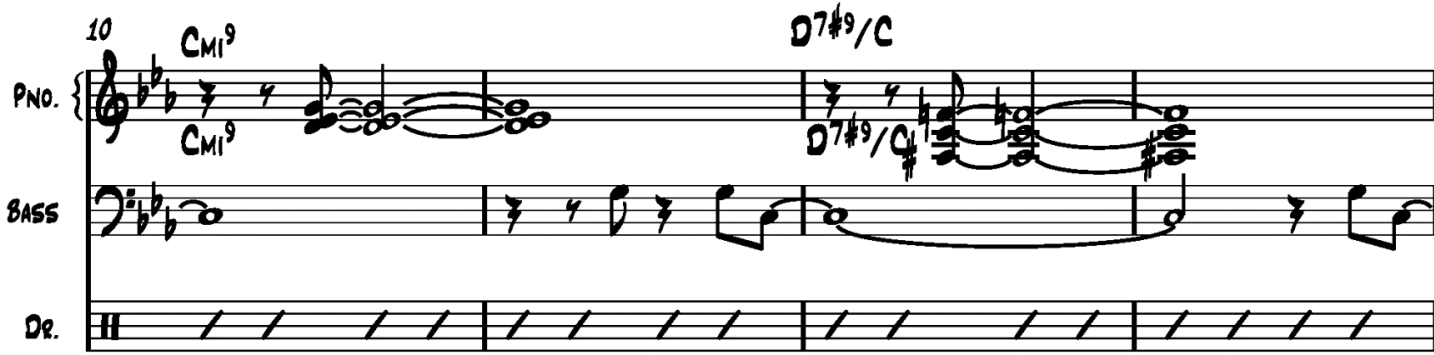
$14 \mathrm{CM}_{11}^{11} \quad B b^{7} / \mathrm{C}$

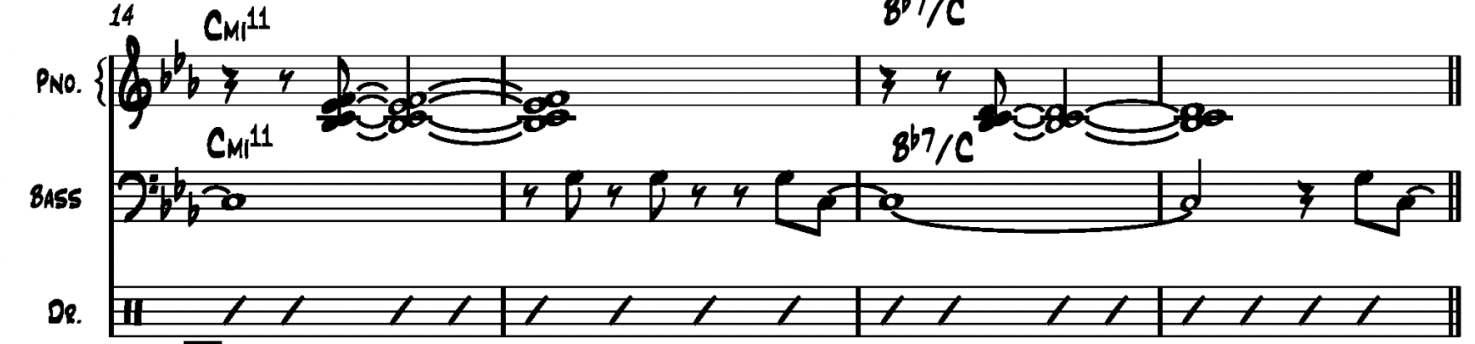
TEN. SAX. 
2

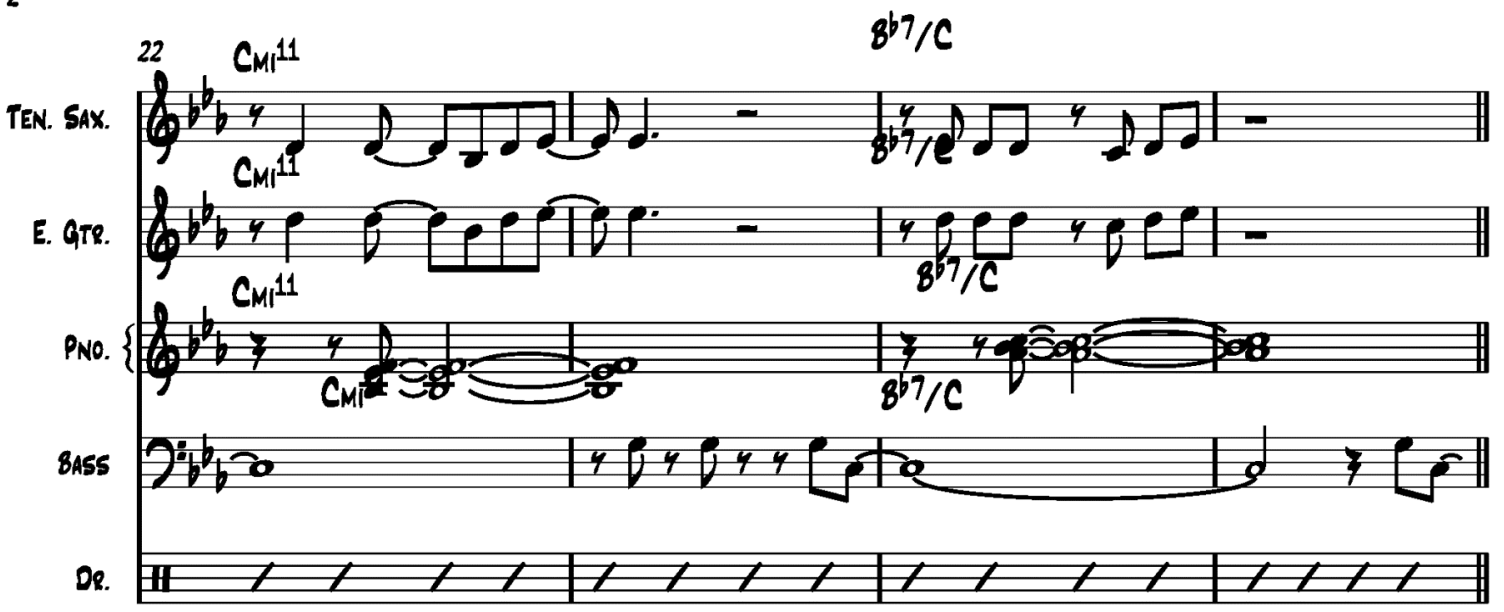

PR.

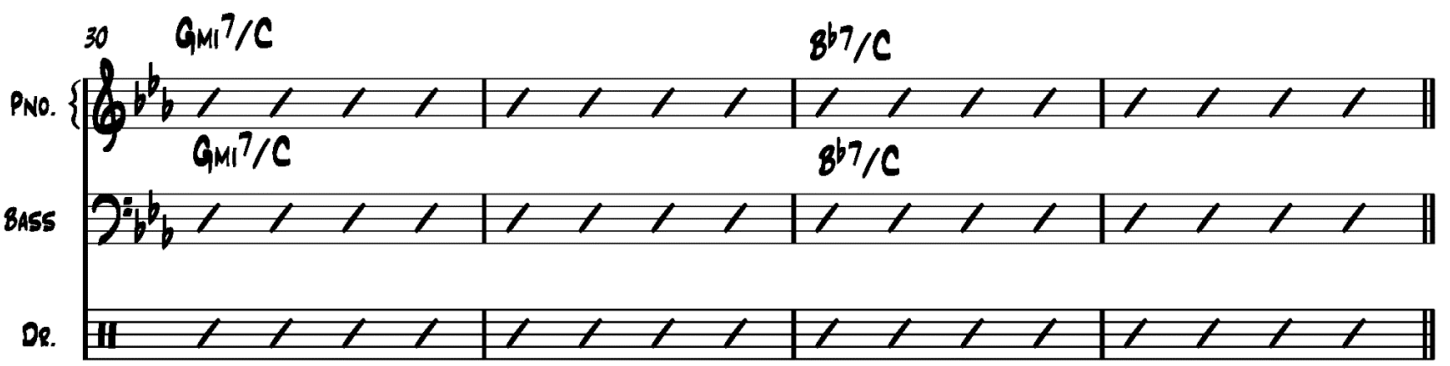

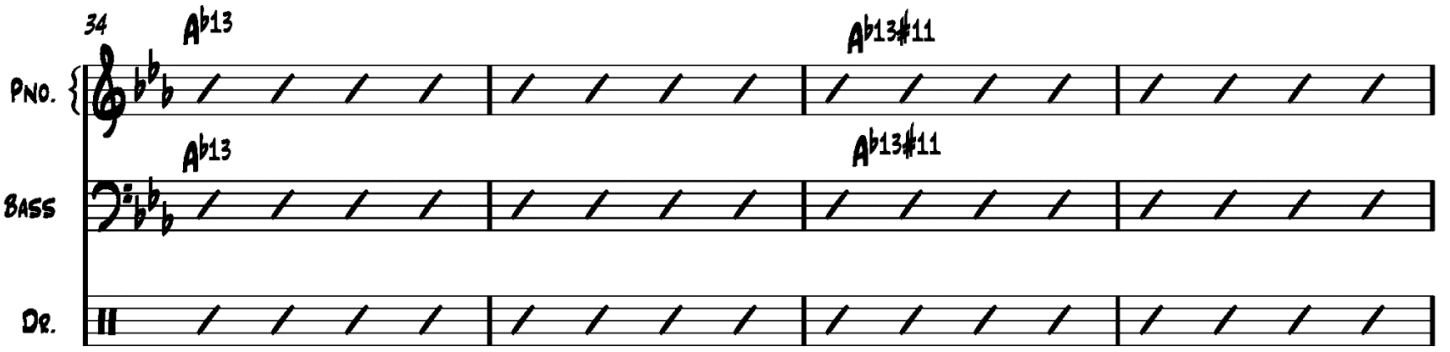

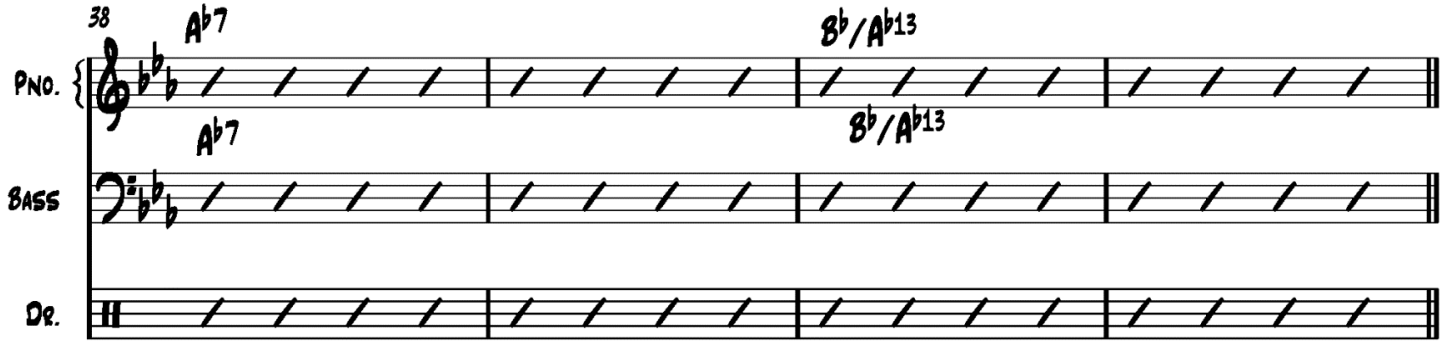



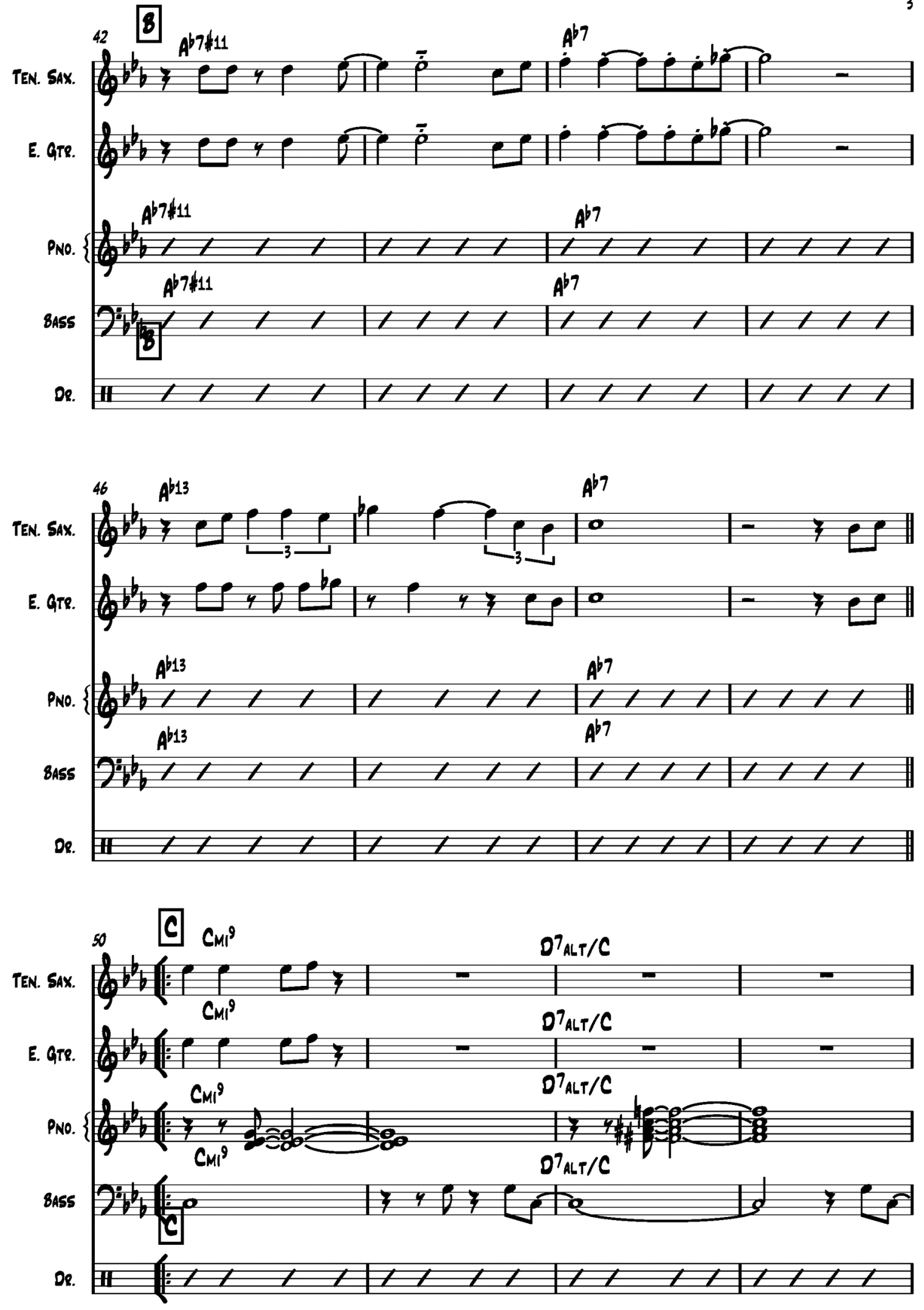


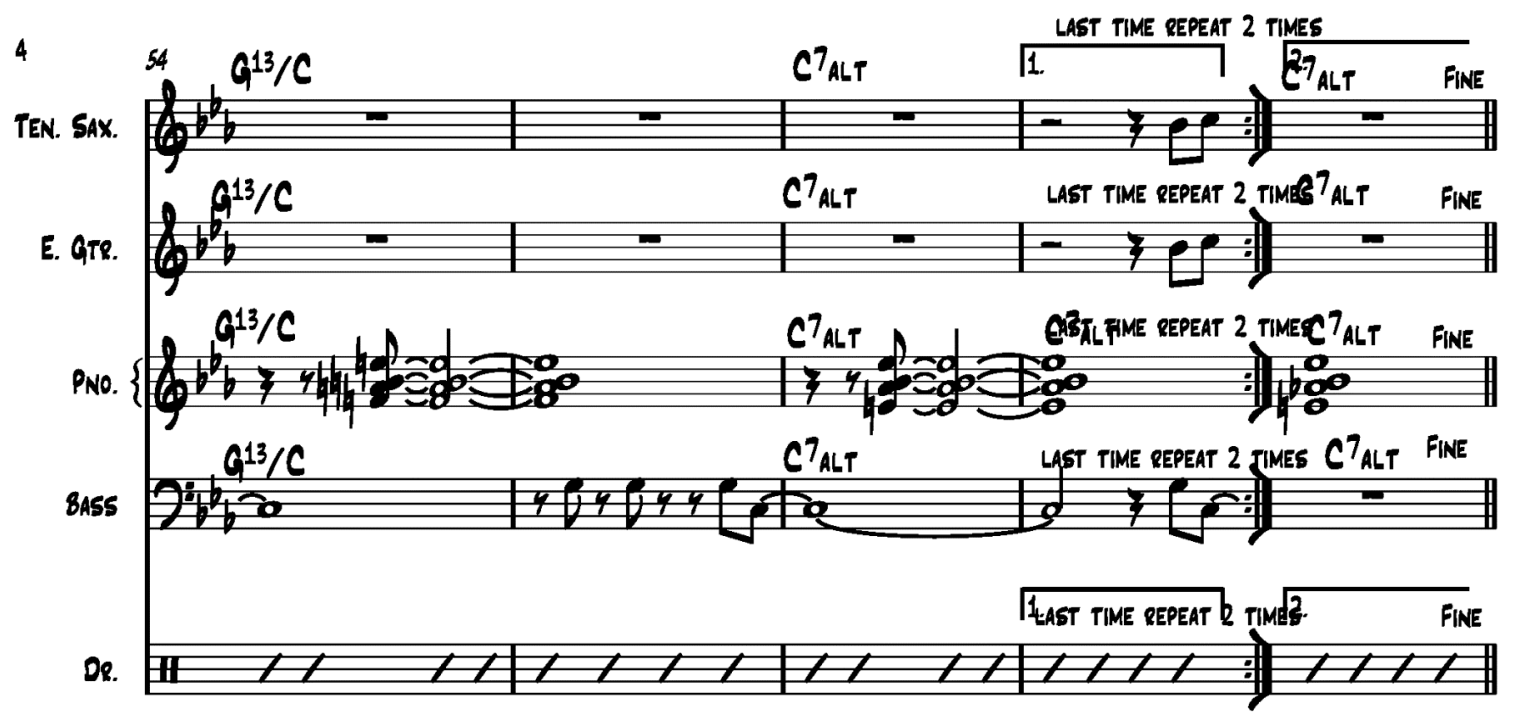

0

TEN. SAX.

E MI

F MI

E. Gre.

$$
\text { FIT GOES INTO SUING FEEL, COMP }
$$

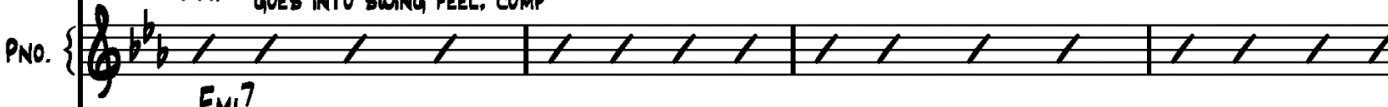

F MI! ${ }^{\text {SUN MG FELL, BASS WALKS }}$

BASS

De.

0

D.

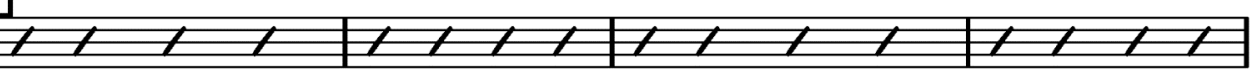

TEN. SAX.

E. GTe.

Pro. \{

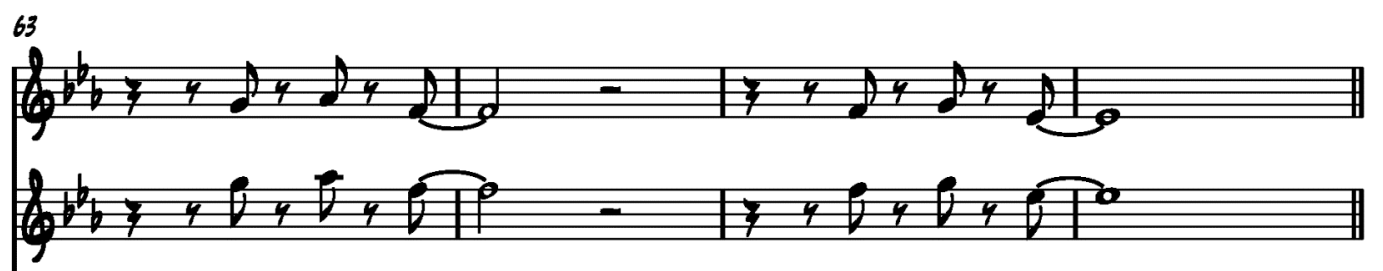

BASS

De.

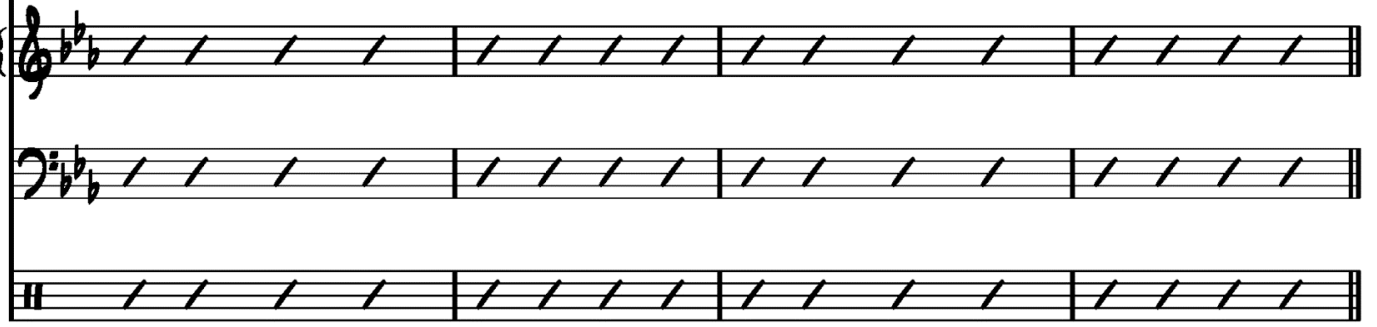

147 

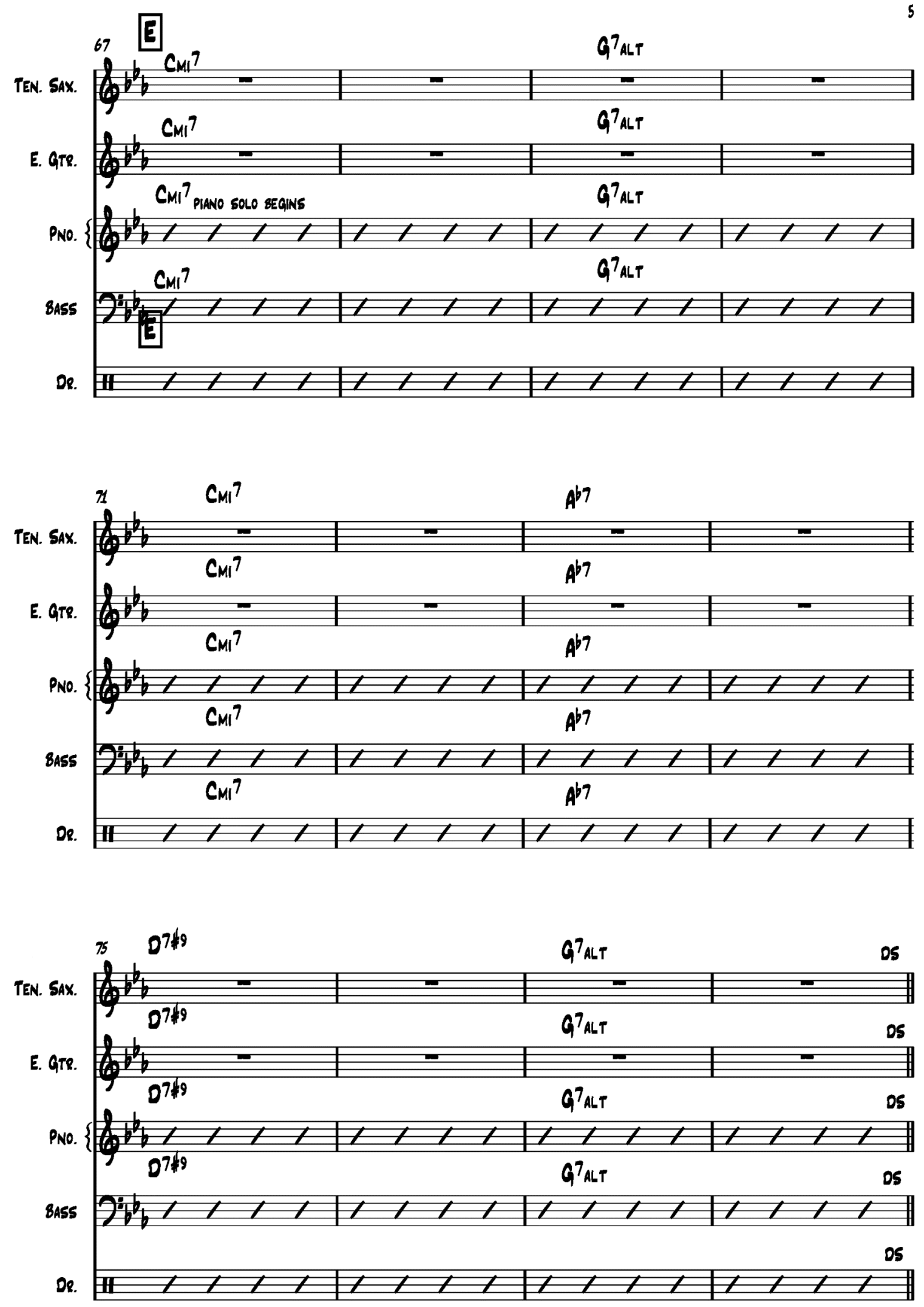

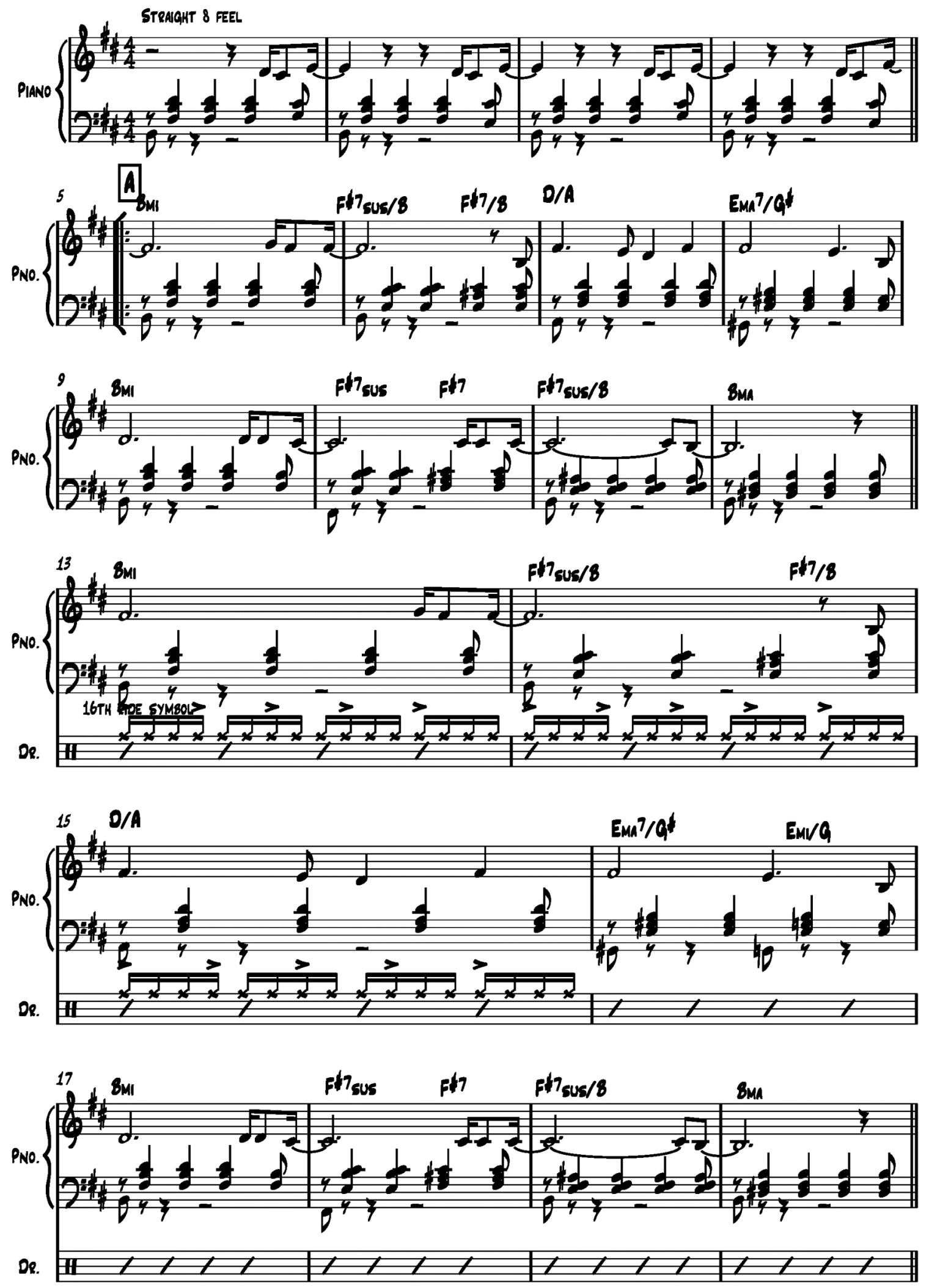
2
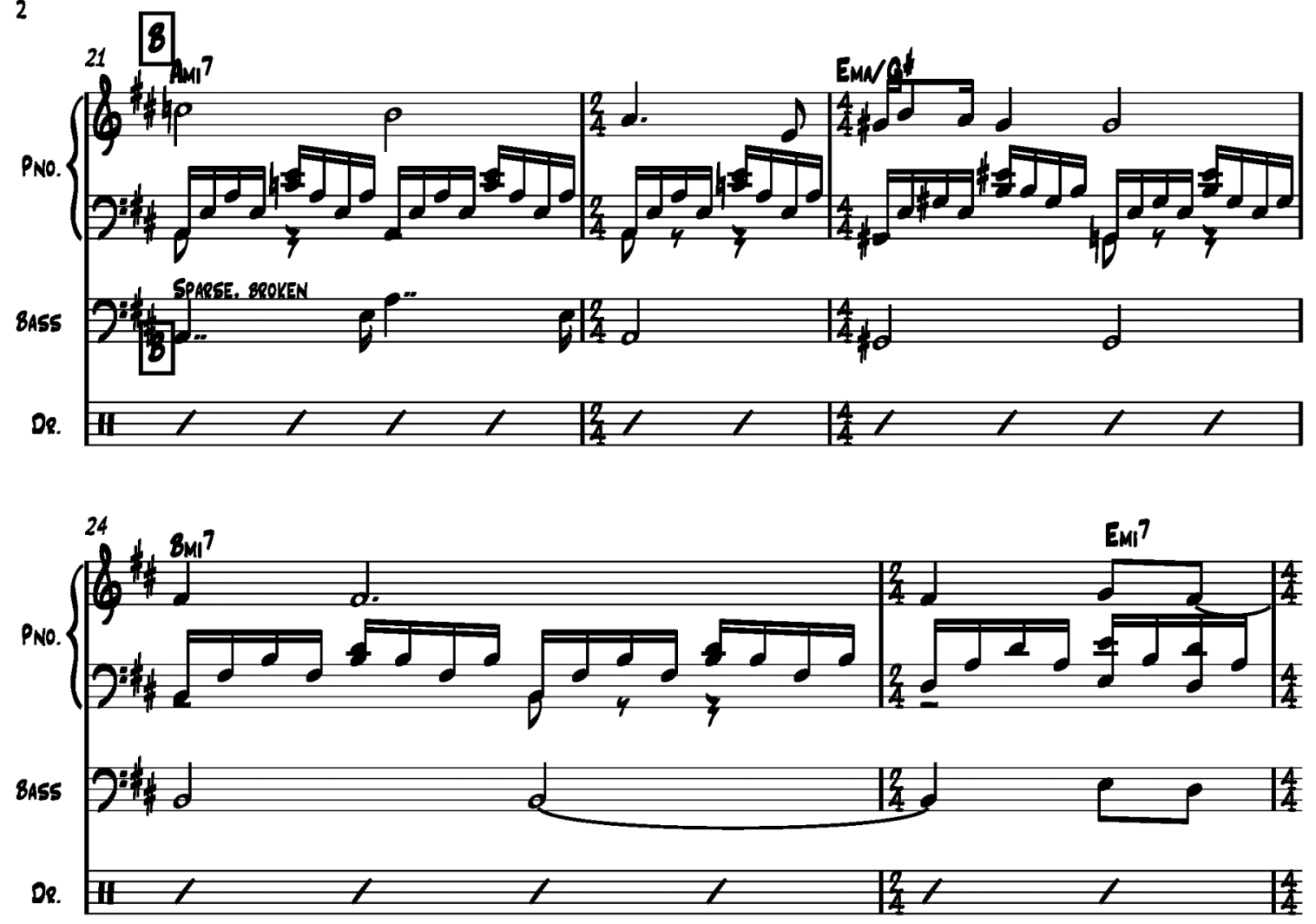

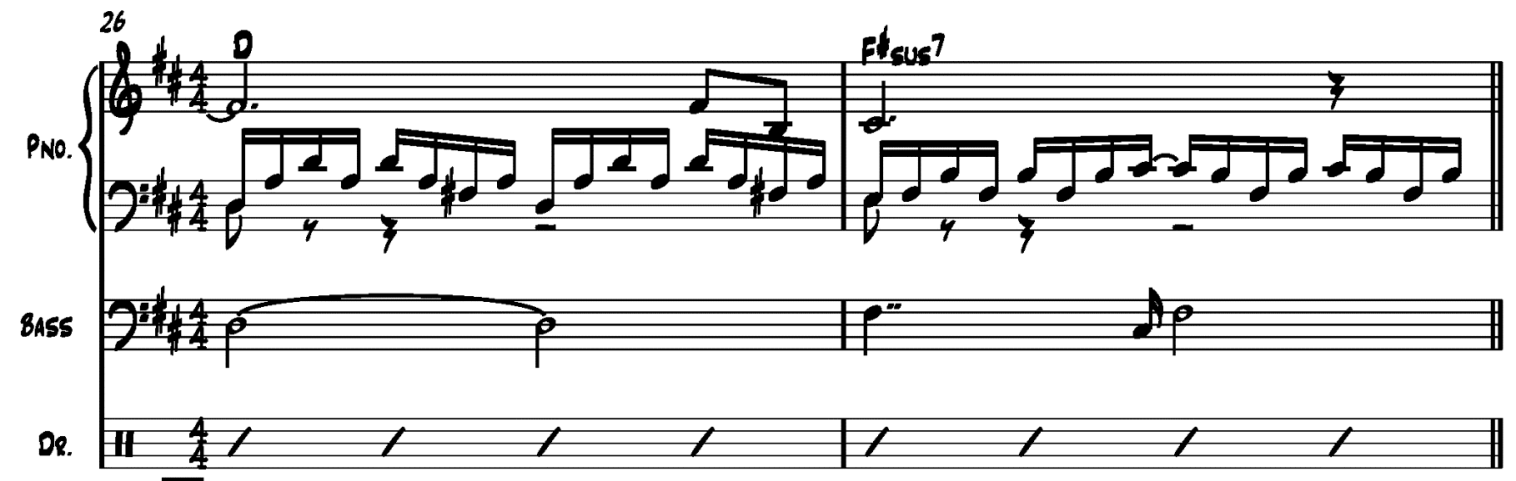

C

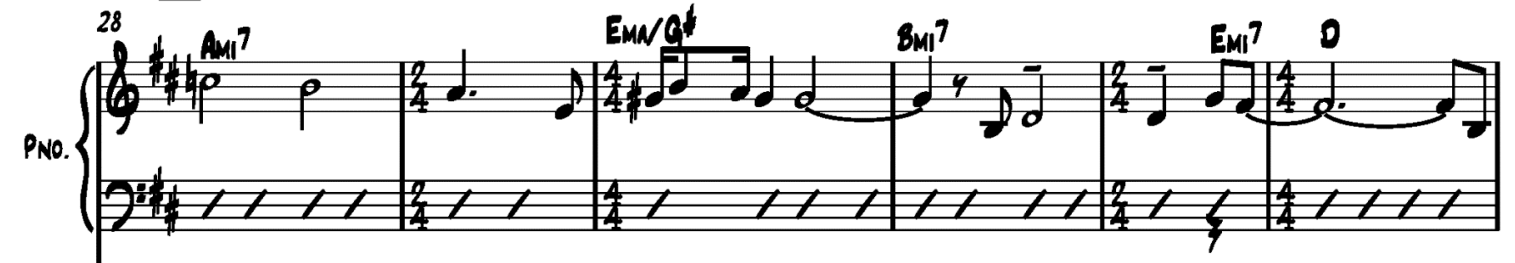

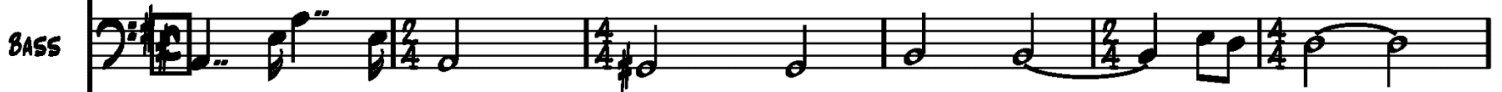

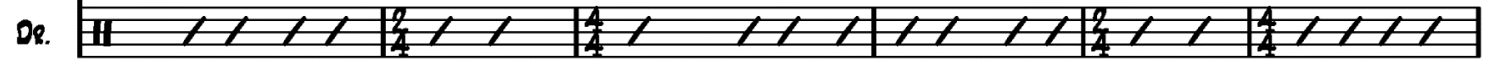


3
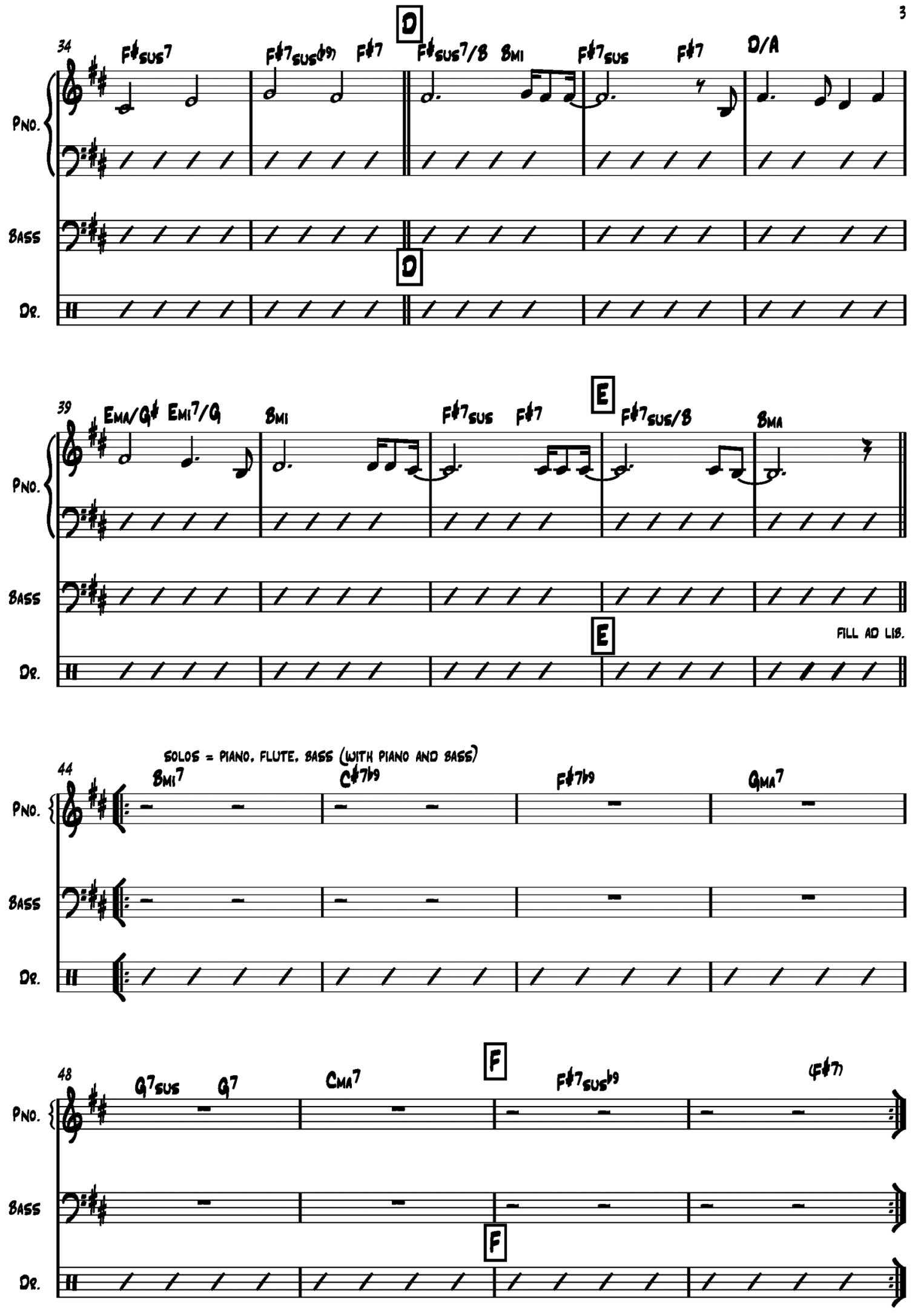

151 

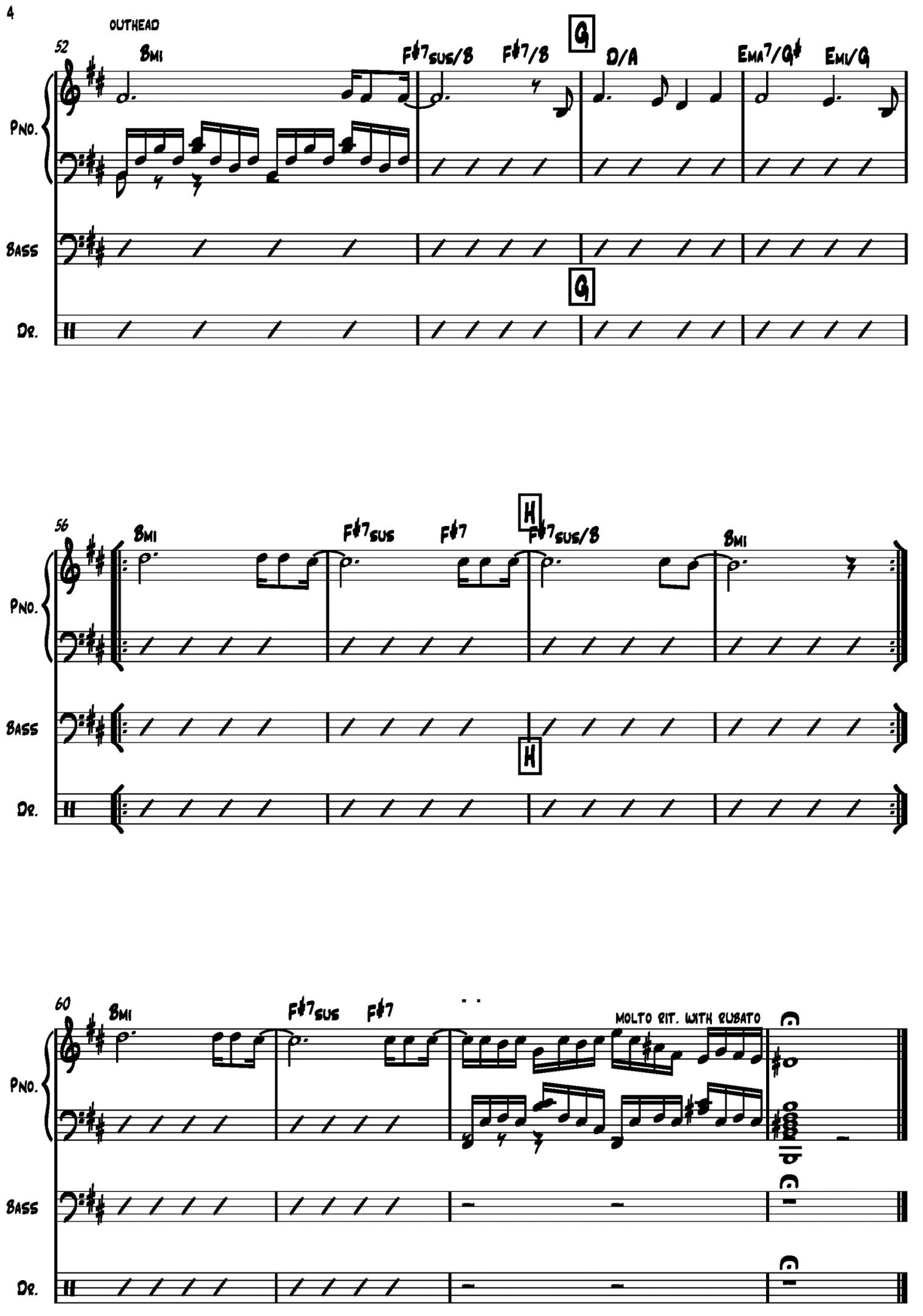

152 

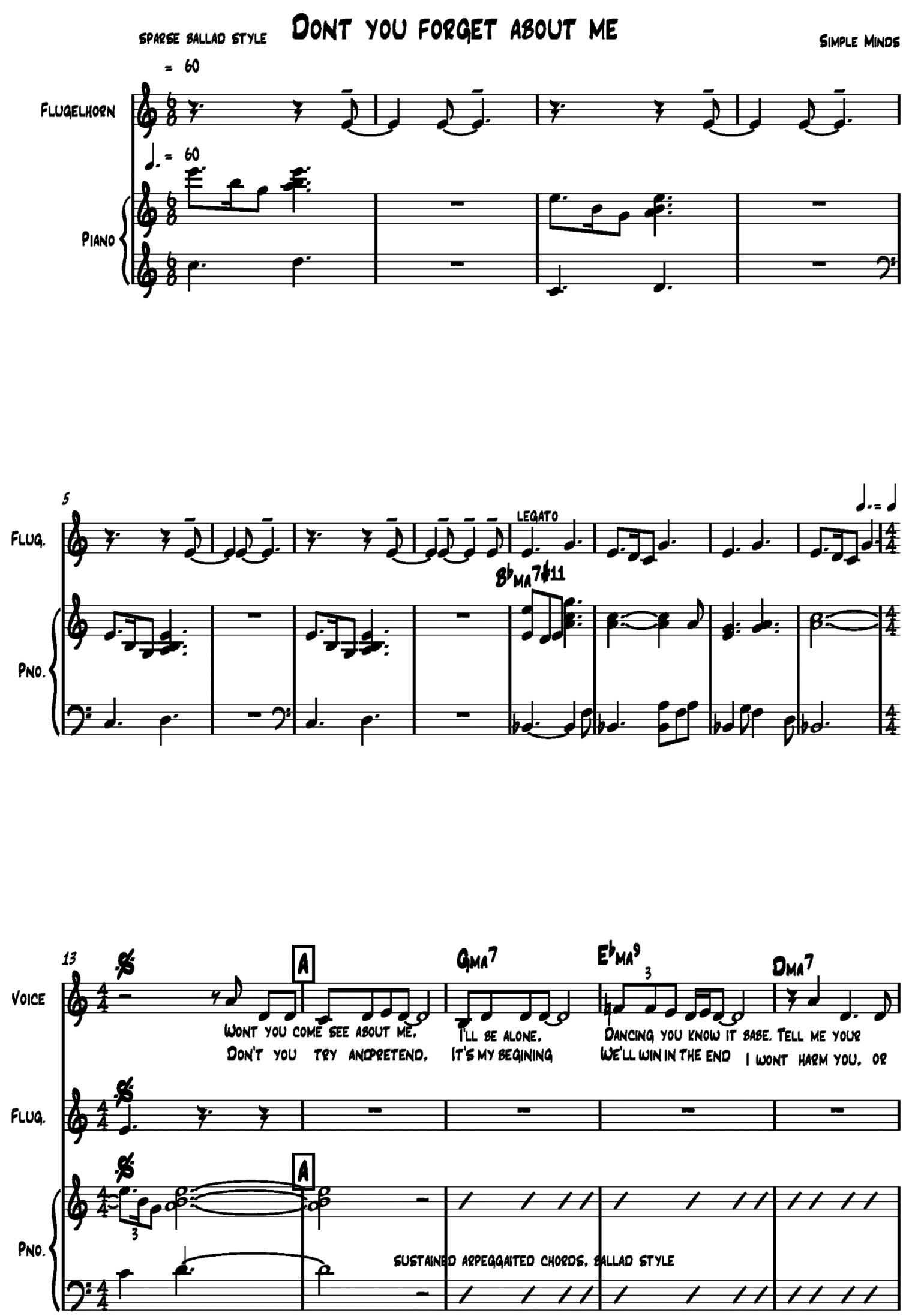
2
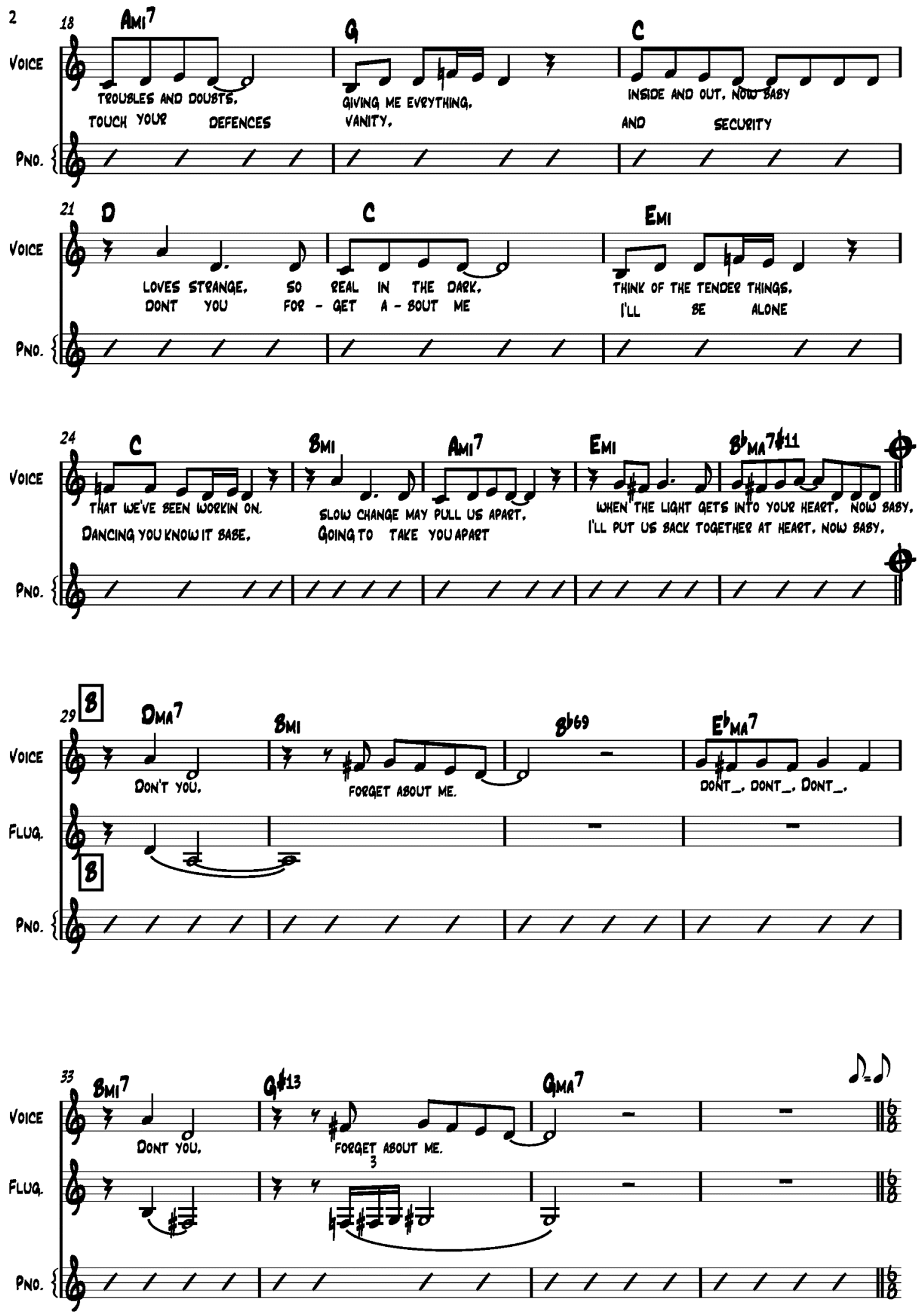

154 
BRIDGE + SOLO SECTION

Fiva.
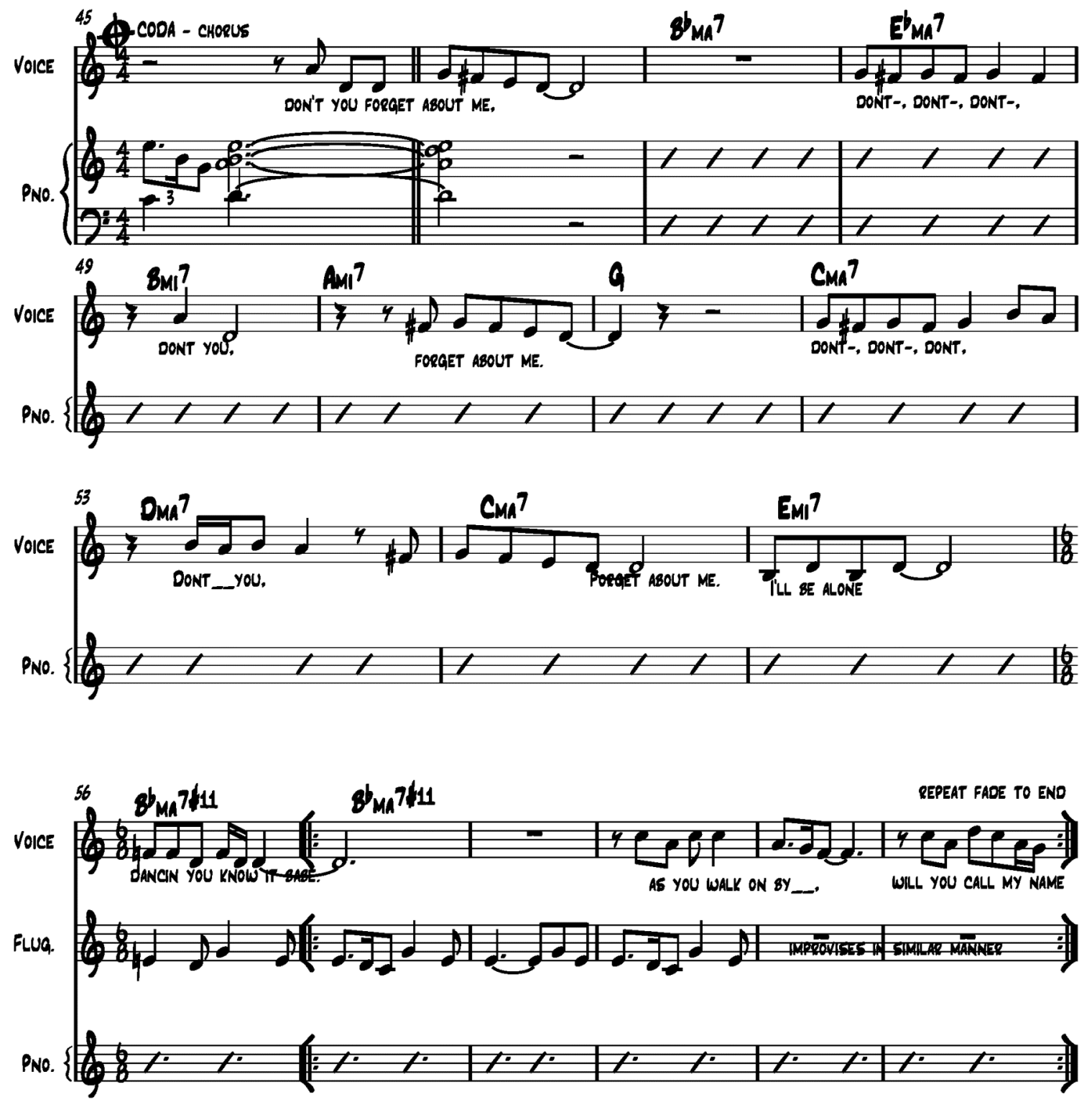
Electric Guitar COME AS YOU ARE
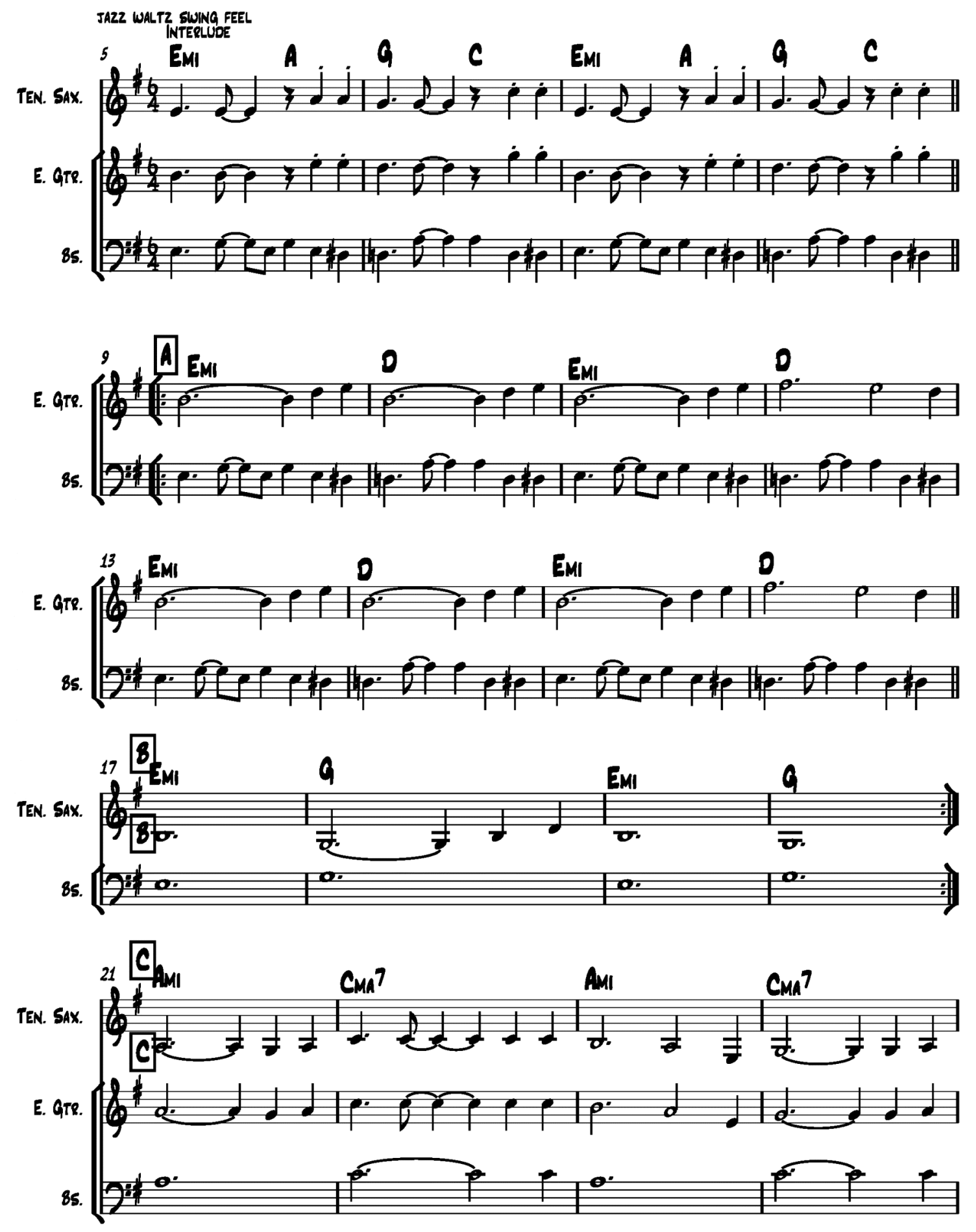

156 
2
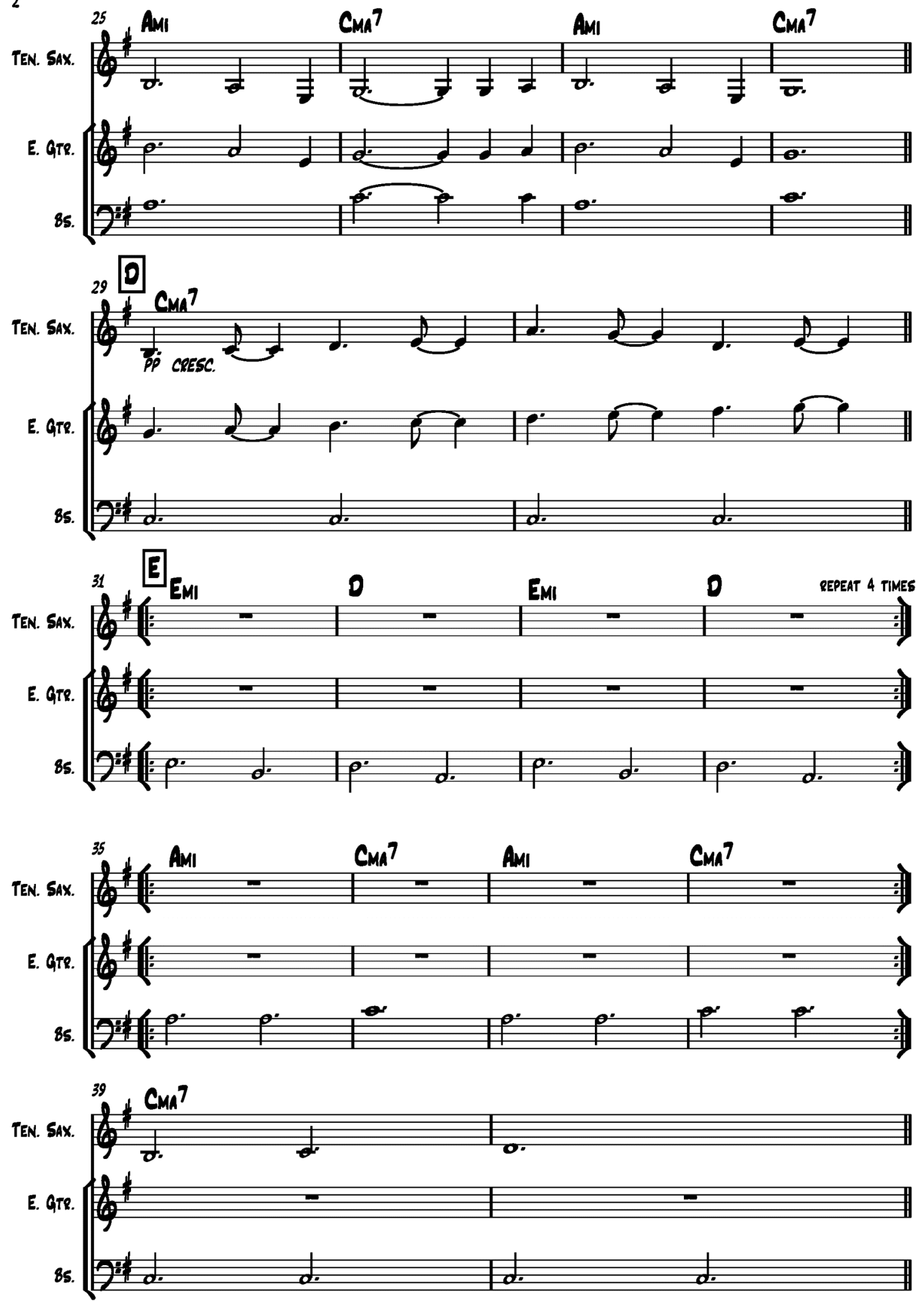

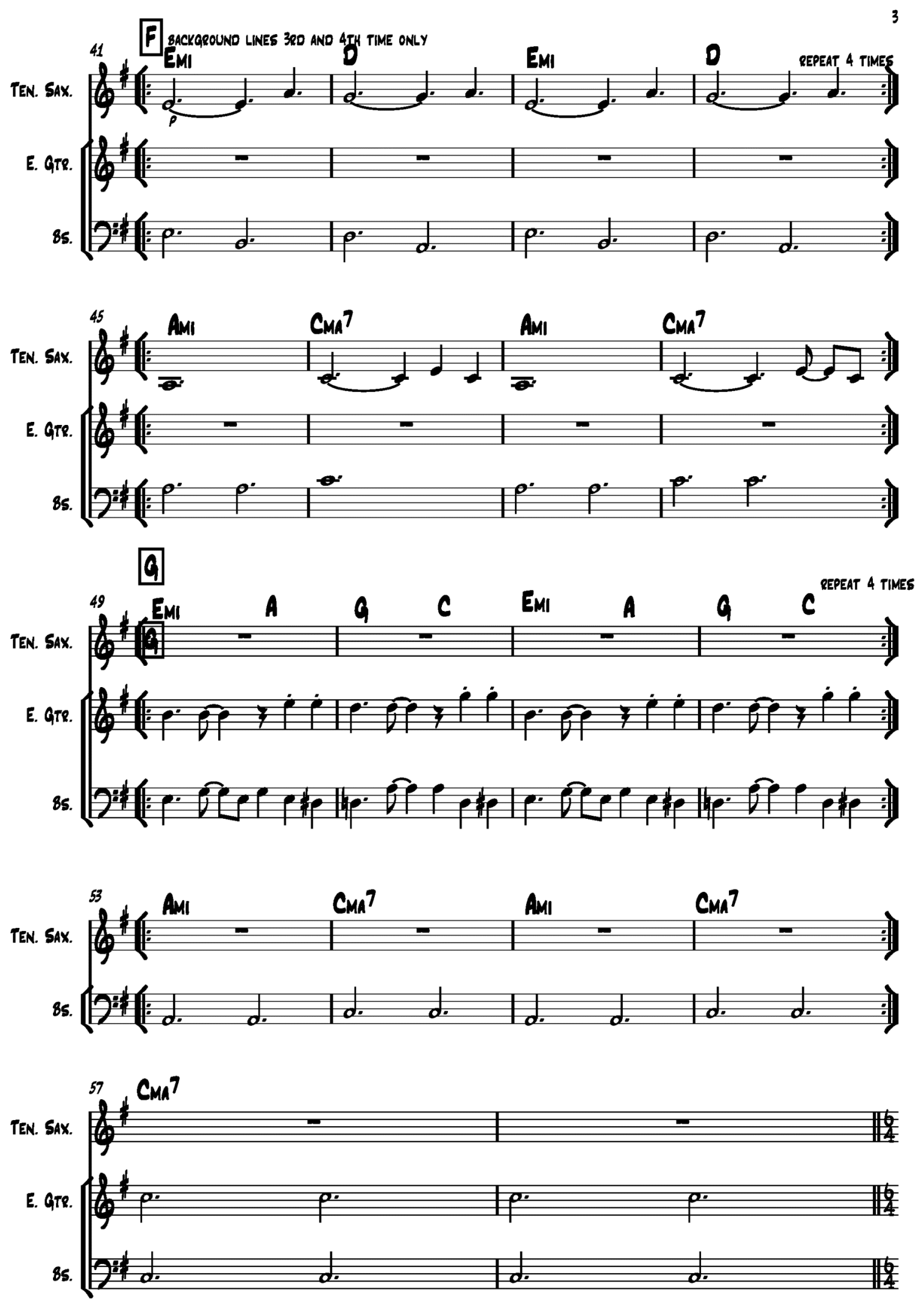

158 
4

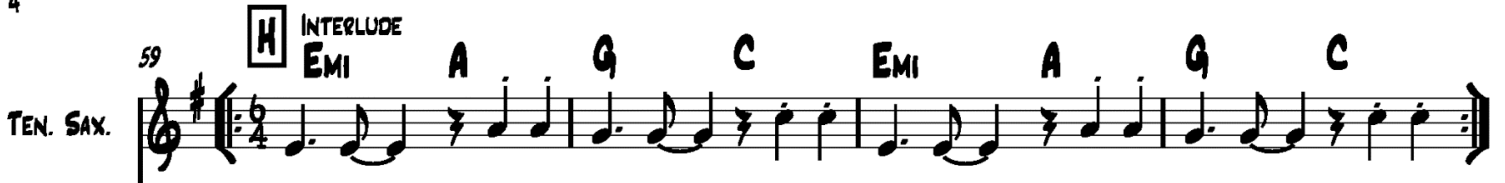

E. Gre.

E. ate
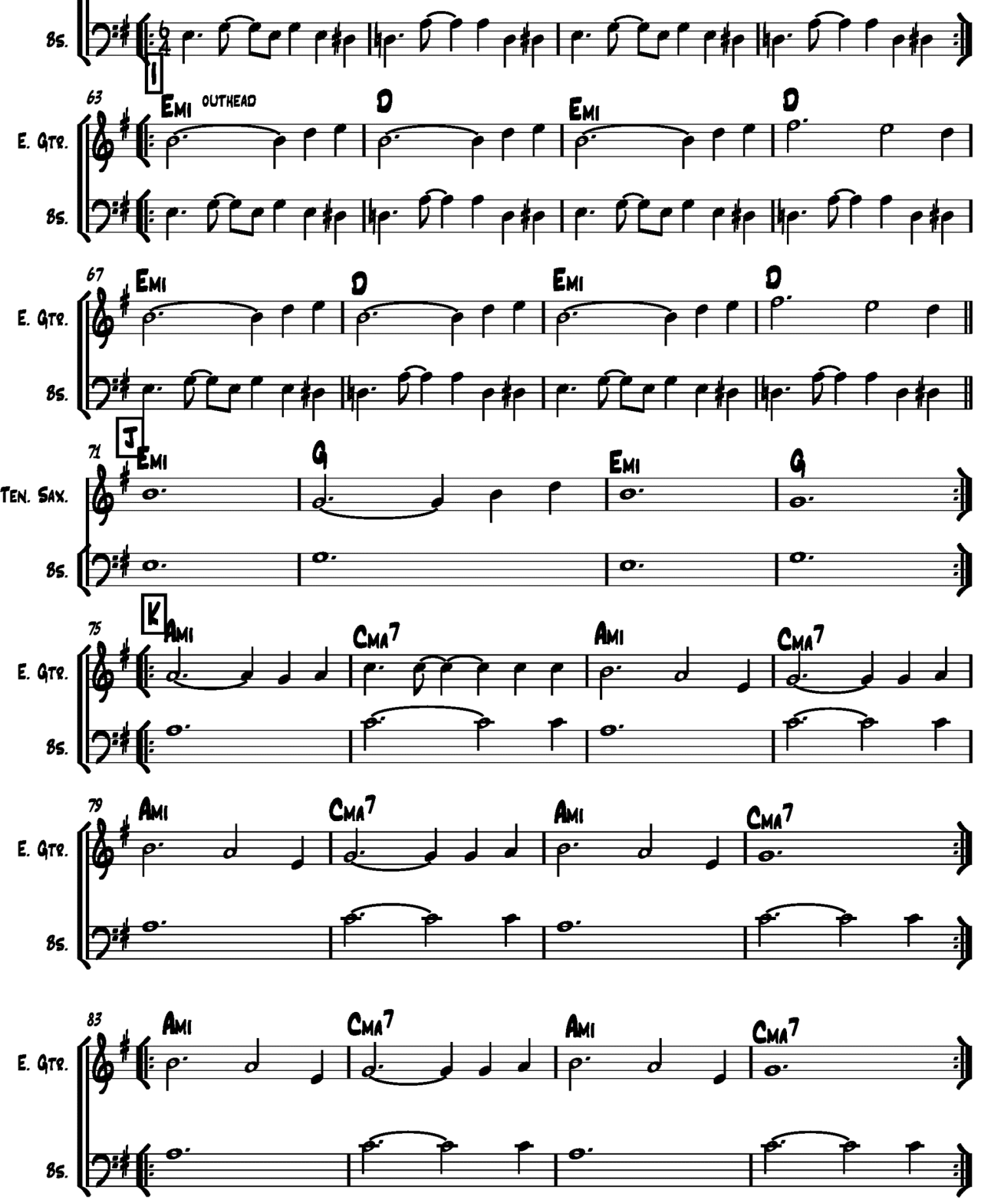

159 

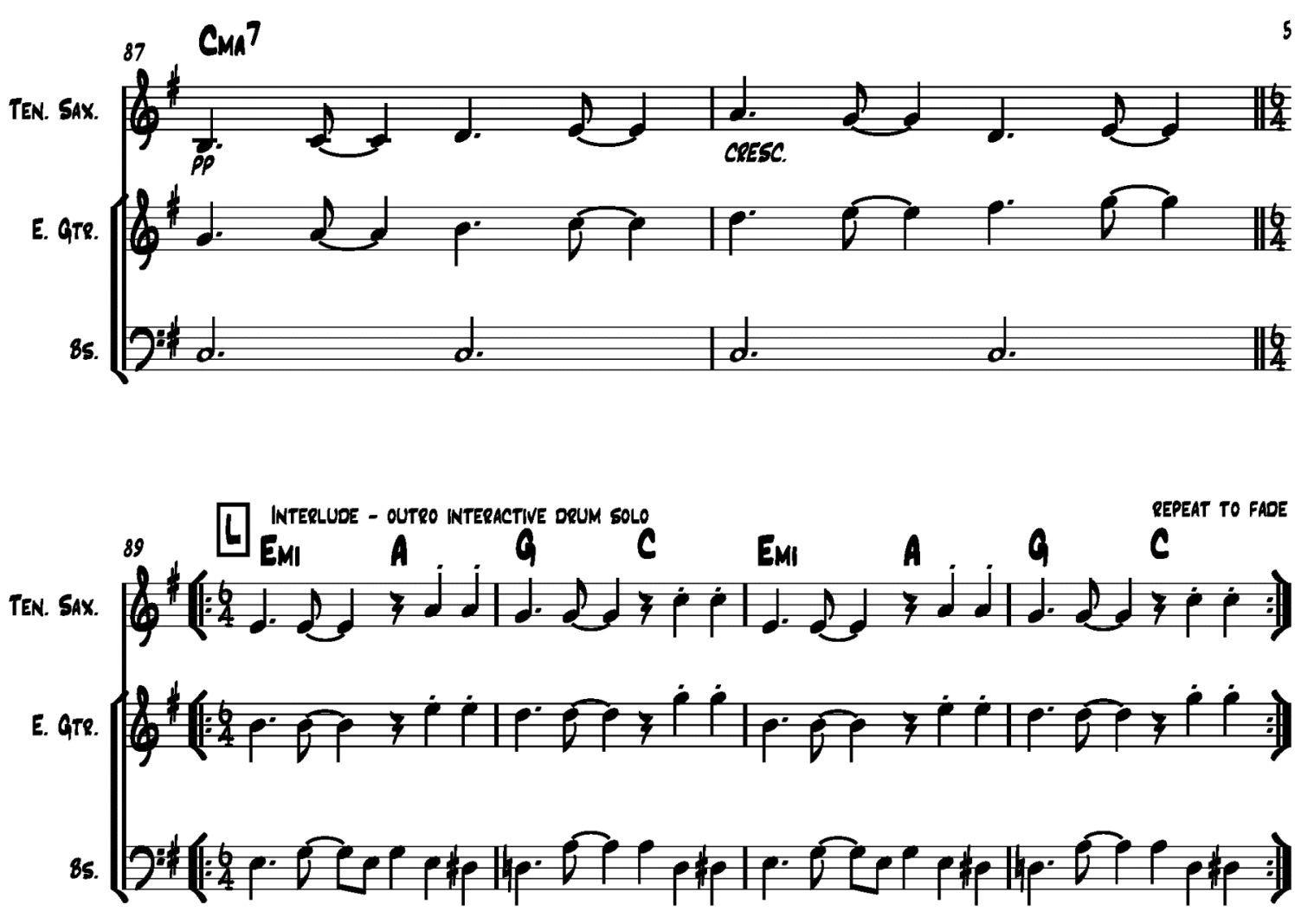

160 


\section{LIKE A VIRGIN}
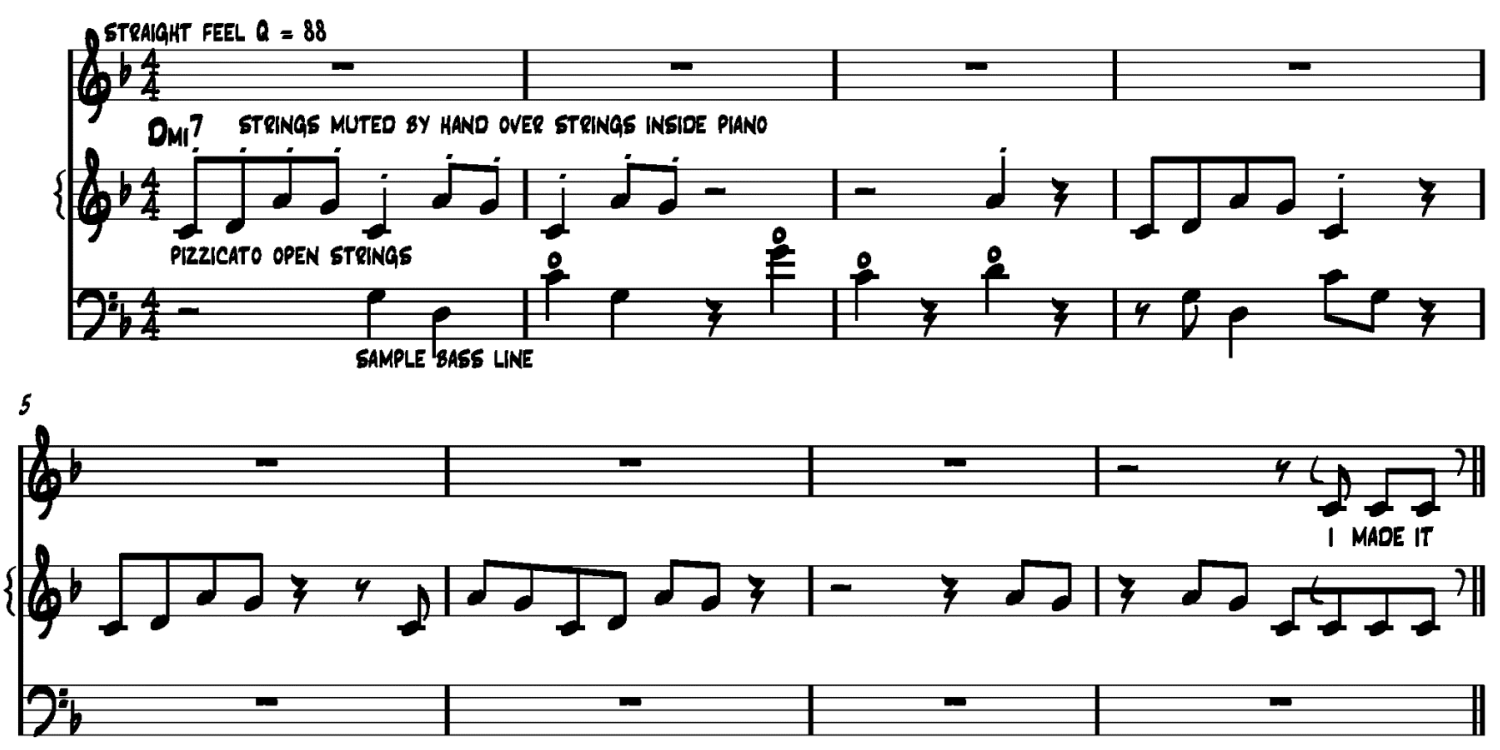

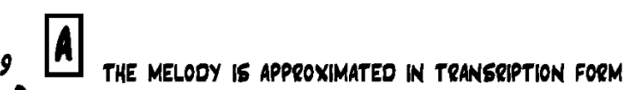
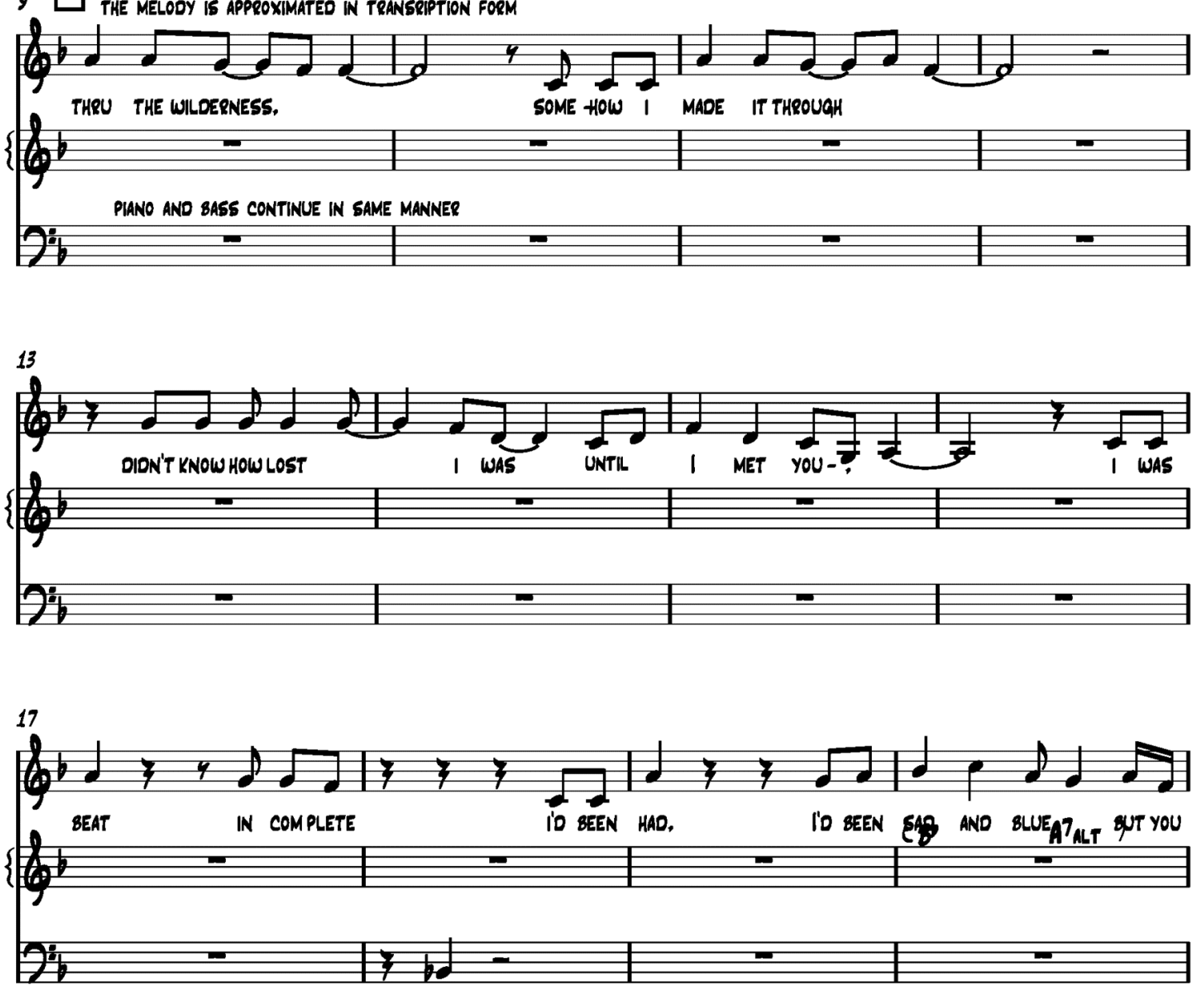
2
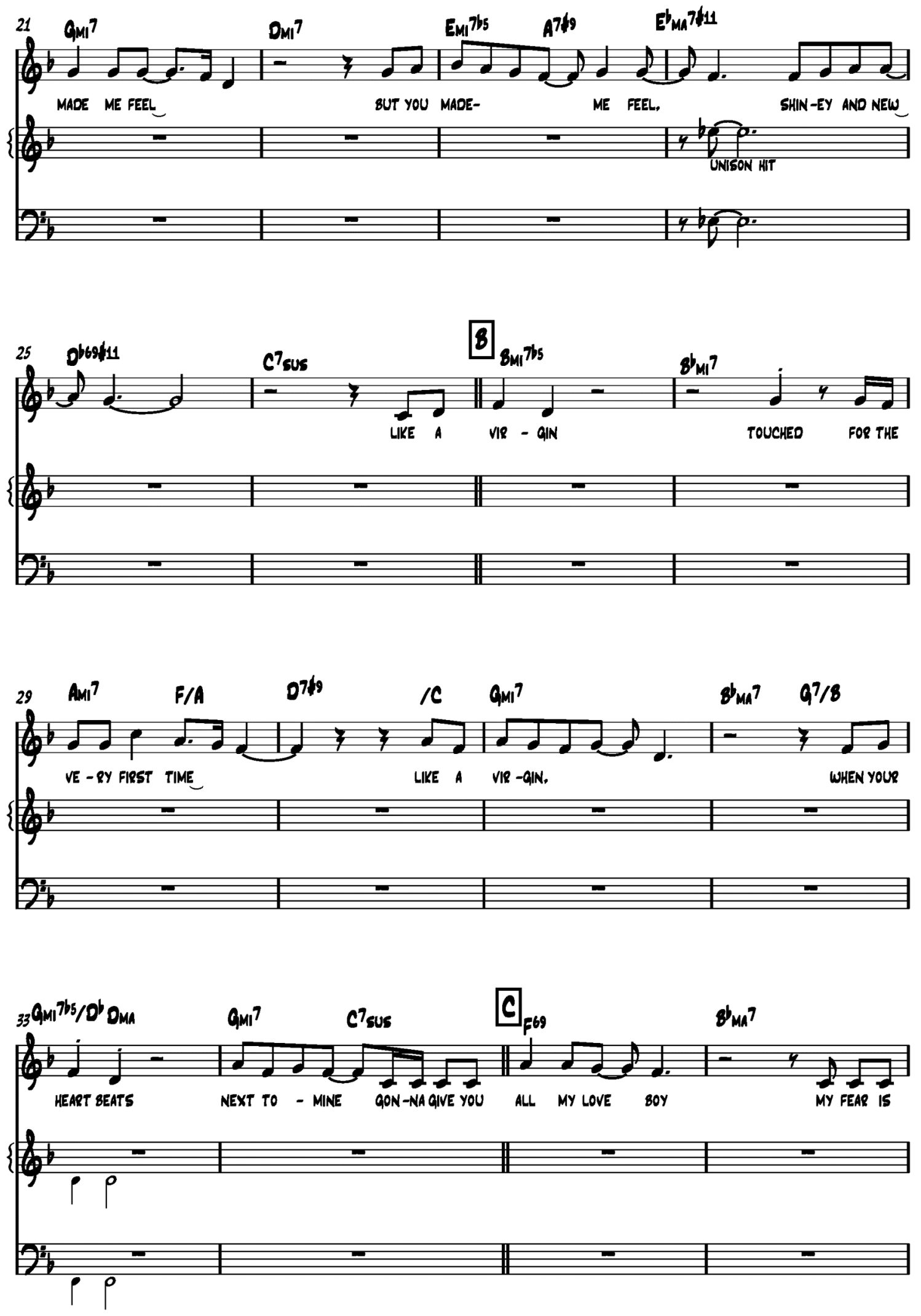

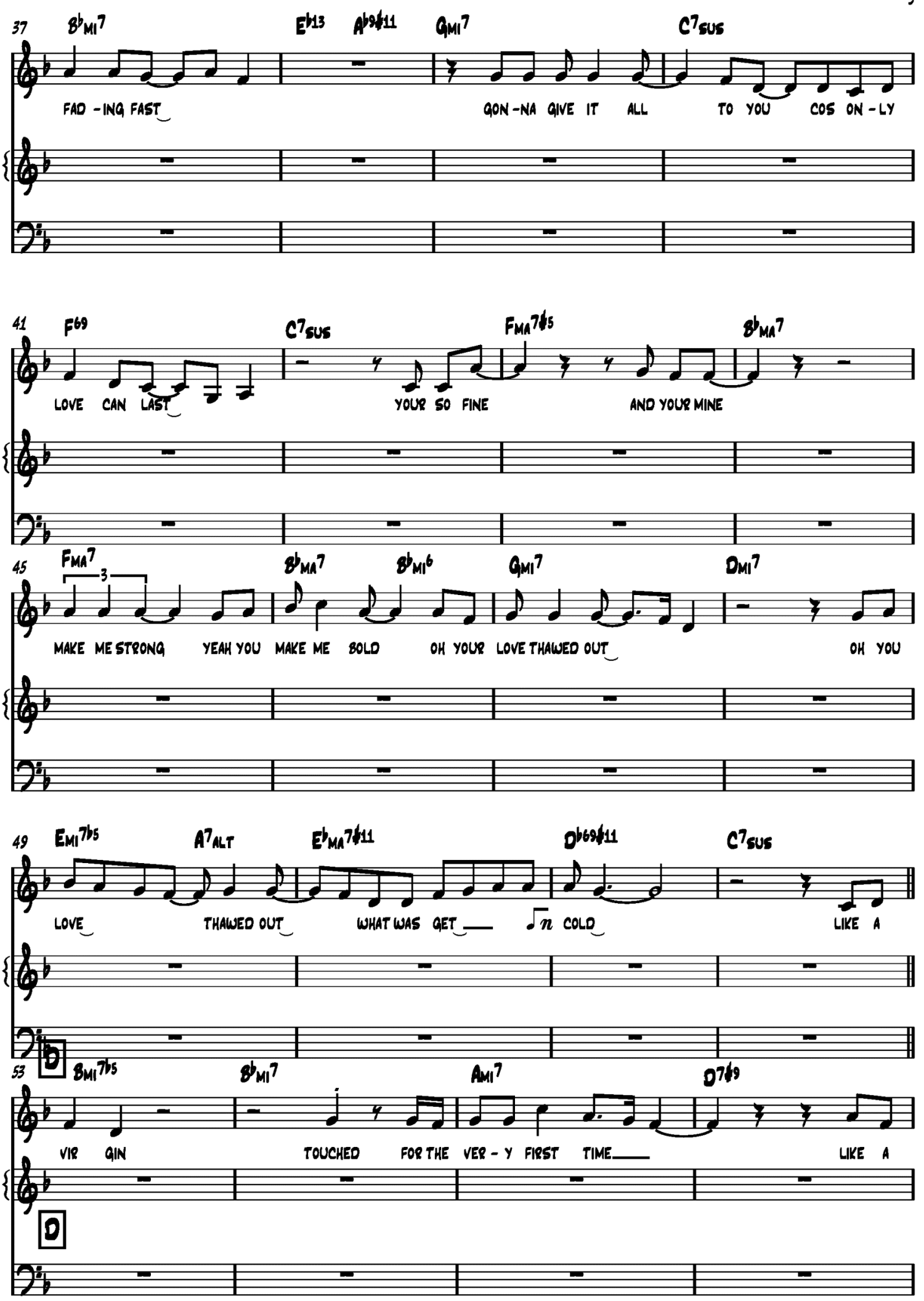
4
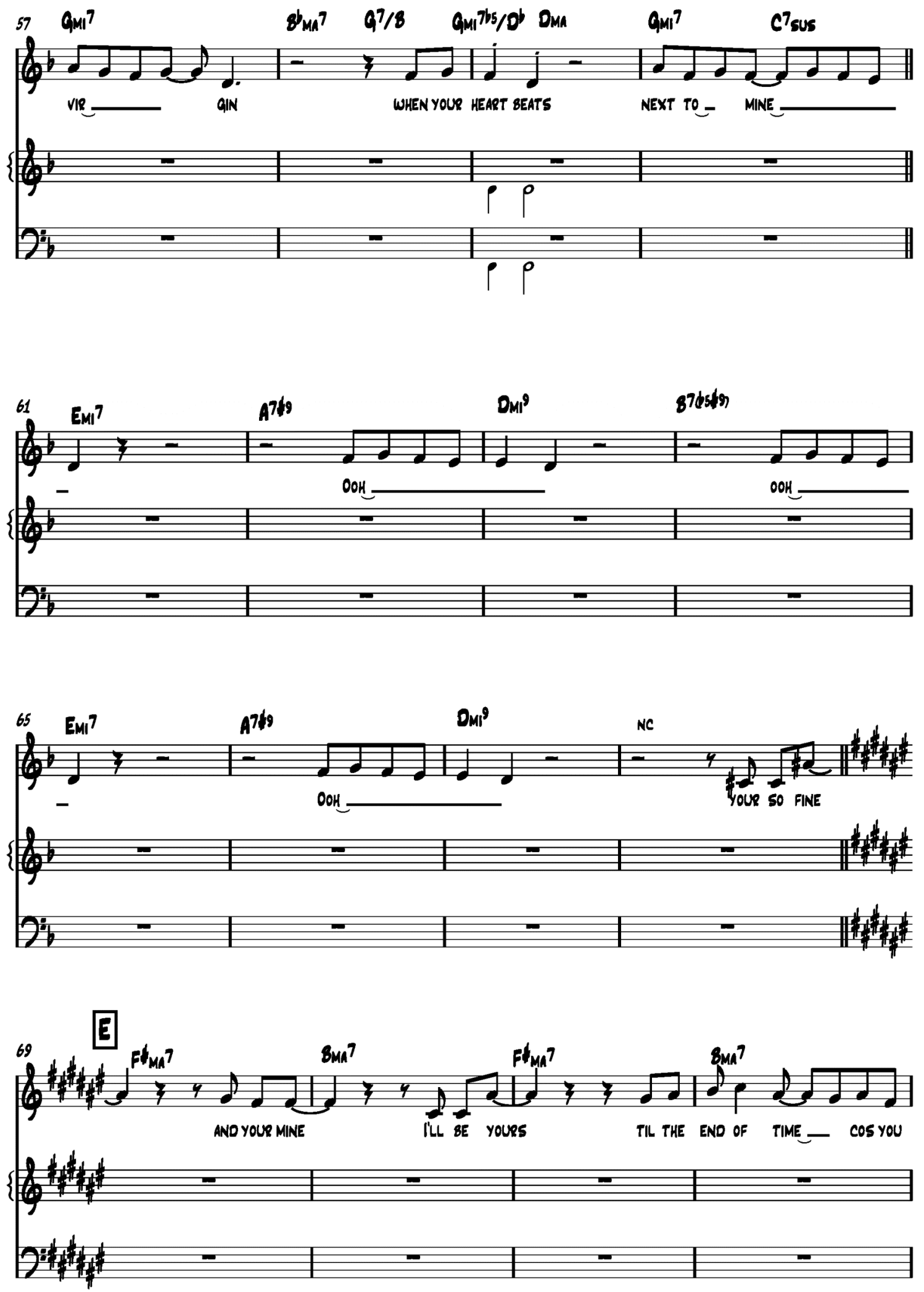

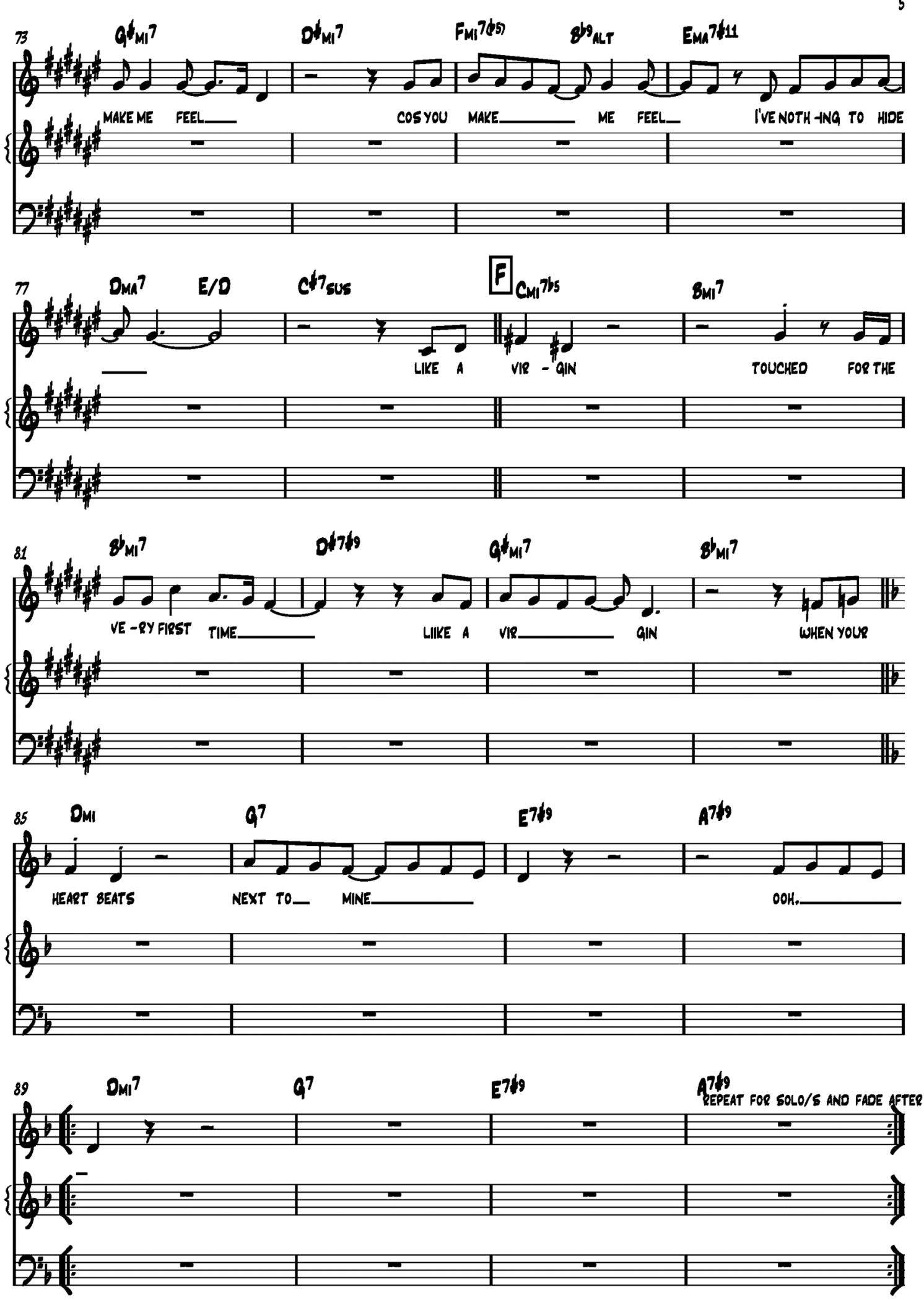

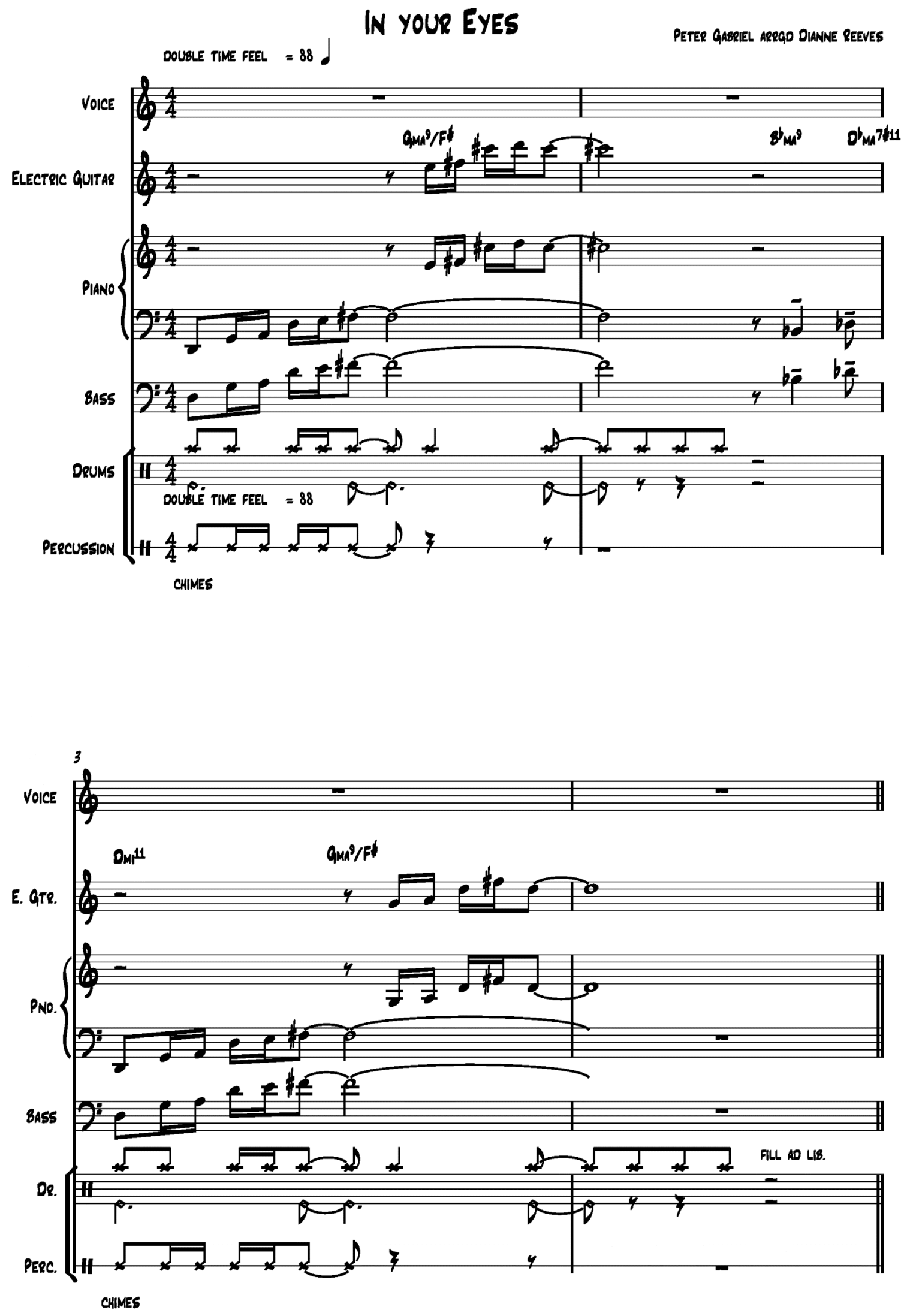

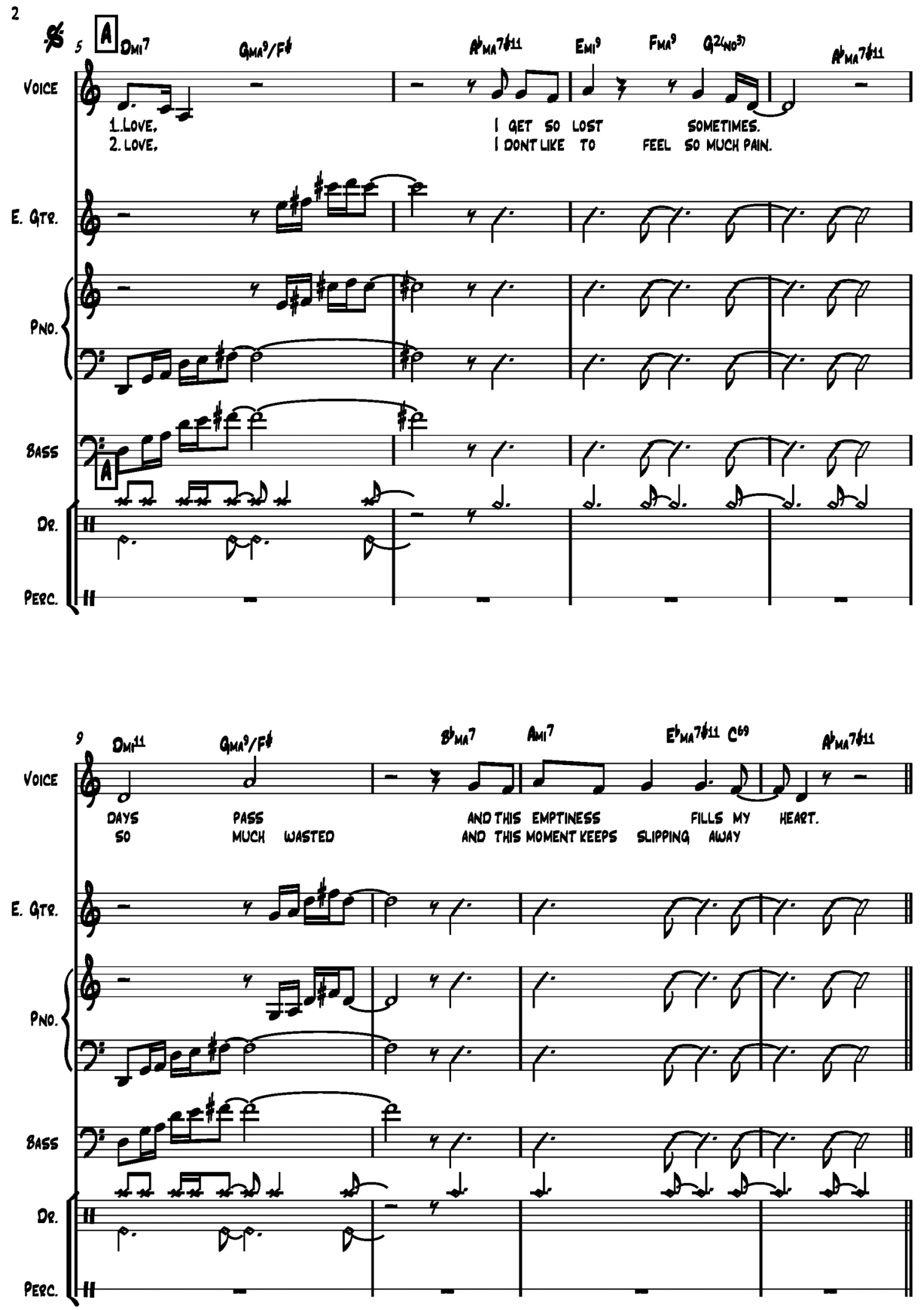

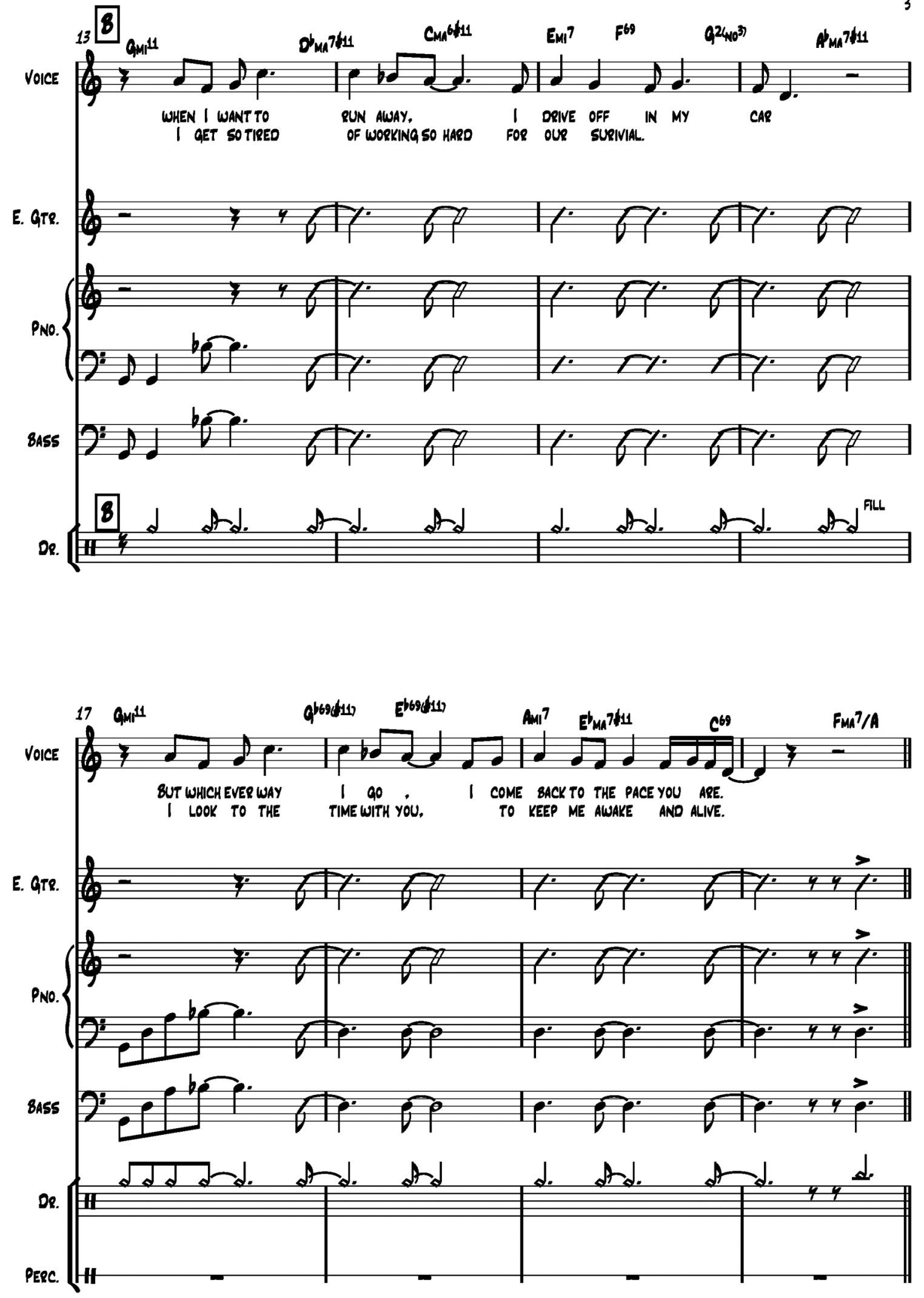

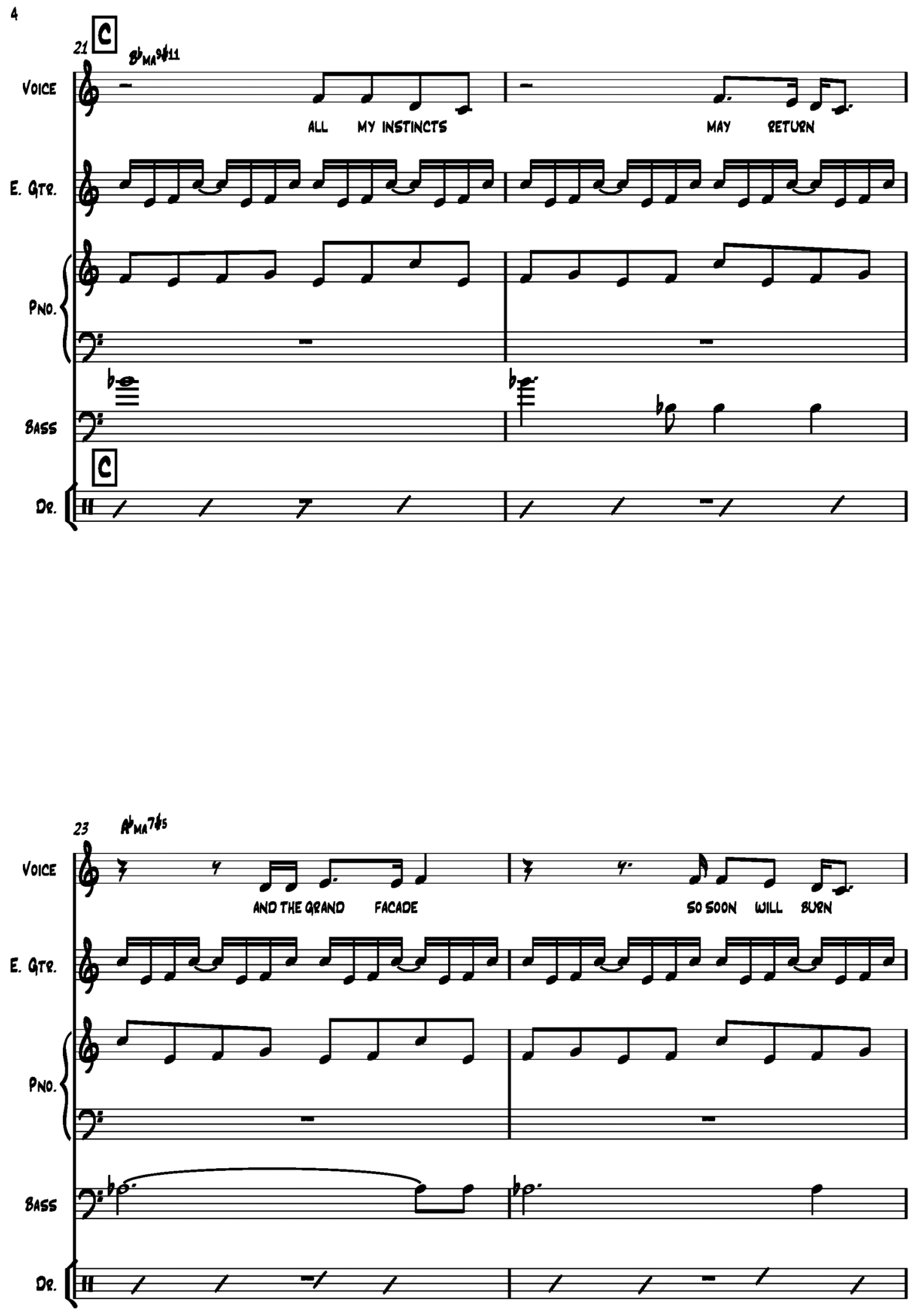

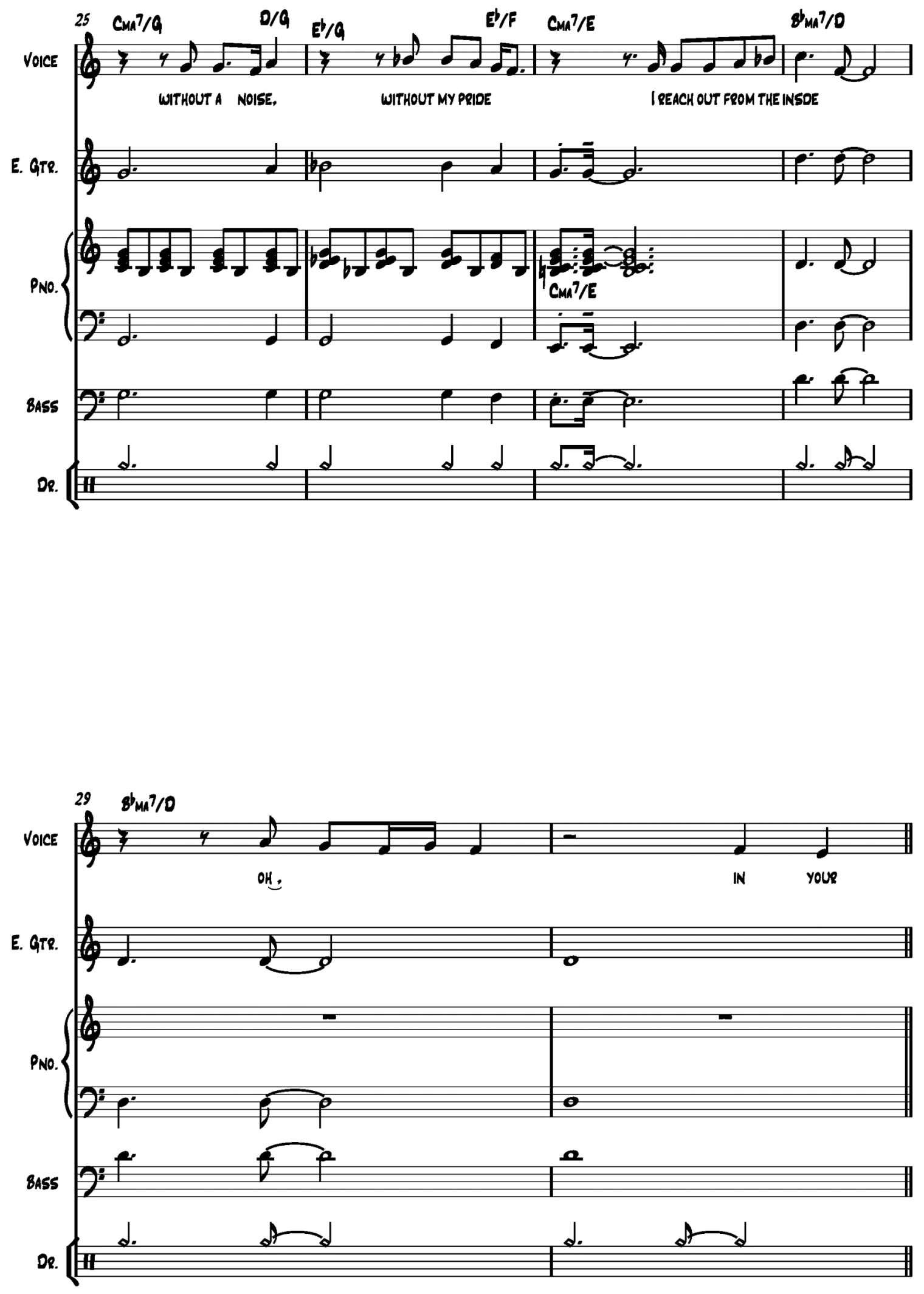


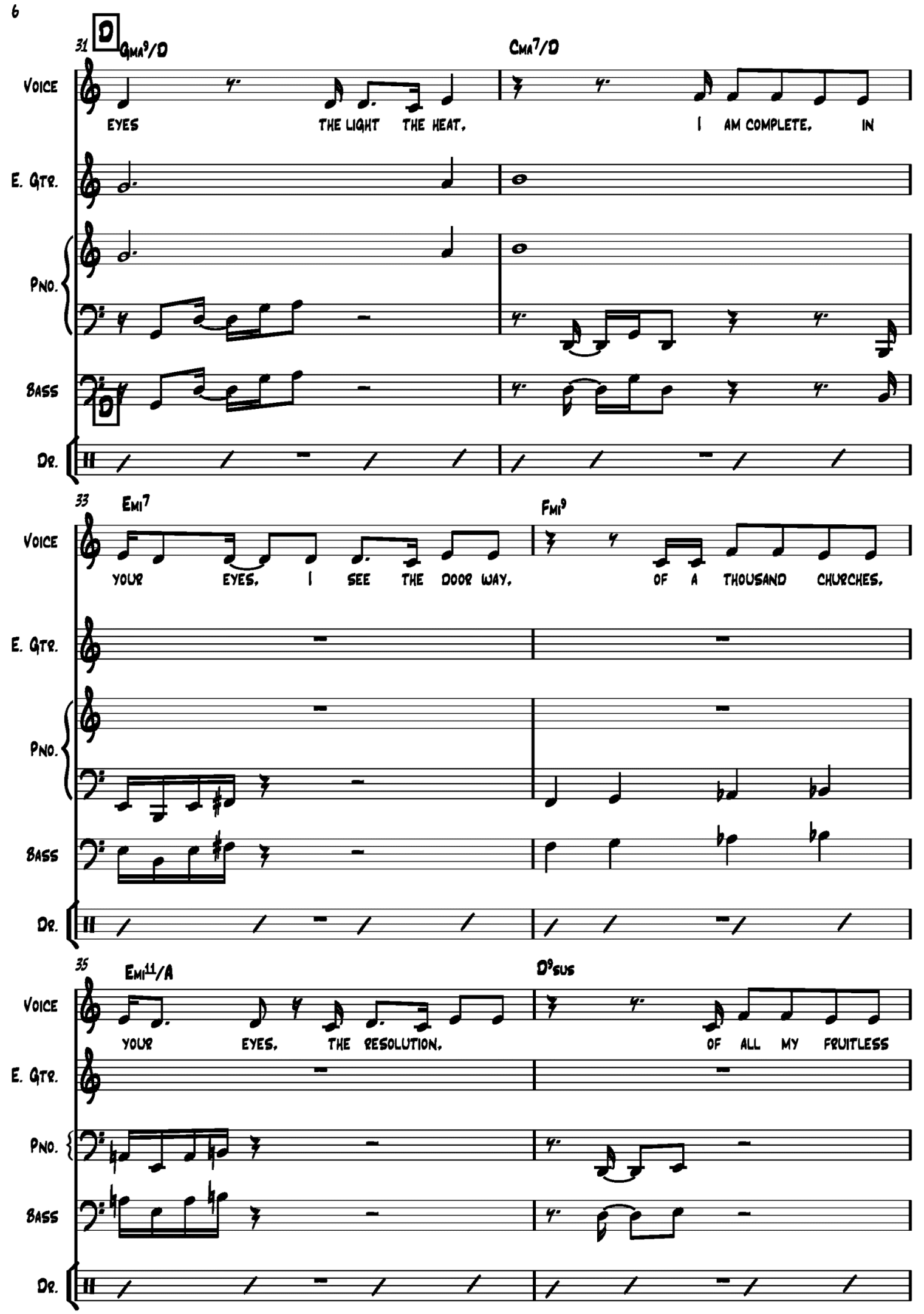




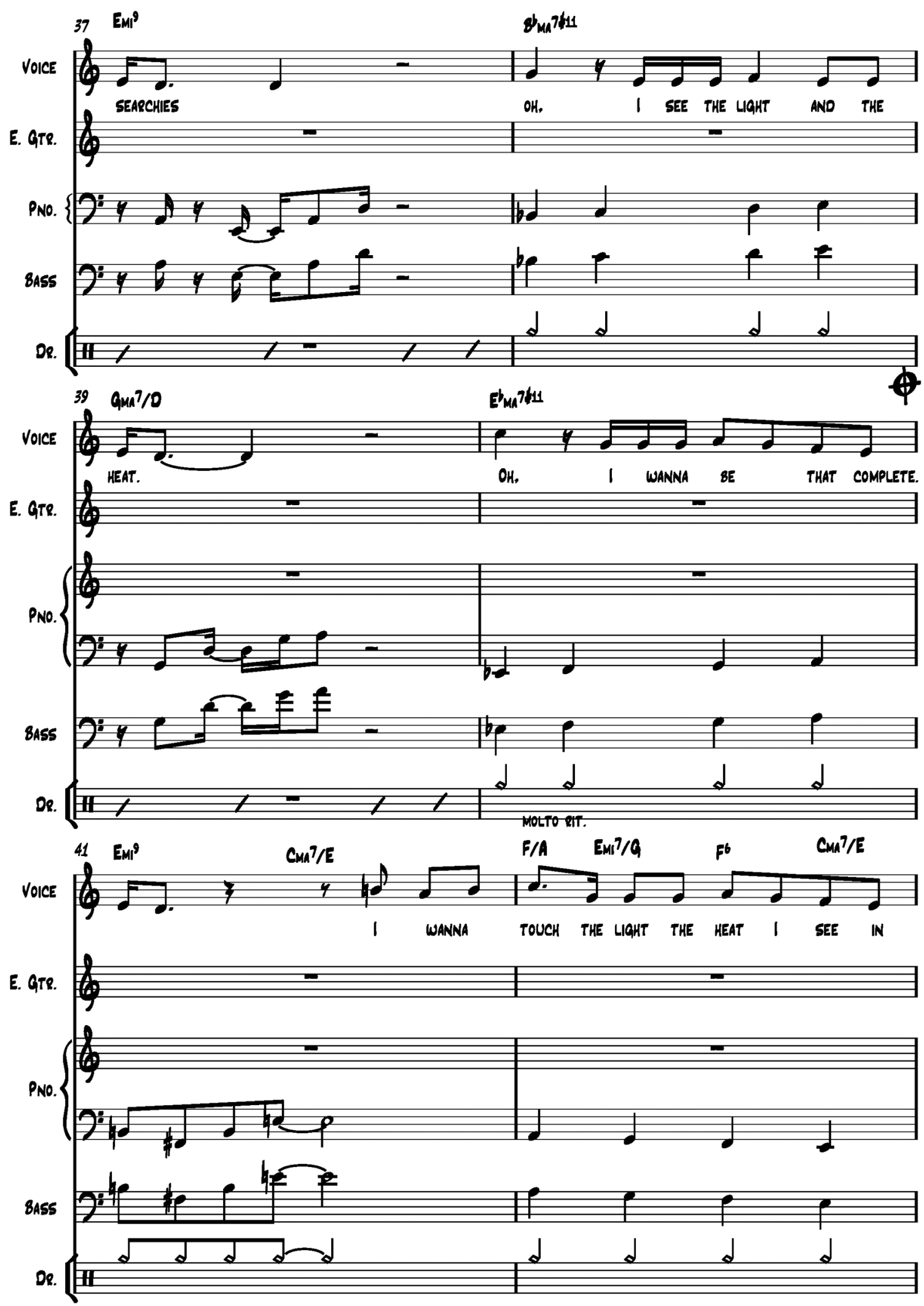


8

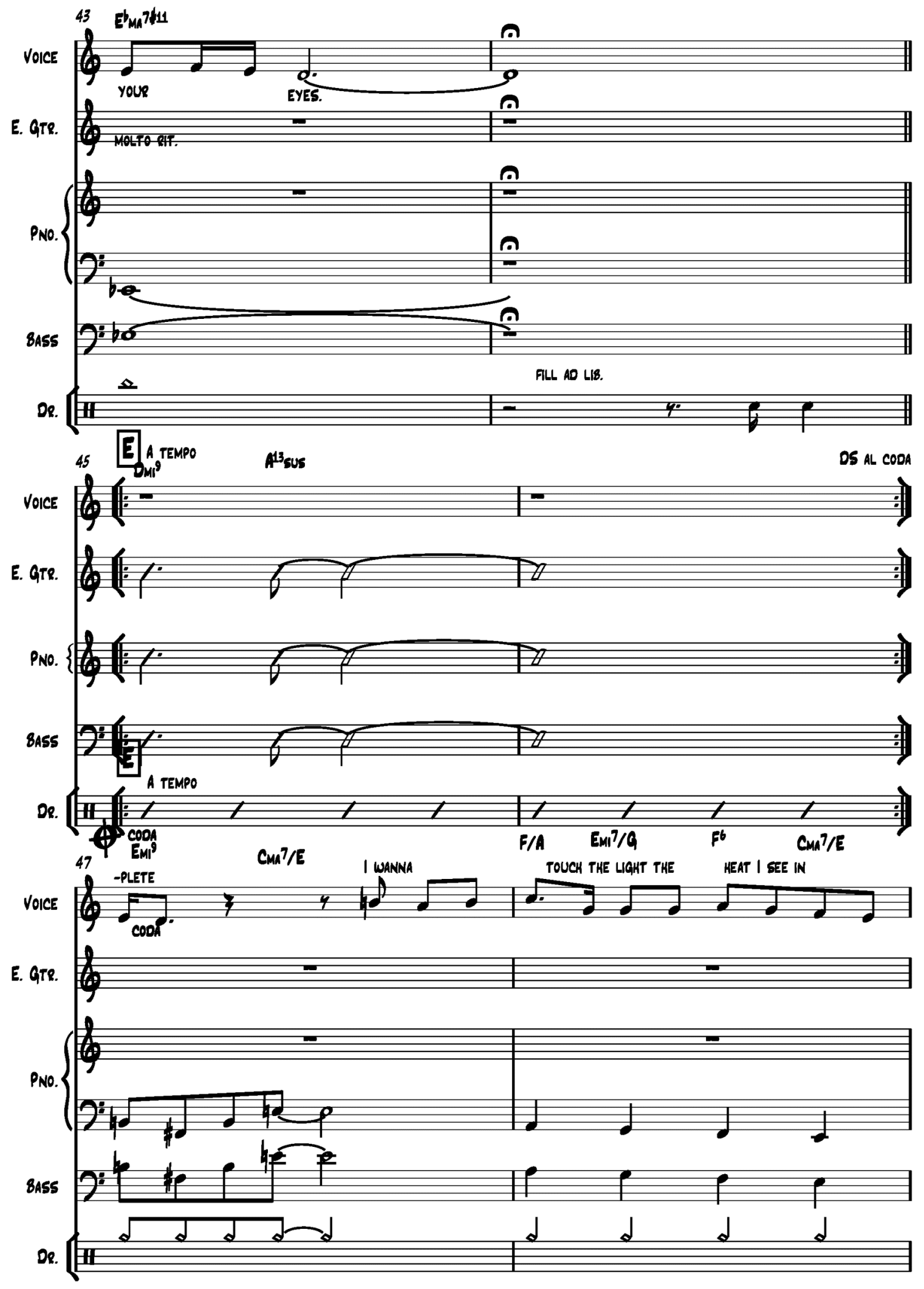



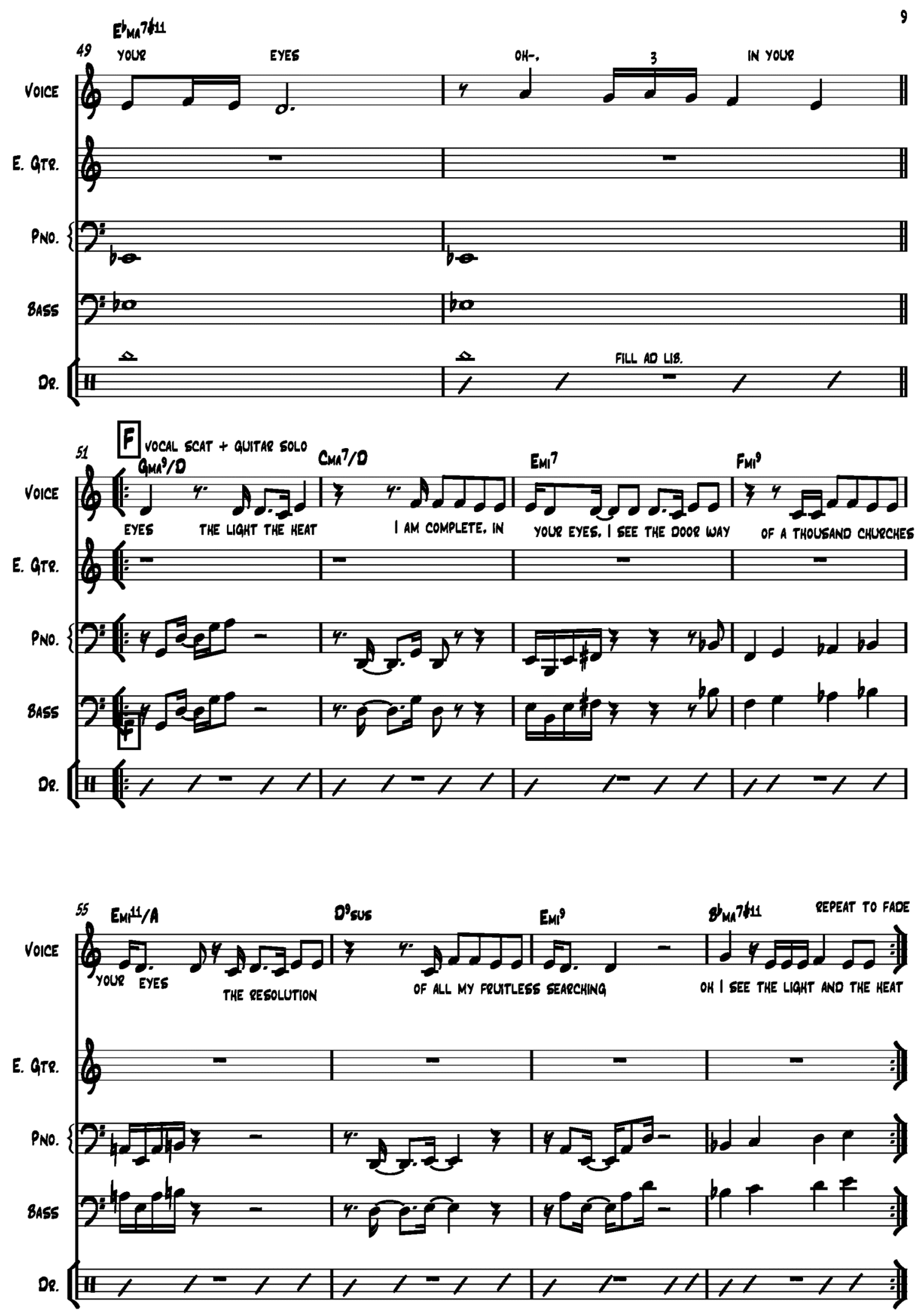

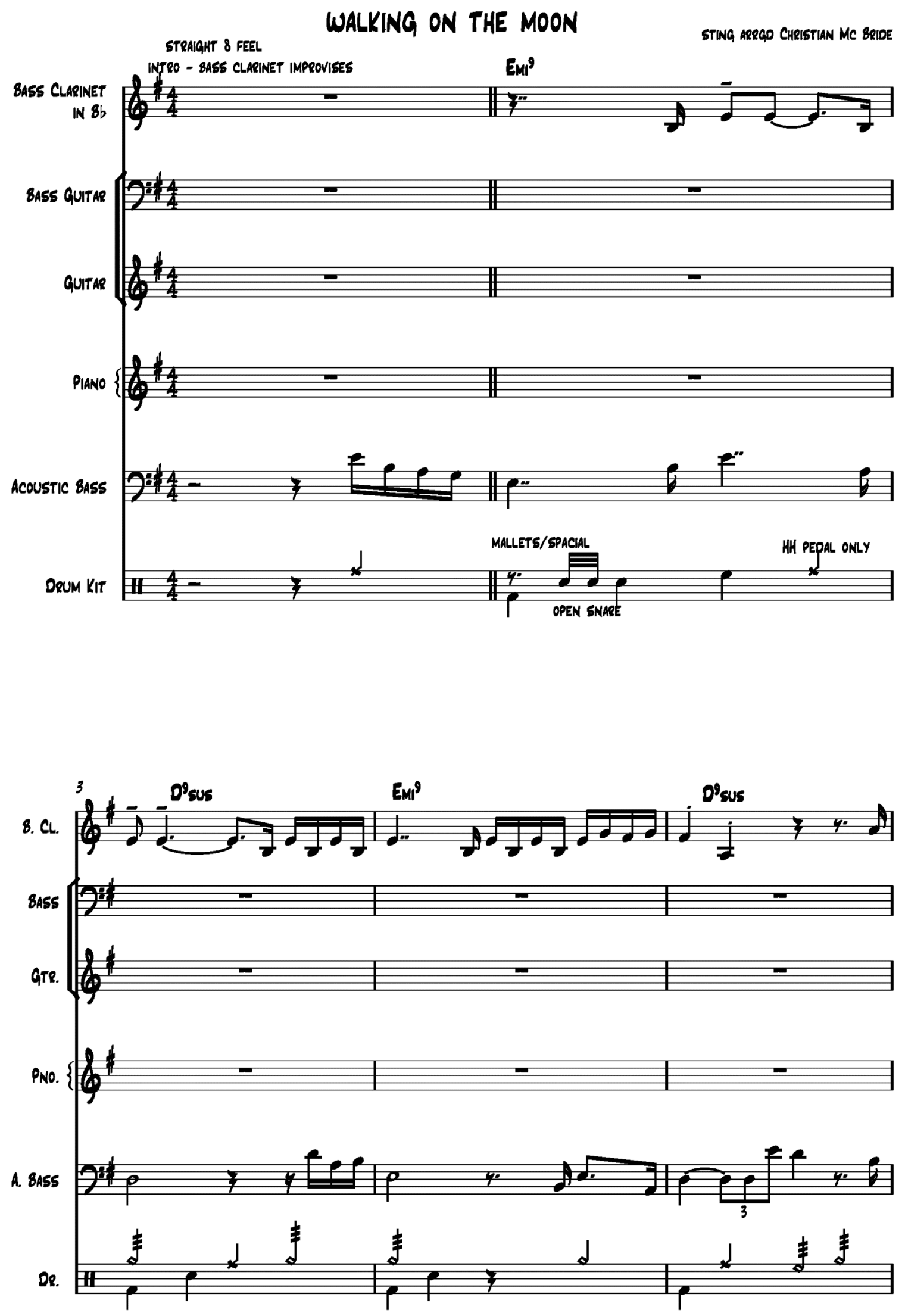
2
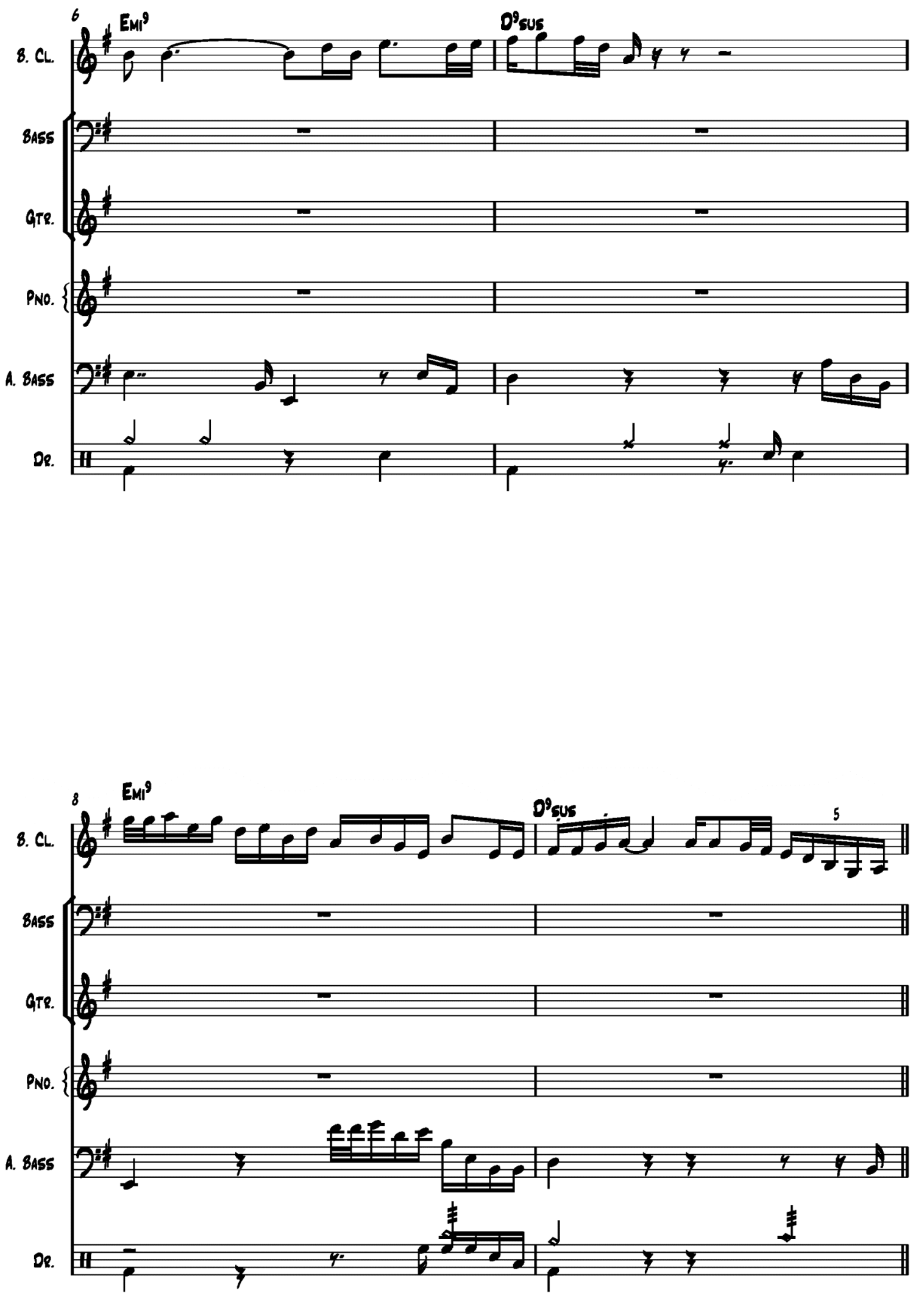

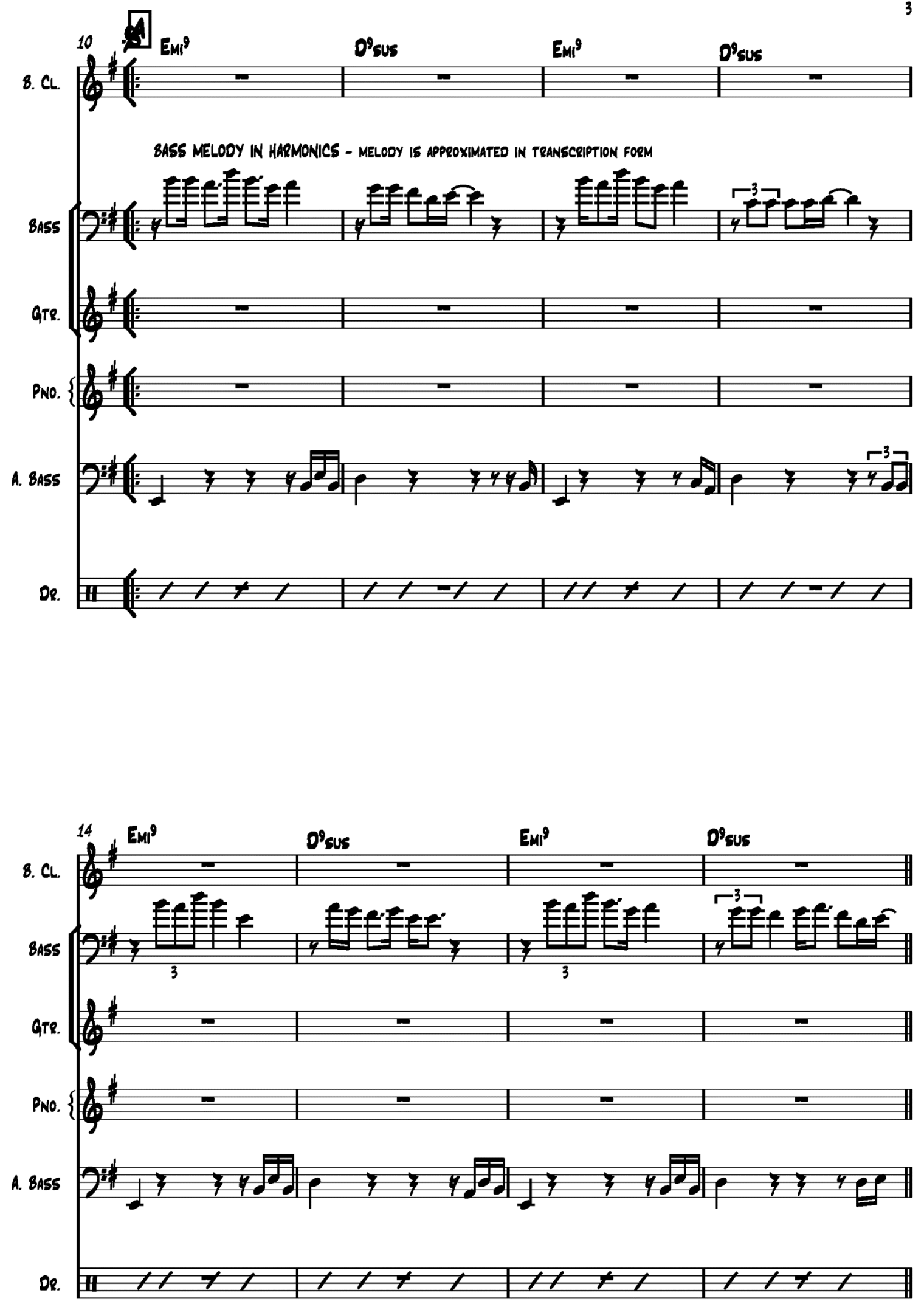


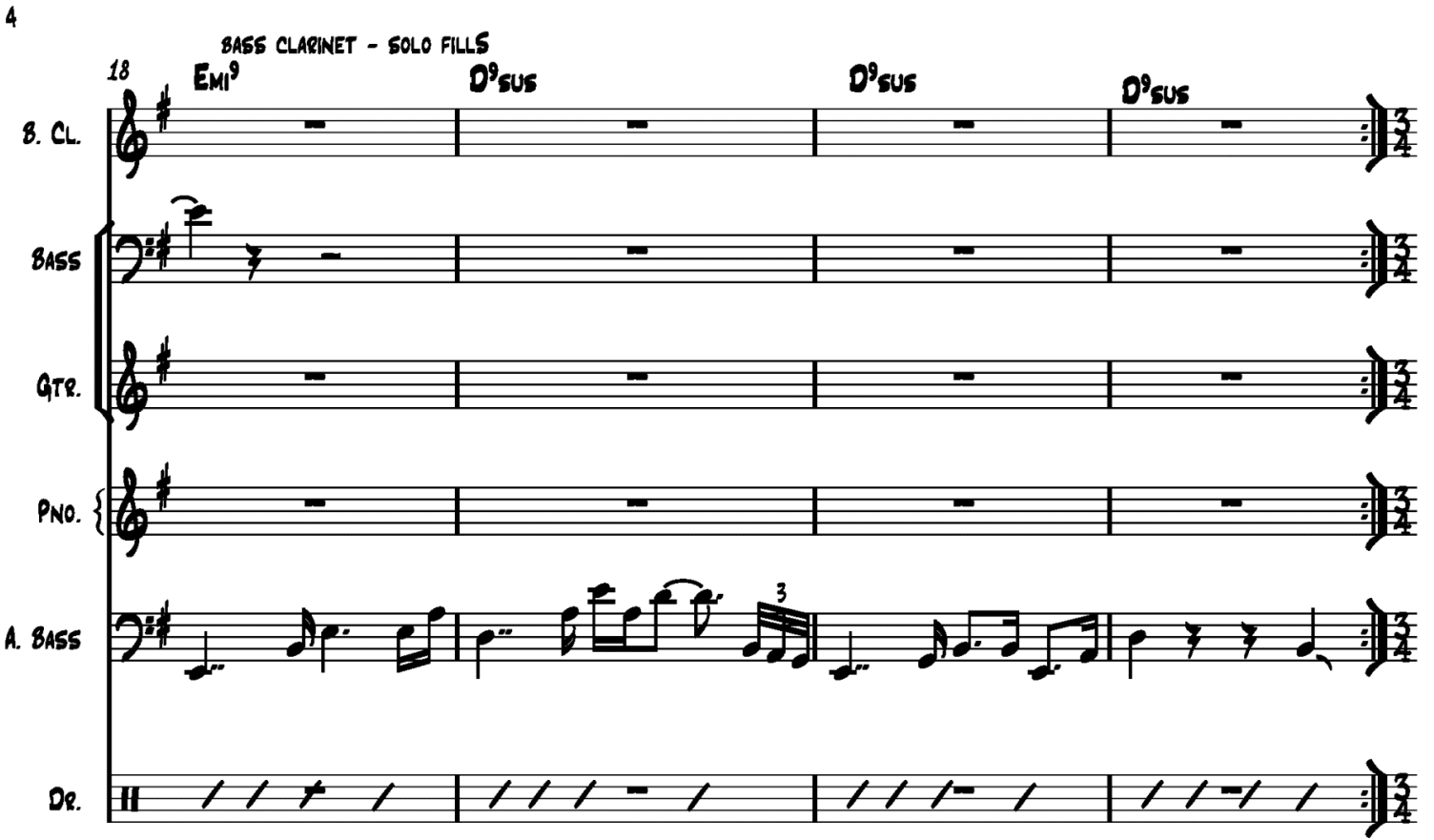

8
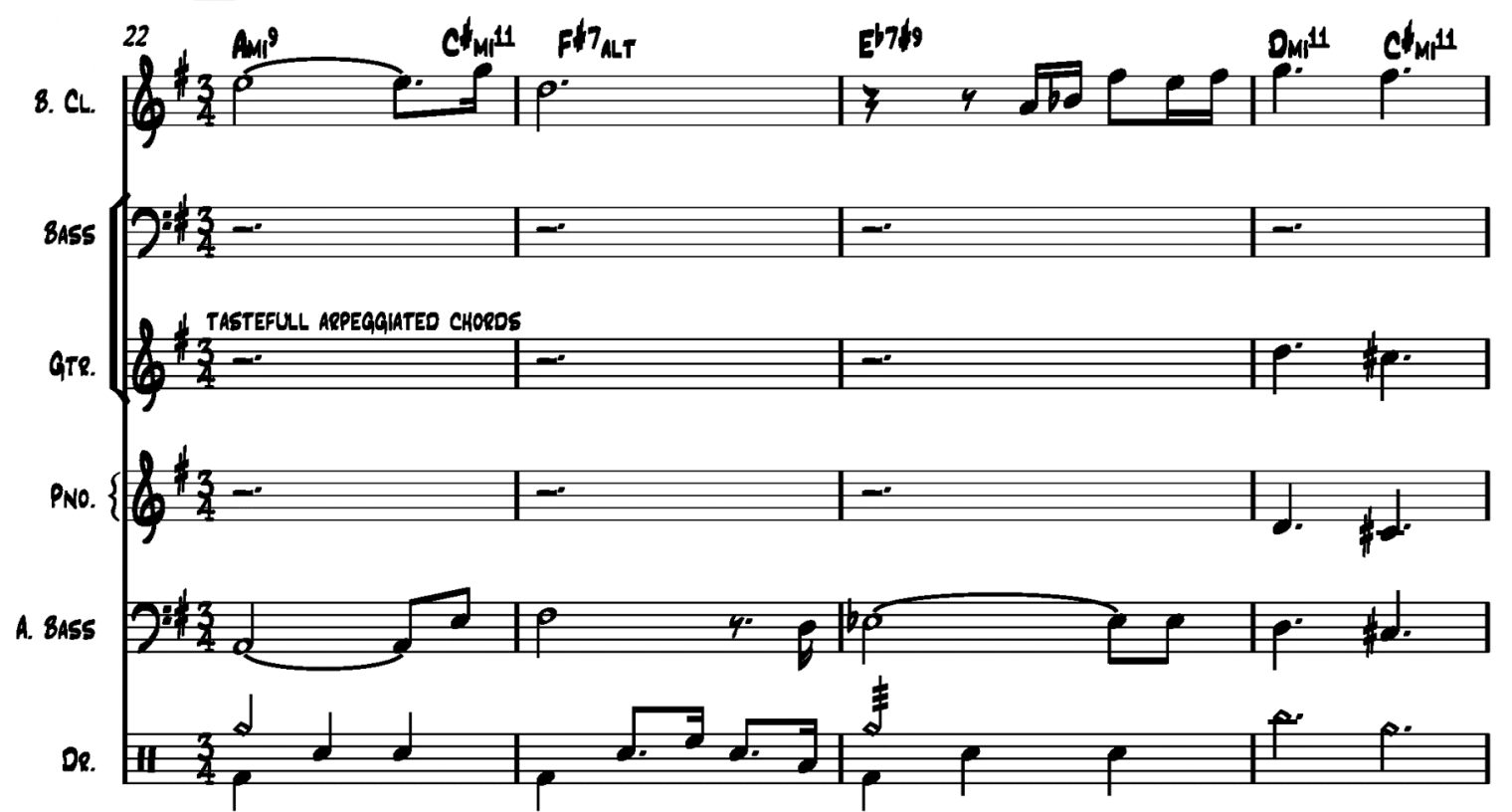

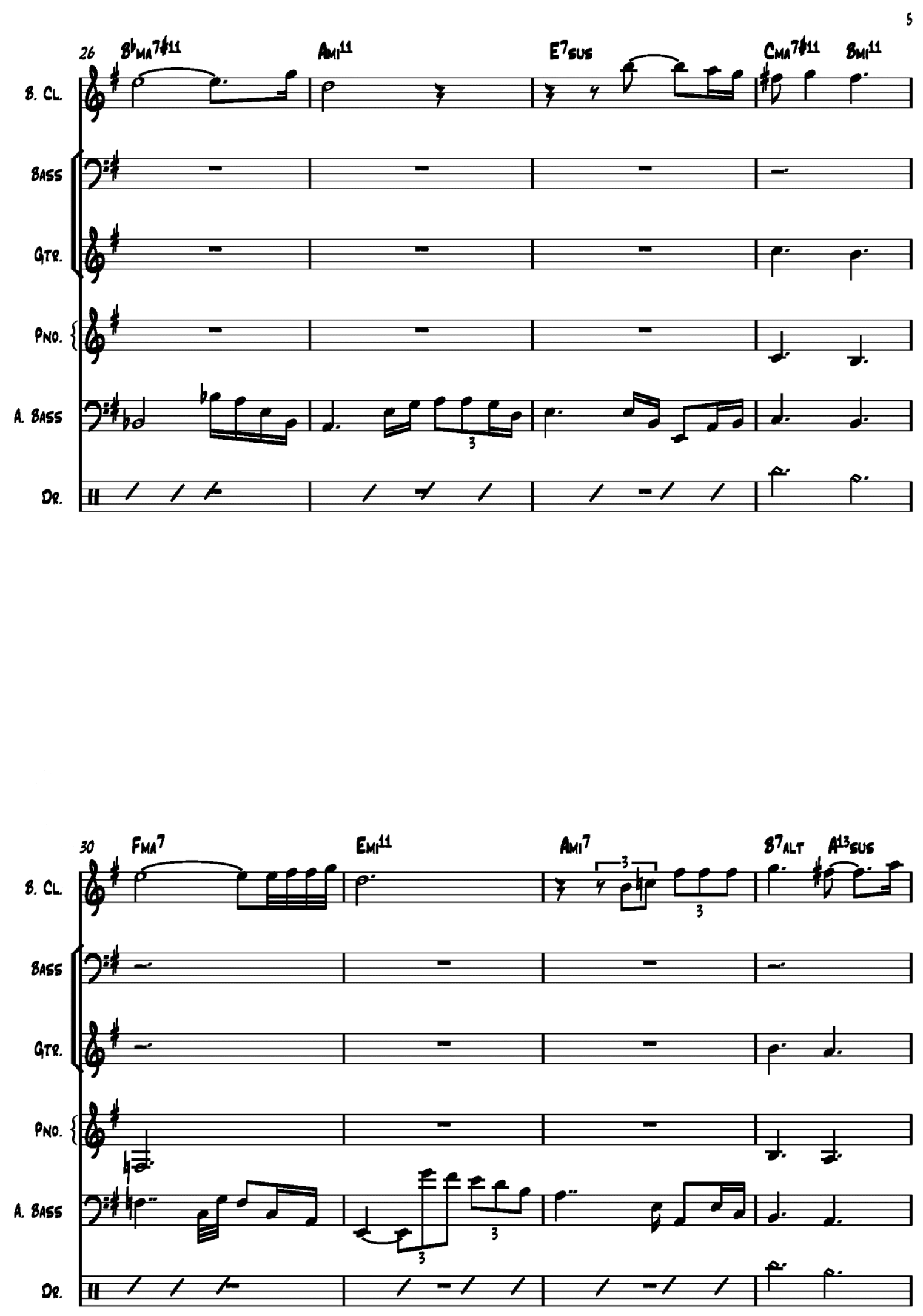


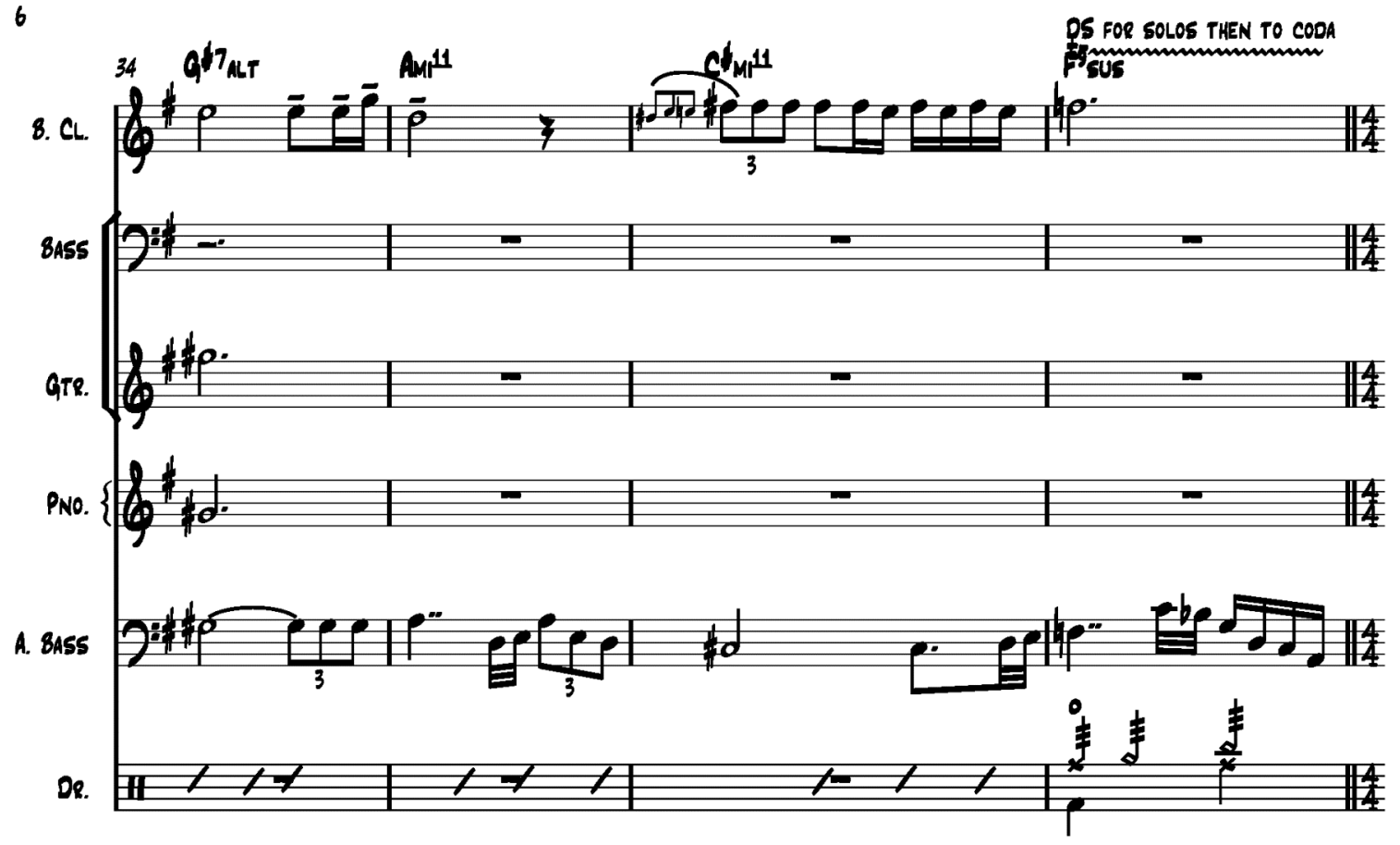

$\Phi_{\text {(tipmm }}$ coof - AFter solos

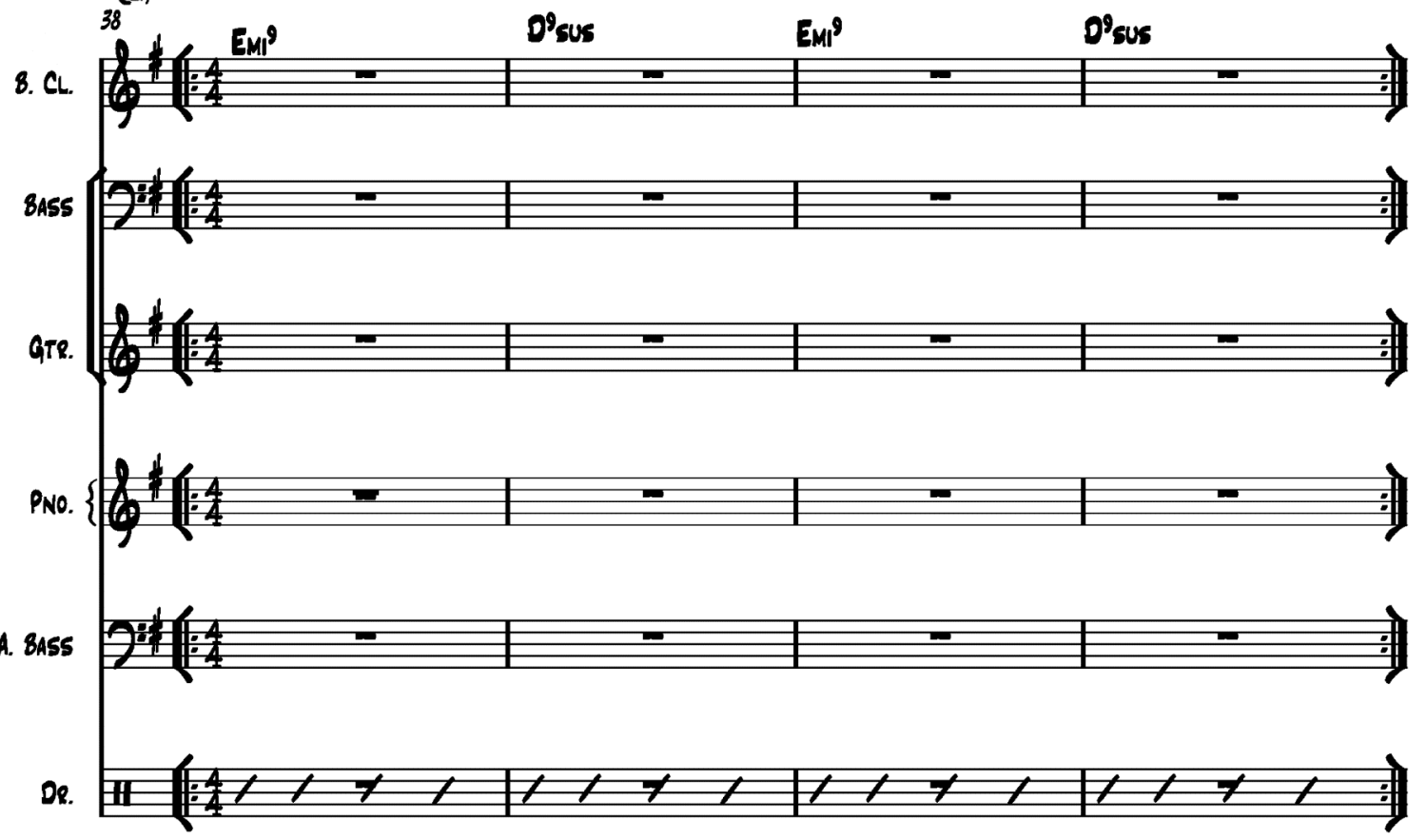




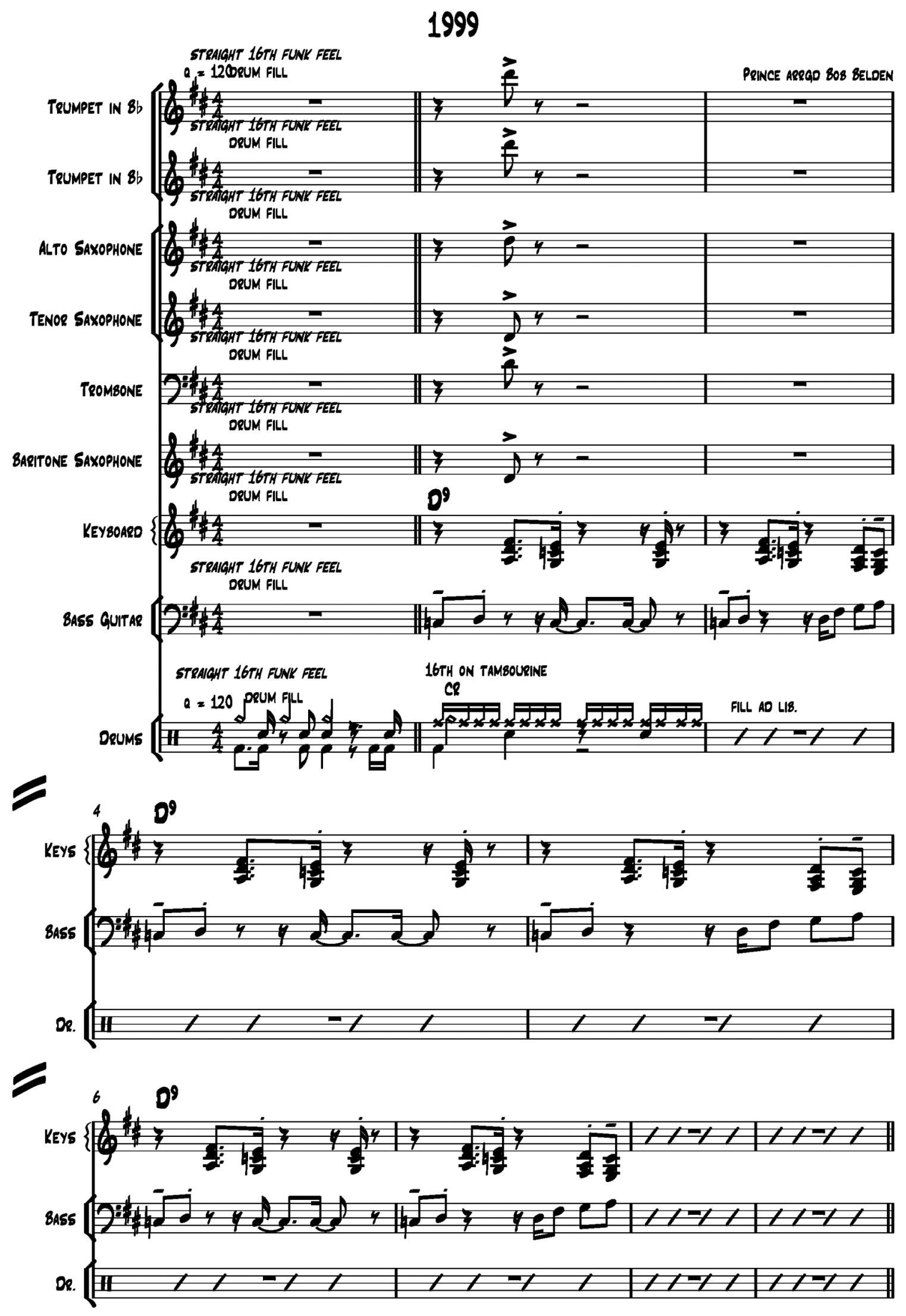



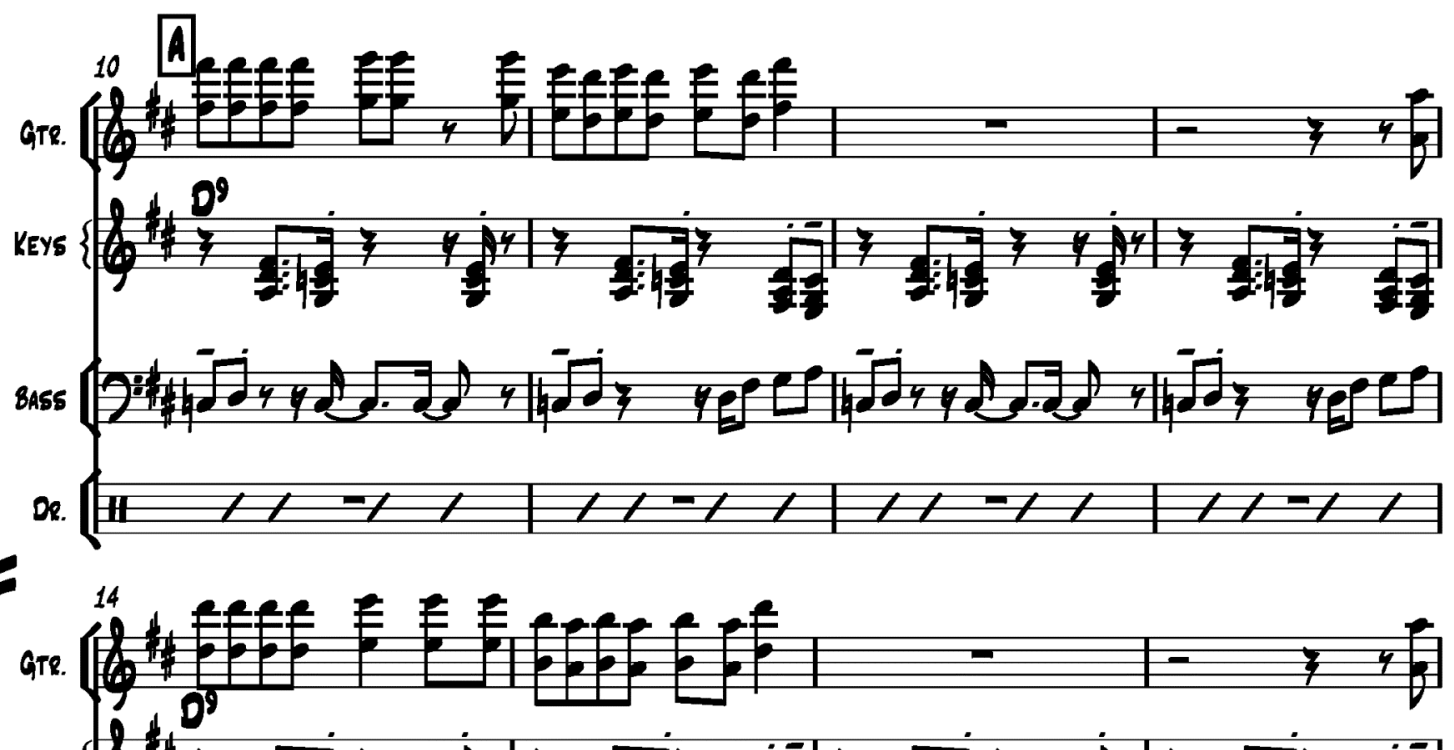

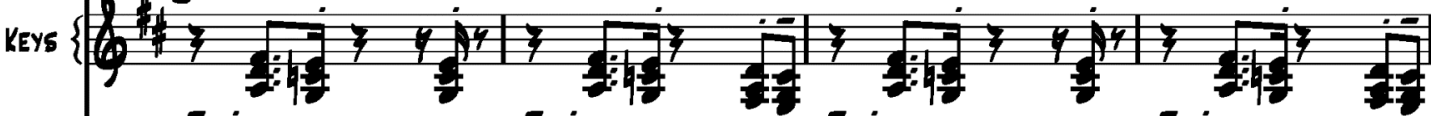
SA55 (20)

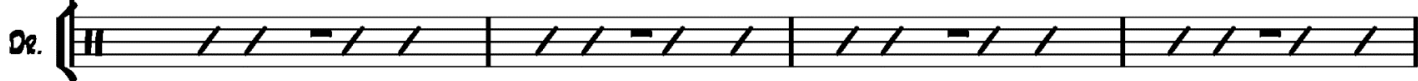
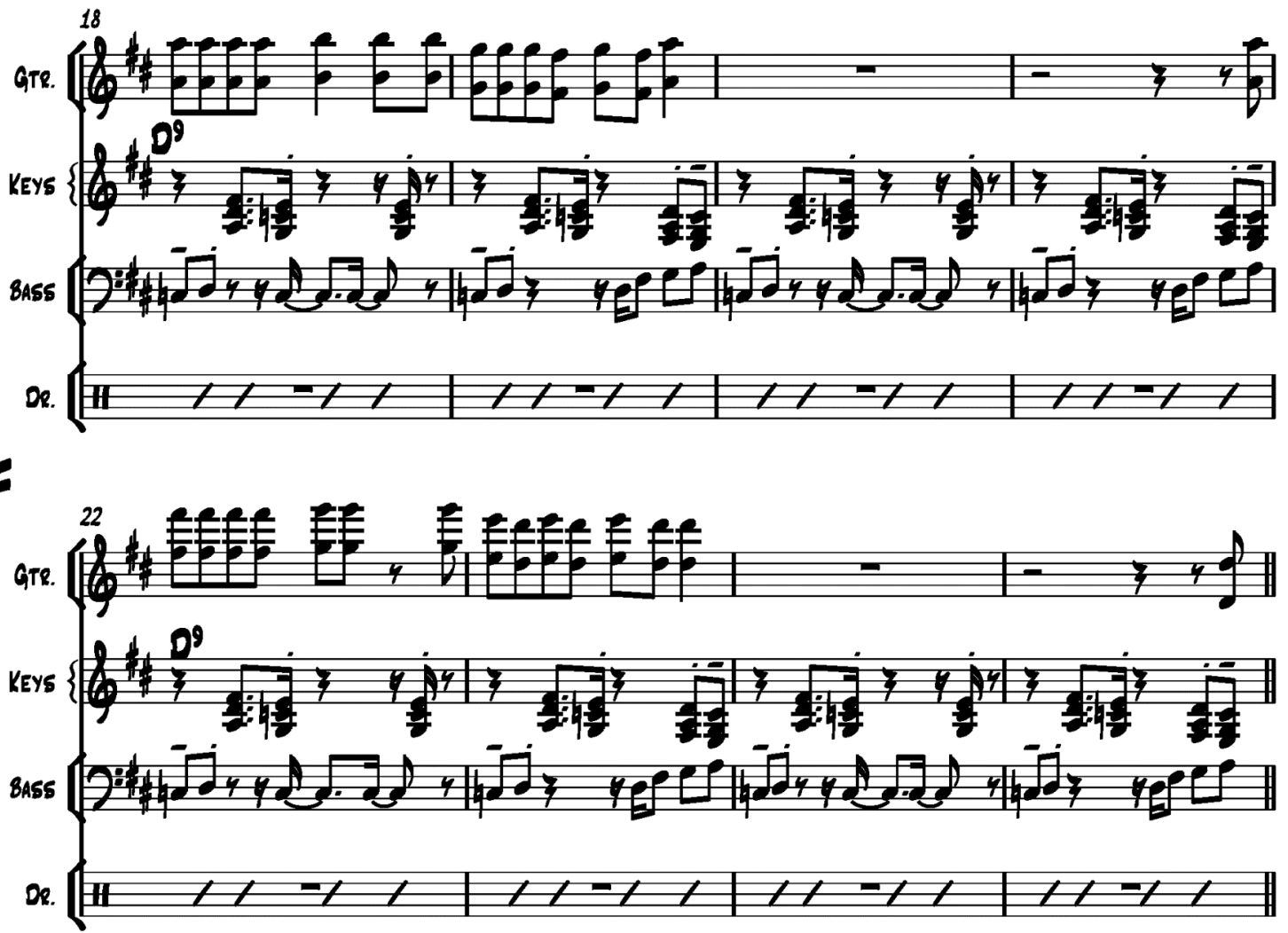


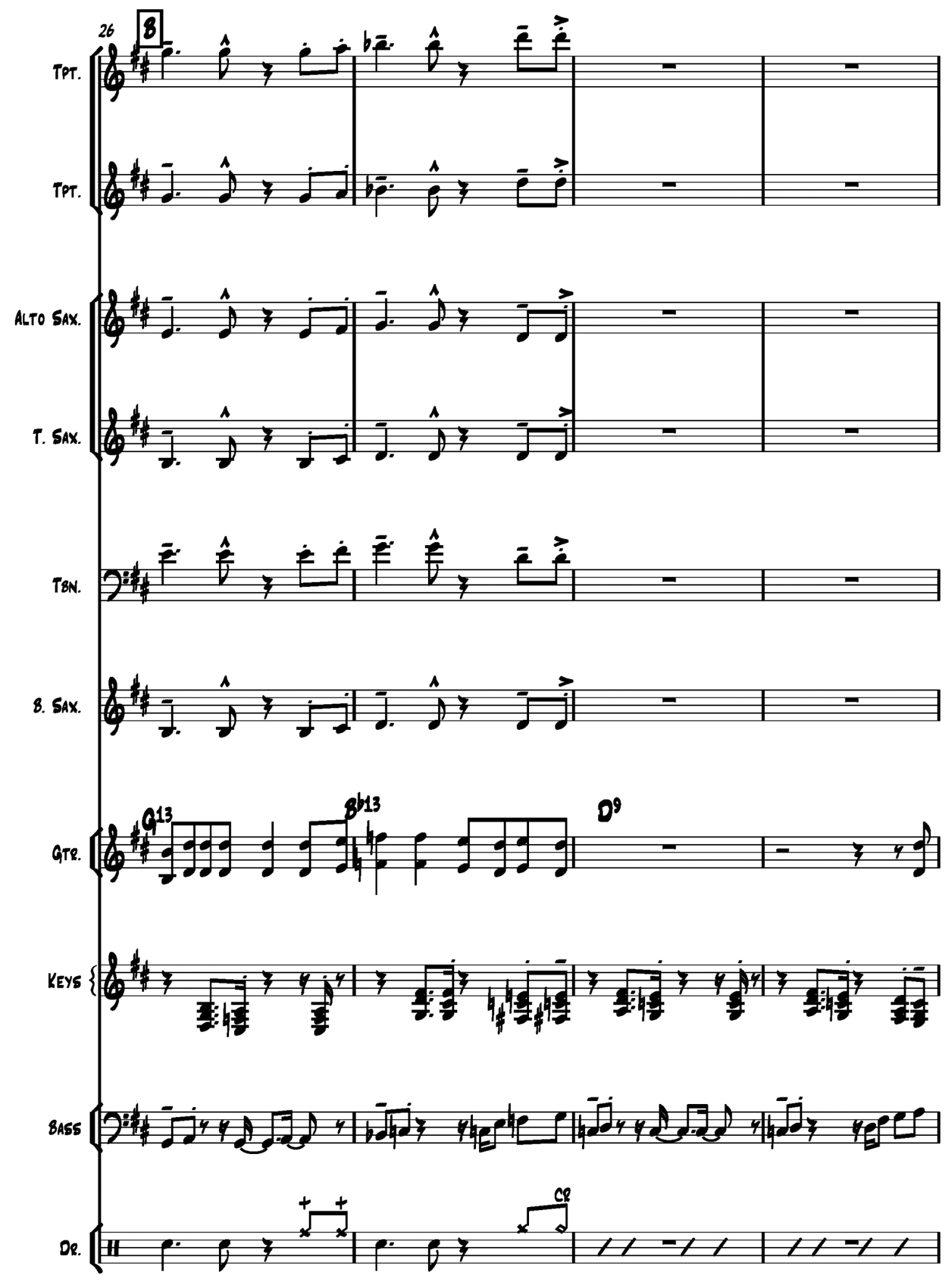




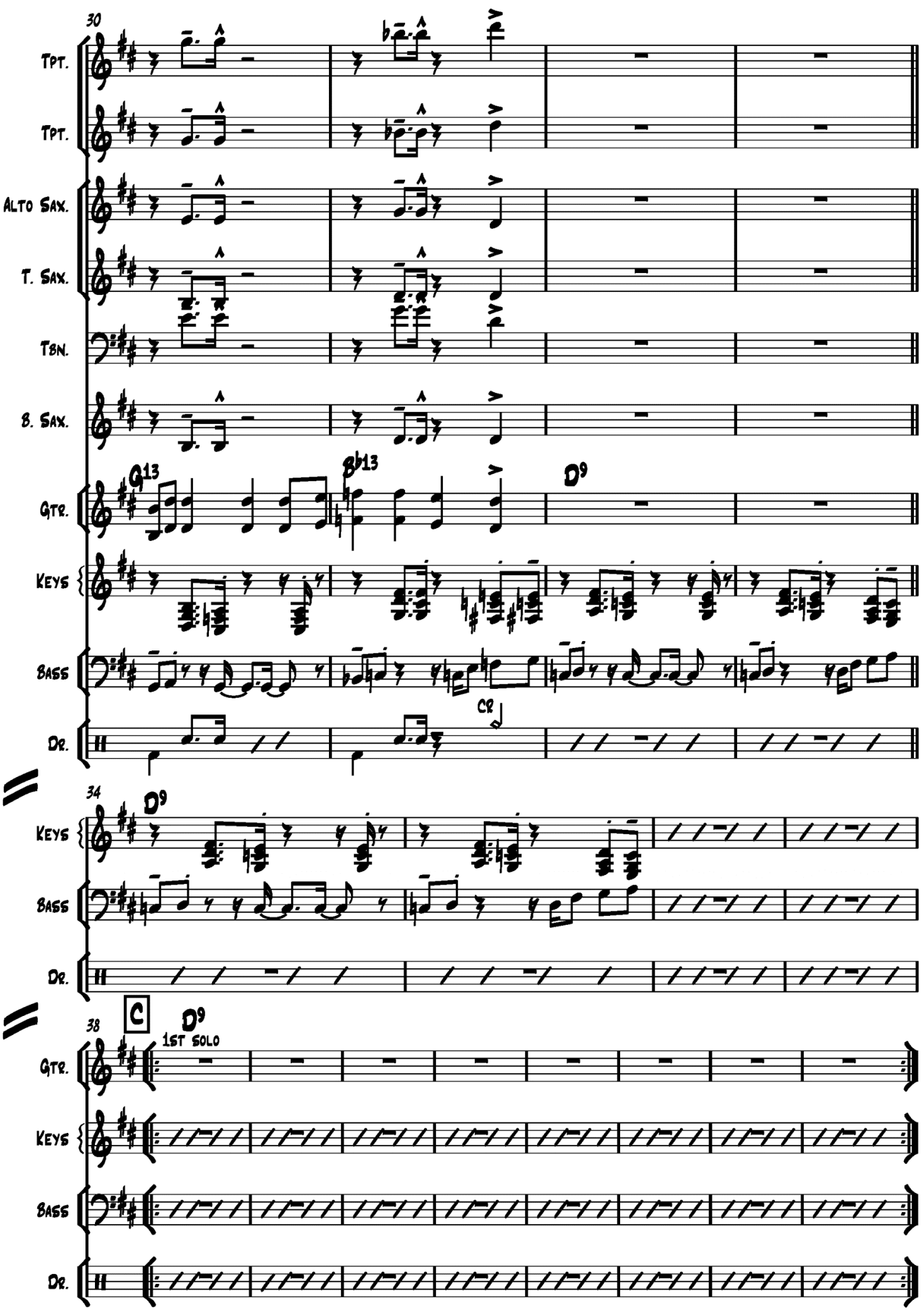




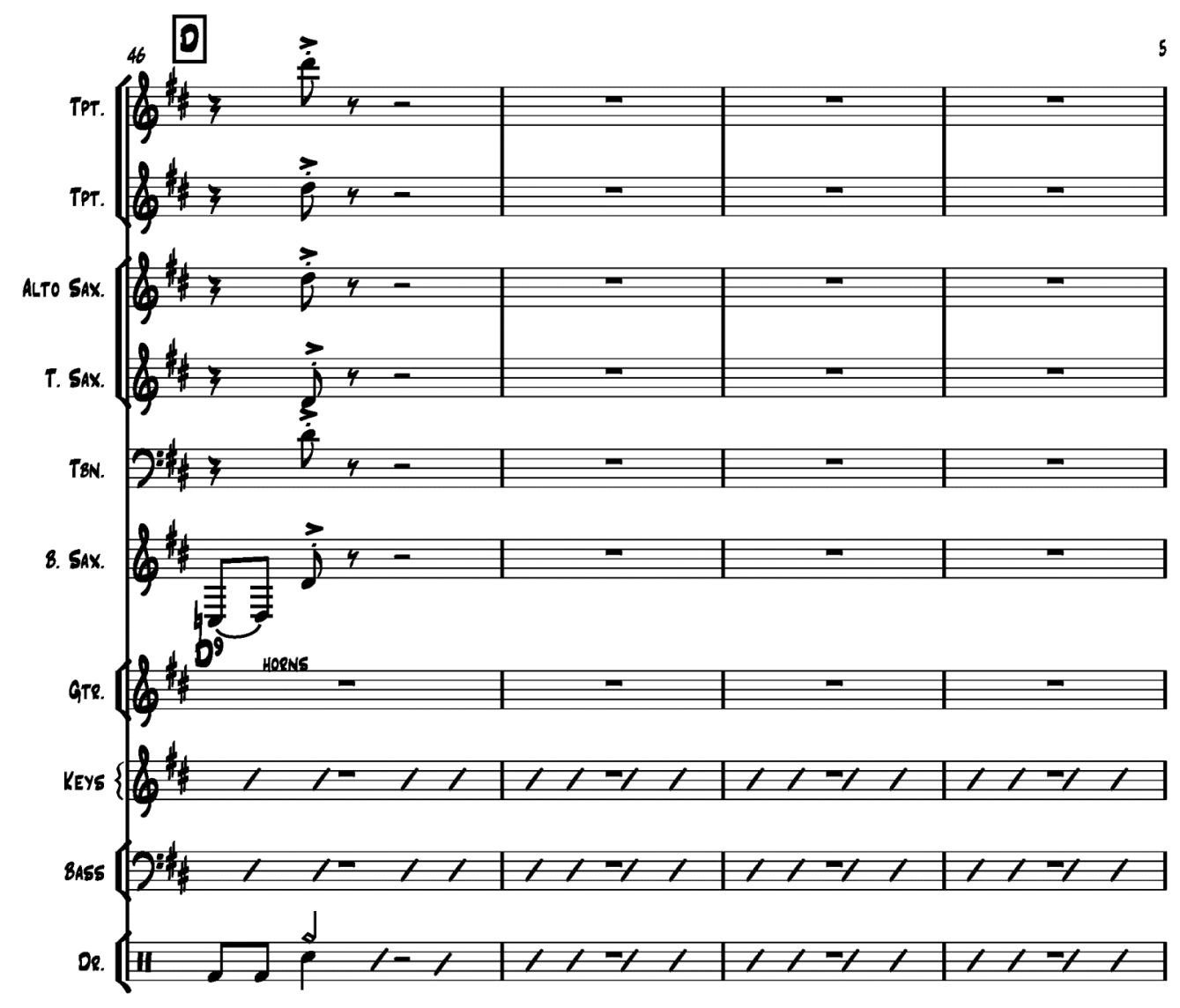



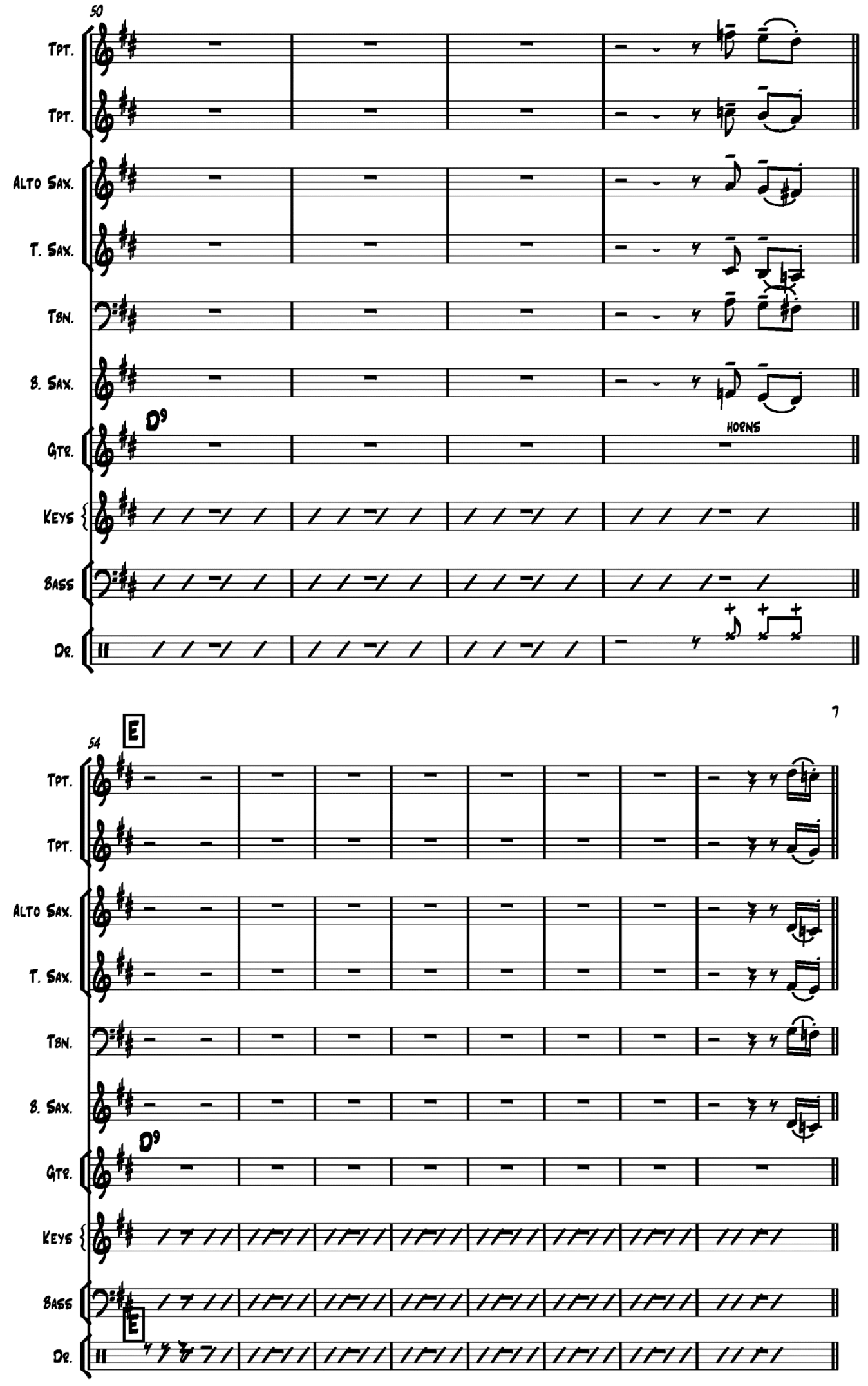


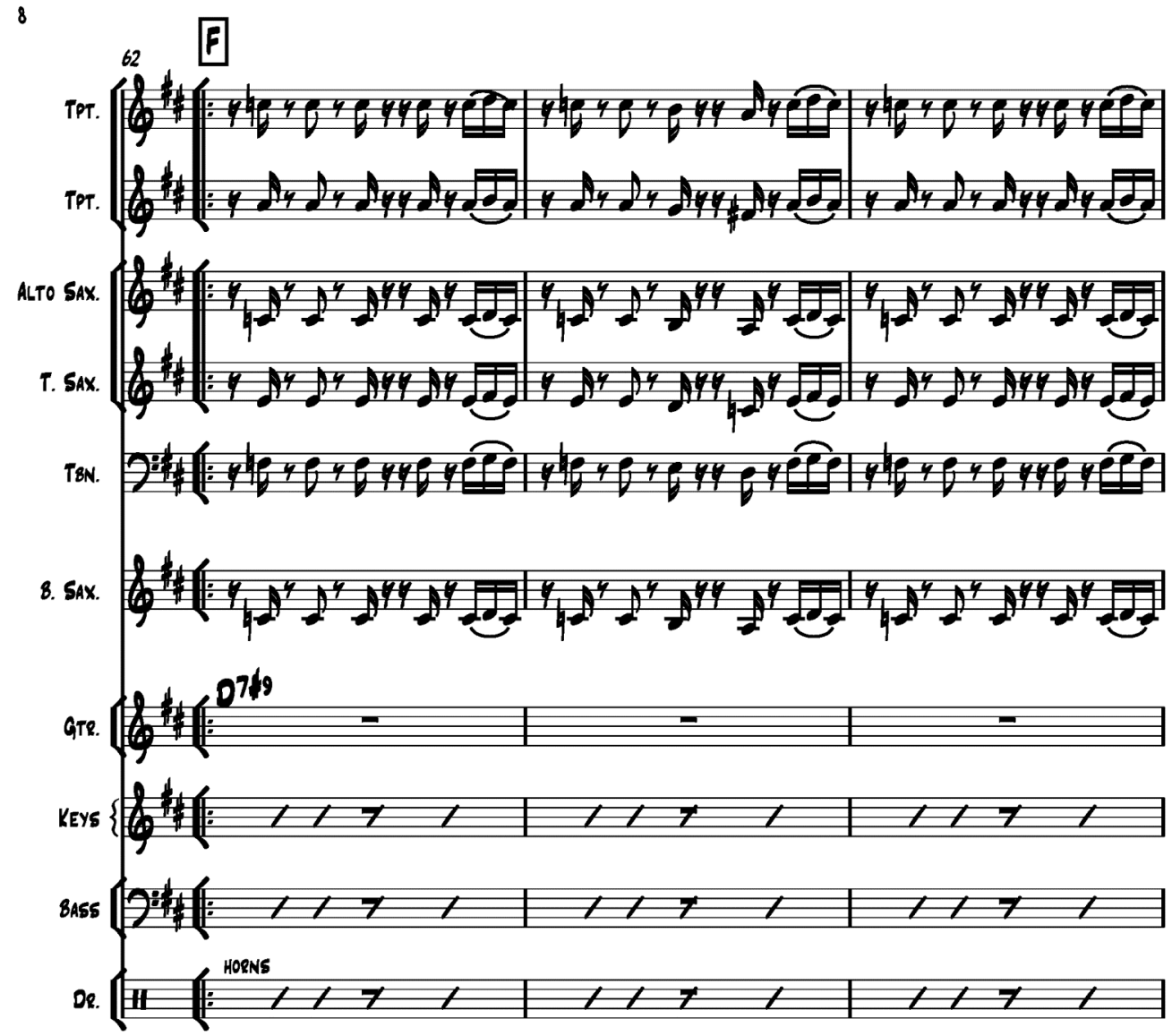




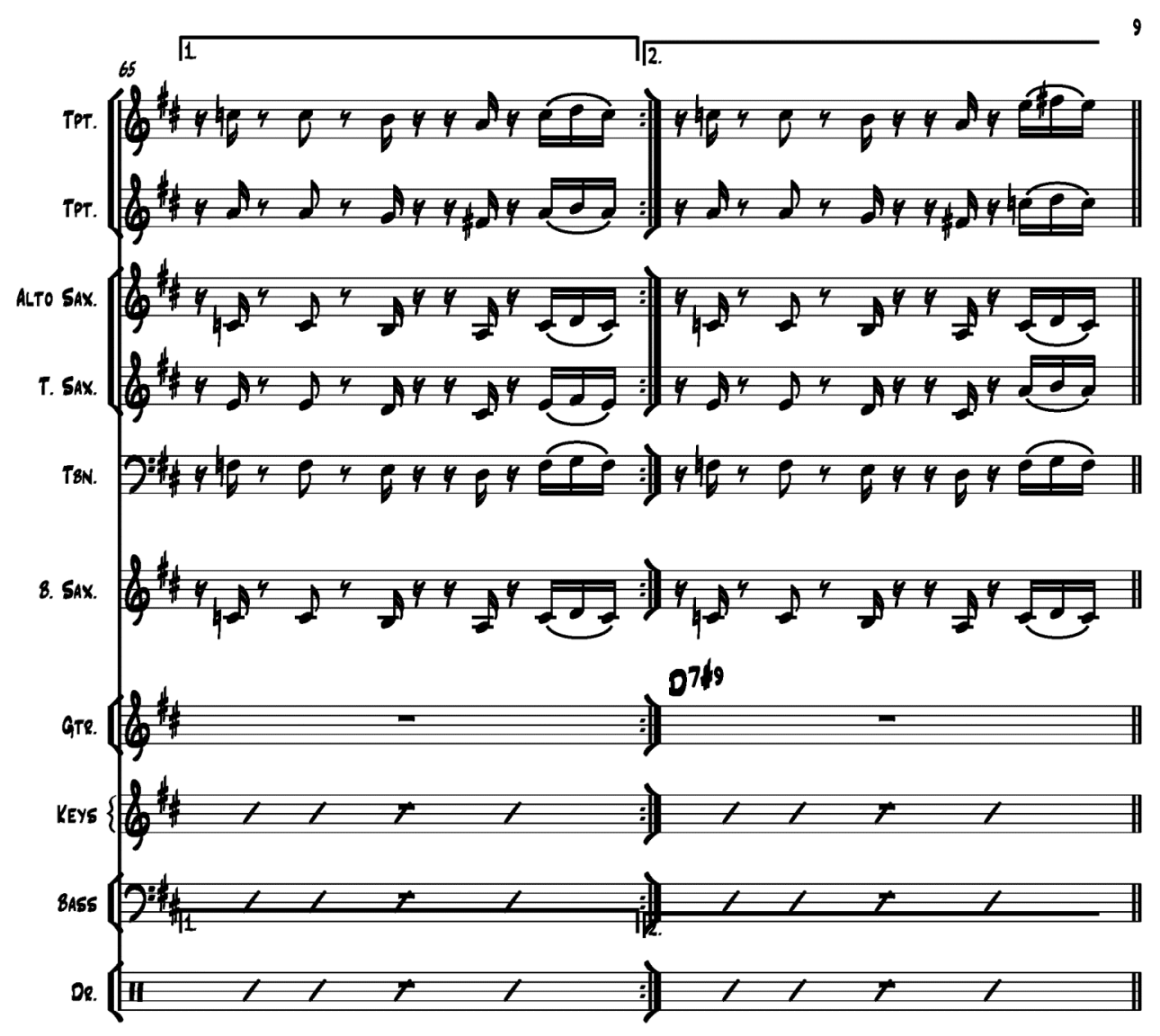


10

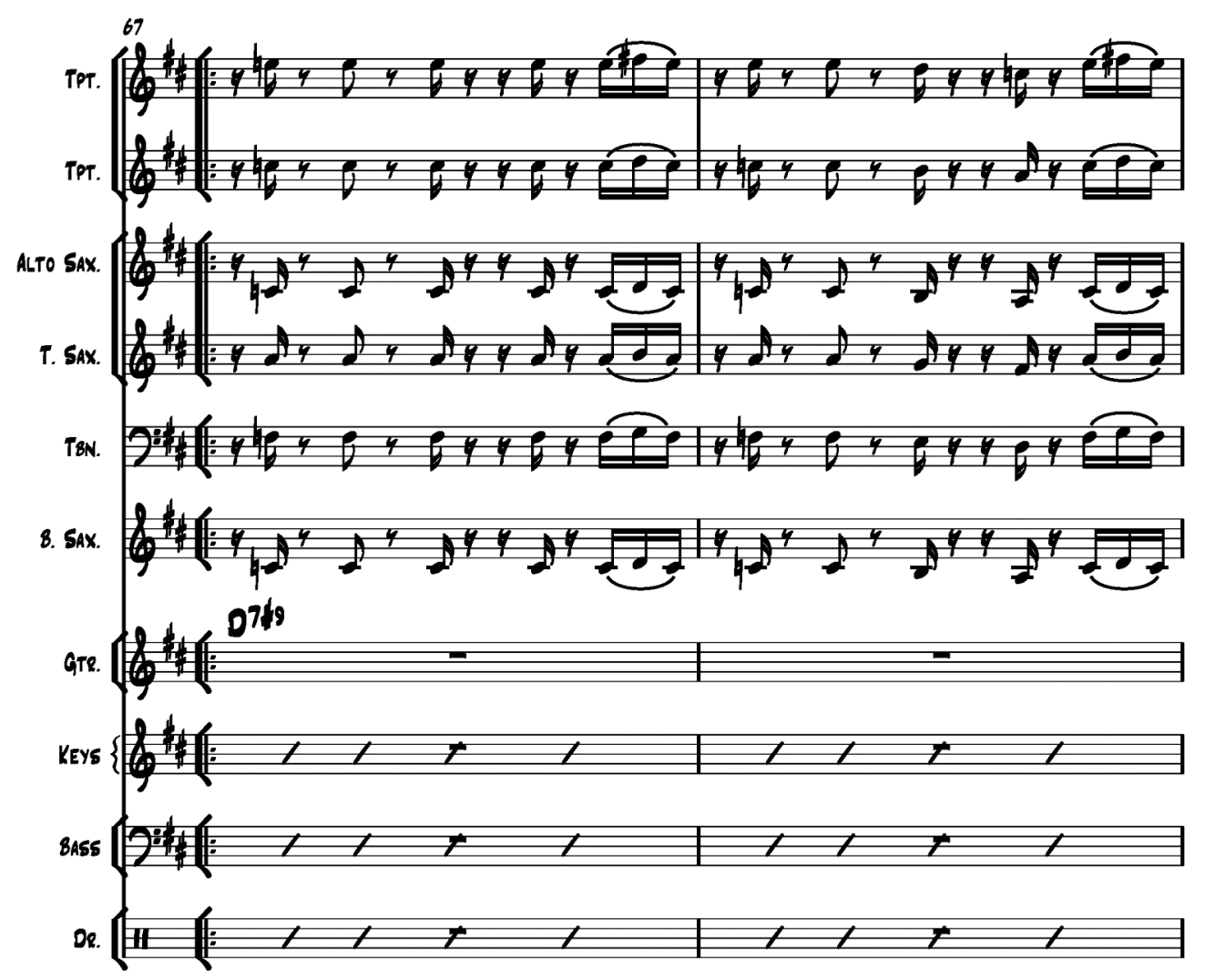


11

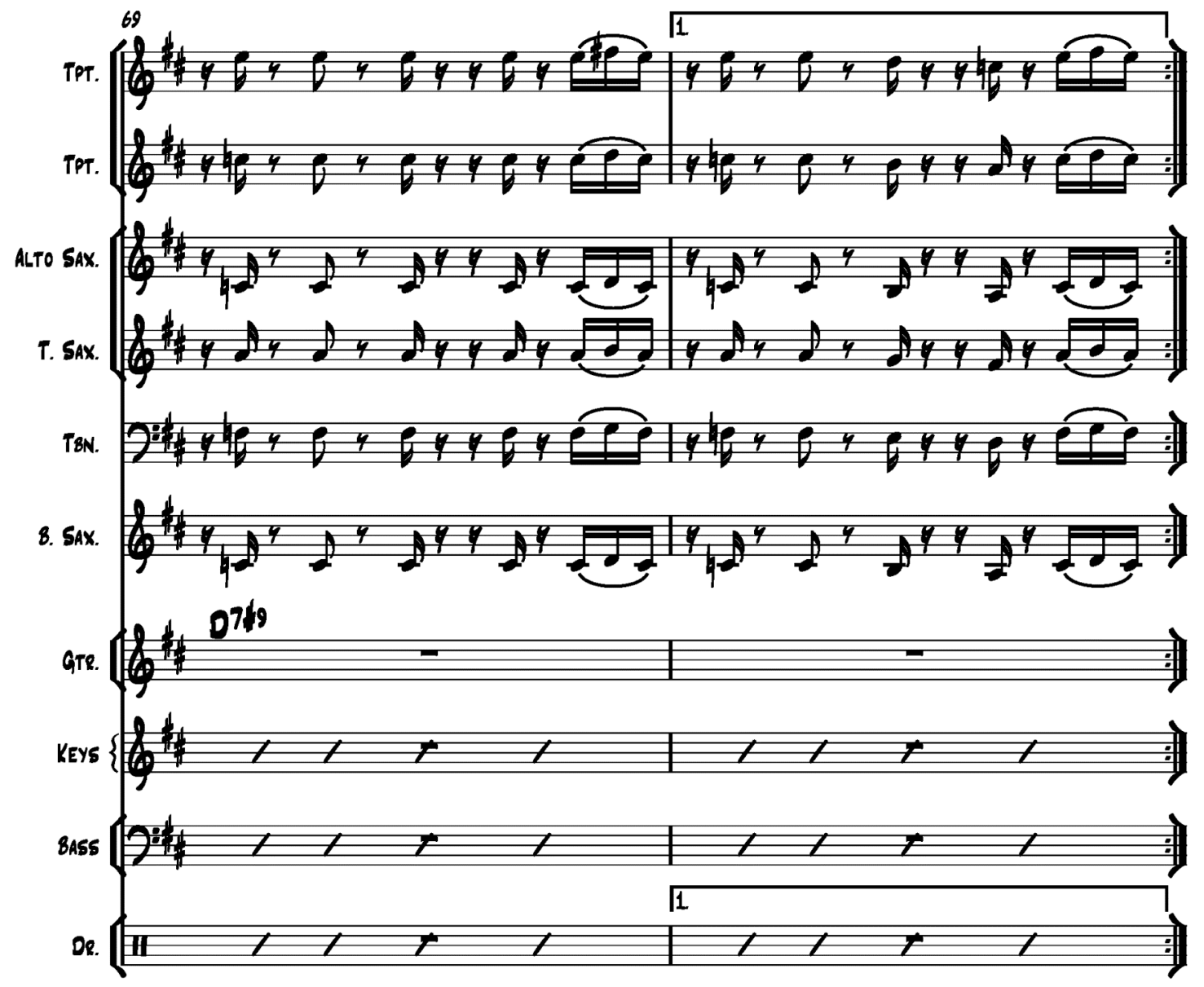




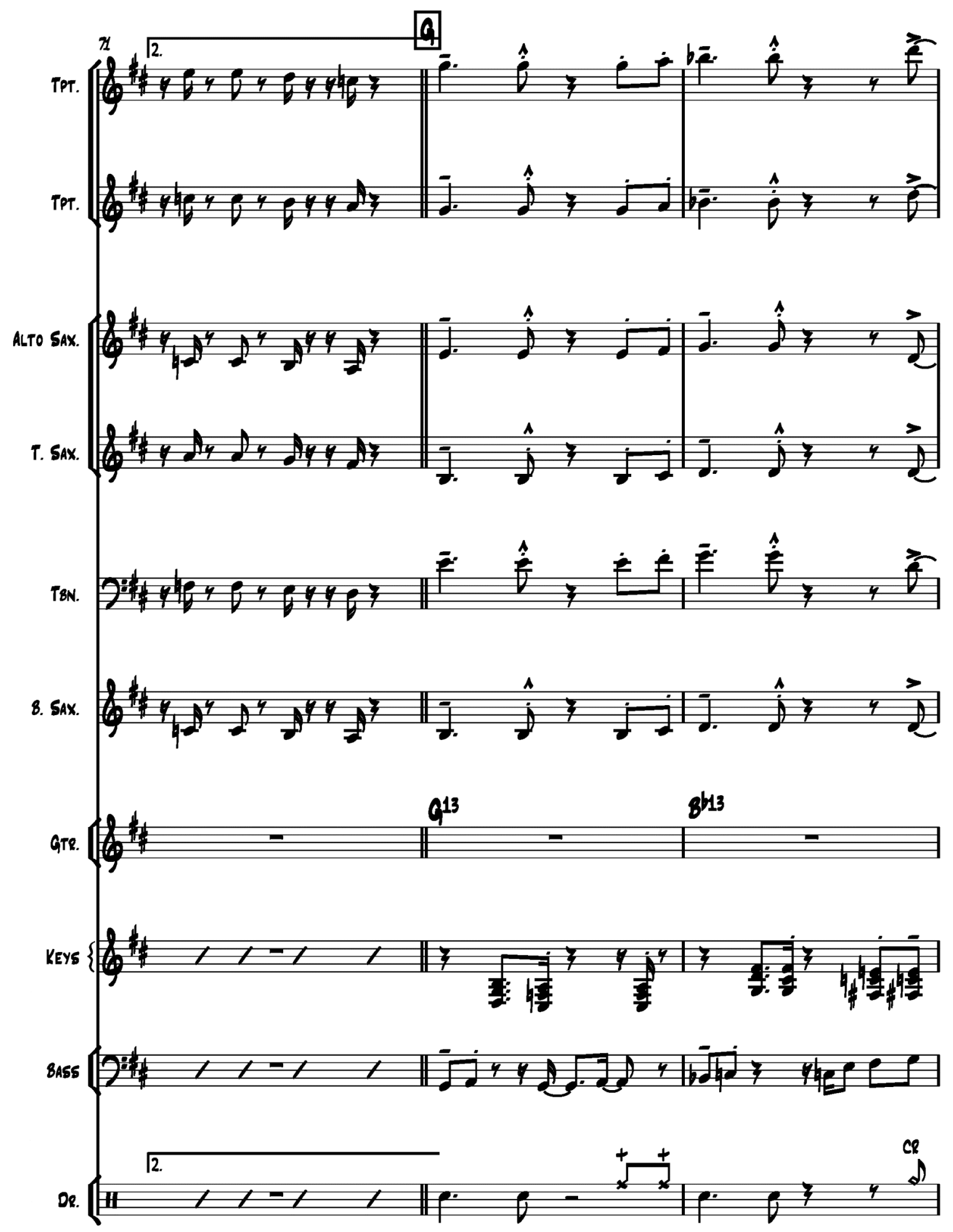




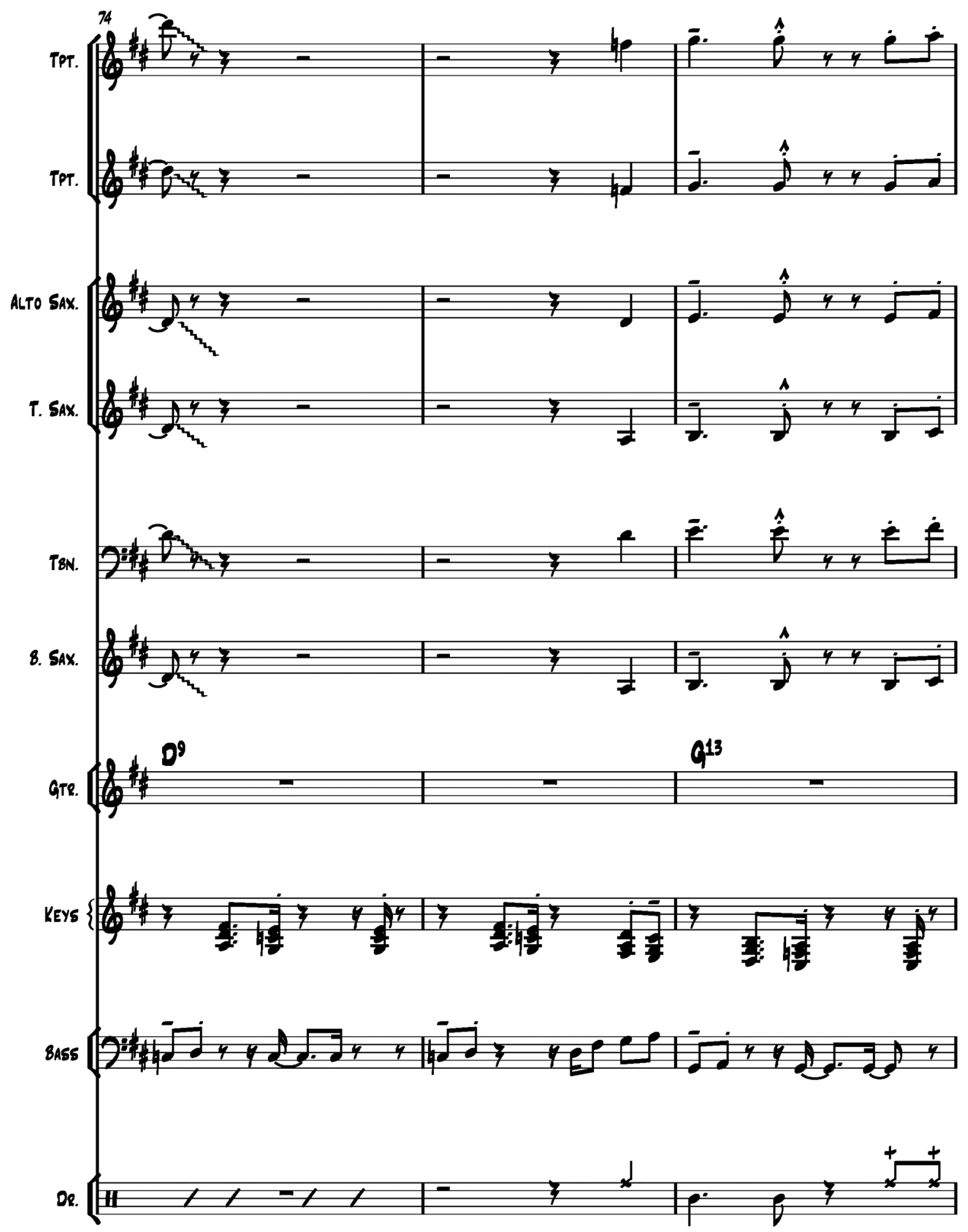


14

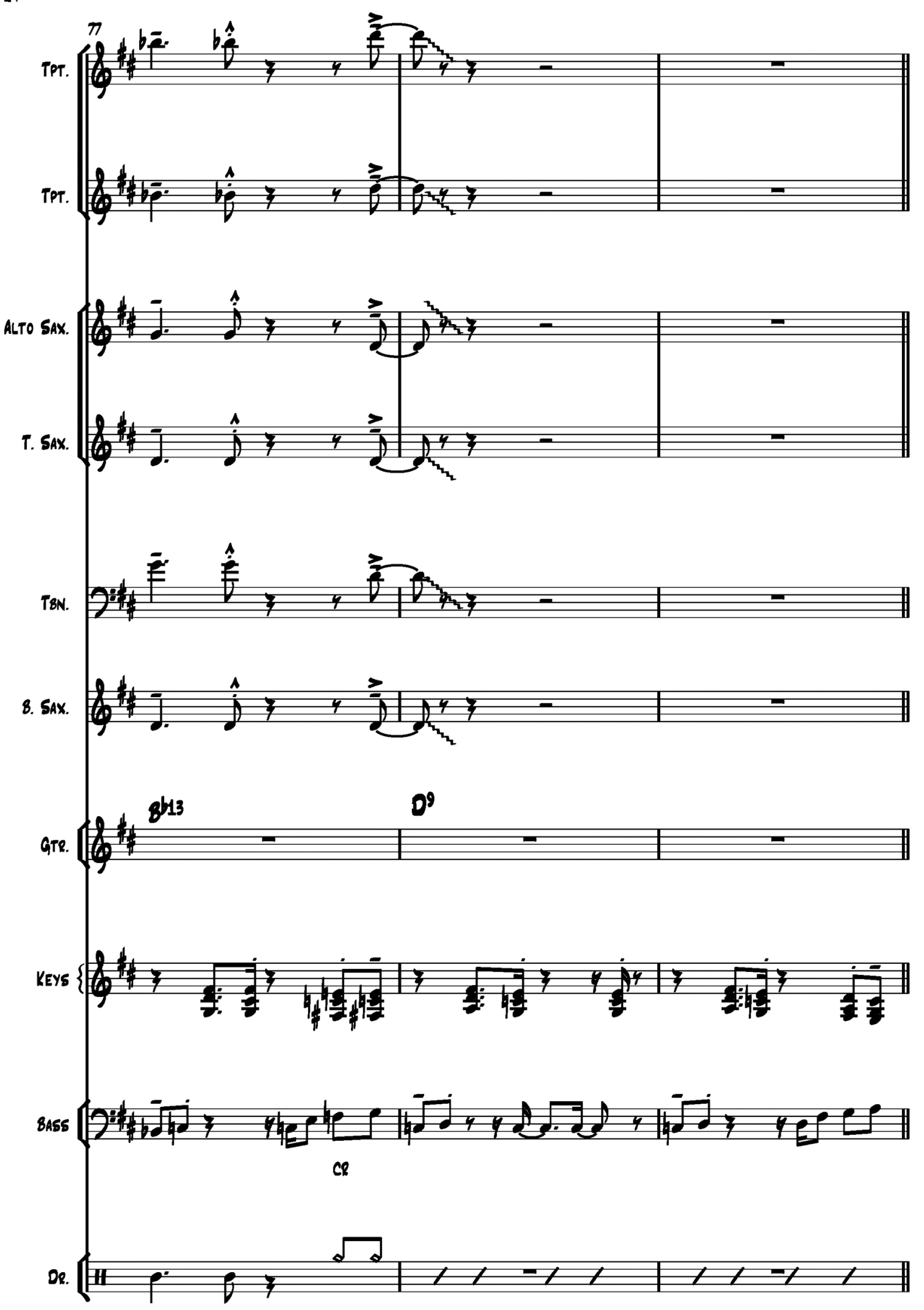

193 


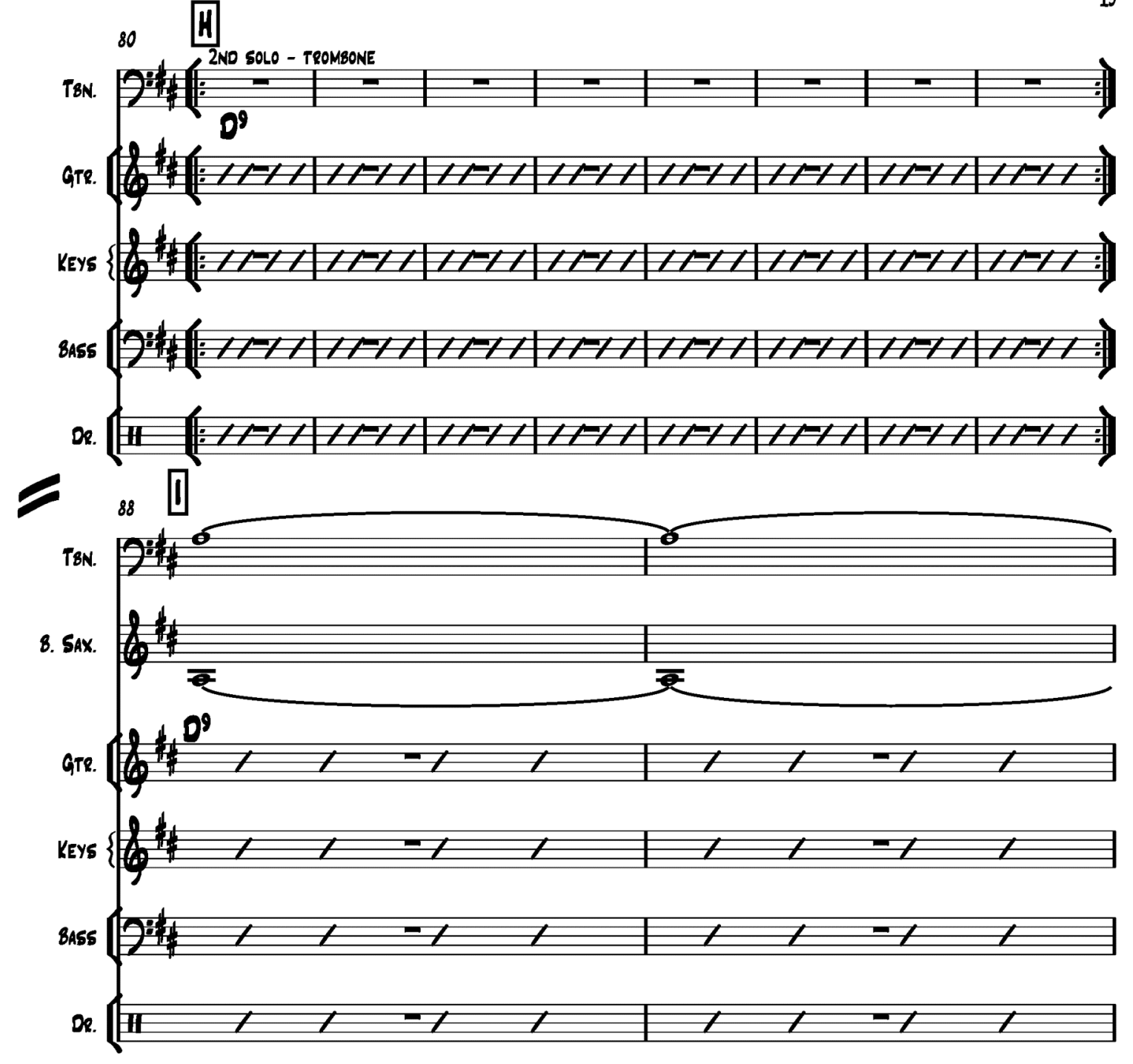


16

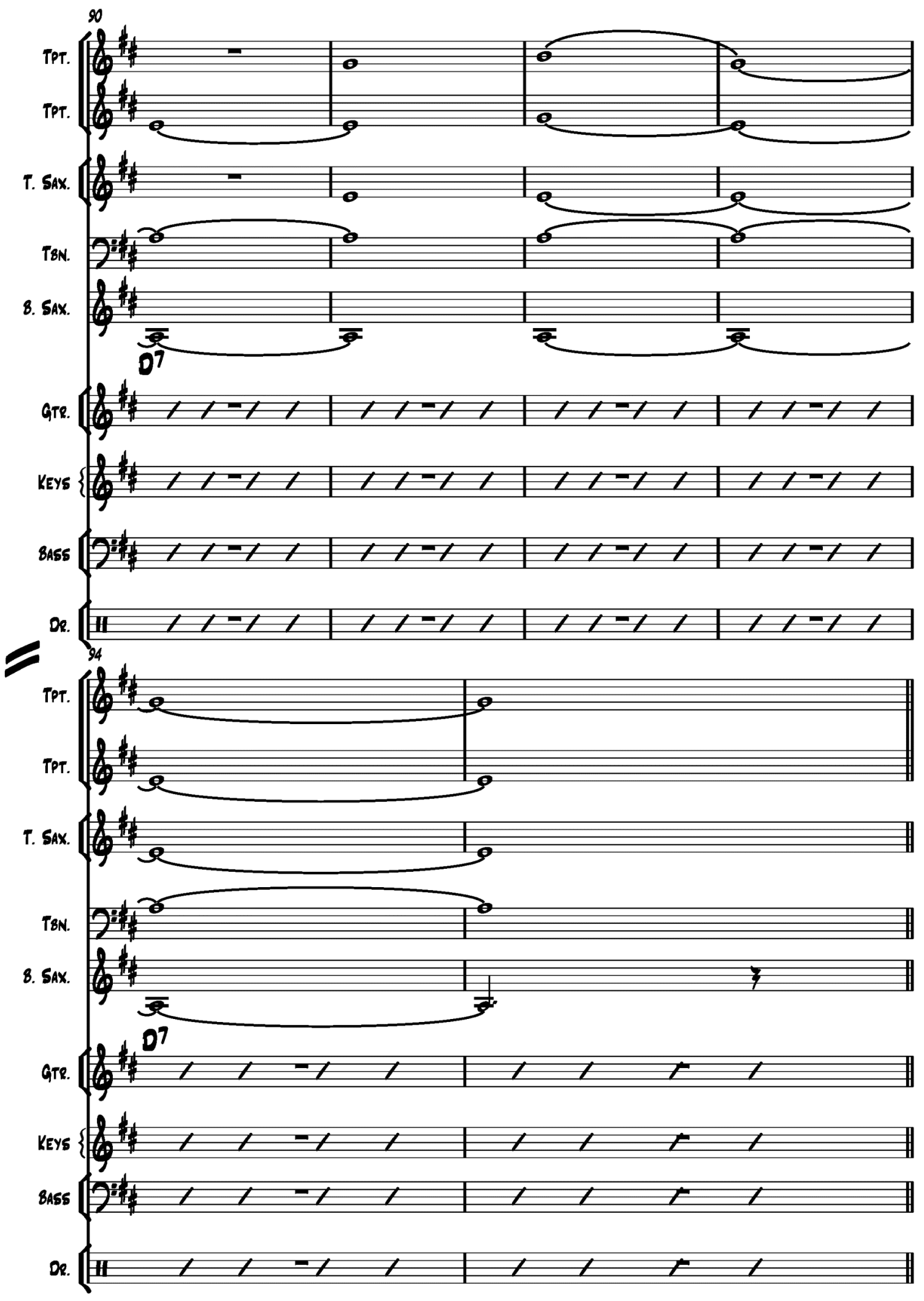




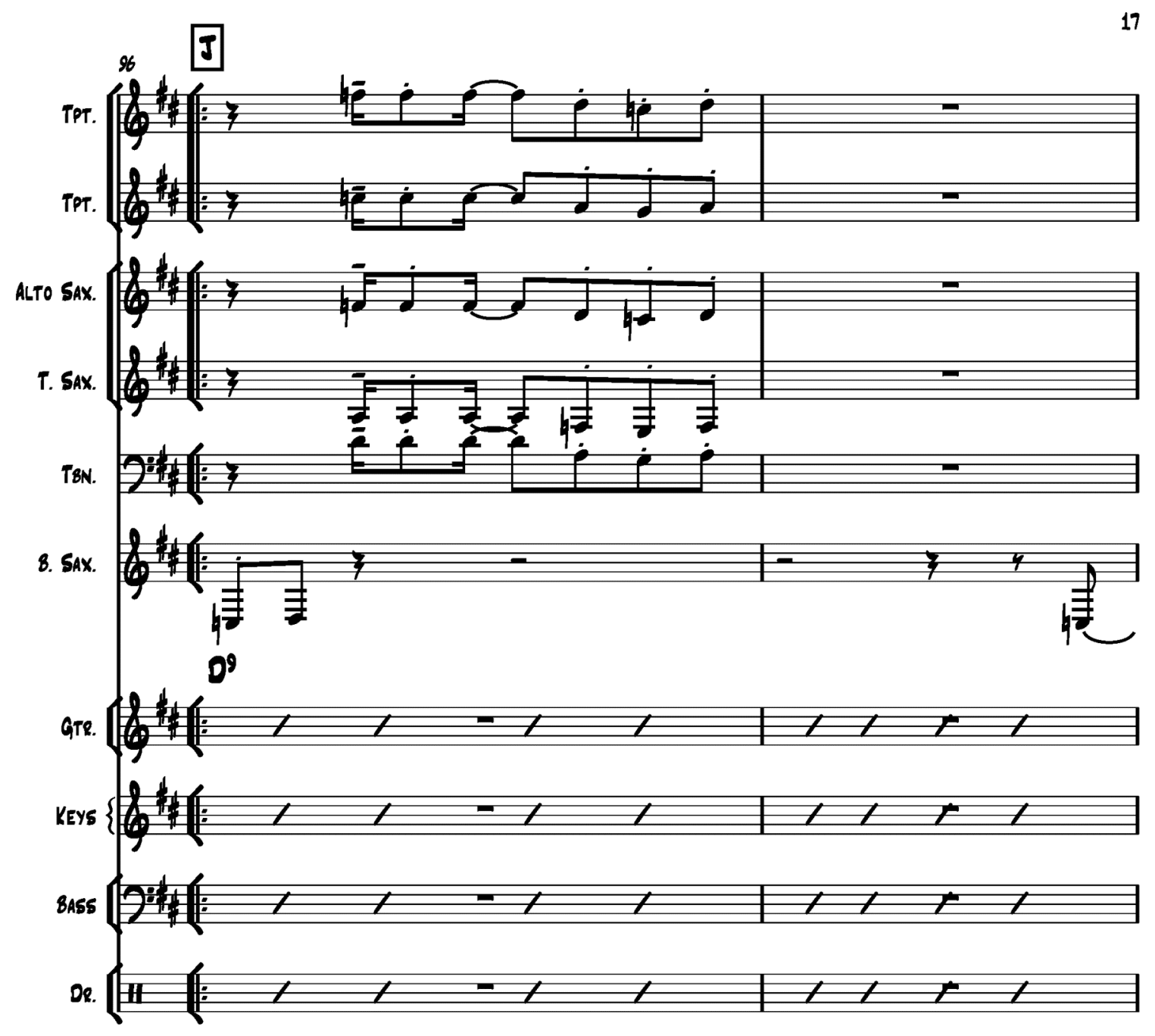




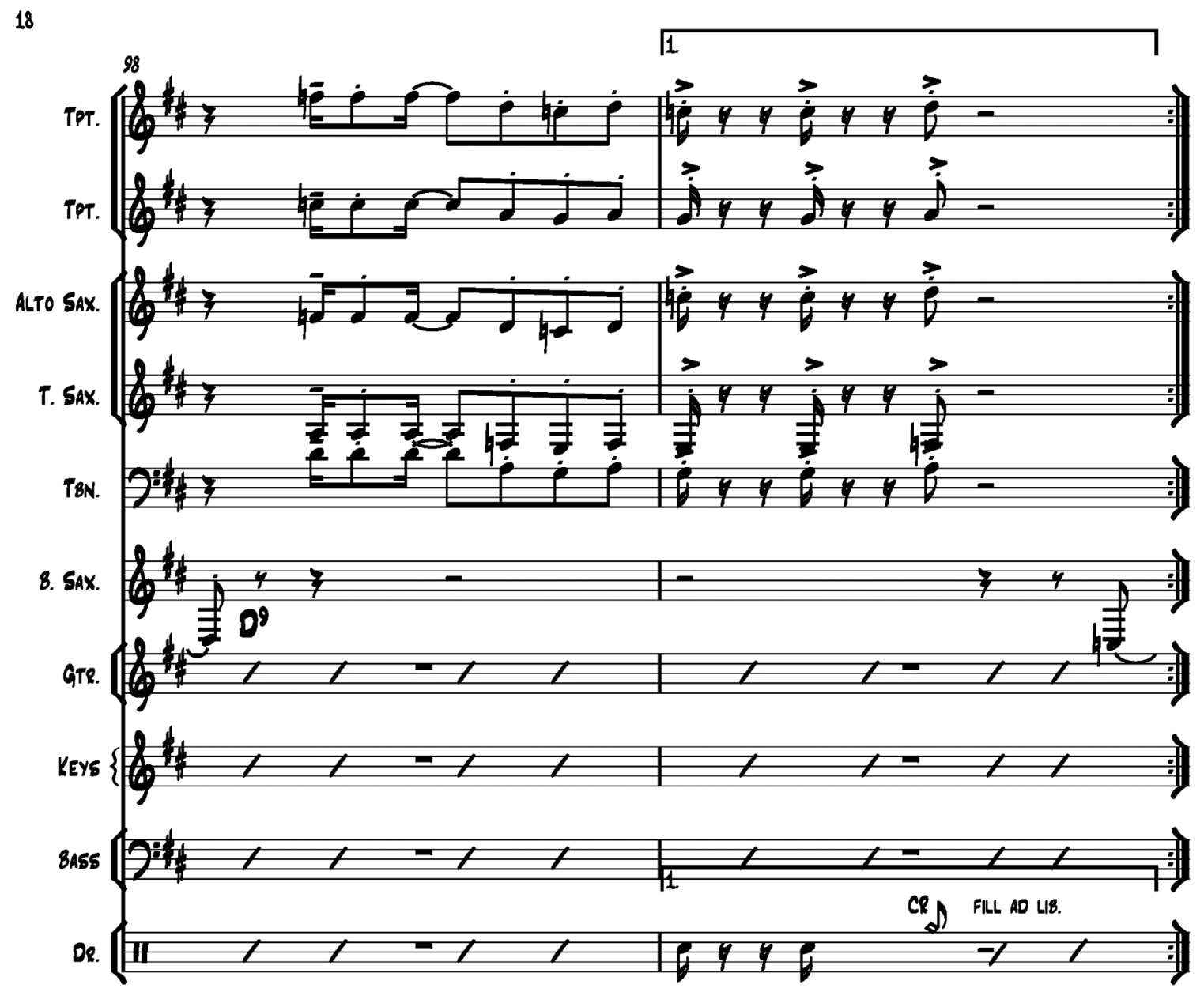




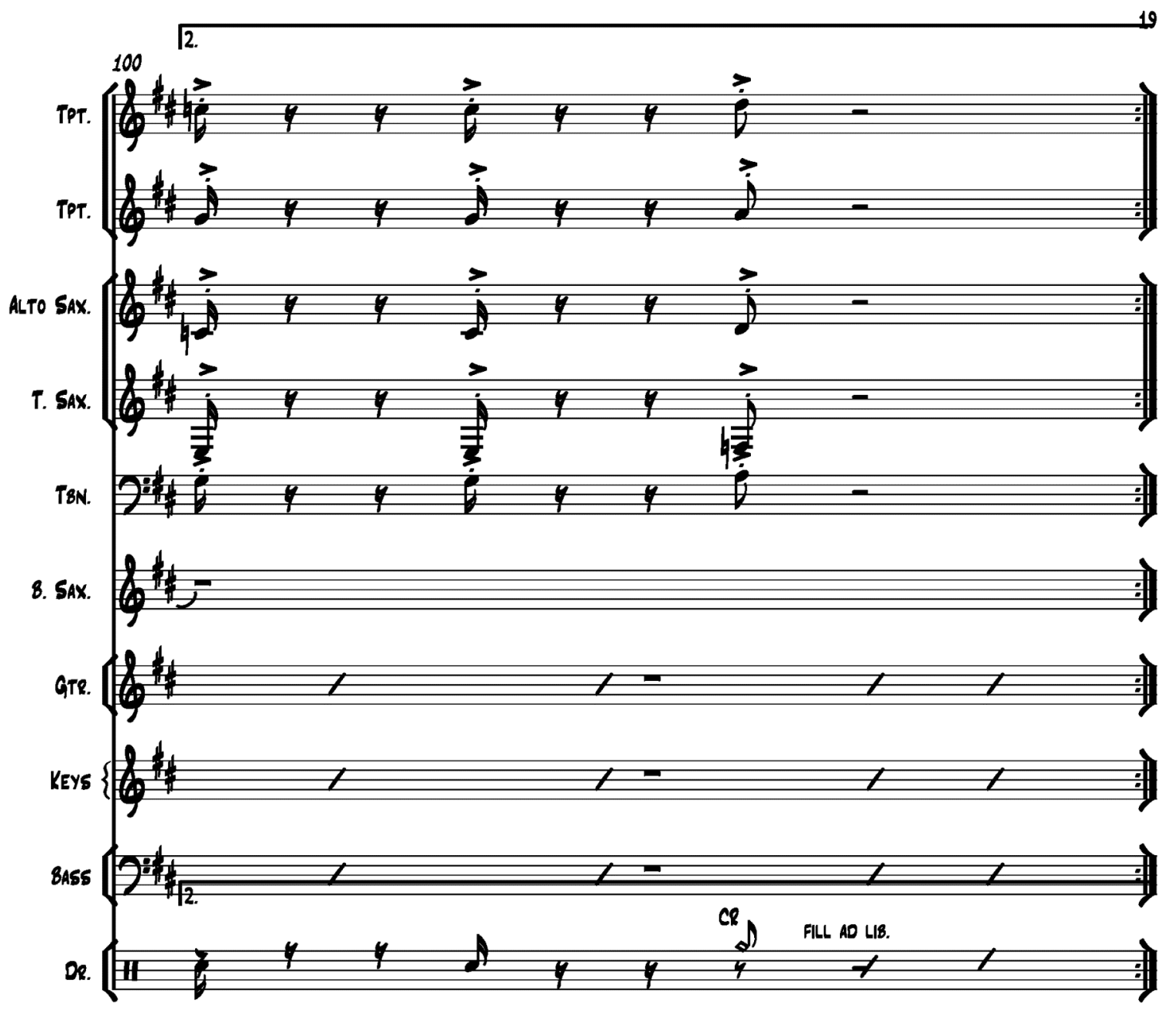

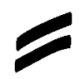

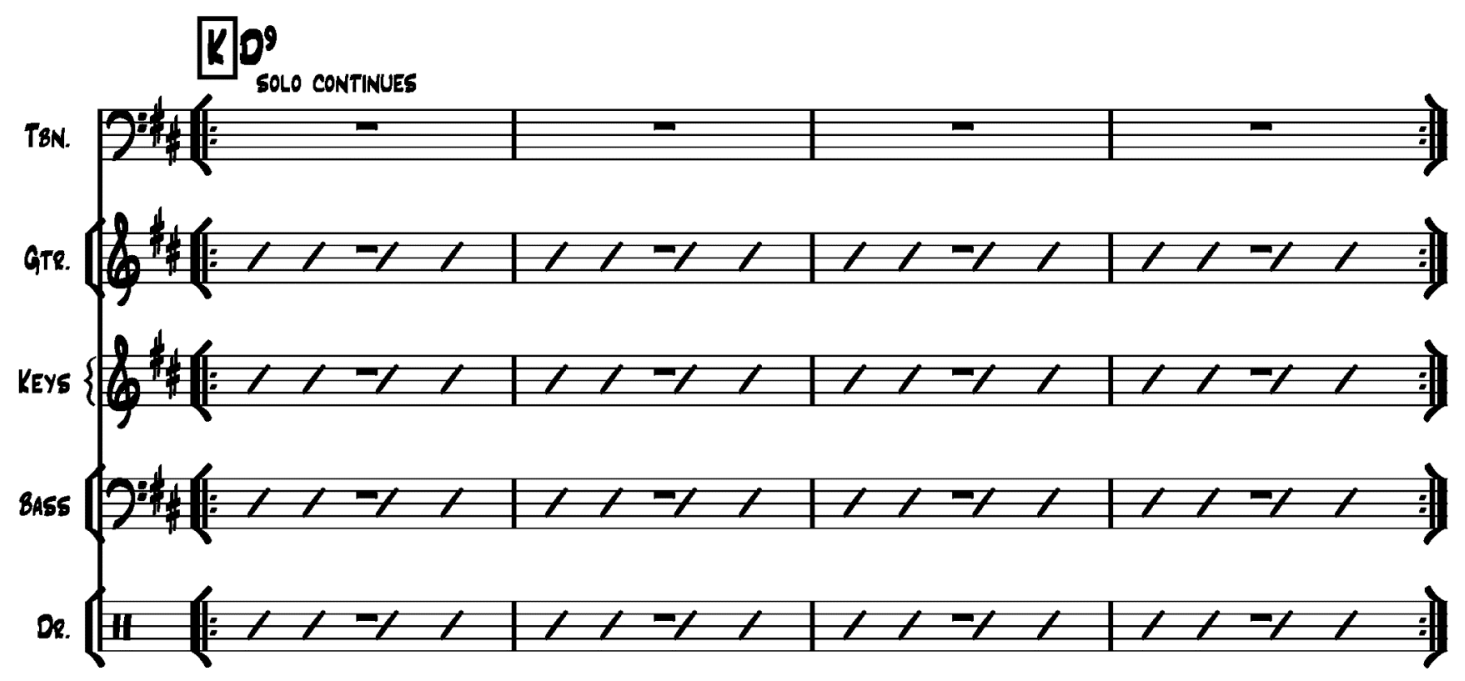

198 


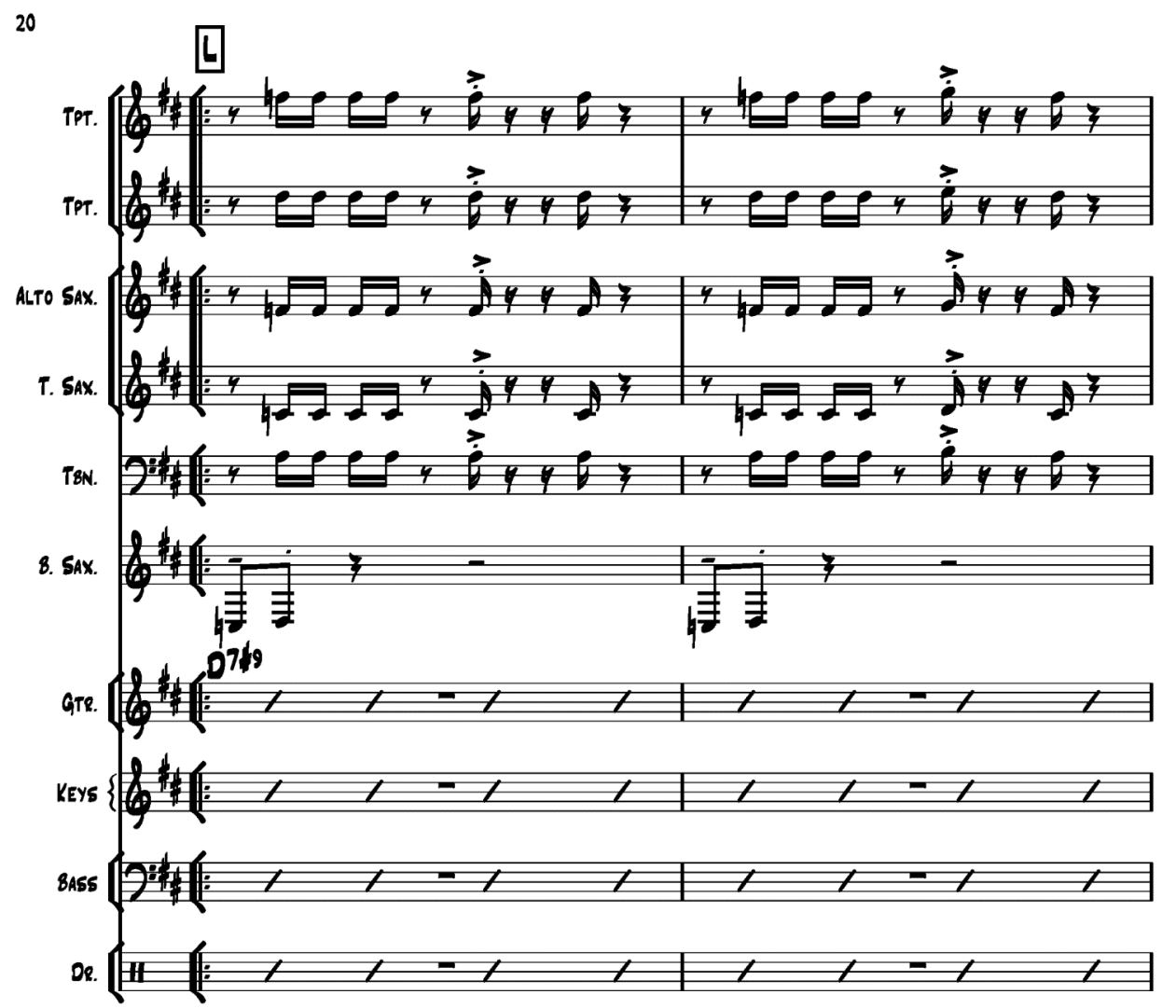




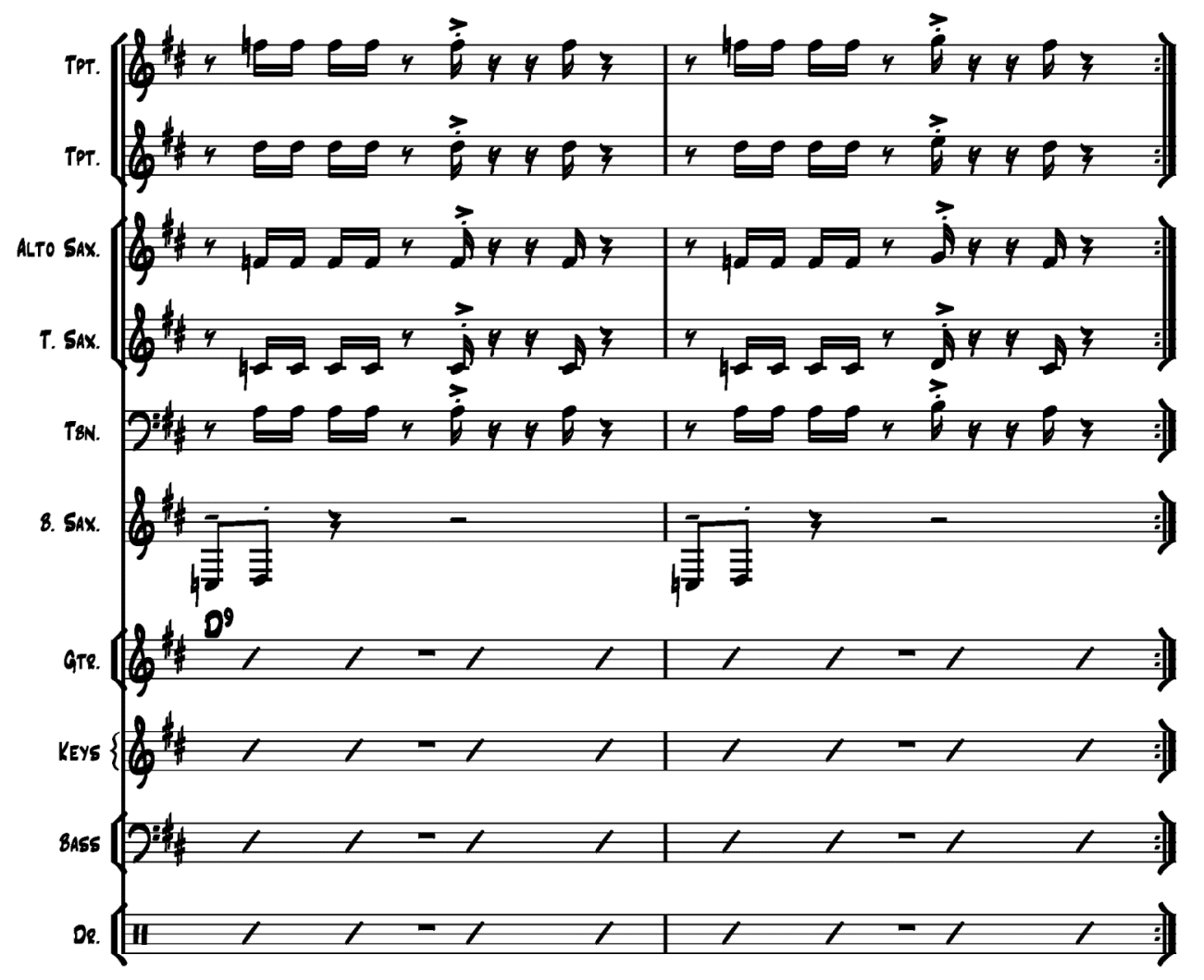


22

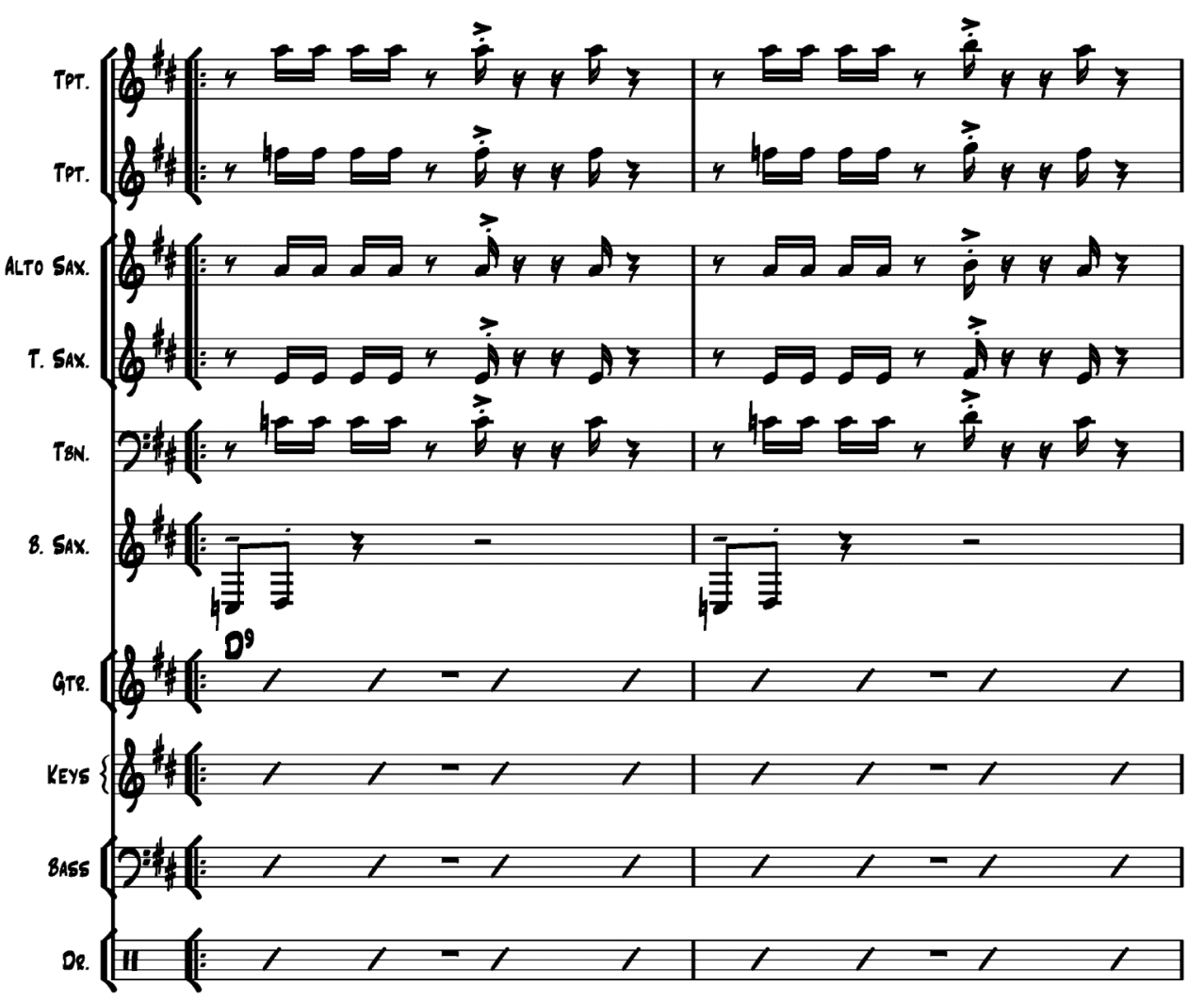

201 


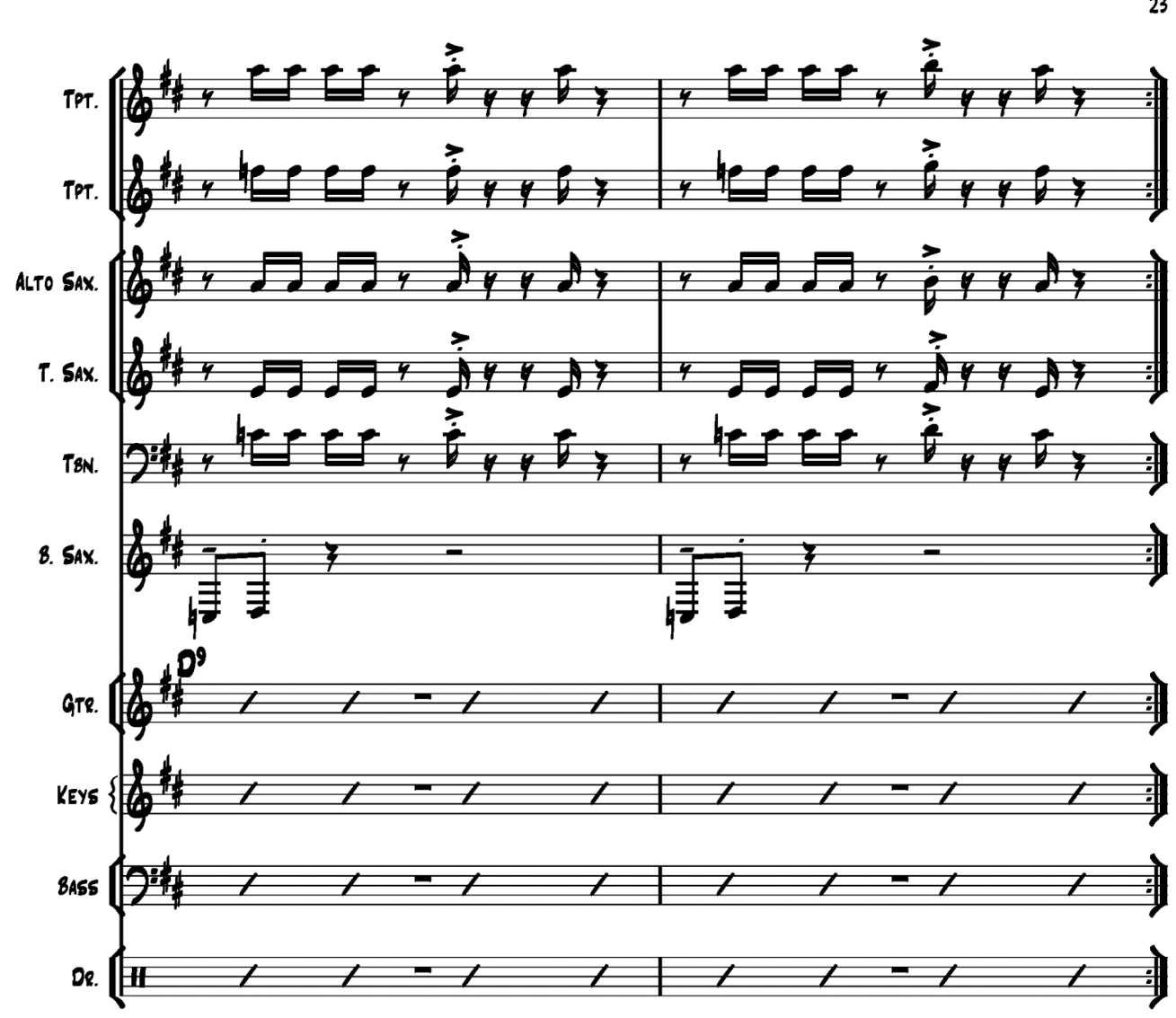




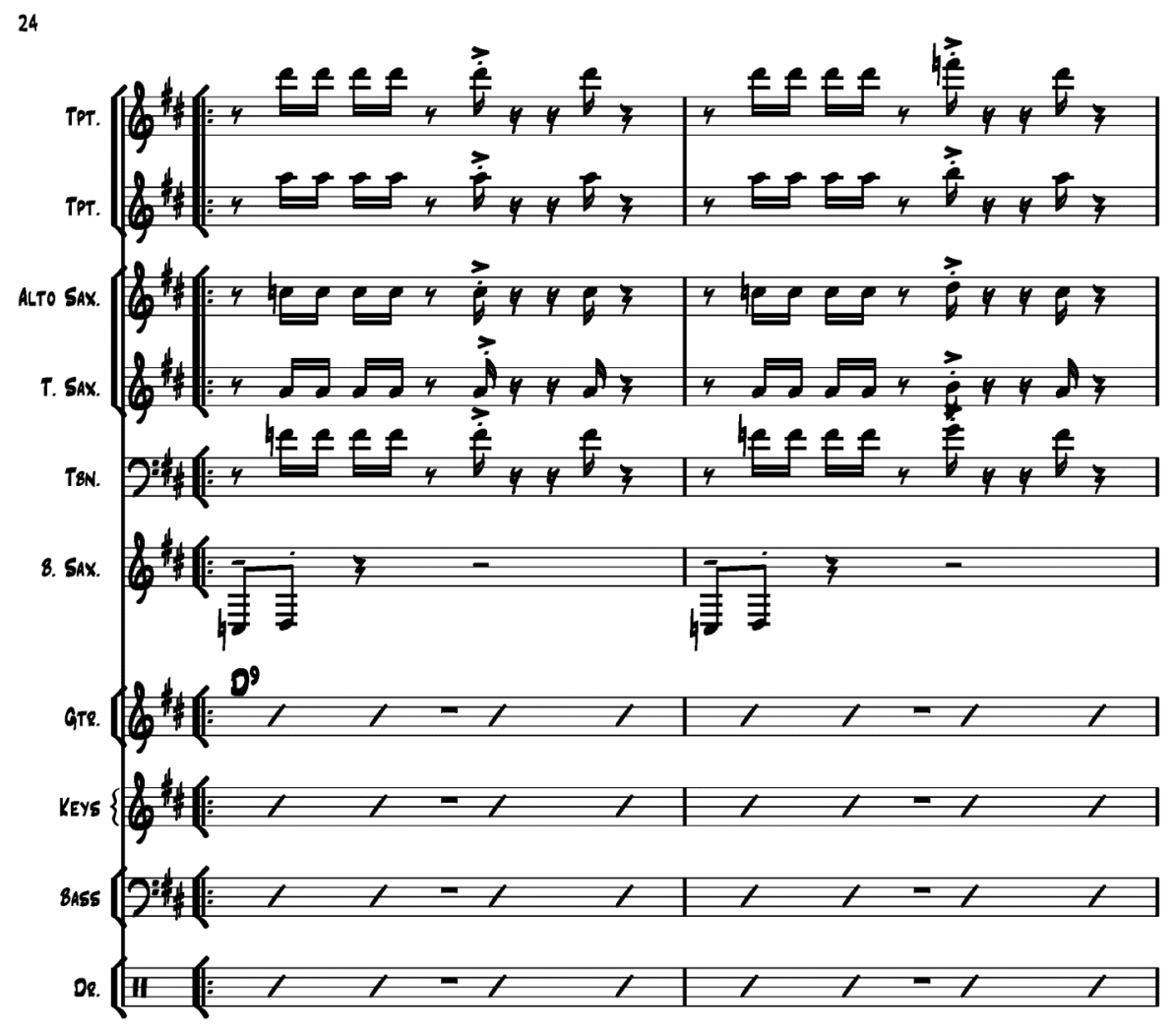



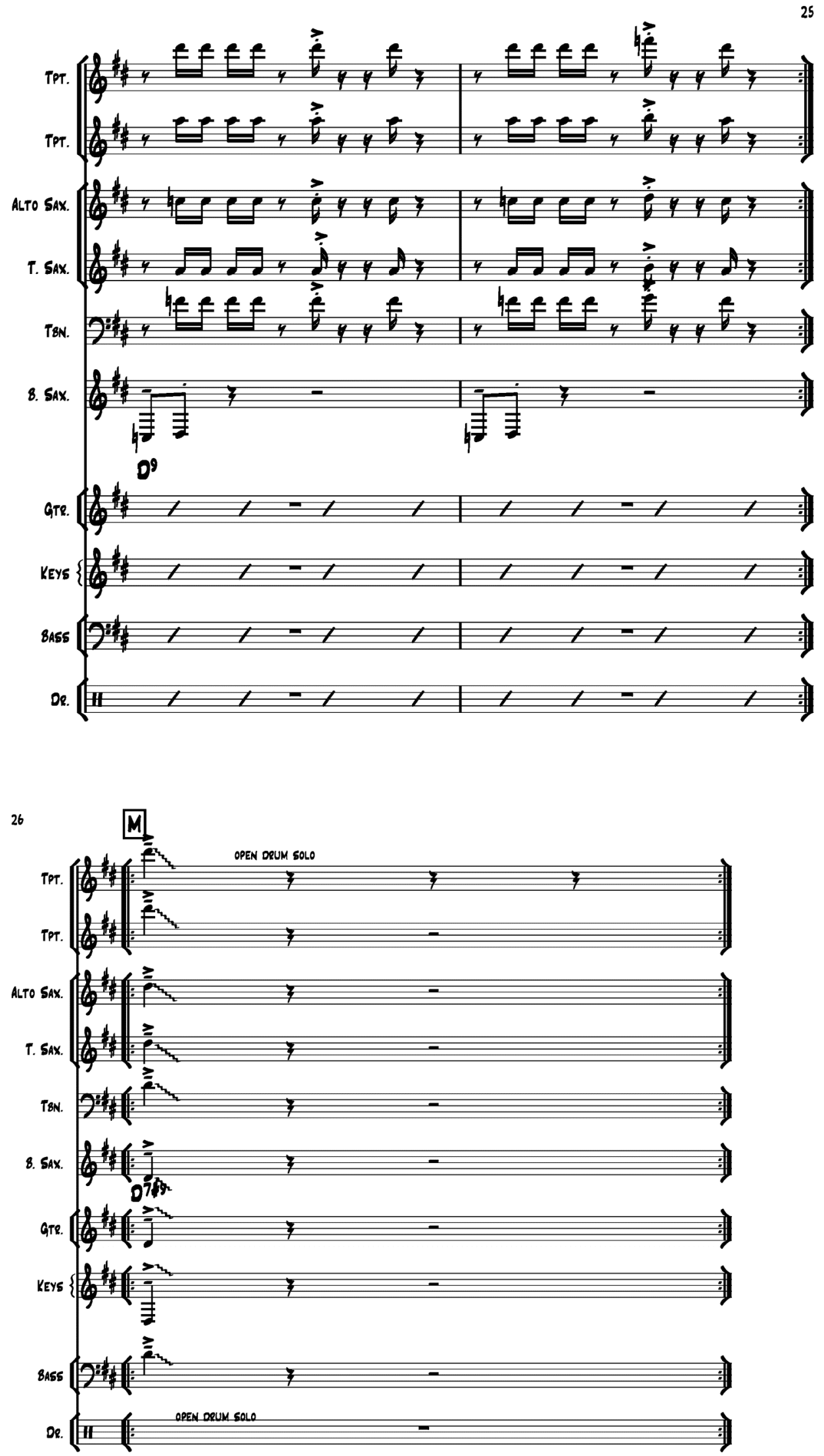


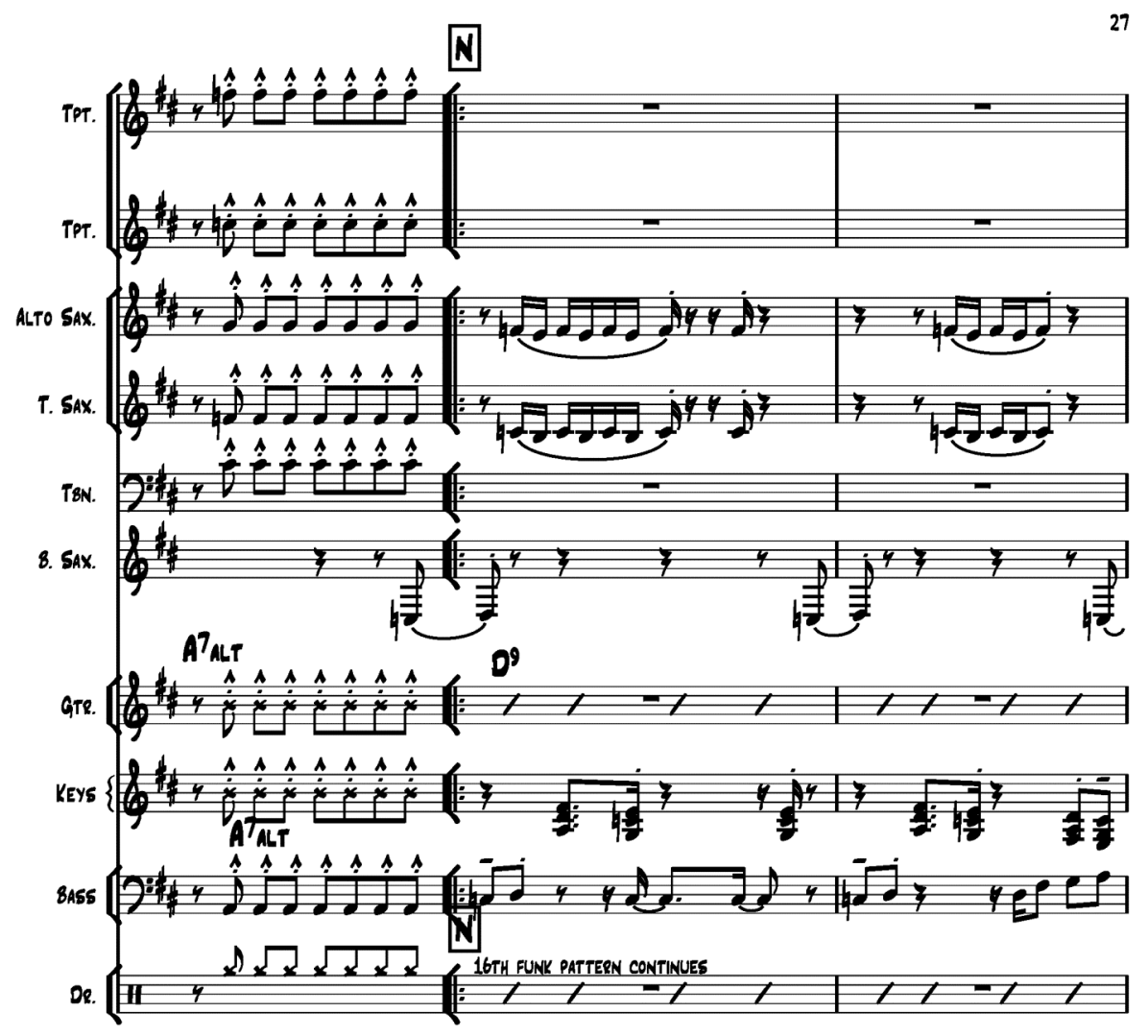



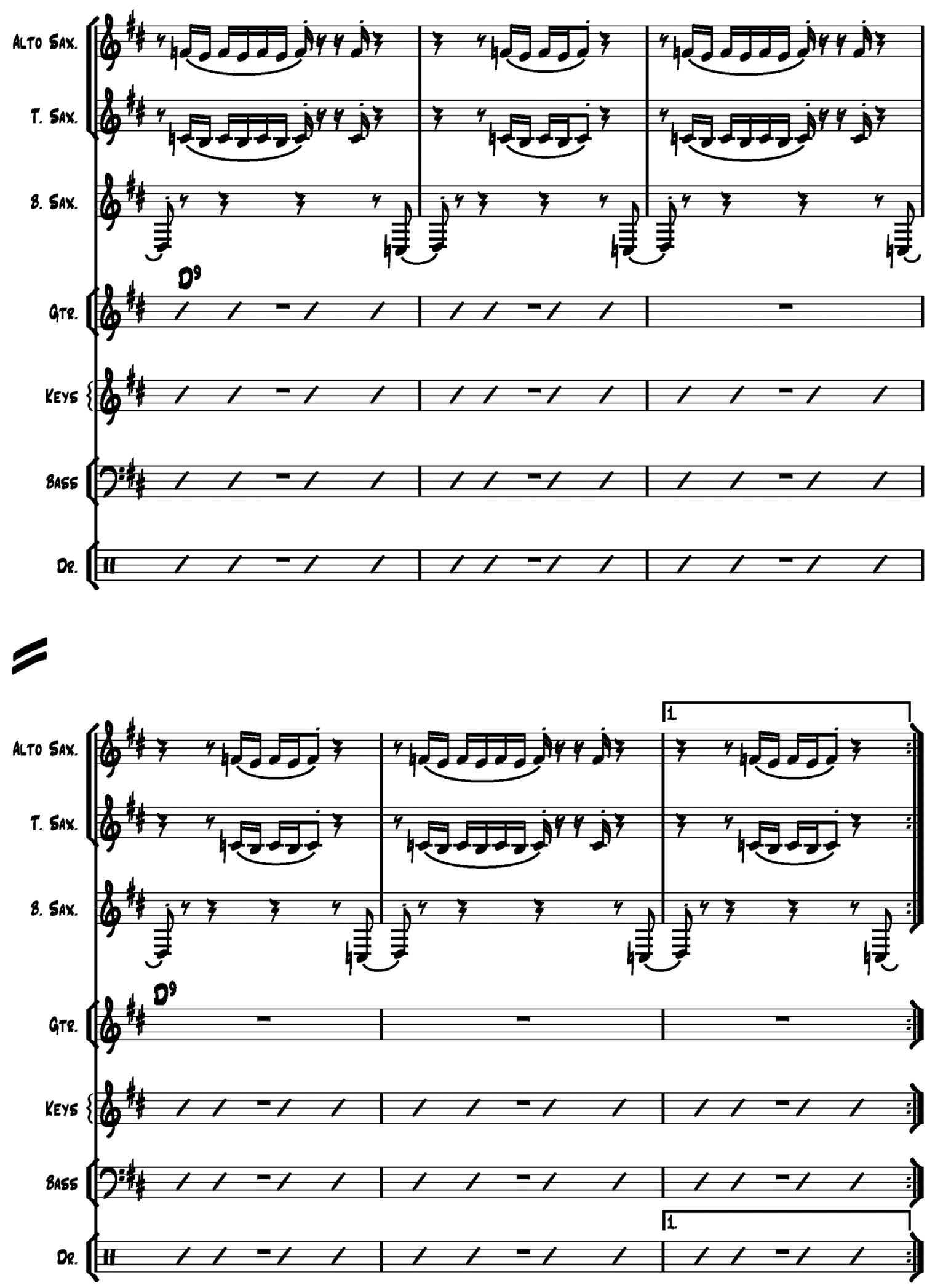

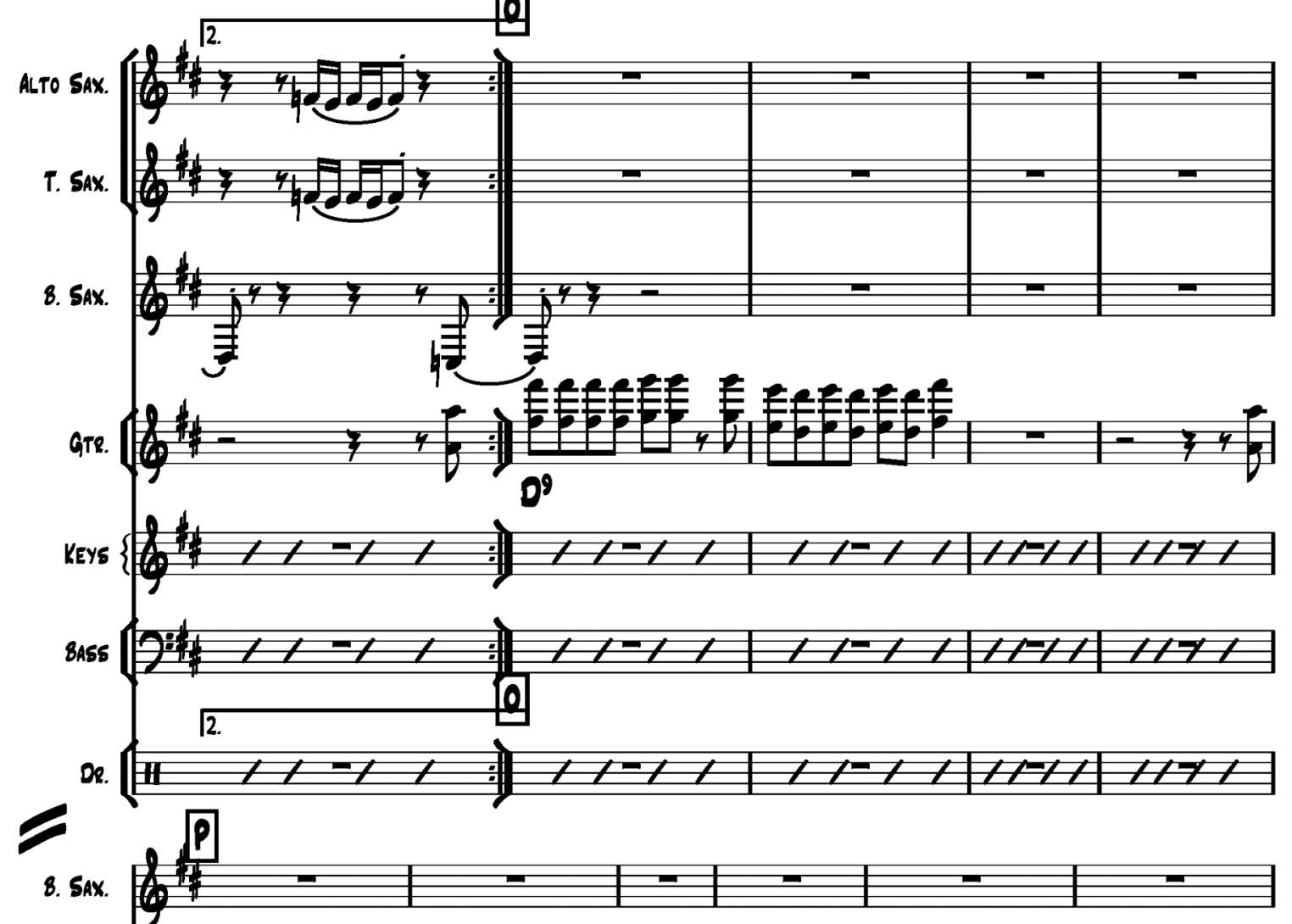
Gтr. $\left\{\begin{array}{l}\text { (1) } \\ 09\end{array}\right.$

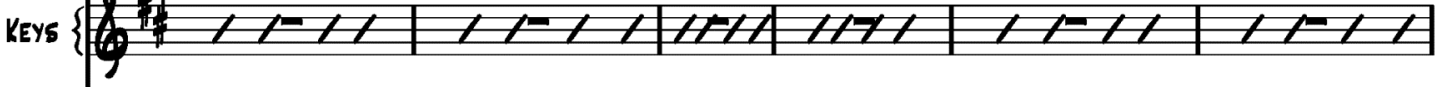

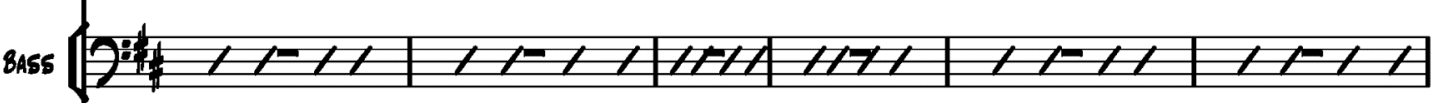
回 or.

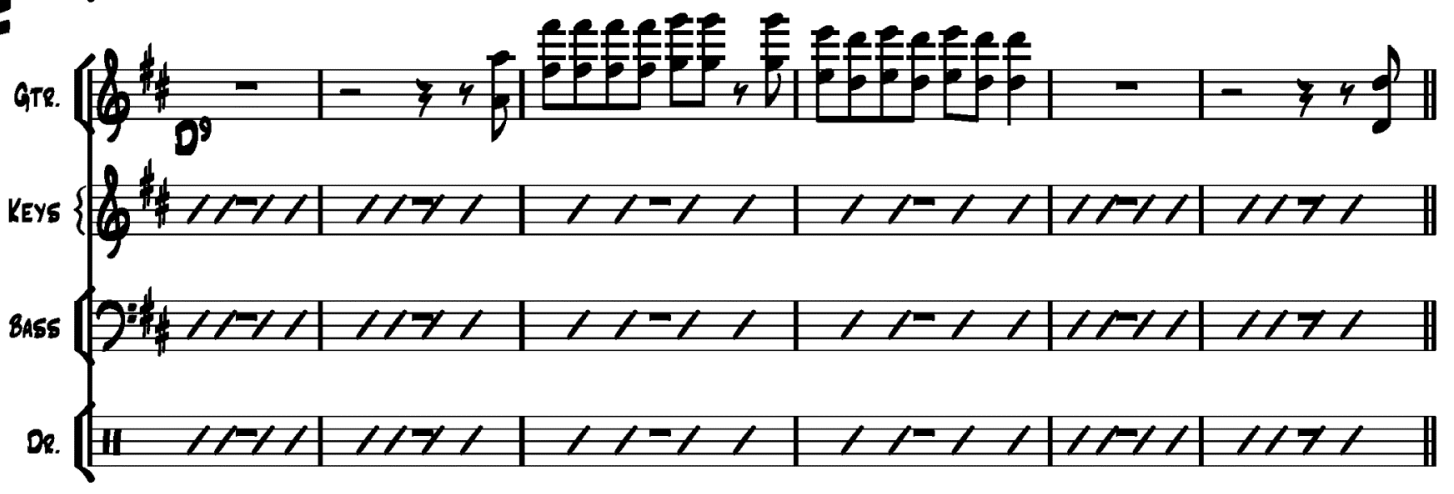




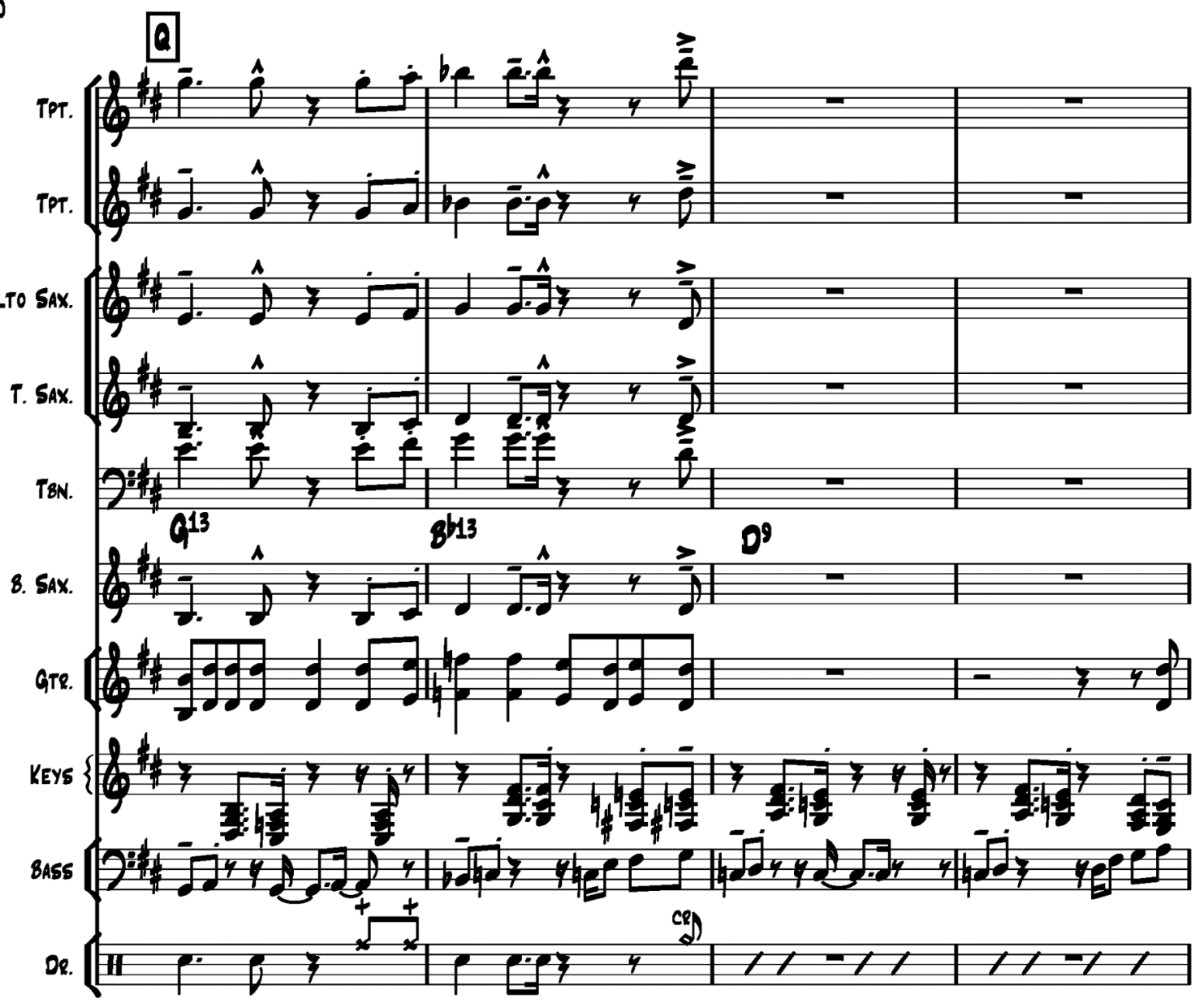




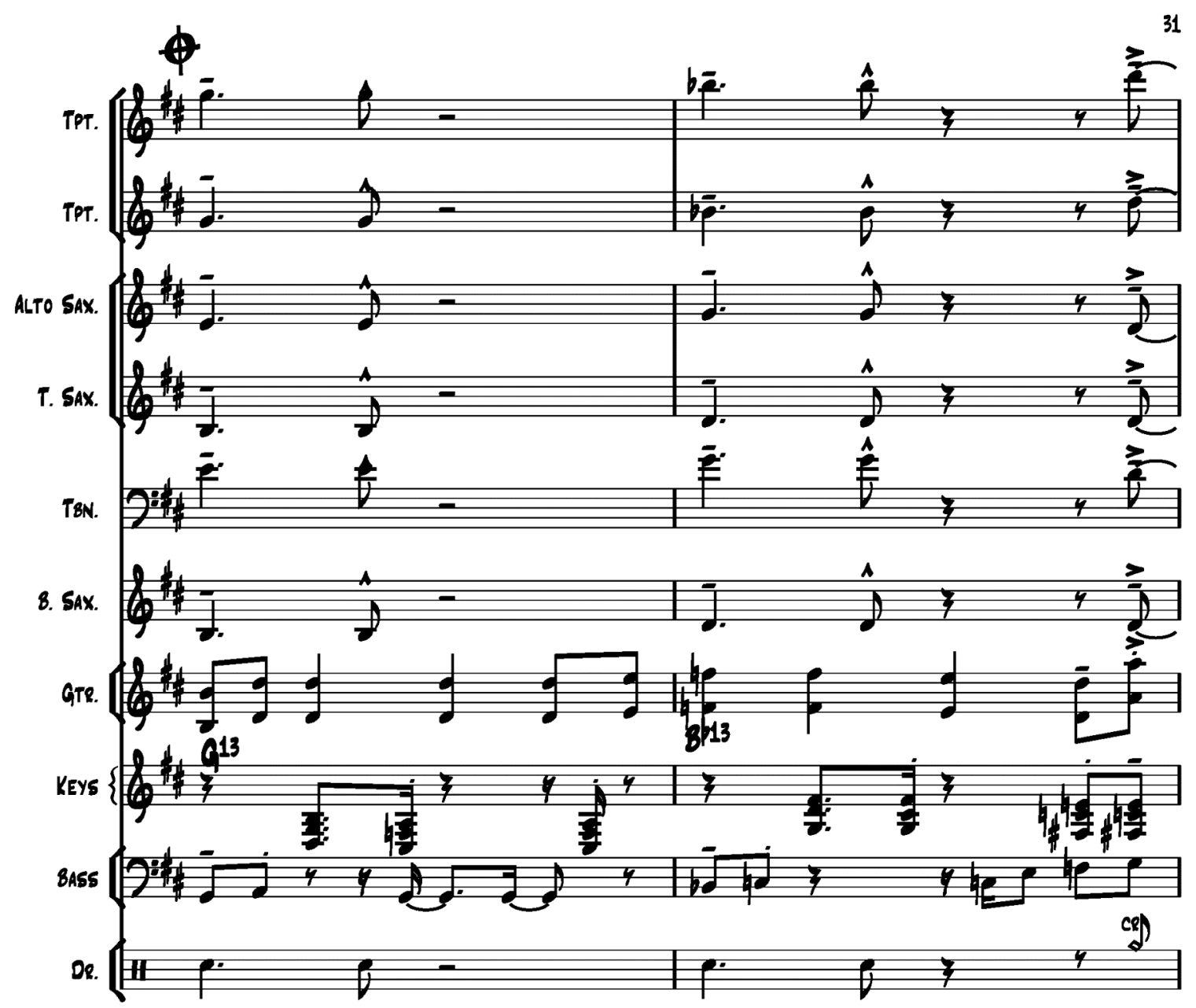


32

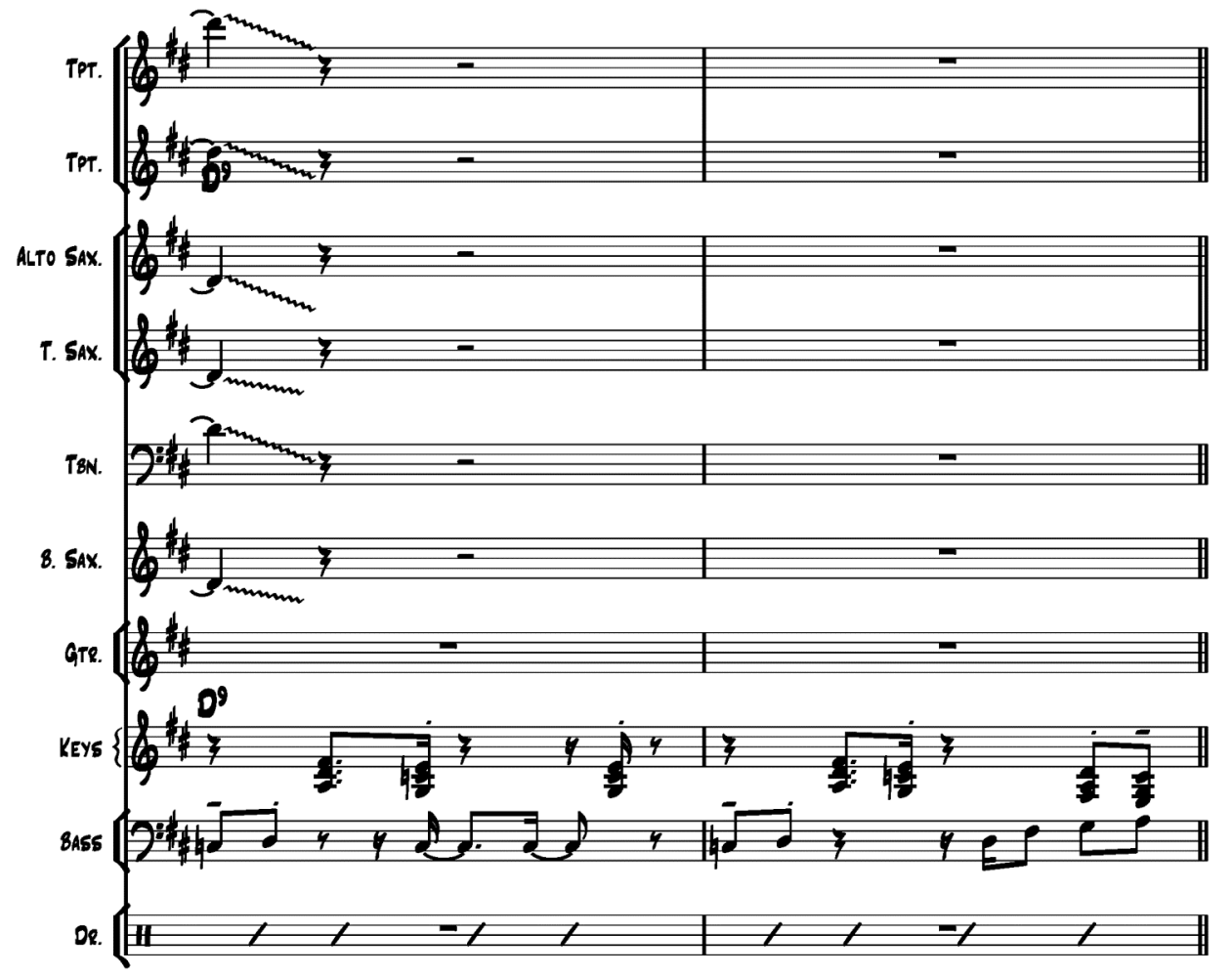




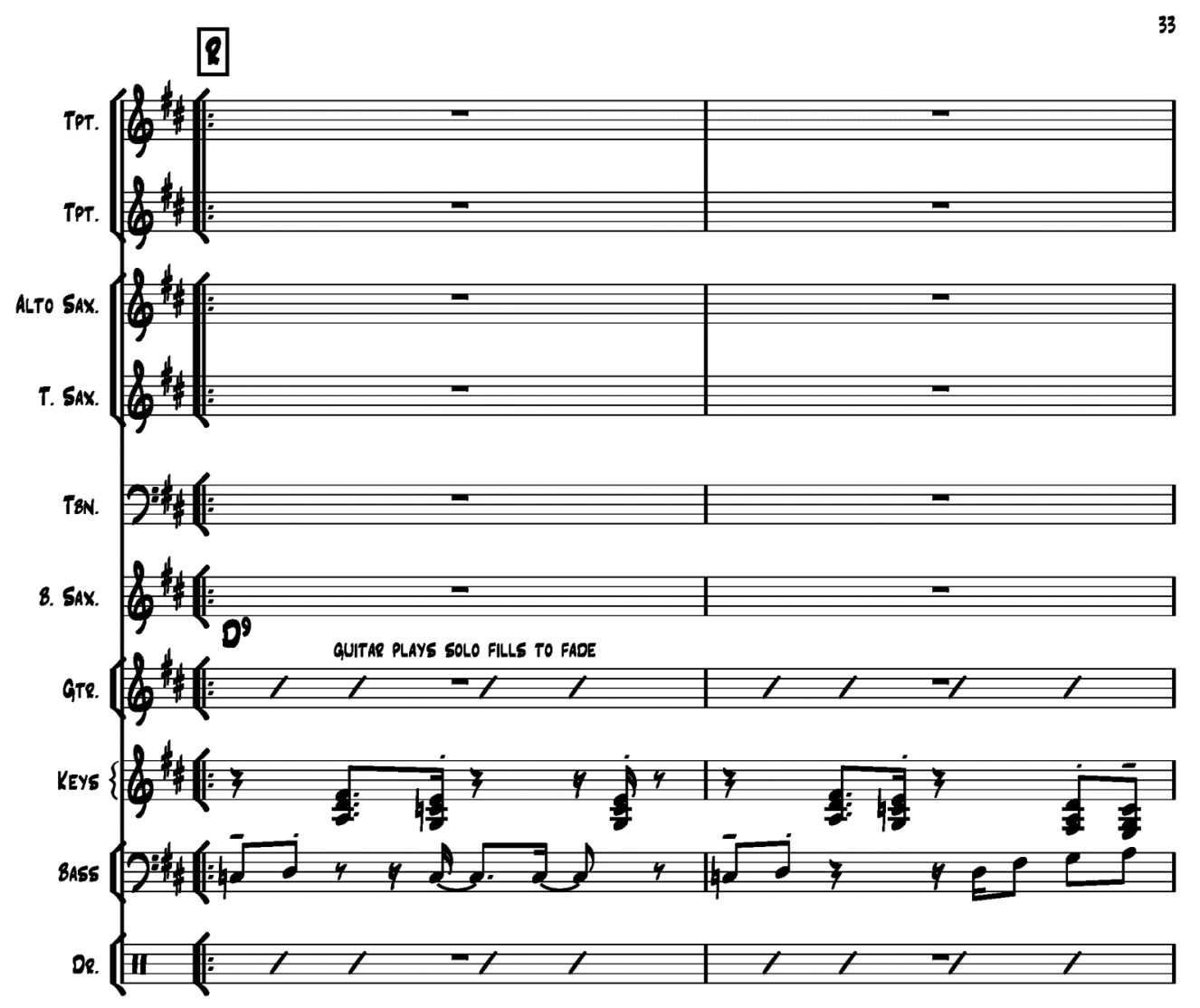


34

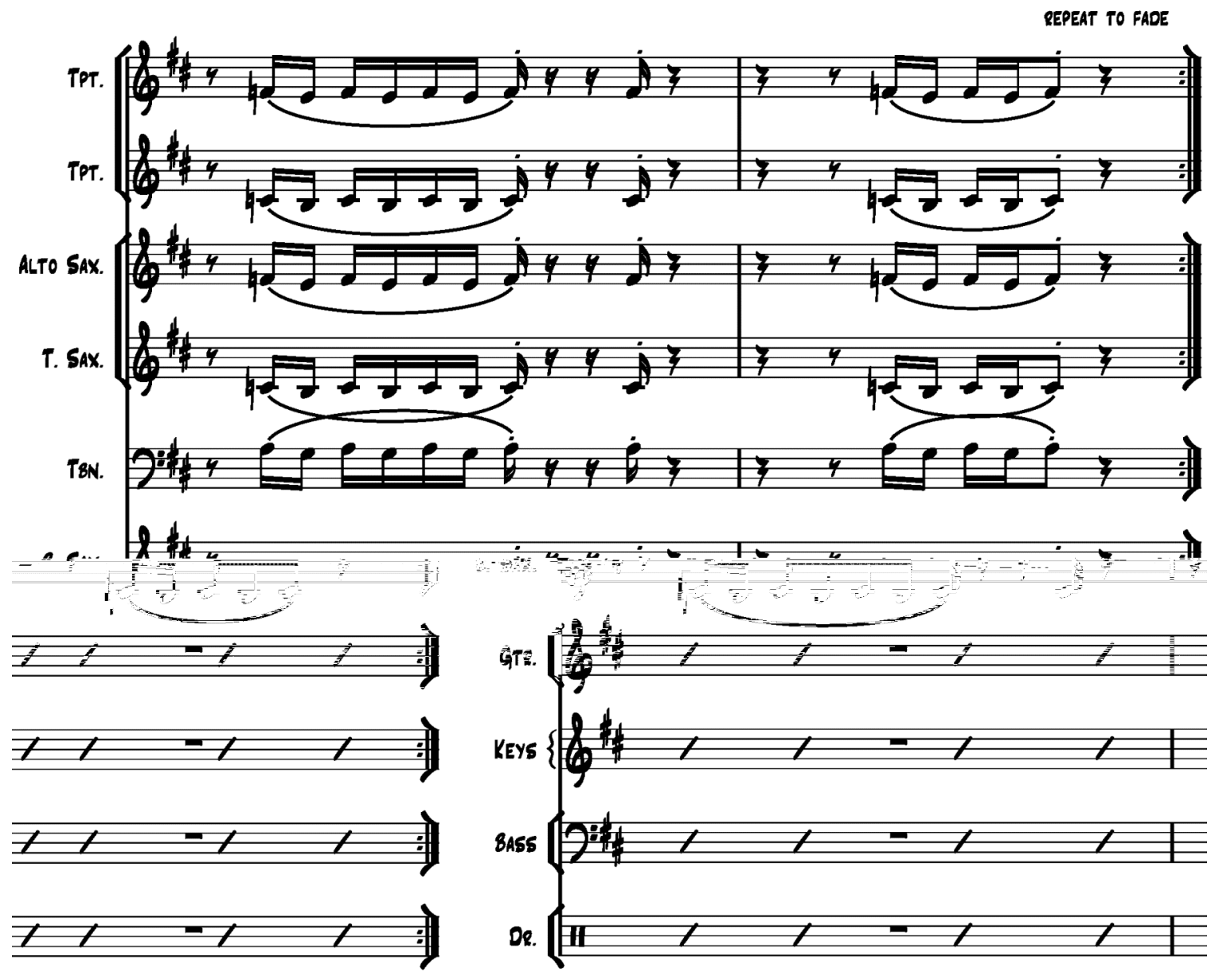




\section{Appendix 4}

Scores of Originals Songs - Part Three 
HEAVY ROCK

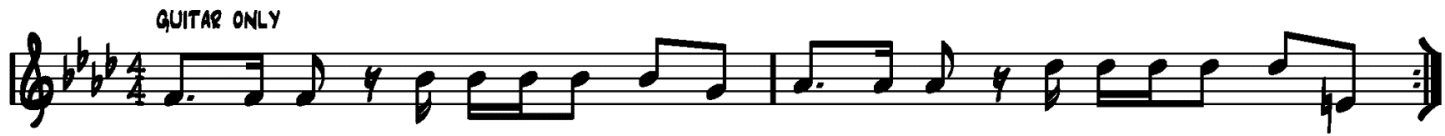

WHOLE BAND UNGON WITH DISTORTED GUITAR
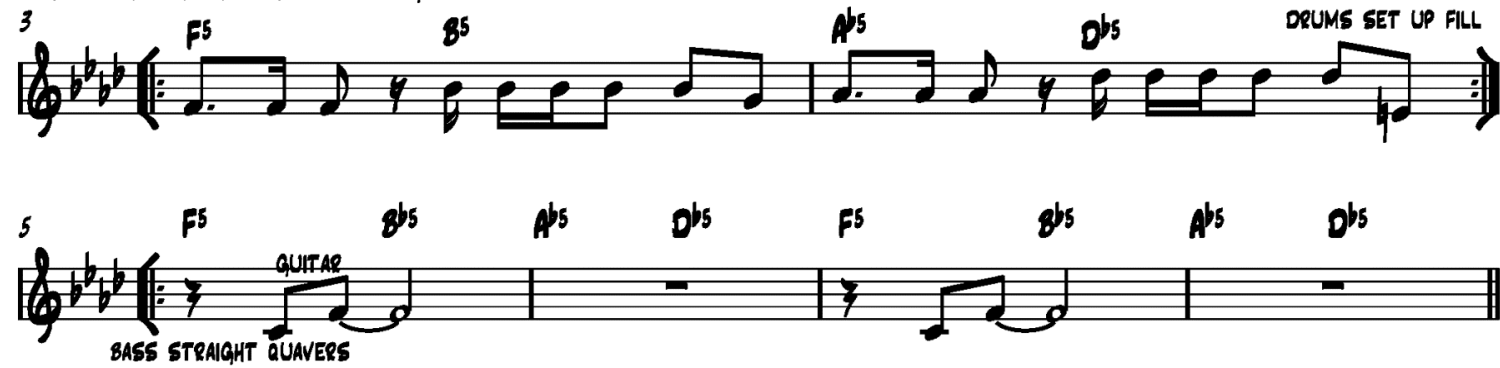

LOAOUP_ON OQANGS

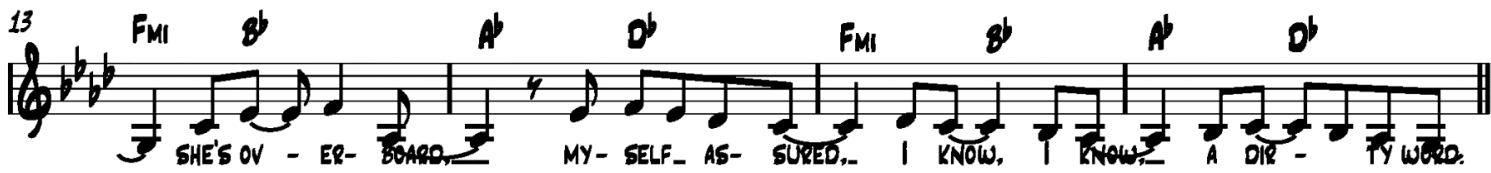

17 8

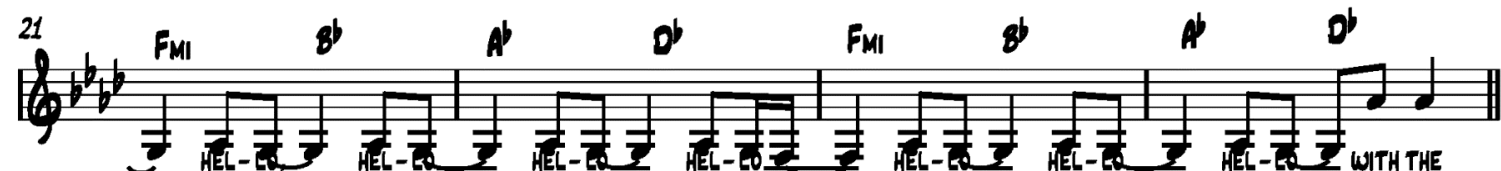
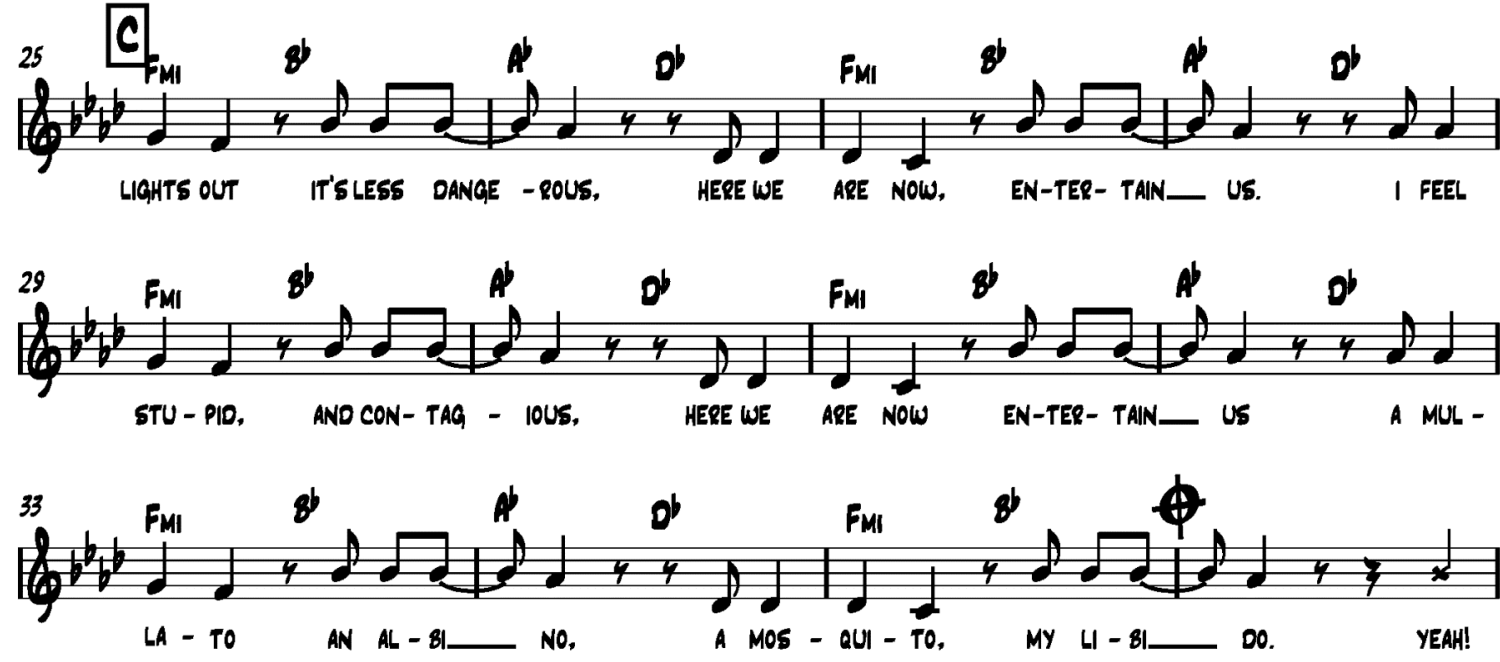

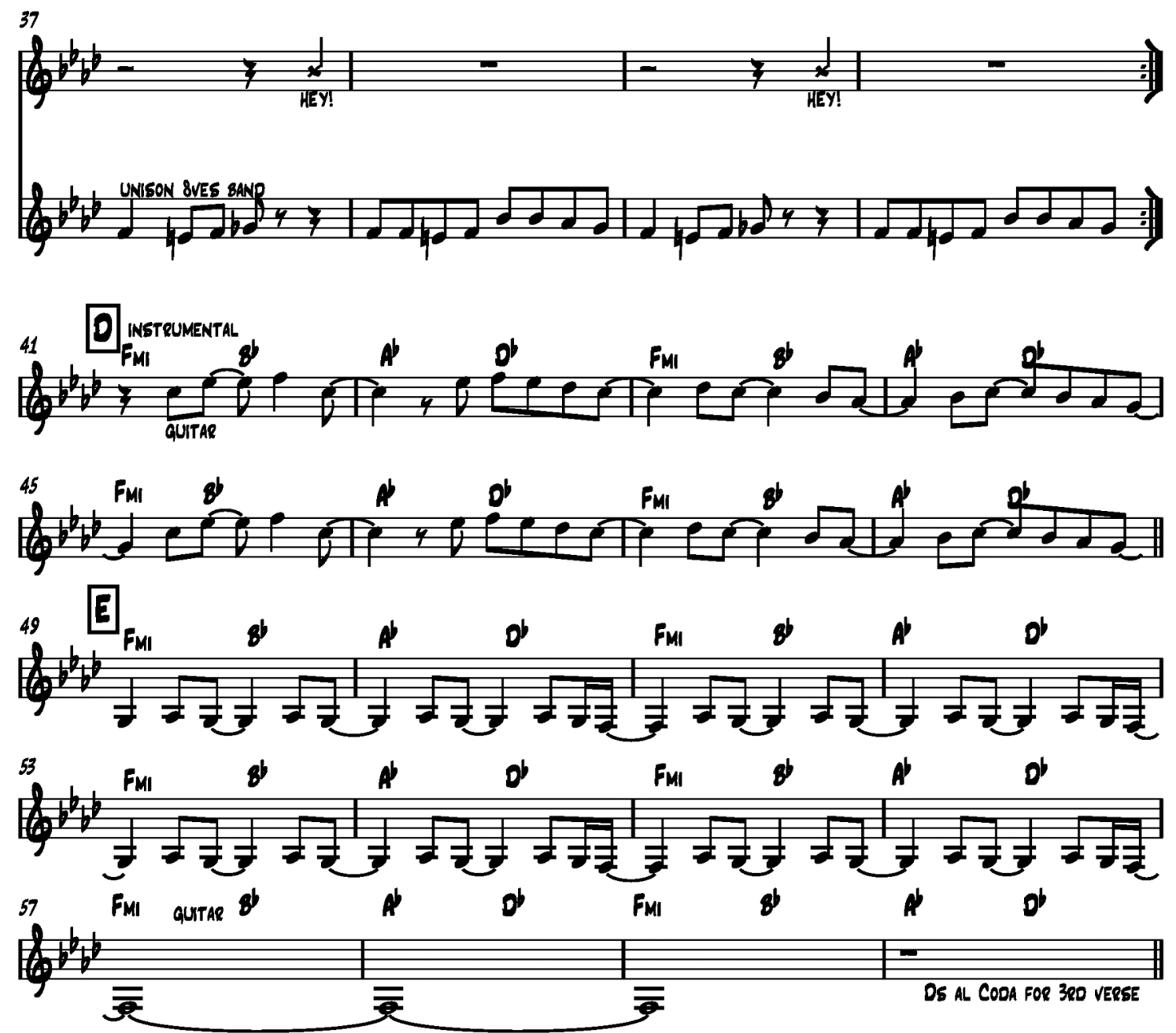

VEREE 2 - IM worse at what I do best, And for this gift I feel blessed

Our little group has always been, And always will until the end

Hello.....

Verse 3 - And I forget Just what it takes And yet I guess it makes me smile,

A. I found it hardlts hard to find Oh well, whatever, nevermind

Hello.....
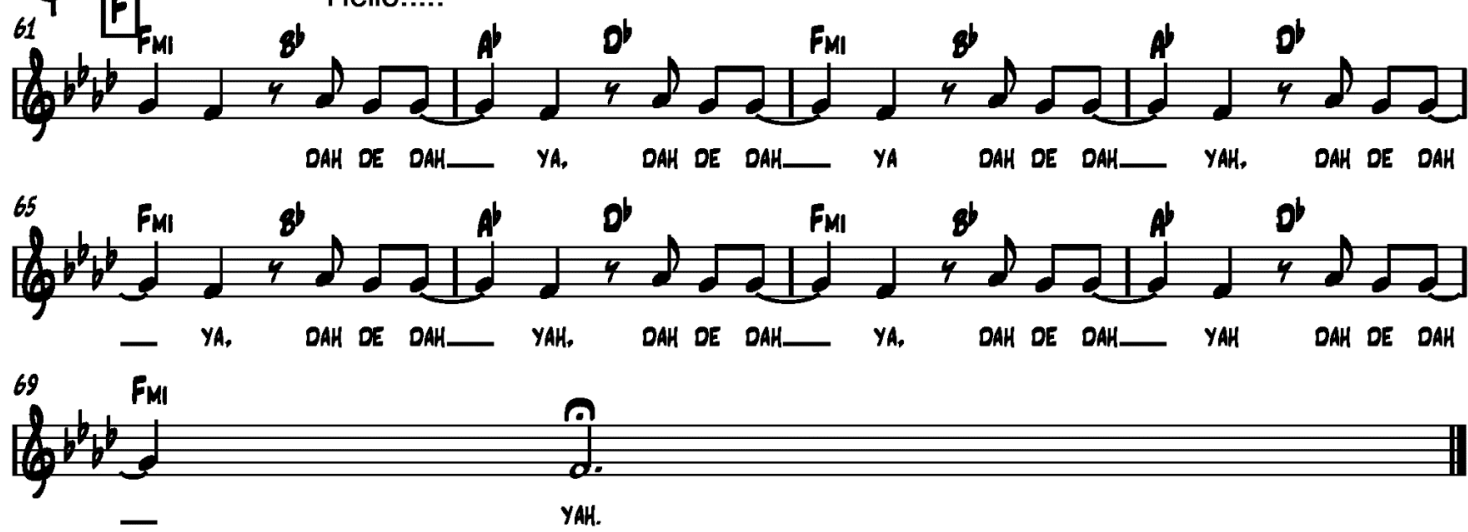

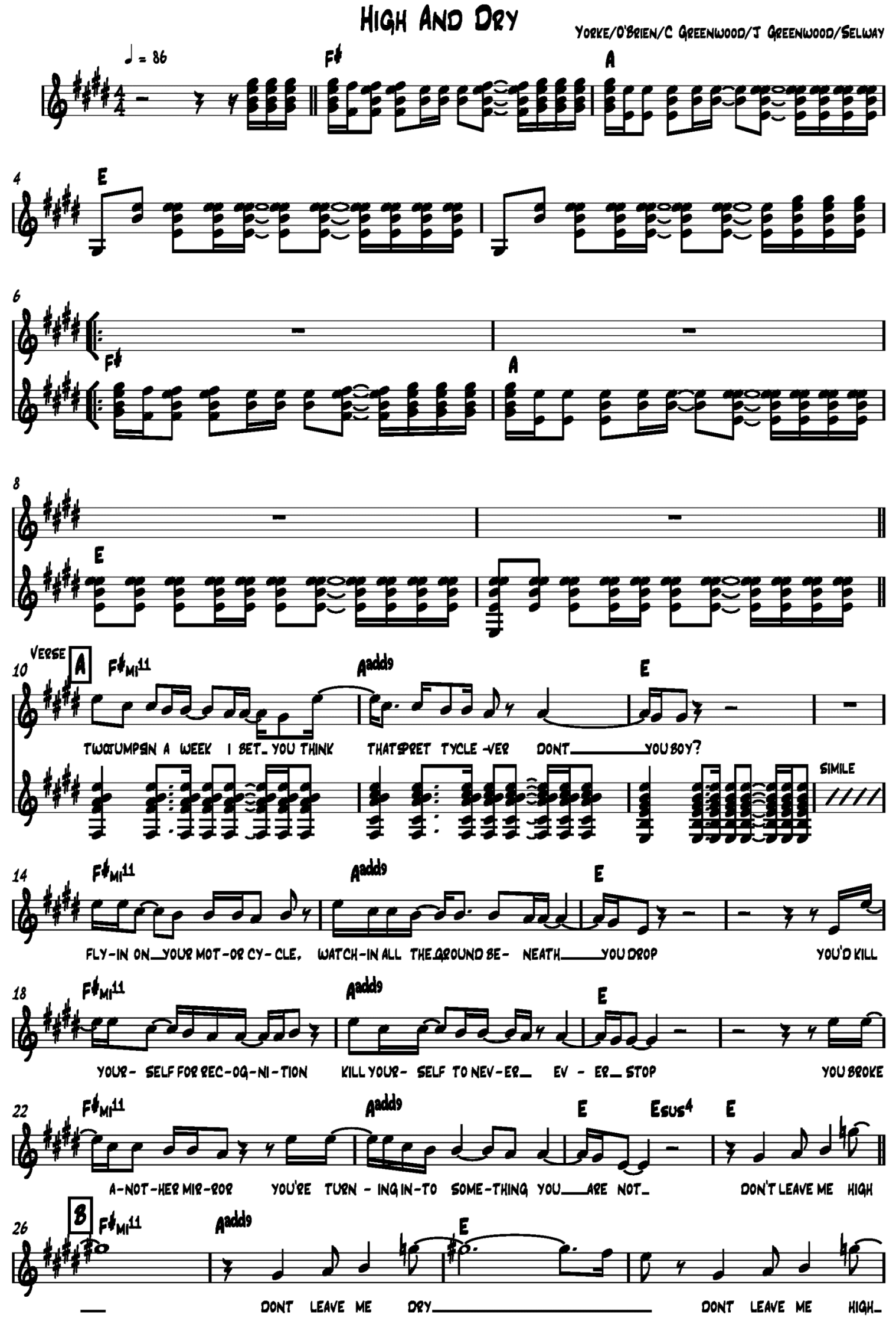


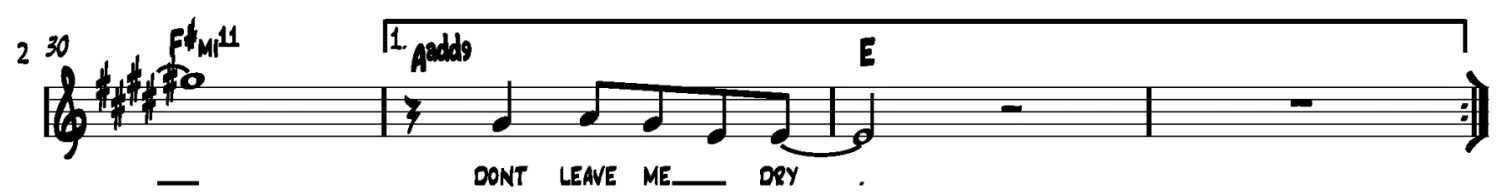

VERSE 2

ORYING UP IN CONVEPSATION, YOU WXLL BE THE ONE WHO CANNOT TALK.

ALL YOUR INSIDES FALL TO PIECES, YOU JUST SIT THERE WIEHING YOU COULD STILL MAKE LOVE.

THEY'RE THE ONES WHO'LL HURT YOU. WHEN YOU THINK YOU'VE GOT THE WORLO ALL SUSSED OUT.

THEY'RE THE ONES WHO'LL SPIT AT YOU, YOU WILL BE THE ONE SCREAMIN OUT.
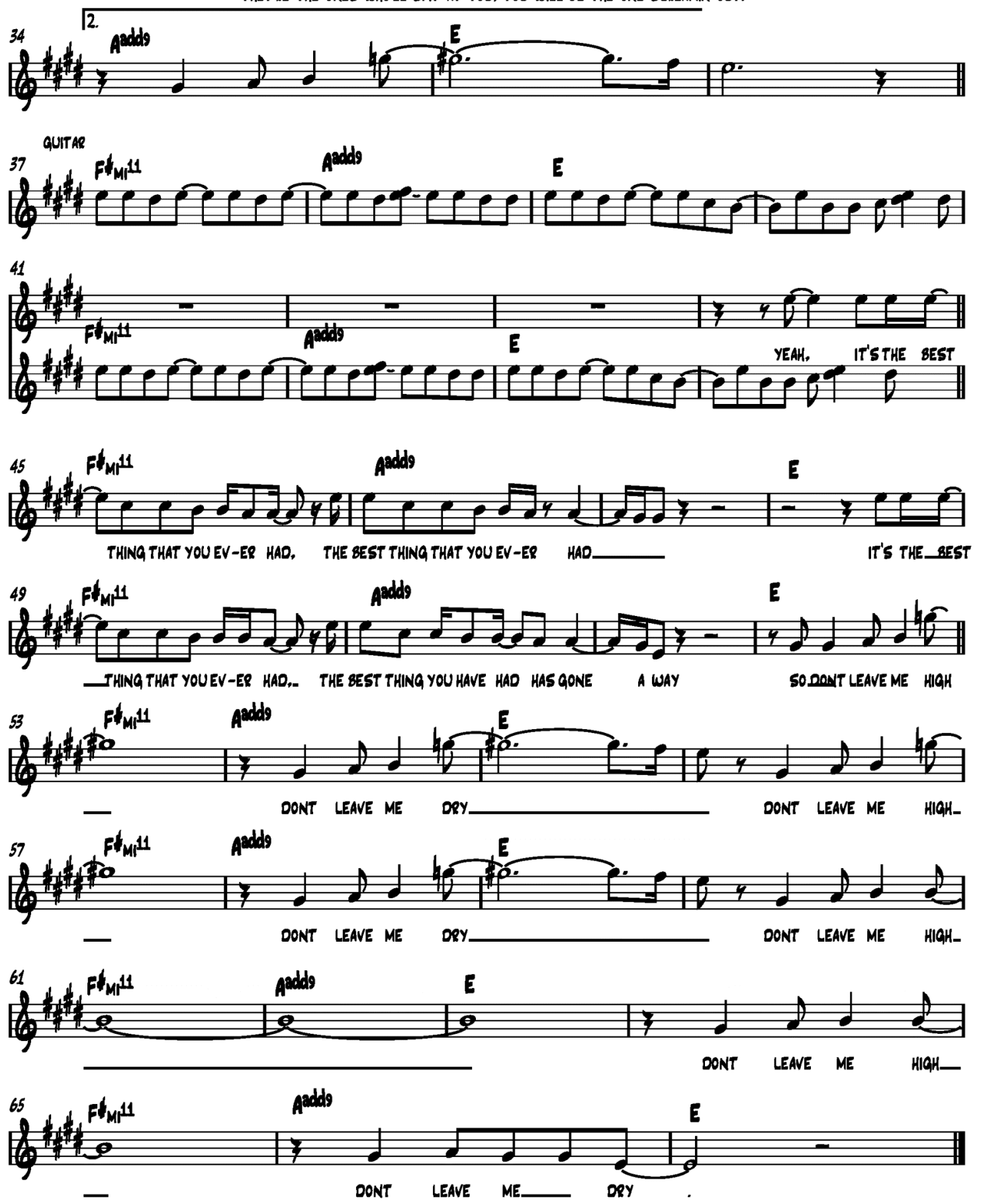
ROCK FEEL $Q=132$
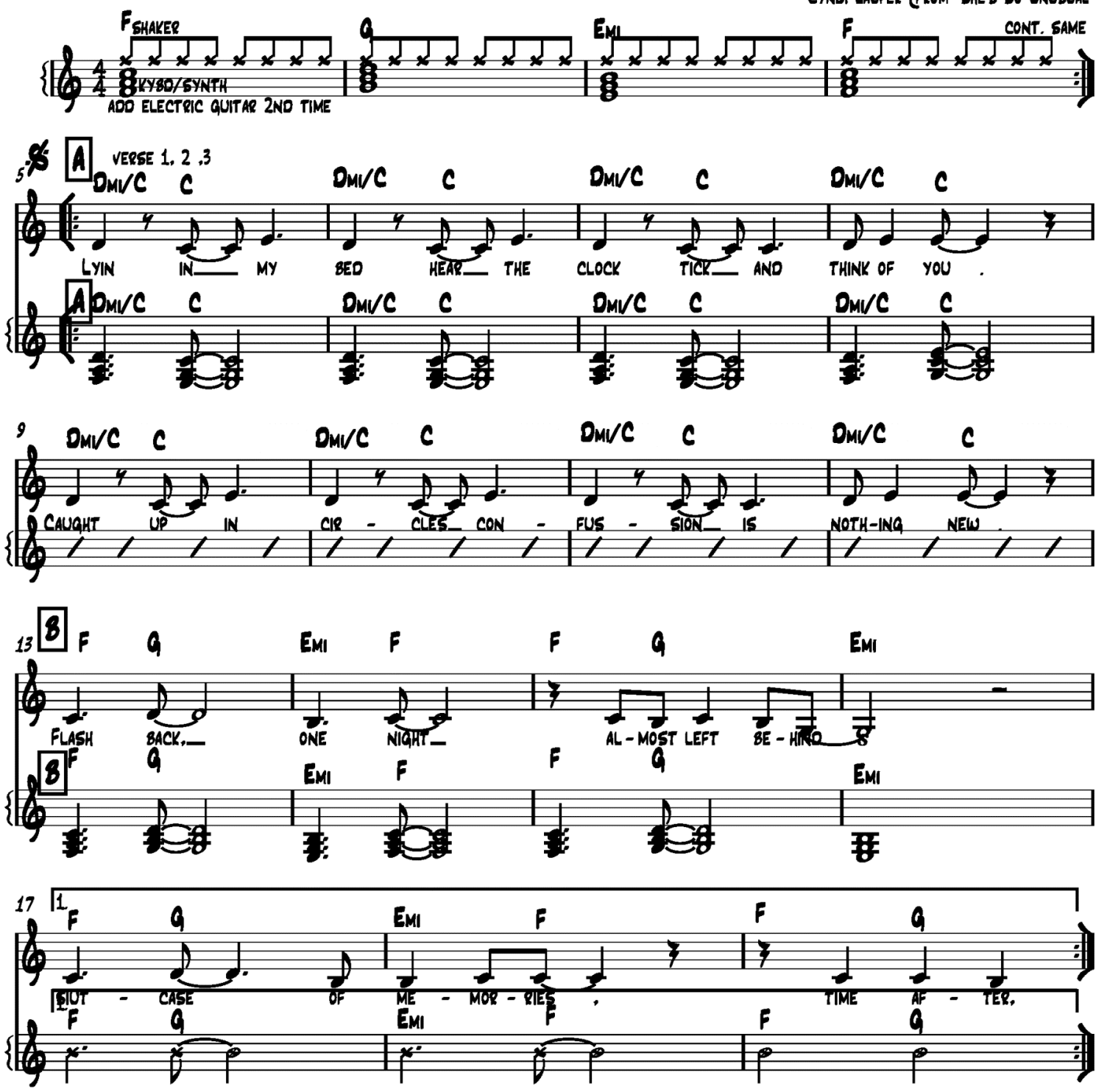

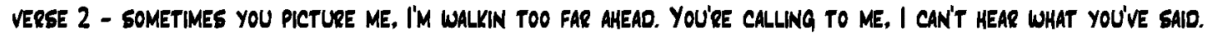
YOU SAY GO SLOW.

VERSE 3 - AFTER MY PICTURE FADEE, AND DARKNESS HAS TURNED TO GREY, WATCHIN THRU WINDOWS, YOU'RE WONDERING IF IM OK, SECRETS. STOLEN, FROM DEEP INSIDE, THE DRUM BEATS OUT OF TIME.

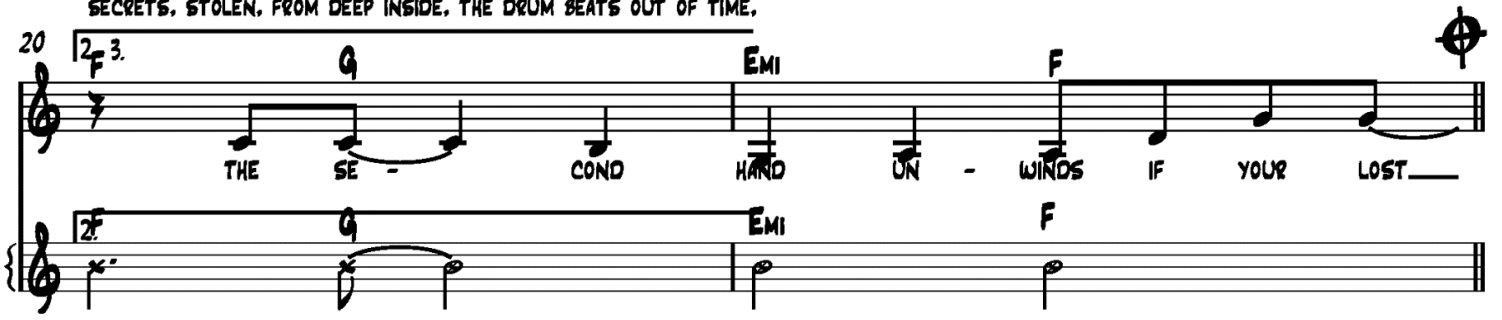



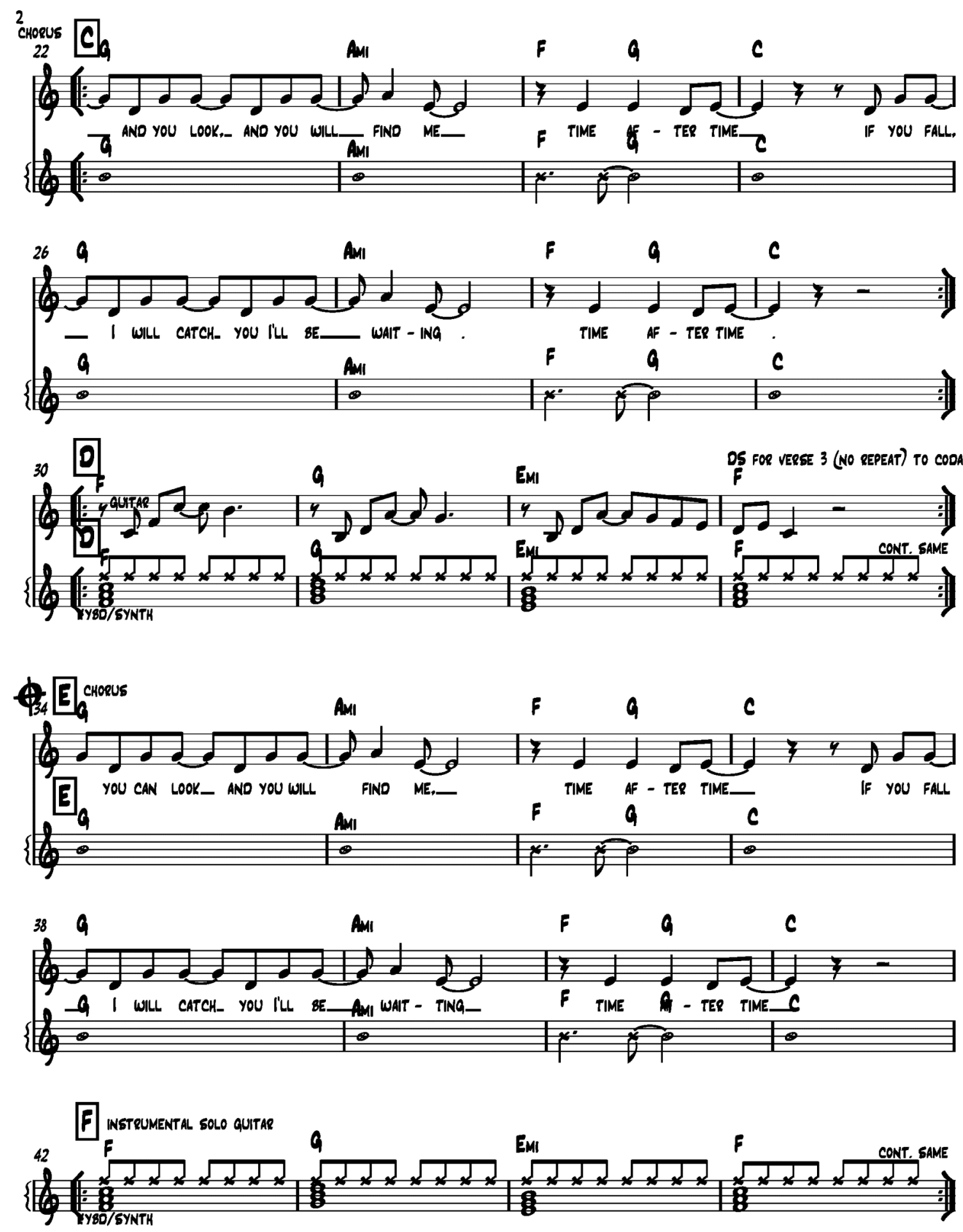

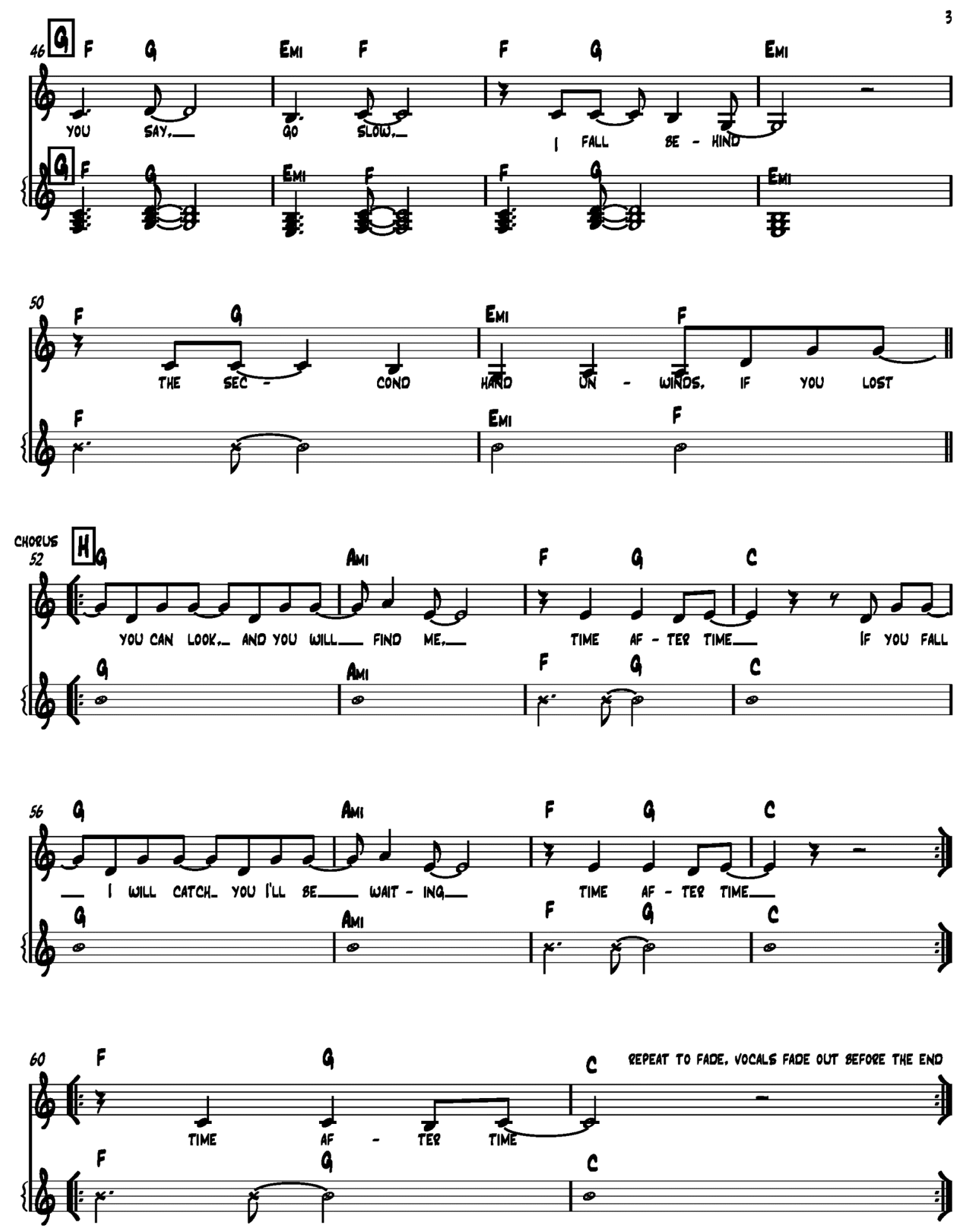
STEADY ROCK BALLAD $Q=100$

NEIL FINN

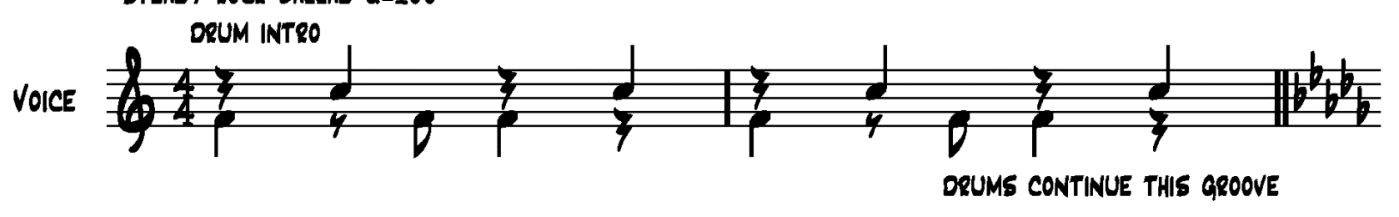

PNo.

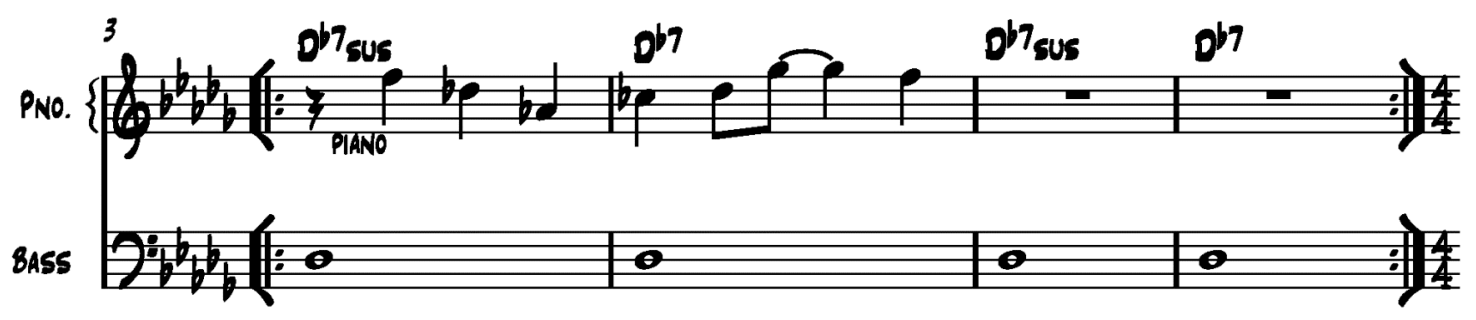

E. BASS
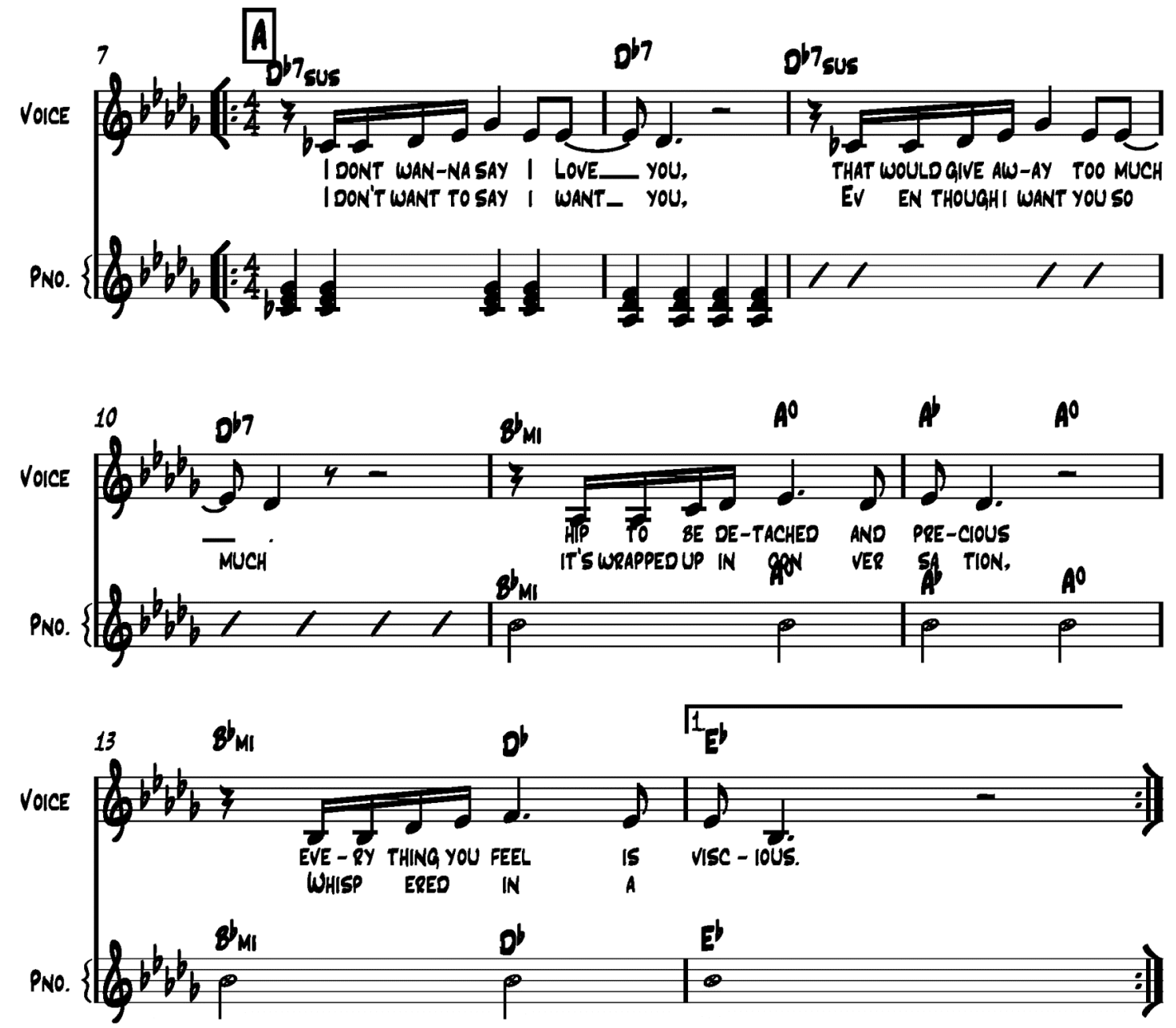

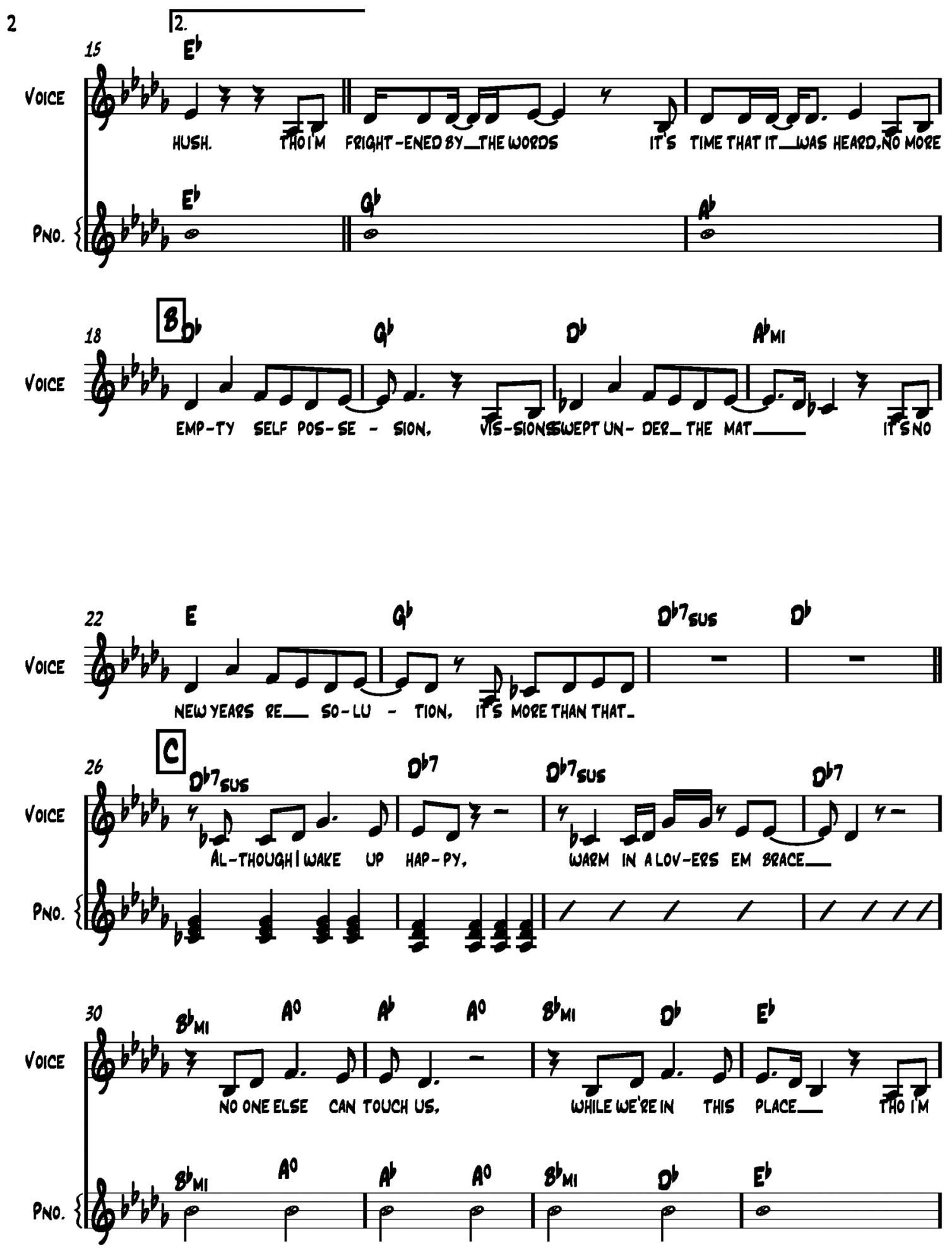

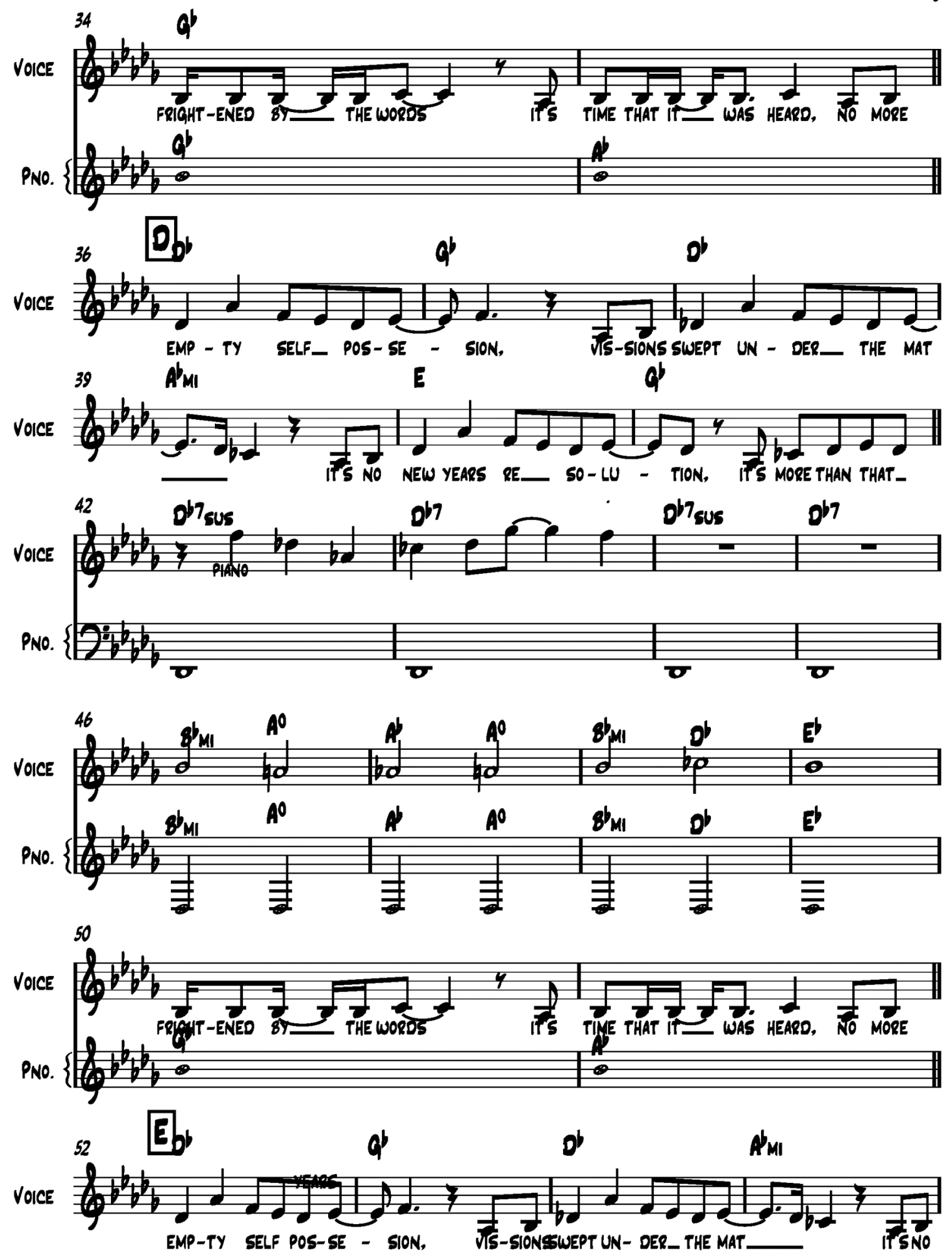
4
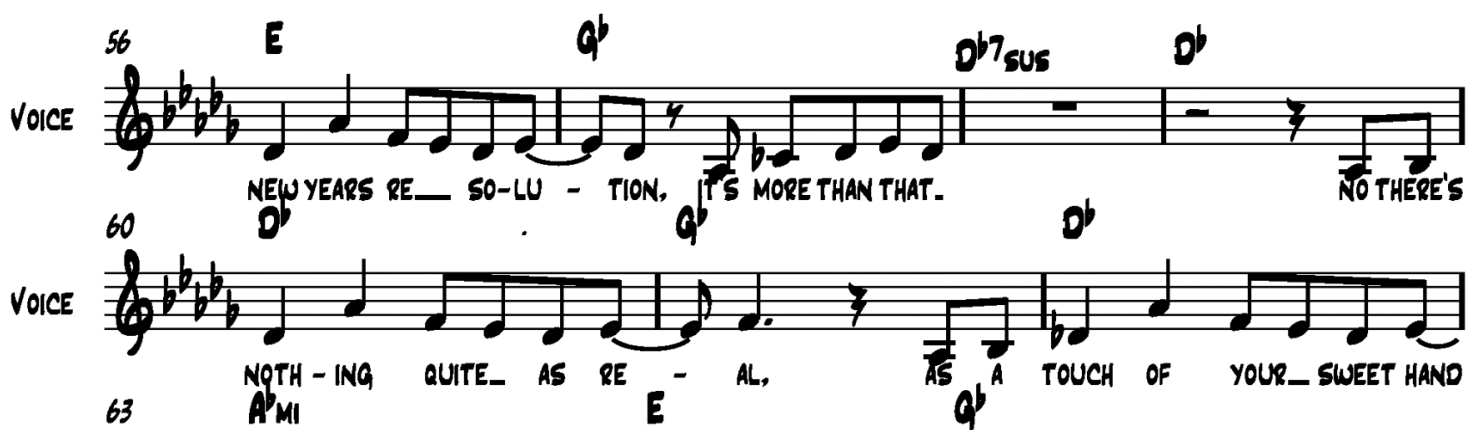
VOICE
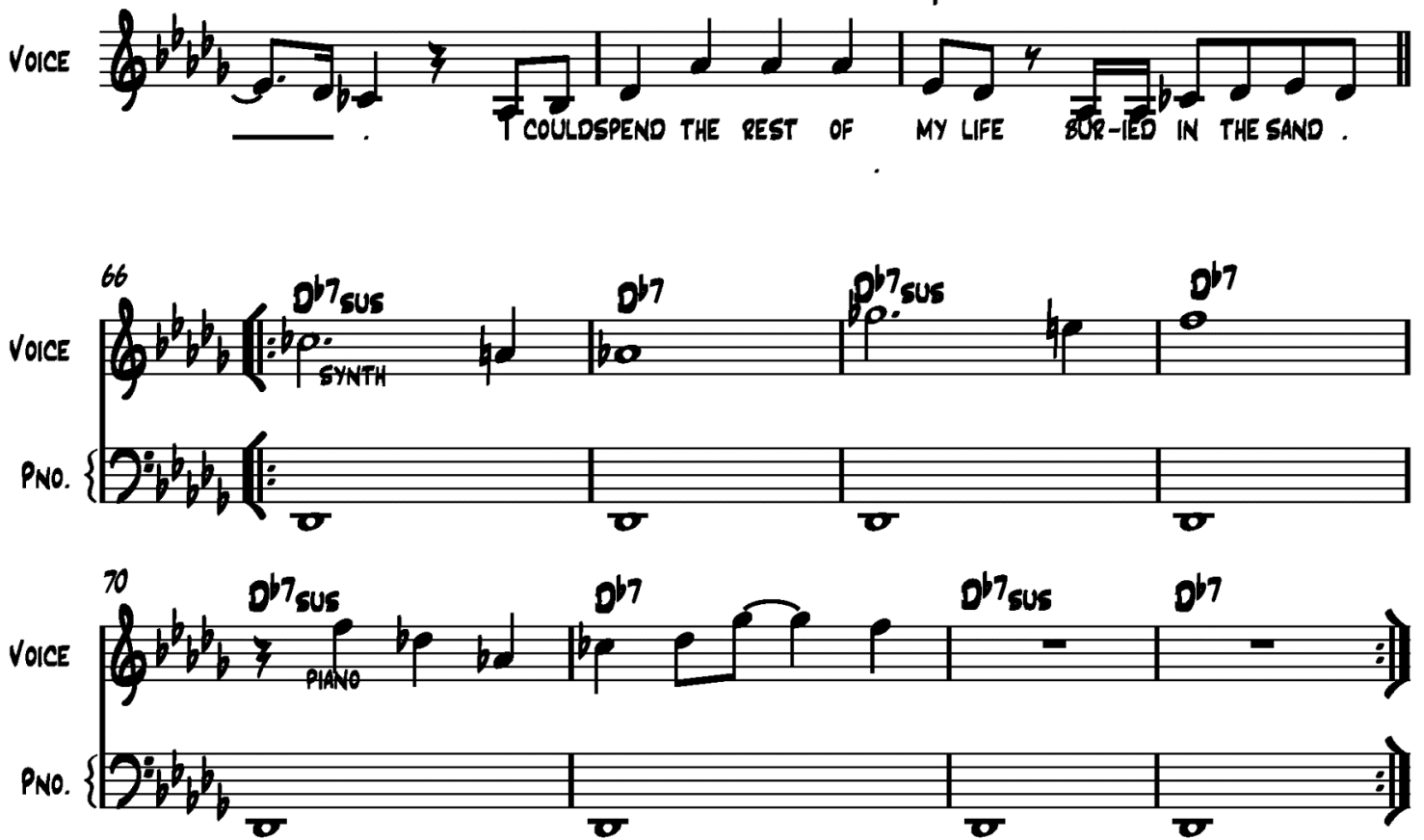

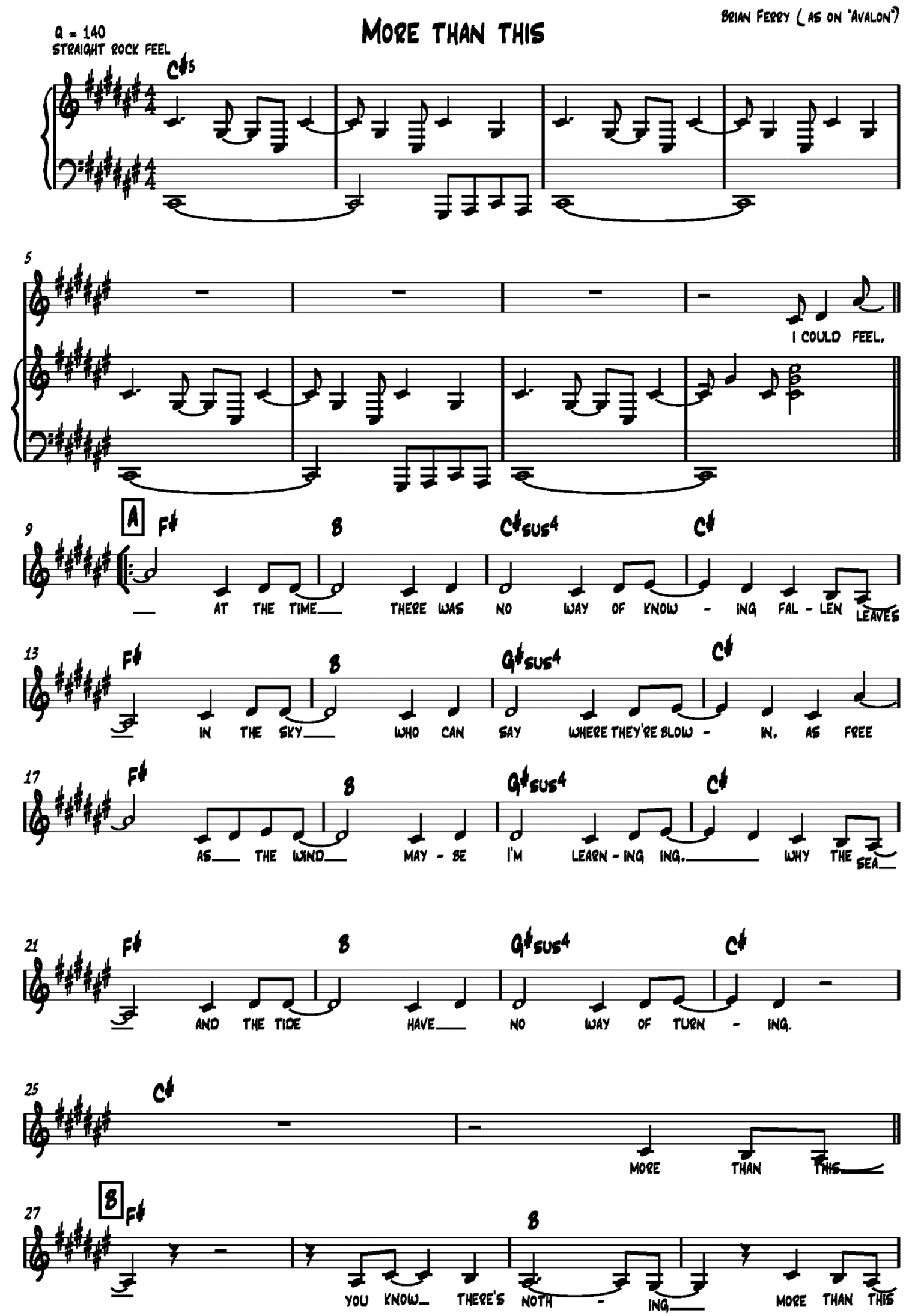
2

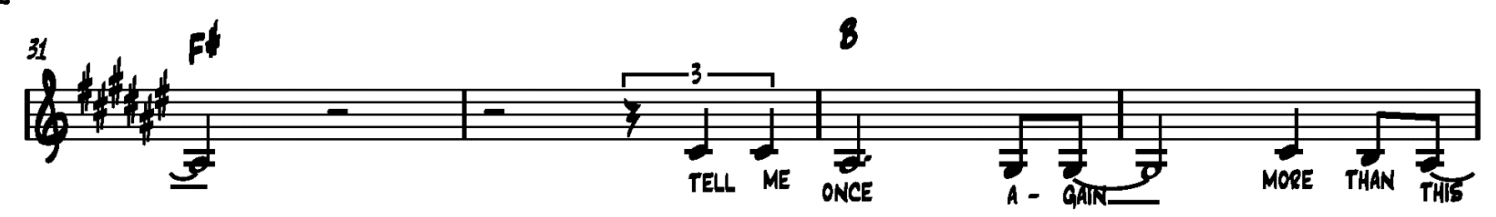

VERSE TWO - IT WAS FUN FOR AWHILE, THERE WAS NO WAY OF KNOWING, LIKE A DREAM IN THE NIGHT, WHO CAN SAY WHERE WE'RE GOING, NO CARE IN THE WORLD, MAYBE I'M LERRNING, WHY THE SEA AND THE TIDE..........
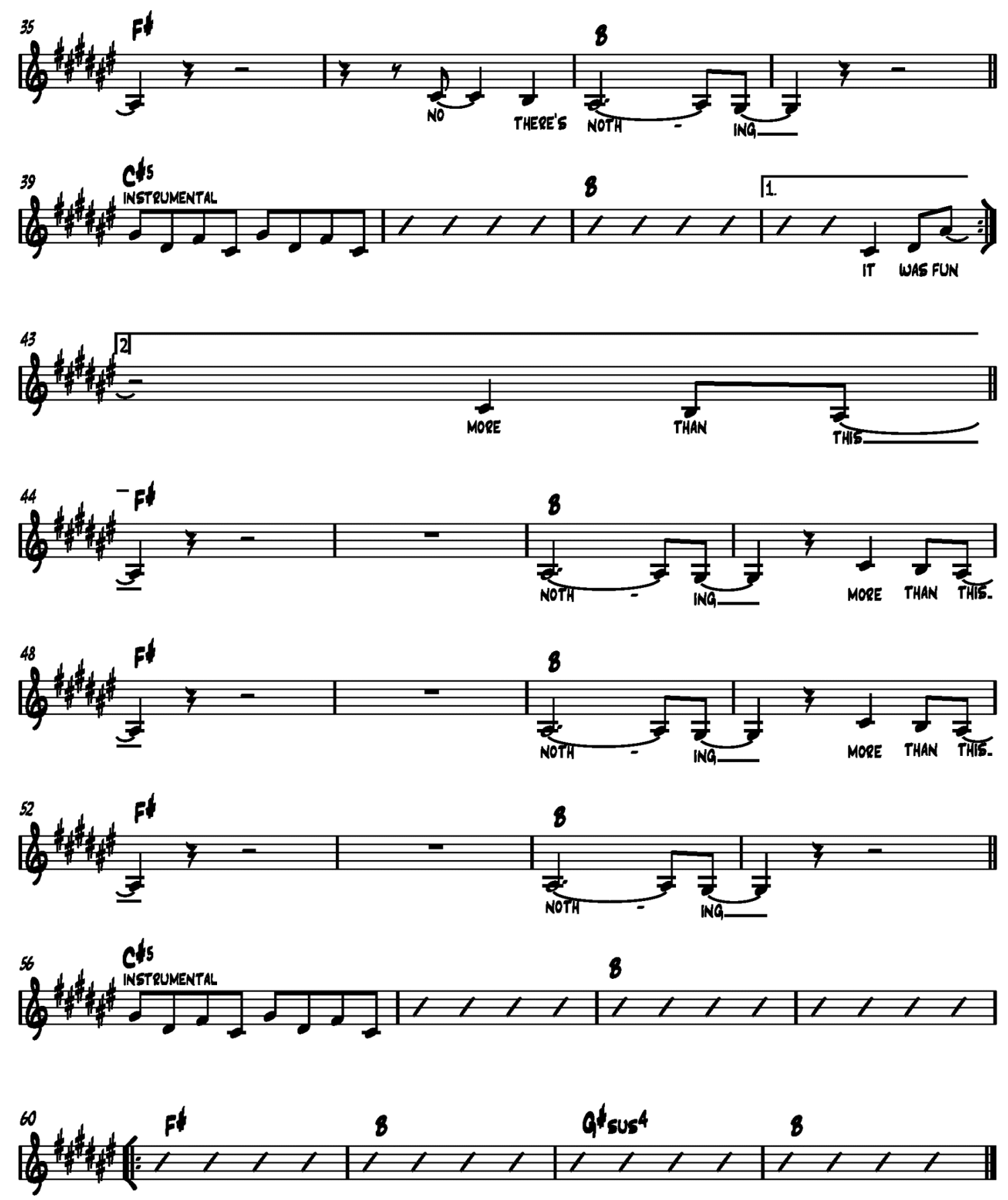

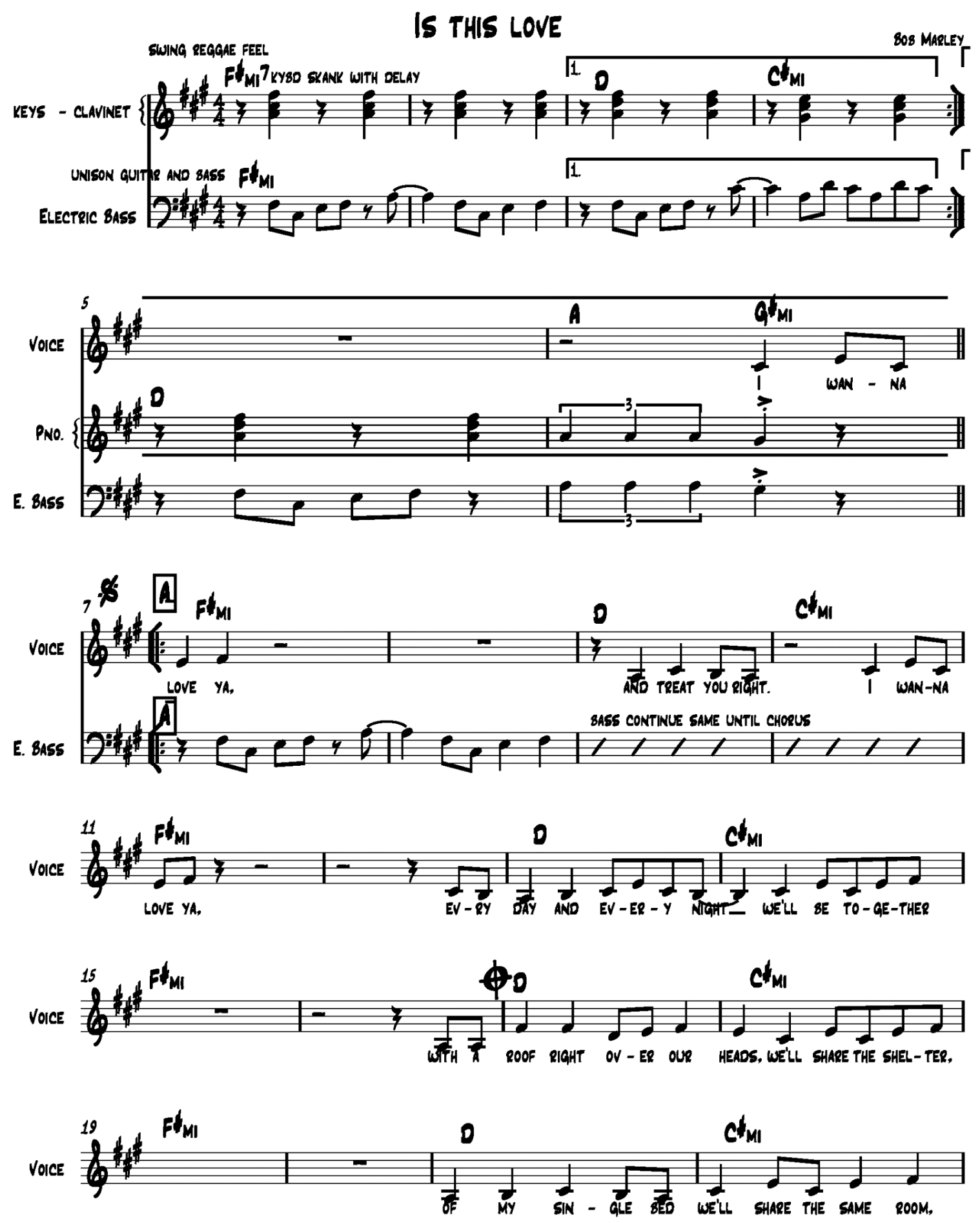
2

VOICE
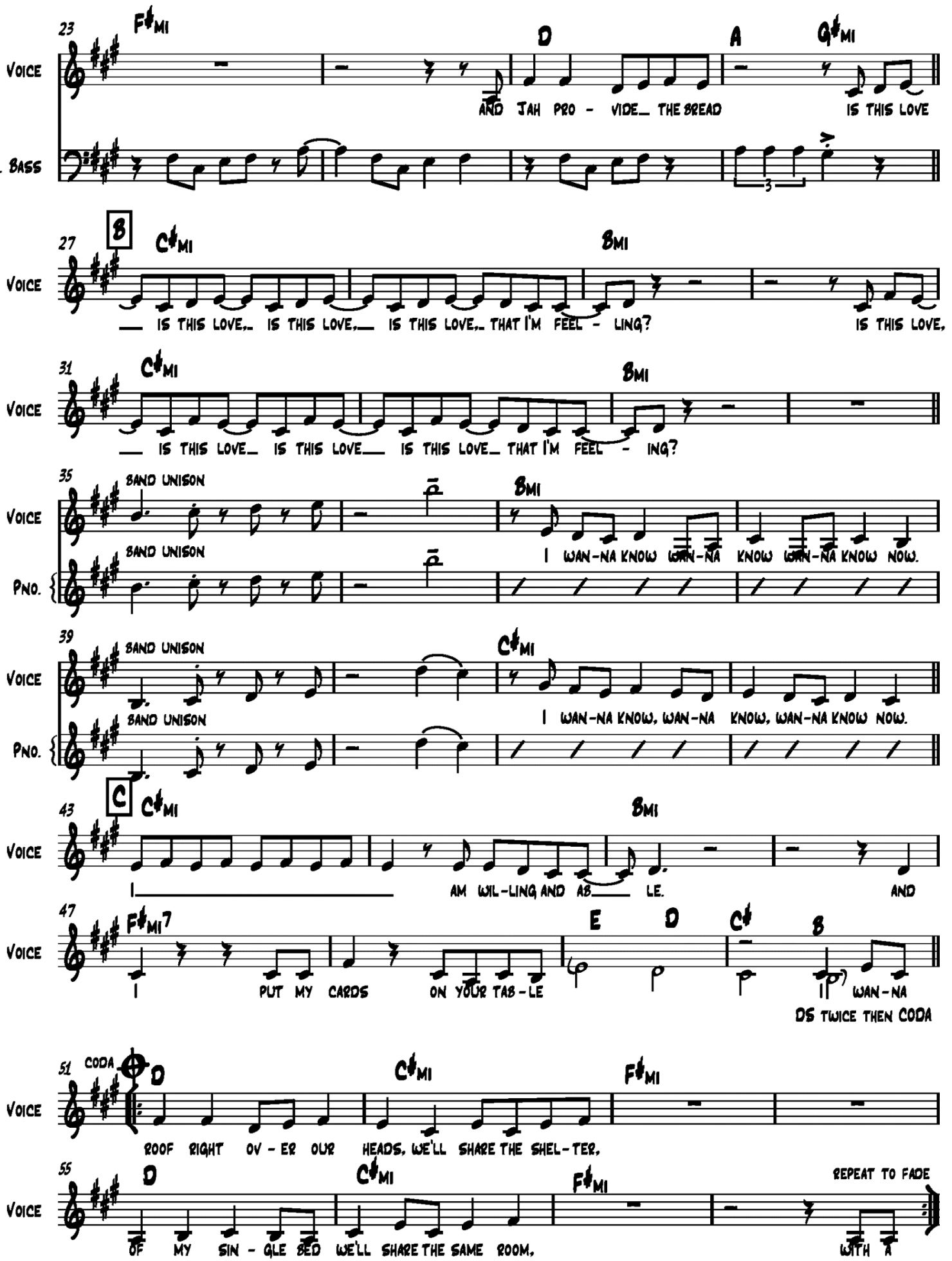
Freely rubato

Fragile

Stina (AS ON "NOThINa LIKE the SUN")

KYBO PAD SOUNOS ON CHORDS B'sUS ACOUSTIC GUITAR ON MELODY

A TEMPO - STRAIGHT LATIN FEEL, $a=108$, LIGHTLY

(1)

9

(6)

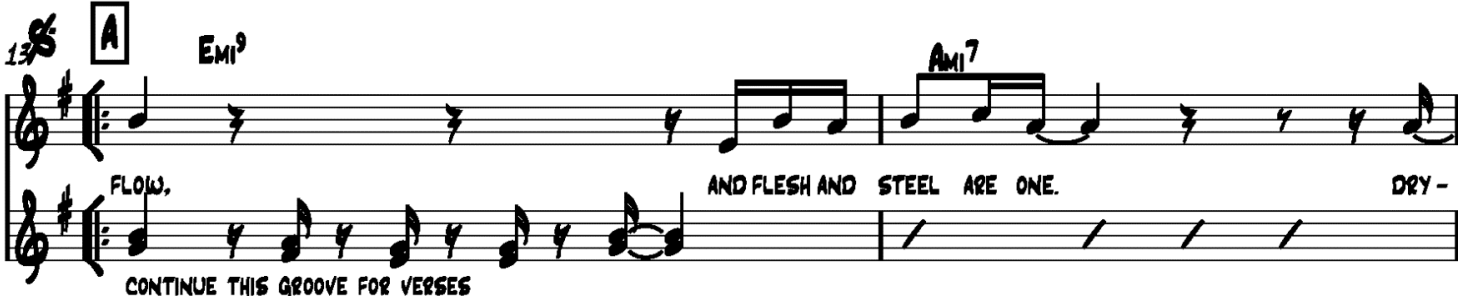
CONTINUE THIS GROOVE FOR VERSES
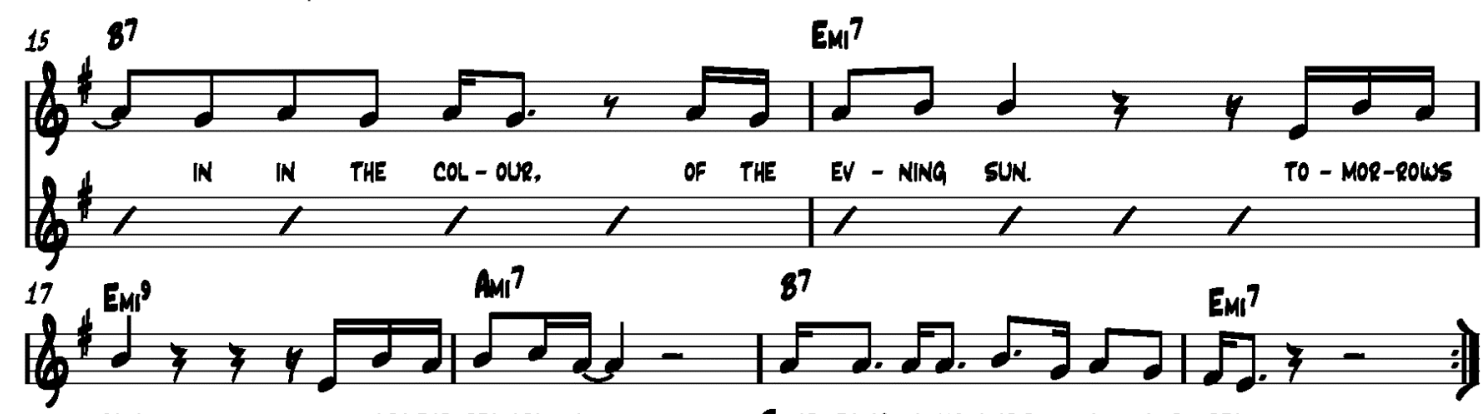

RAIN,

WILL WASH THE STAINSAW AY._-

SOME-THING IN OUR MINDS WILL AL-WAYS STAY VERSE 2 - PERHAPS THIS FINAL ACT WAS MEANT, TO CLINCH A LIFE TIMES ARGUEMENT, NOTHING COMES FROM VIOLENCE AND NTHING EVER COULO,

CHORUS 8 FR ALL THOSE BORN 8ENEATH AN ANGRY STAR, LEAST WE FORGET HOW FRAGILE WE ARE.
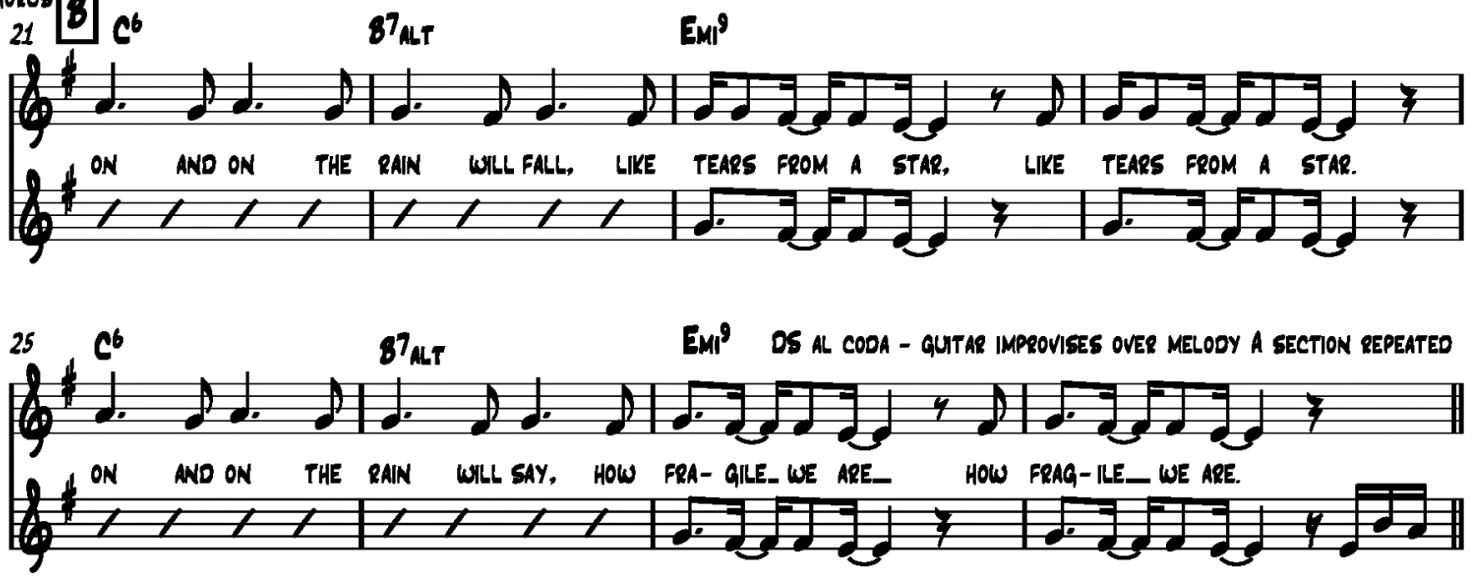

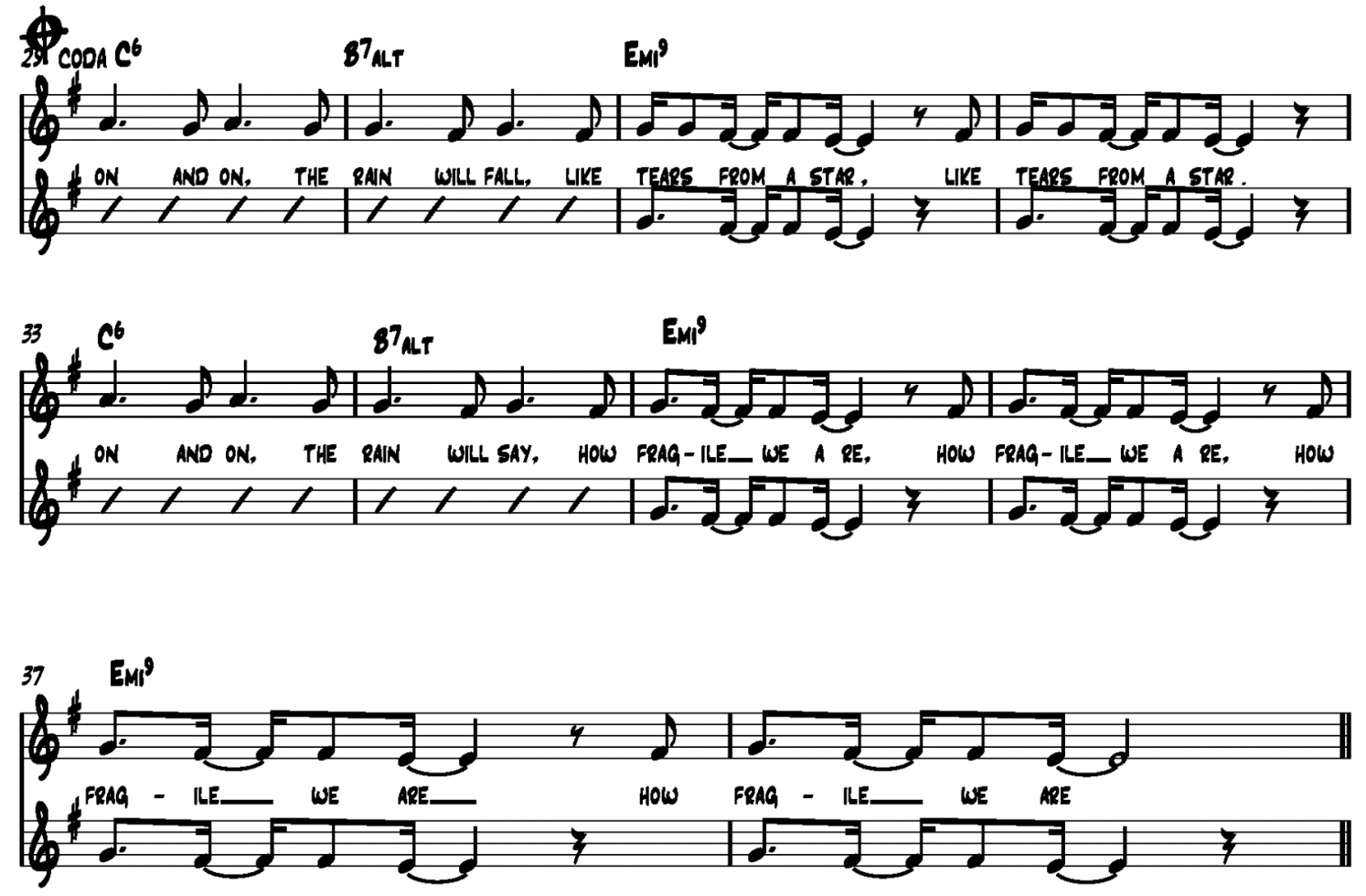

Freely rubato

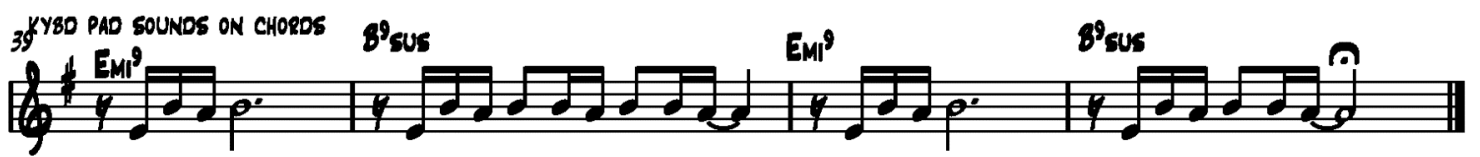

ACOUSTIC gUTTAR ON MELODY 
VOICE

MODERATE OISCD $=108$
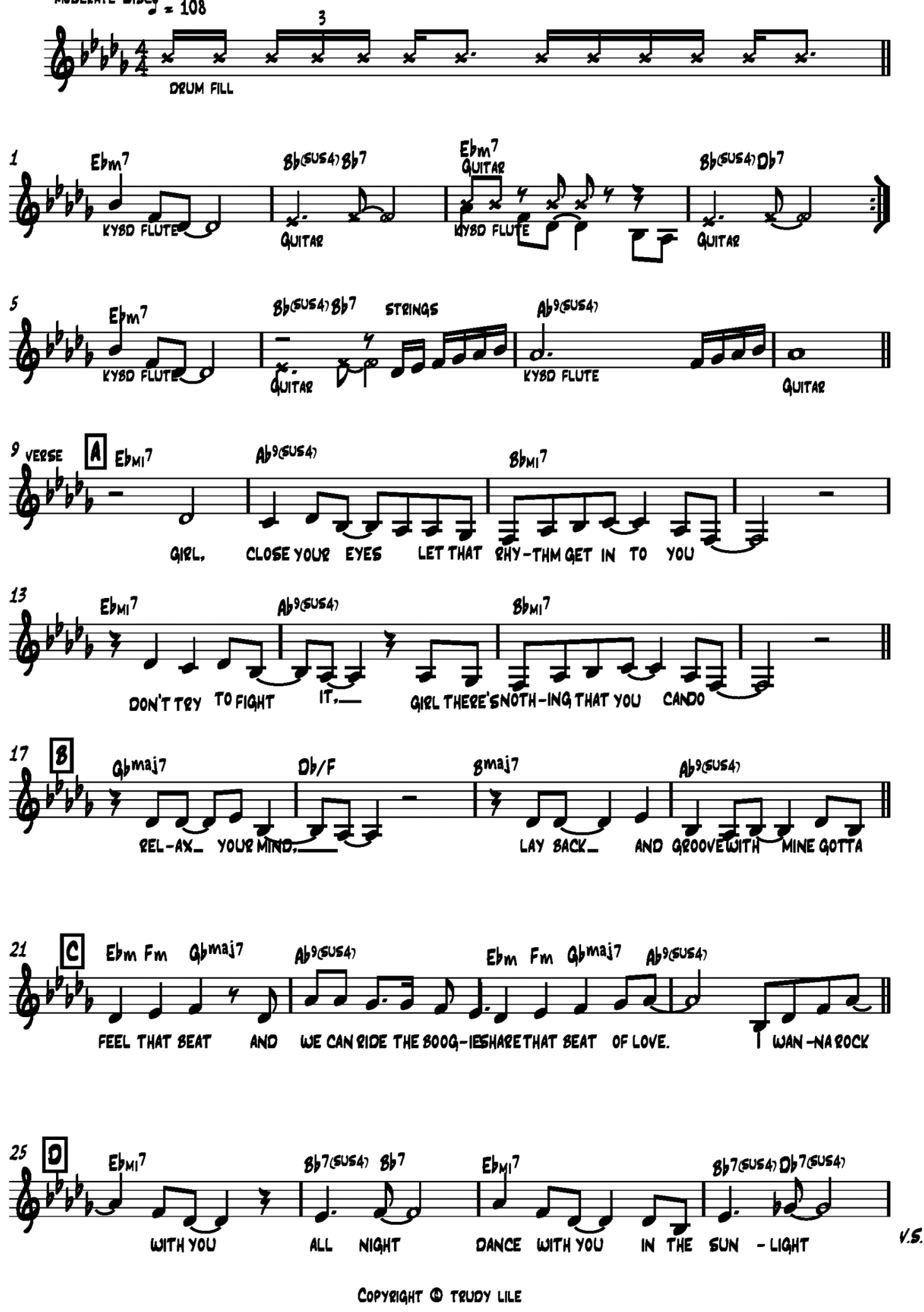

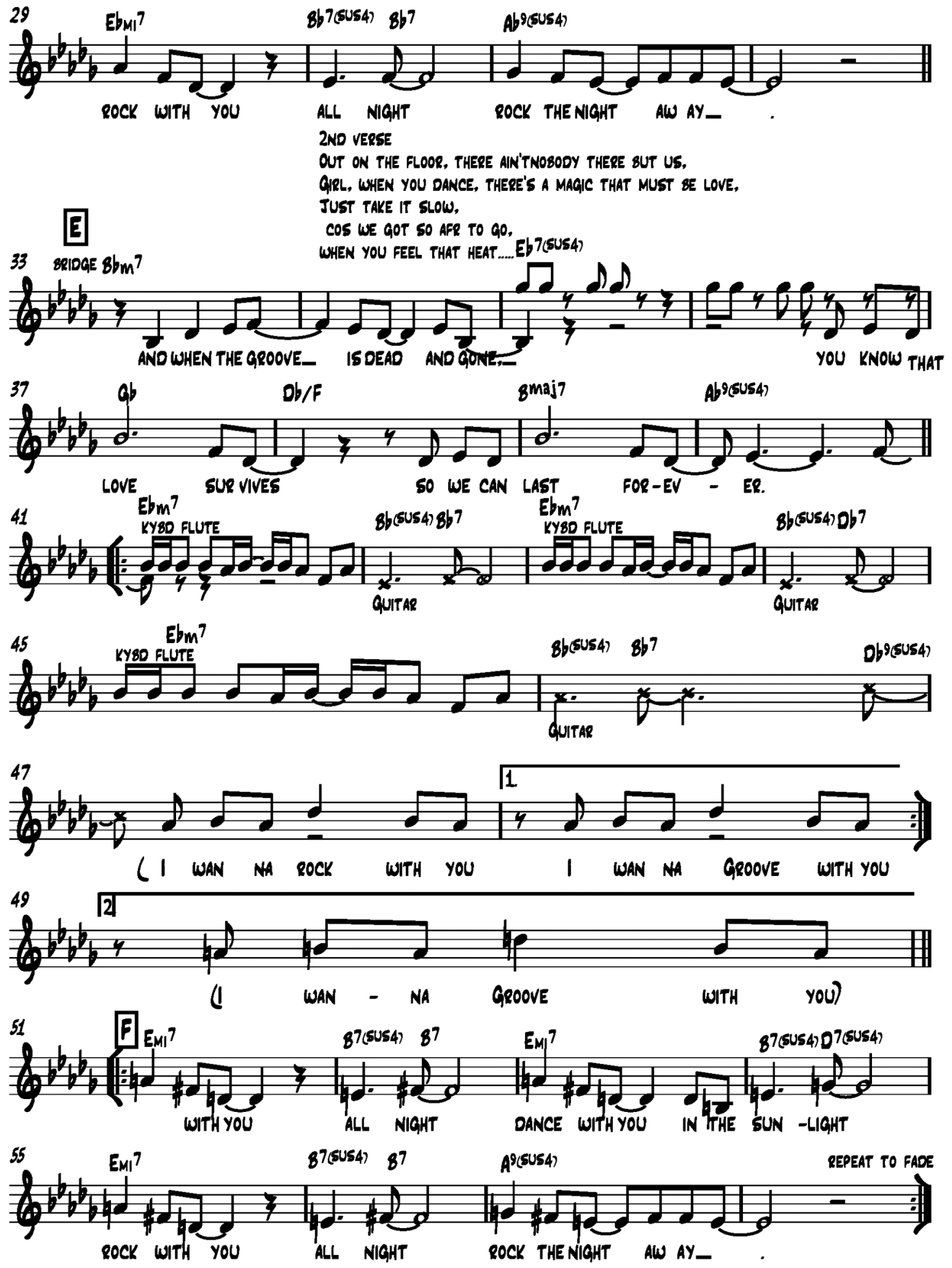

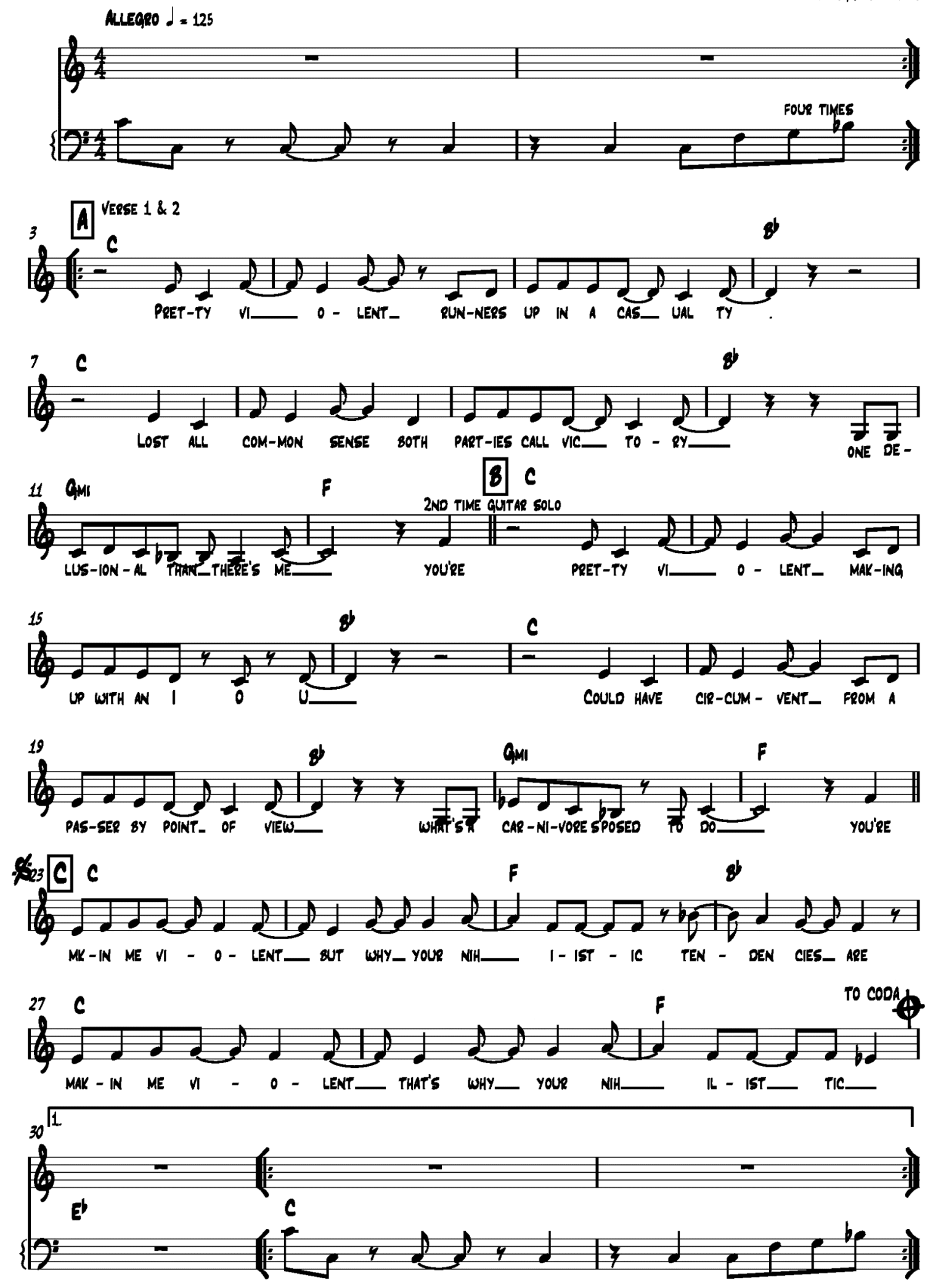
2
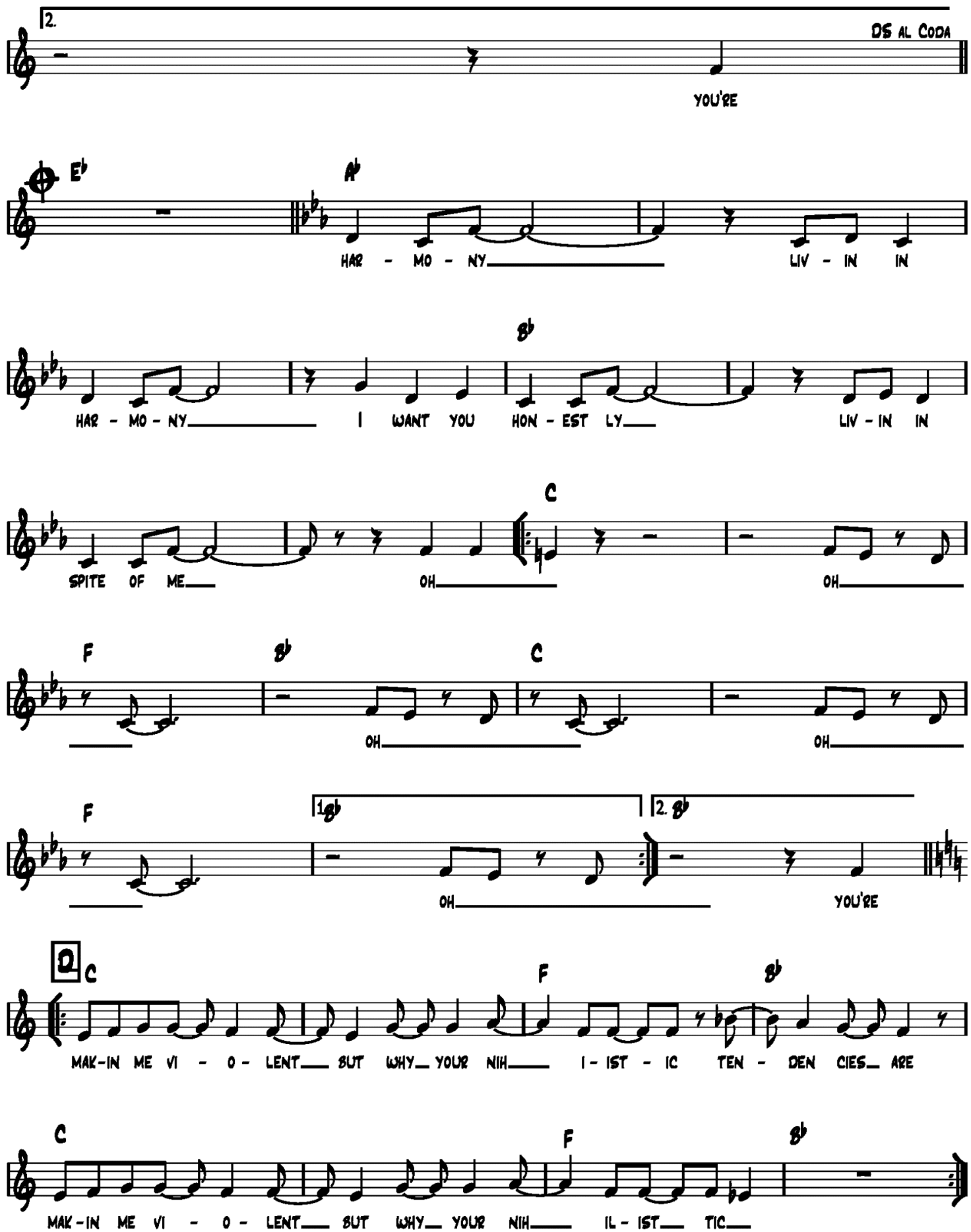

$\begin{array}{r}c \\ \text { ค } \\ \hline \frac{8}{8}\end{array}$ 


\section{Appendix 5}

Scores of new arrangements - Part Three 
SMELLS LIKE TEEN SPIRIT

$A=100$ STRONG ROCK FEE

KURT COBAIN ARGO, TRUDY LITE
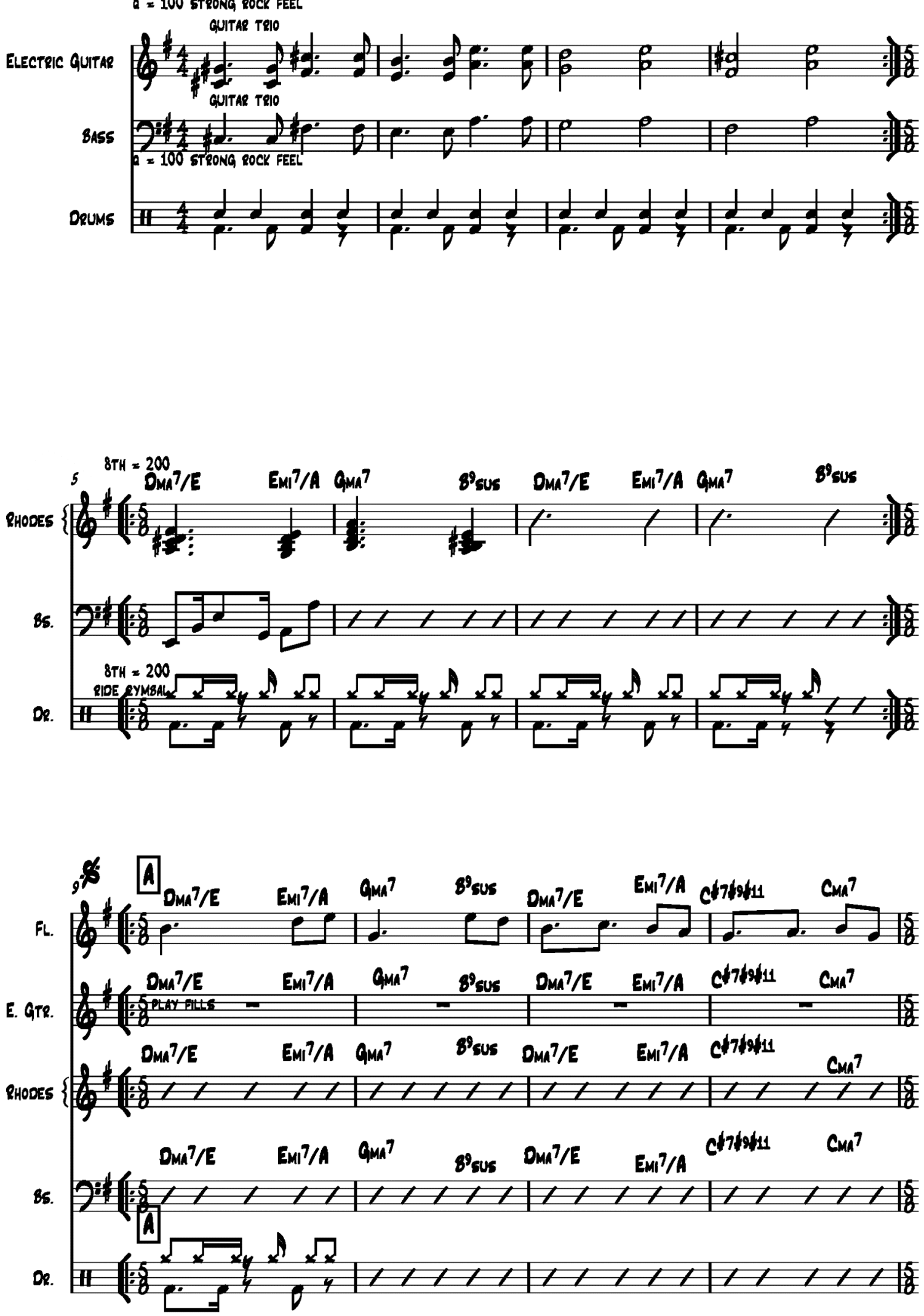

236 


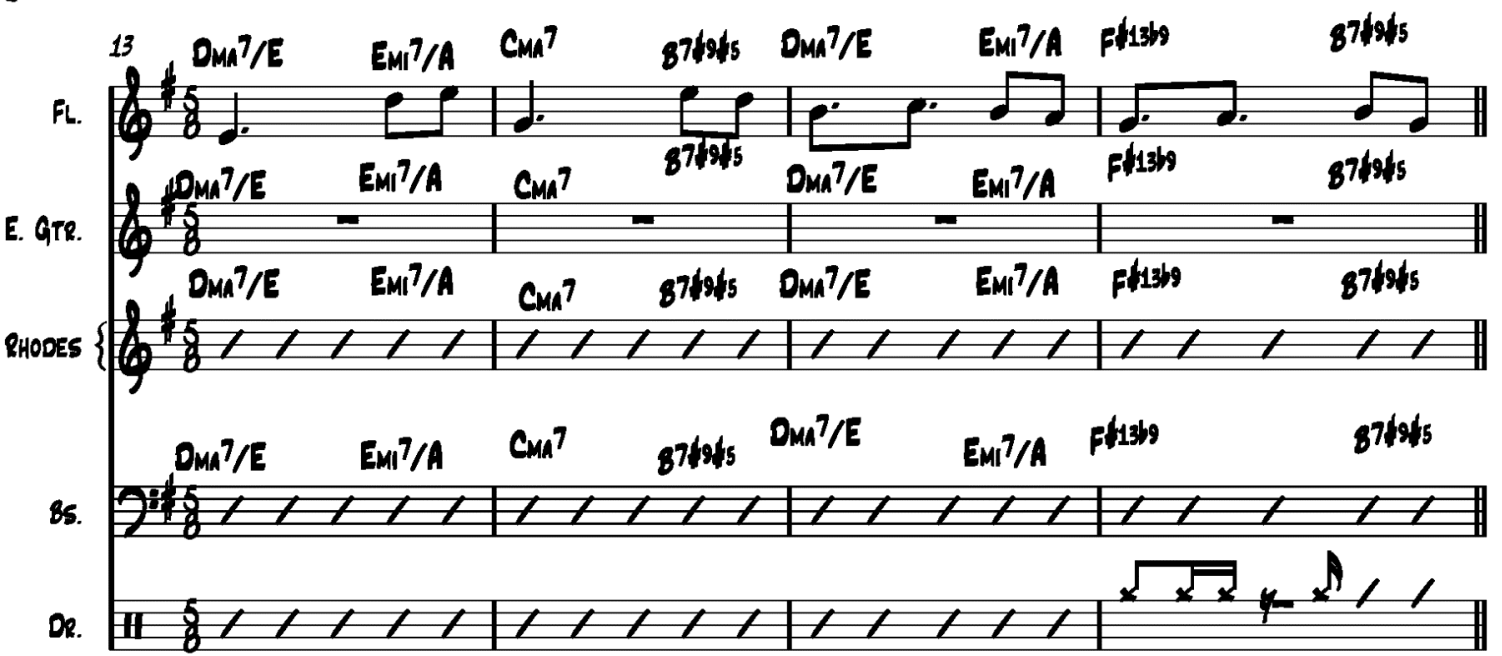

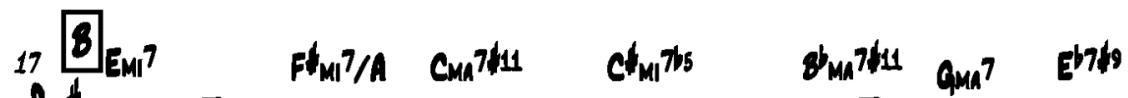
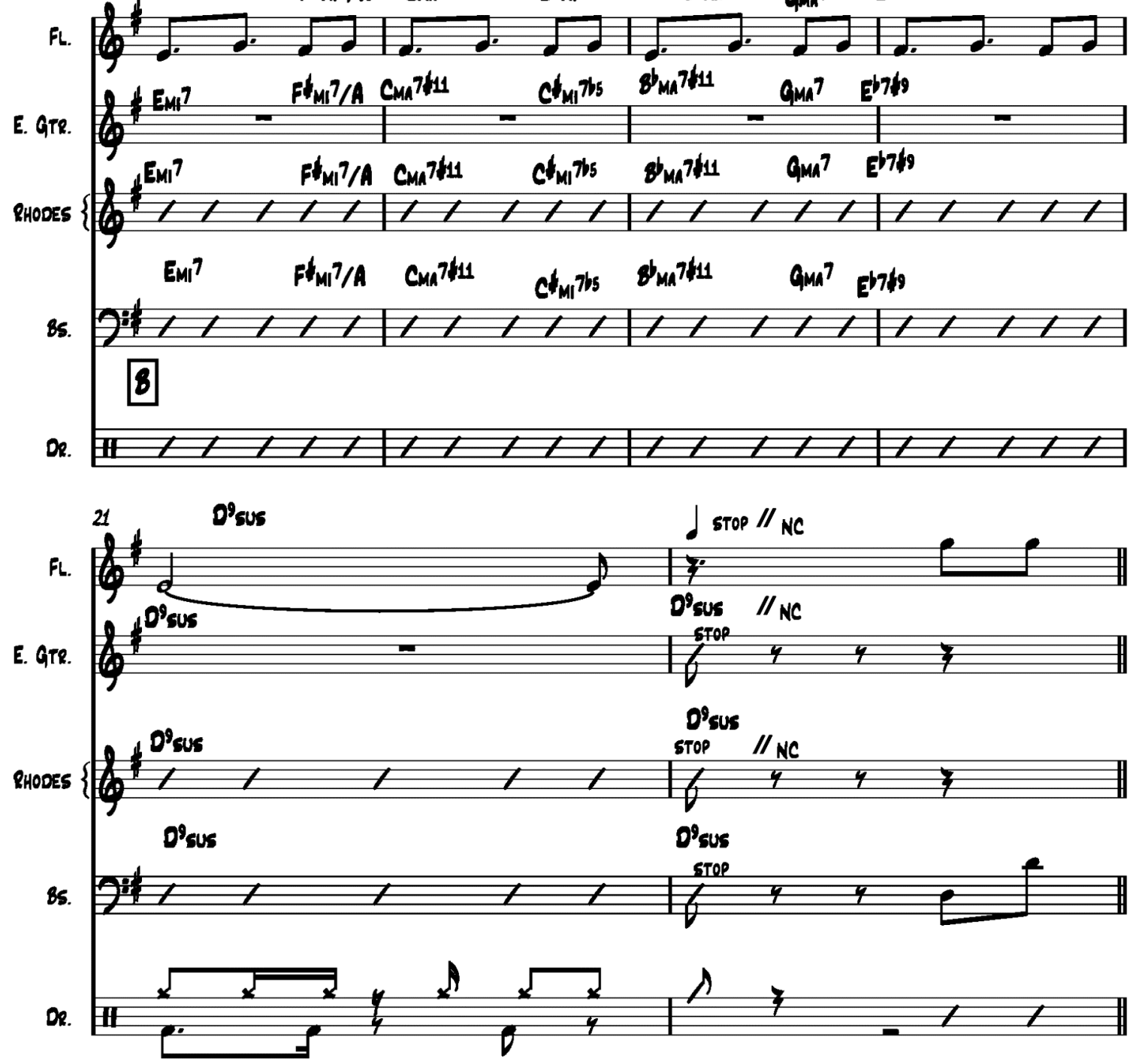
3

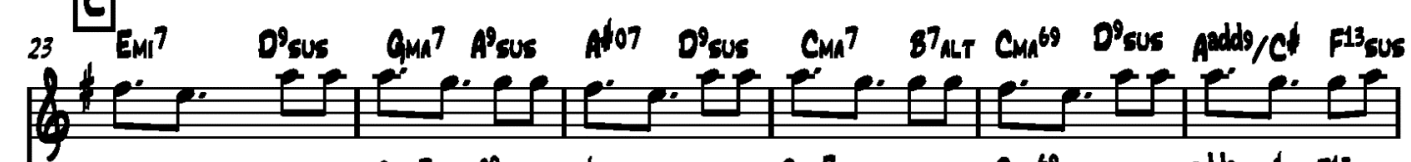

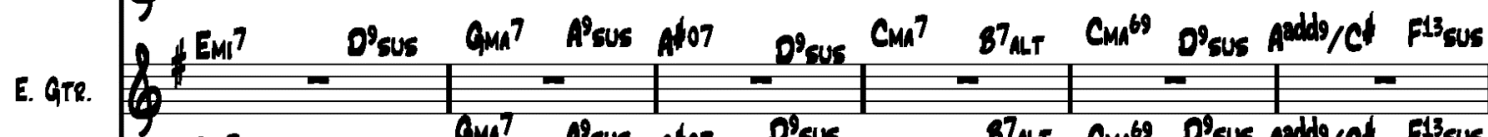

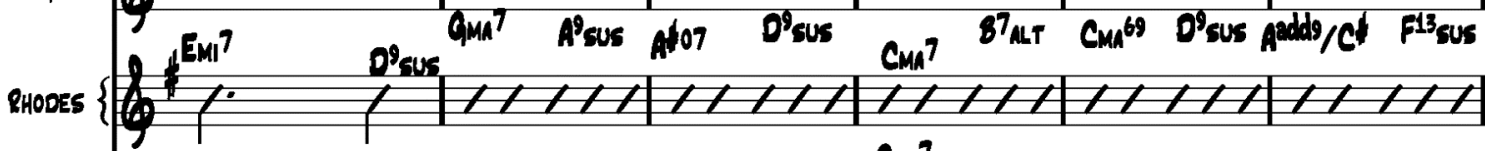

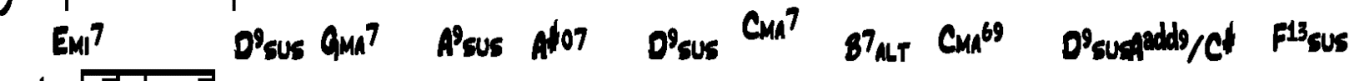

8s. 5 :

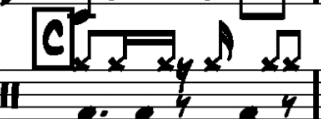

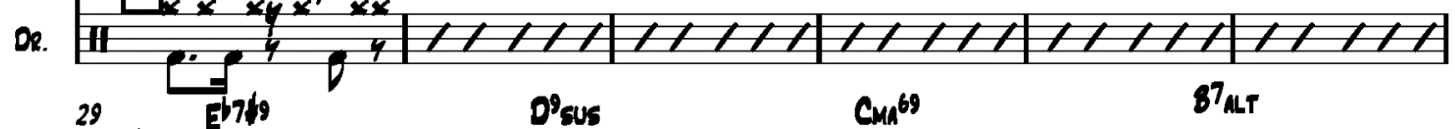

29 Ento

E. GTR.

RHOOES $\{$ :

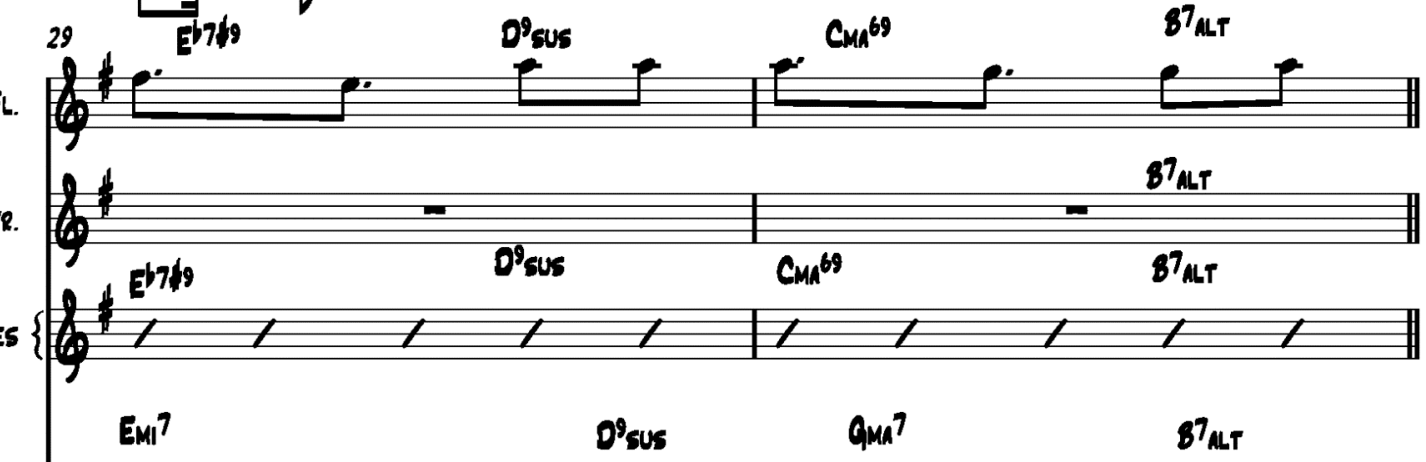

B5.

EMI
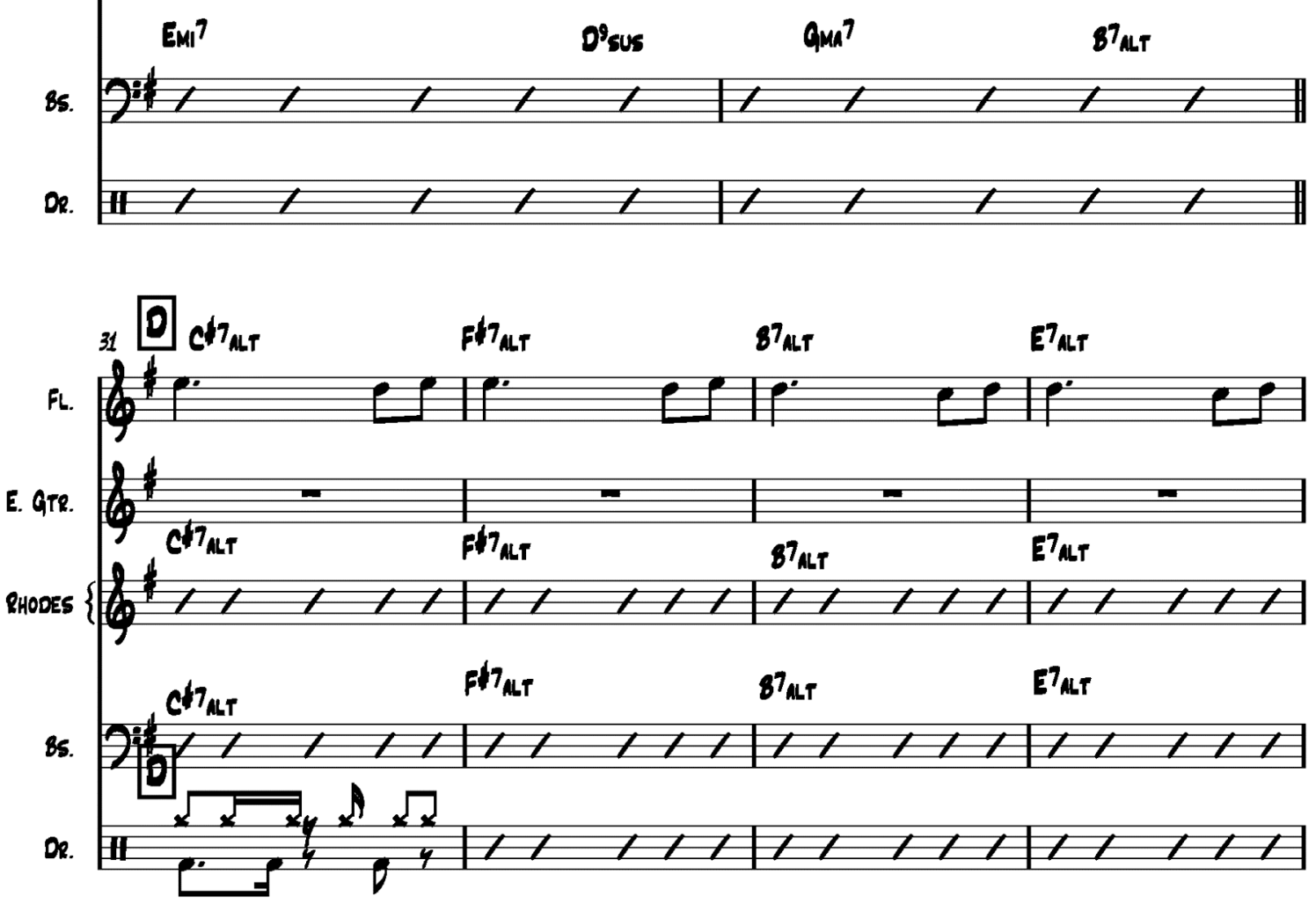

238 
4
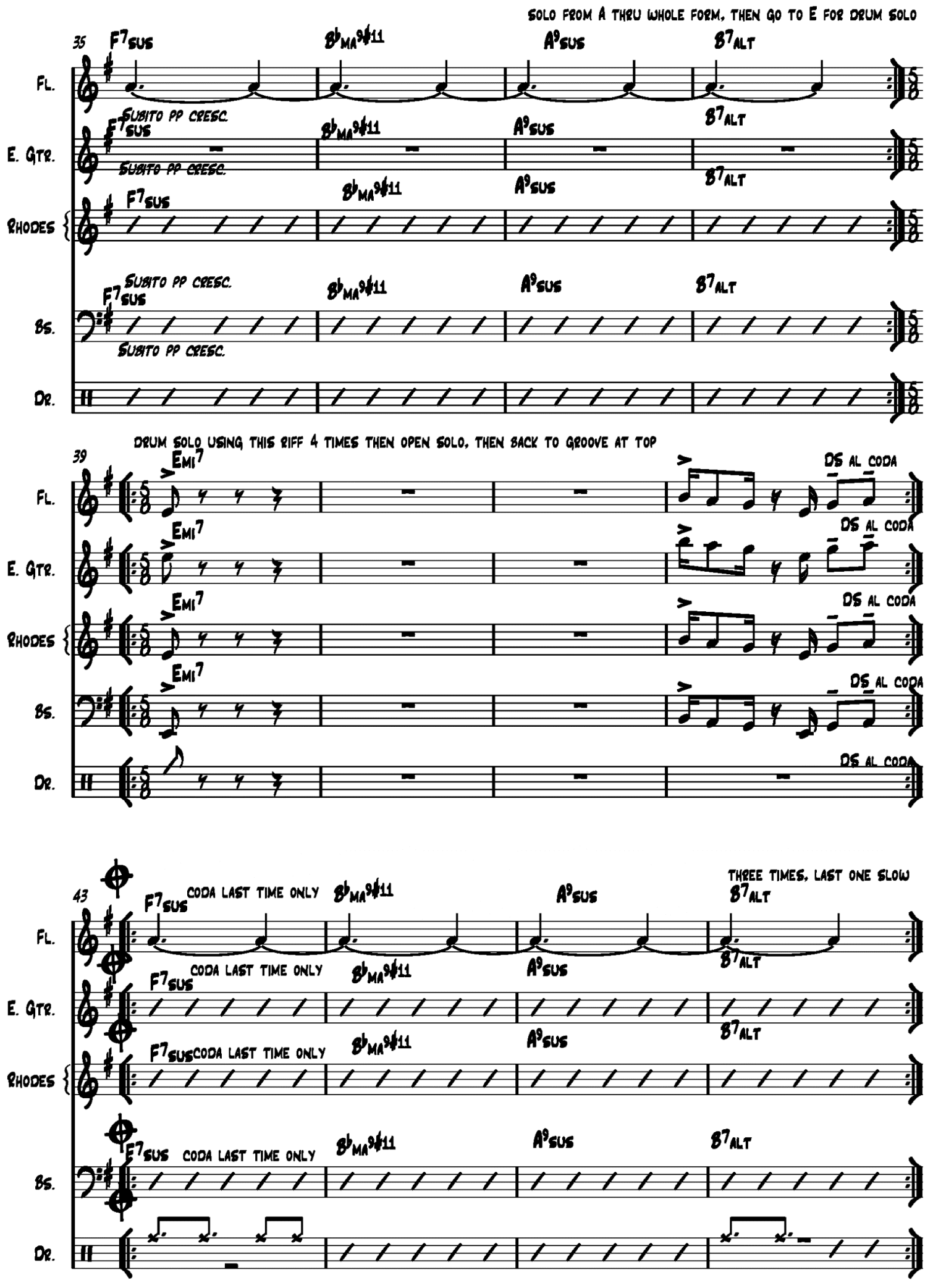

239 

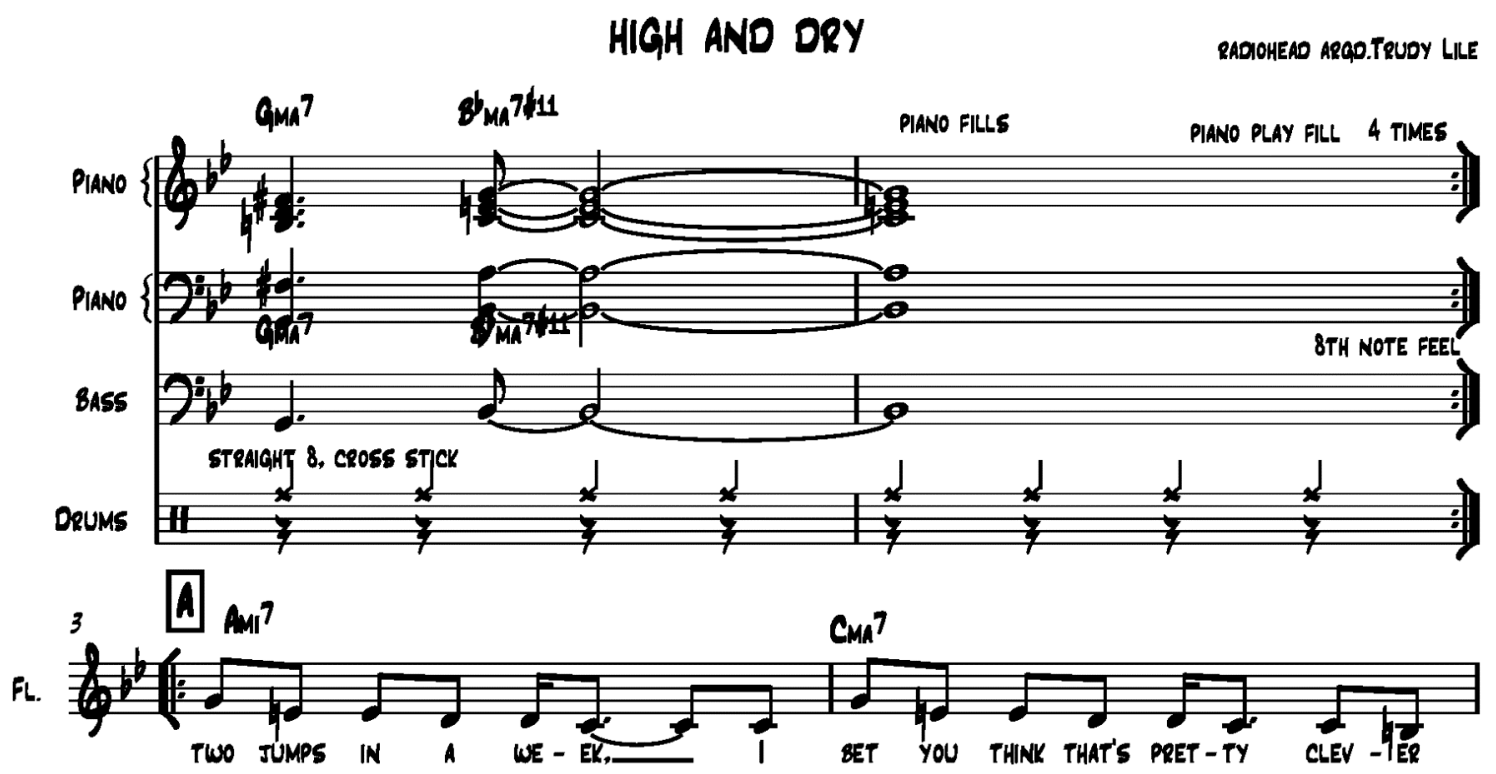

FL.

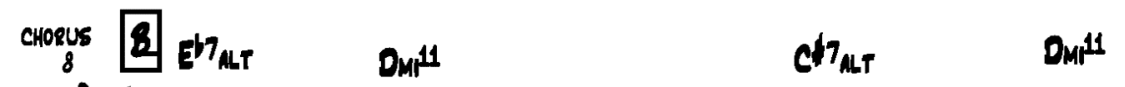

FL.
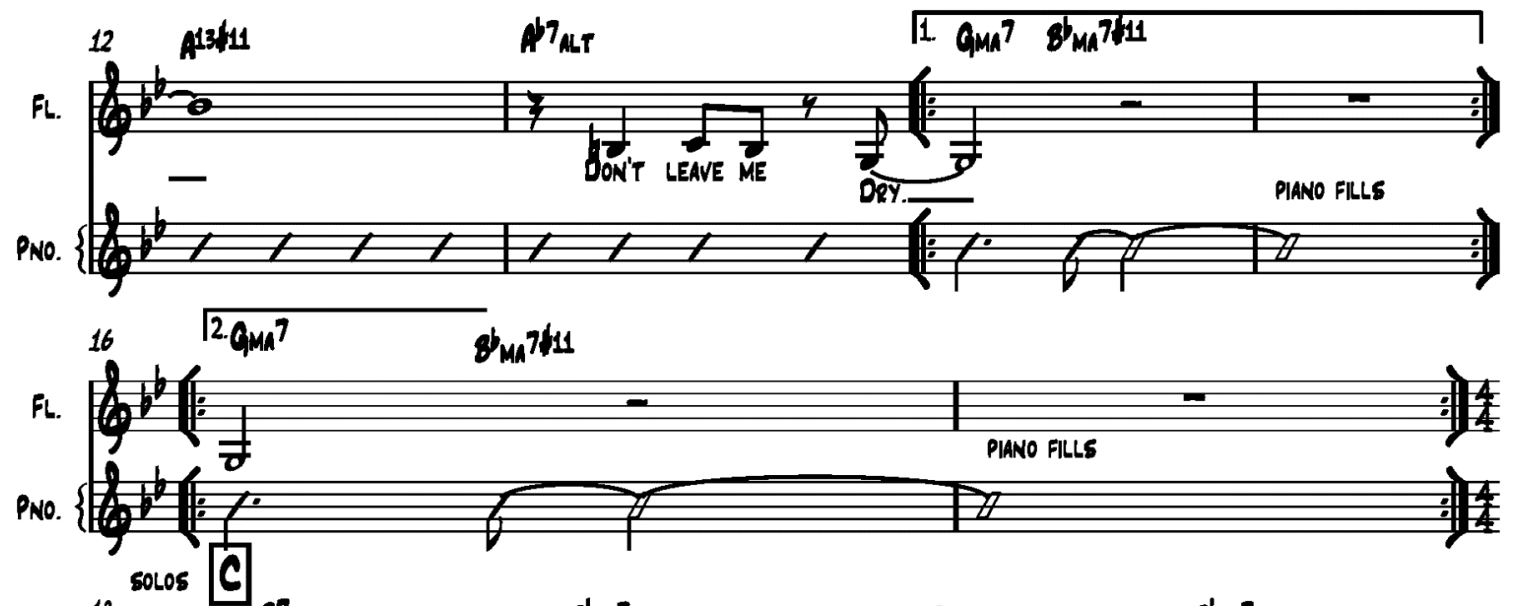

FL.

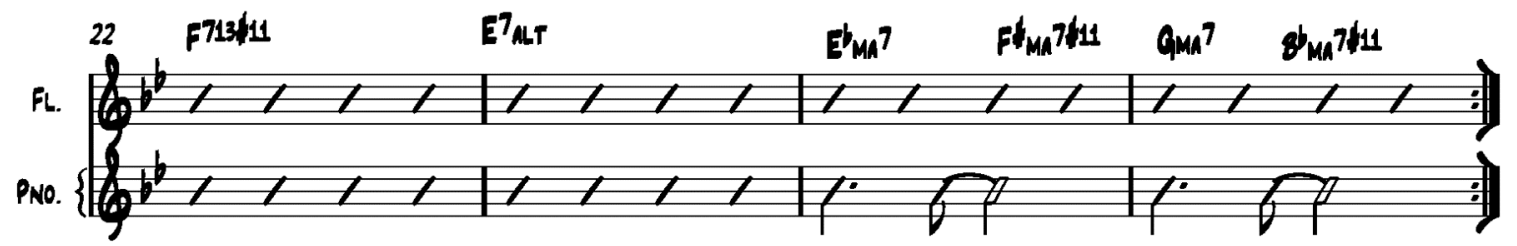



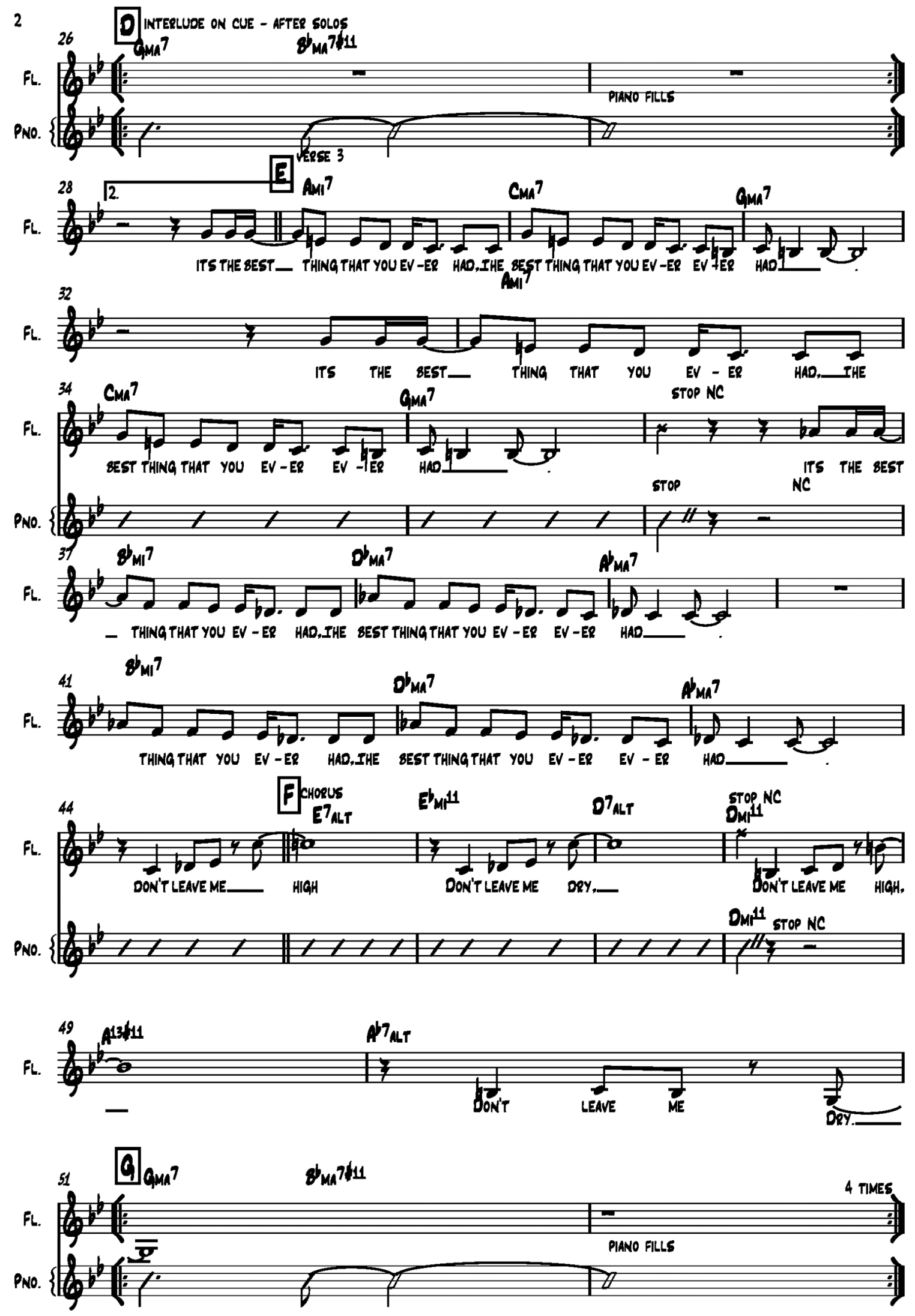


\section{time after time}
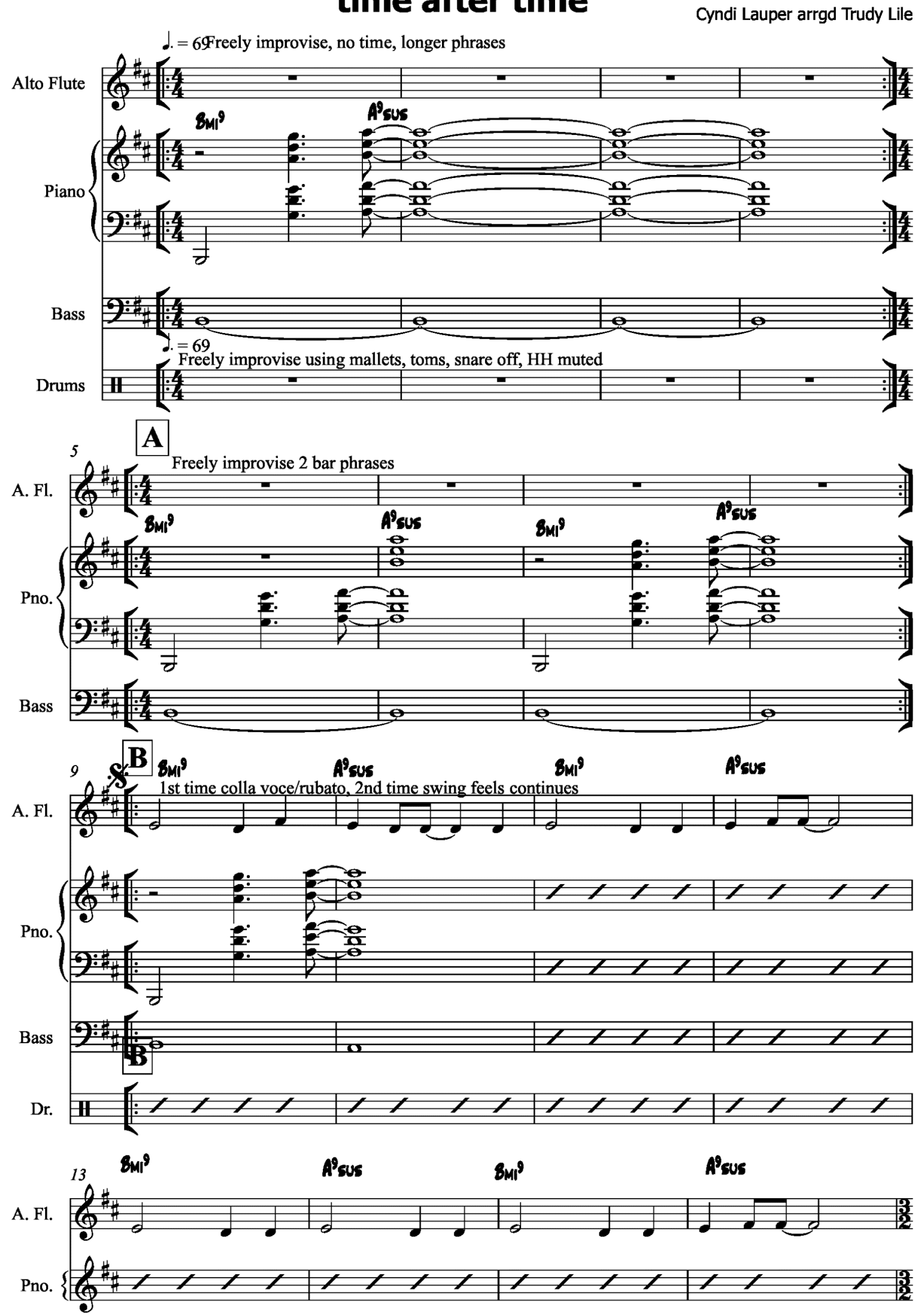

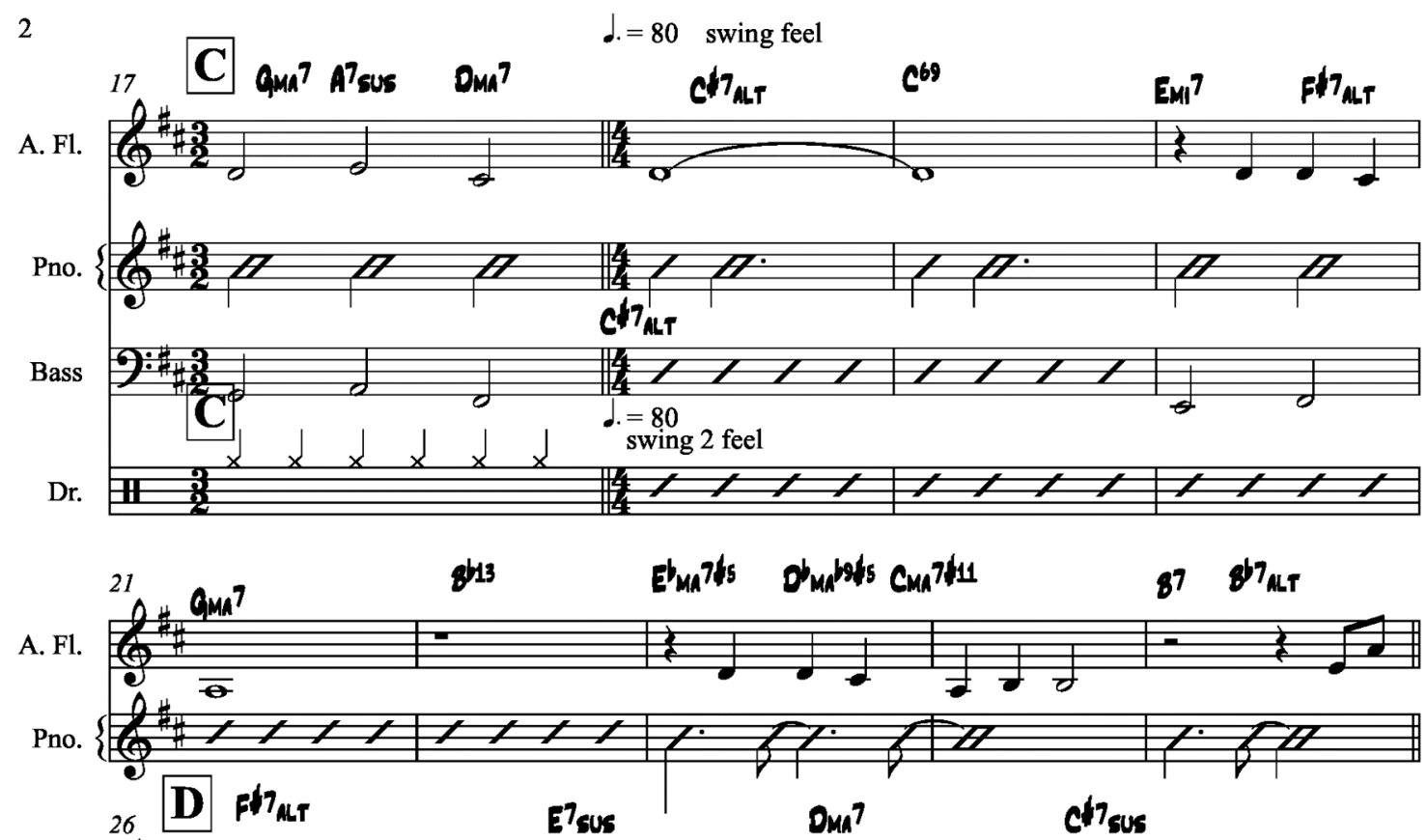

A. Fl.

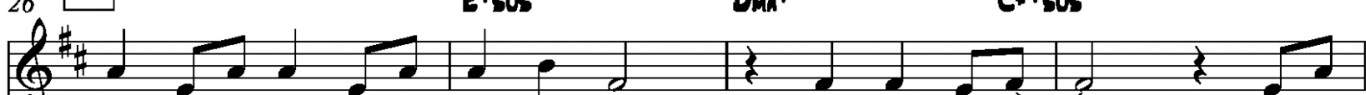

$\{0$

4
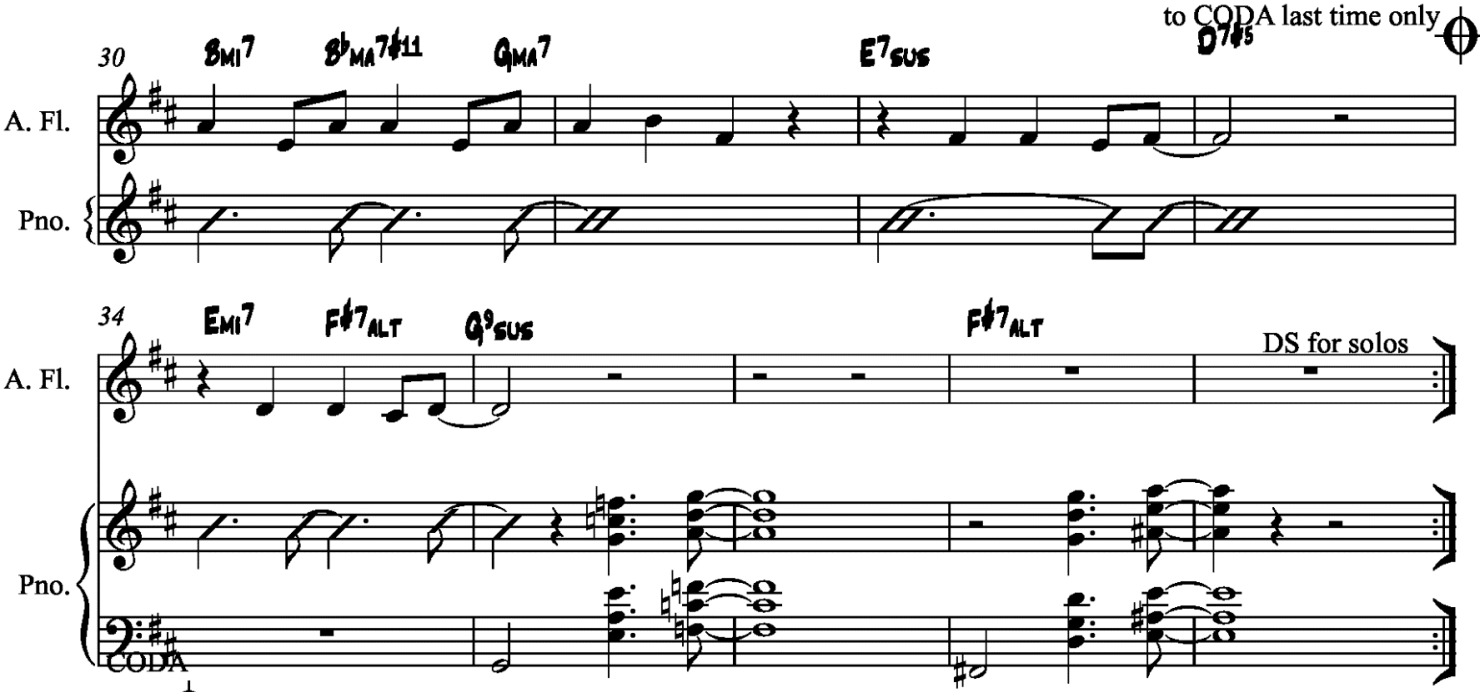

$\phi$

A. Fl.

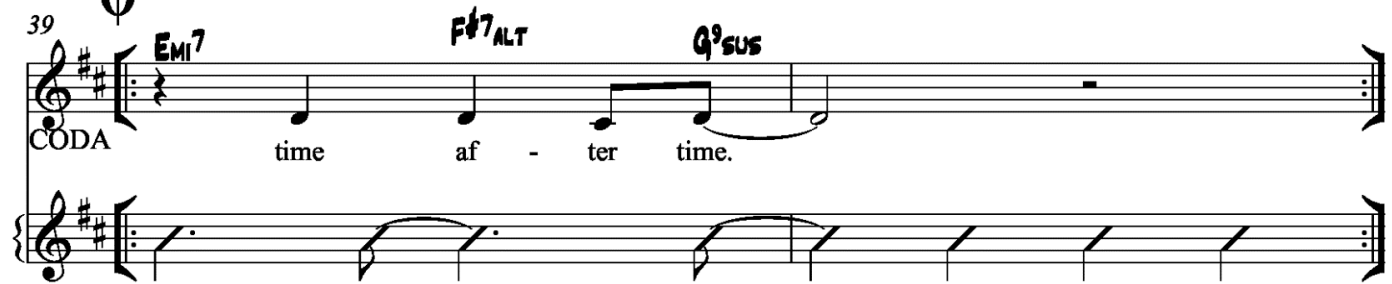




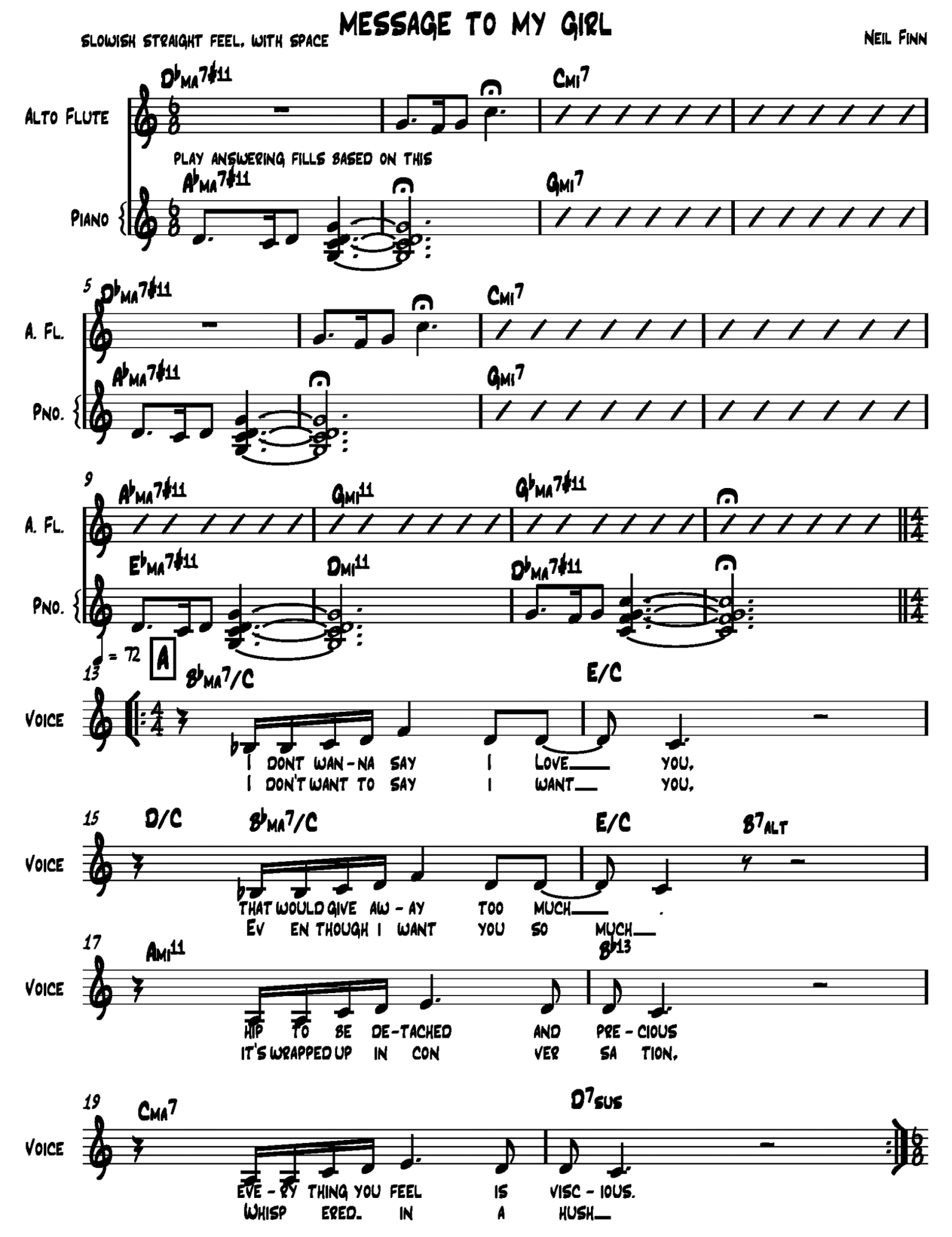



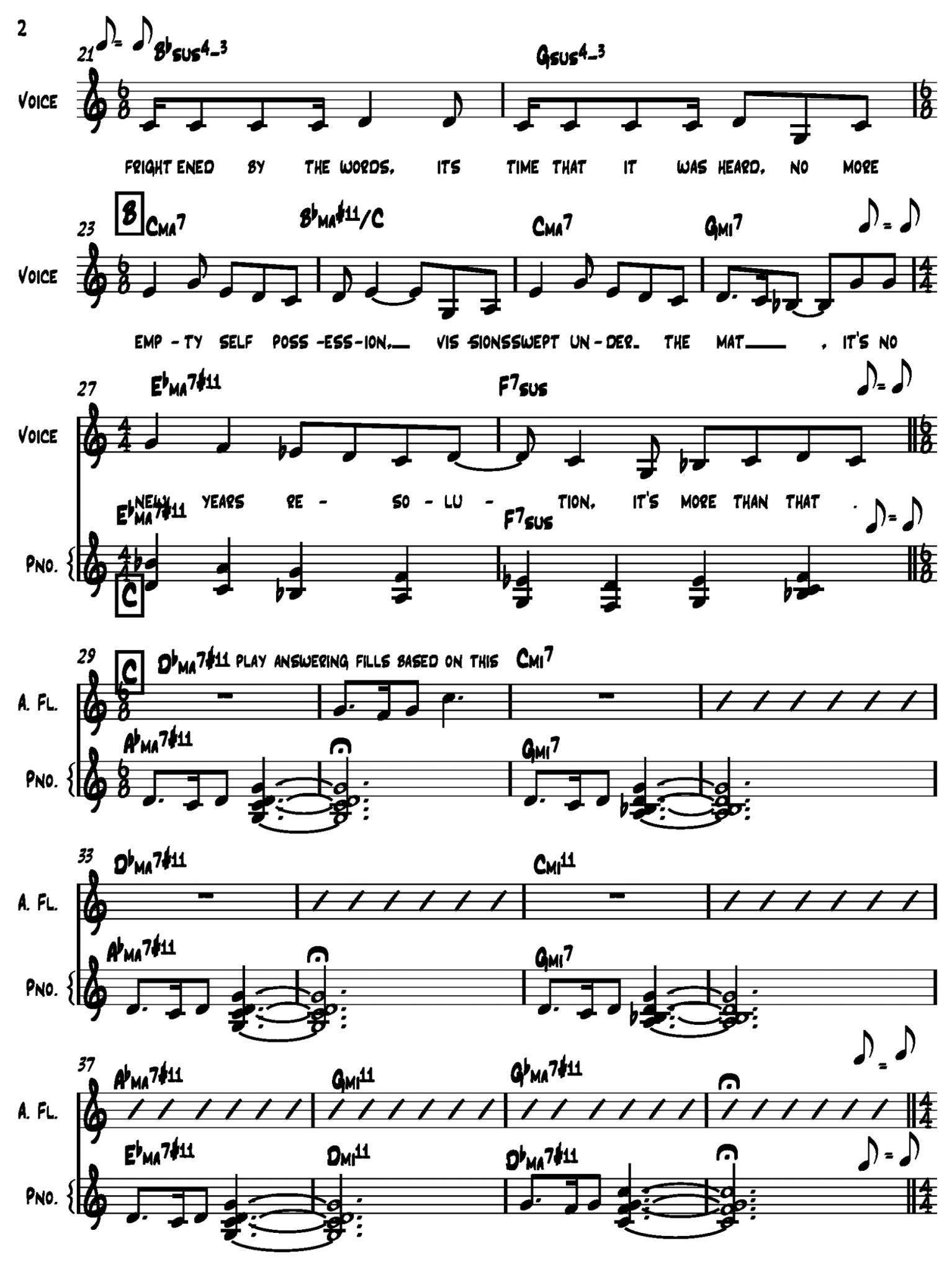

245 
0
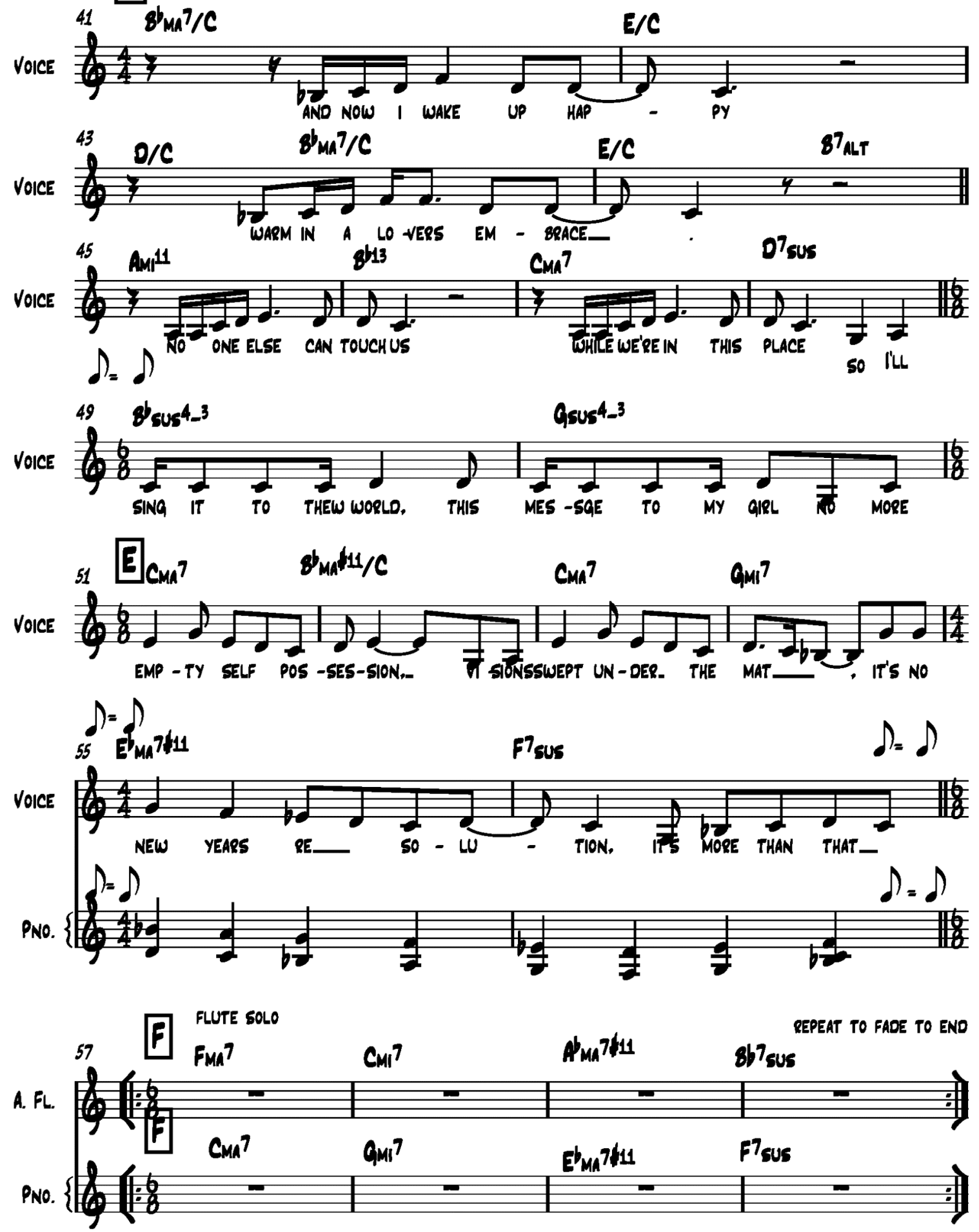
MORE THAN THIS

BRIAN FER RY
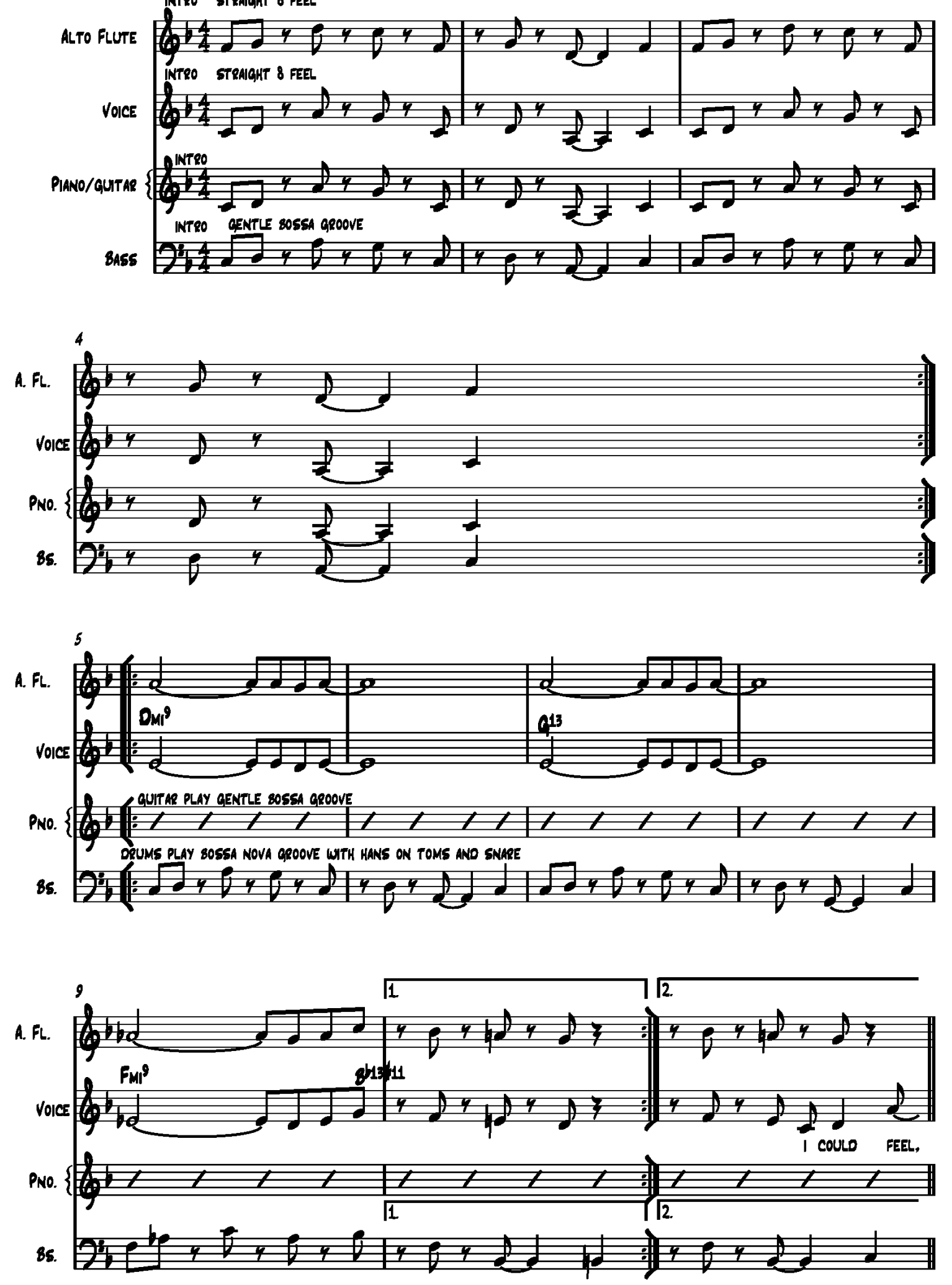

247 
2
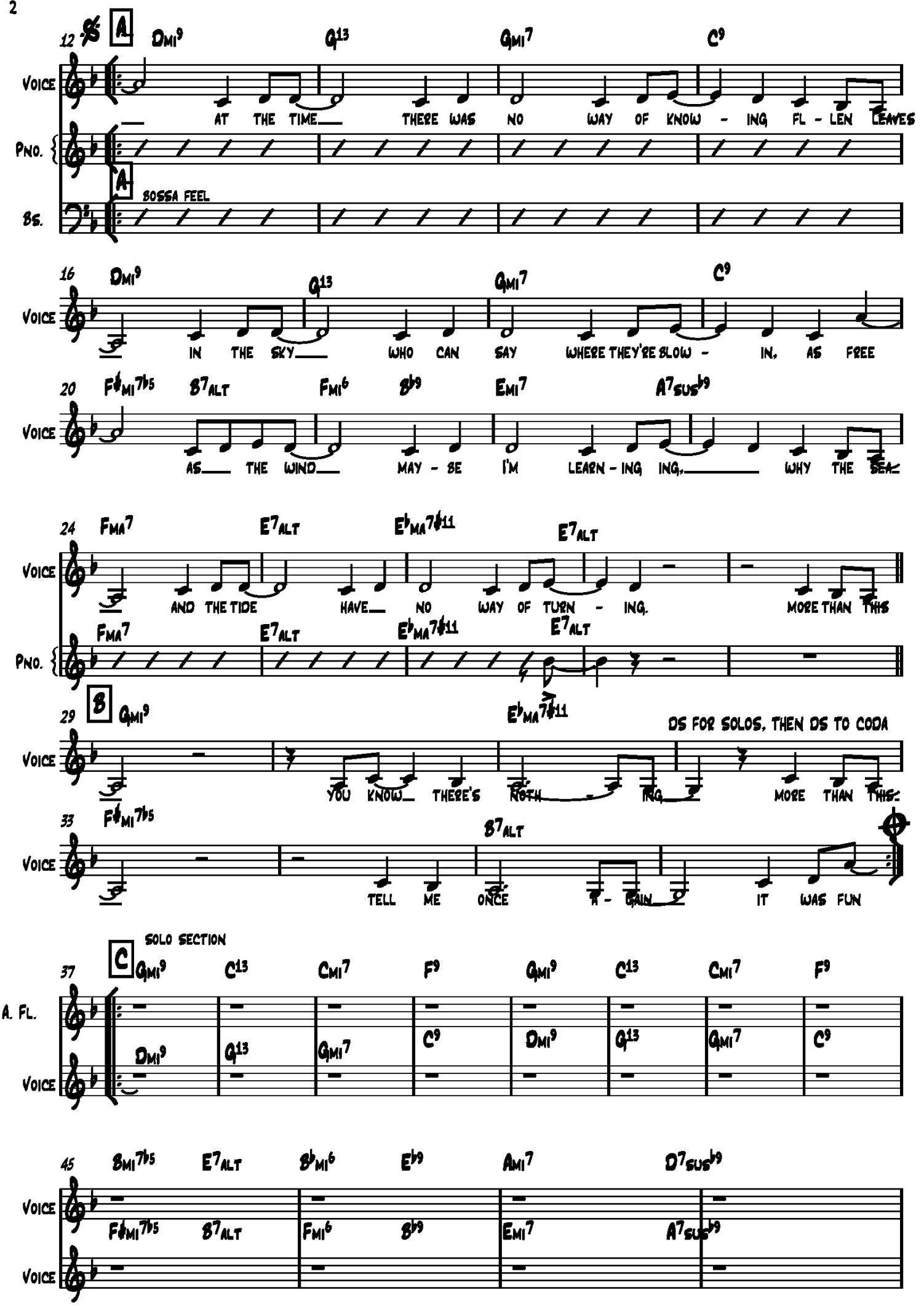

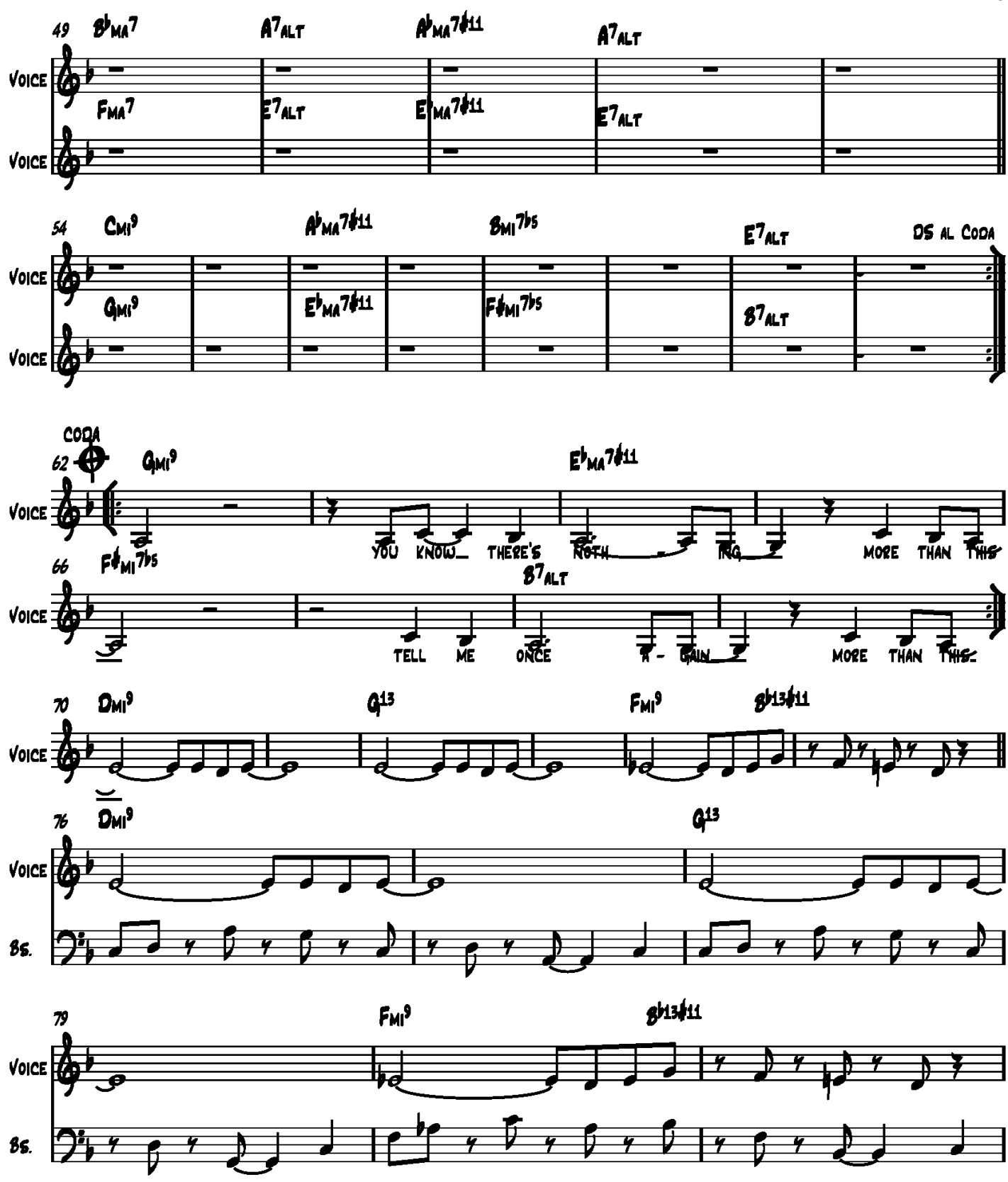

PNO. 


\section{IS THIS LOVE}

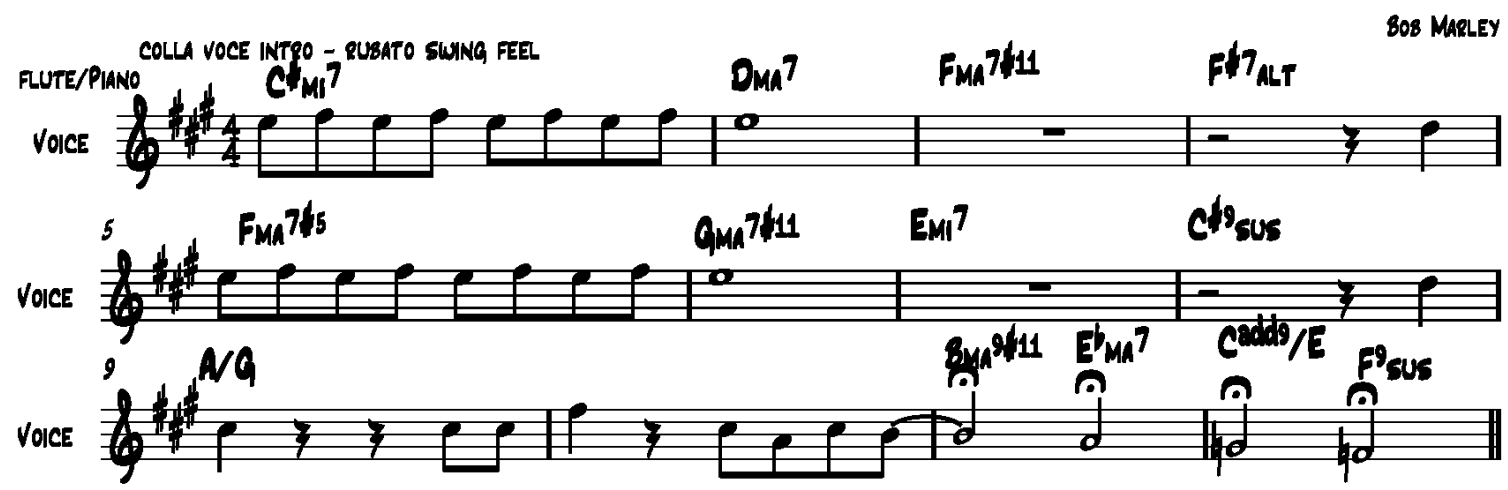

\section{SWING REgGAE FEEL IN 7}
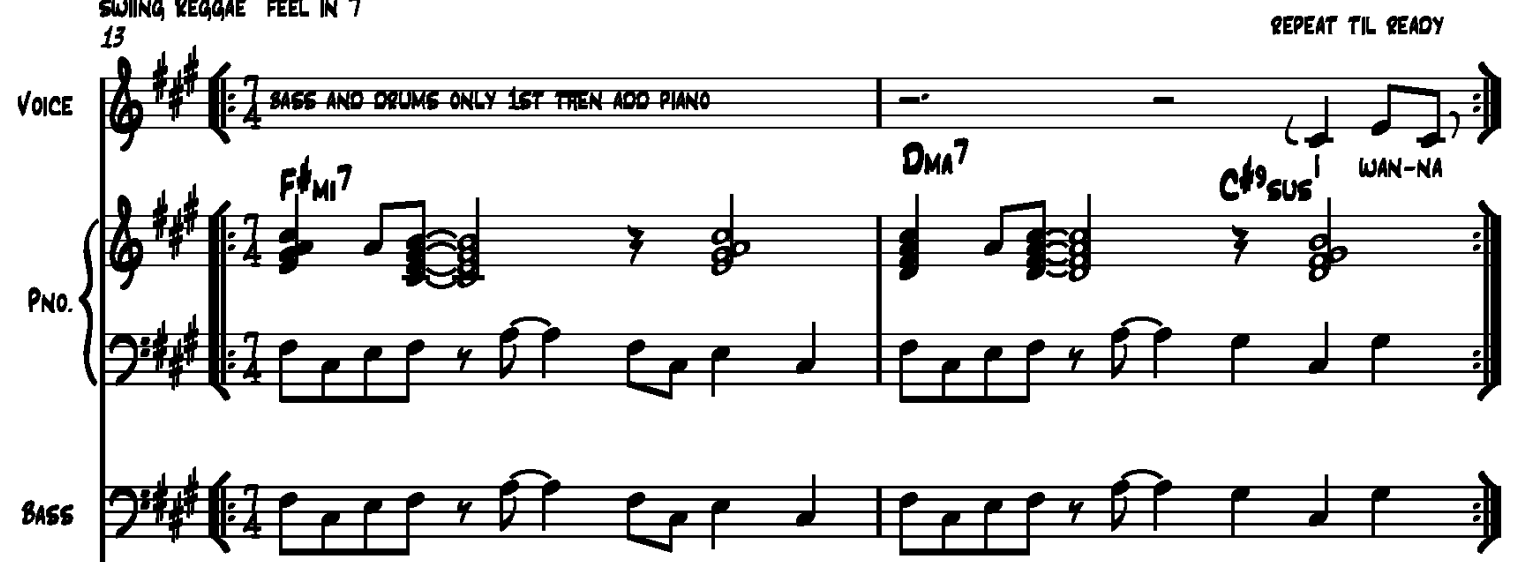

BASS ANO DRUMS ONLY 1ST THEN AOO PIANO
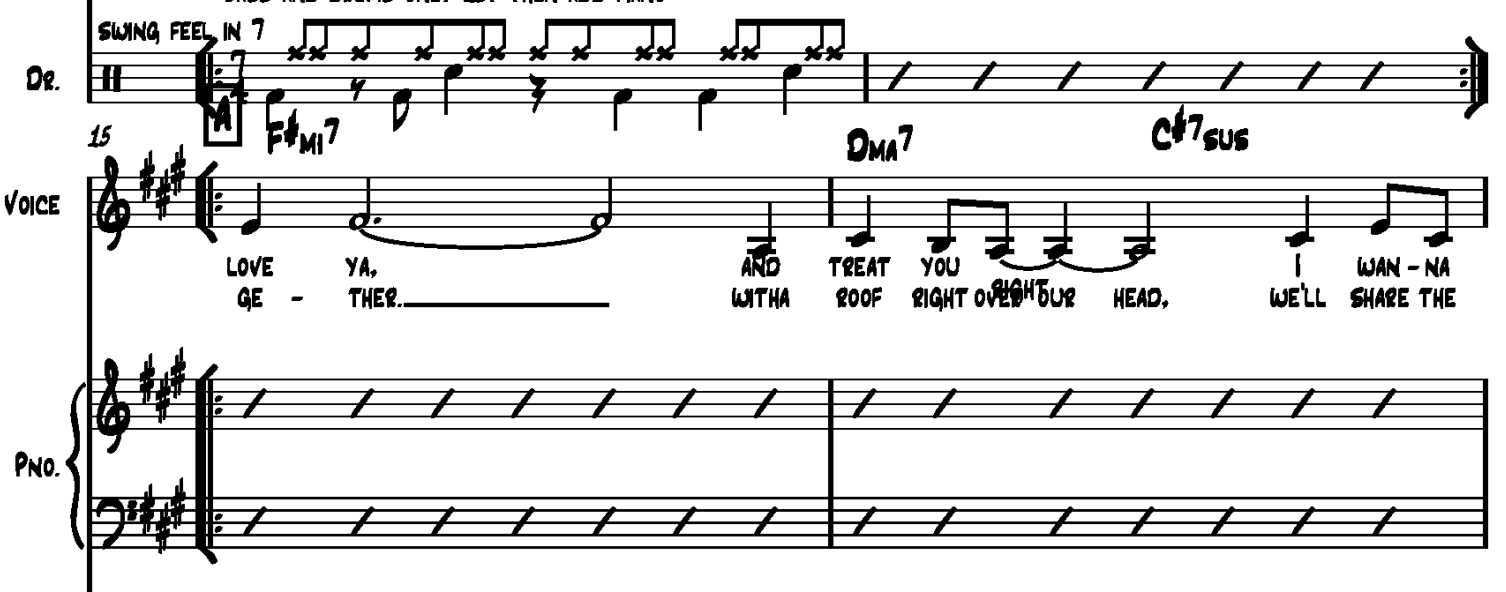

suss 触

Dr.
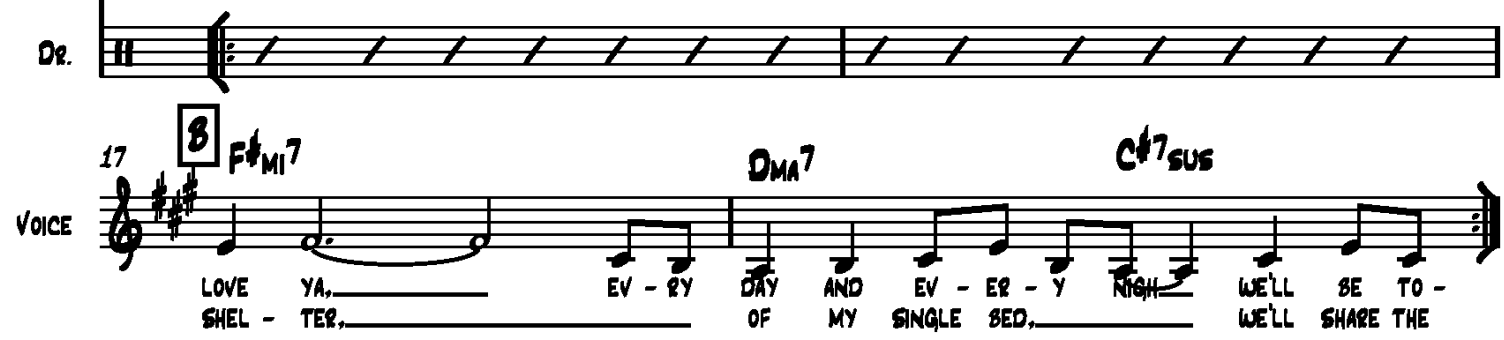
2
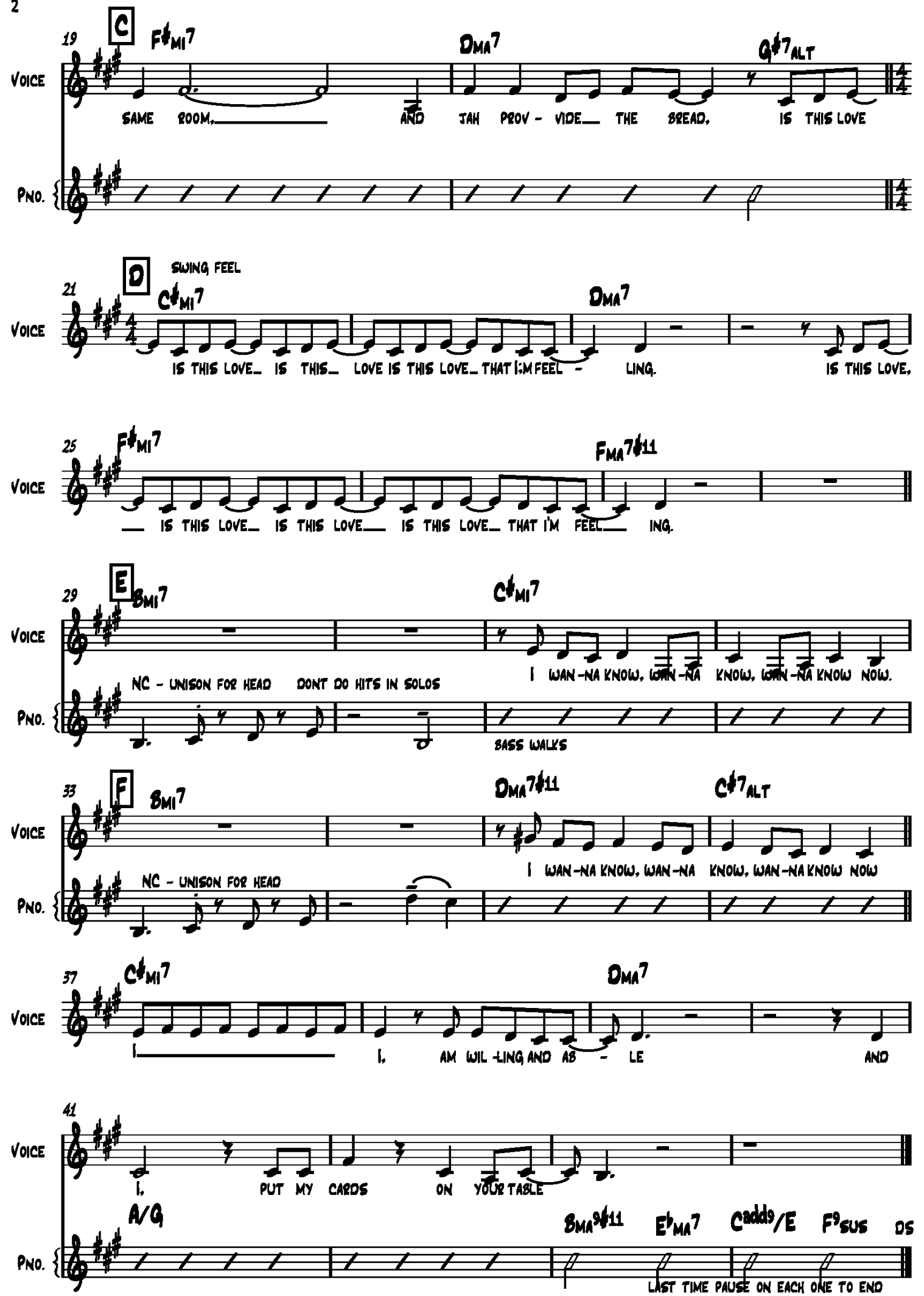


\section{FRAGILE}

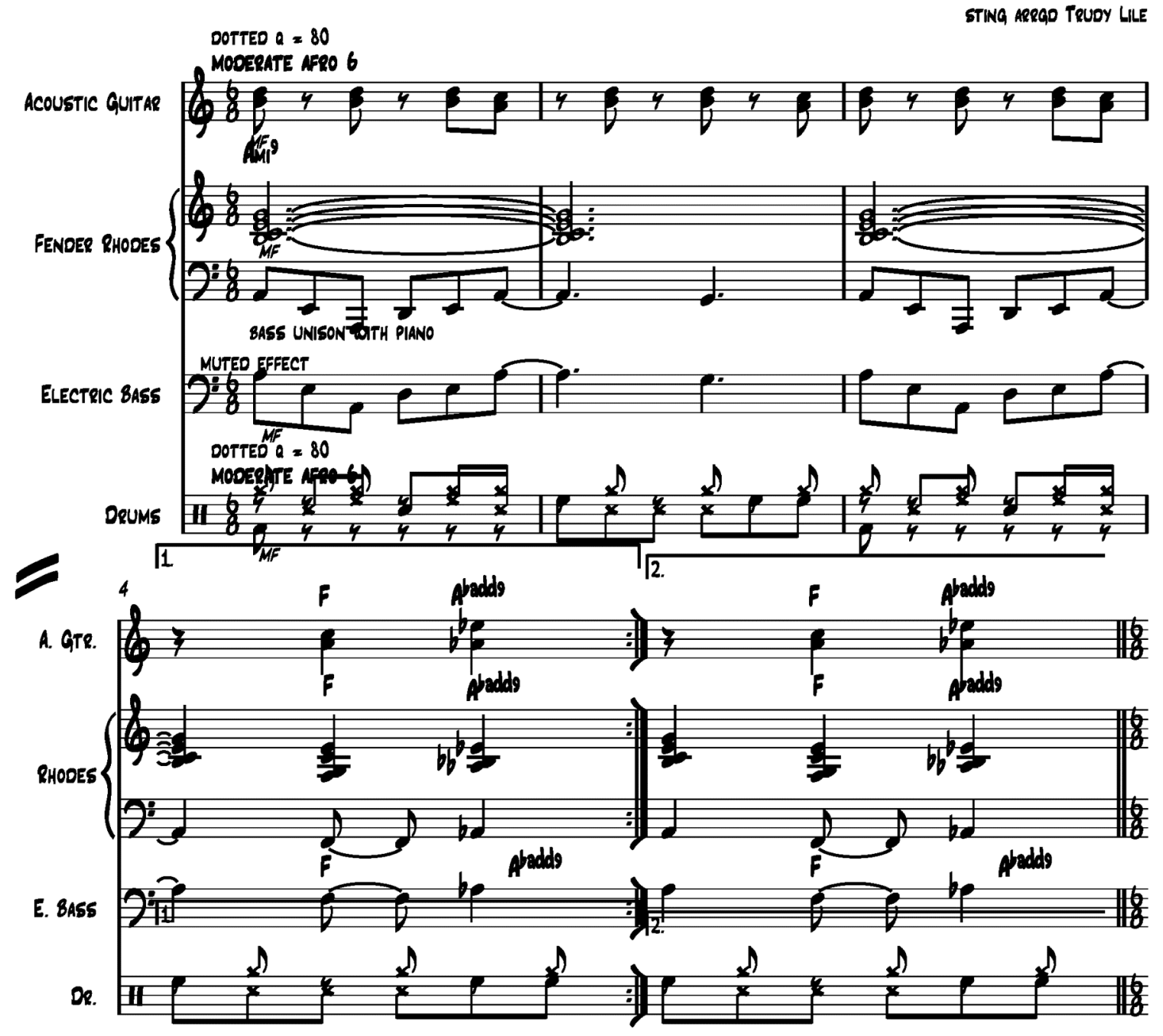


2

12

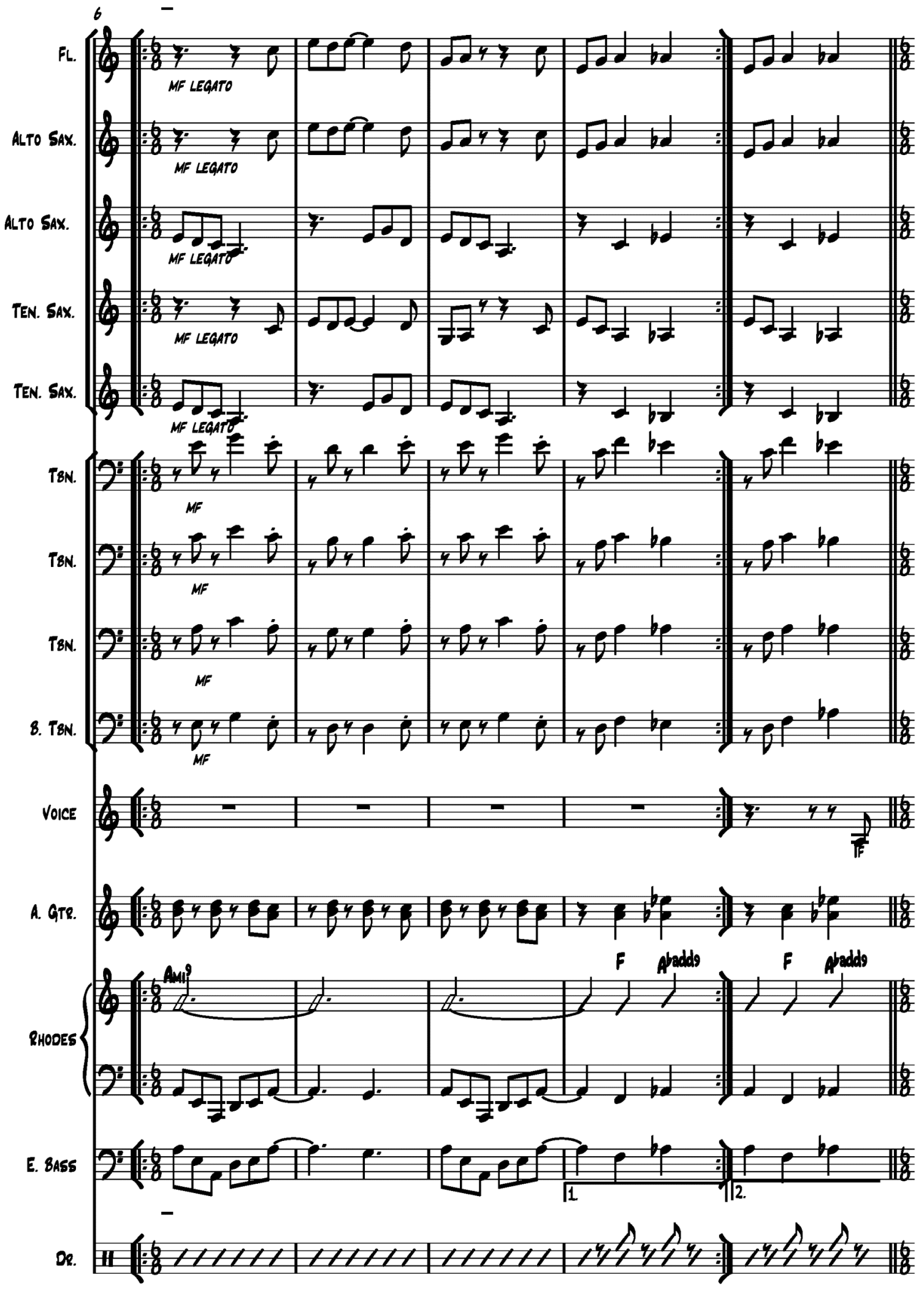




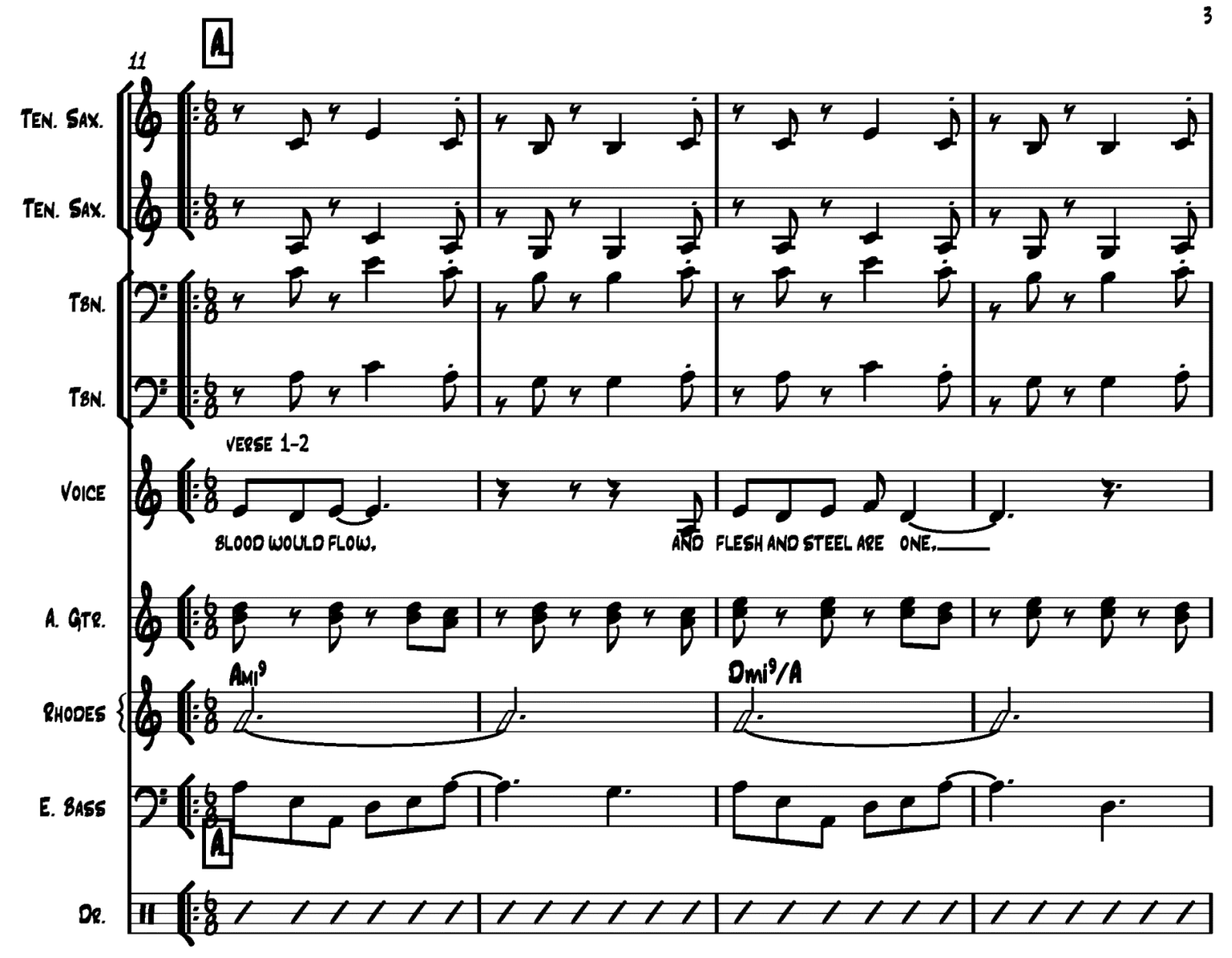


4
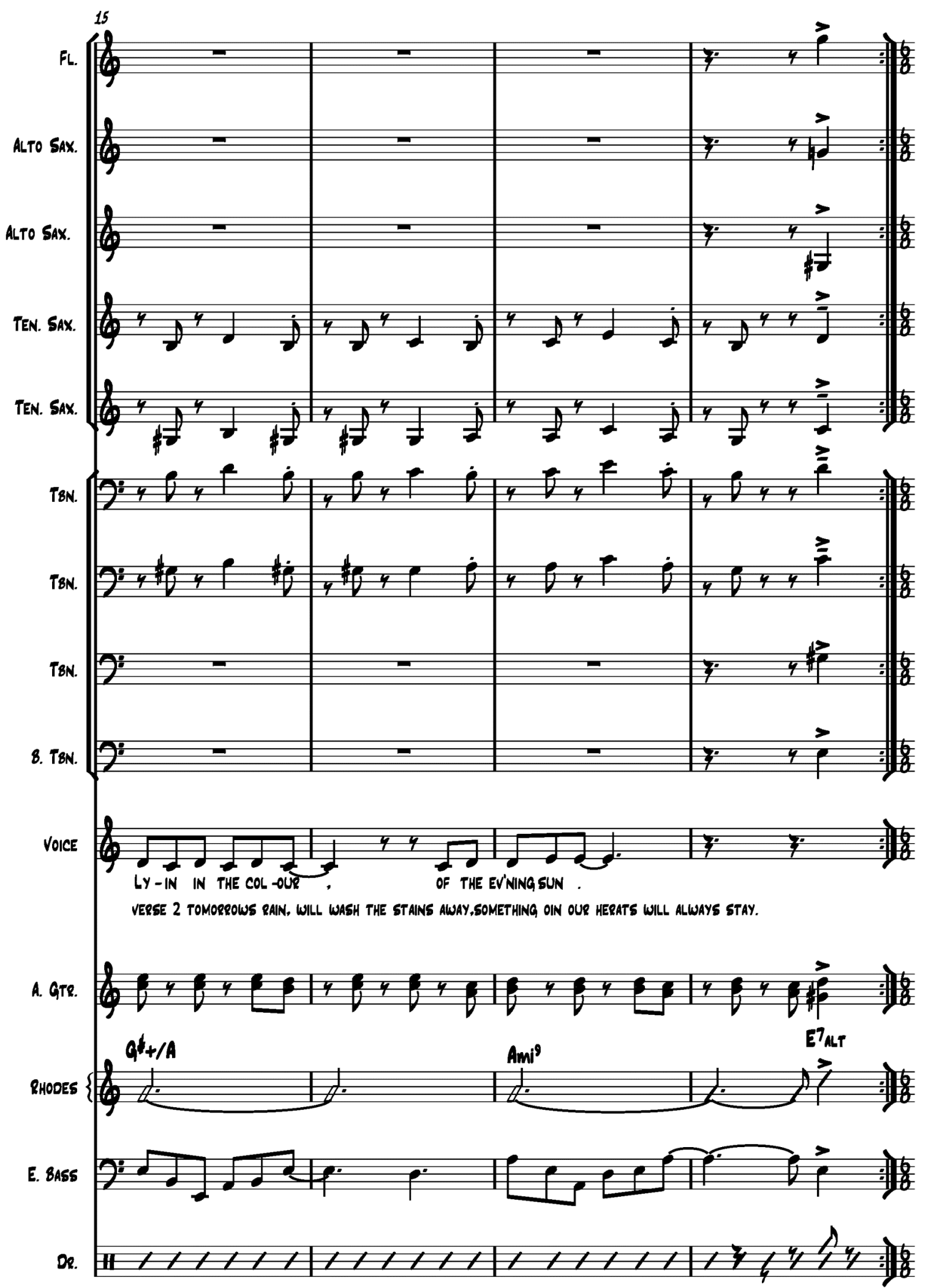

255 


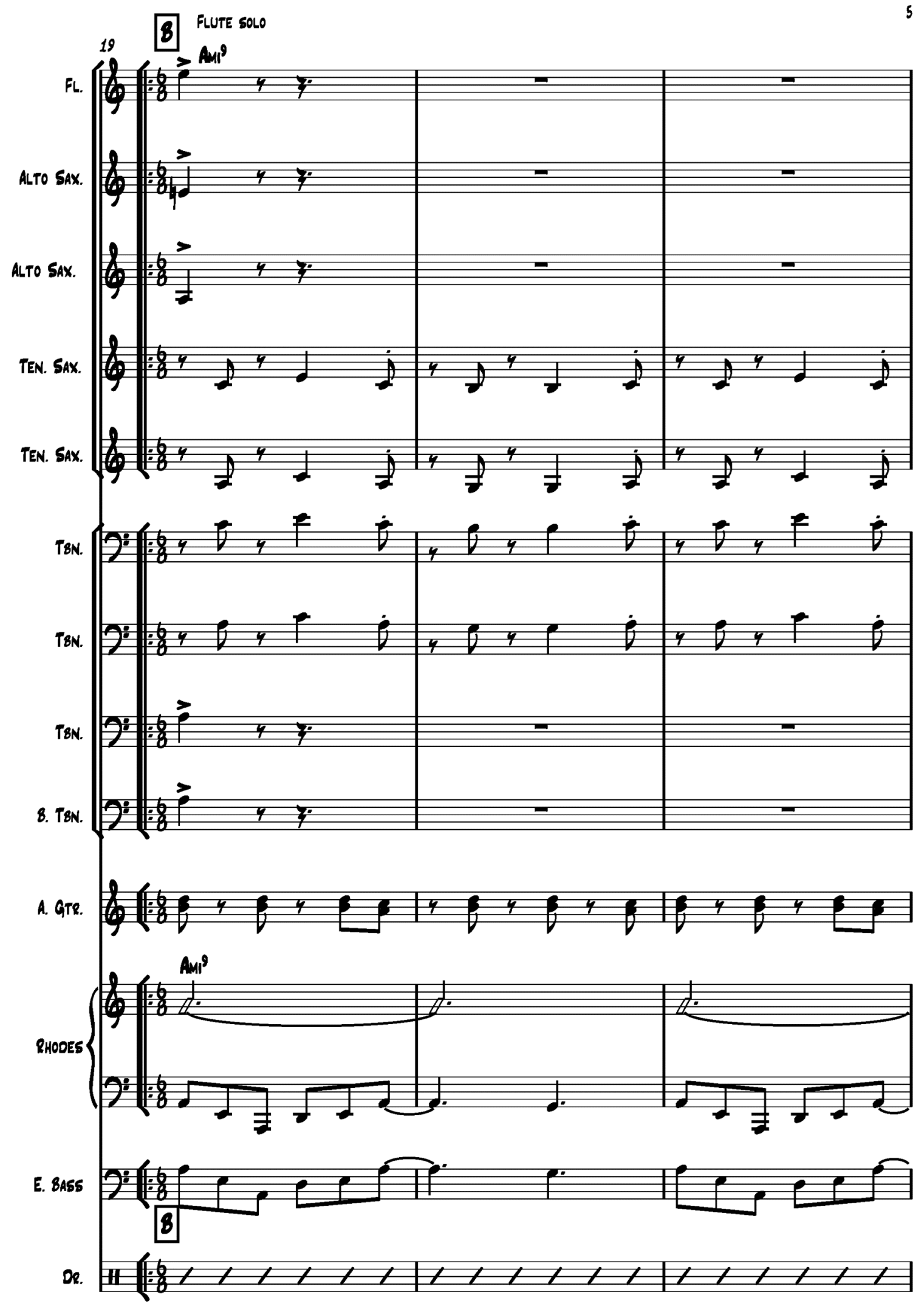




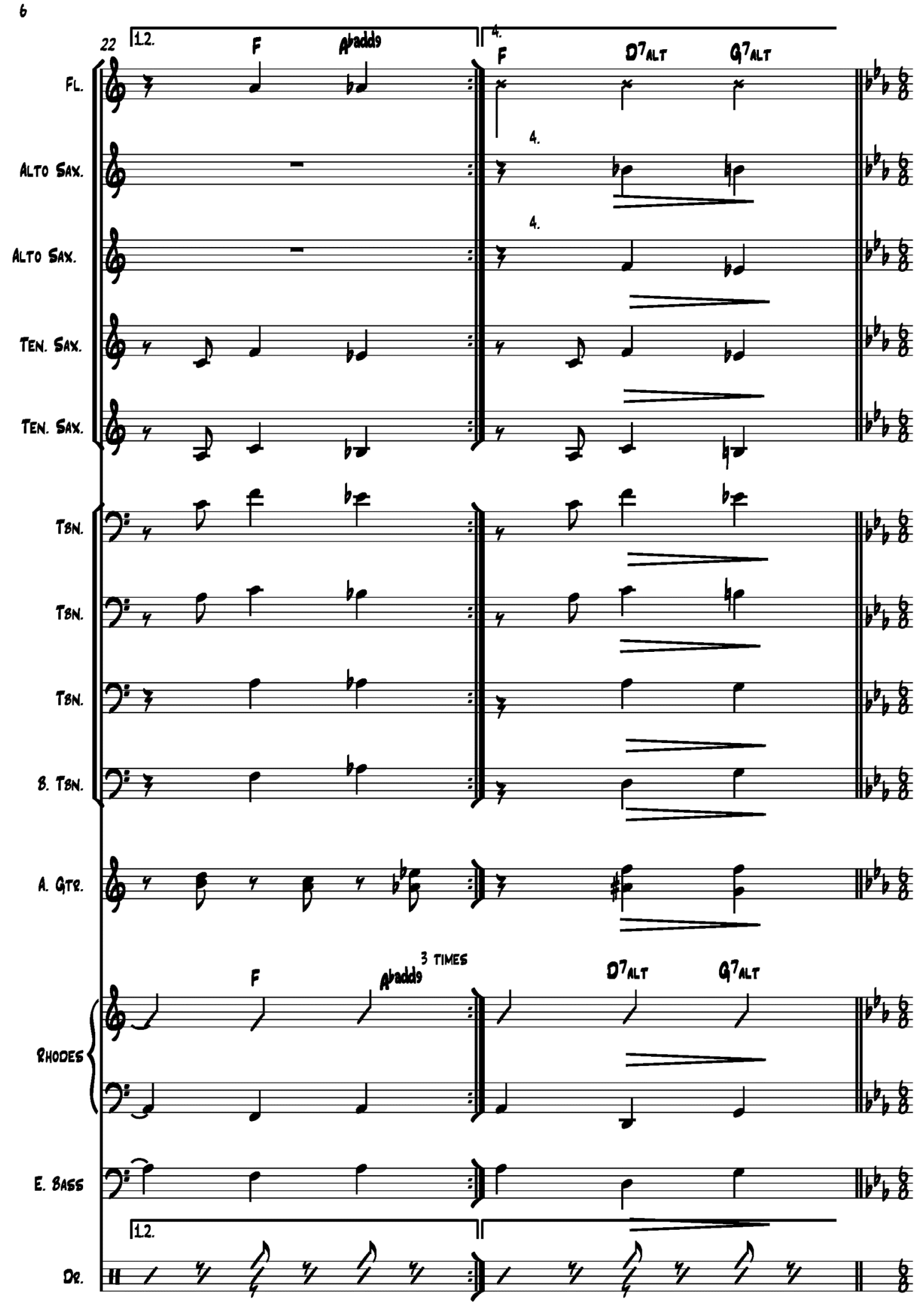




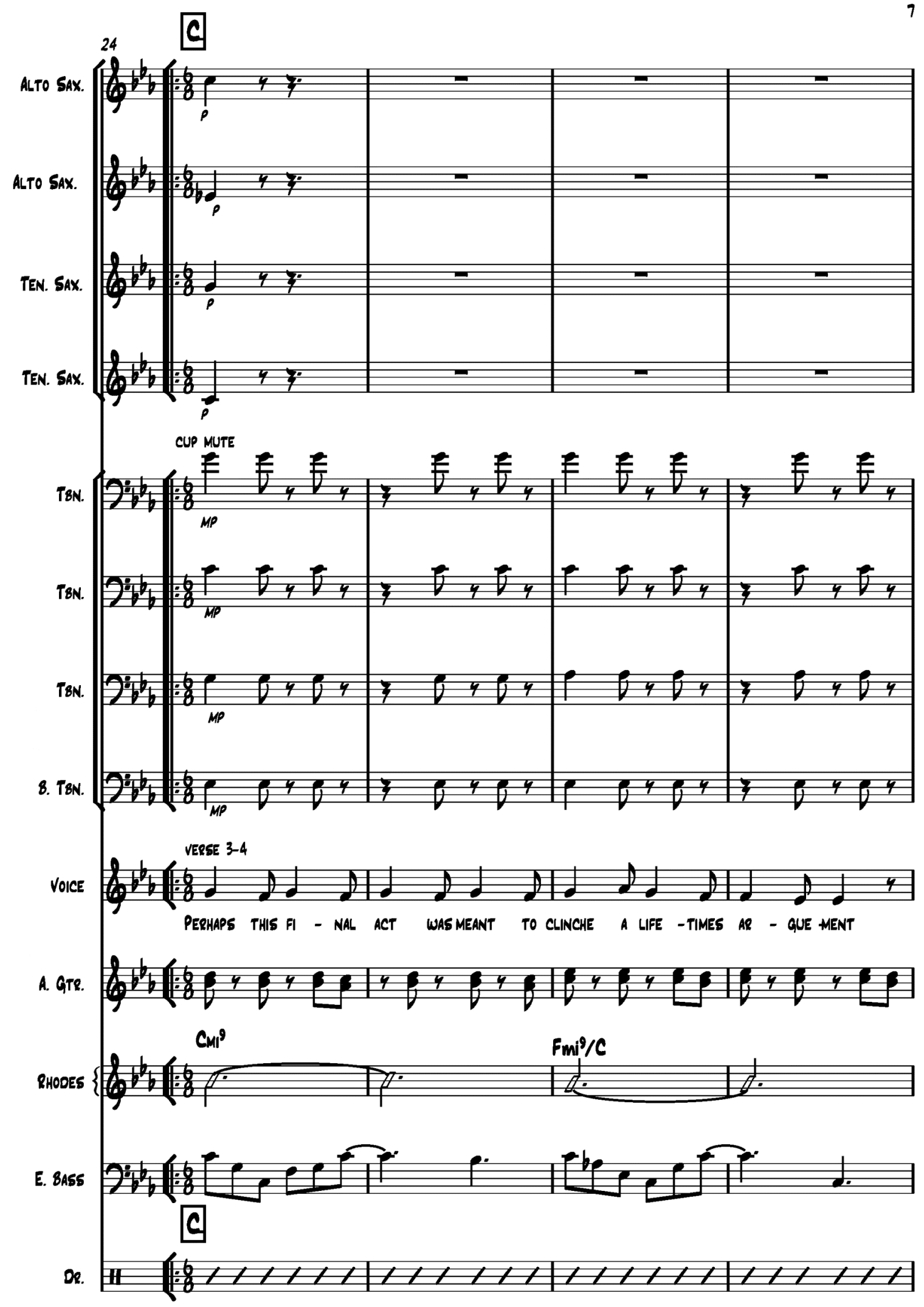


8

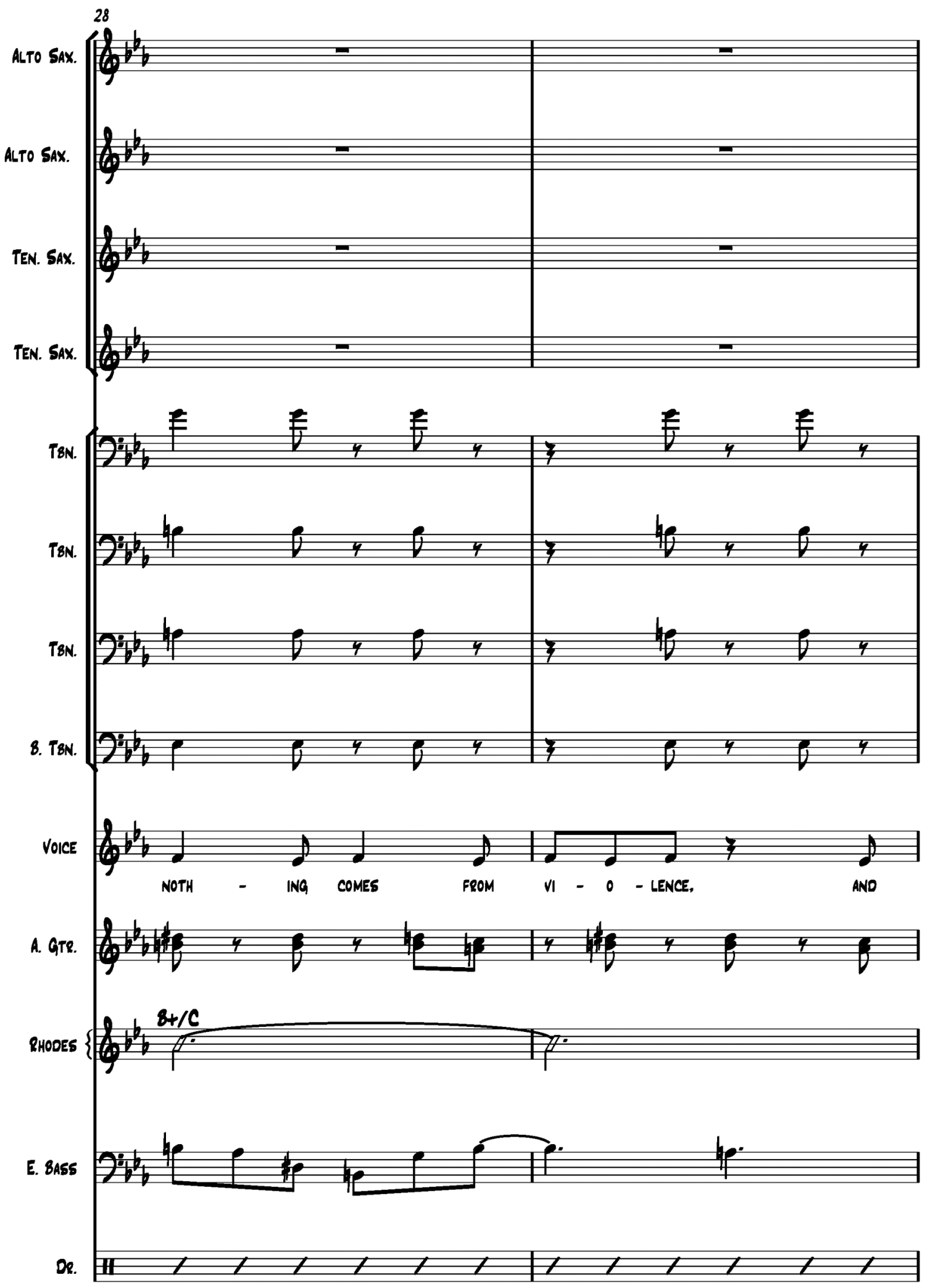




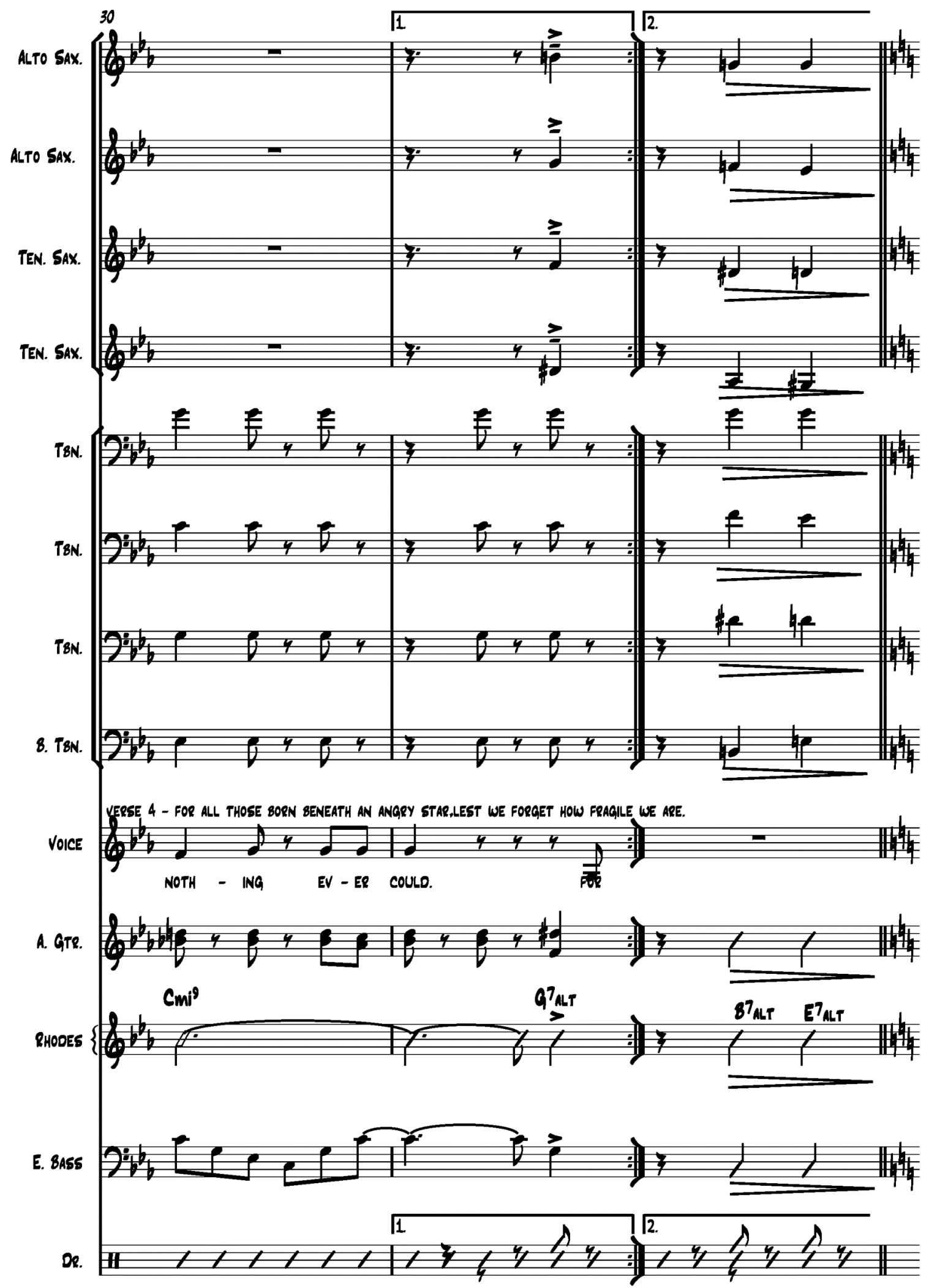




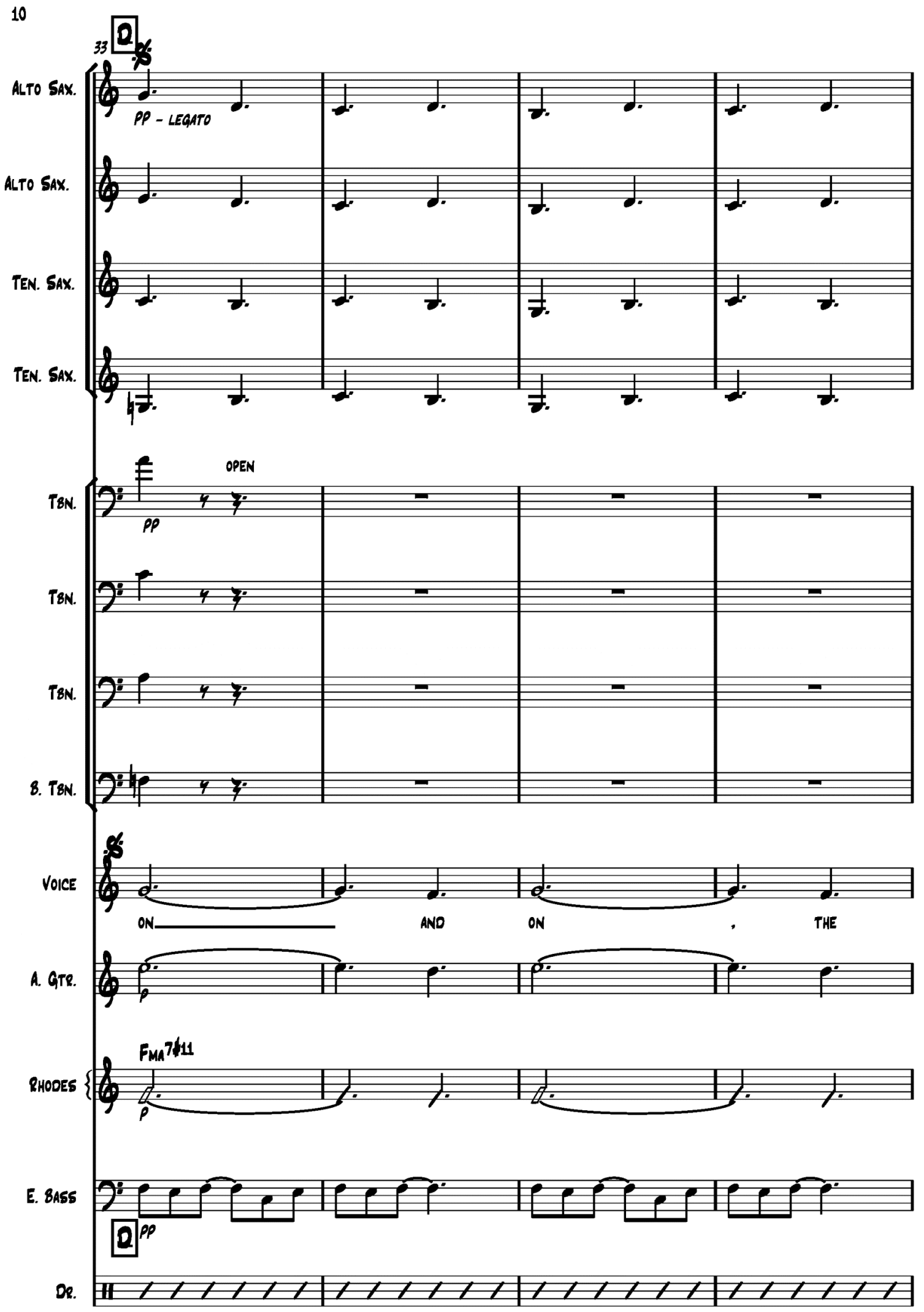




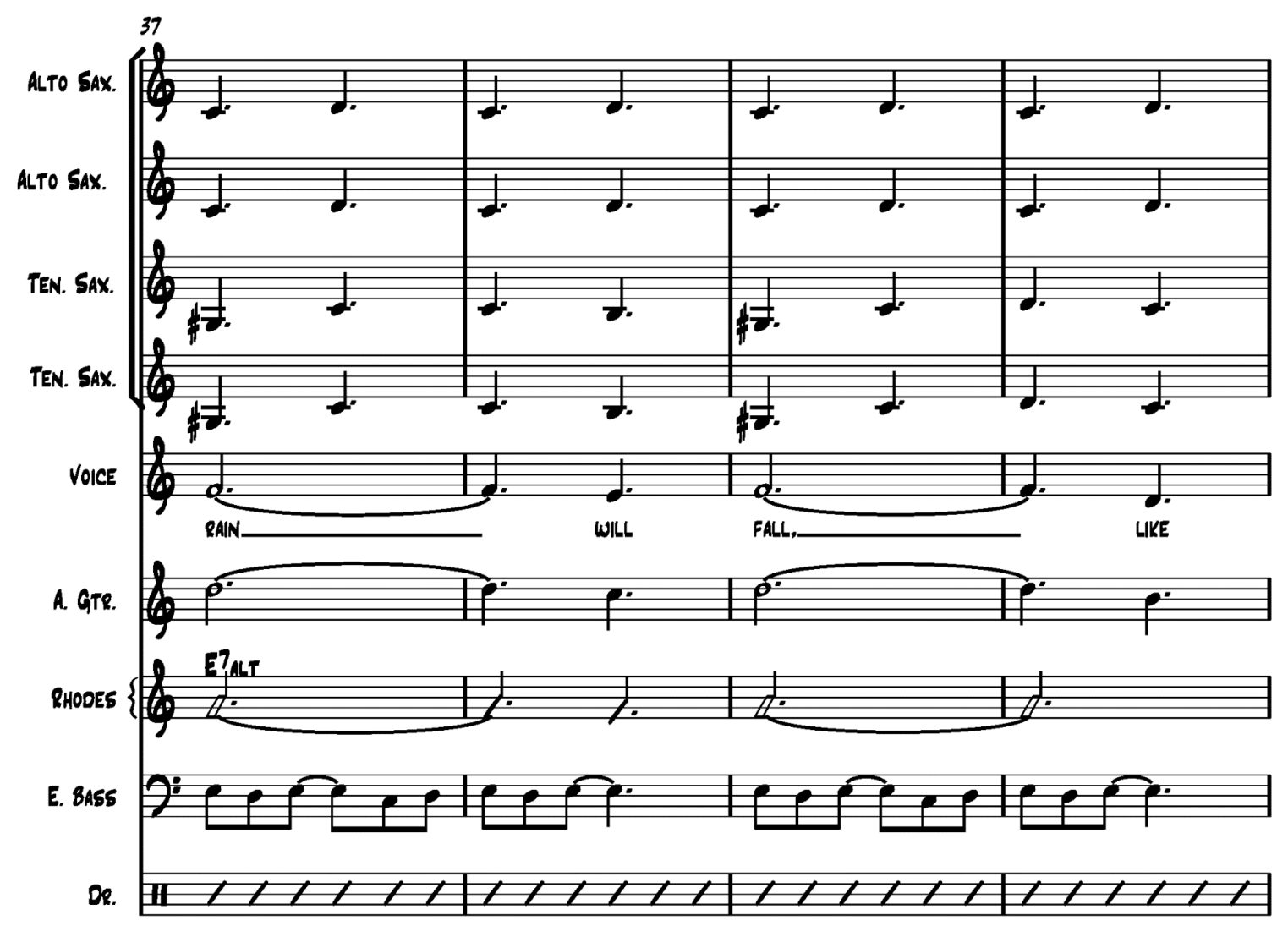




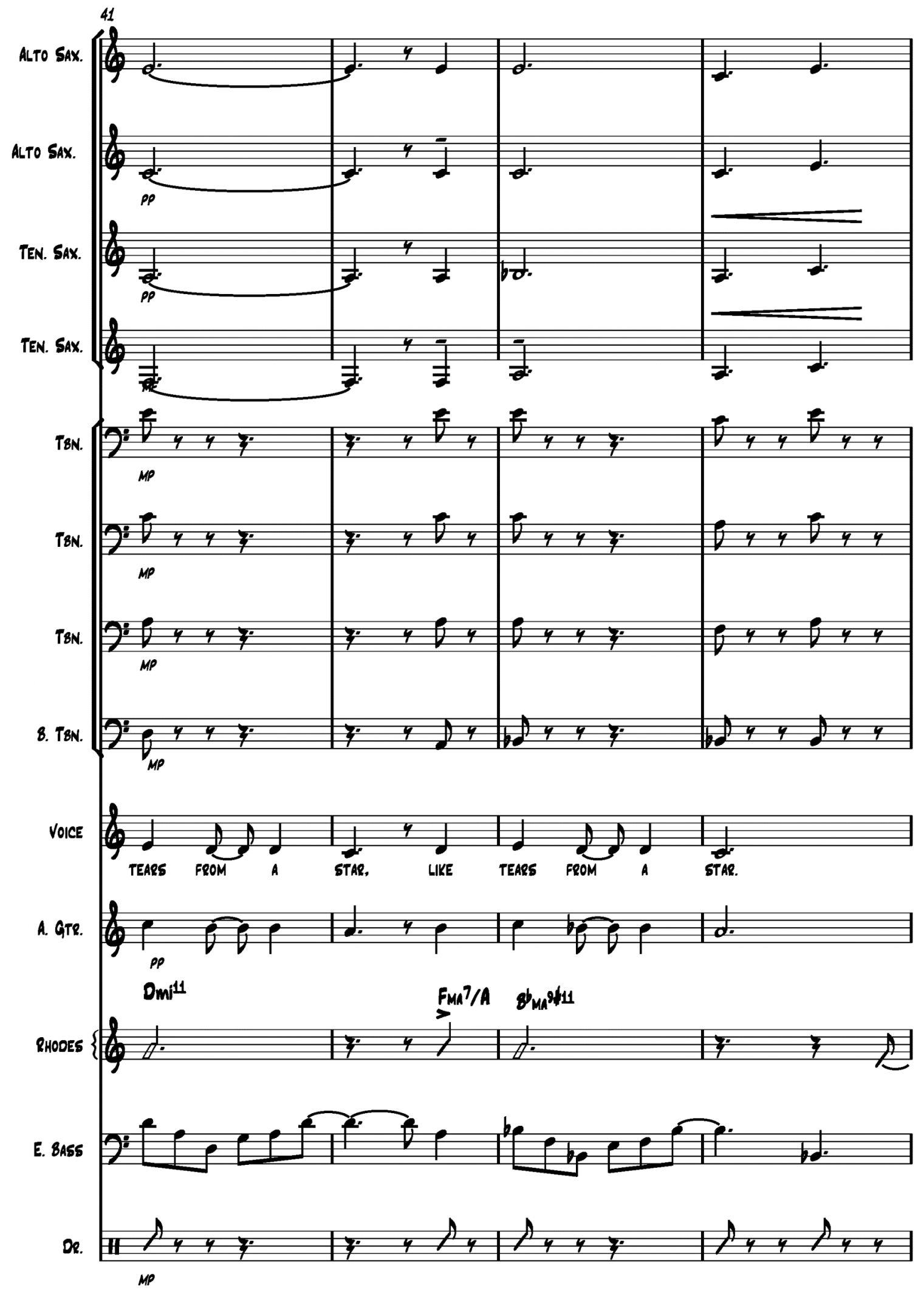


13
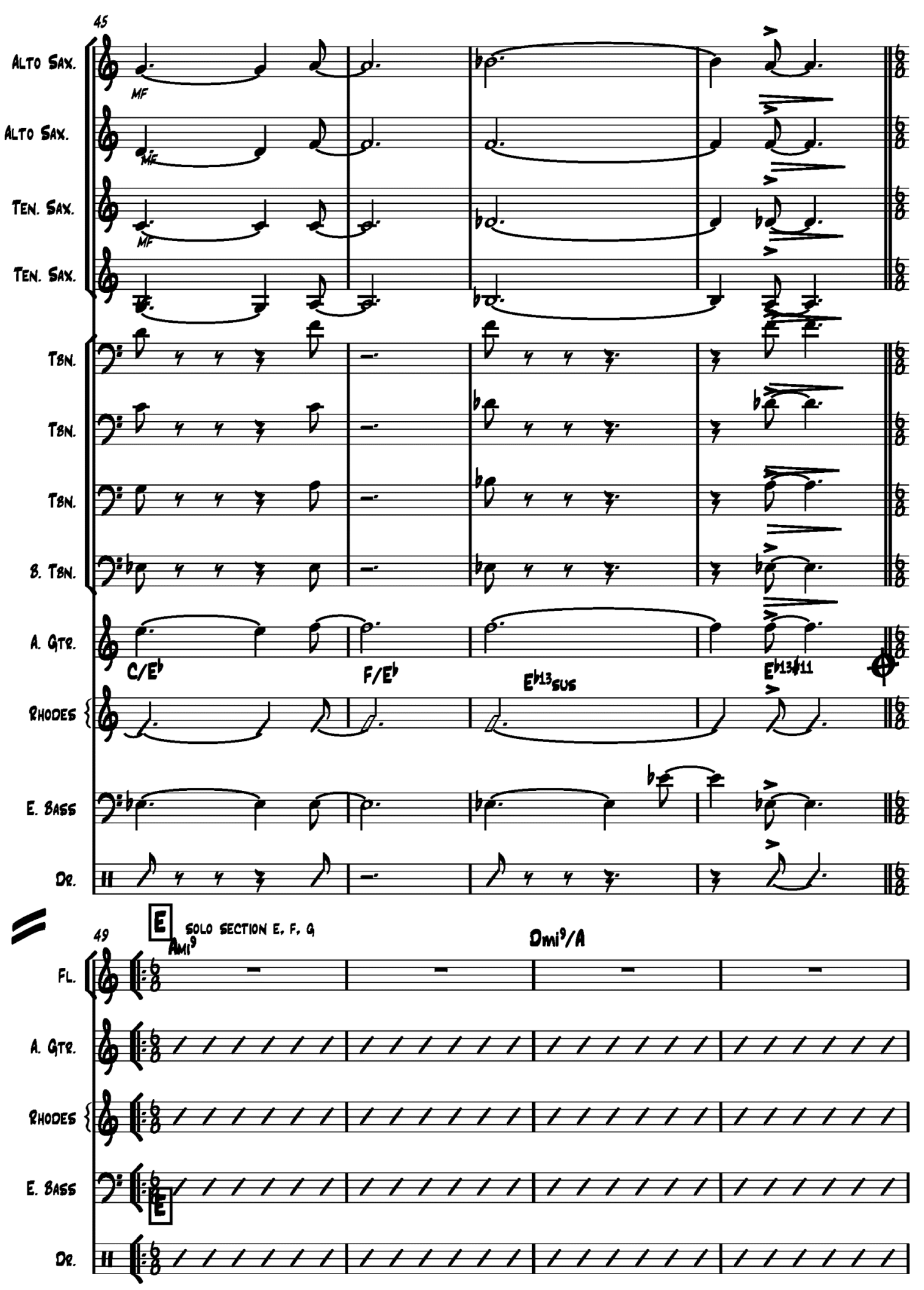

264 
14

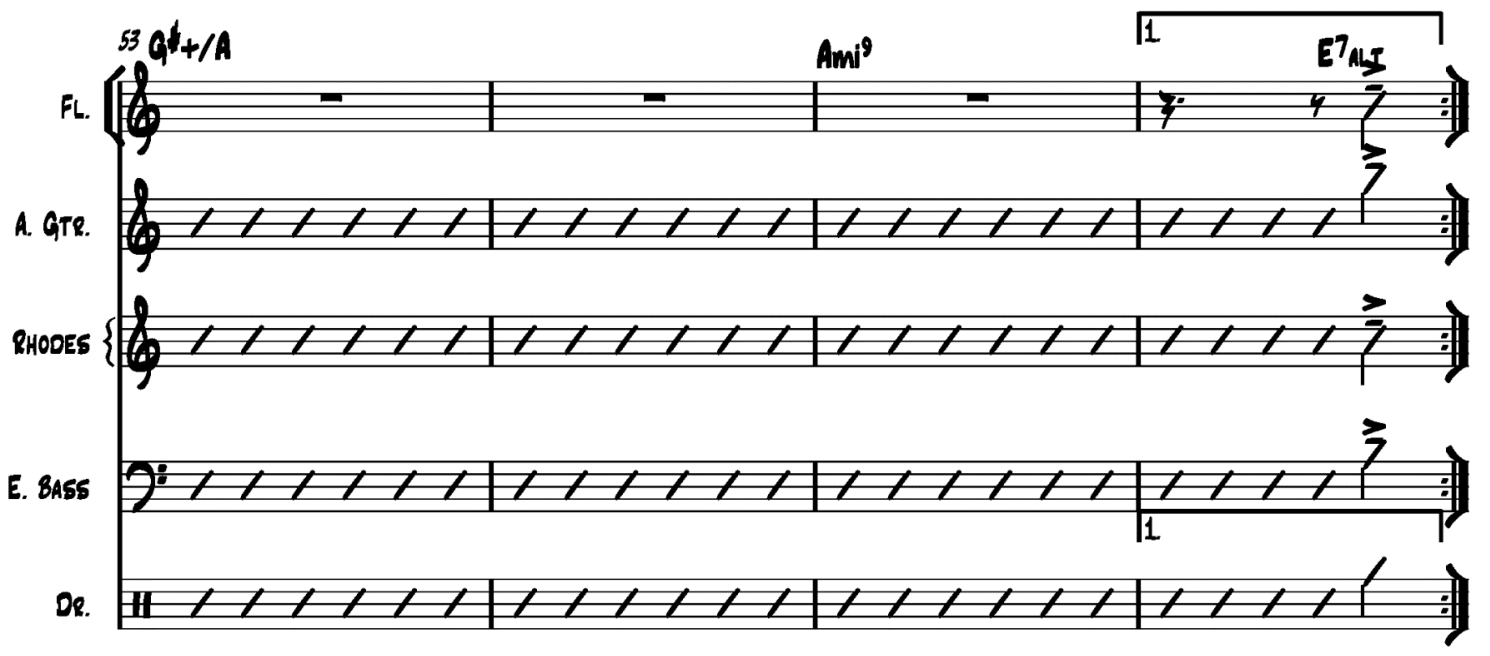

265 


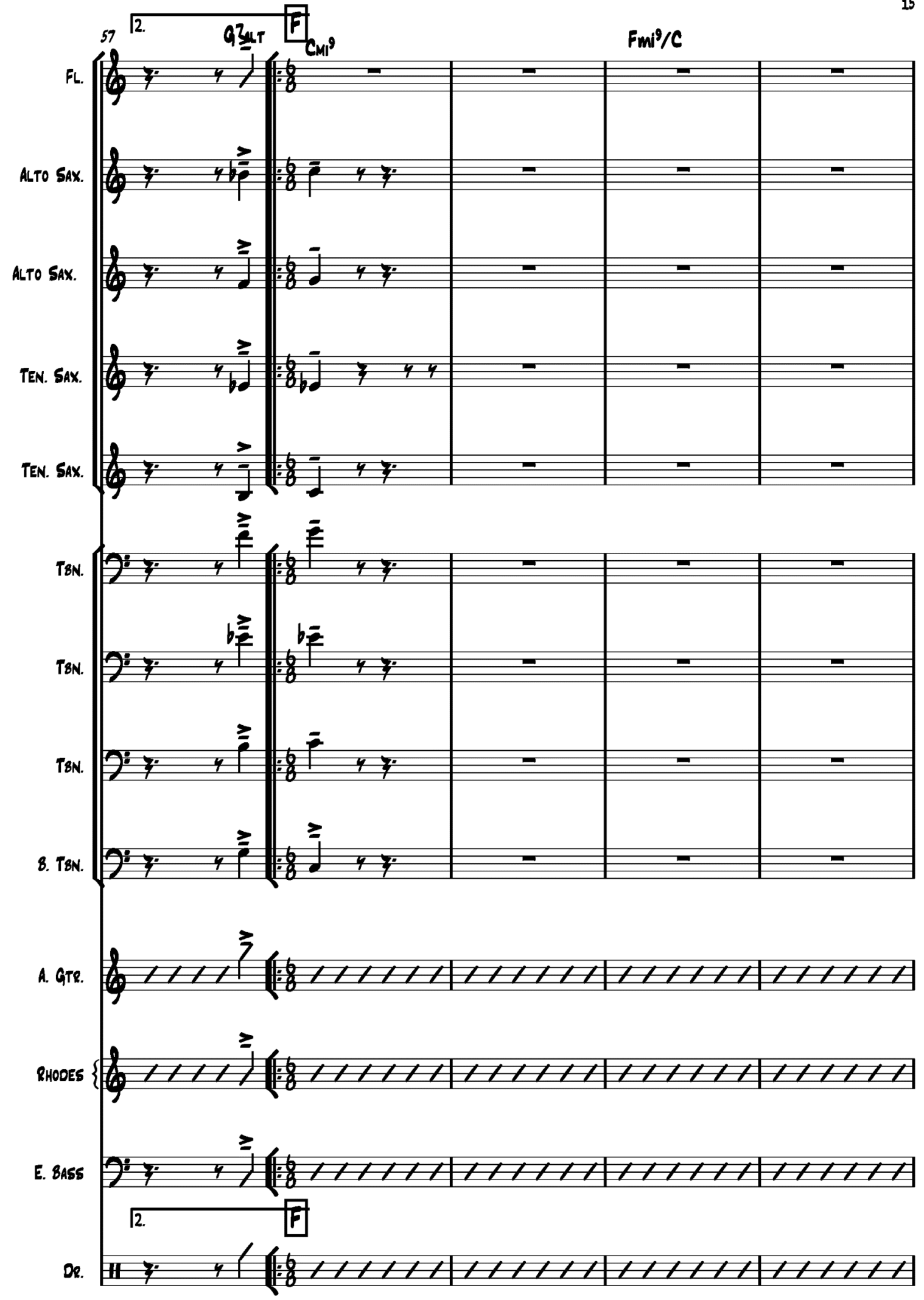




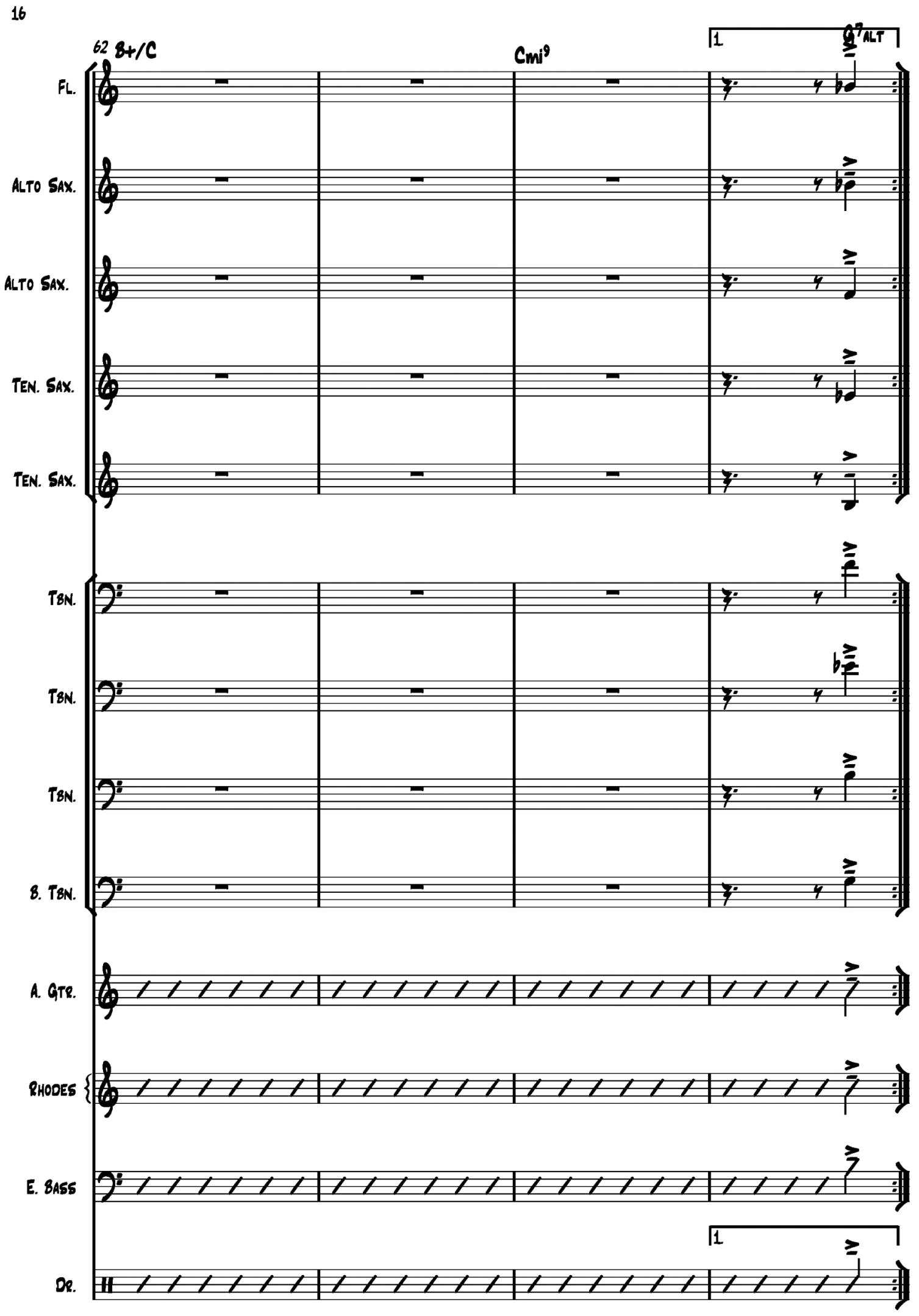




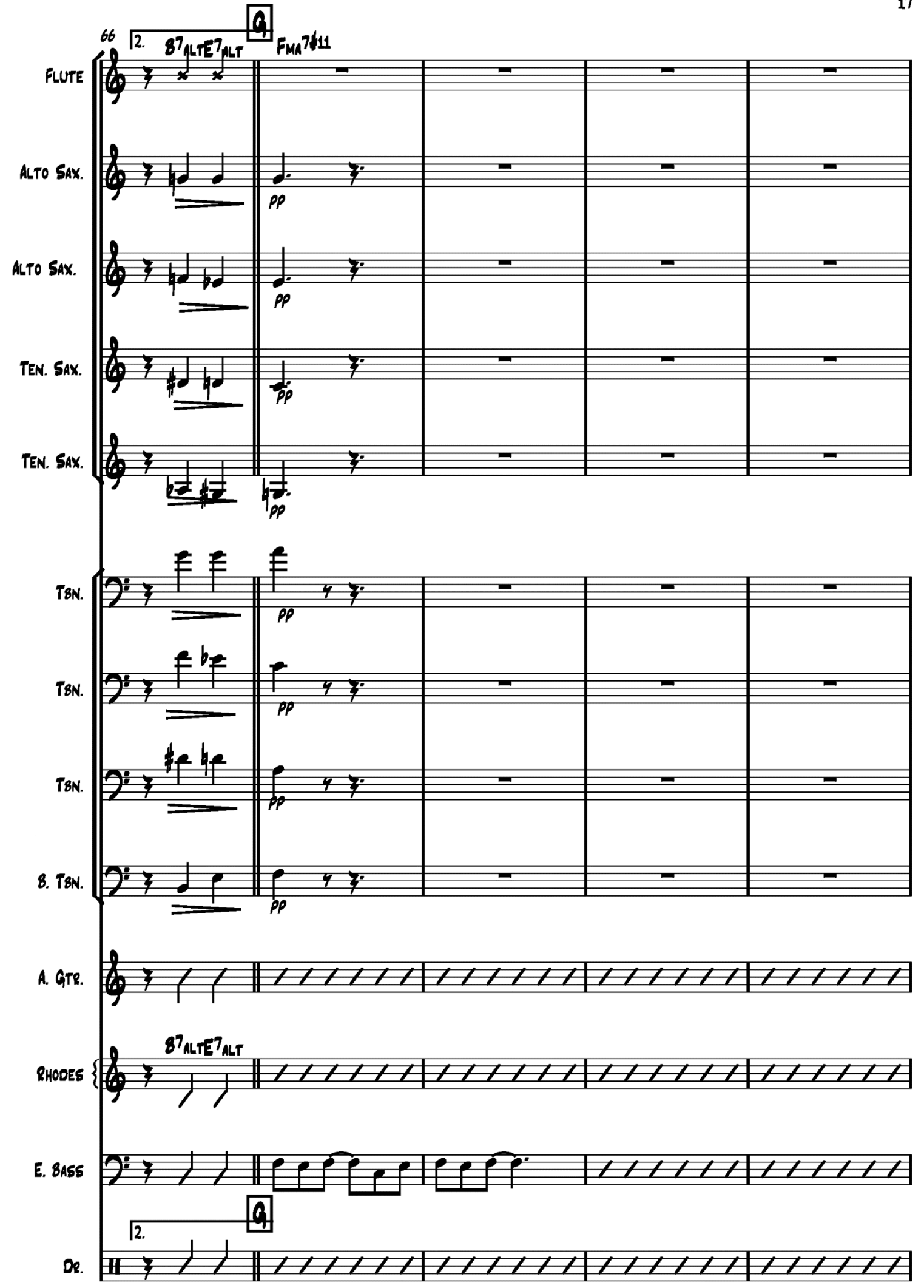



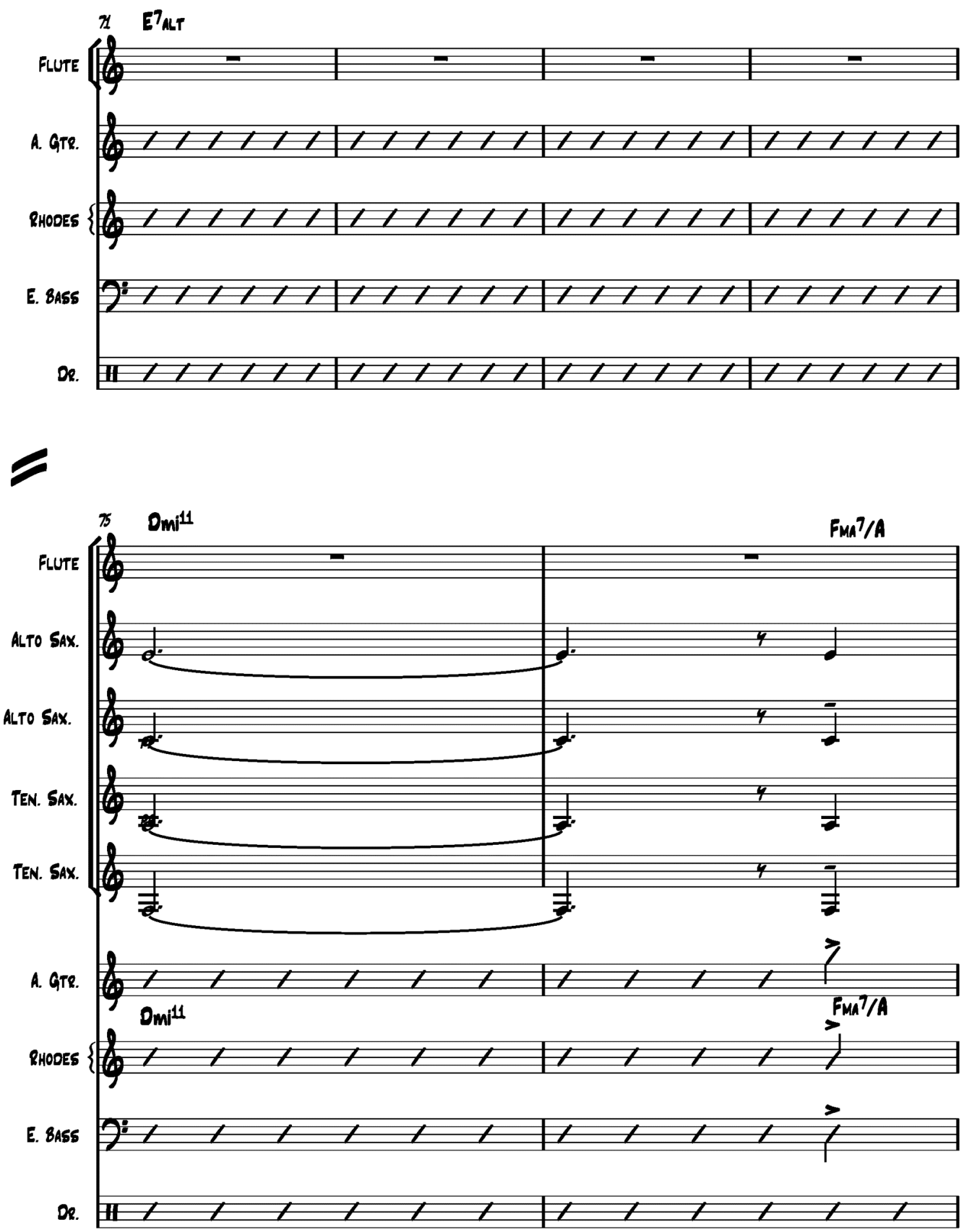


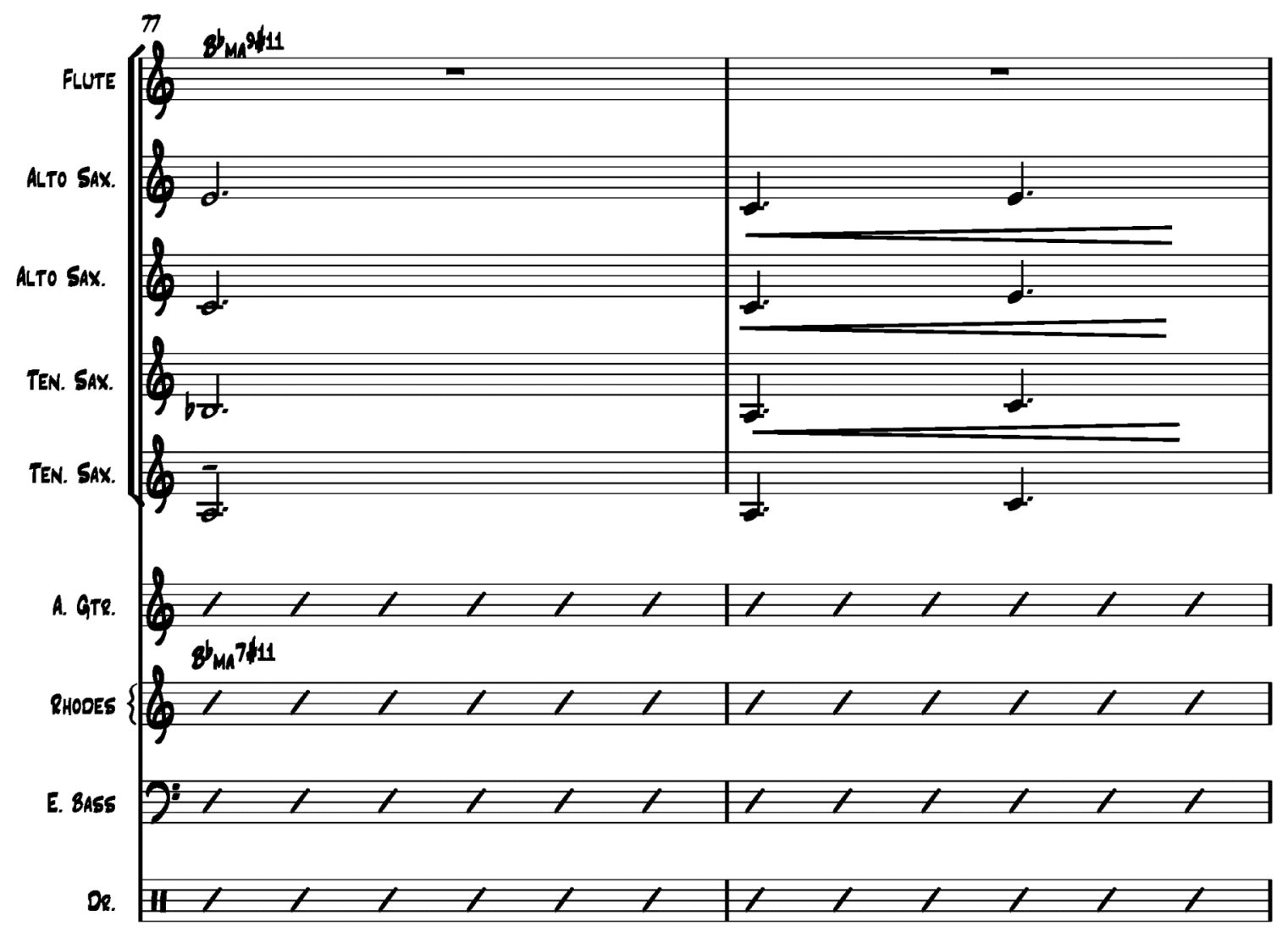


20

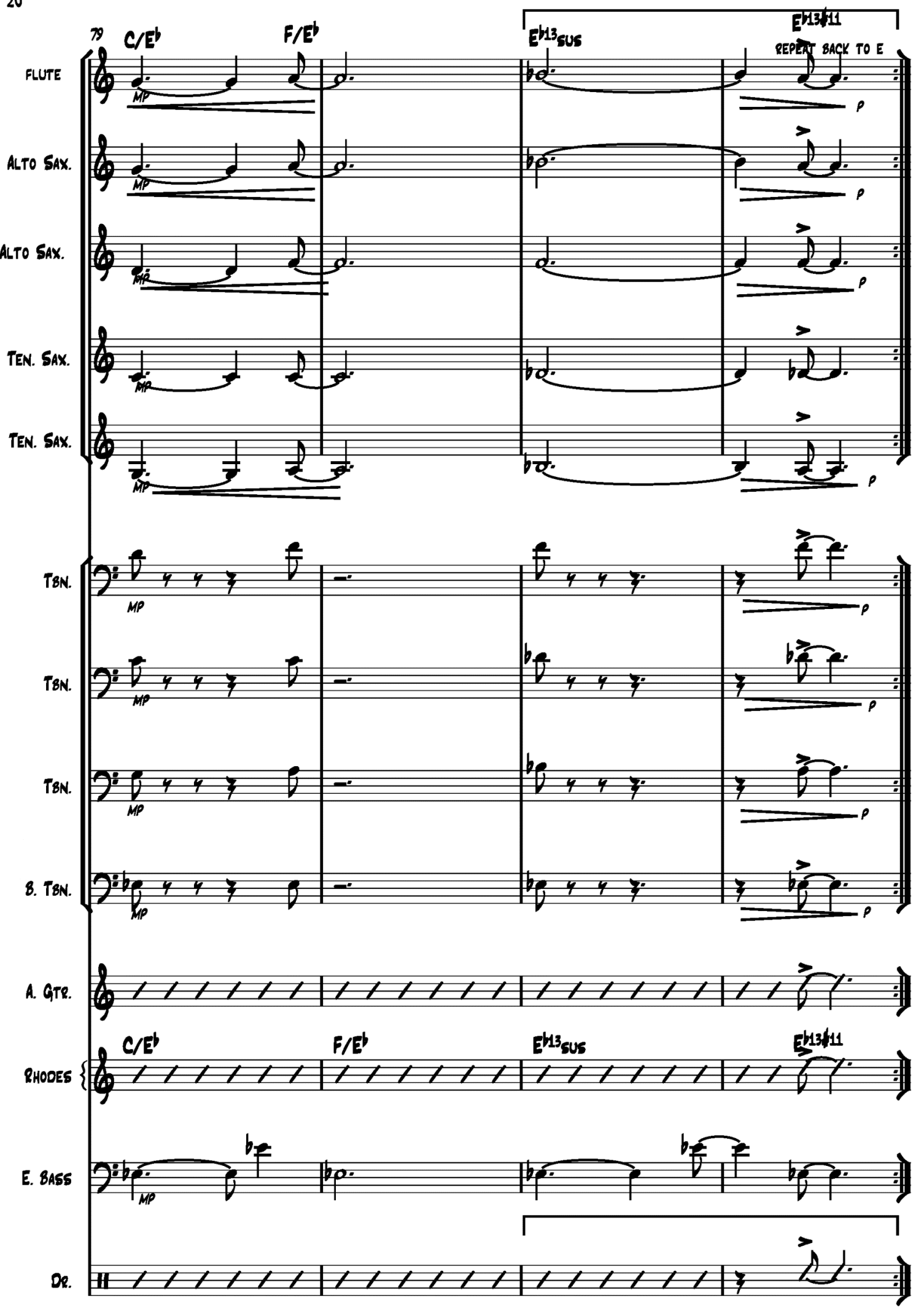

271 


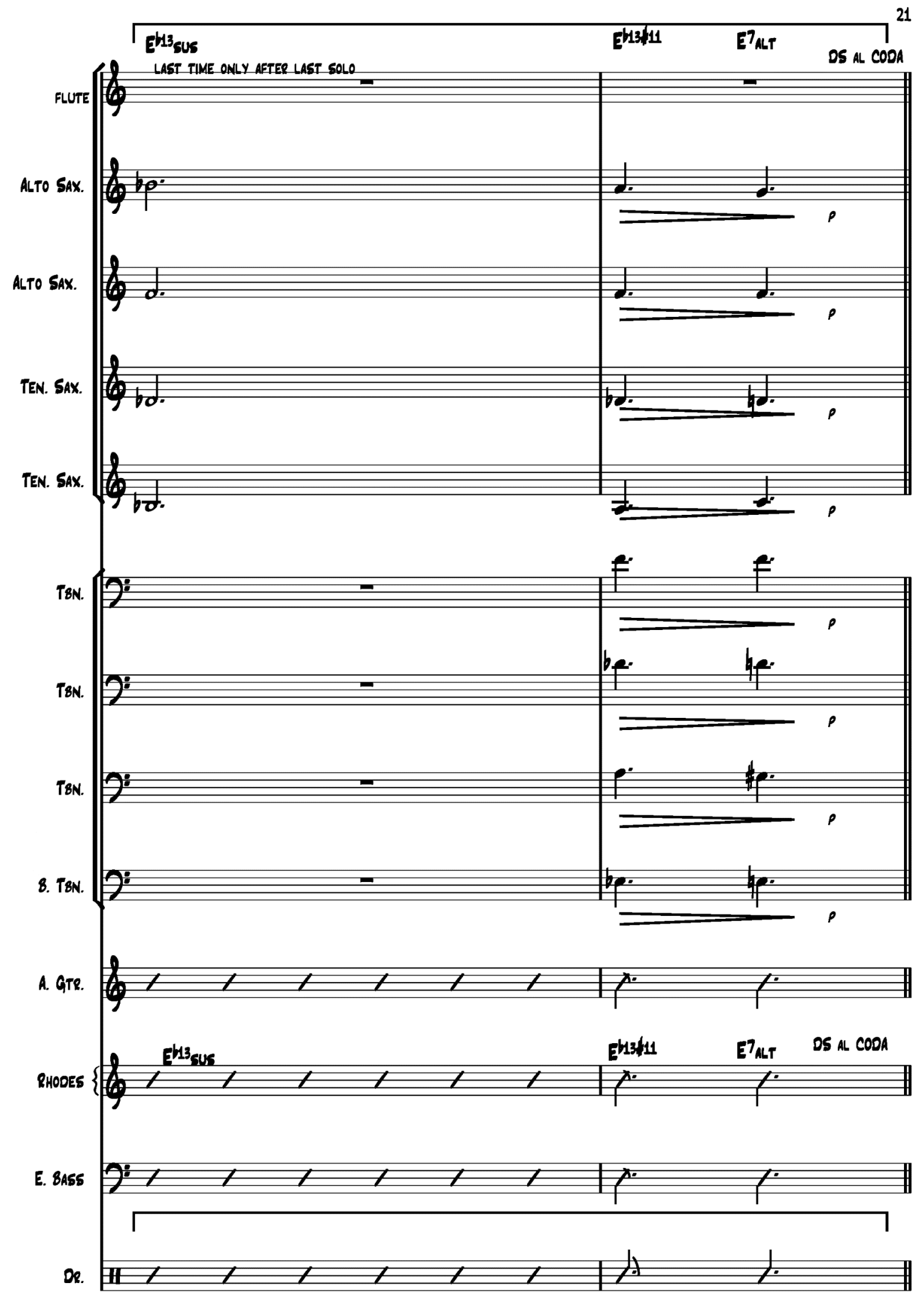




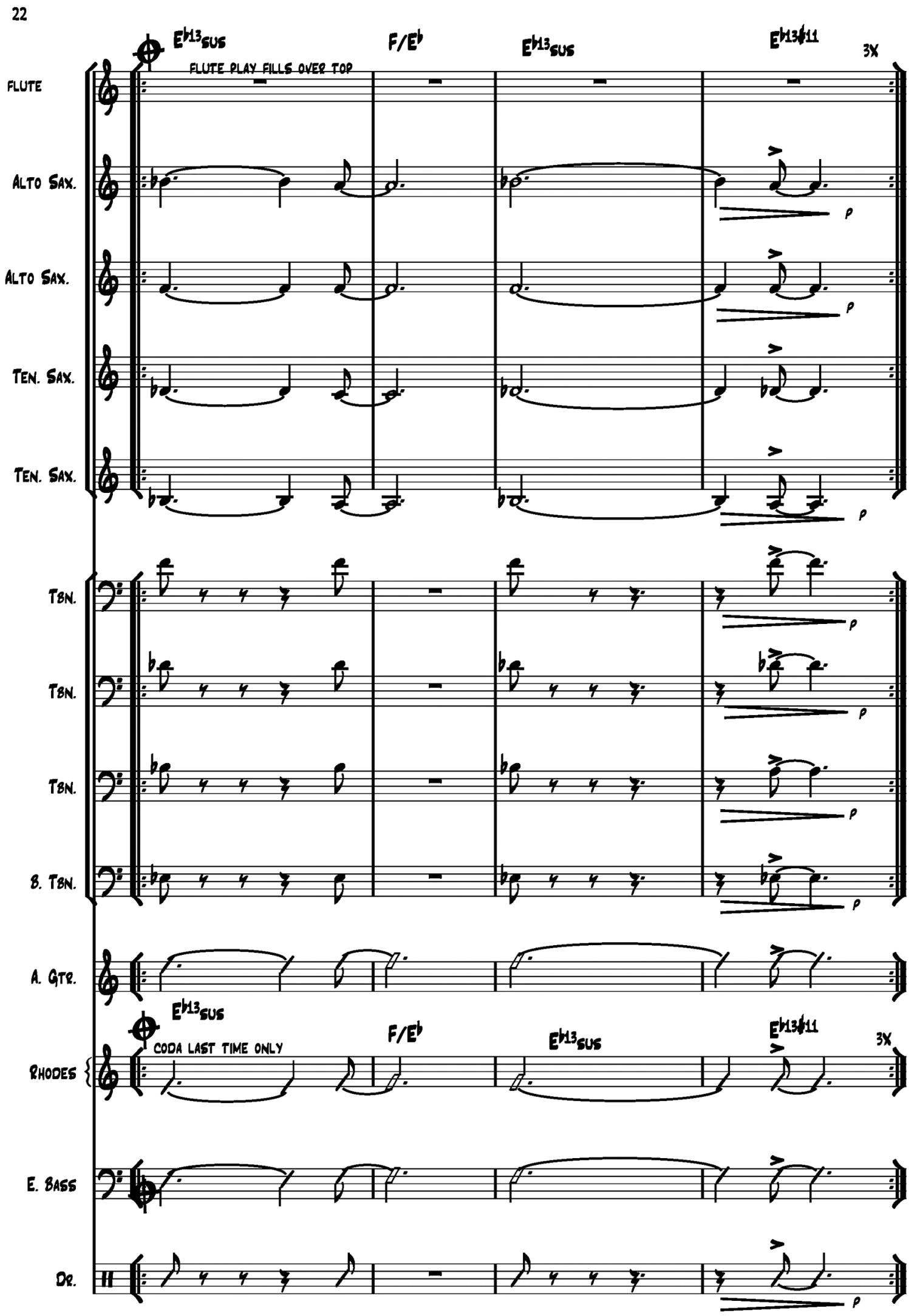


23

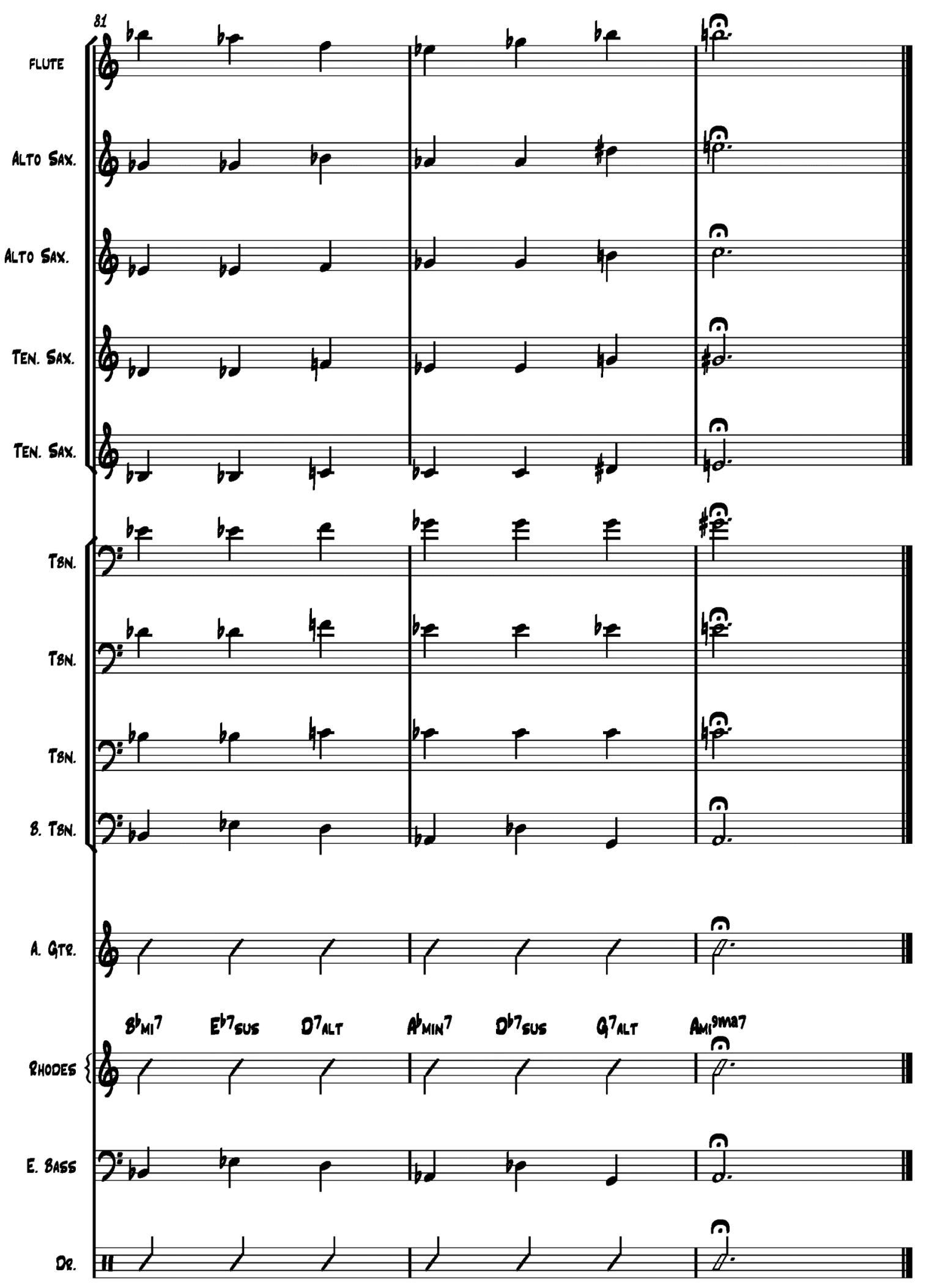

274 


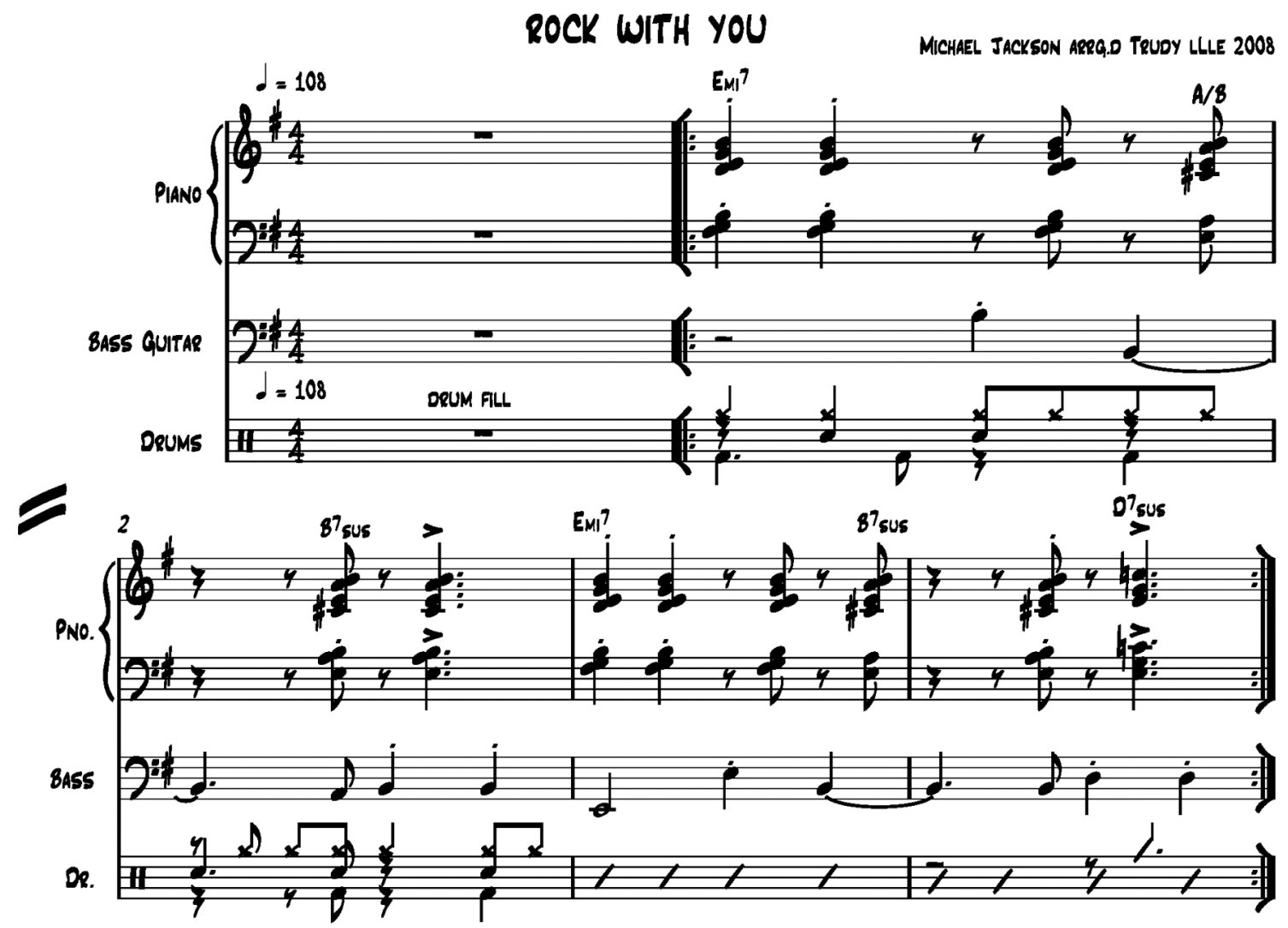




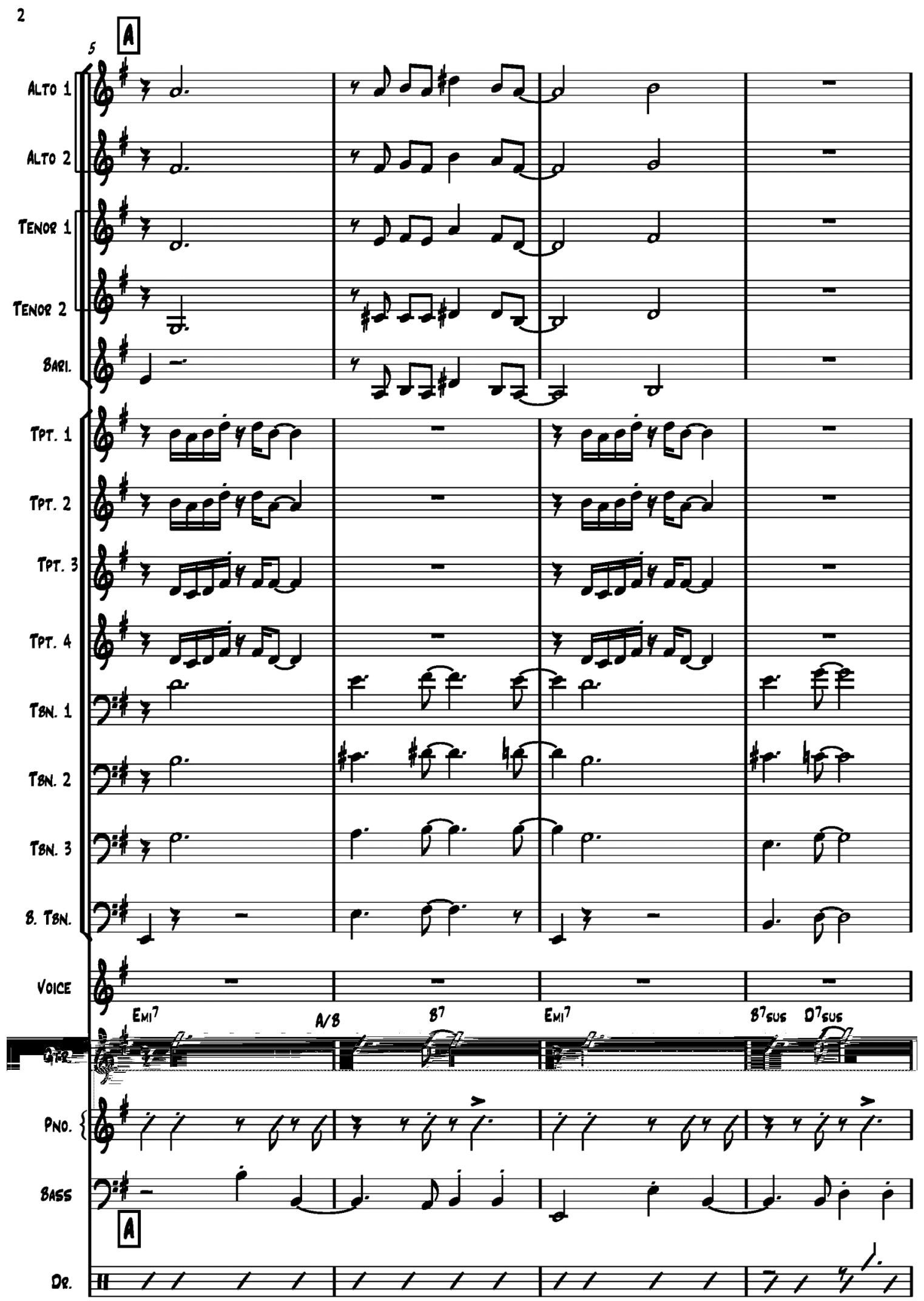




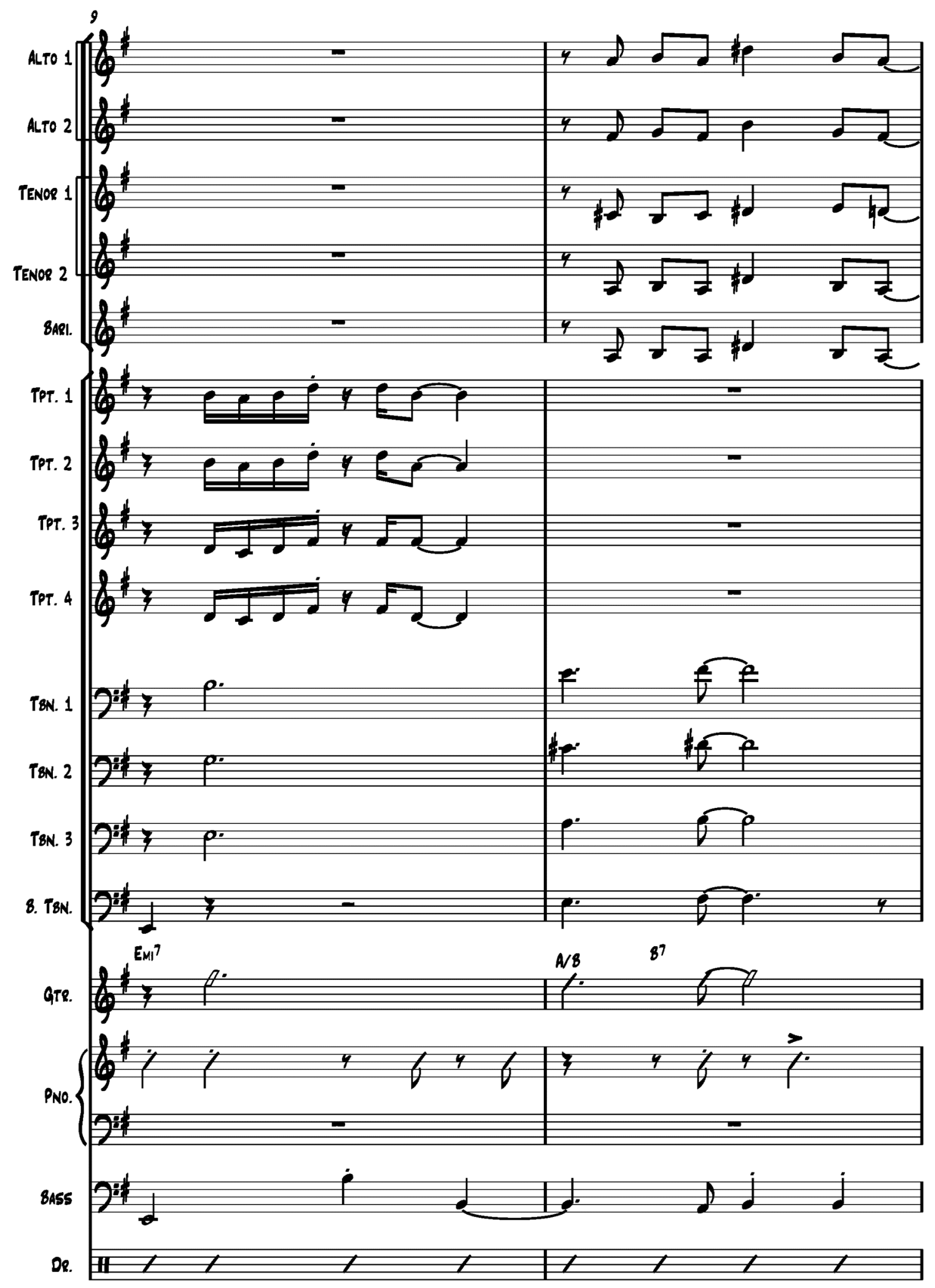




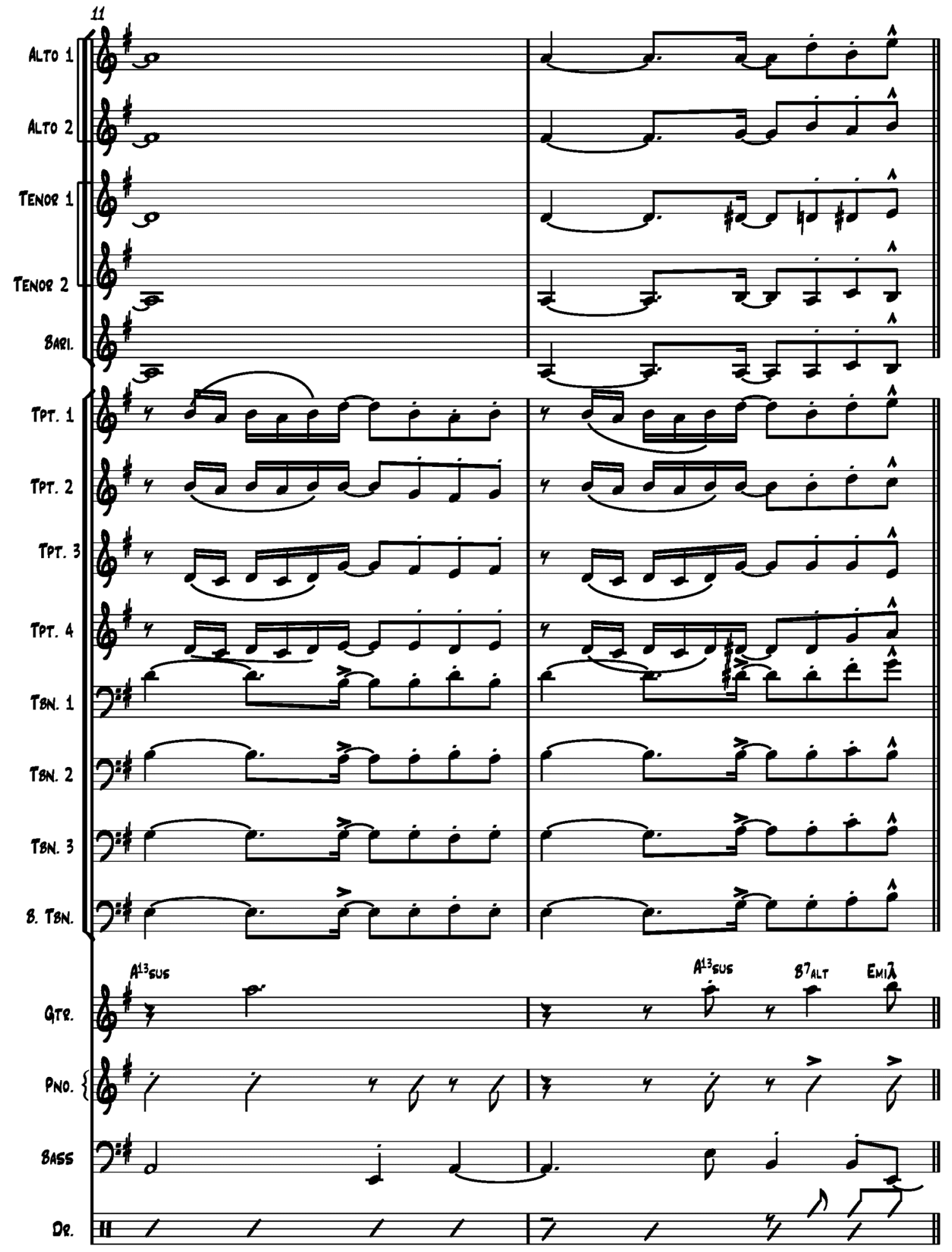




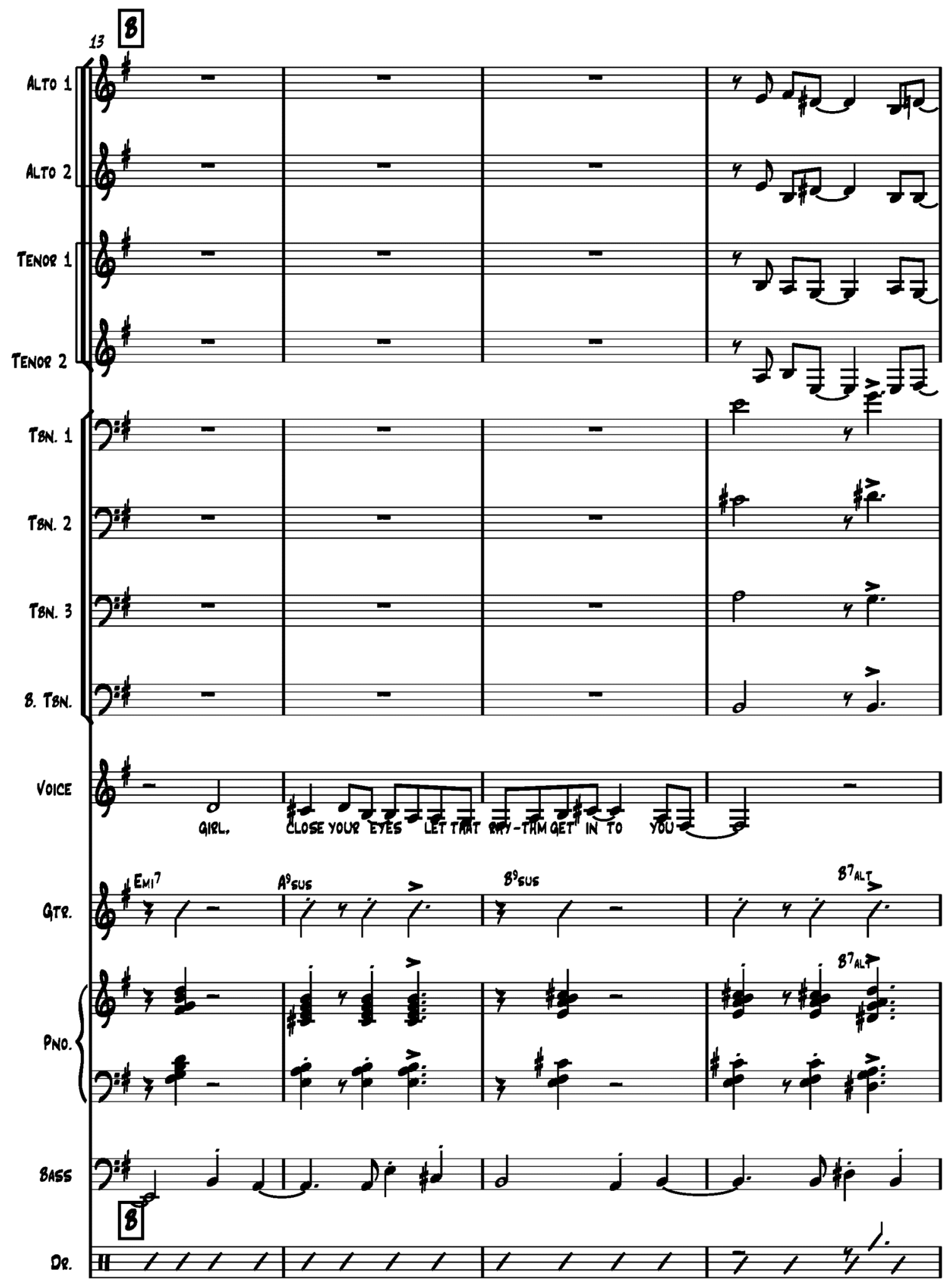


6

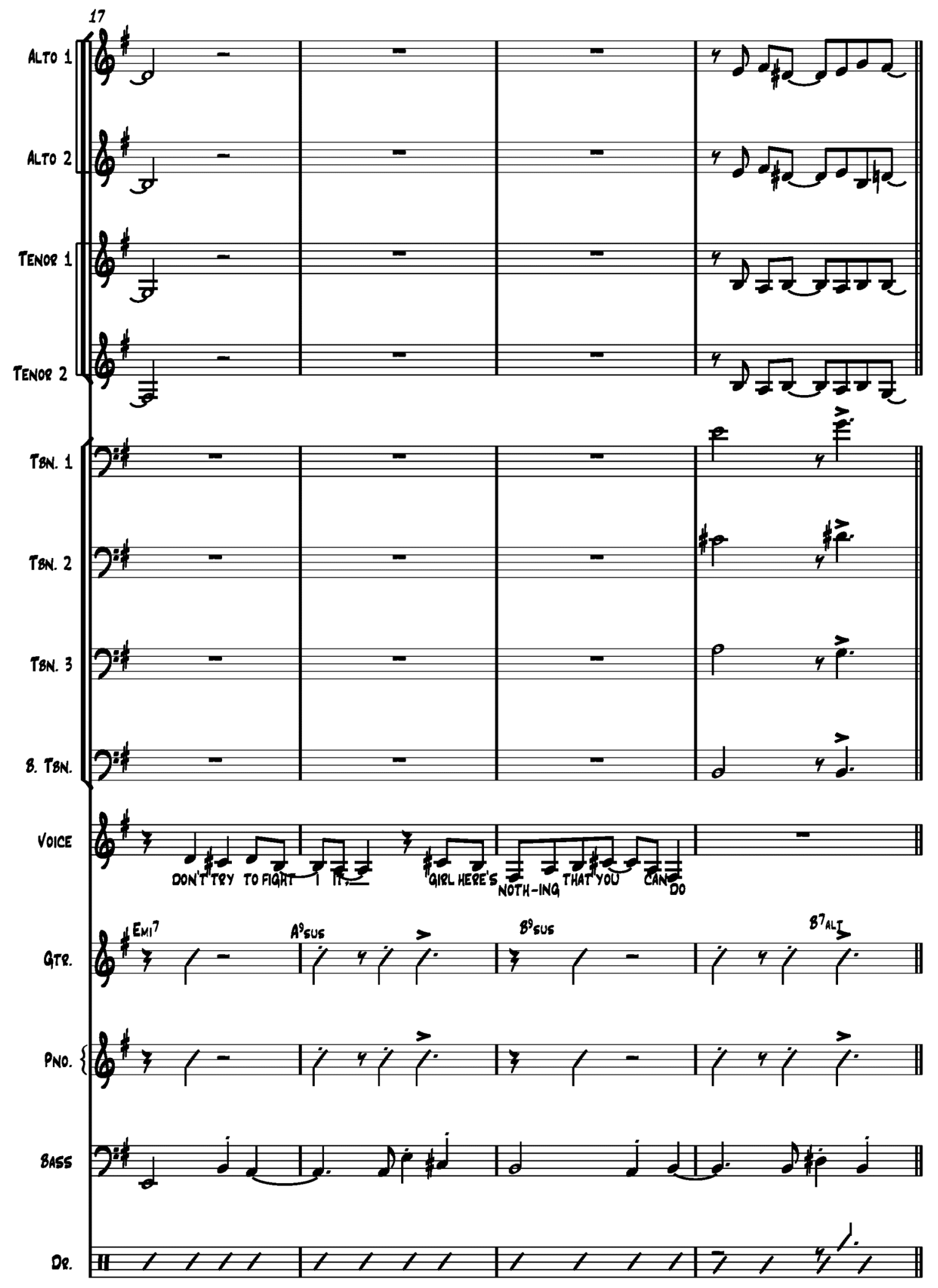




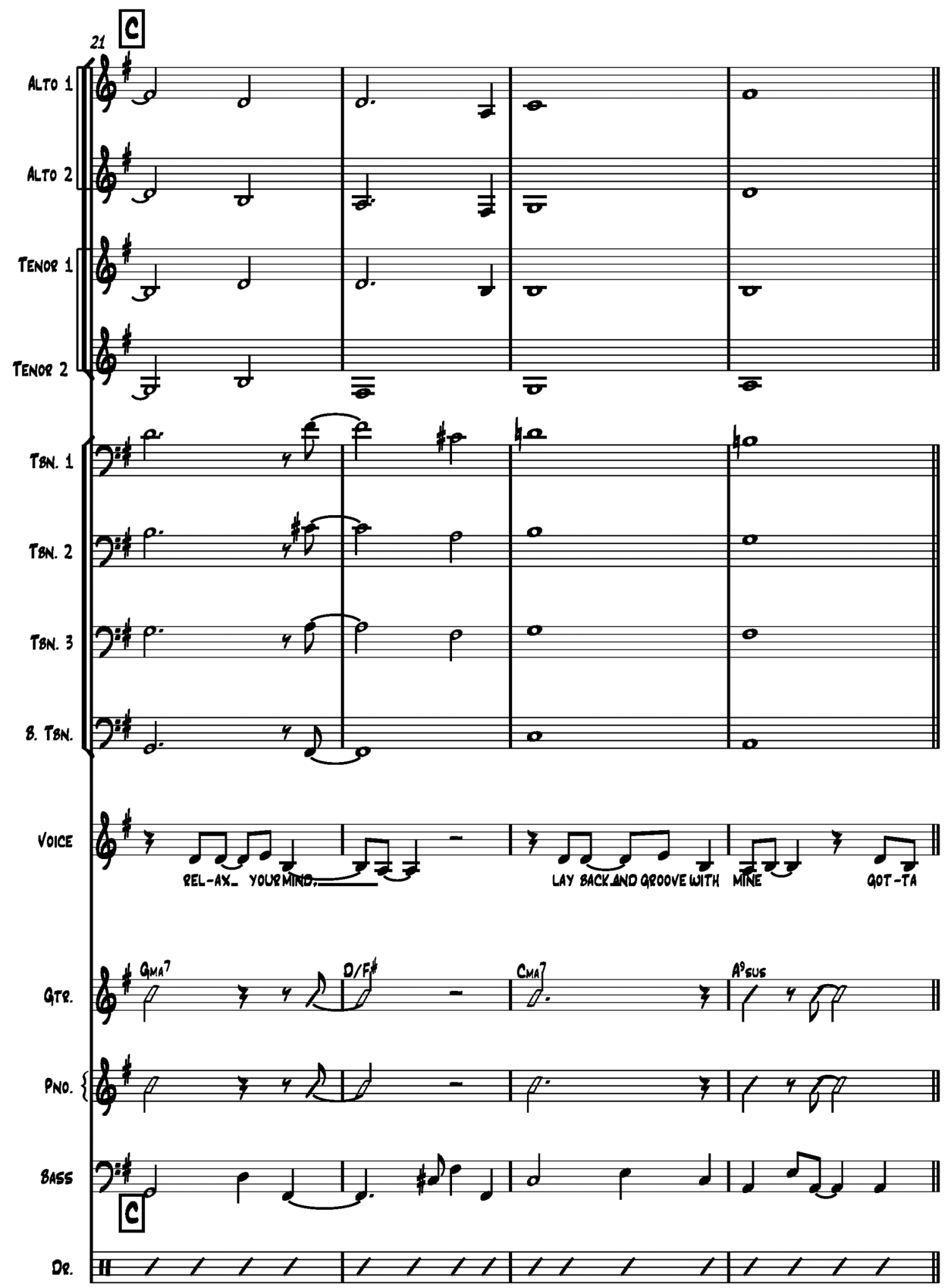




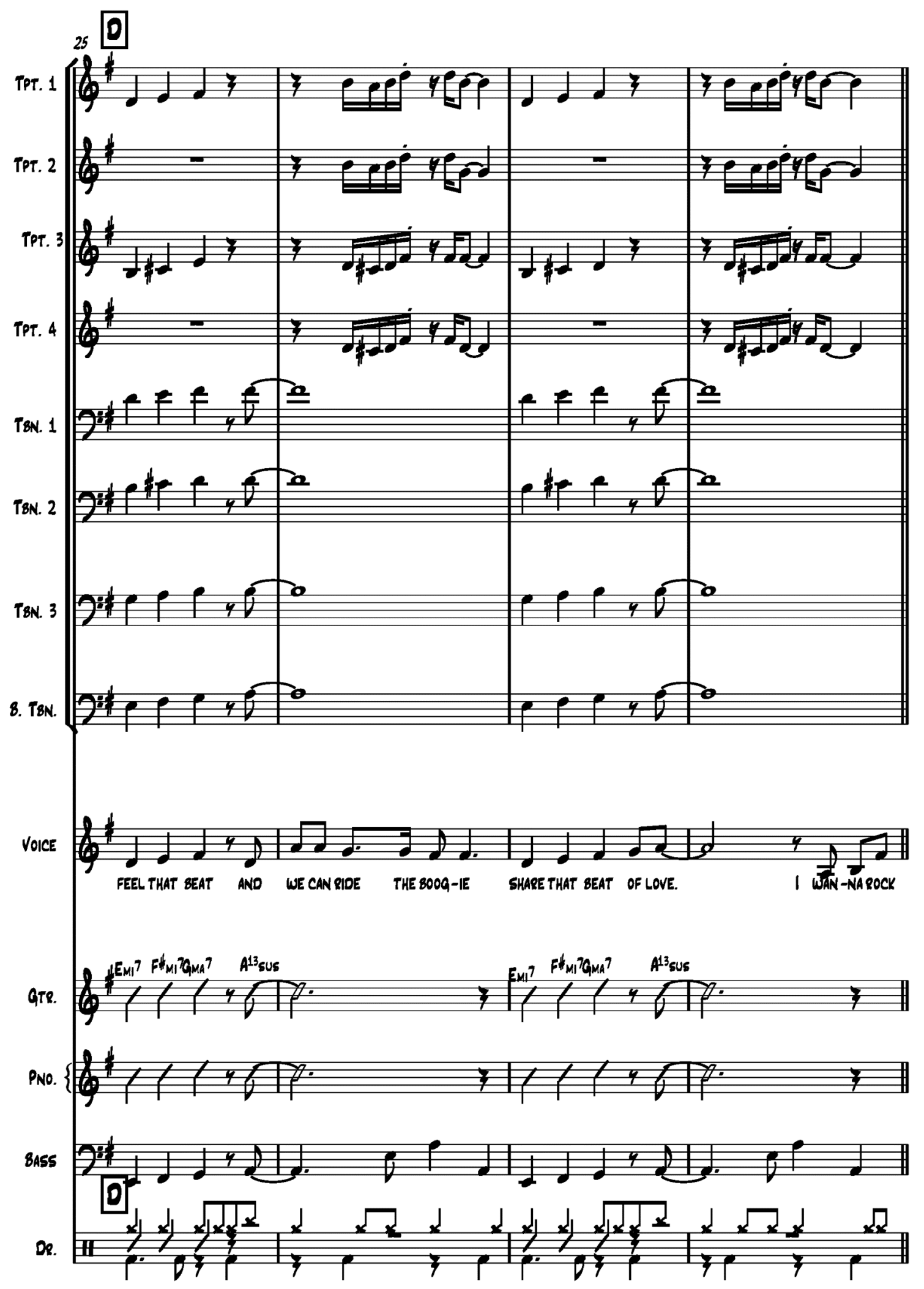




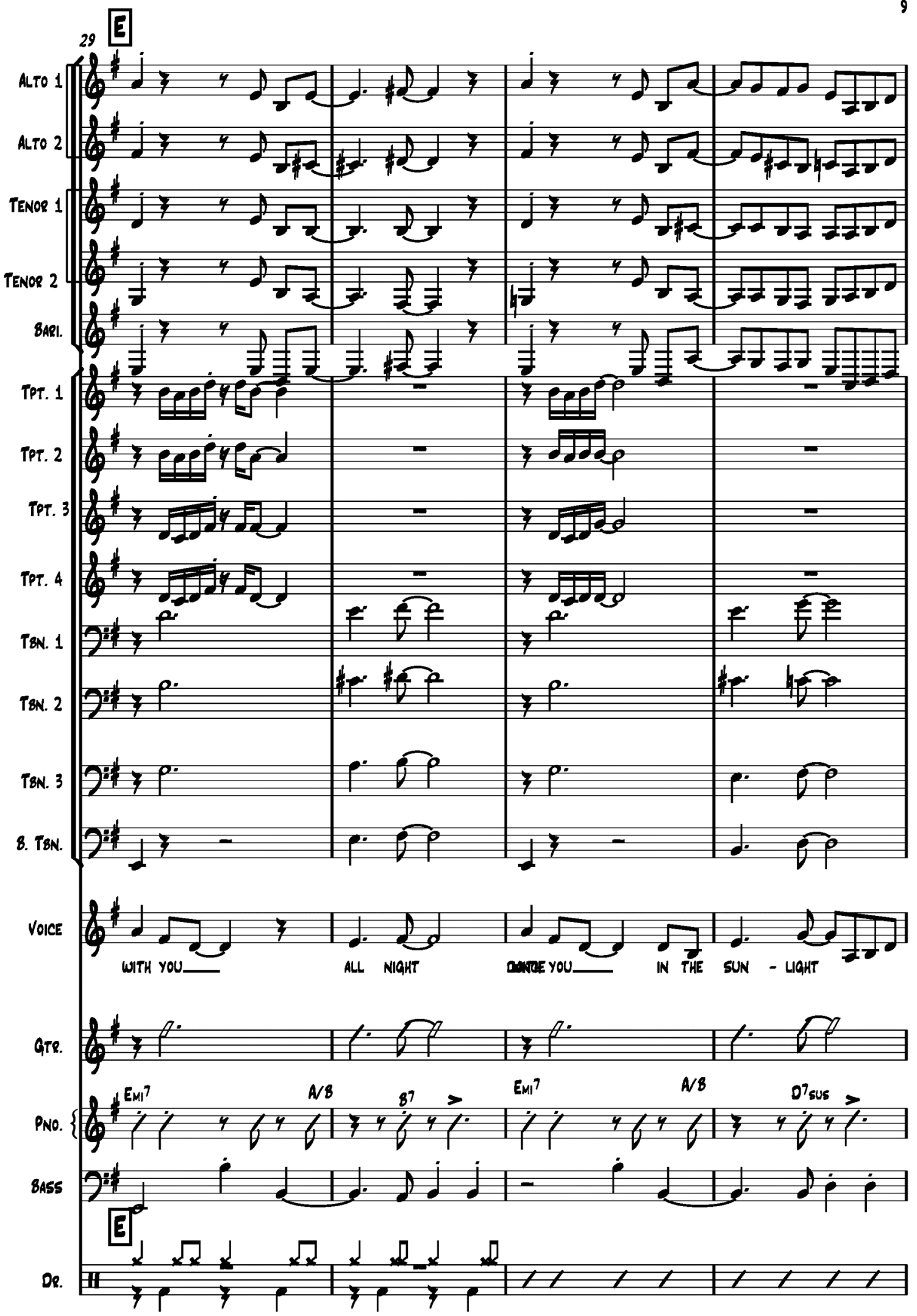


10

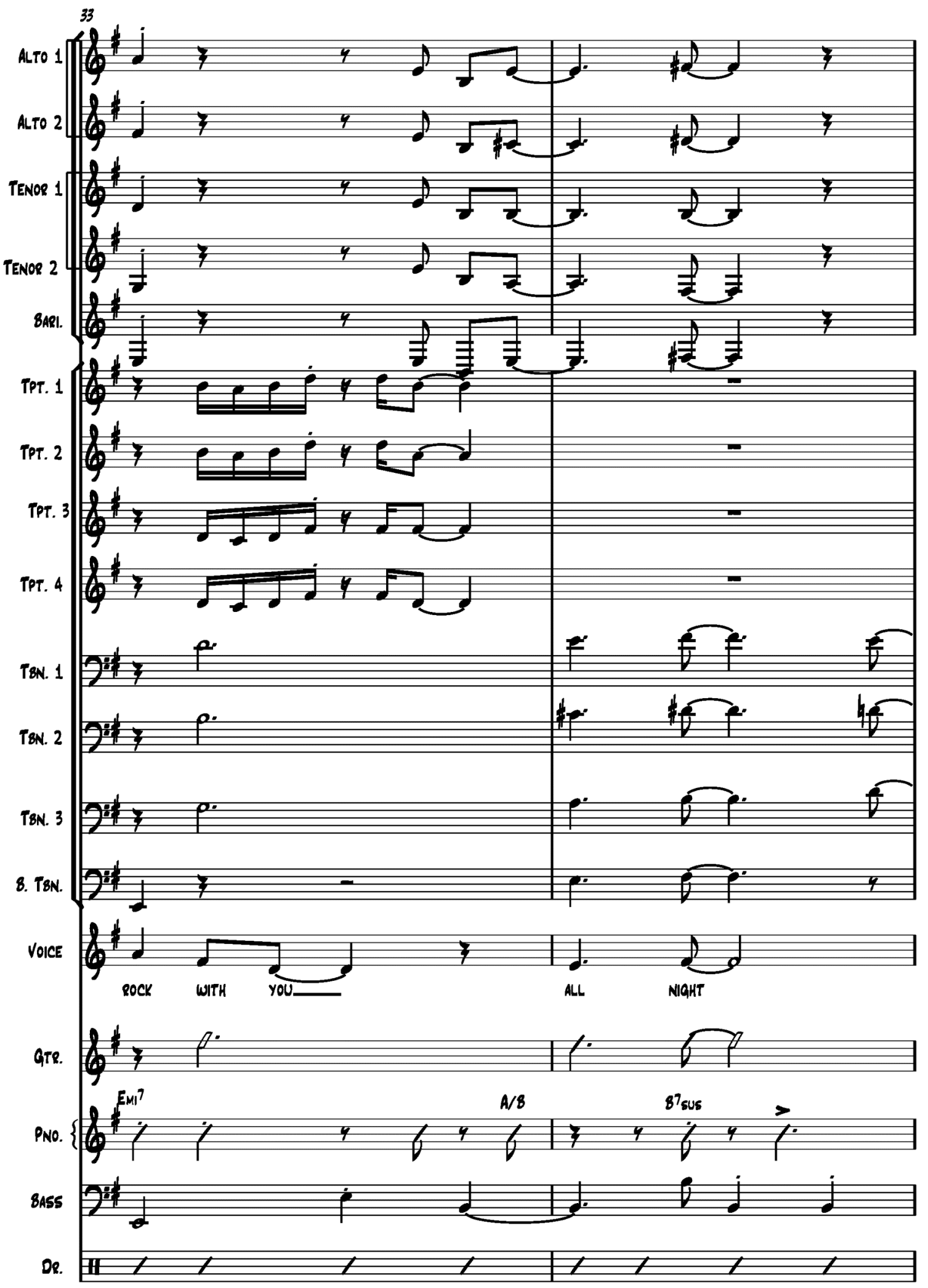




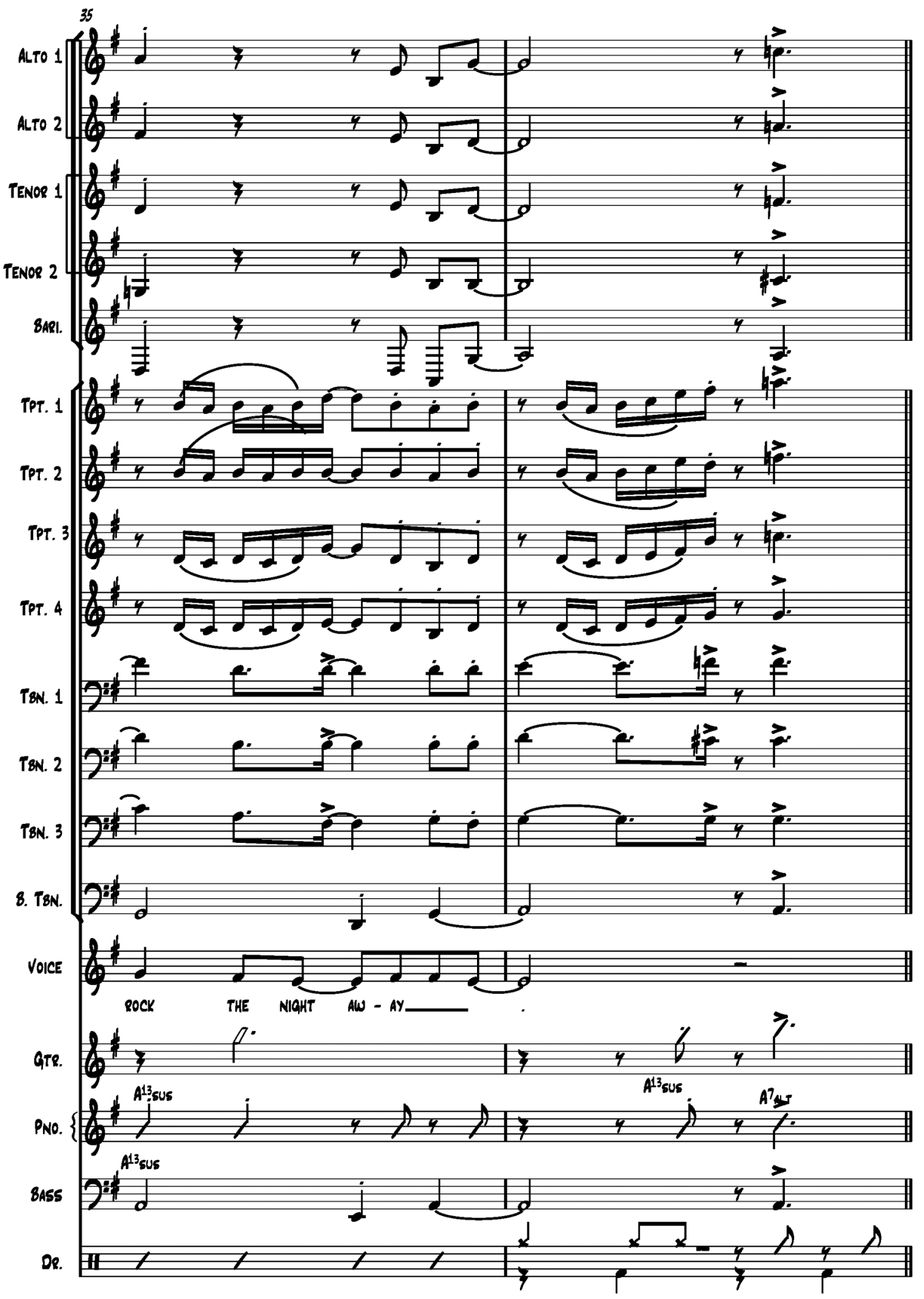


12

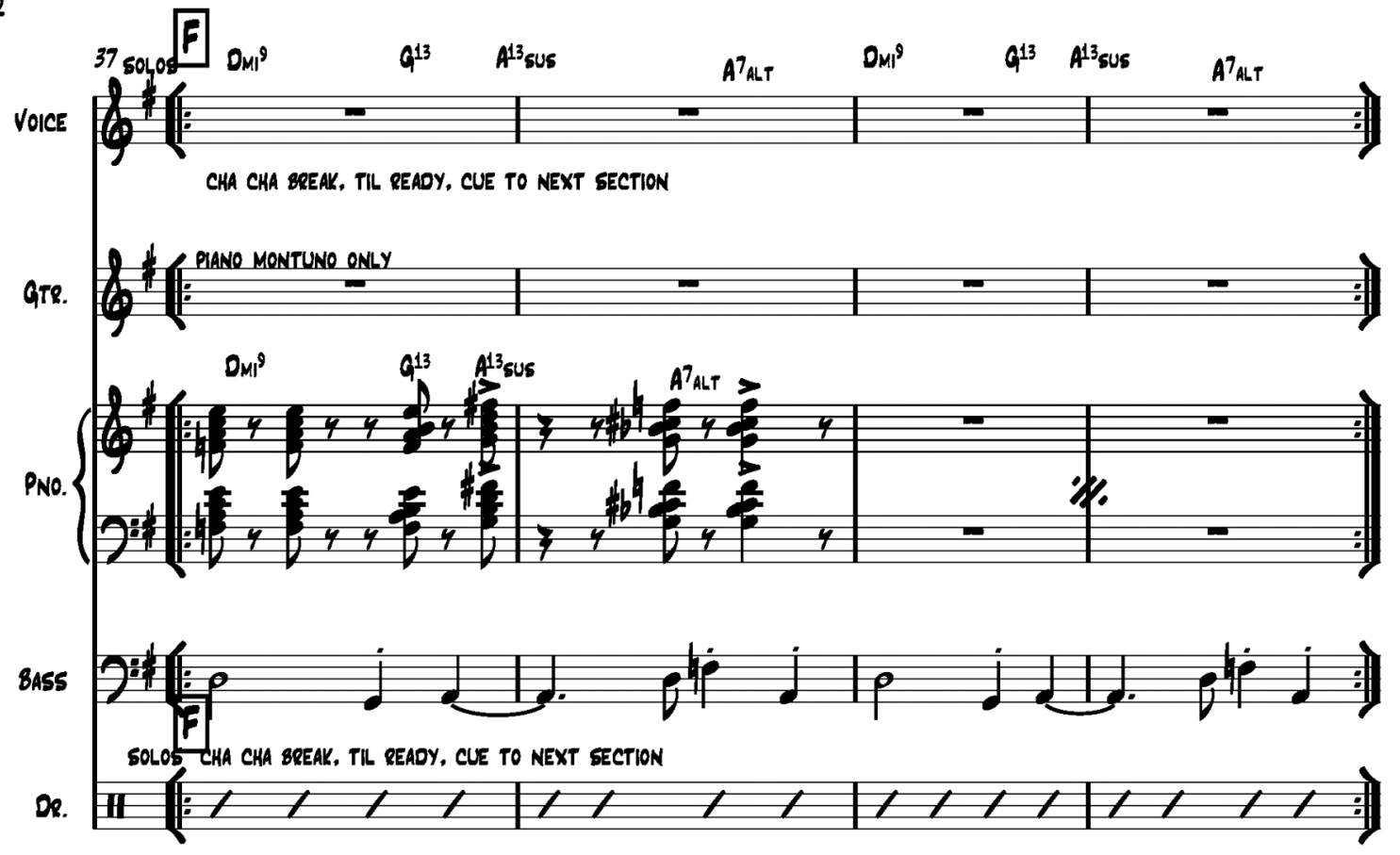

286 


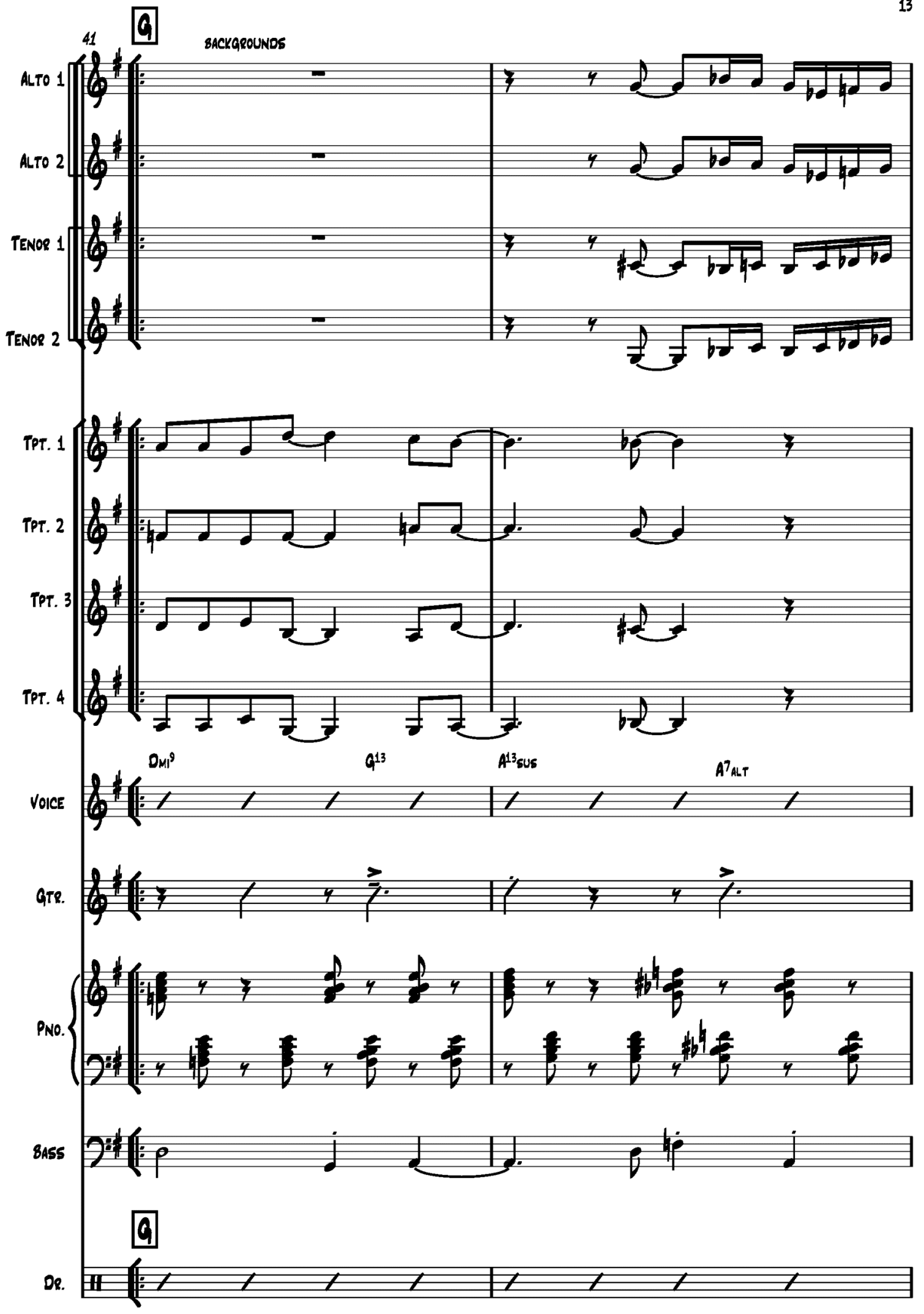




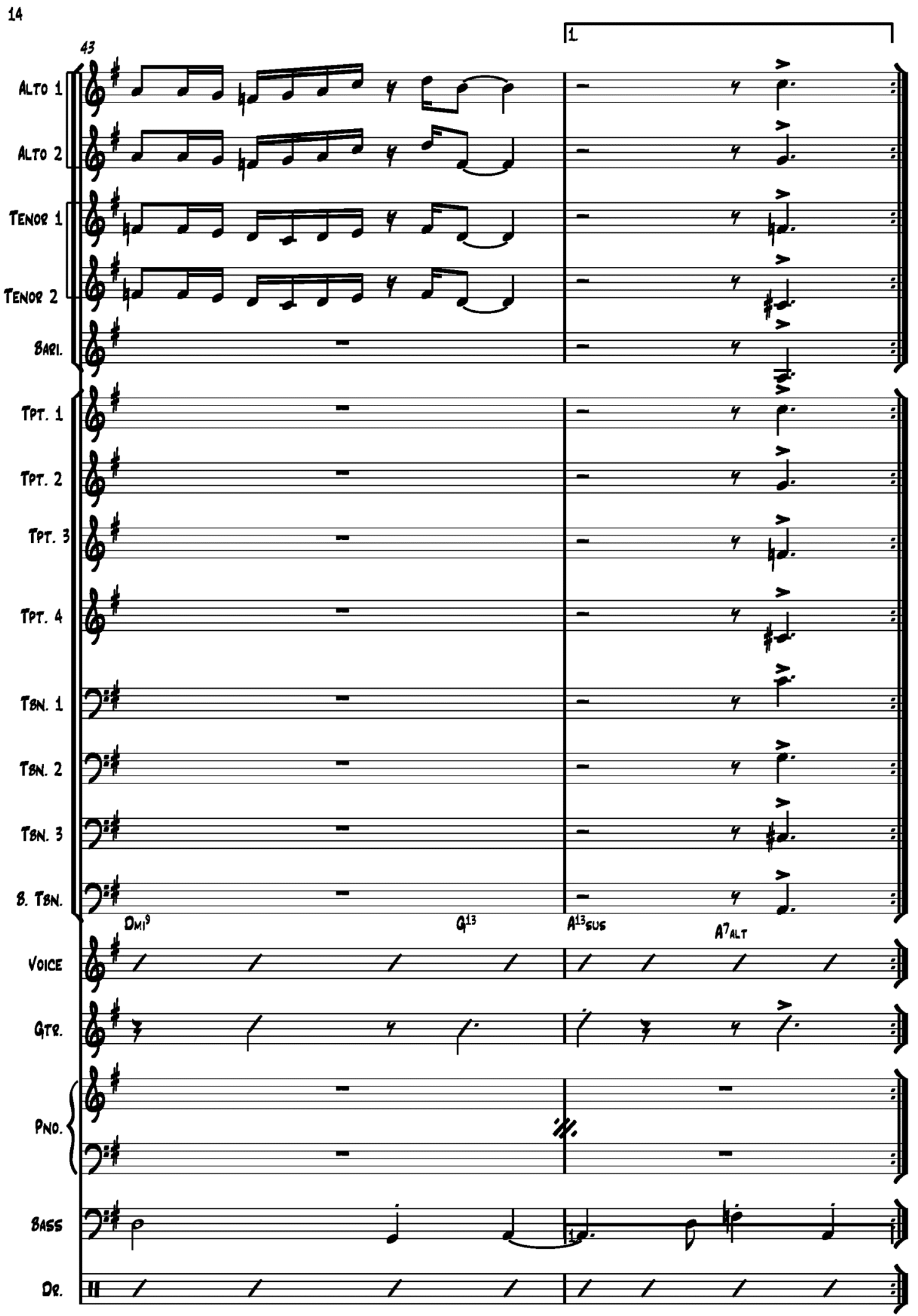




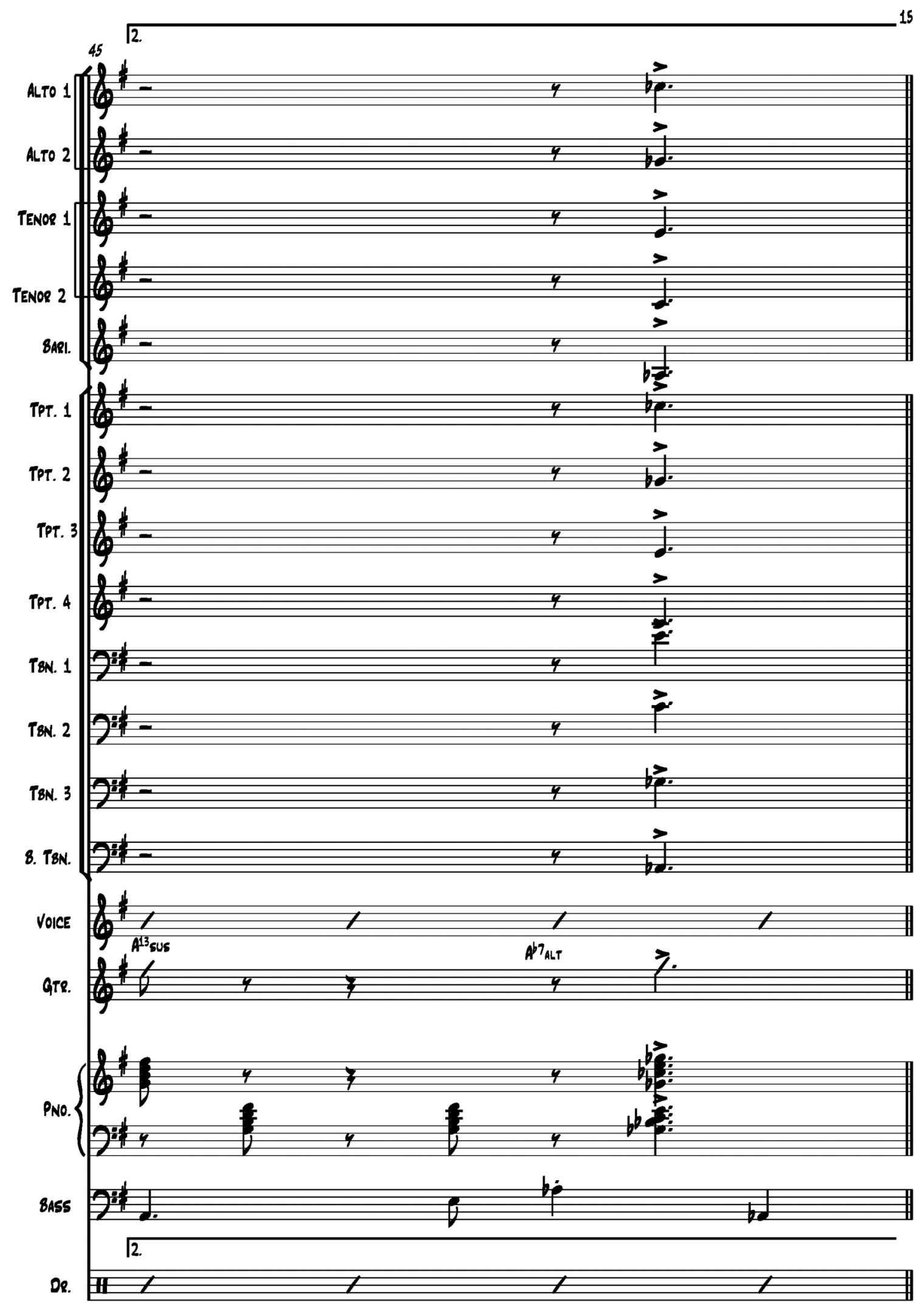




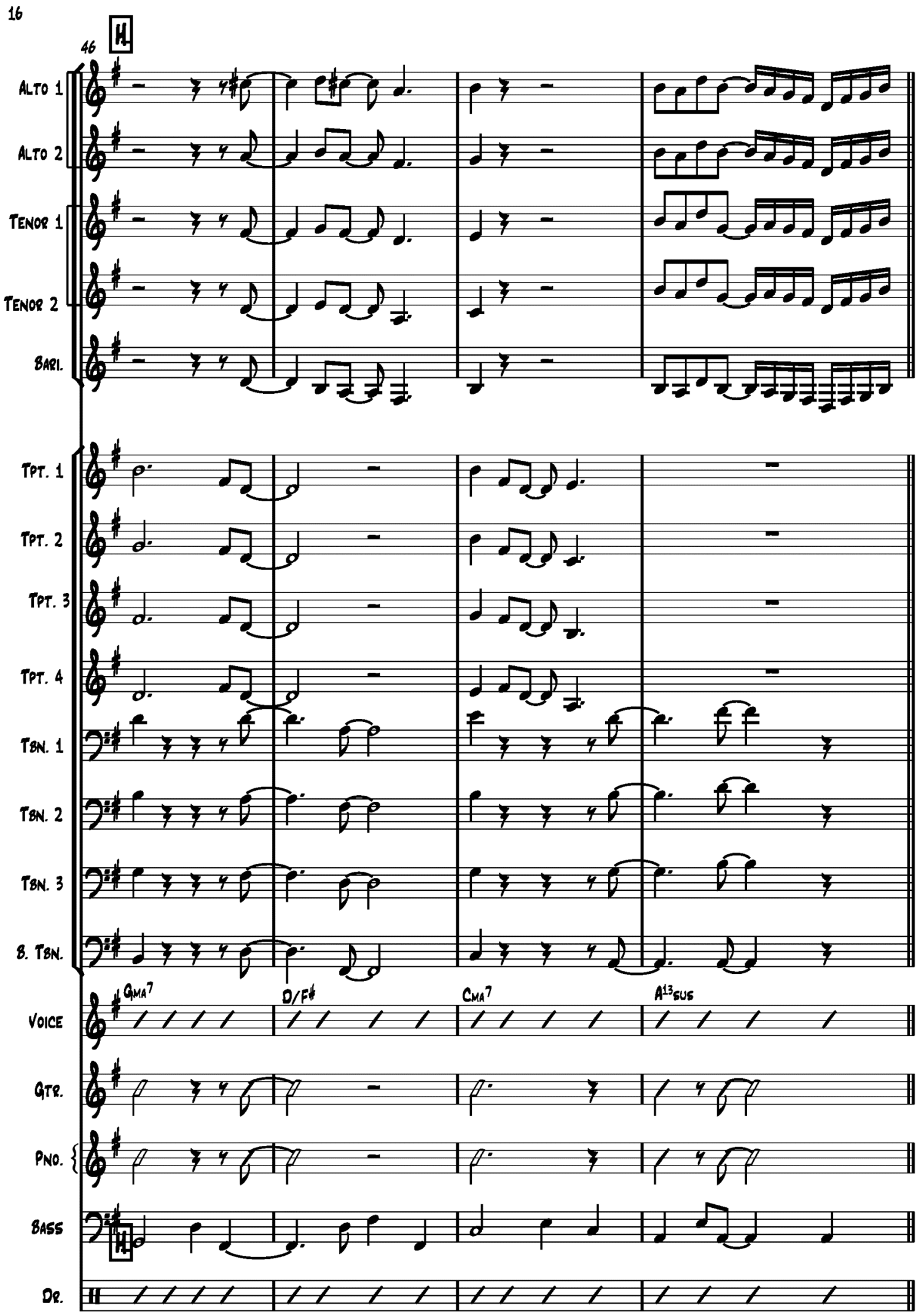



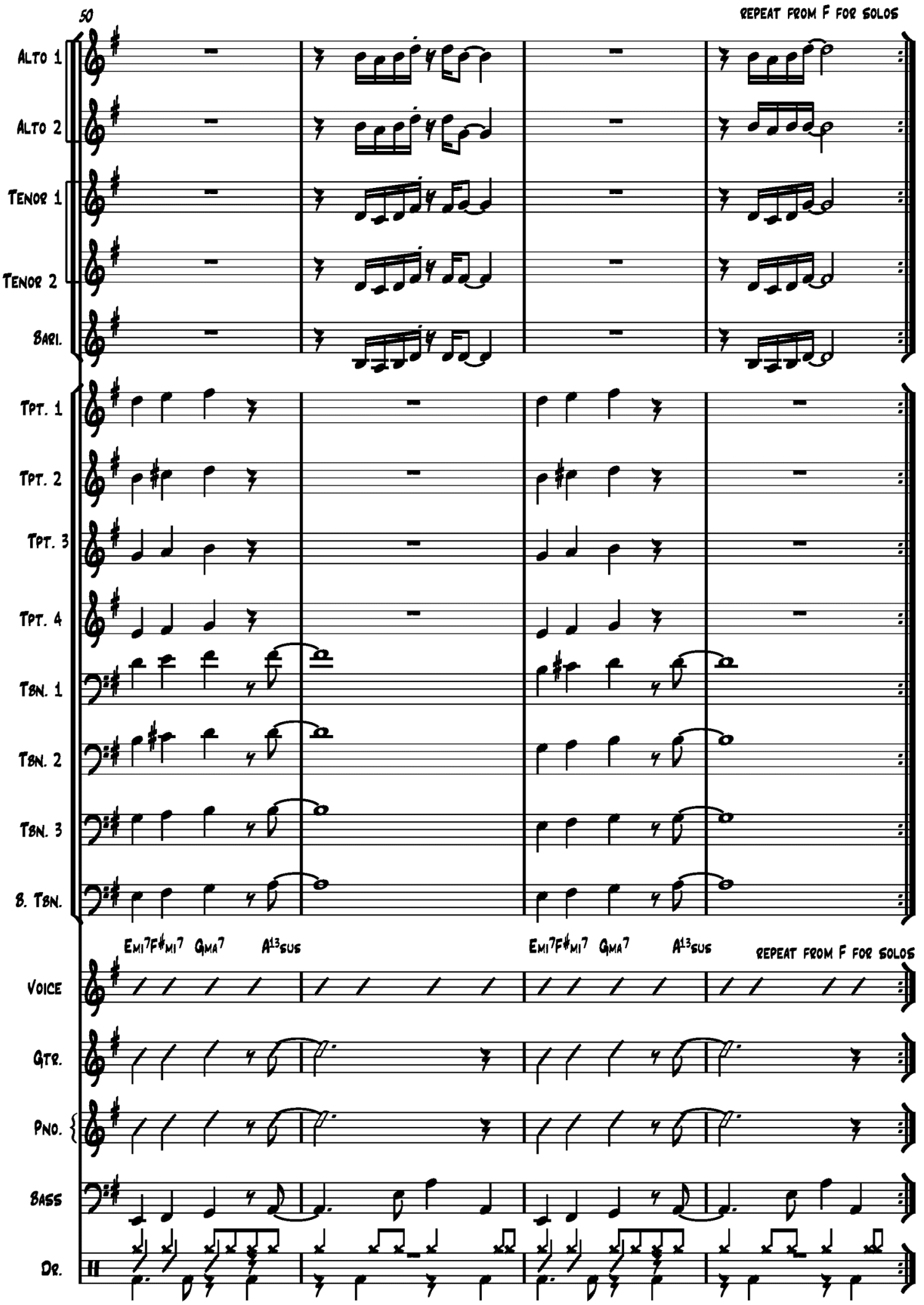


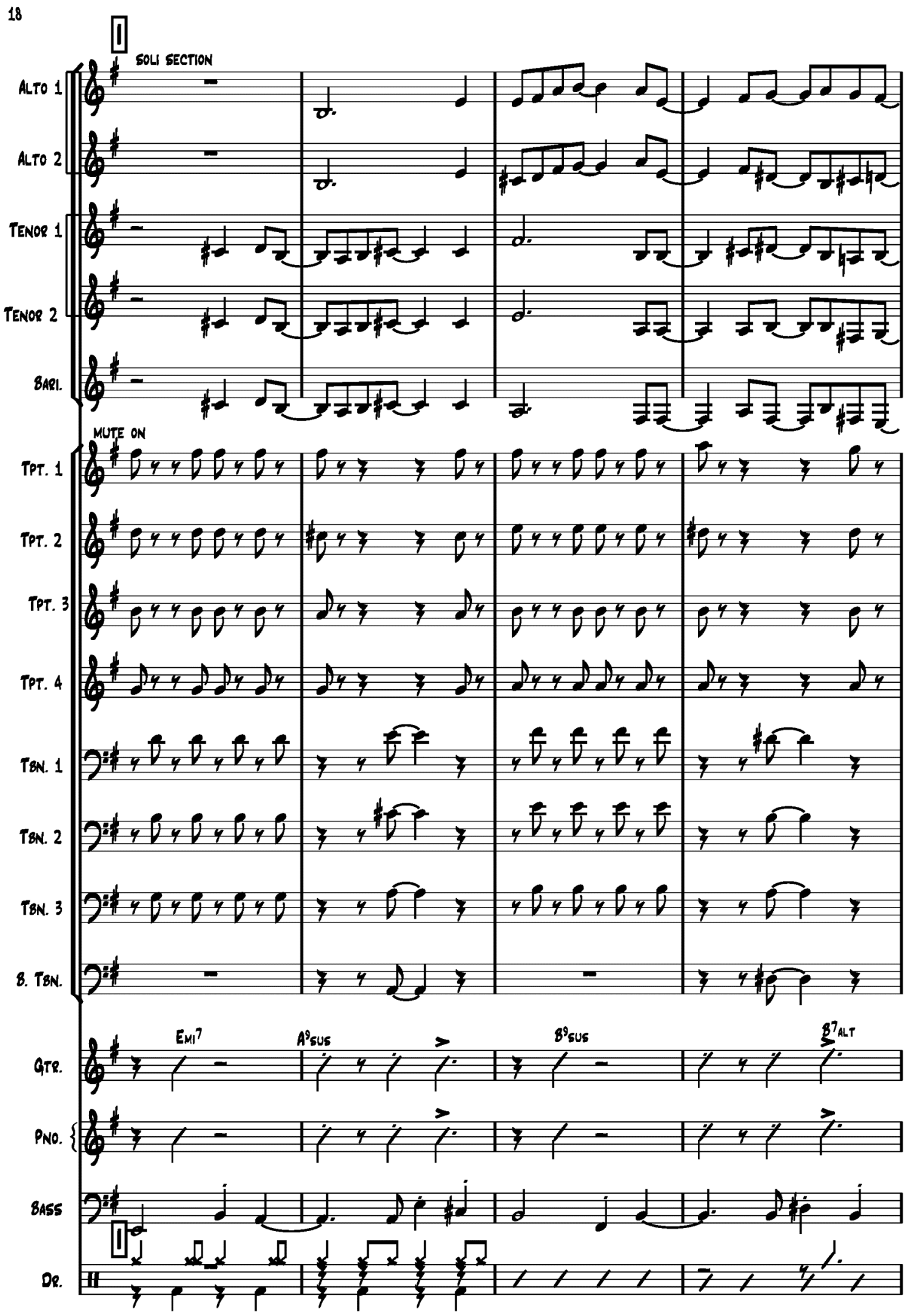




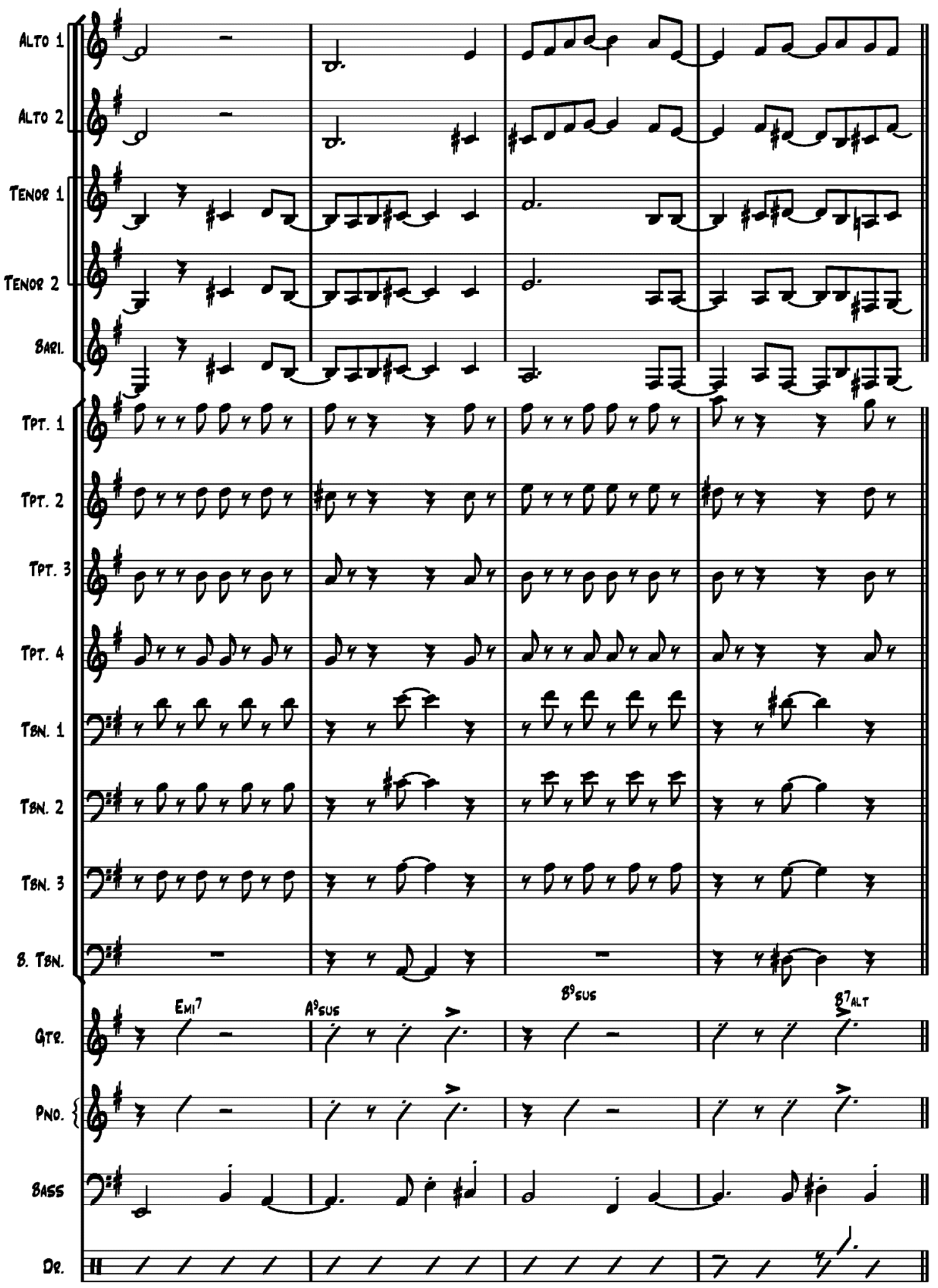




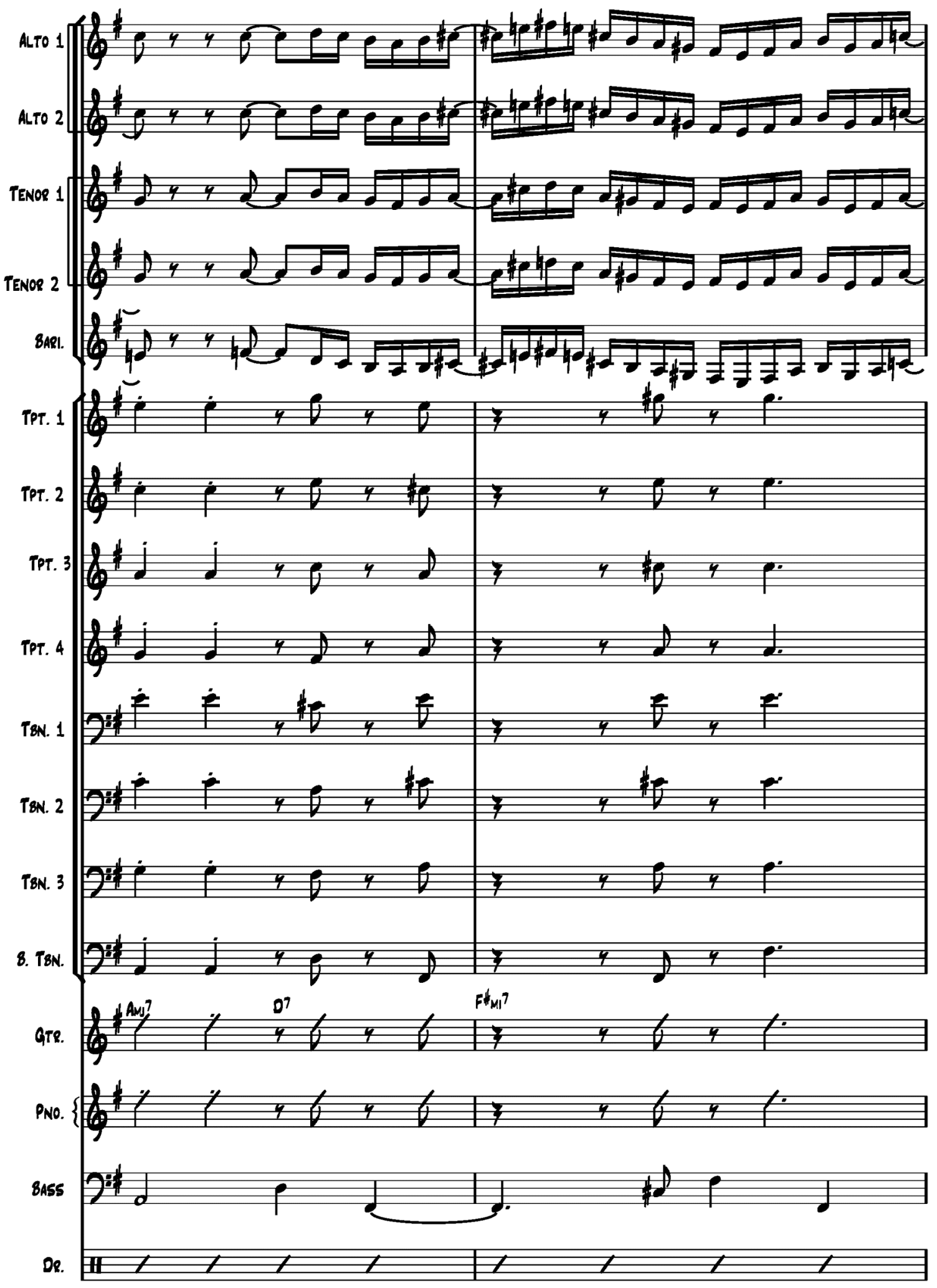




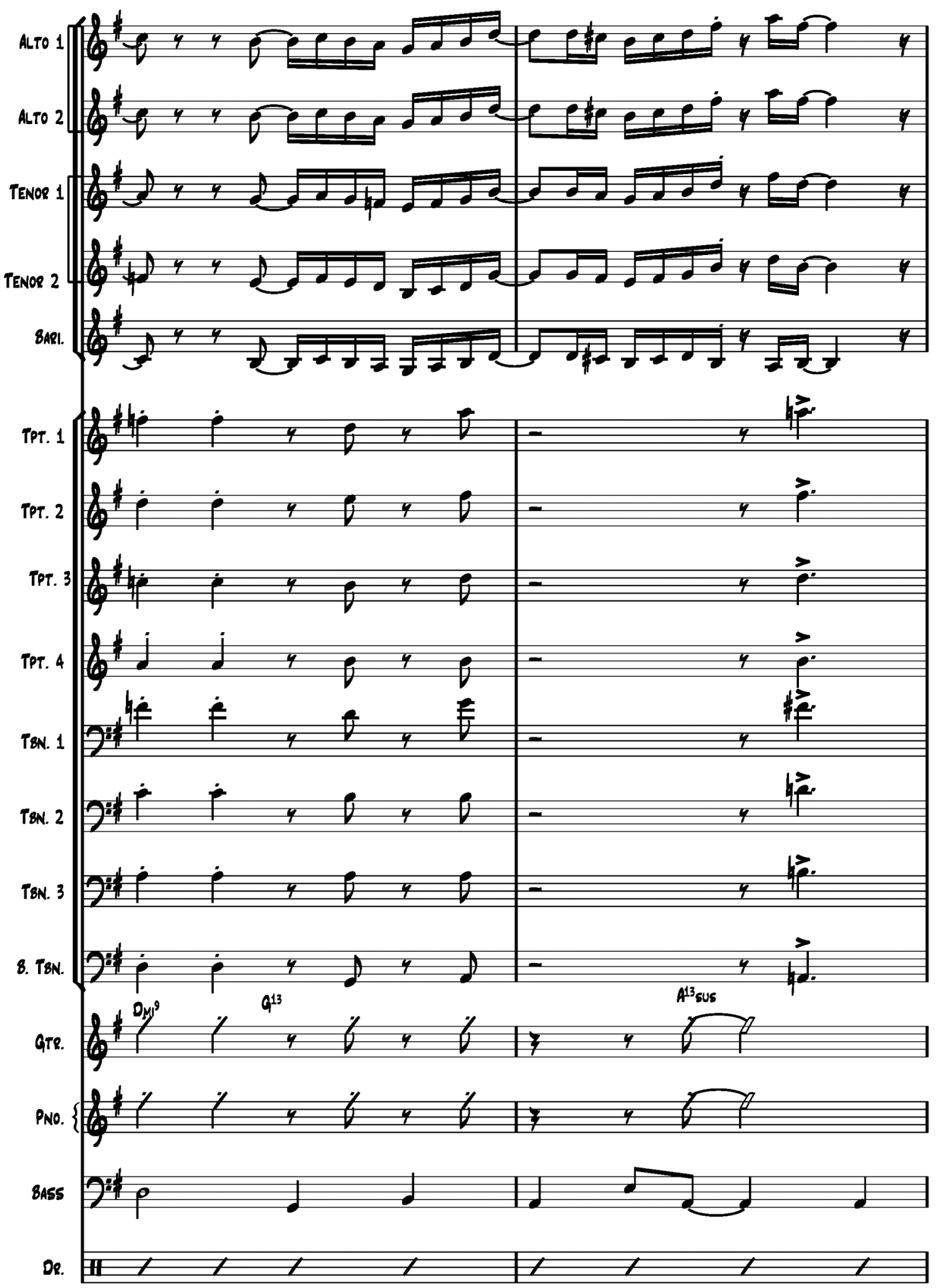




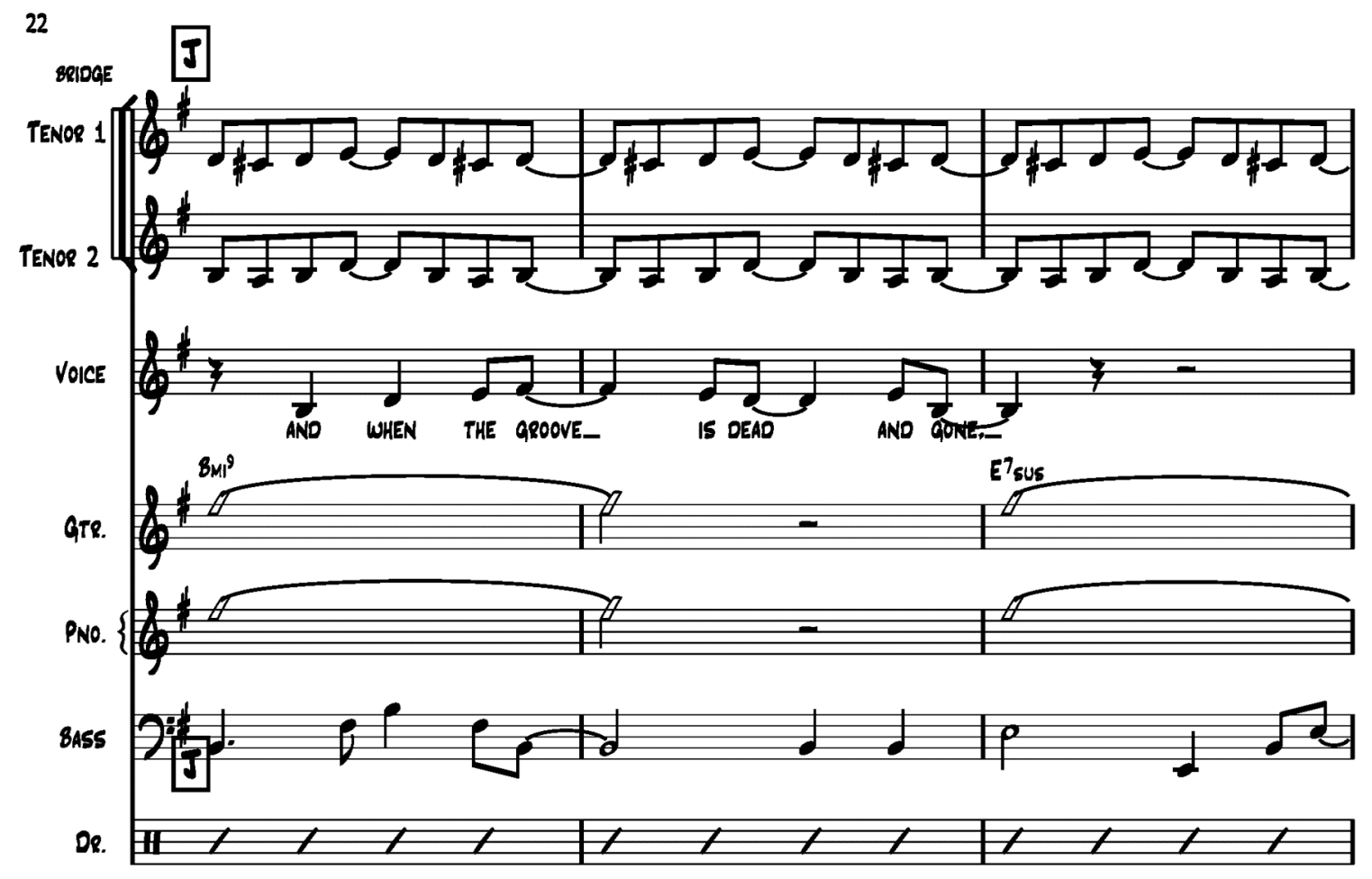




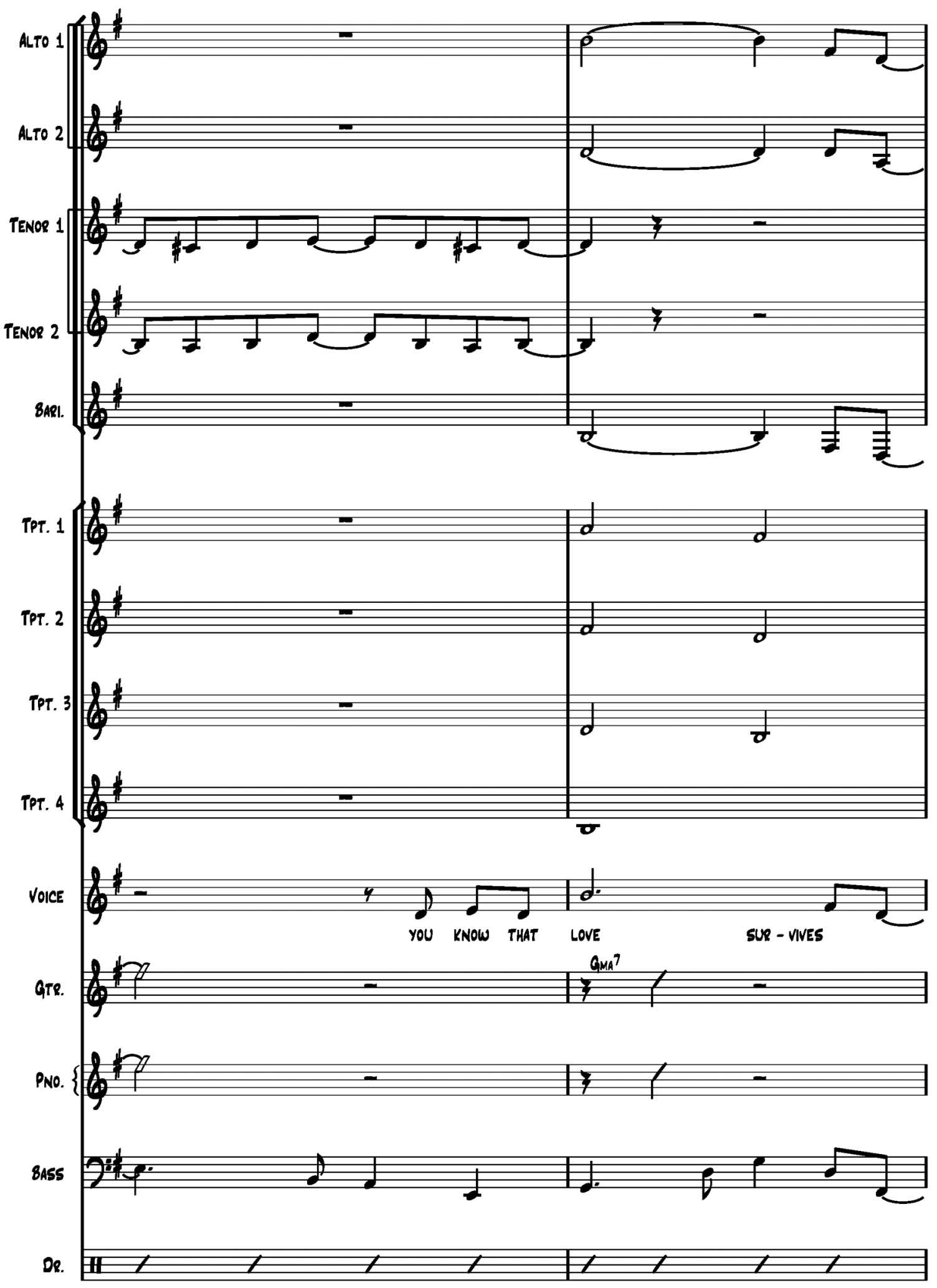




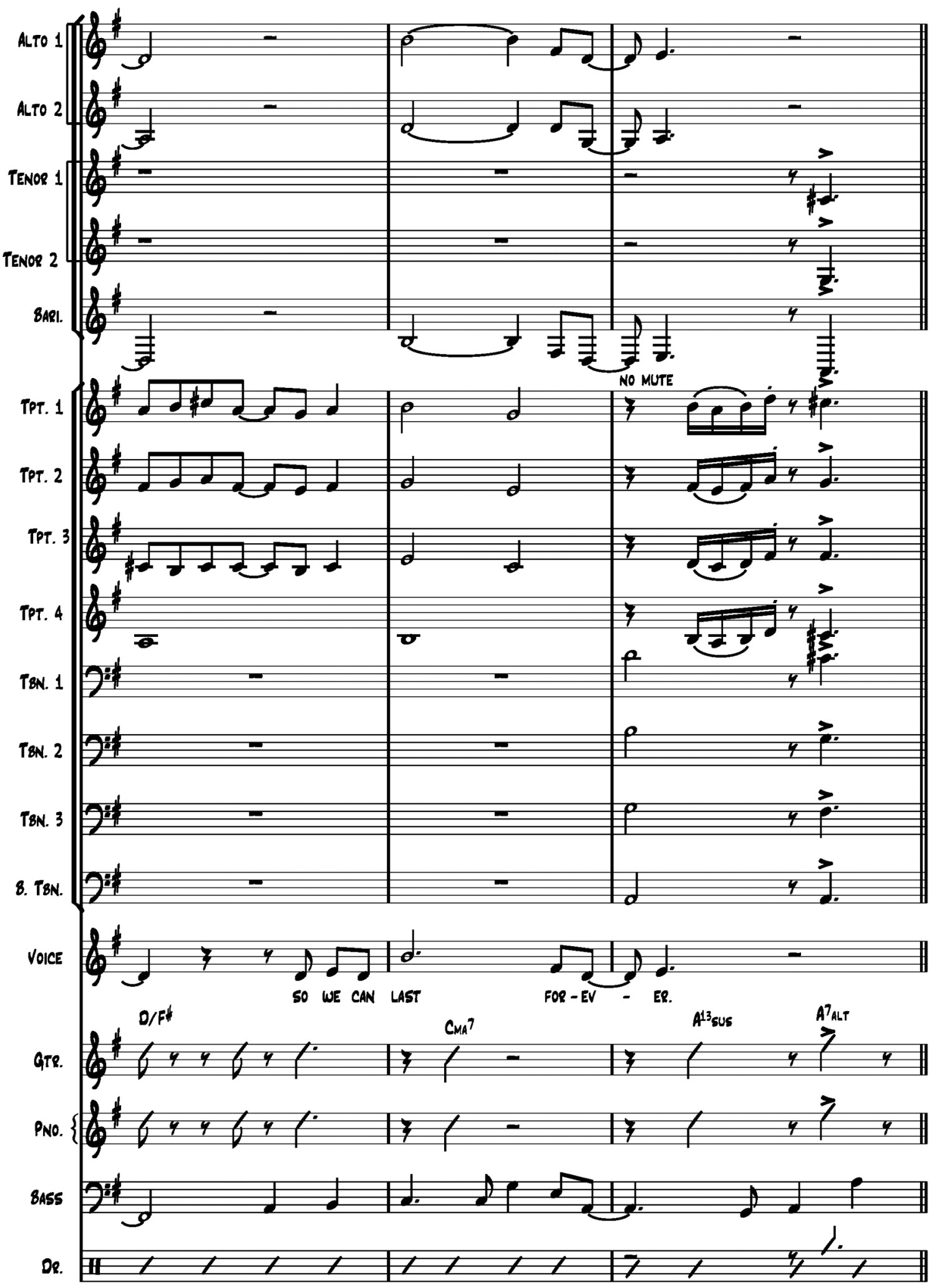




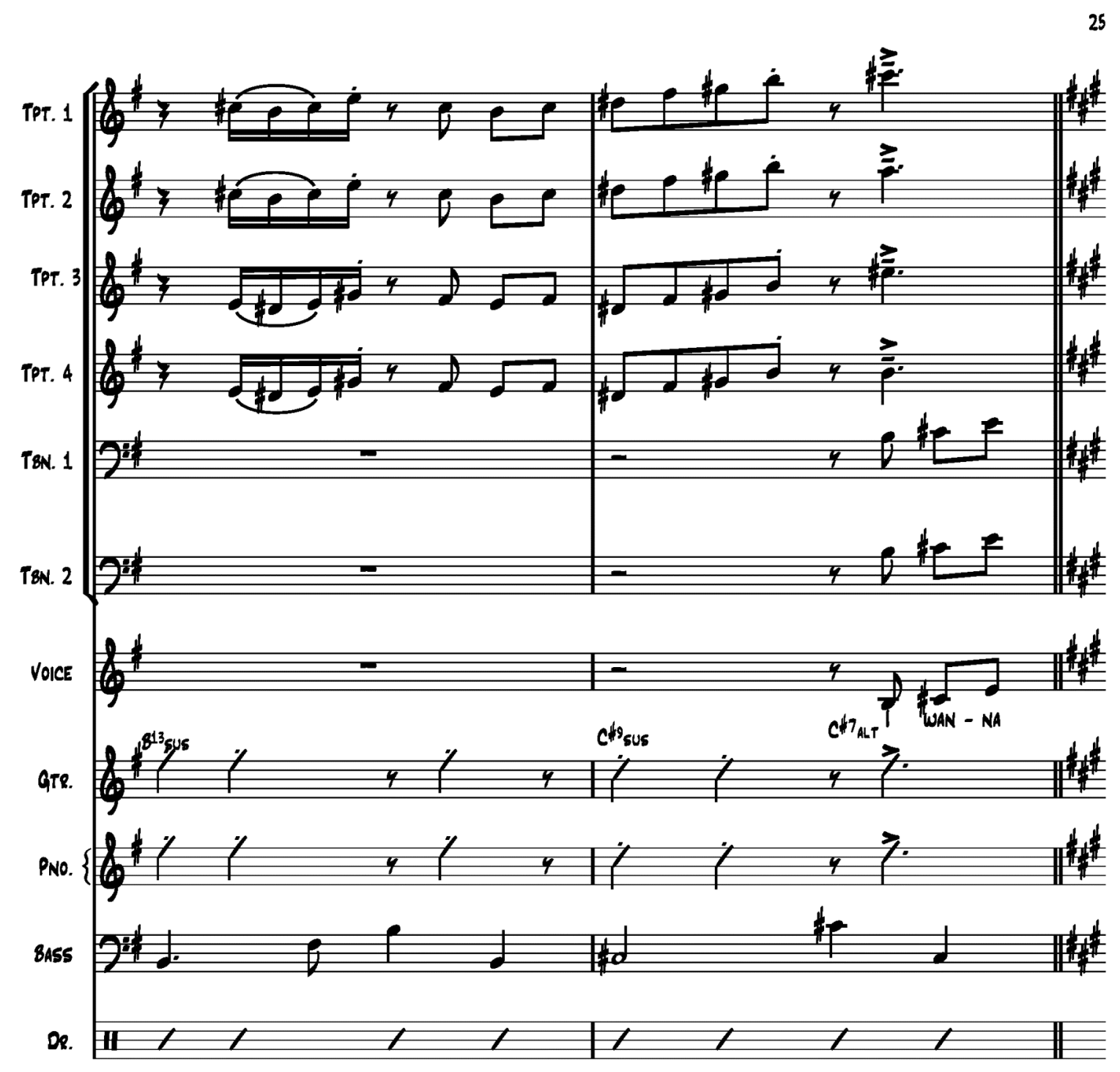




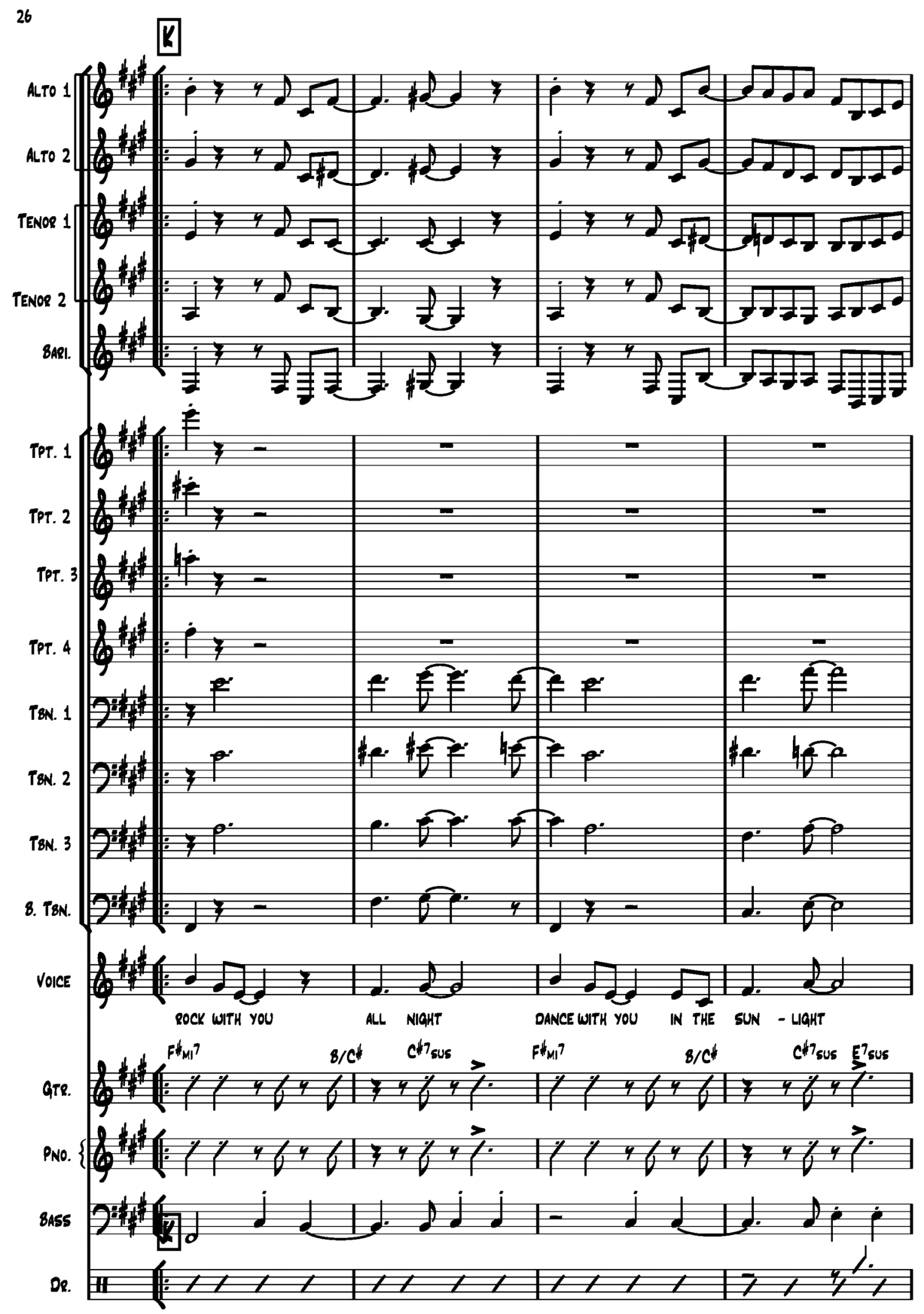




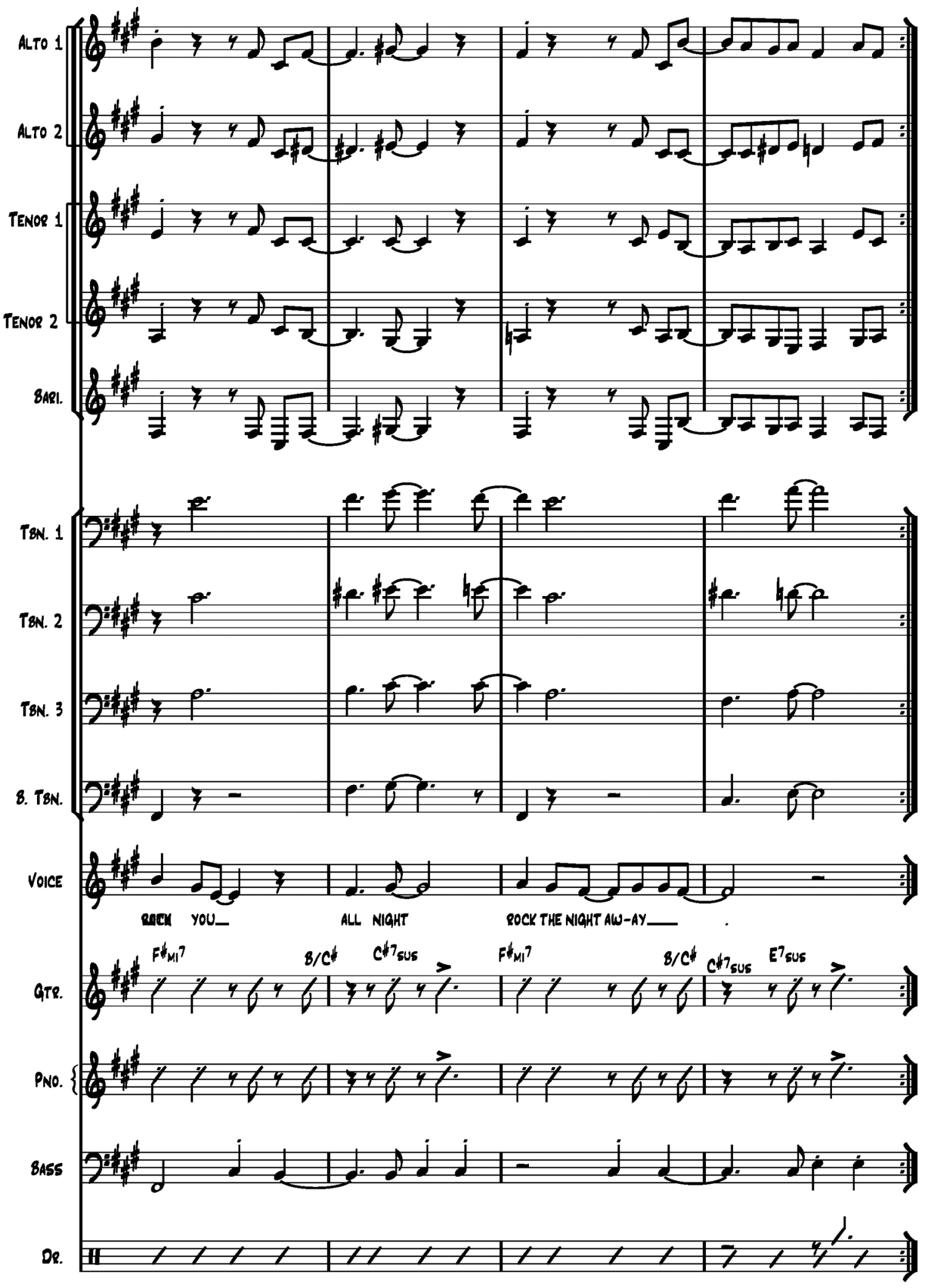




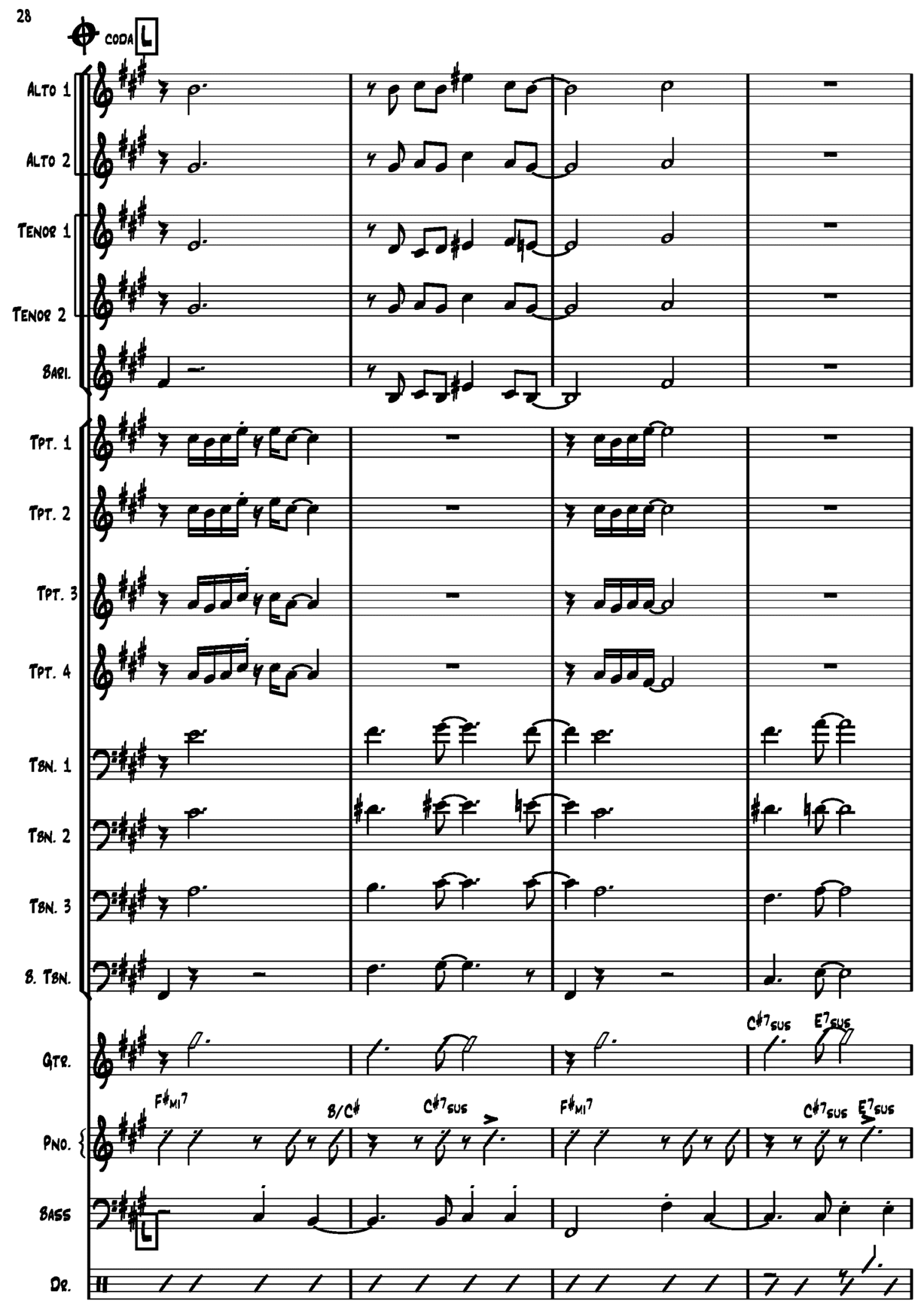




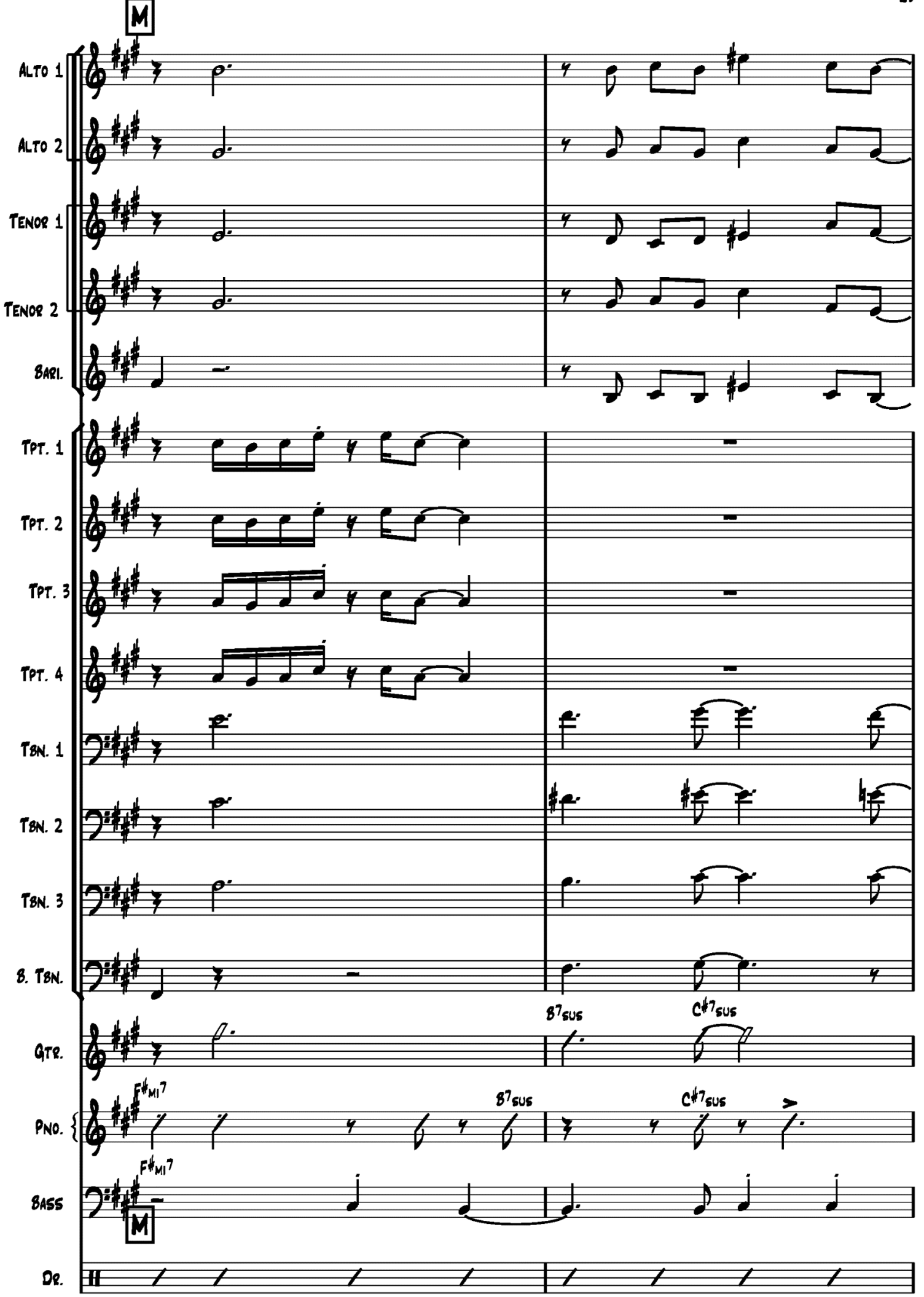




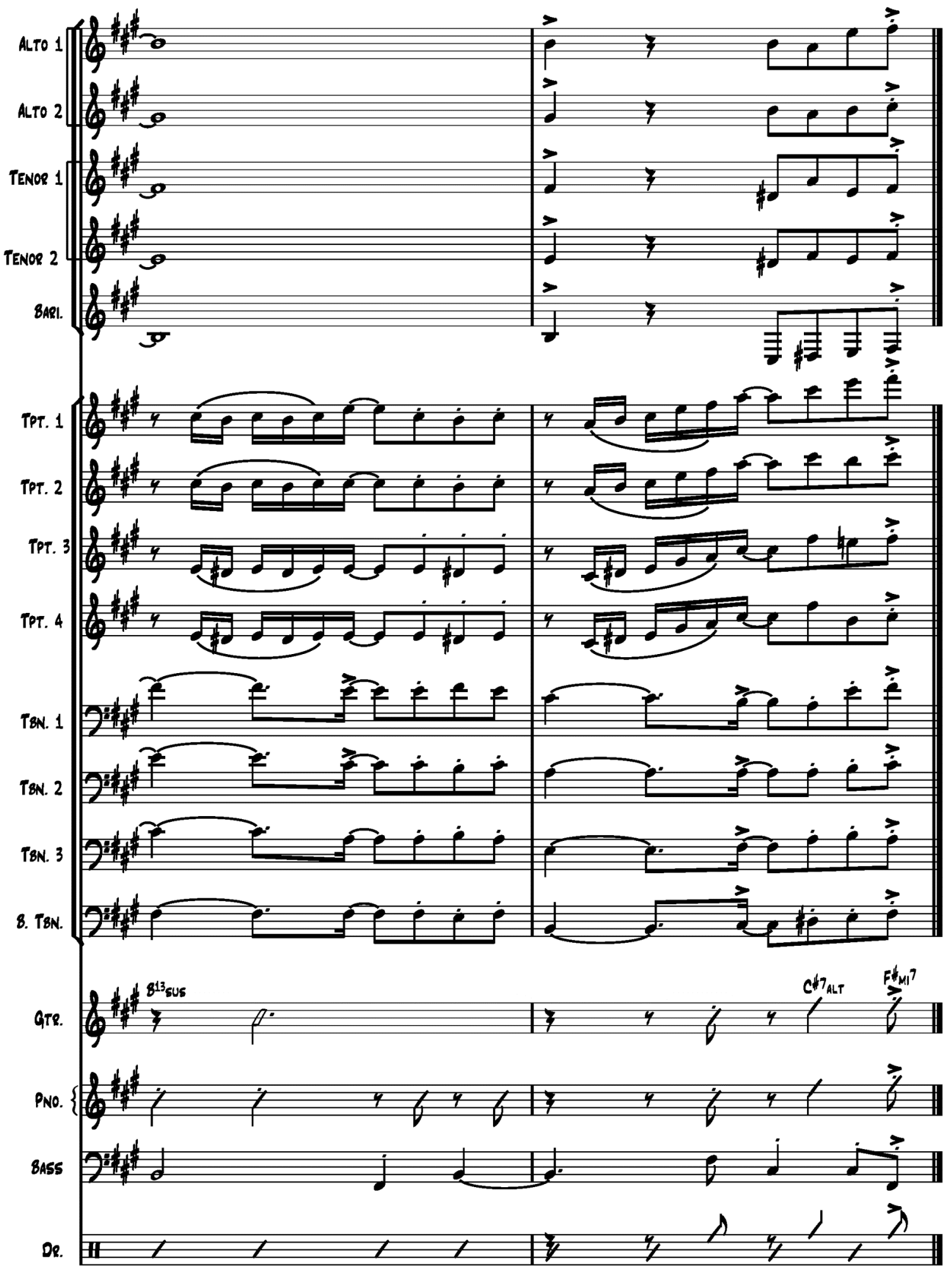




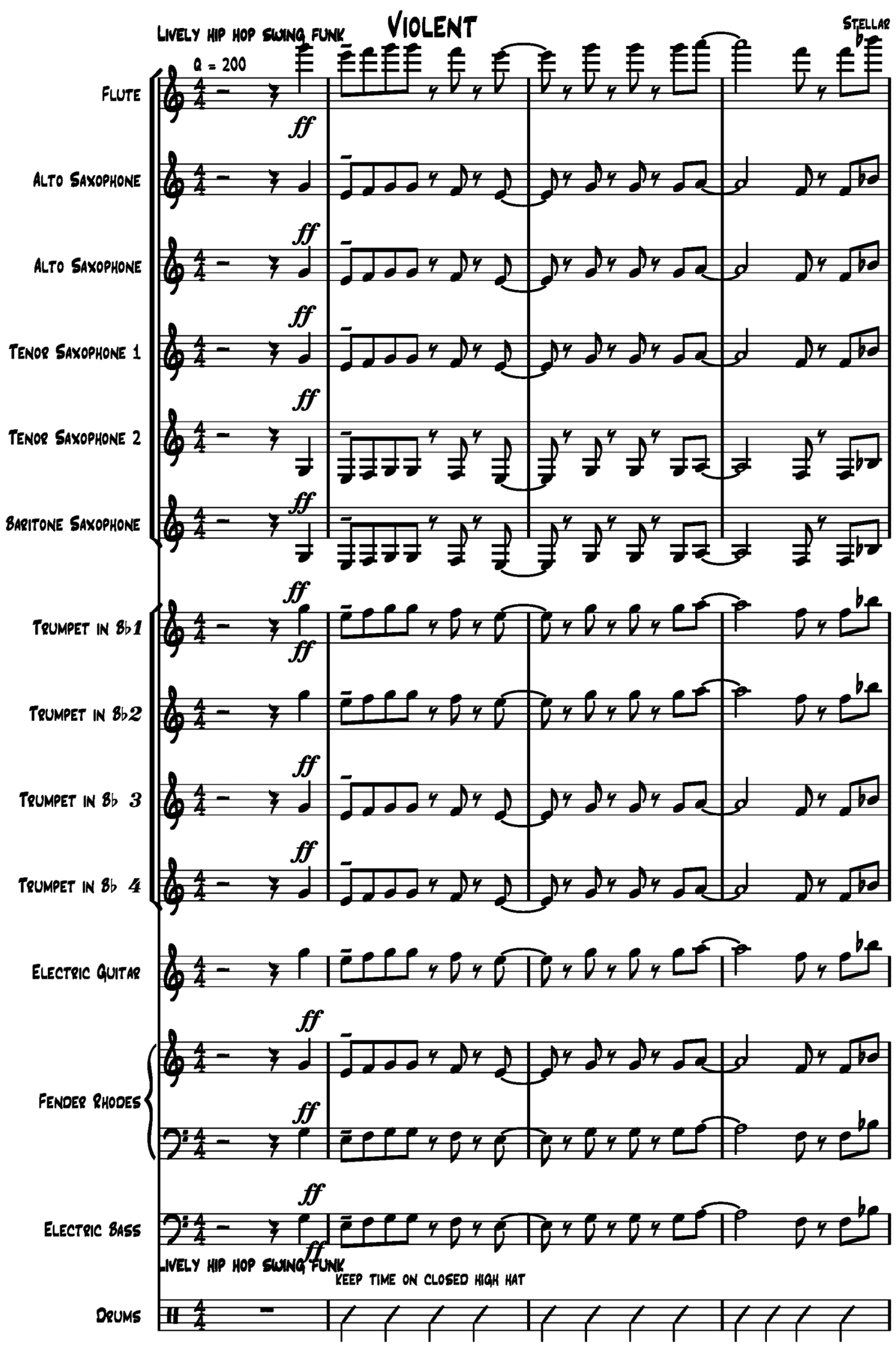


2

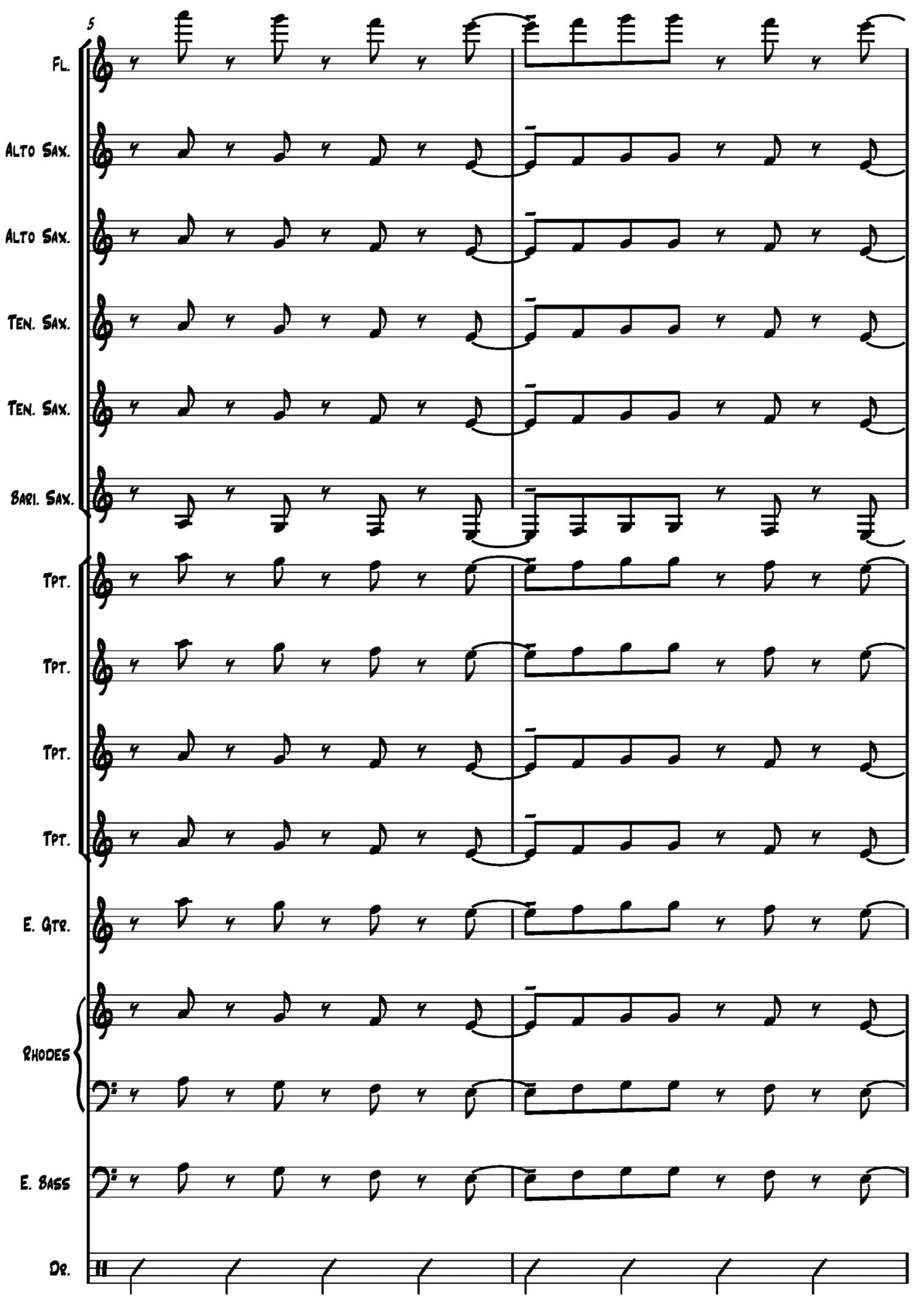

306 

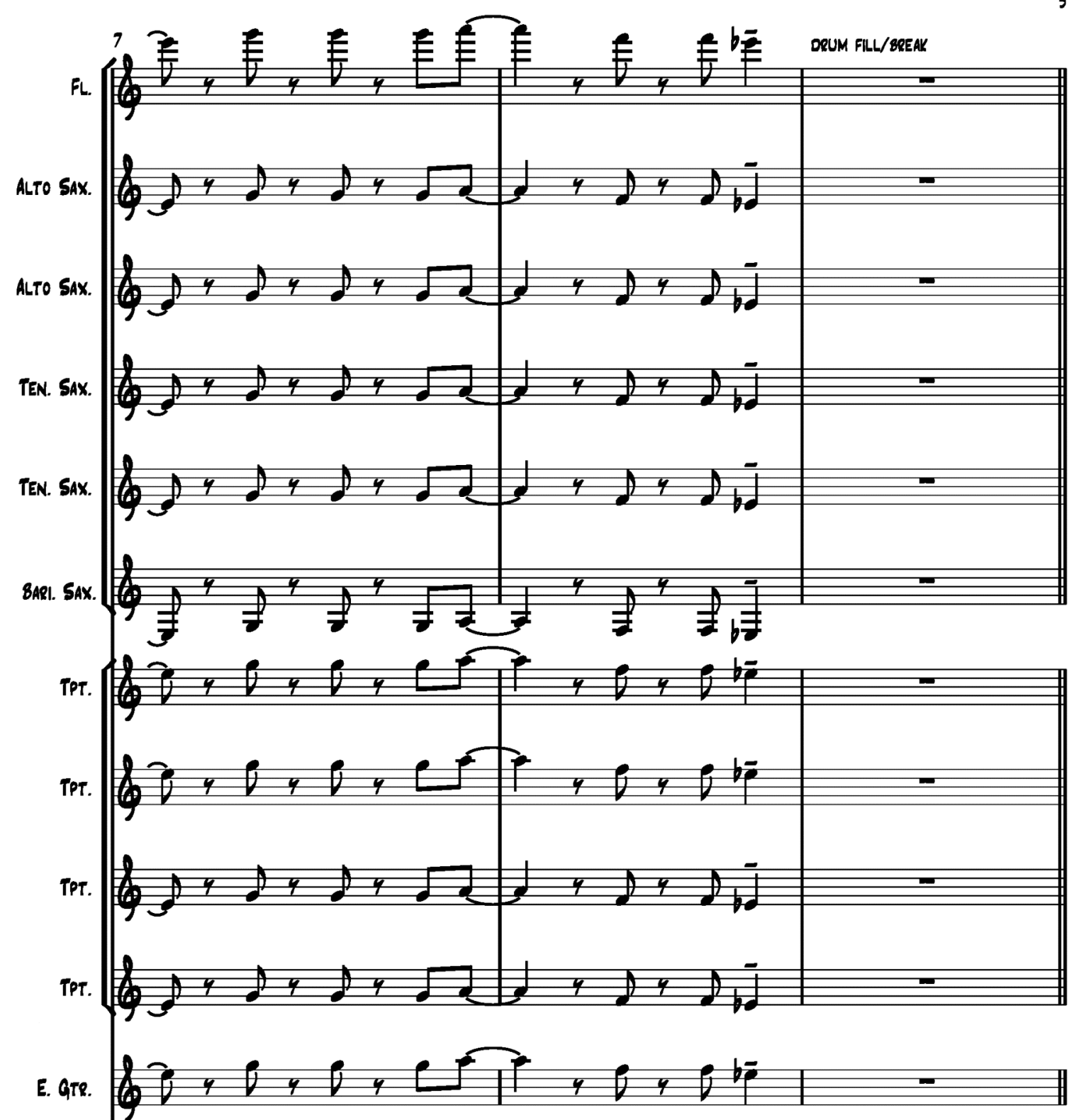

E. GTR.

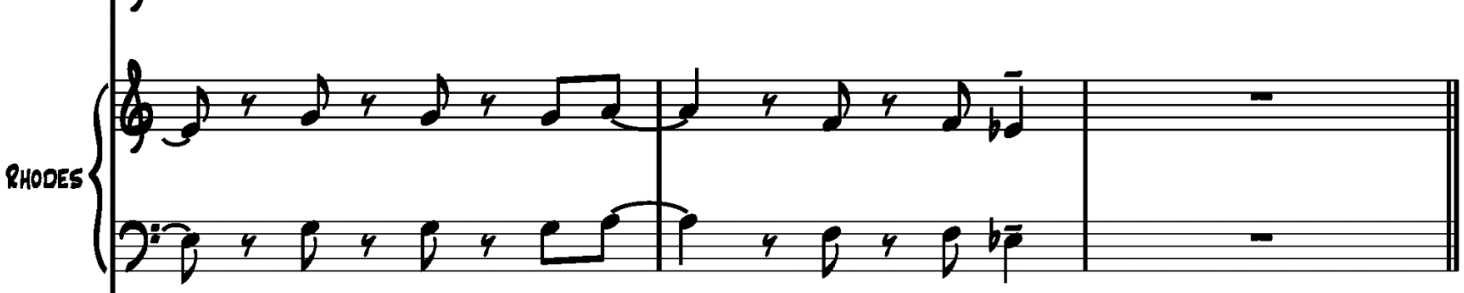

E. BASS

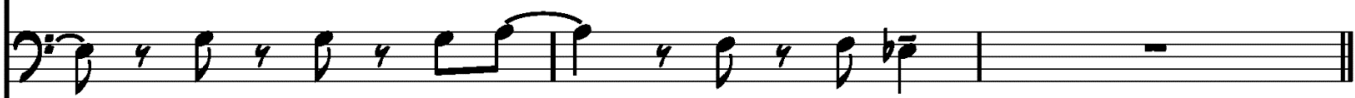

De.

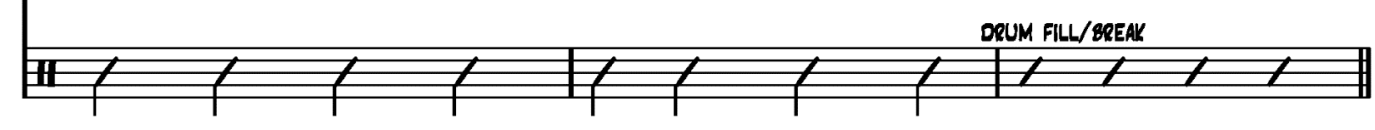




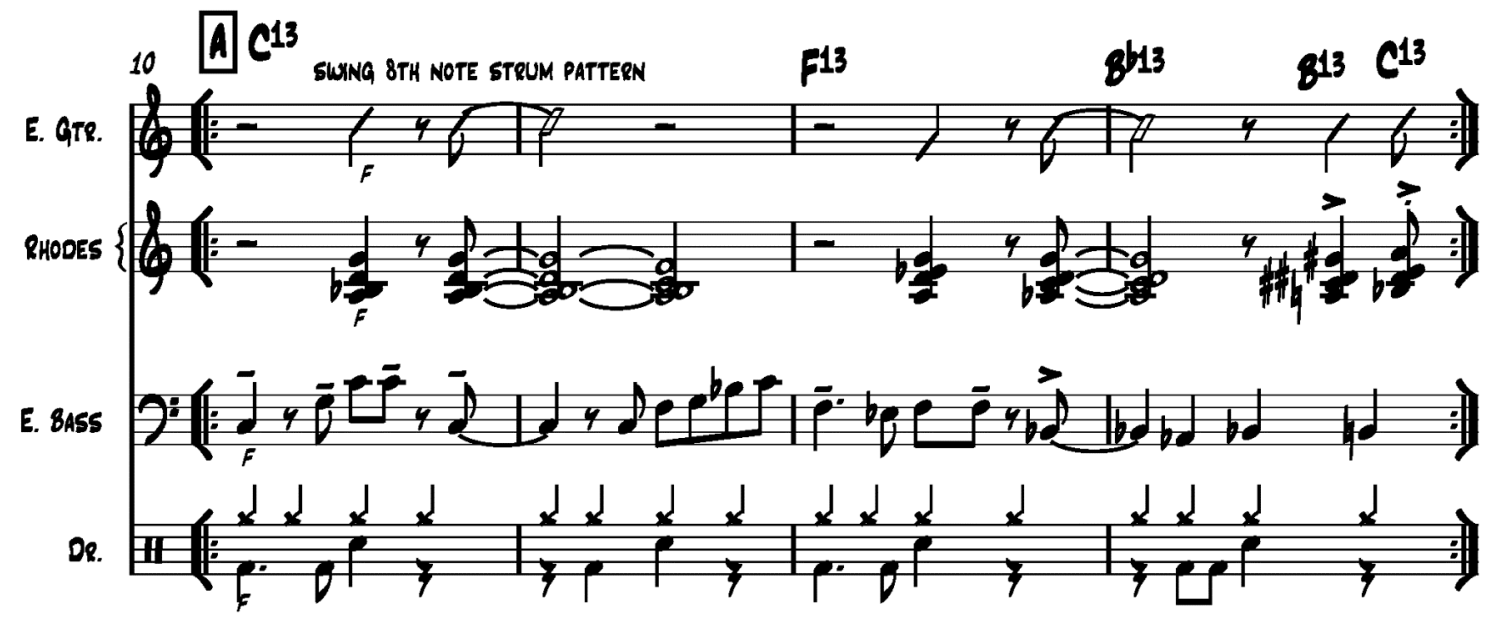




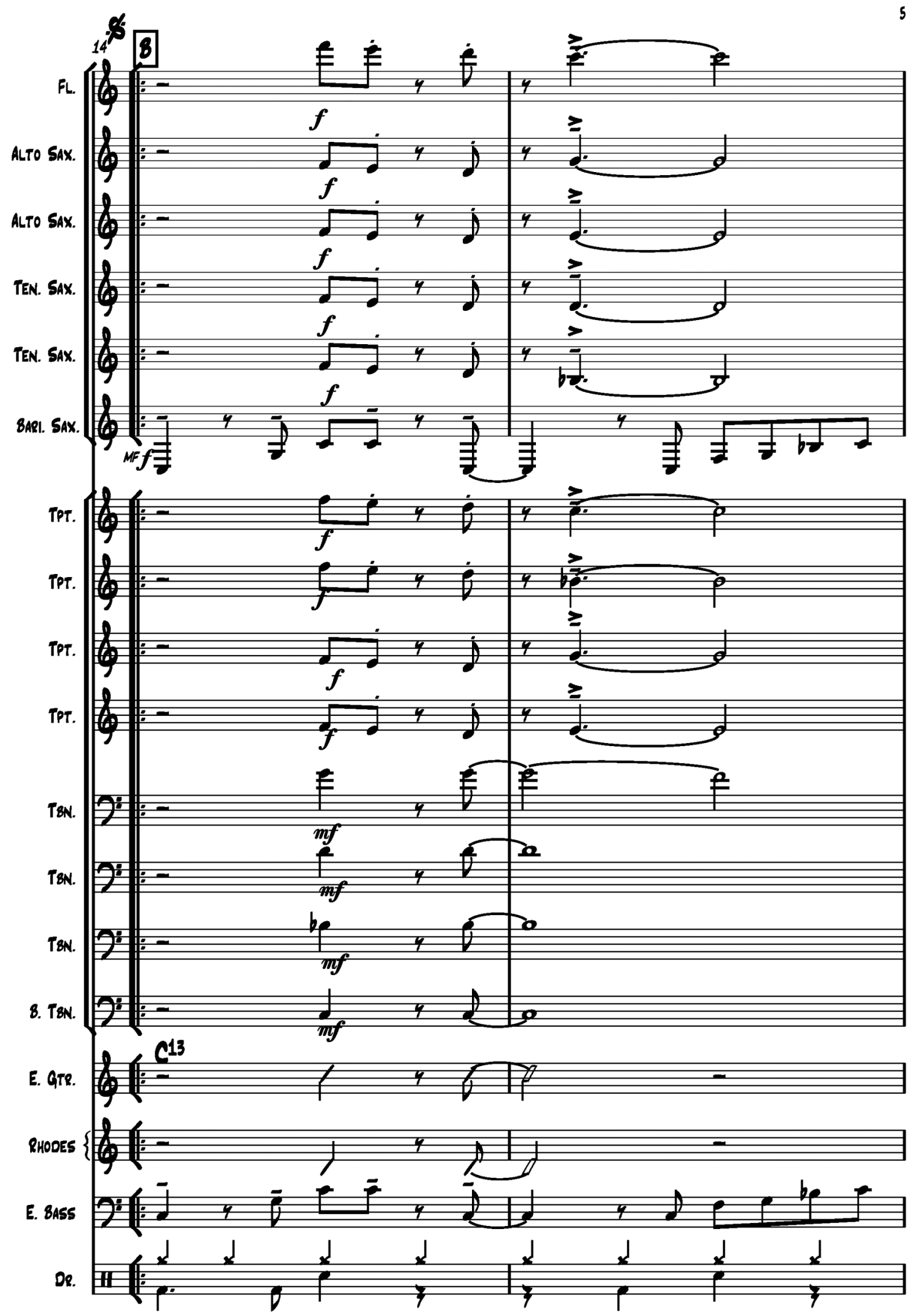


6

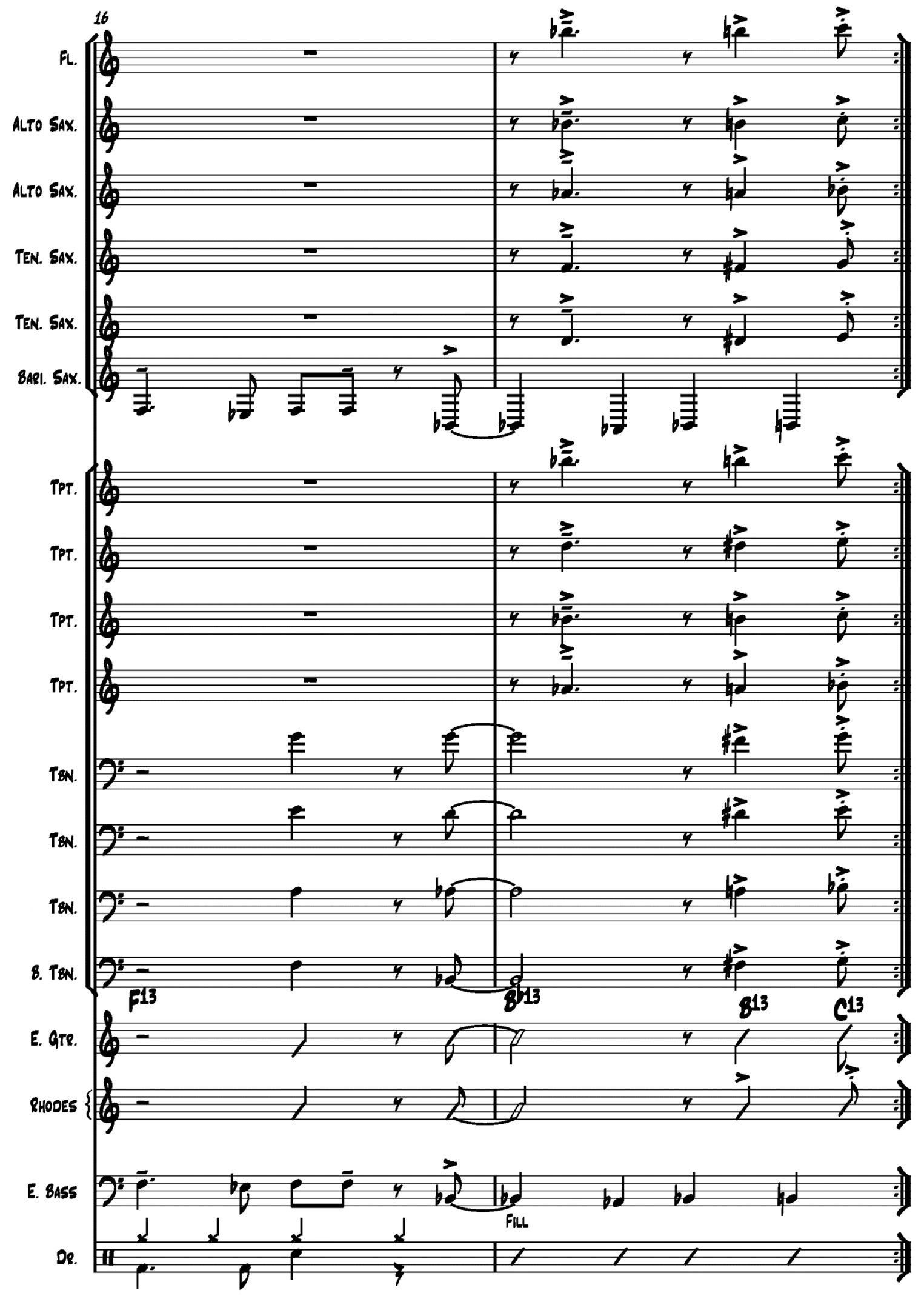




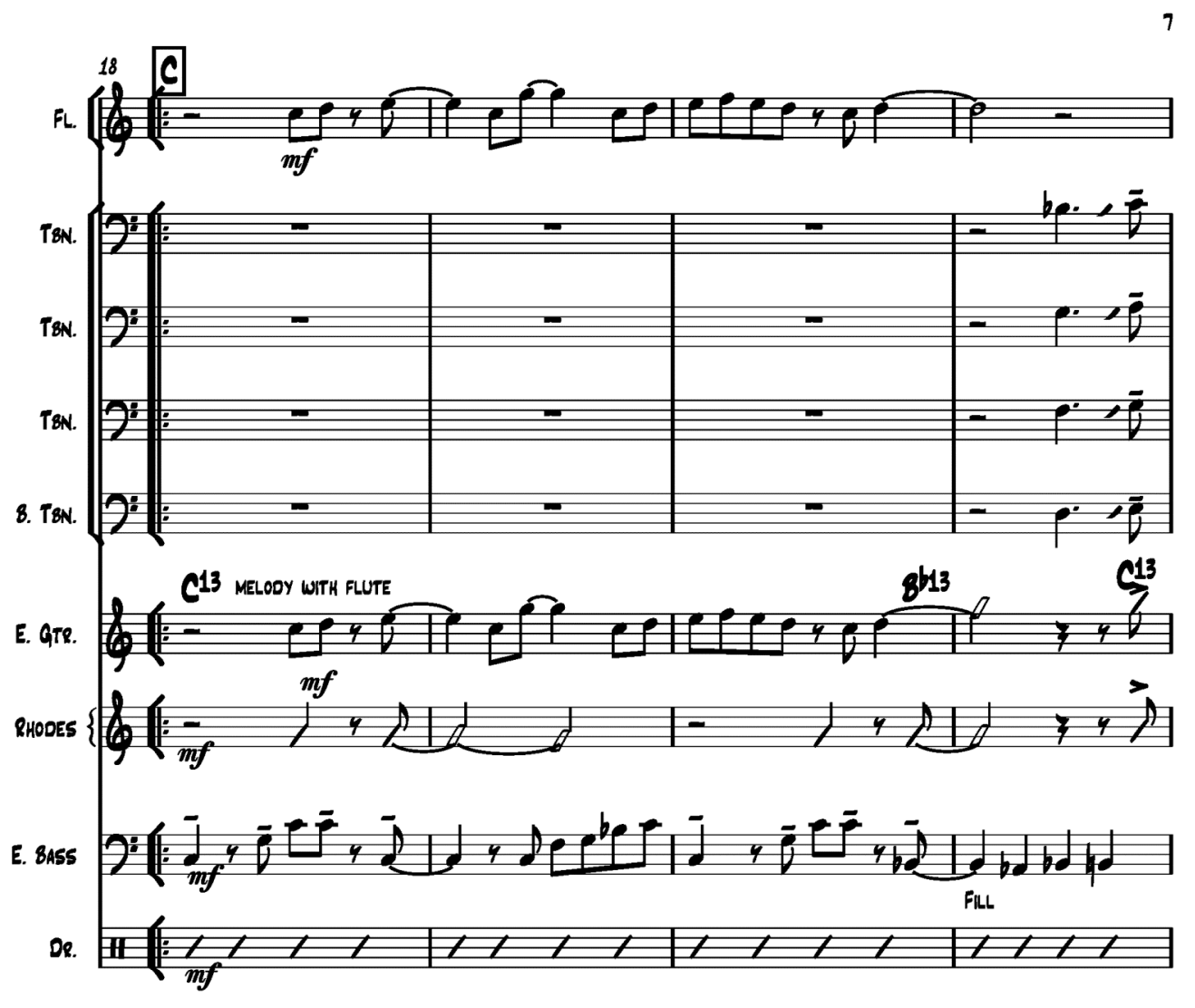

8

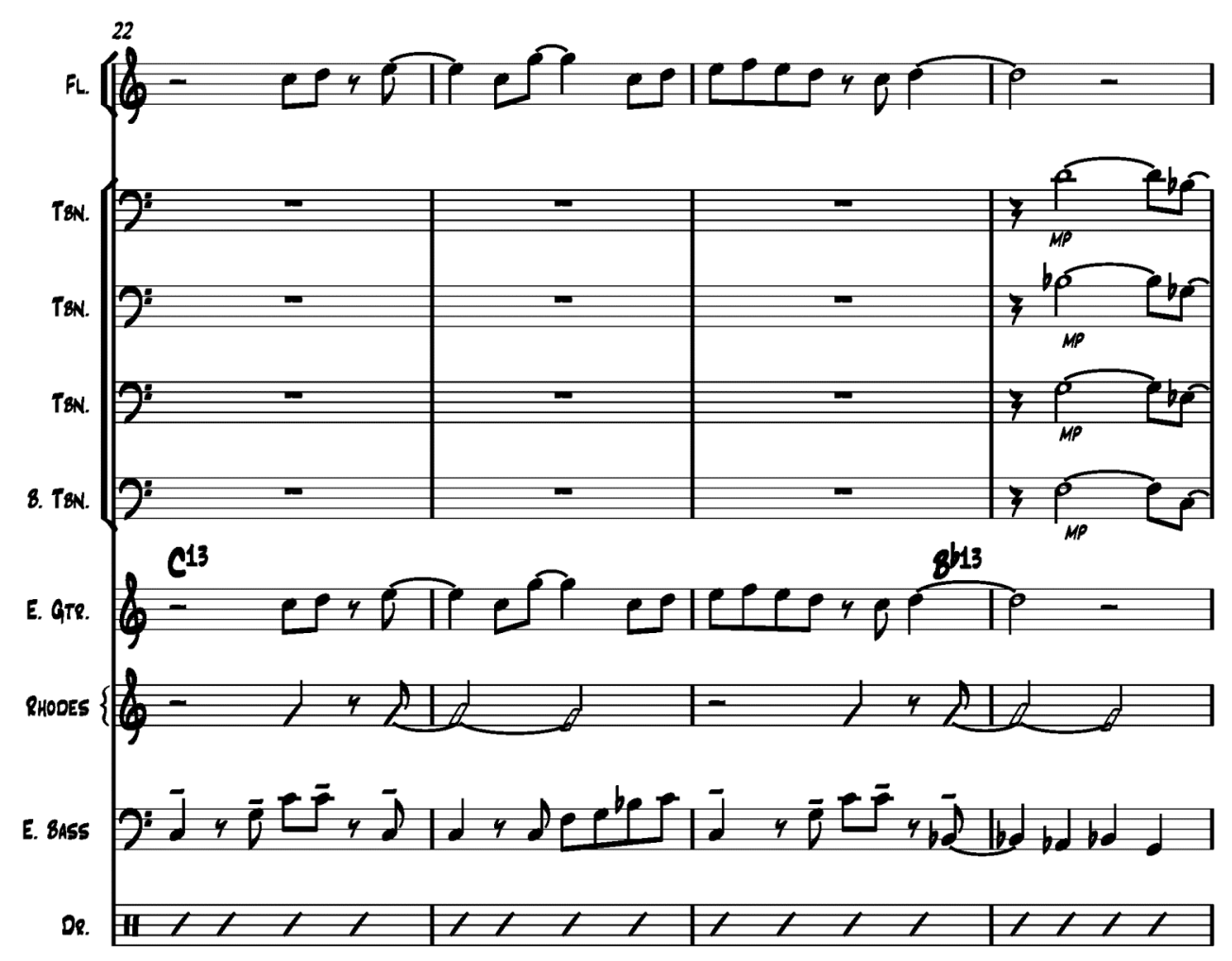

311 


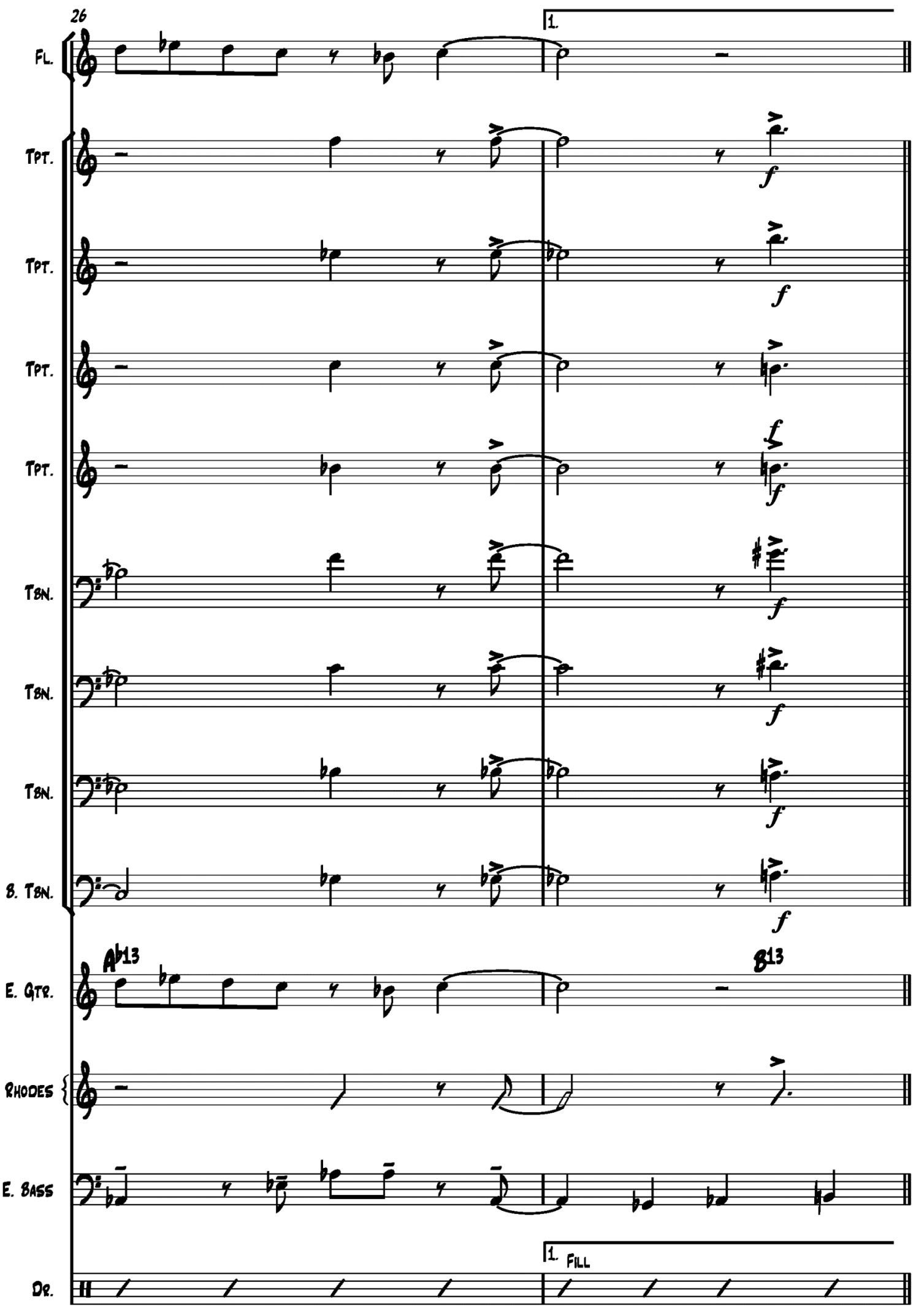


10

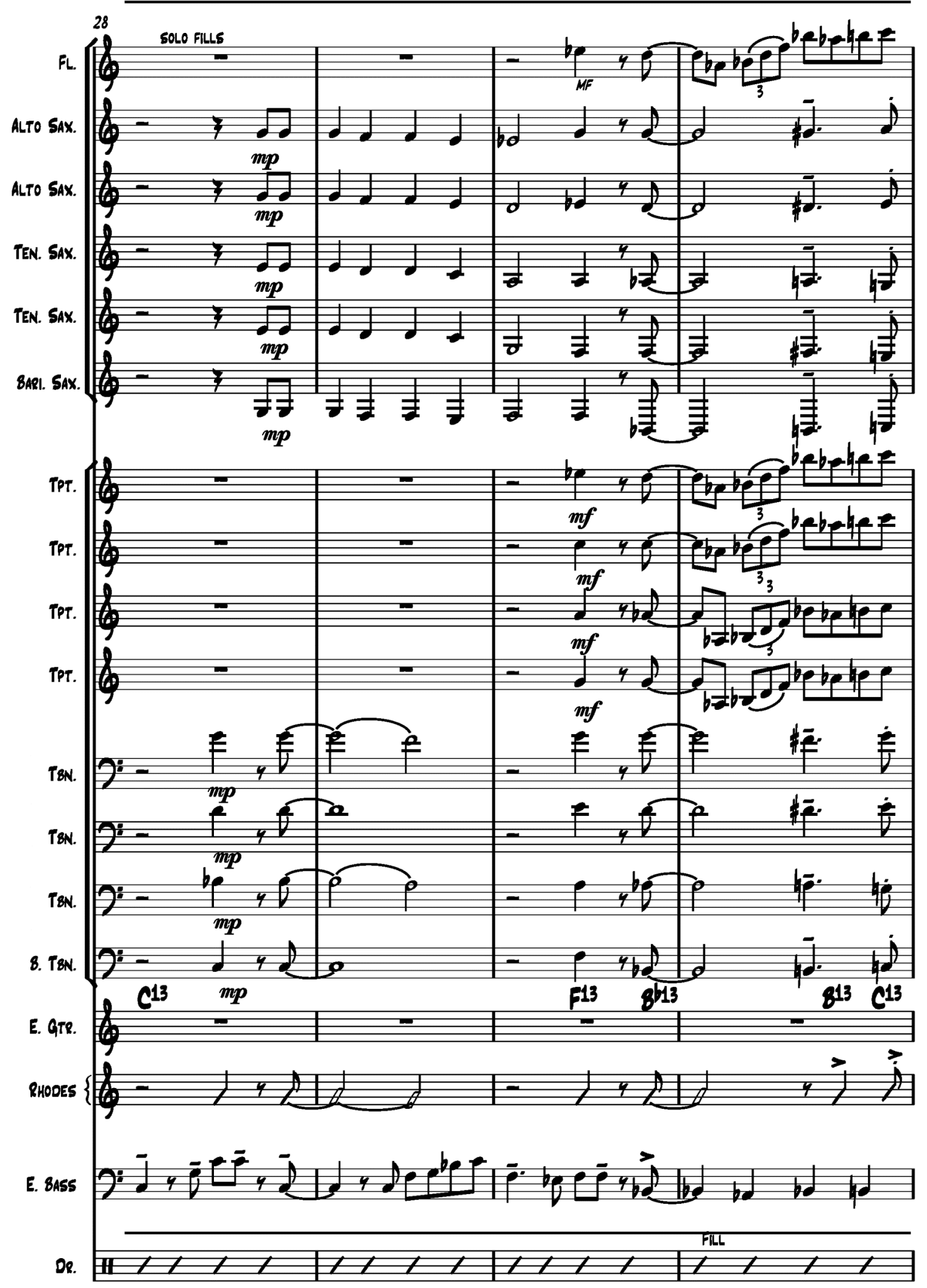




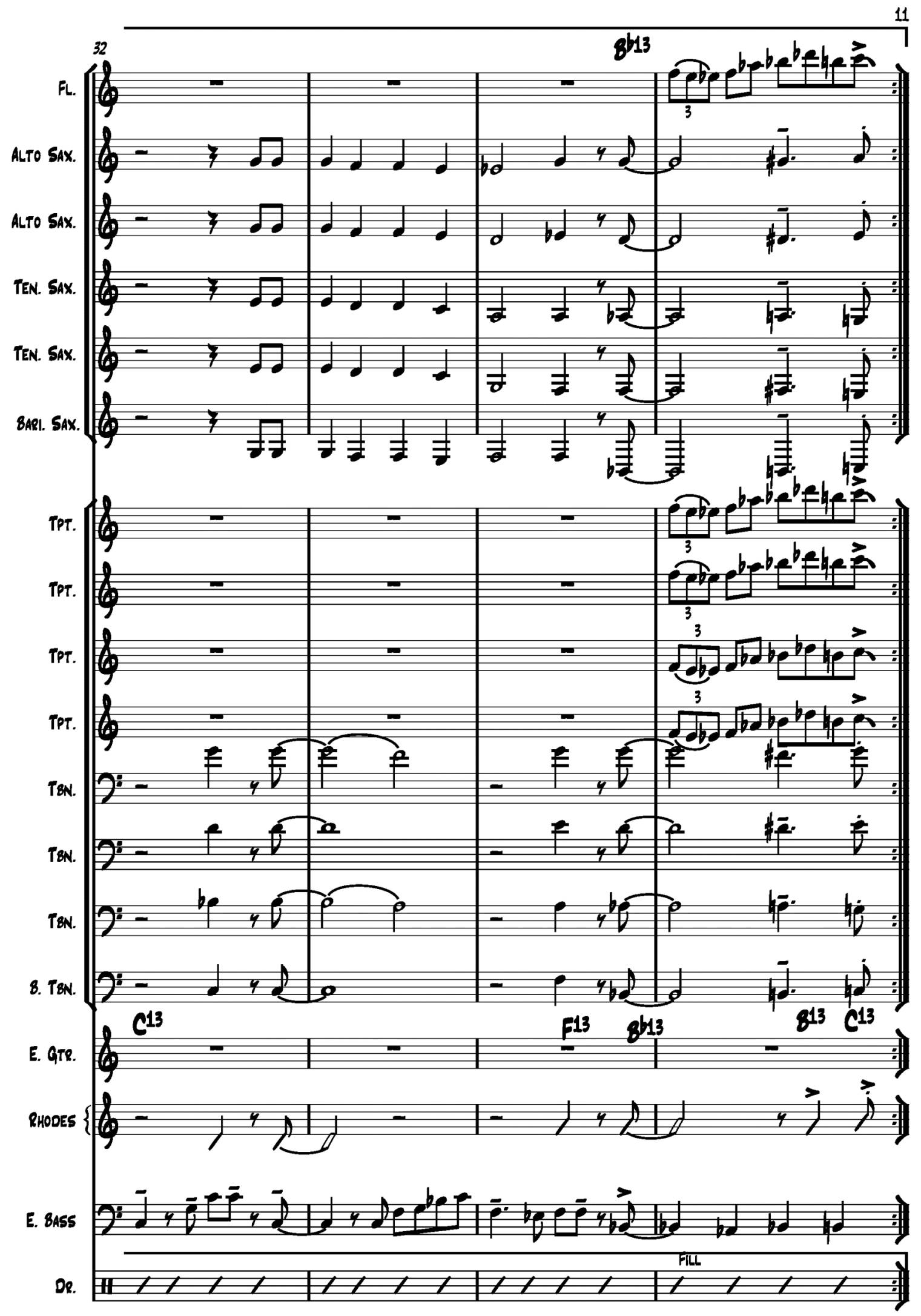


12

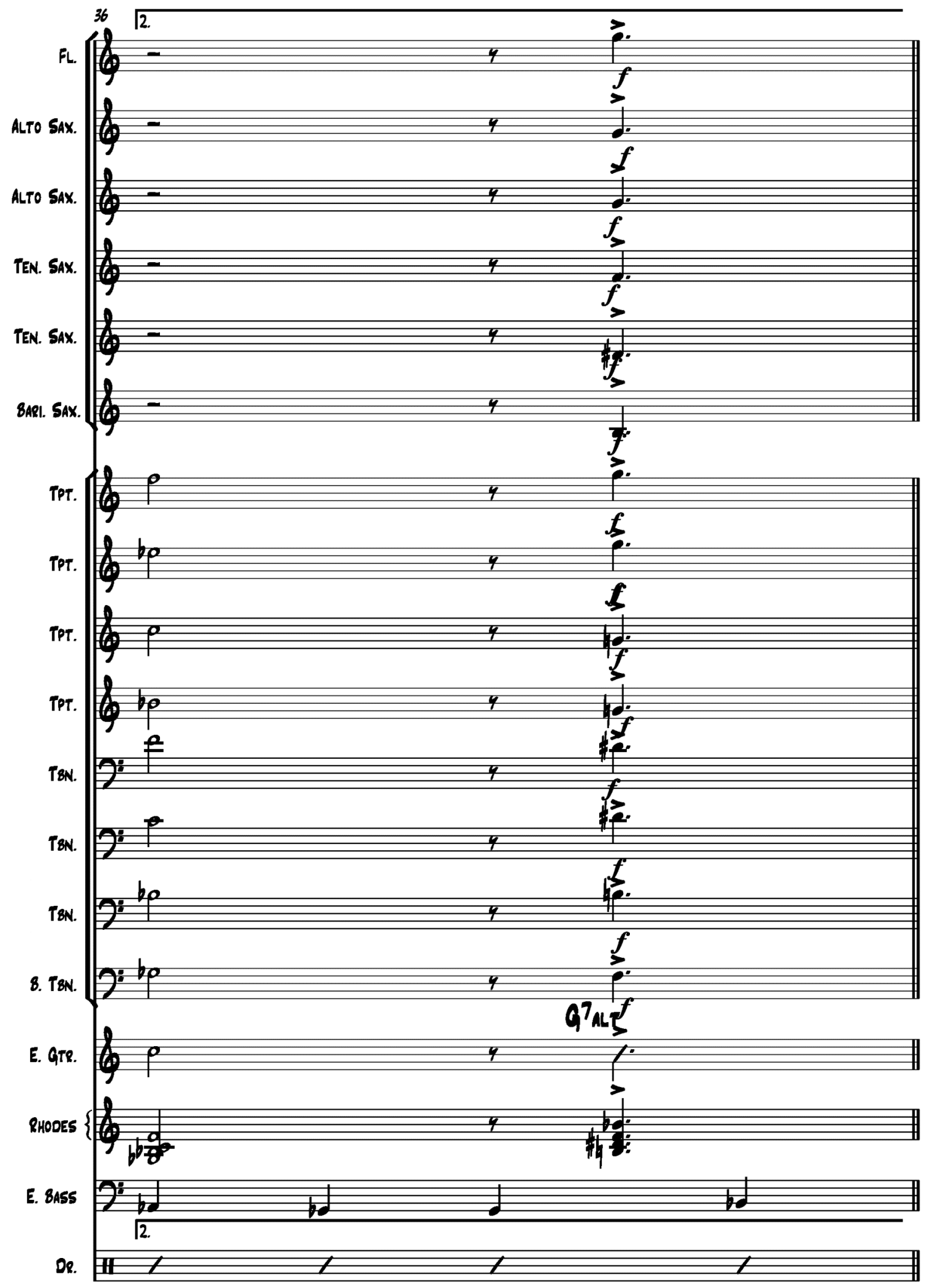




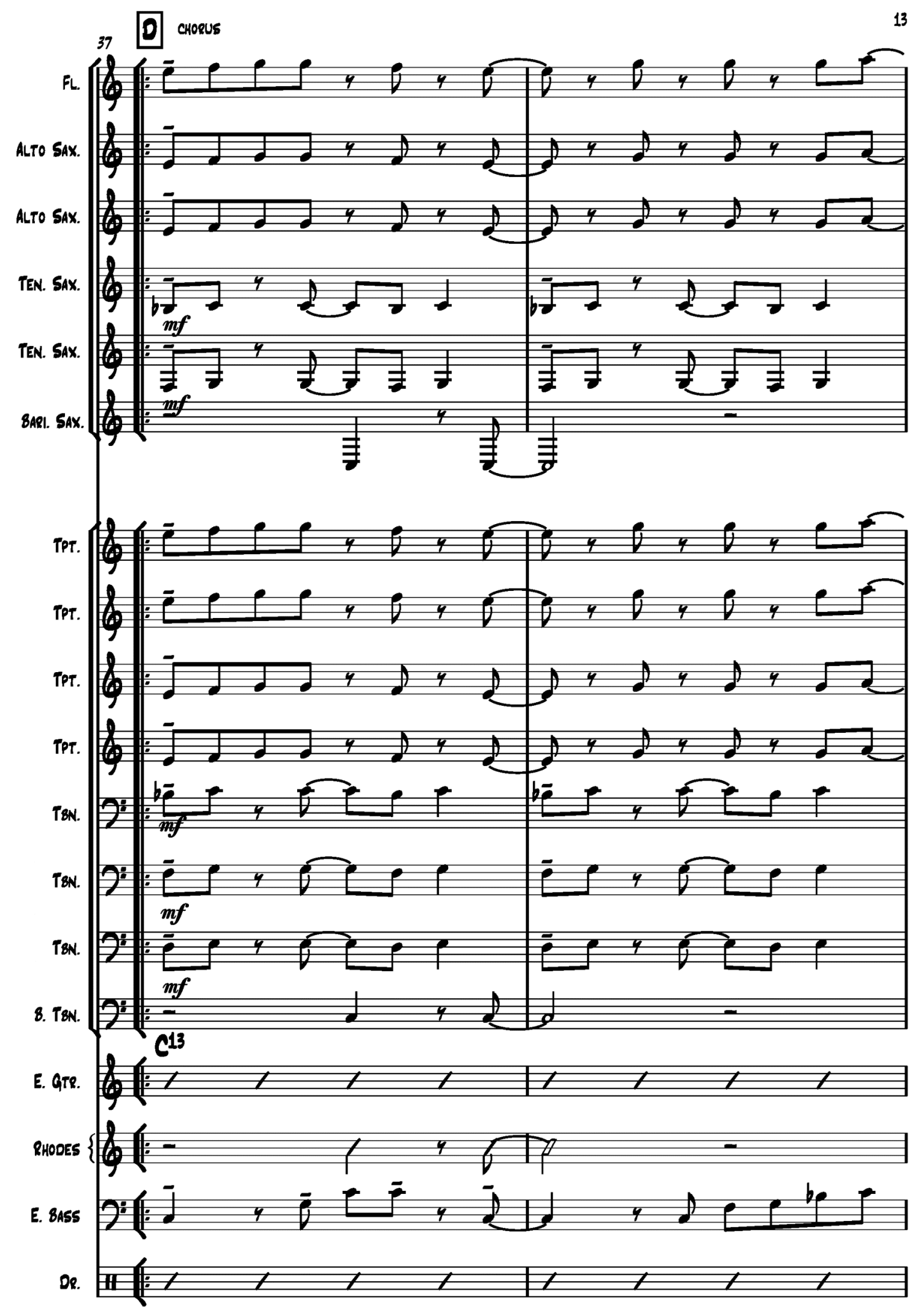


14

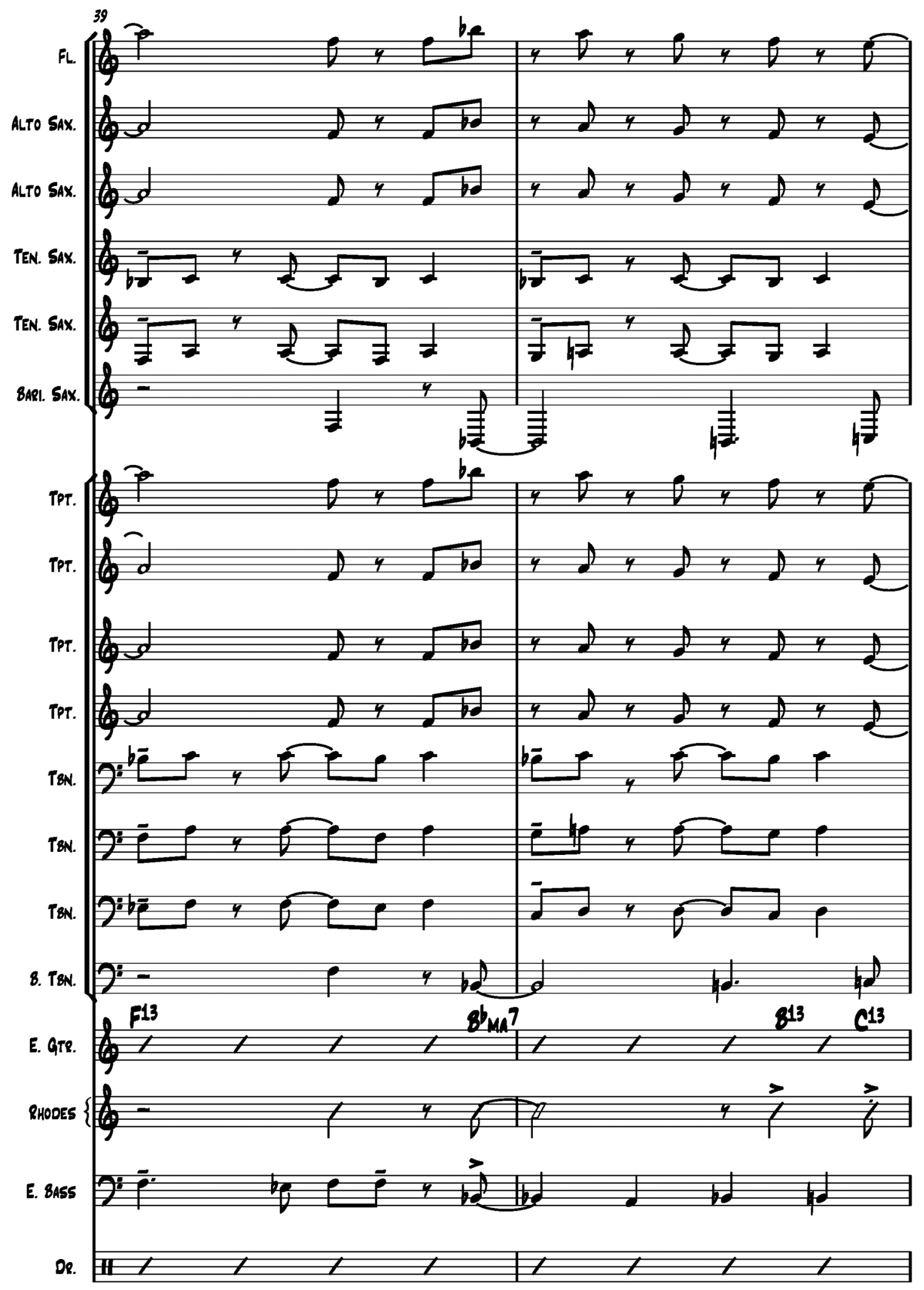




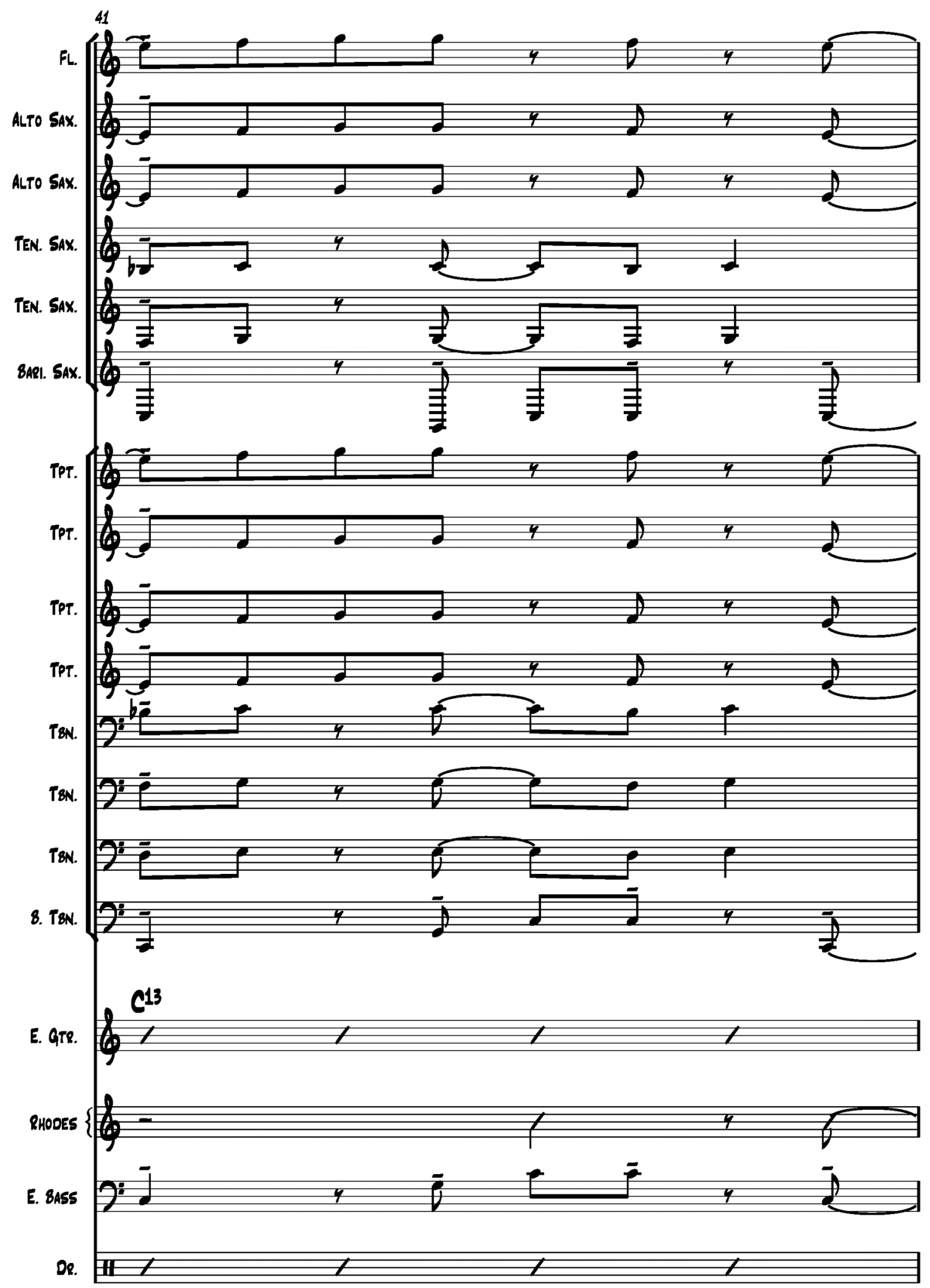


16

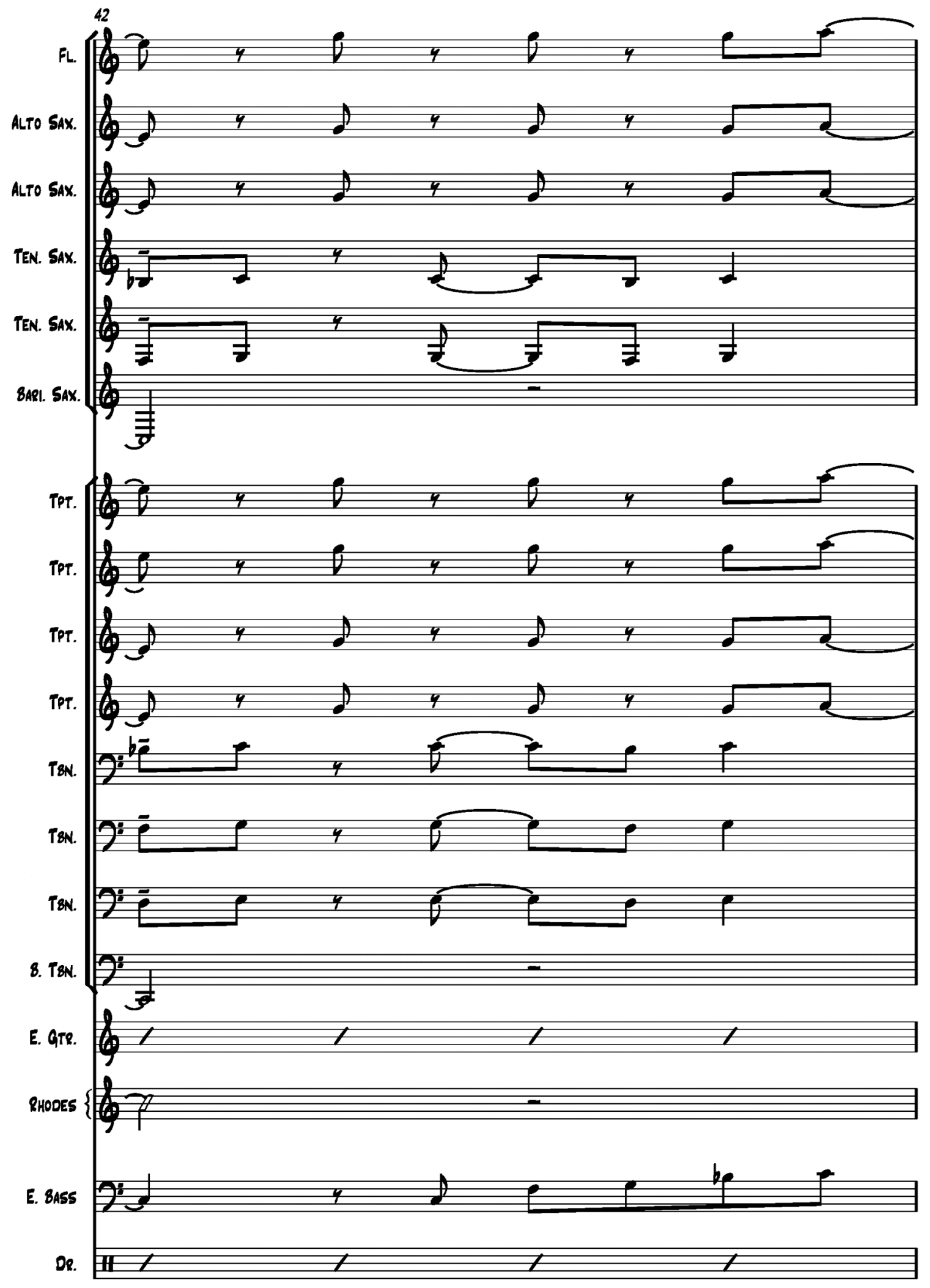


17

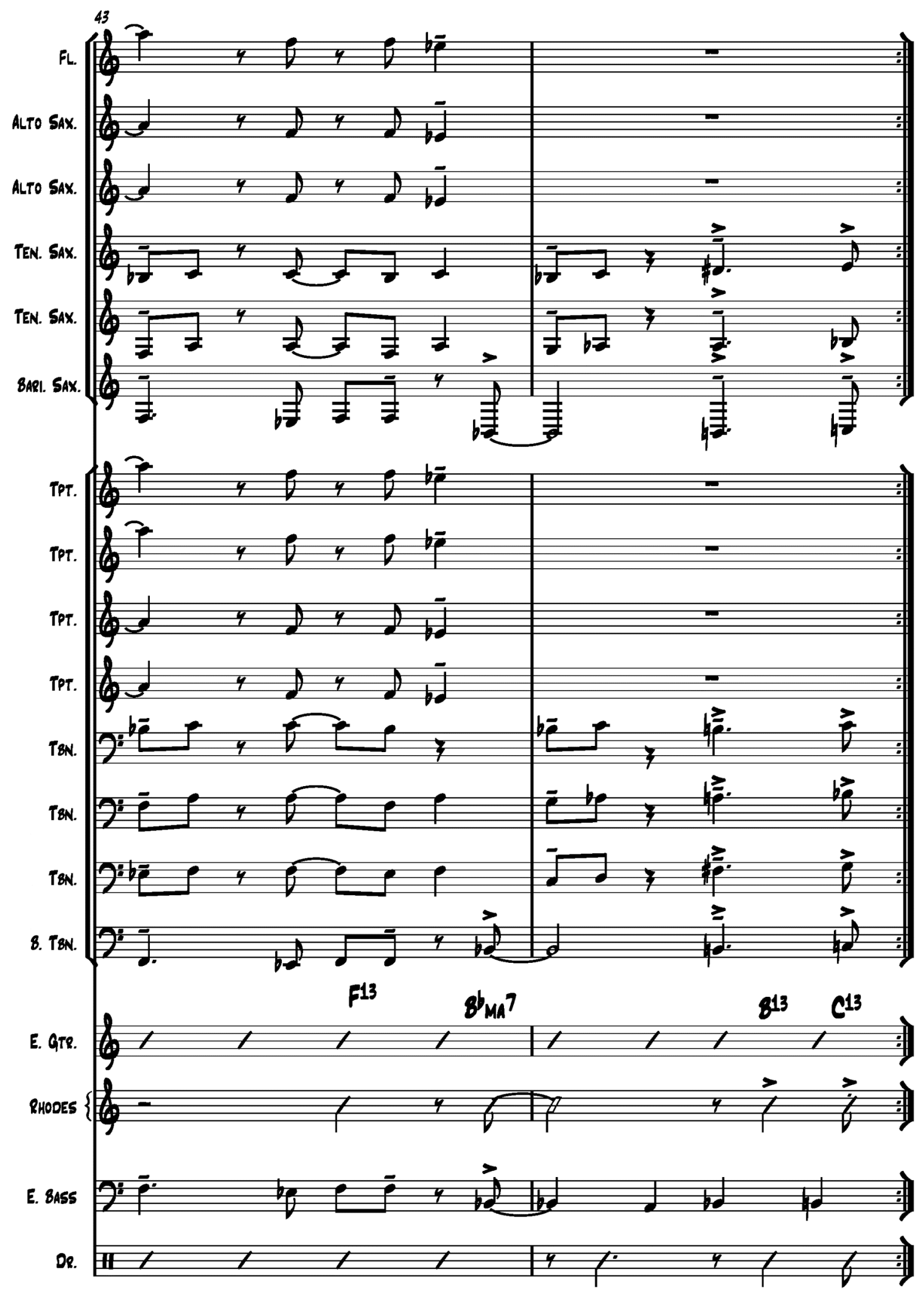


18

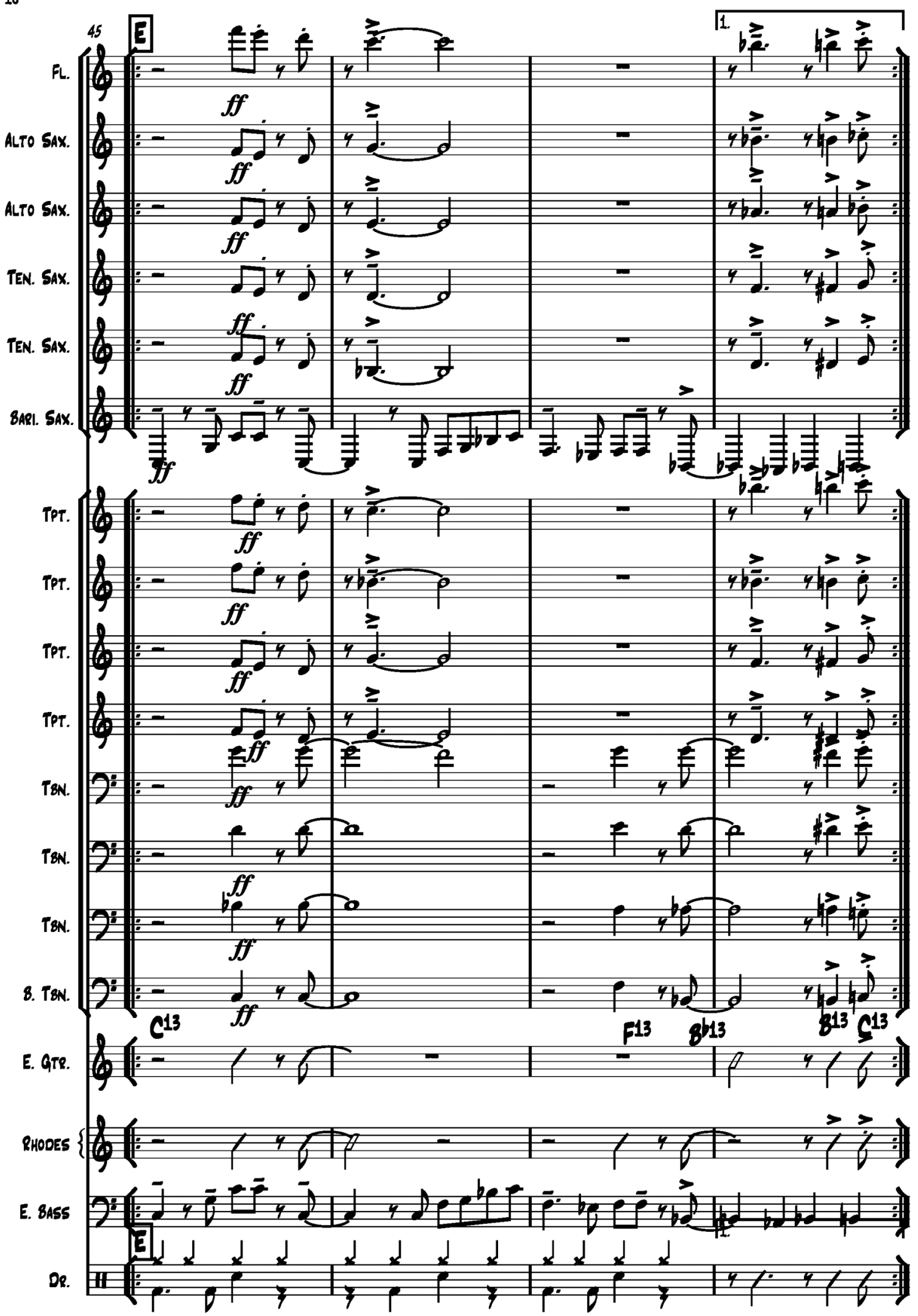




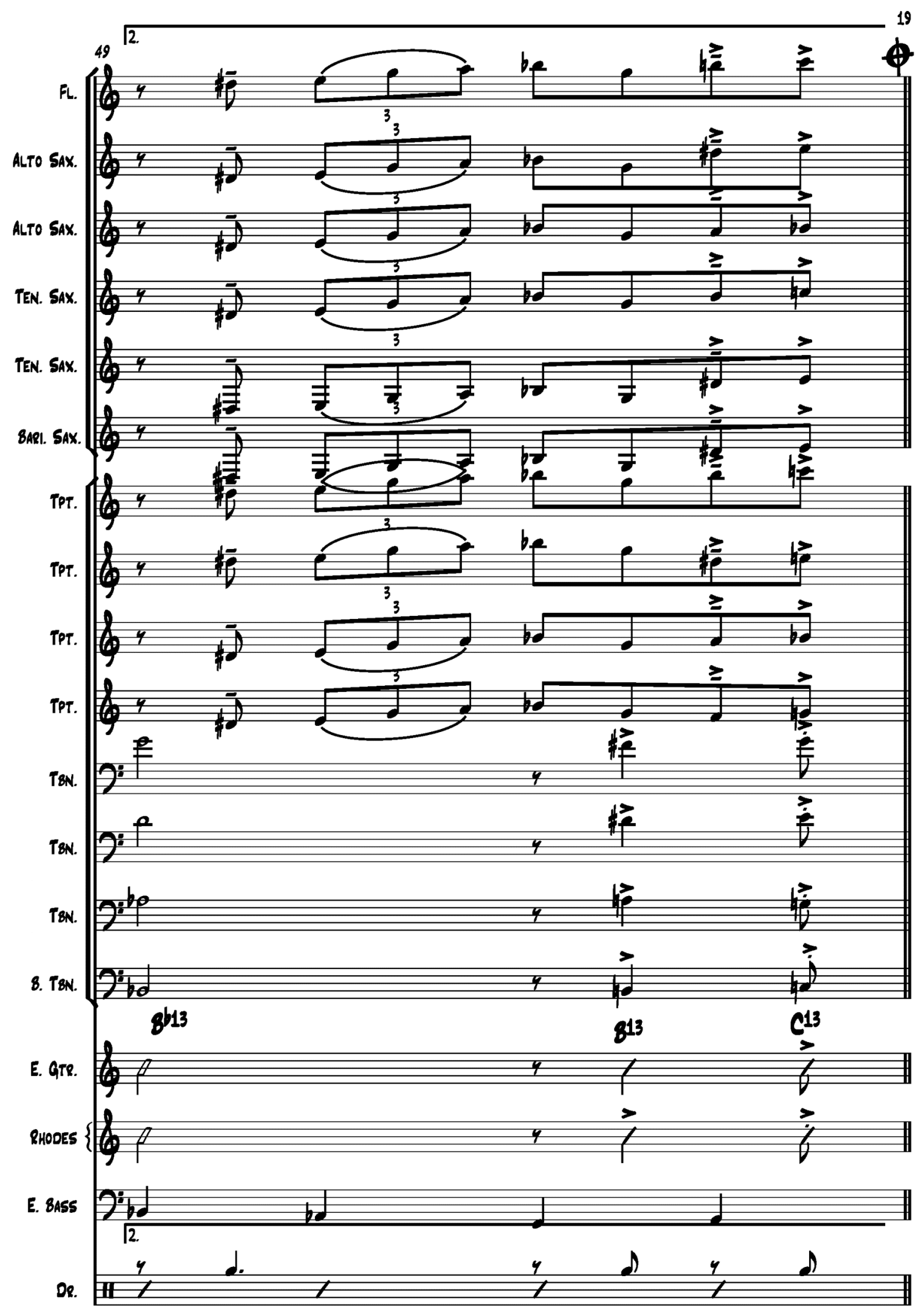


20
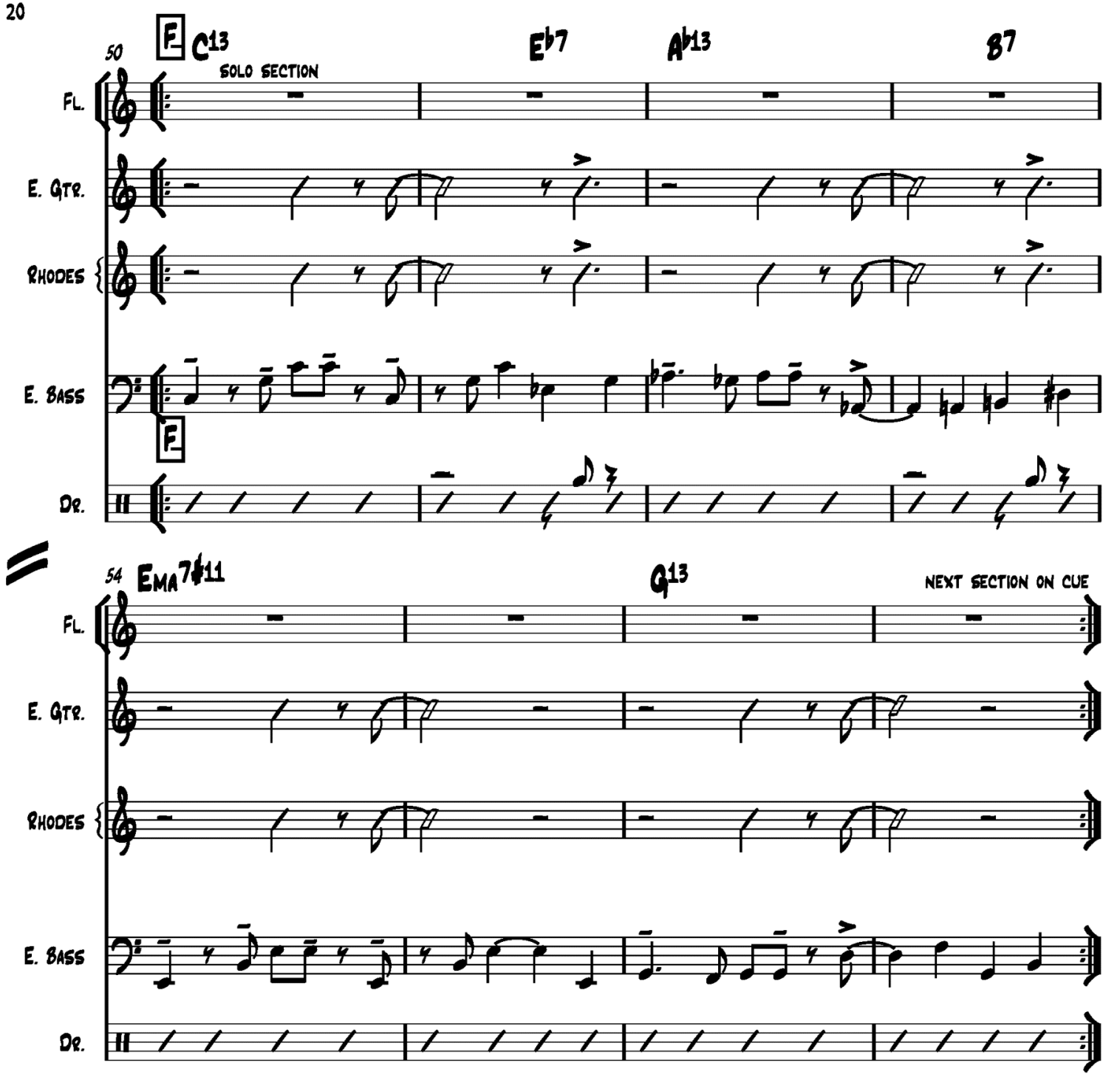

323 


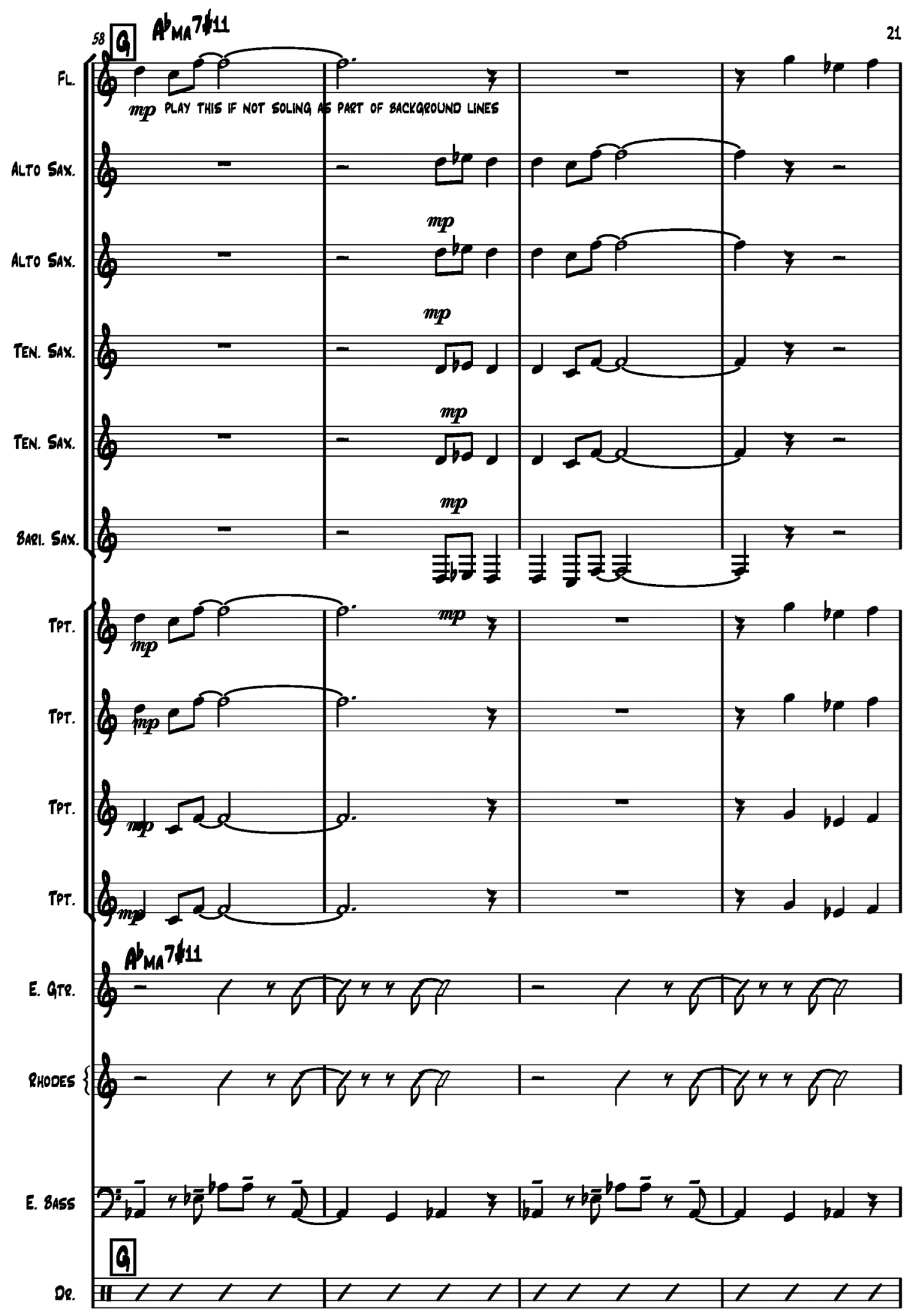




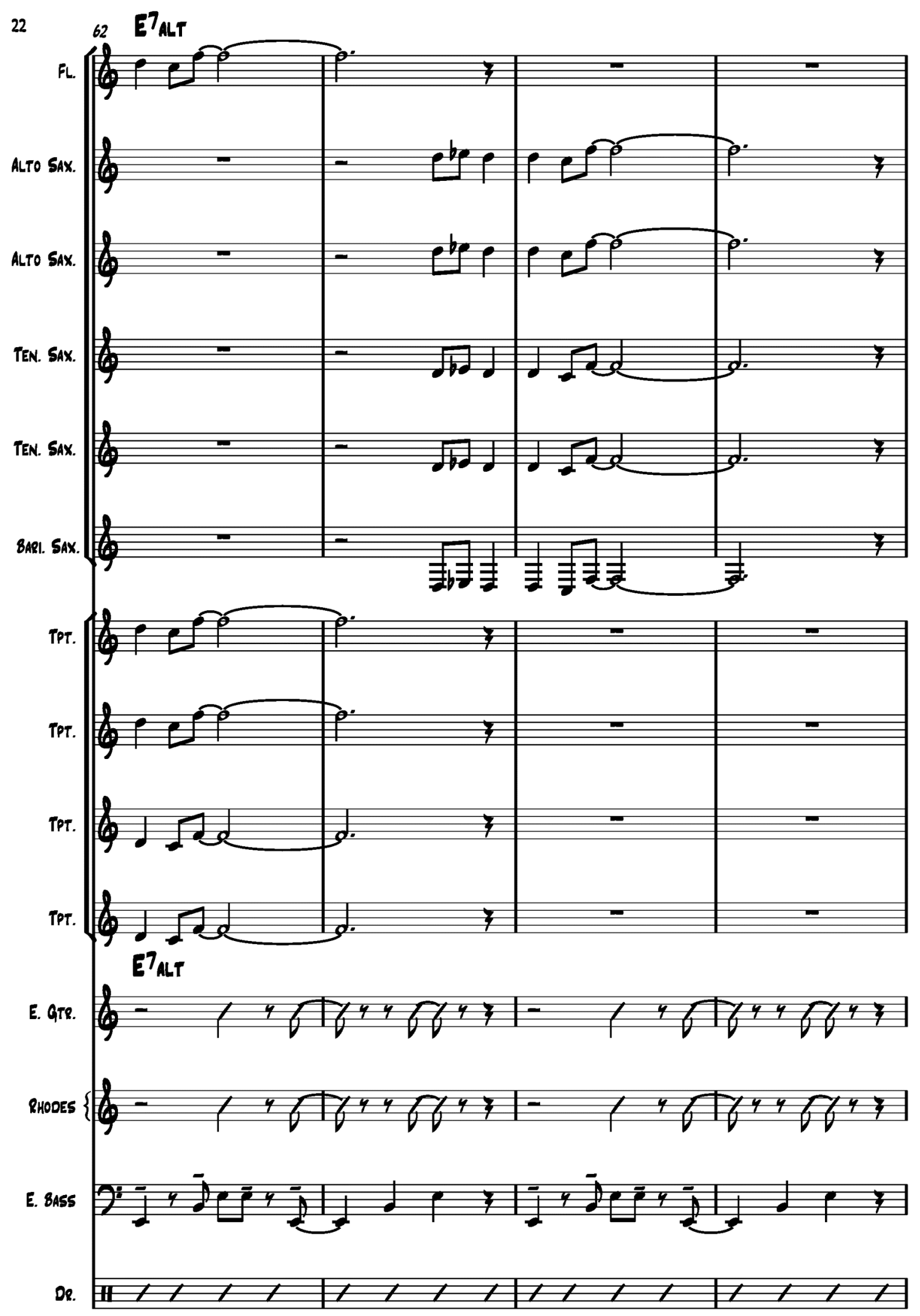




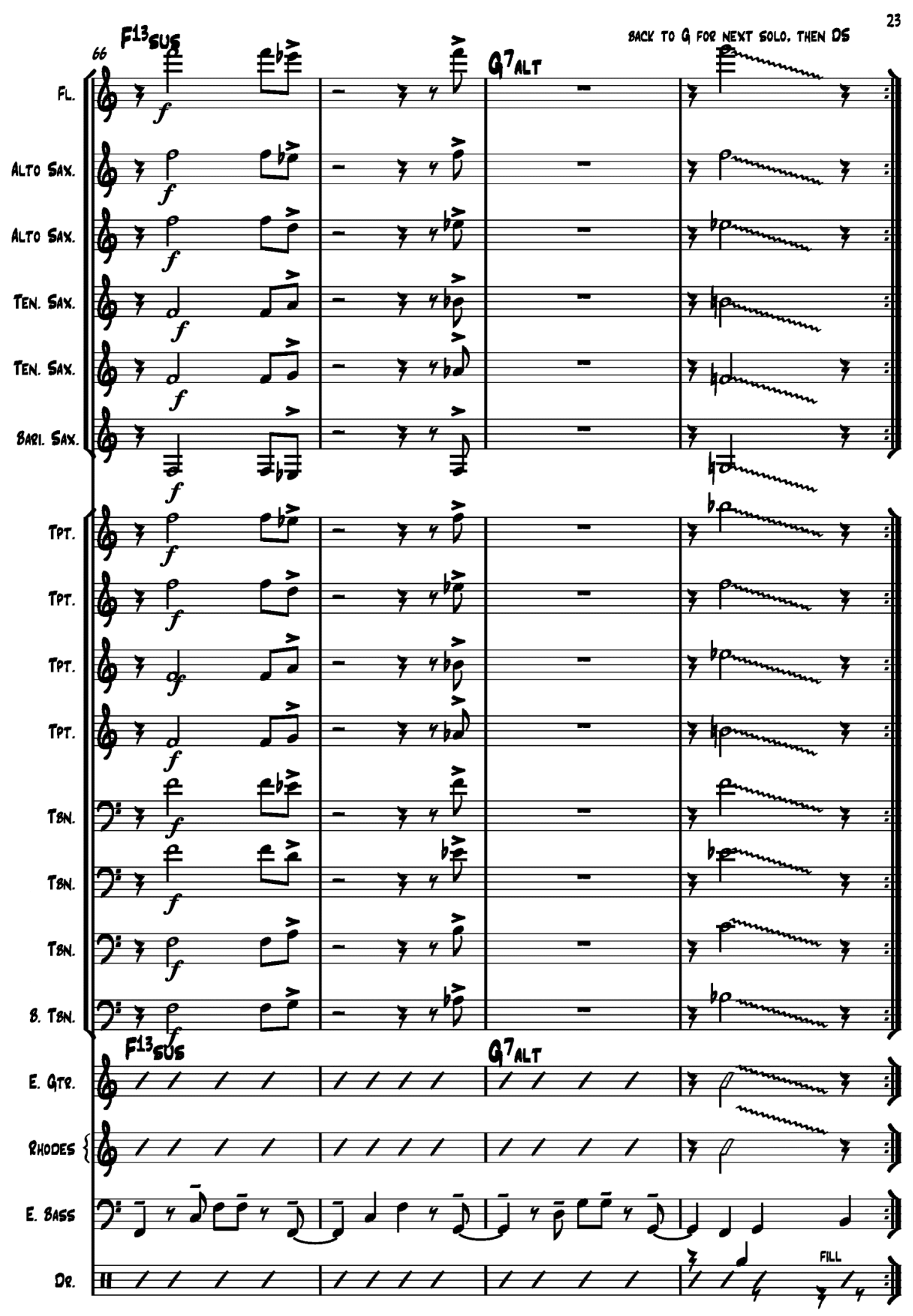




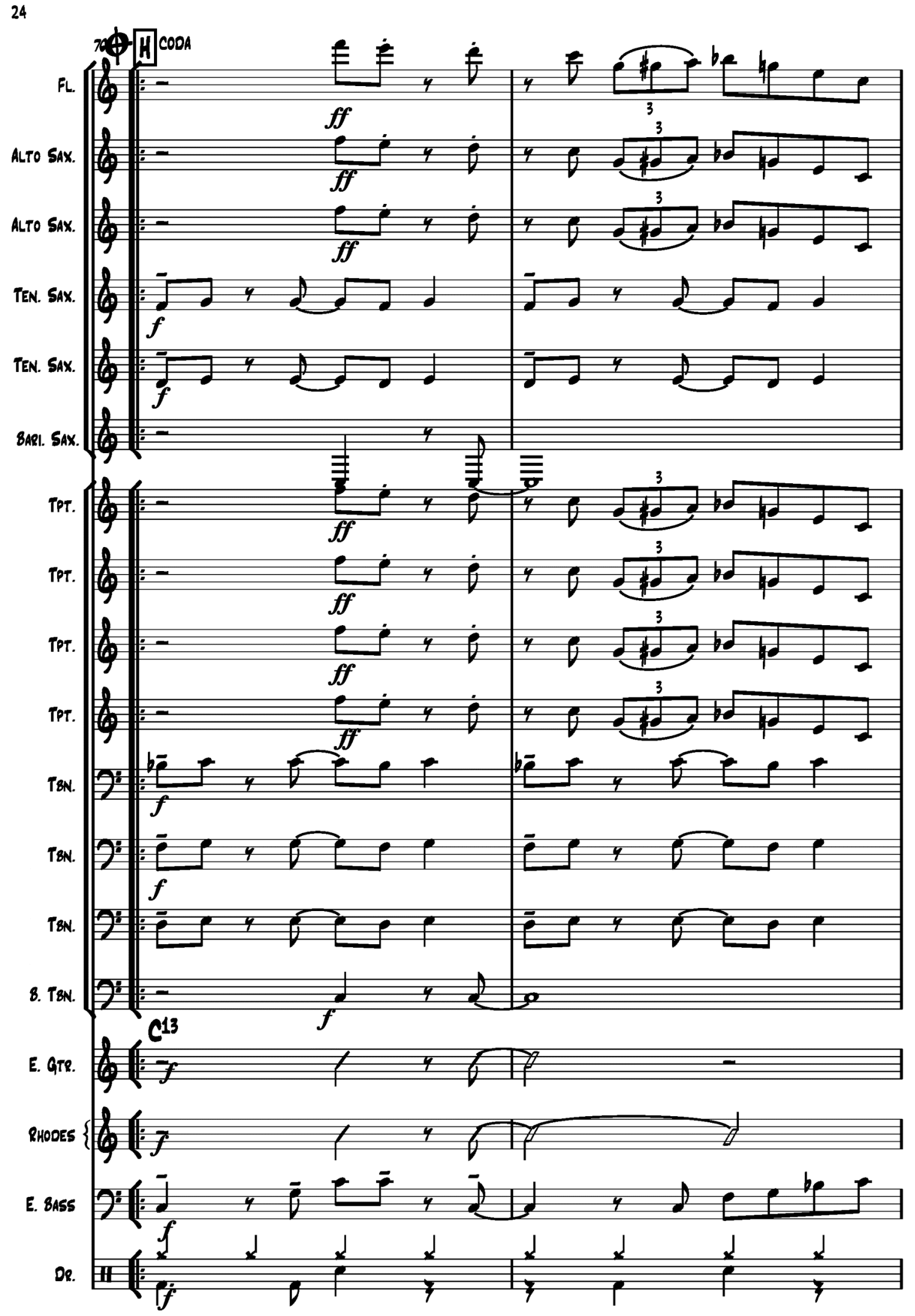




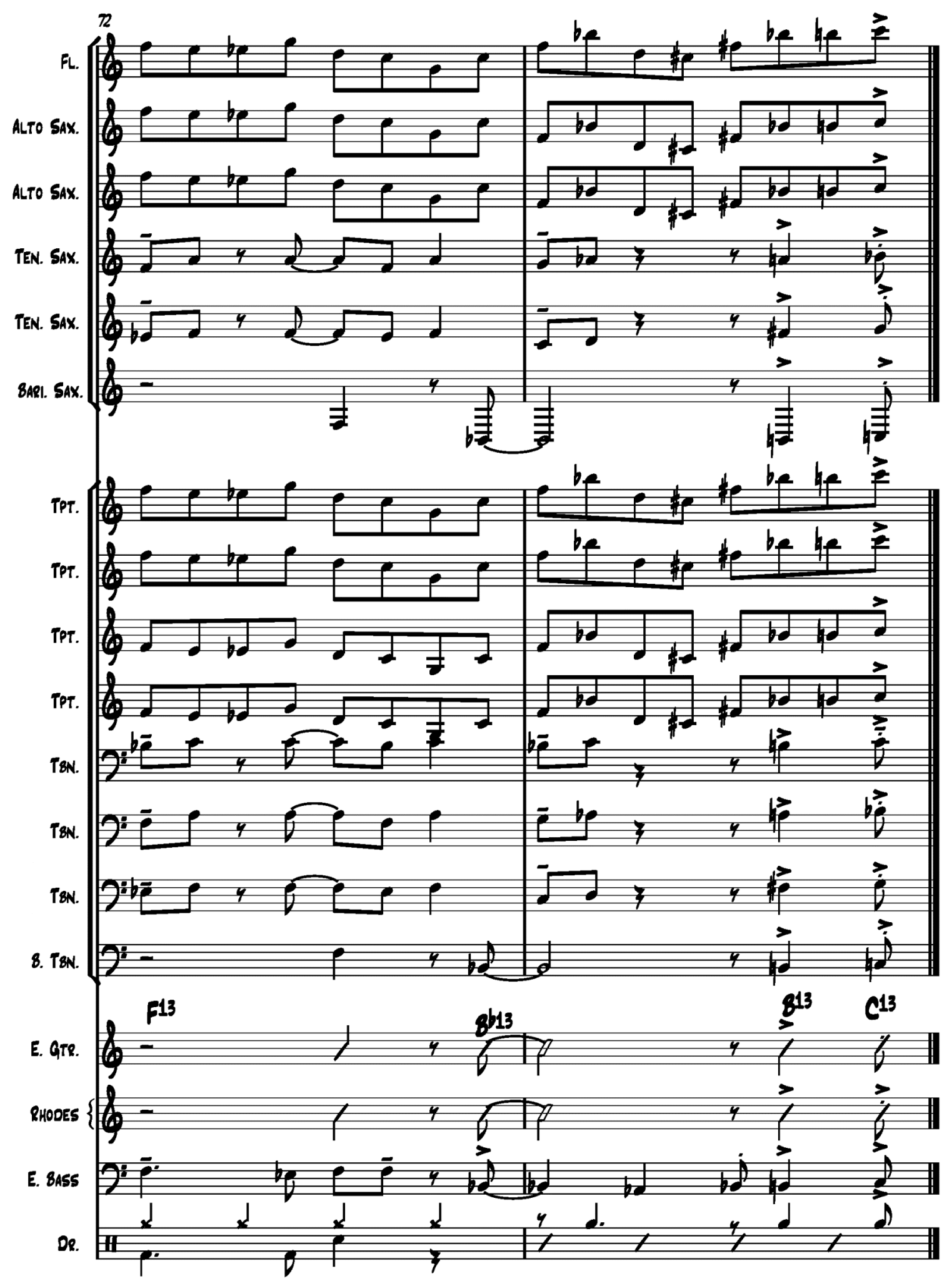

